\title{
Delineamento de sistemas eletrônicos para guiar pessoas com deficiência visual em redes de metrô
}

\section{ELIETE MARIANI}




\section{ELIETE MARIANI}

Delineamento de sistemas eletrônicos para guiar pessoas com deficiência visual em redes de metrô

Dissertação apresentada à Faculdade de Arquitetura e Urbanismo da Universidade de São Paulo para obtenção do título de Mestre em Arquitetura e Urbanismo

Área de concentração: Tecnologia da Arquitetura

Orientador: Prof. Dr. Marcelo Eduardo Giacaglia

São Paulo 
AUTORIZO A REPRODUÇÃO E DIVULGAÇÃO TOTAL OU PARCIAL DESTE TRABALHO, POR QUALQUER MEIO CONVENCIONAL OU ELETRÔNICO, PARA FINS DE ESTUDO E PESQUISA, DESDE QUE CITADA A FONTE.

E-MAIL DA AUTORA: eliete.mariani@gmail.com

Mariani, Eliete

M333d Delineamento de sistemas eletrônicos para guiar pessoas com

deficiência visual em redes de metrô / Eliete Mariani. -- São Paulo, 2016. 362 p. : il.

Dissertação (Mestrado - Área de Concentração: Tecnologia da Arquitetura) - FAUUSP.

Orientador: Marcelo Eduardo Giacaglia

1.Acessibilidade ao meio físico 2.Deficiência visual 3.Percepção espacial 4.Cognição 5.Dispositivos eletrônicos 6.Metrô 7.Navegação 8.Orientação 9.Mobilidade 10.Aplicativo I.Título

CDU 72-056.26 
Dedico este trabalho ao meu filho Luca, como exemplo de determinação. 



\section{AGRADECIMENTOS}

À Faculdade de Arquitetura e Urbanismo da Universidade de São Paulo, pela oportunidade de desenvolvimento e concretização deste trabalho.

Ao Prof. Dr. Marcelo Eduardo Giacaglia, por ter aceitado me orientar, e pelo apoio e tempo dedicados. Suas orientações foram imprescindíveis para meu desenvolvimento acadêmico.

Agradecimento especial à Prof ${ }^{a}$ Dr ${ }^{a}$ Sheila Walbe Ornstein, por ter acreditado no meu trabalho.

Às professoras que fizeram parte da banca de qualificação, Drª Rosaria Ono e Drª Denise Dantas, pelos comentários e sugestões pertinentes, decisivas para o prosseguimento da pesquisa. Aos professores da banca examinadora, pelo trabalho dedicado.

Aos professores da pós-graduação da Faculdade de Arquitetura e Urbanismo pela atenção, apoio e ensinamentos proporcionados.

Aos colegas da pós-graduação, pelo incentivo e pelas boas conversas, que muito acrescentaram à realização deste trabalho.

À Companhia do Metropolitano de São Paulo - CMSP, pela possibilidade e recursos disponibilizados para a realização desta dissertação.

À Lígia Catarina Fischer e Maria Beatriz Pestana Barbosa, que me incentivaram e me apoiaram durante todo este processo.

Ao Jaldomir da Silva Filho, que me ajudou imensamente com as questões técnicas e me proporcionou riquíssimas trocas de conhecimentos.

Ao Vagner José de Almeida, pela sensibilidade e competência para realizar a ilustração da capa desta dissertação.

Aos amigos e colegas da CMSP, pelo grande apoio e compartilhamento de experiências, ideias e documentos, os quais muito contribuíram para esta dissertação. Especial 
agradecimento àqueles que participaram das entrevistas e ao Fabio Martini Pontes e Jacqueline Costa, que contribuíram com traduções e tratamento de imagens.

Agradecimento mais do que especial a todos os participantes das observações de campo: Fernando, Renato, Iara, Viviane, Marcelo e Gabriel, com sua Julia. Cada um de vocês agregou muito a esta pesquisa.

Aos especialistas em Orientação e Mobilidade Suzete Rugno Arruda, João Álvaro de Moraes Felippe e Selma Silvestre por compartilharem seus valorosos conhecimentos.

Aos meus amigos que acreditaram e continuam acreditando em mim, nunca me deixando desistir.

Ao Braulio Rodrigues, por ter-me mostrado, há 25 anos, o caminho da iniciação no permanente trabalho pela inclusão das pessoas com deficiência.

À participação especial dos membros de minha família, que me ajudaram incentivando em todos os momentos, especialmente à minha mãe Esthér, pela disciplina ensinada, e ao meu pai Dudú (in memorian), pela sensibilidade legada. Aos queridos Franco e Luca, pelo apoio e pela compreensão das minhas ausências.

Especiais agradecimentos ao arquiteto Manuel Paulo Teixeira, à arquiteta Joana Baptista, da empresa Metro do Porto, e ao Prof. Dr. Diamantino Freitas, da Faculdade de Engenharia da Universidade do Porto, por todo o trabalho despendido para que eu pudesse realizar uma pesquisa científica sobre o sistema Navmetro ${ }^{\circledR}$. Obrigada pelo acolhimento e profissionalismo com que me trataram durante todo o processo.

A todos, muito obrigada! 


\section{RESUMO}

MARIANI, Eliete. Delineamento de sistemas eletrônicos para guiar pessoas com deficiência visual em redes de metrô. 2016. 362 p. Dissertação (Mestrado) Faculdade de Arquitetura e Urbanismo da Universidade de São Paulo, São Paulo, 2016.

Redes de metrô são responsáveis pelos deslocamentos urbanos diários de milhões de pessoas. Estações de metrô são espaços pensados para a mobilidade, como zonas de transição. Devido à sua complexidade (diferentes configurações, circulação de trens em seu interior e pessoas andando apressadas), esses ambientes tornam-se confusos para os deslocamentos autônomos de pessoas com deficiência visual. Sistemas de metrô têm recebido constantes solicitações por parte de grupos de pessoas com deficiência visual, que fazem referência a aplicativos para smartphones ou utilização de outros dispositivos móveis que auxiliem nos seus deslocamentos. Entretanto, constata-se que leis e normas técnicas não definem parâmetros para tais sistemas, e ainda não existe um consenso entre os profissionais ou acadêmicos, quanto ao seu projeto e uso. Por meio desta pesquisa objetivou-se investigar as formas como as pessoas com deficiência visual interagem em seus percursos por estações e trens de metrô, procurando-se conhecer suas habilidades, limitações e temores, à luz de suas variáveis cognitivas, tendo sido realizadas observações participantes no metrô de São Paulo. Buscou-se ainda, a observação da experiência da utilização de um sistema de informação e navegação na prática, optando-se por realizar uma pesquisa no metrô da cidade do Porto, em Portugal, a respeito do sistema Navmetro ${ }^{\circledR}$. Para formar considerações coerentes, fez-se necessário trabalhar com diversas áreas de conhecimento, relacionadas à natureza multidisciplinar da pesquisa (psicologia, sociologia, saúde pública, eletrônica e transportes, entre outras). 0 estudo pautou-se por uma abordagem qualitativa, utilizando ferramentas para coleta de dados como observação participante e entrevistas; em paralelo ocorreu a aplicação de um questionário qualiquantitativo para complementação de dados. As entrevistas ocorreram com pessoas diretamente ligadas ao serviço de prover viagem de metrô, com especialistas em projetos de estações e trens, com professores de orientação e mobilidade e com os próprios usuários, foco deste trabalho. Para interpretação dos dados obtidos em campo foram feitos cruzamentos com os dados do referencial bibliográfico, de maneira a se chegar a resultados que pudessem delinear parâmetros de projetos de sistemas que transmitam informações e comandos de navegação em tempo real. Por meio de emissão de sons e vibração, estes sistemas podem representar um auxílio precioso em estações e trens de metrô. Como consequência, este estudo apresenta subsídios que podem servir para o aprimoramento e desenvolvimento de sistemas de tecnologia assistiva voltados à informação e navegação de pessoas com deficiência visual, e base de estudos para desenvolvimento de tecnologias semelhantes nos demais sistemas de transporte.

Palavras-chave: Acessibilidade; deficiência visual; percepção espacial; cognição; navegação; orientação; mobilidade; dispositivos eletrônicos; metrô; aplicativo; Navmetro ${ }^{\circledR}$. 


\begin{abstract}
MARIANI, Eliete. Guidelines for electronic systems designed for aiding the visually impaired people in metro networks. 2016. 362 p. Dissertação (Mestrado) - Faculdade de Arquitetura e Urbanismo da Universidade de São Paulo, São Paulo, 2016.

Metro systems are responsible for the commutes of several million people daily. Stations, as spaces designed for mobility, are transition zones. Their complexity (diverse configurations, train movements in different directions and rushed commuters), environments become somewhat confusing places for the visually impaired. Metro operating companies have been receiving requests from associations that represent the visually impaired people, demanding smartphone applications or the use of dedicated devices to aid them when using the network. However, existing legislation and standards don't provide requirements for such systems, and there is no consensus, among professionals or academics, for their design and usage. This research started by examining the ways found by the visually impaired to interact with space, assessing their abilities, limitations and worries, in consideration of their cognitive variables, within the Sao Paulo metro users. It has also assessed the practical use of a specific information/navigation system called Navmetro ${ }^{\circledR}$, in use at the Porto (Portugal) metro. A multidisciplinary approach was used, by means of qualitative research and the use of data collection tools such as voluntary participant observation and interviews; simultaneously, a qualitative questionnaire was applied for data supplementation. Interviews focused on people with direct operational experience on the metro system, experts in station/train design, guidance and mobility teachers and, most importantly, frequent users. Data obtained in field work was cross-referenced with data found in the bibliographic sources, in order to attain results that may perhaps delineate design parameters for systems able to transmit information and navigational commands in real time. Through the use of sounds and vibrations, these systems can become a precious support for guidance in metro networks. This paper presents elements that can lead to the development and improvement of assistive technologies focusing on information and navigation systems for the visually impaired people, and also to the development of similar technologies in other transportation systems.
\end{abstract}

Keywords: Accessibility; visually impaired; spatial awareness; cognition; navigation; guidance; mobility; device; metro; app; Navmetro ${ }^{\circledR}$. 


\section{LISTA DE FIGURAS}

Figura 2.1 - Exemplos de diferentes tipos de visão................................................................................................ 41

Figura 2.2 - Derivações nas linhas de pisos táteis que podem gerar dúvida quanto à rota a seguir .............61

Figura 2.3 - Atividades de locomoção de pessoas com visão normal .....................................................................65

Figura 2.4 - Atividades de locomoção de pessoas com deficiência visual .............................................................65

Figura 2.5 - Decomposição da tarefa de navegação. ......................................................................................... 71

Figura 2.6 - Exemplo de fone de ouvido externo (ou de condução óssea)...........................................................89

Figura 2.7 - Bengala eletrônica UltraCane, criada em 1998..............................................................................90

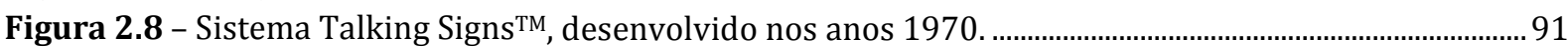

Figura 2.9 - Sistema ViaVoz instalado em Santa Catarina, ano 2015 . .................................................................... 96

Figura 3.1 - Exemplo de um mezanino de metrô......................................................................................................... 103

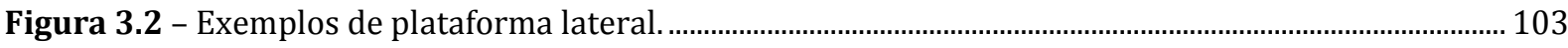

Figura 3.3 - Exemplos de plataforma central............................................................................................... 104

Figura 3.4 - Exemplos de plataforma mista. ................................................................................................... 104

Figura 3.5 - Assentos preferenciais na cor azul claro em trem do metrô de São Paulo................................. 105

Figura 3.6 - Aviso luminoso de fechamento de portas em trem no metrô de Shanghai. ................................. 105

Figura 3.7 - Apoios de mão de cor contrastante em trem do metrô de Hong Kong.......................................... 106

Figura 3.8 - Redutor de vão entre o trem e a plataforma em estação do metrô de Hong Kong. .................. 106

Figura 3.9 - Exemplos de portas de plataforma.................................................................................................... 106

Figura 3.10 - Portas de plataforma no metrô de Paris....................................................................................... 107

Figura 3.11 - Mapa parcial dos transportes metropolitanos - rede do metrô de São Paulo. ........................ 108

Figura 3.12 - Diferenças no leiaute interno dos trens........................................................................................... 110

Figura 3.13 - Região na plataforma de embarque preferencial......................................................................... 110

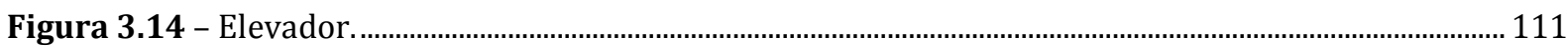

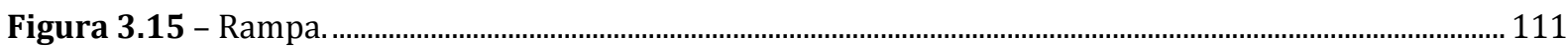

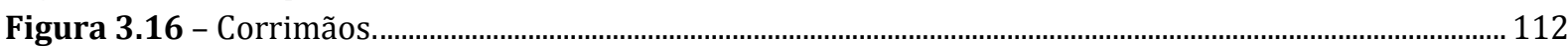

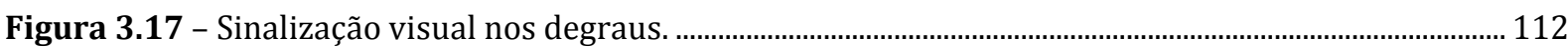

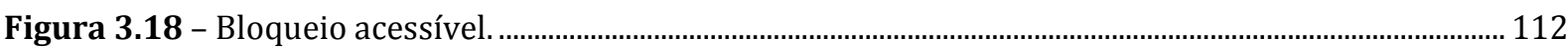

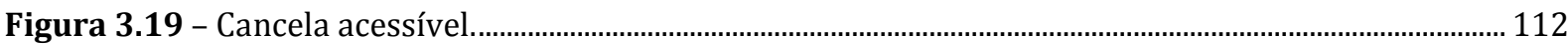

Figura 3.20 - Faixa tátil de alerta amarela e redutor de vão amarelo................................................................ 113

Figura 3.21 - Assento para pessoas obesas. ……............................................................................................... 113

Figura 3.22 - Assento preferencial e espaço para pessoa em cadeira de rodas, no trem.............................. 114

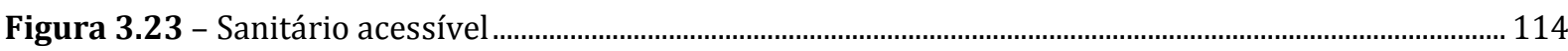

Figura 3.24 - Acompanhamento de pessoa com deficiência. …….................................................................... 115

Figura 3.25 - Centro de Controle Operacional - CCO ……........................................................................... 115

Figura 3.26 - Treinamento de usuário com deficiência visual. .......................................................................... 116

Figura 3.27 - Treinamento de empregado para condução de pessoa em cadeira de rodas nas escadas

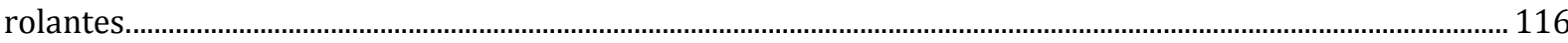

Figura 3.28 - Localização da cidade do Porto (Portugal) e mapa da rede de metrô........................................122

Figura 3.29 - Painel instalado nas plataformas com informações sobre destino do próximo trem............123

Figura 3.30 - Elementos embutidos e coletor localizado fora das regiões de fluxo..................................... 125

Figura 3.31 - Diagrama do funcionamento do sistema de informação do Navmetro ${ }^{\circledR}$...................................127

Figura 3.32 - Diagrama do funcionamento do sistema de navegação do Navmetro ${ }^{\circledR}$....................................... 129

Figura 3.33 - Sequência de uso do Wayfindr na estação Pimlico - metrô de Londres.................................... 131

Figura 3.34 - Perspectiva espacial da estação Pimlico, com indicação do percurso realizado no vídeo sintetizado na Figura 3.32 ................................................................................................................................... 132

Figura 3.35 - Usuário durante o teste no metrô de Paris, 2006, utilizando o sistema BlueEyes................. 133

Figura 3.36 - Sistema Flèche Sonore - SNCF - França..................................................................................... 135

Figura 4.1 - Instrumentos utilizados nas pesquisas de campo. .................................................................... 135

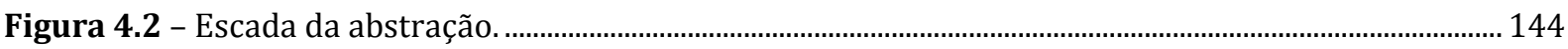




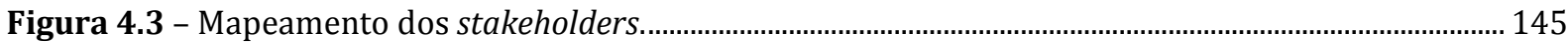

Figura 5.1 - Maneira de encontrar o acesso à estação. .................................................................................. 173

Figura 5.2 - Maneira de caminhar dentro da estação. ....................................................................................... 175

Figura 5.3 - Sequência de ocupação das mãos para validação de título no bloqueio...................................... 176

Figura 5.4 - Maneira de caminhar na plataforma e embarcar/desembarcar do trem...................................178

Figura 5.5 - Comportamento dentro do trem. ....................................................................................................... 182

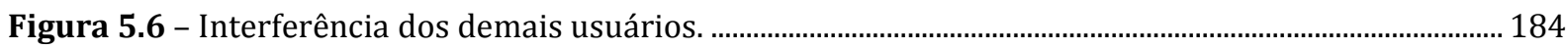

Figura 5.7 - Sequência de interferência de uma usuária................................................................................... 185

Figura 5.8 - Sequência de abordagem de “M.” por um usuário para auxiliá-lo............................................... 185

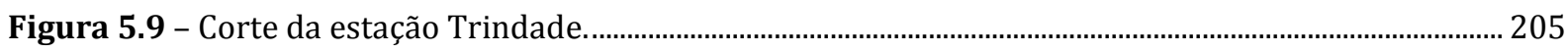

Figura 5.10 - Planta do nível acesso e plataformas linhas A, B, C, E e F da estação Trindade - embarque.

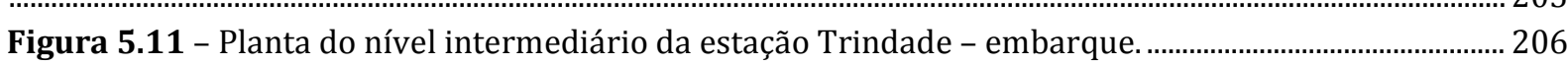

Figura 5.12 - Planta da plataforma da linha D da estação Trindade - embarque e saída............................. 206

Figura 5.13 - Planta da plataforma da linha D da estação Trindade - saída.................................................... 207

Figura 5.14 - Planta do nível acesso e plataformas das linhas A, B, C, E e F da estação Trindade - saída. 207

Figura 5.15 - Vista da chegada pelo acesso da praça à estação Trindade. ..........................................................208

Figura 5.16 - "F." efetuando a ligação para dar início à orientação pelo Navmetro ${ }^{\circledR}$........................................ 209

Figura 5.17 - Após ser identificado pelo sistema, "F." seguiu na direção do som do pássaro...................... 210

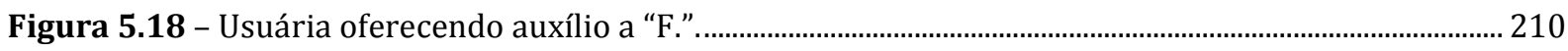

Figura 5.20 - "F." em direção à escada. .................................................................................................................. 211

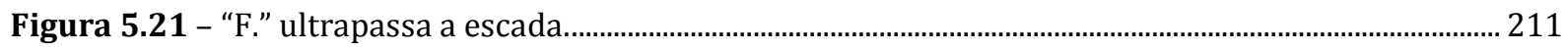

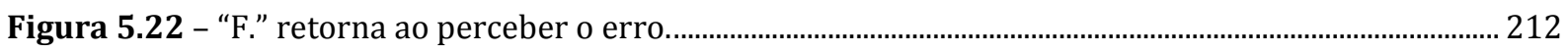

Figura 5.23 - "F." ouvindo as instruções novamente...................................................................................... 212

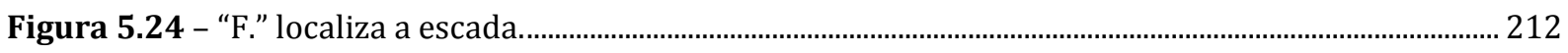

Figura 5.25 - "F." descendo em direção ao piso intermediário............................................................................ 213

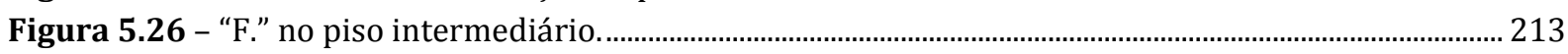

Figura 5.27 - "F." tentando ouvir o sistema na plataforma............................................................................... 214

Figura 5.28 - Após simulação de desembarque na plataforma, "F." utiliza o Navmetro ${ }^{\circledR}$ em direção à saída.

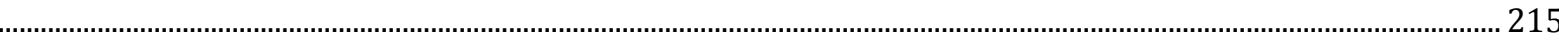

Figura 5.29 - "F." utiliza a escada rolante para se dirigir ao piso intermediário, em direção à saída......... 215

Figura 5.30 - Chegando ao piso intermediário, "F." ouve as instruções pelo celular..................................... 215

Figura 5.31 - Final da observação de "F." "............................................................................................................... 216

Figura 6.1 - Quem deve ser atendido pelo sistema............................................................................................... 219

Figura 6.2 - 0 quê deve ser disponibilizado pelo sistema................................................................................. 219

Figura 6.3 - Onde deve haver cobertura pelo sistema. ..................................................................................... 220

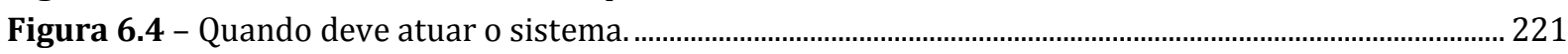

Figura 6.5 - Como o usuário acessa ou recebe o sistema...................................................................................... 222

Figura 6.6 - Diagrama de fluxos para viagem em redes de metrô........................................................................ 223

Figura 6.7 - Percurso a ser realizado - Exemplo 1. ............................................................................................. 231

Figura 6.8 - Orientação inadequada/insuficiente para a navegação.................................................................. 231

Figura 6.9 - Orientação adequada para a navegação......................................................................................... 232

Figura 6.10 - Percursos a serem realizados - Exemplo 2 ..................................................................................... 233

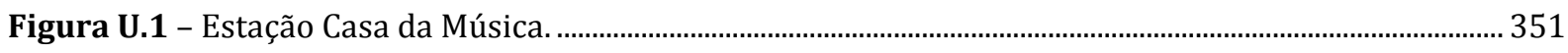

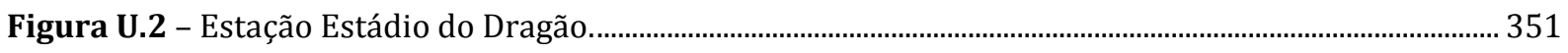

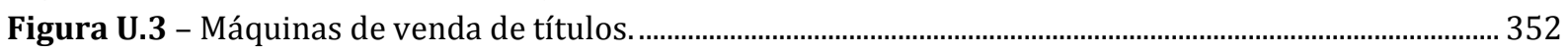

Figura U.4 - Ausência de bloqueios (catracas) em todas as estações................................................................. 352

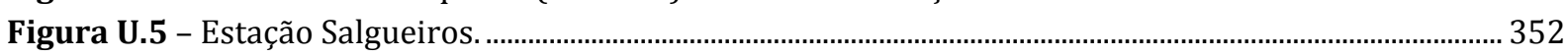

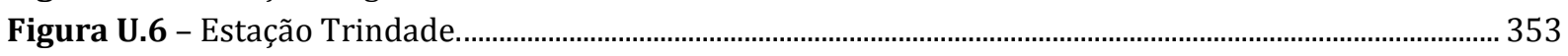

Figura U.7 - Estação São Bento..................................................................................................................................353

Figura U.8 - Passagem do metrô pela ponte D. Luís I, entre Porto e Vila Nova de Gaia. ............................... 354

Figura U.9 - Estação João de Deus. ........................................................................................................................... 354 


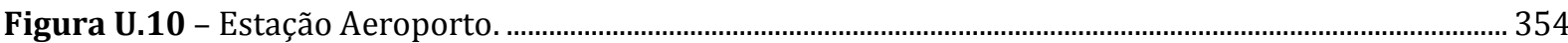

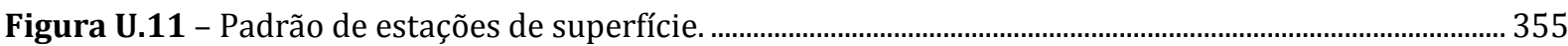

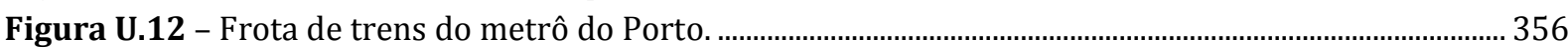

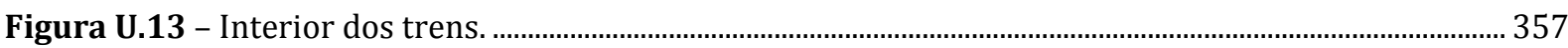

Figura U.14 - Botão para abrir a porta do trem. ……………....................................................................... 357 



\section{LISTA DE TABELAS}

Tabela 2.1 - Classes de acuidade visual definidas pela OMS.

Tabela 2.2 - Classes de informações referenciais usadas por pessoas com visão normal e pessoas com deficiência visual para a navegação.

Tabela 3.1 - Informações sobre o sistema - Situação em fevereiro de 2015 ................................................... 108

Tabela 3.2 - Demanda de passageiros por linha no ano 2014 ......................................................................... 109

Tabela 3.3 - Total de usuários com deficiência visual monitorados em 2014 no Metrô de São Paulo. ..... 117 Tabela 3.4 - Síntese das principais manifestações / reclamações verificadas na pesquisa de Barbosa (2015) com usuários do Metrô de São Paulo com deficiência visual

Tabela 3.5 - Relatório operacional do metrô do Porto - anos 2013 e 2014 ..................................................... 123

Tabela 5.1 - Atividades de campo - observações. 



\section{LISTA DE GRÁFICOS}

Gráfico 2.1 - Porcentagem de pessoas com deficiências, por tipo............................................................................ 46

Gráfico 2.2 - Divisão por grau de dificuldade, dentro de cada tipo de deficiência. ……………………………. 47

Gráfico 2.3 - Grupos de idade de pessoas com deficiência visual - números absolutos..................................... 48

Gráfico 2.4 - Rendimento mensal em salários mínimos - porcentagem dentro de cada grupo....................... 49

Gráfico 2.5 - Comparação das classes de informações referenciais usadas por pessoas com visão normal e pessoas com deficiência visual para a navegação. ..................................................................................................73

Gráfico 2.6 - Respostas em relação à suposta utilização de equipamentos eletrônicos para orientação e mobilidade de pessoas com deficiência visual. …………………………………………………………………...... 78

Gráfico 3.1 - Capacidade de diferentes modais de transporte. ……………………………………………..... 100

Gráfico 3.2 - Porcentagens do total de monitoramentos por linha no ano 2014............................................ 117

Gráfico 3.3 - Índice de verificação "qualidade no atendimento à pessoa com deficiência ou restrição de

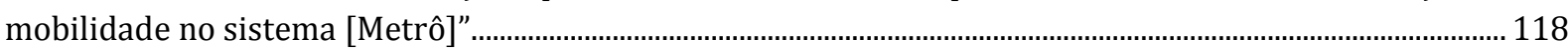

Gráfico 3.4 - Manifestações relacionadas a pessoas com deficiência visual em 2014..................................... 119

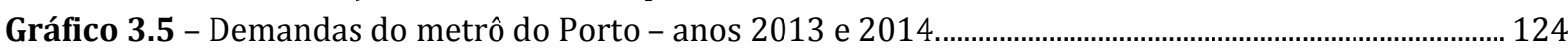

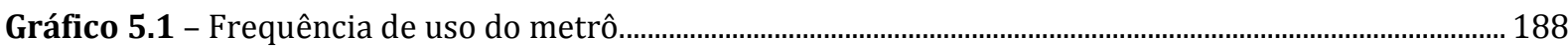

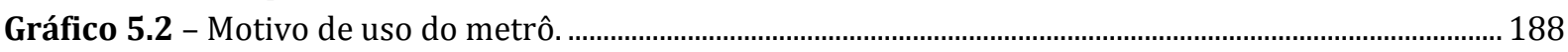

Gráfico 5.3 - Meios de transporte utilizados para chegar ao metrô.................................................................... 188

Gráfico 5.4 - Como costuma chegar às estações do metrô..................................................................................... 189

Gráfico 5.5 - Pede auxílio para utilizar o metrô? ……………………………………………………………... 189

Gráfico 5.6 - Qual o motivo para solicitação de auxílio de funcionário no metrô? ............................................ 190

Gráfico 5.7 - "Qual o local das estações onde se sente mais inseguro?" ............................................................. 190

Gráfico 5.8 - "Gostaria de se deslocar de maneira independente no metrô (sem necessidade de auxílio dos funcionários)?"

Gráfico 5.9 - "O que o metrô dispõe hoje é suficiente para uma pessoa com deficiência visual se deslocar sozinha?"

Gráfico 5.10 - Para quem respondeu "não" na questão do Gráfico 5.9 - principais resultados................... 192

Gráfico 5.11 - Para quem respondeu "em algumas estações sim, em outras não" na questão do Gráfico 5.9

- principais resultados.

Gráfico 5.12 - Para quem respondeu "em algumas estações sim, em outras não" na questão do Gráfico 5.9

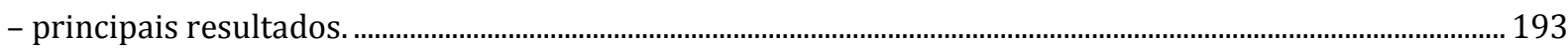

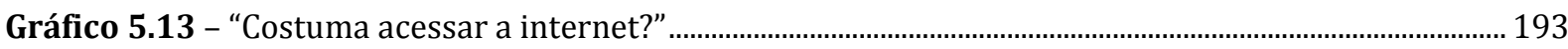





\section{LISTA DE QUADROS}

Quadro 4.1 - Pessoas-chave e temas abordados nas entrevistas................................................................ 154

Quadro 4.2 - Temas abordados no questionário........................................................................................................... 159

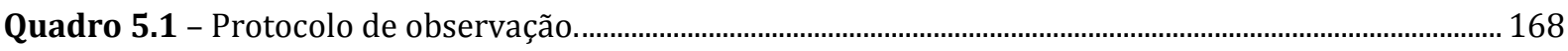

Quadro 5.2 - Maneira de encontrar o acesso à estação. ........................................................................................... 172

Quadro 5.3 - Maneira de caminhar dentro da estação.............................................................................................174

Quadro 5.4 - Maneira de caminhar na plataforma e embarcar/desembarcar do trem...............................177

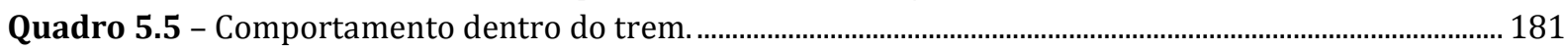

Quadro 5.6 - Interferência dos demais usuários. ................................................................................................... 183

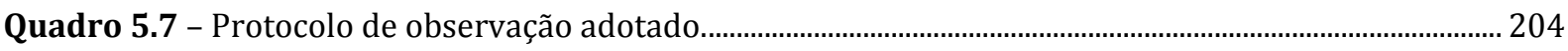

Quadro 6.1 - Etapas do diagrama de fluxos para pessoas com deficiência visual............................................224

Quadro 6.2 - Proposições complementares de melhorias. ................................................................................. 235

Quadro Q.1 - Configuração das estações utilizadas nas observações - Luz................................................... 315

Quadro Q.2 - Configuração das estações utilizadas nas observações - Artur Alvim..................................... 316

Quadro Q.3 - Configuração das estações utilizadas nas observações - Fradique Coutinho. ....................... 316

Quadro Q.4 - Configuração das estações utilizadas nas observações - Marechal Deodoro.......................... 317

Quadro Q.5 - Configuração das estações utilizadas nas observações - Palmeiras-Barra Funda................. 317

Quadro Q.6 - Configuração das estações utilizadas nas observações - Pedro II............................................ 318

Quadro Q.7 - Configuração das estações utilizadas nas observações - Vergueiro.......................................... 318

Quadro Q.8 - Configuração das estações utilizadas nas observações - Pinheiros........................................... 319

Quadro Q.9 - Configuração das estações utilizadas nas observações - São Bento.......................................... 319

Quadro Q.10 - Configuração das estações utilizadas nas observações - República....................................... 320

Quadro Q.11 - Configuração das estações utilizadas nas observações - Tatuapé ........................................... 320

Quadro Q.12 - Configuração das estações utilizadas nas observações - Sé...................................................... 321

Quadro Q.13 - Configuração das estações utilizadas nas observações - Vila Matilde................................... 322

Quadro R.1 - Configuração dos trens utilizados nas observações........................................................................ 323 



\section{SUMÁRIO}

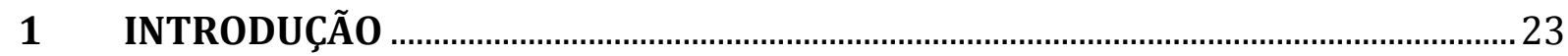

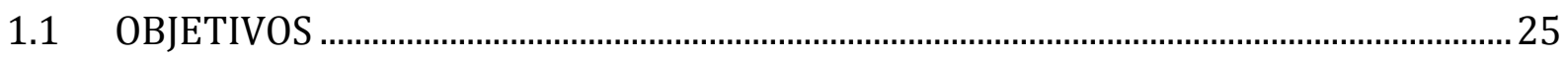

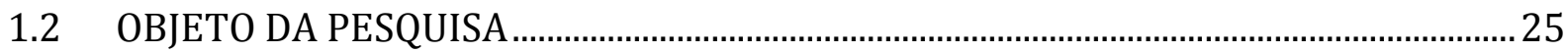

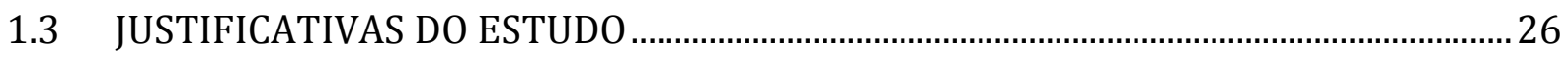

1.4 ESTRUTURA DA DISSERTAÇÃO................................................................................2

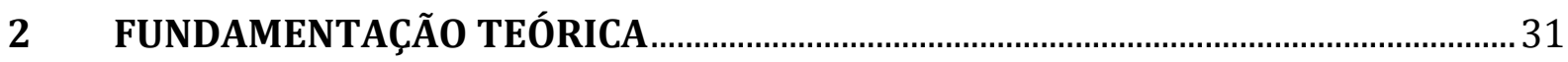

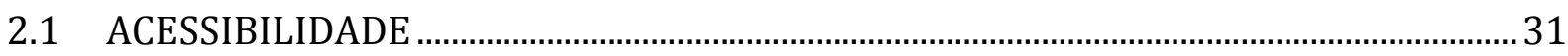

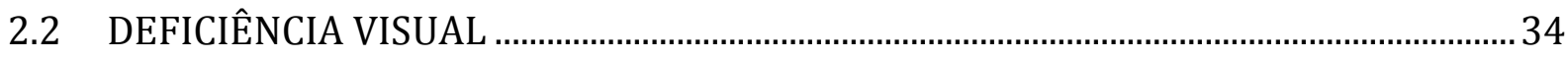

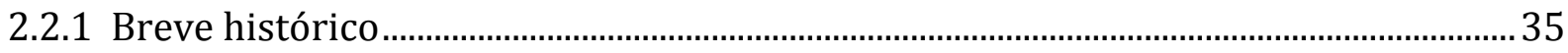

2.2.2 Conceituação..............................................................................................................

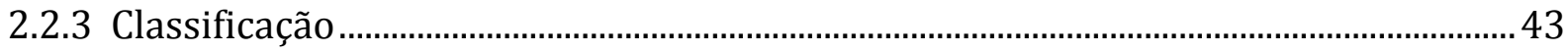

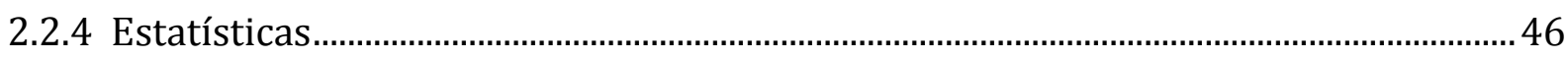

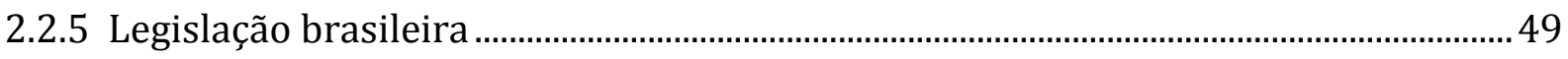

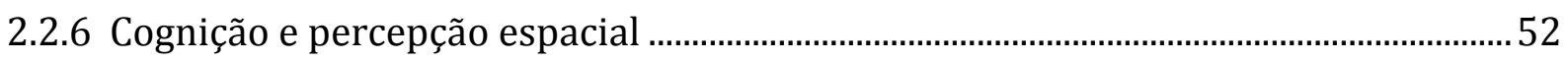

2.2.7 Treinamento em Orientação e Mobilidade (OM)..........................................................58

2.2.8 0 uso do cão-guia nos deslocamentos urbanos .............................................................. 62

2.2.9 O sistema Braille e seu uso em referenciais espaciais..................................................6

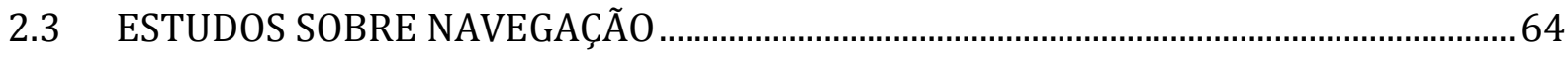

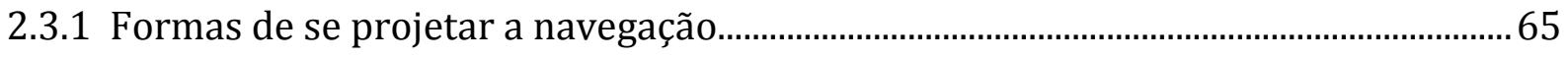

2.3.2 Formas de se prover a navegação ……………………………………………………... 68

2.4 TECNOLOGIAS ELETRÔNICAS PARA GUIAR PESSOAS COM DEFICIÊNCIA VISUAL

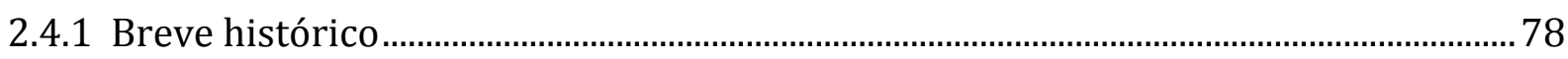

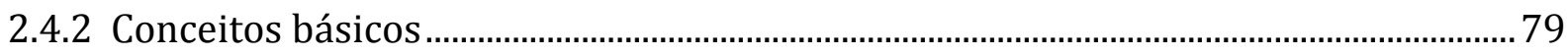

2.4.3 Tecnologias de comunicação via rádio .......................................................................... 80

2.4.4 Tecnologias de comunicação via luz.............................................................................. 83

2.4.5 Tecnologias de comunicação via som .......................................................................... 85

2.4.6 Tecnologias de comunicação via vibração .................................................................... 86

2.4.7 Considerações a respeito das tecnologias de comunicação .......................................... 86

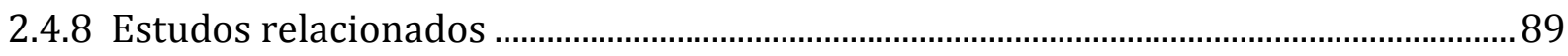

3 REDES DE METRô, ACESSIBILIDADE E NAVEGAÇÃO ELETRÔNICA......................99

3.1 CONFIGURAÇÕES DE ESTAÇÕES E TRENS DE METRÔ ……………………………... 100

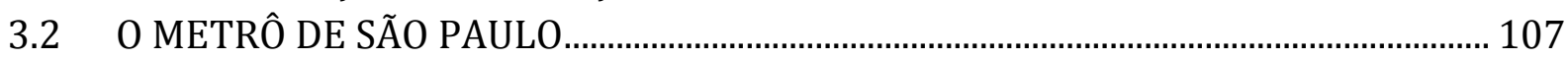

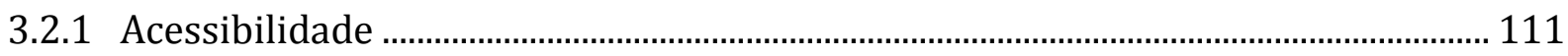

3.2.2 Pesquisas e indicadores ................................................................................................ 117

3.3 O METRÔ DO PORTO ………………………………………………………………... 121

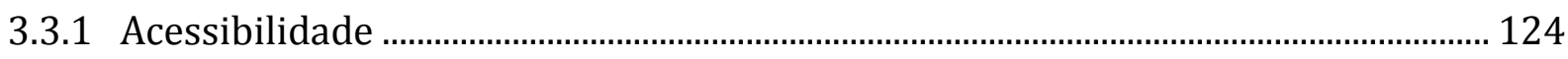

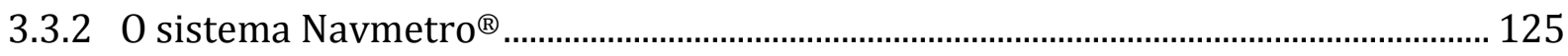


3.4 SISTEMAS ELETRÔNICOS DE NAVEGAÇÃO EM OUTROS METRÔS........................... 129

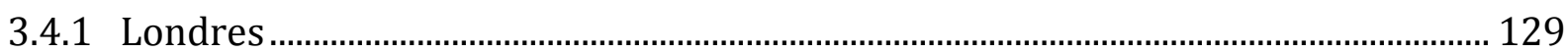

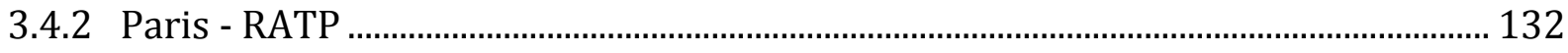

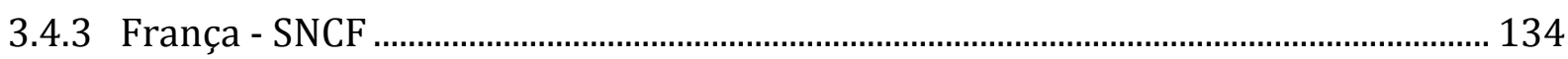

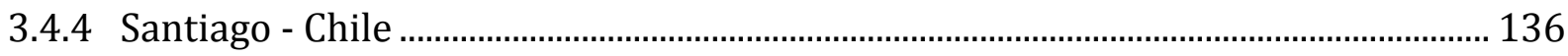

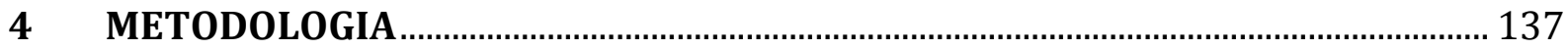

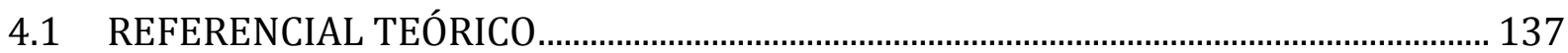

4.2 PESQUISAS DE CAMPO - INSTRUMENTOS DE COLETA DE DADOS ......................... 137

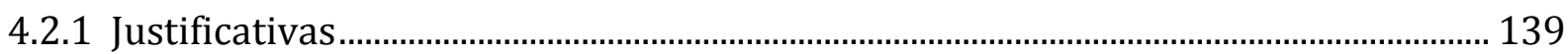

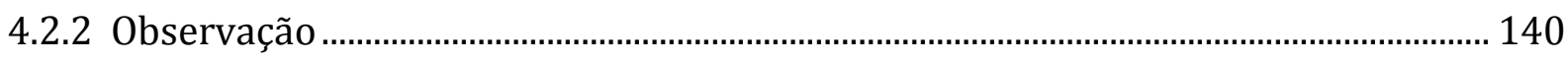

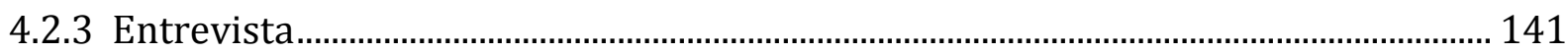

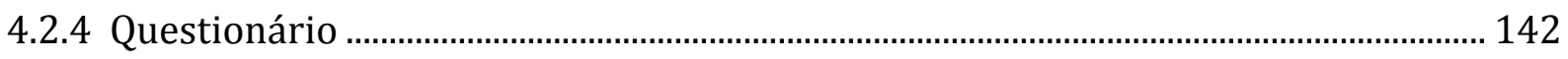

4.3 PESQUISA NO METRÔ DE SÃO PAULO......................................................................... 143

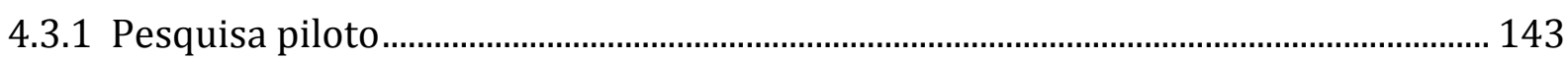

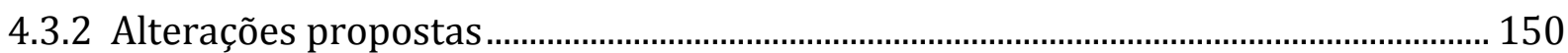

4.3.3 Observação complementar ............................................................................................ 151

4.3.4 Entrevistas com funcionários e projetistas do metrô................................................. 152

4.3.5 Entrevistas com professores de Orientação e Mobilidade........................................... 155

4.3.6 Entrevista com designer de produtos de ajudas técnicas .............................................. 156

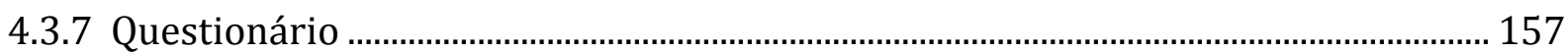

4.4 PESQUISA NO METRÔ DO PORTO ……....................................................................... 159

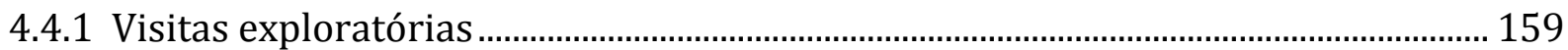

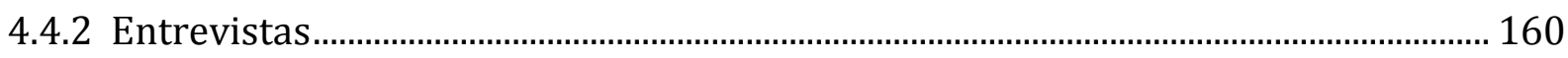

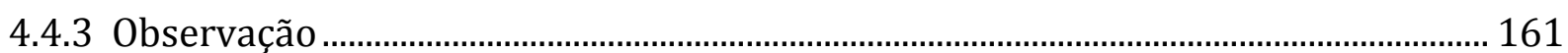

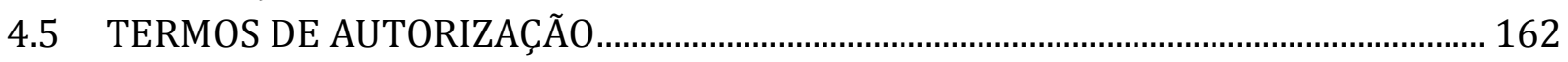

4.6 ANÁLISE E INTERPRETAÇÃO ...................................................................................... 164

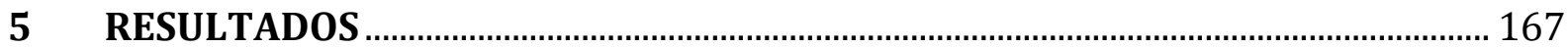

5.1 OBSERVAÇÕES PARTICIPANTES NO METRÔ DE SÃO PAULO ….................................. 167

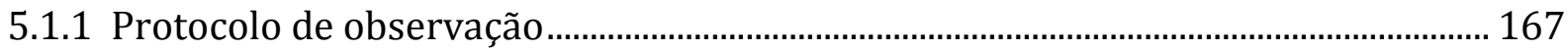

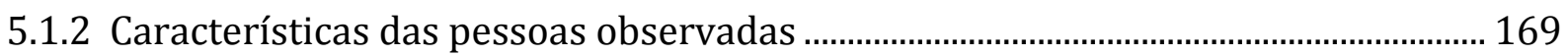

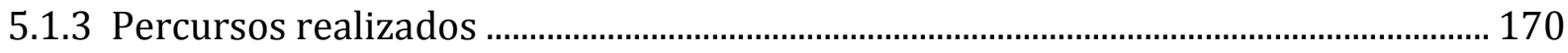

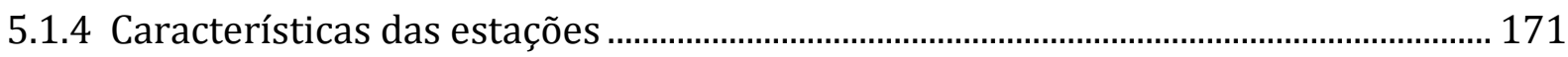

5.1.5 Características dos trens ................................................................................................ 171

5.1.6 Registros dos comportamentos e falas nas observações ............................................. 171

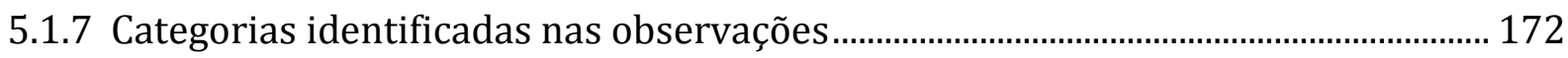

5.1.8 Padrões identificados nas observações........................................................................ 186

5.2 ENTREVISTAS NO METRÔ DE SÃO PAULO ……........................................................... 186

5.2.1 Temas identificados nas entrevistas .......................................................................... 186

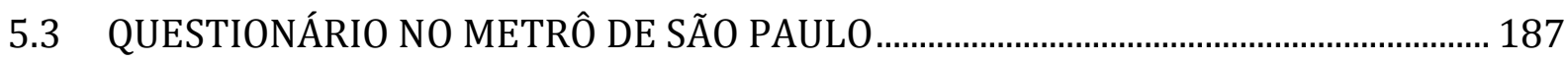

5.4 CONSIDERAÇÕES SOBRE A PESQUISA NO METRÔ DE SÃO PAULO........................... 194

5.5 VISITAS EXPLORATÓRIAS NO METRÔ DO PORTO ……................................................. 195 
5.6 ENTREVISTAS NO METRÔ DO PORTO ………………………………………………….... 196

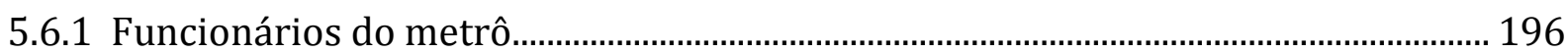

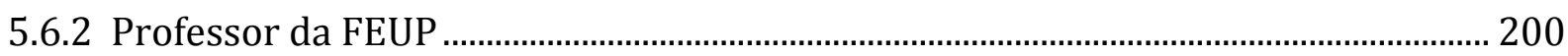

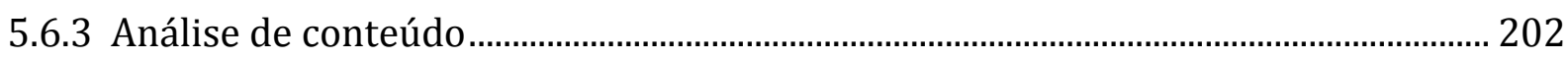

5.7 OBSERVAÇÃO PARTICIPANTE NO METRÔ DO PORTO ………………………………... 203

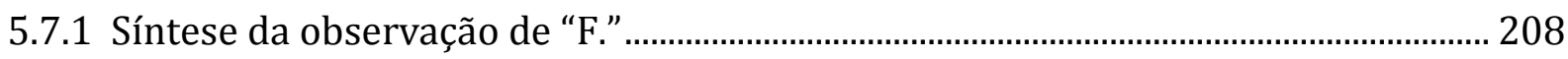

5.7.2 Teste prático realizado pela pesquisadora ................................................................ 216

5.8 CONSIDERAÇÕES SOBRE A PESQUISA NO METRÔ DO PORTO.................................... 217

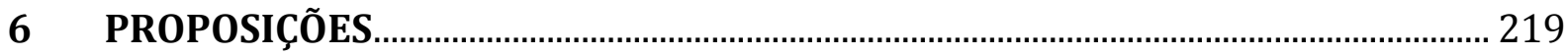

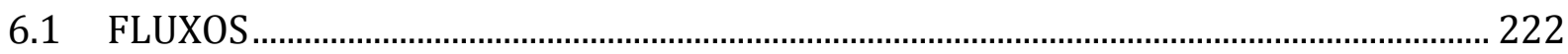

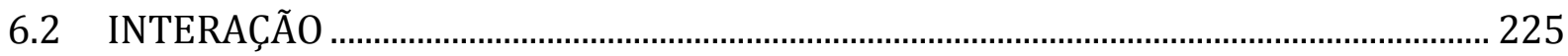

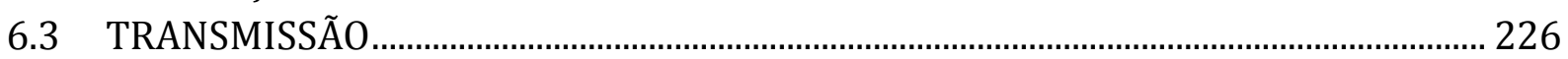

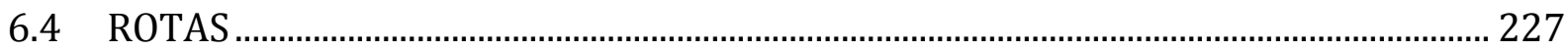

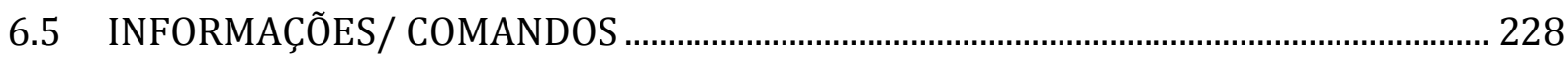

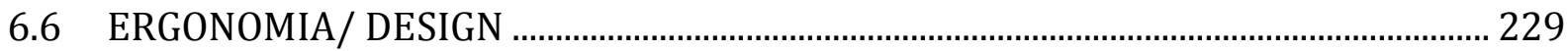

6.7 ILUSTRAÇס̃ES ............................................................................................................ 230

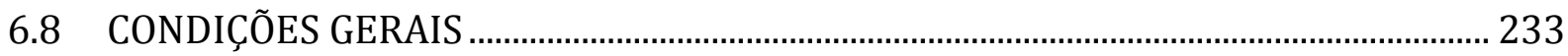

6.9 PROPOSIÇÕES COMPLEMENTARES ……………………………………………..... 234

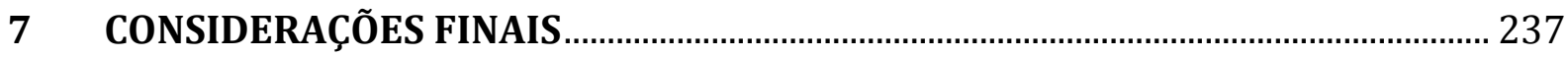

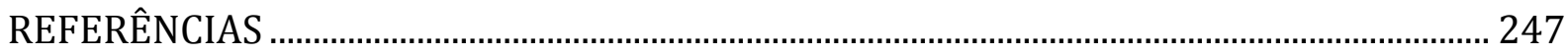

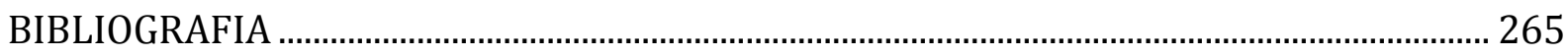

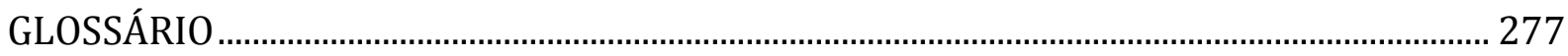

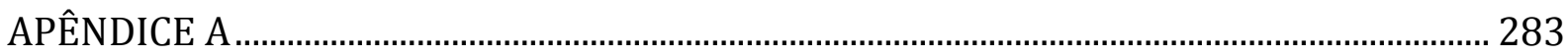

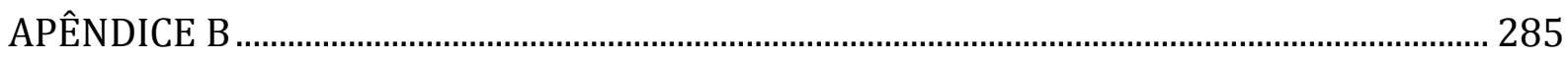

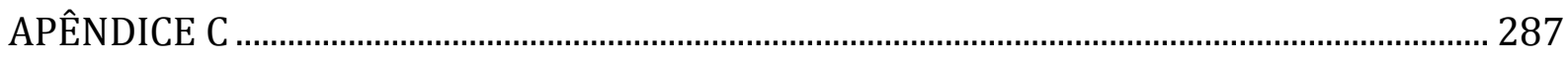

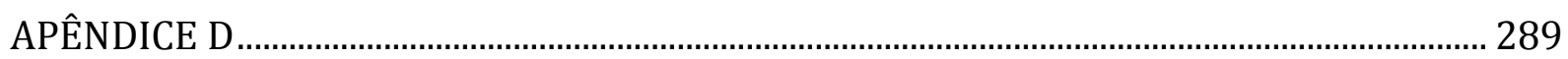

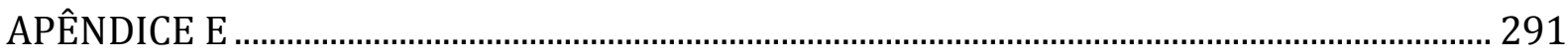

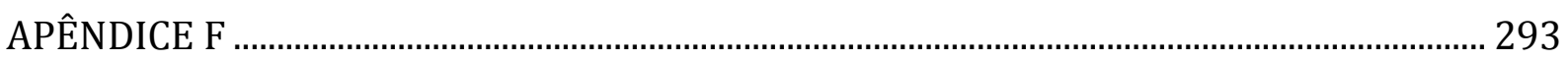

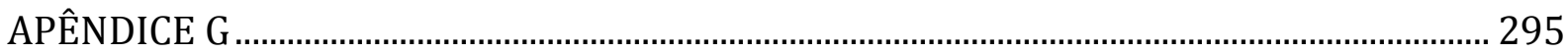

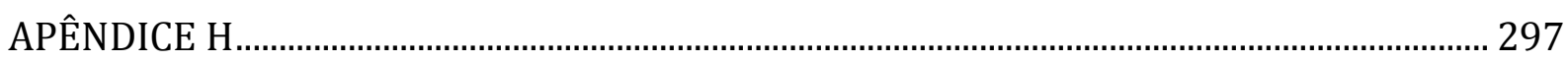

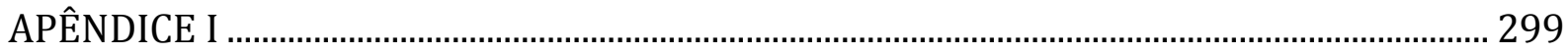

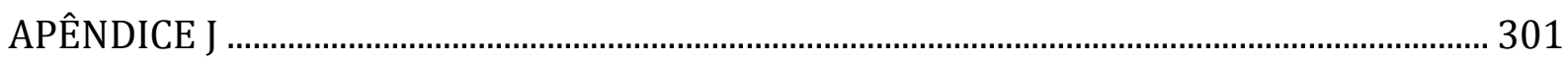

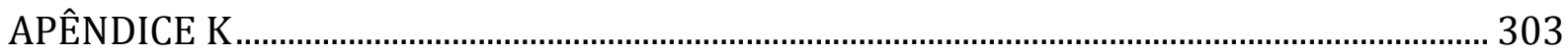

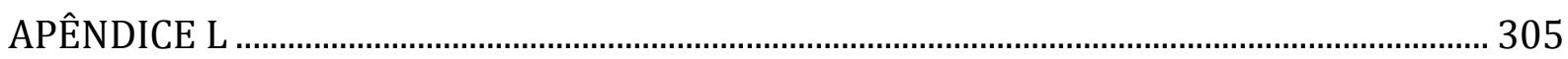

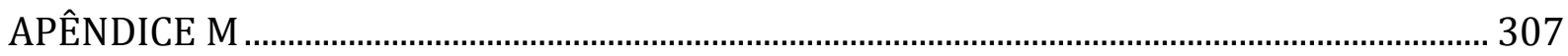

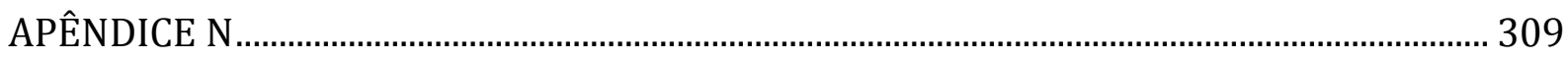

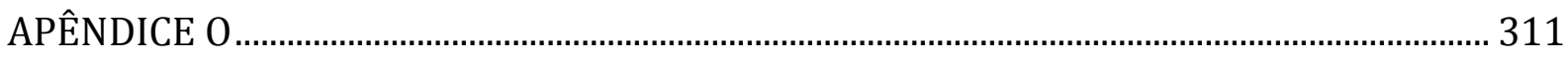

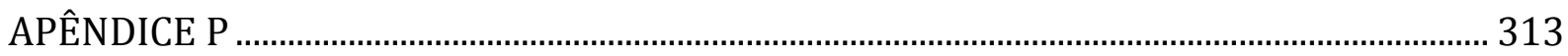


APÊNDICE Q

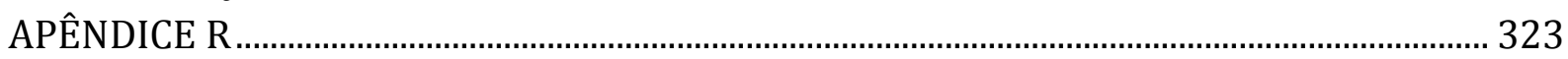

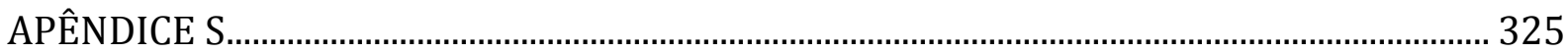

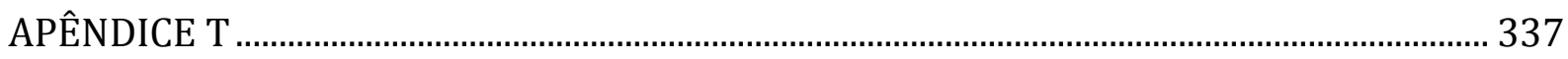

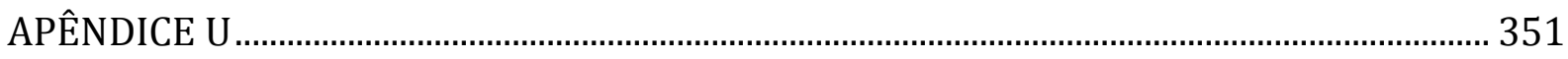

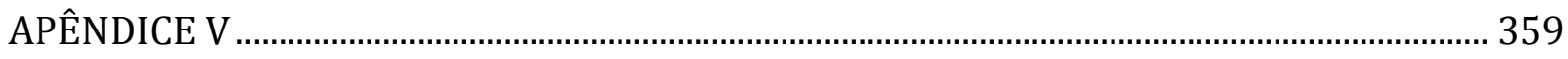




\section{INTRODUÇÃO}

Após quase vinte e cinco anos de promulgação da Lei № 8.213 de 24 de julho de 1991 (BRASIL, 1991), conhecida como a Lei de Cotas de contratação de pessoas com deficiência nas empresas, a qual teve grande influência na prestação de serviços de transportes públicos, ainda se sente a escassez de informações concretas e centralizadas que norteiem projetistas de arquitetura e desenvolvedores de produtos quando o assunto é acessibilidade.

Ao longo desse período foram sancionadas leis relacionadas à acessibilidade e mais recentemente a Organização Mundial de Saúde - OMS e o Banco Mundial lançaram o Relatório Mundial da Deficiência (OMS, 2012), documento redigido para proporcionar evidências em favor de políticas e programas inovadores capazes de melhorar a vida das pessoas com deficiência e facilitar a aplicação da Convenção das Nações Unidas sobre os Direitos das Pessoas com Deficiência. Surgiram termos como "inclusão", "desenho universal" e "acessibilidade" para tentar expressar a nova postura de valorizar as capacidades das pessoas acima de qualquer incapacidade ou dificuldade.

Analisando-se o histórico de reivindicações de pessoas com deficiências em geral, e que gerou boa parte dessas transformações, observa-se que, desde os anos 1950 até o final dos anos 1990, o principal foco dessa legislação foram as pessoas com deficiência física ou motora, em especial as pessoas que utilizam cadeira de rodas, o que pode explicar a falta de pesquisas, e consequentemente de propostas eficazes na área de adequações e orientações para pessoas com deficiência visual.

Apesar de ainda hoje a deficiência visual ser a mais comum das deficiências em todo o mundo, a acessibilidade dessas pessoas somente começou a ser discutida quando essas passaram a exigir da sociedade o pleno exercício da cidadania, demonstrando serem capazes de se relacionar socialmente, trabalhar e estudar, principalmente depois que passaram a contar com softwares leitores de tela de computador. Para Masini (1994) "pode-se supor que a desconsideração dos autores em relação a essas diferenças [entre a percepção de uma pessoa com deficiência visual e outra sem deficiência] tenha sido determinada pela desatenção à predominância da visão ou àquilo que ficou encoberto 
pela familiaridade, oculto pelo hábito, linguagem e senso comum numa cultura de videntes ${ }^{1} . "$

Face aos estudos iniciais terem sido voltados para as deficiências físicas, os primeiros parâmetros de acessibilidade em áreas públicas (ABNT, 1985; ABNT, 1994) foram focados na eliminação das chamadas barreiras arquitetônicas, chegando-se a definições como a construção de rampas, instalação de elevadores e adaptação de sanitários, entre outros. Somente mais tarde (ABNT, 2004) surgiriam parâmetros específicos destinados à acessibilidade de pessoas com deficiência visual, dentre eles, como principal, a sinalização por meio de pisos táteis.

Os parâmetros de acessibilidade definidos nas normas ABNT abrangeram edifícios públicos e a multimodalidade do sistema de transporte integrado - táxi, van, ônibus, metrô, trem. Até o surgimento das definições de acessibilidade ABNT era comum que meios de transporte fossem concebidos sem a acessibilidade para pessoas com deficiência, ou concebidos parcialmente, existindo fatores até o presente que dificultam ou mesmo impedem a sua adequação e exigem maiores intervenções e investimentos.

Adequar redes de metrô e fazer com que novas linhas e estações já nasçam acessíveis tem sido um desafio encontrado por profissionais da área metroferroviária, conforme identificado no trabalho diário de equipes de atendimento técnico e atendimento ao cliente do Metrô de São Paulo (FRATOCCHI et al., 2015). Mesmo após a adequação estabelecida pelas normas e leis, constata-se que muitos usuários com deficiência visual permanecem confusos, inseguros, solicitando o acompanhamento de funcionários do metrô para se deslocarem pelas estações.

O estímulo para a produção desta pesquisa ocorreu após a constatação da possibilidade do uso de sistemas eletrônicos no auxílio aos deslocamentos de pessoas com deficiência visual em redes de metrô. A interdisciplinaridade arquitetura/tecnologias eletrônicas tem sido usada com diversas finalidades, levando a pesquisadora a entender que poderia ser possível melhorar a acessibilidade com o desenvolvimento de um sistema integrado.

1 "Vidente" - termo comumente utilizado para referência a pessoa que enxerga, que não possui deficiência visual. 
Em detrimento das dificuldades de adequação, existe a necessidade e as evidências de que um ambiente acessível, além de especialmente importante para as pessoas com deficiência, traz benefícios para uma ampla variedade de pessoas, em vários âmbitos:

\footnotetext{
Por exemplo, os rebaixamentos de calçadas (rampas) ajudam os pais a empurrar carrinhos de bebê. Informações em linguagem simples ajudam aqueles com menor escolaridade ou aqueles não bem familiarizados com $o$ idioma local. Anúncios de cada parada no transporte público podem ajudar aos viajantes não familiarizados com a rota, bem como aqueles com deficiência visual. Além disso, os benefícios para muitas pessoas podem ajudar a gerar um amplo apoio para fazer com que as mudanças aconteçam. (OMS, 2012, p. 177)
}

\subsection{OBJETIVOS}

Investigar as formas como as pessoas com deficiência visual utilizam e interagem em seus percursos por estações e trens de metrô, para subsidiar uma possível utilização de sistemas eletrônicos para informação e navegação, à luz das variáveis cognitivas desses usuários.

Propor diretrizes a serem adotadas em projetos de sistemas eletrônicos para informação e navegação de pessoas com deficiência visual se deslocarem nas estações e trens de metrô de maneira autônoma e segura, com a definição de parâmetros necessários ao seu funcionamento.

\subsection{OBJETO DA PESQUISA}

O objeto de estudo desta pesquisa são as pessoas com deficiência visual que utilizam redes de metrô. A pesquisa de campo foi realizada no metrô de São Paulo e no metrô da cidade do Porto, em Portugal.

A escolha do metrô de São Paulo se deu por diversos motivos, dentre eles, o Metrô é um grande responsável pela operação e expansão do transporte metroviário, sistema de alta capacidade e articulador do transporte público na Região Metropolitana de São Paulo, destacando-se mundialmente pelos resultados obtidos na produção e na qualidade do serviço de transporte público de passageiros sobre trilhos, o que lhe confere características compatíveis com as necessárias para realização das pesquisas (demanda, diversidade de configurações arquitetônicas etc.). 0 metrô de São Paulo também foi 
selecionado pela disponibilidade de dados, documentos e autorização para realização de coleta de dados primários.

A escolha da realização de pesquisa no metrô do Porto, Portugal, se deu por ser este um sistema de transporte do tipo metrô que já havia instalado um serviço de informação e navegação assistida a pessoas com deficiência visual, o Navmetro ${ }^{\circledR}$, em funcionamento desde 2009. Com esse serviço, o metrô do Porto - Portugal visa proporcionar de forma gratuita aos usuários com deficiência visual, acesso a informações referentes ao transporte, tais como linhas, horários e títulos, bem como um serviço para auxílio na orientação dessas pessoas dentro das estações.

\subsection{JUSTIFICATIVAS DO ESTUDO}

A deficiência visual é a mais comum das deficiências em todo o mundo. No Brasil o IBGE (IBGE, 2012) identificou que $18,8 \%$ da população possui algum tipo de deficiência visual, enquanto que a deficiência motora, a deficiência auditiva e a deficiência mental/intelectual representam 7\%, 5,1\% e 1,4\%, respectivamente.

Espaços públicos nem sempre oferecem pontos de referência para que pessoas com deficiência visual possam circular de maneira autônoma e segura. As cidades não foram projetadas considerando-se as pessoas com deficiência visual. Por não terem acesso às informações visuais que facilitam na orientação para a mobilidade, essas pessoas ficam limitadas a certos espaços físicos, tendo restrito seu direito à liberdade de ir e vir. Os ambientes públicos, sistemas de transporte e de informação ainda são frequentemente inacessíveis a pessoas com deficiência visual. A falta de acesso ao transporte é uma razão frequente para desencorajar essas pessoas a procurar trabalho ou dificultar o uso de serviços de saúde.

Nos grandes espaços públicos, pessoas com deficiência visual têm maiores dificuldades para compreender o leiaute, a direção e a orientação, por não poderem perceber referências visuais que as pessoas sem deficiência utilizam para perceber o ambiente ou atualizar uma informação (JACOBSON, 1999). Estações de metrô, além de serem grandes espaços públicos, com diferentes configurações, ainda integram um sistema de circulação de trens, com um grande número de pessoas gerando fluxos que variam ao 
longo do dia, e até ao longo dos anos. Estações de metrô podem parecer confusas e perigosas para quem não enxerga e não está treinado para circular por elas, ainda que essas estações atendam plenamente a todos os requisitos das normas técnicas e legislação referentes ao assunto, o que torna evidente que ainda existem lacunas a esse respeito.

No Brasil, a legislação (BRASIL, 2004; ABNT, 2004; ABNT, 2005; ABNT, 2008) atualmente define basicamente a instalação de sinalização por meio de pisos táteis, mensagens sonoras de ordem informativa veiculadas nas estações e trens, e placas em Braille e letras em relevo nos elevadores, além de condições gerais, como piso nivelado, instalação de corrimãos adequados e pessoal treinado para atendimento.

Faltam definições quanto às características a serem utilizadas para suprir informações não perceptíveis por pessoas com problemas de visão, como por exemplo, a comunicação visual. Como resultado, é possível se verificar as dificuldades encontradas pelas pessoas com deficiência visual para um caminhar autônomo e seguro em ambientes de metrô, ficando clara a necessidade de haver o incremento de algum tipo de orientação para se prover melhor acessibilidade.

Cada dia mais essa situação é objeto de estudo por profissionais que executam e operam esse sistema de transporte, interessados em melhorar as condições de acessibilidade. Uma ideia que surge com frequência durante esses estudos é a de se utilizar sistemas eletrônicos para guiar esses usuários. A ideia de se utilizar tecnologias eletrônicas para esse fim surgiu originalmente nos anos 1970, e veio tomando vulto com o desenvolvimento e popularização de tecnologias que podem contribuir para seu desenvolvimento e uso.

Nos últimos anos, usuários com deficiência visual passaram a solicitar que metrôs instalem recursos eletrônicos para auxiliá-los. Tal fato pode ser explicado pelo surgimento da microeletrônica e, posteriormente, da internet, quando esse público passou a ter acesso a informações e interagir com o mundo, mitigando a necessidade de pedir ajuda a outras pessoas, permitindo-lhes experimentar uma liberdade desejada. A forte penetração de dispositivos móveis nos mercados mundiais, como aparelhos celulares e smartphones, fazem parte desse processo como uma opção estratégica para auxiliar os deslocamentos, acompanhando as pessoas no seu quotidiano. 
Por meio de pesquisas anteriores ao mestrado, obteve-se informações a respeito de pesquisas de equipamentos eletrônicos para guiar pessoas com deficiência visual em áreas públicas, verificando que as dificuldades de se realizar um projeto de sistema de orientação em estações e trens de metrô vão além da impossibilidade de uso de sinais GNSS$^{2}$ em ambientes internos. A existência de diversos sistemas nas estações, para o funcionamento da rede de metrô, também interfere em projetos de adequação, pois sistemas elétricos e eletrônicos, sistemas de ventilação e sistemas hidráulicos, não podem sofrer ou causar interferências entre si. Além disso, a maioria das estações não possui portas de plataforma, exigindo grande precisão na transmissão de sinais e nas mensagens de comando para guiar uma pessoa que não enxerga nesse ambiente.

De maneira geral, verifica-se a ausência de estudos ou trabalhos a respeito do assunto, que apresentem dados que possibilitem a profissionais realizarem projetos. Em uma investigação mais ampla, também se constata a ausência de trabalhos a respeito das formas como as pessoas com deficiência visual utilizam e se comportam em seus percursos por estações e trens de metrô, o que poderia servir de base para projetistas.

Estudos científicos têm sido estimulados pela OMS, conforme citado no seu Relatório Mundial sobre a Deficiência (OMS, 2012):

\begin{abstract}
Para ter sucesso, as iniciativas de acessibilidade precisam levar em conta as restrições externas, incluindo a exequibilidade em termos de custos, prioridades concomitantes, disponibilidade de tecnologia e conhecimento, e diferenças culturais. Estas iniciativas têm que estar baseadas em evidências científicas sólidas. (OMS, 2012, p. 177, grifo nosso)
\end{abstract}

Esse incentivo da OMS é procedente, pois o número de pessoas com deficiência está aumentando, assim como o número de pessoas idosas, conforme afirma em seu Relatório (OMS, 2012). Há também um aumento global de condições crônicas, como diabetes, doenças cardiovasculares, e distúrbios mentais, influenciando a natureza e prevalência de deficiências. Nos diferentes países, os padrões de deficiência também são influenciados por tendências nas condições de saúde, fatores ambientais e outros como acidentes automobilísticos, desastres naturais, conflitos, dietas, e abuso de drogas. (OMS, 2012).

\footnotetext{
2 GNSS - sistemas de navegação por satélite que possuam a capacidade de oferecer posicionamento em qualquer ponto da superfície terrestre. Refere-se a sistemas como o estadunidense GPS e o russo GLONASS. Existem novos sistemas em estudo, como o europeu Galileo, que promete garantias de operação. Esse assunto será abordado na fundamentação teórica.
} 
Diante do exposto, o desafio assumido foi investigar o tema, de maneira a se chegar a um delineamento de parâmetros para projeto de sistemas para guiar pessoas com deficiência visual, compreendendo-se que estes sistemas devem prover informação ${ }^{3}$ e navegação ${ }^{4}$ a seus usuários.

\subsection{ESTRUTURA DA DISSERTAÇÃO}

Este capítulo faz a introdução da dissertação. Os demais, conforme apresentado:

0 capítulo 2 apresenta a pesquisa bibliográfica de conceitos a respeito de acessibilidade, deficiência visual e cognição, percepção espacial e técnicas atualmente utilizadas em treinamentos voltados à mobilidade de pessoas com deficiência visual, para se delinear as características das pessoas que irão utilizar os sistemas eletrônicos, para se embasar um programa de necessidades a ser atendido no projeto do sistema. Ainda dentro do capítulo 2 é apresentado um balanço do atual "estado da arte" das tecnologias disponíveis para emissão de sinais e formas de captação desses sinais.

O capítulo 3 faz uma abordagem sobre metrôs, com uma explanação sobre suas principais características, de maneira a fornecer um panorama geral desse meio de transporte. Também apresenta dados pertinentes das duas redes de metrô objeto desta pesquisa: o metrô de São Paulo e o metrô do Porto.

O capítulo 4 apresenta os métodos utilizados para desenvolver esta pesquisa e como foi feita a análise dos resultados.

Os dados obtidos e as análises têm lugar no capítulo 5. São relatadas as pesquisas de campo realizadas como investigação no metrô de São Paulo e no metrô do Porto.

\footnotetext{
3 Neste estudo, o termo informação está sendo usado como referência às informações estáticas e dinâmicas necessárias para realização de uma viagem de metrô, tais como horários, linhas, estações, serviços prestados e tarifas, que geralmente são fornecidas por meio de comunicação visual, restringindo seu acesso a pessoas com deficiência visual.

${ }^{4} \mathrm{O}$ termo navegação, por muito tempo foi usado apenas como sinônimo de determinação de curso de navios e aviões, o que se dava por meio da geometria e astronomia (BAKER, 1981, p. 4). Contudo, o sistema de navegação dos aviões modernos passou a se basear em outras tecnologias que não envolvem astronomia e, mais recentemente, o termo navegação passou a ter seu uso ampliado, como por exemplo, para a navegação de automóveis e de pessoas por caminhos terrestres e ambientes construídos.
} 
As proposições baseadas na análise dos demais capítulos são feitas no capítulo 6, relacionando itens e fazendo considerações sobre parâmetros de projeto e uso de sistemas eletrônicos de informação e navegação de pessoas com deficiência visual em redes de metrô.

O capítulo 7 conclui e apresenta recomendações para dar continuidade a esta pesquisa.

Os apêndices trazem os resultados complementares obtidos nas pesquisas de campo, além do material de apoio a essas pesquisas. 


\section{FUNDAMENTAÇÃO TEÓRICA}

Este capítulo apresenta a fundamentação obtida com a pesquisa bibliográfica a respeito de acessibilidade, deficiência visual e da tarefa de navegação, assim como de tecnologias eletrônicas que possam servir de informação e/ou navegação a pessoas com deficiência visual nesse meio de transporte.

Antes de propor qualquer auxílio para a mobilidade dessas pessoas, faz-se necessário conhecer quem são, como agem, como percebem o mundo, quais suas reais dificuldades e habilidades. De acordo com Masini (1999, p.34) “[...] voltar-se para a pessoa, na totalidade de seu viver, e procurar conhecê-la, (no seu sentir, pensar e agir), e saber o que sente e entende de seus pontos de cegueira, ou áreas de visão diminuída".

Durante a investigação bibliográfica, percebeu-se que as pessoas com deficiência possuem uma estrutura corporal própria, situada em um tempo e em um espaço. Elas organizam seu mundo de acordo com sua maneira de caminhar, seus percursos e seus acessos configurados por esse corpo em movimento dentro de um contexto histórico de construção de suas identidades na cidade.

Complementarmente à maneira como se dá a relação de seu corpo com o ambiente, surgem questões a respeito das particularidades intrínsecas aos seres humanos, surgindo assim, a necessidade de se buscar informações em diversas disciplinas, em especial na psicologia ambiental, na fenomenologia, na antropologia, na sociologia, no urbanismo e na educação.

\section{$2.1 \quad$ ACESSIBILIDADE}

Para o Relatório Mundial sobre a Deficiência (OMS, 2012, p. 22), publicado com base no World Report on Disability de 2011 da OMS:

As deficiências podem ser conceituadas num continuo de dificuldades menores de funcionalidade a grandes impactos sobre a vida de uma pessoa. Os países estão cada vez mais adotando uma abordagem continuada para a mensuração, onde as estimativas de prevalência de deficiência - e funcionalidade - são derivadas da avaliação dos níveis de deficiência em múltiplas áreas [...]. 
Diversas são as conceituações de acessibilidade, mas a maioria converge para um mesmo sentido ou se complementa. As definições apresentadas neste trabalho foram selecionadas com foco na acessibilidade de pessoas com deficiência visual, para ilustrar a necessidade de adequações dos espaços públicos a esse público, em detrimento da acessibilidade pensada somente para pessoas com deficiências físicas ou também chamadas motoras.

Para Sassaki (1999), a acessibilidade é definida como a qualidade de ser acessível e facilmente compreensível por qualquer pessoa, independentemente de sua condição. Os diversos métodos de projeto concebidos nos últimos anos para resolver as inadequações entre as aptidões das pessoas e a exigência do meio podem conter pequenas diferenças conceituais, porém em todas as abordagens eliminou-se a "ditadura do Homem Médio e se reconhece e se valoriza a diversidade" (SIMÕES, 2001, p. 83).

Bins Ely (2004a, p. 20) conceitua acessibilidade como "a possibilidade tanto de acesso a um lugar quanto de uso de seus equipamentos de maneira independente". E complementa colocando que a garantia de acessibilidade se dá por meio da “identificação dos elementos que impedem ou restringem a percepção, compreensão, circulação ou apropriação por parte dos usuários dos espaços e atividades, bem como obstáculos de ordem social e psicológica que impedem seu uso efetivo".

O foco na diversidade sintetiza a essência da possibilidade de utilização por todos, e traduz o grande desafio e também a inspiração para projetos de design direcionados para fomentar um processo continuo de melhoria das condições gerais do ambiente construído.

Dentre as definições legais, no Brasil a norma NBR 9050 (ABNT, 2015, p. 2) define acessibilidade como:

possibilidade e condição de alcance, percepção e entendimento para utilização, com segurança e autonomia, de espaços, mobiliários, equipamentos urbanos, edificações, transportes, informação e comunicação, inclusive seus sistemas e tecnologias, bem como outros serviços e instalações abertos ao público, de uso público ou privado de uso coletivo, tanto na zona urbana como na rural, por pessoa com deficiência ou mobilidade reduzida. 
O termo acessível implica tanto em acessibilidade física como de comunicação. Ainda segundo a NBR 9050 (ABNT, 2015, p. 2),

acessível são os espaços, mobiliários, equipamentos urbanos, edificações, transportes, informação e comunicação, inclusive seus sistemas e tecnologias ou elemento que possa ser alcançado, acionado, utilizado e vivenciado por qualquer pessoa.

Um conceito relacionado à acessibilidade, porém mais abrangente, o Desenho Universal chegou ao Brasil na década de 1980, junto com as mobilizações e ações advindas de diversos países, na data definida como Ano Internacional de Atenção às Pessoas com Deficiência, em 1981, conforme relata Sarraf (2013). Essa data marcou o início de intercâmbios de conceitos, teorias e boas práticas, que influenciaram diretamente a criação da principal norma brasileira de acessibilidade, a ABNT NBR 9050, em 1985, cuja versão mais atual é a de 2015.

O termo Universal Design foi proposto pelo arquiteto norte-americano Ron Mace, tetraplégico, que formou, na década de 1980, um grupo de estudos ativo até a atualidade, o Center of Universal Design. A proposta de Mace é de que a concepção de ambientes acessíveis se desvinculasse de qualquer indício de exclusividade ou necessidade especial, defendendo uma arquitetura que atendesse ao máximo de usuários, sem segregação ou adequações exclusivas, proporcionando o convívio entre os diferentes, alavancando, assim, os ideais de inclusão social. (SARRAF, 2013).

Os sete princípios do Desenho Universal, definidos pelo grupo de pesquisadores associados ao projeto de Ron Mace, com o objetivo de serem aplicados a todos os ambientes, produtos e serviços, visando a maior abrangência possível de usuários, são apresentados por Sarraf (2013, p. 65):

1. IGUALITÁRIO uso equiparável: são espaços, objetos e produtos que podem ser utilizados por pessoas com diferentes capacidades, tornando os ambientes iguais para todos;

2. ADAPTÁVEL uso flexível: design de produtos ou espaços que atendam pessoas com diferentes habilidades e diversas preferências, sendo adaptáveis para qualquer uso;

3. ÓBVIO uso simples e intuitivo: de fácil entendimento para que uma pessoa possa compreender, independente de sua experiência, conhecimento, habilidades de linguagem, ou nível de concentração;

4. CONHECIDO informação de fácil percepção: quando a informação necessária é transmitida de forma a atender às necessidades do receptador, seja ela uma pessoa estrangeira, com dificuldades de visão ou audição; 
5. SEGURO tolerante ao erro: previsto para minimizar os riscos e possíveis consequências de ações acidentais ou não intencionais;

6. SEM ESFORÇO baixo esforço físico: para ser usado eficientemente, com conforto e com o mínimo de fadiga;

7. ABRANGENTE dimensão e espaço para aproximação e uso: que estabelece dimensões e espaços apropriados para o acesso, o alcance, a manipulação e o uso, independentemente do tamanho do corpo (obesos, anões etc.), da postura ou mobilidade do usuário (pessoas em cadeiras de rodas, com carrinhos de bebê, bengalas etc.).

O conceito de Desenho Universal não se aplica somente aos espaços construídos, mas também aos serviços e produtos, incluindo-se as tecnologias assistivas ${ }^{5}$. Sarraf (2013, p. 64) cita um exemplo desse tipo de aplicação:

[...] a criação dos softwares de sintetização de voz para computadores, que possibilitam que pessoas com deficiência visual trabalhem, estudem e se beneficiem socialmente dos computadores e redes de informação por meio do acesso auditivo aos dados e comandos informatizados, sendo que o uso desse recurso tem sido ampliado para as pessoas com dificuldade de locomoção nos membros superiores, pescoço e cabeça e para as pessoas com dificuldade de aprendizado. (SARRAF, 2013, p. 64).

Relacionando o conceito da acessibilidade de pessoas com deficiência visual às redes de metrô, Barbosa (2015, p. 3) complementa com outro aspecto, o de que "a acessibilidade depende não só da estação, do trem e das condições do serviço ofertado, mas também das habilidades dos usuários.".

\subsection{DEFICIÊNCIA VISUAL}

Quando se fala a respeito de uma pessoa com deficiência visual, muitas vezes se remete à ideia de uma pessoa completamente cega, que não possui nenhum resquício de visão, e que nasceu com essa deficiência. No entanto, esta é apenas uma das características de deficiência visual, cujo conceito é mais abrangente, visto que engloba desde a cegueira total até a baixa visão.

Existem muitos paradigmas a respeito das pessoas com deficiência visual como, por exemplo, pensar que elas veem tudo escuro e leem Braille obrigatoriamente, quando

\footnotetext{
${ }^{5}$ Conforme definido pelo Comitê de Ajudas Técnicas da Secretaria Nacional dos Direitos Humanos da Presidência da República do Brasil, em 2008, Tecnologia Assistiva - TA é uma área do conhecimento, de característica interdisciplinar, que engloba produtos, recursos, metodologias, estratégias, práticas e serviços que objetivam promover a funcionalidade, relacionada à atividade e participação, de pessoas com deficiência, incapacidades ou mobilidade reduzida, visando sua autonomia, independência, qualidade de vida e inclusão social.
} 
isso que não é verdade (ACAPO, 2013b). Elas também não possuem os sentidos extraordinariamente desenvolvidos; eles apenas são exercitados, como qualquer pessoa poderia fazer (HARPER, 1998).

Ressalta-se que qualquer projeto ou intervenção em espaços de metrô devem considerar seu uso por pessoas com todos os tipos e graus de deficiência visual, com as especificidades apresentadas neste estudo.

\subsubsection{Breve histórico}

Ao longo da história as pessoas cegas foram tratadas de diferentes formas, desde sinônimo de pecado a símbolo de divindade. Até hoje muitas atitudes em relação às deficiências estão presas a antigos paradigmas, tais como o tratamento assistencialista que caracterizou a Idade Média. Mosquera (2000) justifica as dificuldades para a reconstrução histórica dos relatos sobre os deficientes visuais, com a inexistência de restos arqueológicos do período pré-histórico. Segundo os diários de exploradores, os deficientes, principalmente os cegos, eram eliminados, em algumas tribos africanas. 0 nascimento de uma criança com alguma deficiência anunciava "carestia e fome”.

Baseado em vários autores, tais como Silva (1987), Amaral (1999), Bianchetti e Freire (2000), Gil (2000) e Mosquera (2000), pode-se observar que desde o princípio da história da humanidade as pessoas cegas receberam o rótulo de incapazes e, por sua vez, essa condição remetia os povos da antiguidade a pensarem que tais pessoas poderiam ser causadoras de prejuízos sociais. Para as pessoas que viveram na antiguidade, as crianças cegas eram seres tão assustadores que chegavam a ser eliminadas, tirando-se assim a possibilidade delas se desenvolverem e demonstrar seu potencial.

Ao longo da história da humanidade foram surgindo outras maneiras de tratamento às pessoas com deficiência e, com muitas dificuldades, chegou o fim do período histórico no qual não se cuidava adequadamente delas, a fim de que morressem (AMARAL, 1999). 0 novo período é então caracterizado pelo assistencialismo, com as pessoas passando a cuidar daquelas que possuíam deficiências não porque as considerassem merecedoras de auxílio, mas porque passou a existir um pensamento místico em torno da deficiência, ressaltando a crença de que "quem cuida bem de seus deficientes tem um lugar no céu". 
Por conta disso, muitas eram enviadas a conventos, a mosteiros ou a outras instituições, onde ficavam convenientemente confinadas.

Até o século XIV não se acreditava que essas pessoas pudessem se desenvolver, em função da sua "anormalidade" (SILVA, 1987). A partir de então, educadores interessados começaram a instruir, de maneira particular, crianças com deficiência. Inicialmente eram filhos de famílias bem-sucedidas financeiramente.

Telford e Sawrey (1988) mencionam que, no século XVI, um médico da cidade de Paiva, na Itália, concebeu a ideia de que seria possível ensinar os cegos a ler por meio do sentido do tato e procurou oferecer algumas instruções por aquele meio. Surgiram, então, os primeiros livros para a educação de pessoas cegas.

A partir do período denominado renascimento, com a filosofia veio a valorização do indivíduo e as pessoas começaram a gozar de uma independência religiosa e vivenciar a realidade tal como ela se apresentava, ou seja, naquela oportunidade a pessoa com deficiência passou a ser vista como pessoa. A ciência medieval amparada pela fé se desvaneceu, dando lugar ao pensamento matemático e mecânico. Esses, aliados aos outros motivos ajudaram a influenciar as necessidades educacionais de pessoas que possuíam deficiência visual (GAIO, 2006).

Foi na Europa que surgiram os primeiros movimentos em prol das medidas educacionais e atendimento a essas pessoas, esclarece Mazzotta (1996). Essas medidas foram, aos poucos, levadas para os Estados Unidos e Canadá e, posteriormente, para outros países, inclusive o Brasil. Silva (1987) menciona sobre o filósofo Diderot, que nos deixou como herança a famosa "Carta sobre os cegos", cuja importância é a proposta de ensino por meio da leitura pelo uso do tato.

Com o advento do capitalismo, cresceu a necessidade de produtividade e independência. Dessa forma, a escrita em Braille veio para dar amparo à melhoria da comunicação e da educação. Os processos de produção por meio das indústrias passaram a exigir das pessoas destreza e habilidades para o trabalho, servindo de estímulo para as pessoas com deficiência visual buscarem novas técnicas para desenvolverem suas tarefas. Paralelamente, o restante da sociedade passou a ter um compromisso, mesmo que elementar, de auxiliar nesse processo. 
Os avanços tecnológicos, a globalização do conhecimento e o aumento do volume de trabalho intelectual criaram mais oportunidades de inclusão de pessoas com deficiência. Os estudos desenvolvidos pelas universidades, junto a instituições públicas e organizações privadas, tornaram-se mais fortes, com melhores propostas e resultados sobre o tema (CARLIN, 2004). Somado a isso, temos a crescente conscientização da população com respeito aos seus direitos e à melhoria da qualidade dos serviços oferecidos à comunidade, o que acarretou a demanda por ambientes de trabalho e espaços urbanos mais acessíveis. (BINS ELY et al., 2007).

Muito tempo se passou até que começaram a surgir as primeiras instituições especializadas. Foi na França, no ano de 1760, que foi criado o Instituto Nacional de Surdos-Mudos e, em 1784, foi criado o Instituto Nacional dos Jovens Cegos. (SILVA, 1987). Com a criação desses institutos, a educação das pessoas com deficiência foi se desenvolvendo (SANT'ANNA, 2010) e, graças a essas iniciativas, a participação desse público cresceu na sociedade moderna e é, hoje, uma realidade.

No Brasil, o aparecimento da primeira instituição voltada a pessoas com deficiência visual se deu em 1600, em São Paulo, e chamava-se Irmandade da Santa Casa de Misericórdia. Em 1854, ocorreu a instalação do Instituto Benjamin Constant - IBC, organizado segundo os moldes franceses, tendo adotado o sistema Braille em seu processo educativo, aproveitando seus ex-alunos para lecionar.

Com o desenvolvimento industrial e educacional voltados para interesses da elite, instalou-se a falta de condições para o êxito institucional, de modo que nos anos 1870 e 1880 essa instituição ficou reconhecida mais como asilo do que como escola (HILDEBRANDT, 1998). Masini (1994) esclarece que, antes de ser denominado Instituto Benjamim Constant, era mencionado como Instituto dos Meninos Cegos, criado pelo Imperador Dom Pedro II, por meio do Decreto Imperial no 1.482 e que somente no período Republicano passou a se chamar Instituto Benjamim Constant, sendo essa a única instituição educacional para deficientes visuais até 1926, quando foi inaugurado o Instituto São Rafael, em Belo Horizonte.

Mazzotta (1996) cita que em 1928 foi fundado, em São Paulo, o Instituto Padre Chico. Outra grande contribuição para as pessoas com deficiência visual foi a inauguração da 
Fundação Dorina Nowill para Cegos, em 1946, antiga Fundação para o Livro do Cego no Brasil, fundada pela professora Dorina de Gouvêa Nowill.

Desde a década de 1950, segundo Gil (2000) há salas de recursos para pessoas com deficiência visual nas escolas públicas do Brasil, sendo este o país pioneiro na América Latina nesse tipo de atendimento. Em geral, os alunos com essa deficiência são alfabetizados por professores especializados e, em seguida, integrados às classes de ensino regular. Porém, somente no ano de 1975, conforme relata Amaral (1999) o documento "Declaração dos Direitos das Pessoas Deficientes", resolução elaborada pela Organização das Nações Unidas - ONU garantiu esse direito, e tais mudanças não ocorreram rapidamente. Ainda na década de 1970, as pessoas com deficiência, incluindo-se os cegos, continuavam à margem das decisões políticas e administrativas relativas ao próprio processo de desenvolvimento.

Nos anos 1990 surgiram outras propostas reafirmando a inclusão, como a Declaração Mundial de Educação Para Todos, aprovada pela ONU e, em seguida, a Organização das Nações Unidas para Educação, Ciência e Cultura - UNESCO registrou na Declaração de Salamanca, em 1994, o conceito de inclusão no campo da educação comum, e também o de sociedade inclusiva. Em 1996, na Assembleia Geral da ONU, foi aprovado o Documento de Normas sobre a Equiparação de Oportunidades para Pessoa com Deficiência, no qual apontam que a educação comum é responsável pela educação de pessoas com deficiência em ambientes inclusivos (SASSAKI, 1999).

Com o acesso ao trabalho, essas pessoas passaram a poder adquirir produtos que lhes permitem melhor qualidade de vida, diferentemente de uma época em que dependiam do assistencialismo para sobreviver; hoje já possuem autonomia inclusive para intervir efetivamente no planejamento e desenvolvimento de produtos e serviços que sejam de seu interesse. (SANT'ANNA, 2010, p. 155).

Atualmente, de acordo com Pereira (2015):

Pessoas cegas ou com baixa visão que tenham passado por um processo de habilitação ou reabilitação e estão ativas no mercado de trabalho, viajam; utilizam táxis, hospedam-se em pousadas, hotéis, frequentam festas, teatros e shows; e consomem em restaurantes, bares, mercados, farmácias, perfumarias e outros, comumente com total independência. 


\subsubsection{Conceituação}

De maneira geral, deficiência visual é um termo utilizado para referência a impedimentos de origem orgânica relacionados a patologias oculares, que levam a um mau funcionamento visual ou à ausência de visão. Para se referir às diferentes modalidades de deficiência visual, são utilizados os termos "cegueira" e "baixa visão" ou "visão subnormal".

Entre $70 \%$ e $80 \%$ das pessoas que possuem deficiência visual não são totalmente cegas, possuindo alguma visão útil (HARPER, 1998; AMIRALIAN, 2004; HONORATO, 2013). Esta informação é pouco conhecida pela maioria da população, mas muito importante para que se compreenda um dos motivos pelo qual sinalizações, como pisos táteis, e objetos, como os apoios de mão de trens e de ônibus, devam ter cores contrastantes com as do ambiente. Qualquer resíduo visual poderá ajudar as pessoas com baixa visão na realização de inúmeras tarefas (AMIRALIAN, 2004). A Associação de Cegos e Amblíopes de Portugal (ACAPO, 2013a) resume: "a maioria de pessoas com deficiência visual tem alguma visão e pretende tirar proveito dela".

Embora há muito tempo as conceituações sobre deficiência visual considerem as diferenças entre pessoas cegas e pessoas com baixa visão, só a partir da década de 1970, aqui no Brasil, é que se observa uma preocupação dos especialistas com a questão da baixa visão. Conforme Amiralian (2004, p. 17):

[...] o nome que, no Brasil, passou-se a usar foi "visão subnormal", uma tradução do termo "low vision" usado por BARRAGA $(1964)^{6}$. Esse termo é, até o momento, bastante usado, inclusive em documentos oficiais. Observa-se, todavia, que também essa terminologia está em processo de transformação.

Segundo a mesma autora, os especialistas têm procurado utilizar o termo "baixa visão", acreditando que isto tende a minimizar o preconceito que o termo "subnormal" pode provocar. Esses termos se baseiam na avaliação da acuidade visual, campo visual, sensibilidade ao contraste, visão de cores e outros aspectos. Acuidade se refere à capacidade de discriminação de formas, avaliada por meio da apresentação de linhas, símbolos ou letras progressivamente menores. Quando a acuidade é baixa, a pessoa tem dificuldade de perceber formas, seja de perto, à distância, ou em ambas as situações.

\footnotetext{
${ }^{6}$ BARRAGA, N. C. Increased visual behavior in low vision children. New York: American Foundation for
} the Blind, 1964. 
Campo visual se refere à amplitude de estímulos que a pessoa tem condições de perceber, sendo o campo normal de quase 180 graus, e havendo patologias em que este campo se restringe a menos de 20 graus, o que dificulta a sua mobilidade (BATISTA; ENUMO, 2000).

Como exemplos ilustrativos sobre as formas como pessoas com baixa visão enxergam, as que tiveram problema devido à catarata, deslocamento de retina ou retinopatia diabética possuem a visão turva, como um borrão; quando o problema foi a degeneração macular, a pessoa não possui a visão central, apenas a periférica; a retinose pigmentosa, de forma oposta, leva a uma condição conhecida como visão de túnel, quando um indivíduo só pode ver o que está à sua frente, sem a visão periférica.

Conforme Bernardi (2007, p. 91), “o campo visual central é mais importante para a percepção de detalhes e cores, enquanto o campo periférico é importante para a localização de objetos, orientação e locomoção. A ocorrência de determinadas patologias pode comprometer o campo visual na região central ou periférica e, consequentemente, influenciar no funcionamento visual". A Figura 2.1 mostra alguns exemplos de diferentes tipos de visão fornecidos por Bradley e Dunlop (2005, p. 2). 
Figura 2.1 - Exemplos de diferentes tipos de visão.

(a) - Visão normal.

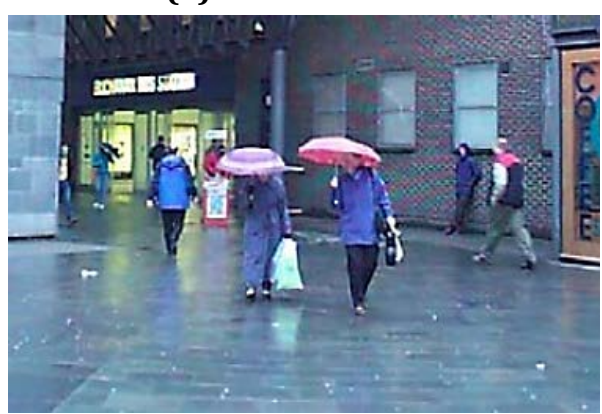

(c) - Possível efeito de catarata avançada.

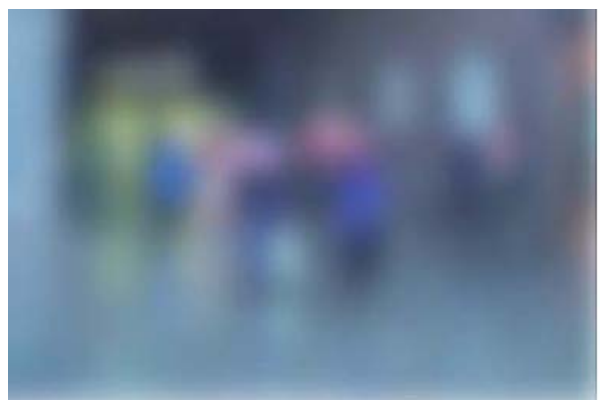

(b) - Perda da visão central (geralmente causada pela degeneração macular).

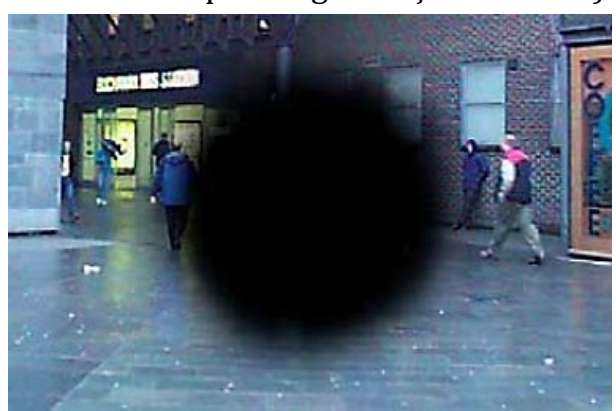

(d) - Metade do campo de visão perdida (possivelmente devido a acidente vascular cerebral ou traumatismo craniano).

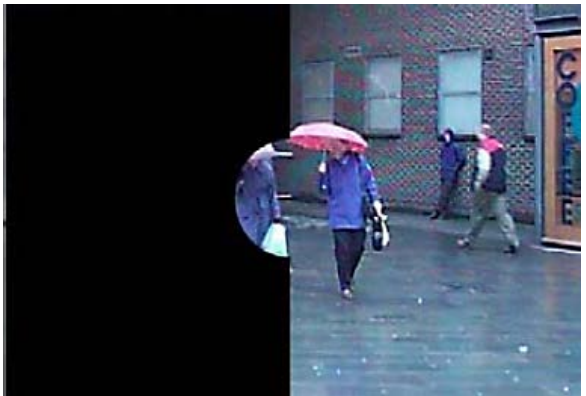

Fonte: Bradley e Dunlop (2005, p. 2 - tradução nossa).

Apesar da busca pela compreensão a respeito da capacidade visual de pessoas com baixa visão, testes demonstraram que sujeitos com acuidade visual idêntica podem possuir eficiência visual diversa (AMIRALIAN, 1997). A grande maioria de sujeitos com a mesma medida oftalmológica de visão apresentam diferenças na utilização do resíduo visual, dependendo, nestes casos, da condição psíquica de tais pacientes, na conclusão desse autor. Como as medidas de quantificação das dificuldades visuais mostram-se insuficientes ou insatisfatórias por si só, é muito importante estabelecer uma relação entre a mensuração e o uso prático da visão. Segundo Ferroni e Gasparetto (2011, p. 1092),

a necessidade visual irá depender de indivíduo para indivíduo. Algumas pessoas podem apresentar a mesma acuidade visual, no entanto, fazem uso de formas diferentes de seu resíduo visual e conseguem aproveitá-lo mais que outros que possuem o mesmo tipo de problema. Daí a necessidade de compreensão dos fatores psicológicos, ambientais, pessoais e sociais que permeiam esta problemática (GASPARETTO et al., 2004)7.

\footnotetext{
${ }^{7}$ GASPARETTO, M. E. R. F. et al. Dificuldade visual em escolares: conhecimentos e ações de professores do ensino fundamental que atuam com alunos que apresentam visão subnormal. Arquivos brasileiros de oftalmologia, São Paulo, 2004. v. 67, n.1, p. 65-71.
} 
Felippe (Informação verbal) ${ }^{8}$ reforça a colocação a respeito da diversidade, afirmando que "compreender o que uma pessoa com baixa visão consegue enxergar é um desafio até para os oftalmologistas; pode-se ter dois diagnósticos idênticos com resultados completamente diferentes".

Quando o indivíduo nasce ou adquire a deficiência até aos cinco anos de idade é considerada deficiência visual congênita. Após isso, é denominada deficiência visual adquirida ou adventícia (ORMELEZI, 2000; NUNES; LOMÔNACO, 2008). Segundo Ormelezi (2000, p. 28), "estudos indicam que, perdendo a visão até esse momento, não há retenção de imagens visuais, ou seja, a criança não poderá contar com uma memória visual como referência para suas construções mentais".

A proporção de pessoas com deficiência visual congênita é muito pequena, em relação à quantidade da adquirida. Segundo a OMS, a proporção de pessoas com cegueira adquirida na infância sobre o universo total de pessoas com deficiência visual é de apenas 6,4 \%, conforme relação das principais causas de cegueira no Brasil ${ }^{9}$ (OMS, 2014):

- Catarata não operada - $40 \%$

- Glaucoma - $15 \%$

- Retinopatia diabética - $7 \%$

- Cegueira na infância $10-6,4 \%$

- Degeneração macular relacionada à idade - $5 \%$

Harper (1998) destaca que, estudos de indivíduos com deficiência visual congênita e adquirida demonstraram existir diferenças entre os dois tipos, com relação às informações espaciais. Os congênitos apresentam dificuldades para acompanhar a sua posição no ambiente, embora não haja uma perda significativa da mobilidade; já os que tiveram experiência visual anterior são melhores em decodificar informações espaciais. Isto tem implicações significativas no planejamento de dispositivos de auxílio à mobilidade.

\footnotetext{
${ }^{8}$ Informação fornecida pelo professor de Orientação e Mobilidade João Álvaro de Moraes Felippe em 16 dez. 2014, São Paulo.

${ }^{9}$ As demais causas são outros tipos de doenças e acidentes, que neste caso, não são relevantes para a OMS, que é focada em condições de saúde e de doenças.

${ }^{10}$ A principal causa da cegueira na infância é a exposição de bebês prematuros em câmaras de oxigênio, causando a denominada retinopatia da prematuridade.
} 


\subsubsection{Classificação}

As classificações de deficiência visual são utilizadas para diversos fins. Este trabalho aborda somente as mais relevantes para o tema da pesquisa.

A classificação legal é utilizada por programas de assistência e previdência social para fornecimento de benefícios, assim como para proporcionar a equiparação de oportunidades; apoia-se em níveis de acuidade visual utilizados na oftalmologia, dividindo-a em "cegueira" e em "baixa visão". No Brasil o Decreto Federal No 5.296 (BRASIL, 2004) define como:

Deficiência visual/cegueira, na qual a acuidade visual é igual ou menor que 0,05 no melhor olho, com a melhor correção óptica; a baixa visão, que significa acuidade visual entre 0,3 e 0,05 no melhor olho, com a melhor correção óptica; os casos nos quais a somatória da medida do campo visual em ambos os olhos for igual ou menor que $60^{\circ}$; ou a ocorrência simultânea de quaisquer das condições anteriores.

A classificação médica é utilizada por oftalmologistas para diagnosticar, tratar e orientar a pessoa com deficiência visual. É definida por meio de exames oftalmológicos e segue parâmetros internacionais. A partir de reunião realizada em Sidnei, Austrália, pelo Conselho Internacional de Oftalmologia (ICO, 2002), a Organização Mundial De Saúde (MASINI; CHAGAS; COVRE, 2006), passou a utilizar a classificação da Tabela 2.1. 
Tabela 2.1 - Classes de acuidade visual definidas pela OMS.

\begin{tabular}{|c|c|}
\hline Classificação & Acuidade visual \\
\hline Visão normal & $\begin{array}{c}20 / 10 \text { a } 20 / 25 \\
2,0 \text { a } 0,8\end{array}$ \\
\hline Próxima do normal & $\begin{array}{c}20 / 30 \text { a } 20 / 60 \\
0,7 \text { a } 0,3\end{array}$ \\
\hline Baixa visão moderada & $\begin{array}{c}20 / 70 \text { a } 20 / 160 \\
0,25 \text { a } 0,12\end{array}$ \\
\hline Baixa visão severa & $\begin{array}{c}20 / 200 \text { a } 20 / 400 \\
0,10 \text { a } 0,05 \\
\text { Campo visual: } 20 \text { graus ou menos }\end{array}$ \\
\hline Baixa visão profunda & $\begin{array}{c}20 / 500 \text { a } 20 / 1000 \\
0,04 \text { a } 0,02 \\
\text { Capaz de contar dedos a } 3 \text { m ou menos } \\
\text { Campo visual: } 10 \text { graus ou menos }\end{array}$ \\
\hline Próximo à cegueira & $\begin{array}{c}\text { menos de } 20 / 1000 \\
\text { menos de } 0,02 \\
\text { Capaz de contar dedos a } 1 \text { m ou menos } \\
\text { Capaz de ver movimentos das mãos a } 5 \mathrm{~m} \text { ou } \\
\text { menos } \\
\text { Luz projetada, luz percebida } \\
\text { Campo visual: } 5 \text { graus ou menos }\end{array}$ \\
\hline Cegueira total & Sem percepção de luz \\
\hline
\end{tabular}

Fonte: Elaborado a partir de ICD-9-CM (CDC, 2003, p. 215).

Mas não é somente a acuidade visual que define a deficiência. De acordo com Amiralian (1997, p. 12):

A restrição do campo visual, a chamada visão de túnel, também é considerada cegueira, independentemente da acuidade visual possuída pelo sujeito, porque qualquer visão nesta amplitude impede a apreensão do ambiente como um todo, uma das características fundamentais da percepção visual.

A Classificação Internacional de Funcionalidade, Incapacidade e Saúde - CIF publicada pela Organização Mundial da Saúde - OMS em maio de 2001 e traduzida para a língua portuguesa em 2003, apresenta o modelo mais sistêmico, que analisa as diversas condições de saúde do ser humano, em associação aos aspectos ambientais.

A CIF substitui os conceitos negativos utilizados pela classificação anterior, a CIDID ${ }^{11}$, de "deficiência", "incapacidade" e "desvantagem". Teixeira (2013, p. 29) explica que "a CIF é considerada um modelo social de classificação de incapacidade, diferente do modelo médico que considera a incapacidade como um problema da pessoa, causado diretamente pela doença, trauma ou outro estado de saúde". Na CIF, a incapacidade é um conjunto de condições muitas vezes criado pelo ambiente social, conforme completa a

${ }^{11}$ Classificação Internacional das Deficiências, Incapacidades e Desvantagens (handicaps) - CIDID 
mesma autora: "o modelo social da CIF considera a questão principalmente como um problema criado socialmente e basicamente, como uma questão de interação plena do indivíduo com a sociedade" (TEIXEIRA, 2013, p. 29).

O primeiro capítulo da CIF "trata dos produtos naturais ou fabricados pelo homem ou sistemas de produtos, equipamentos e tecnologias existentes no ambiente imediato do indivíduo que são reunidos, criados, produzidos ou manufaturados" (OMS, 2004, p. 154) e cita a definição das ajudas técnicas contida na classificação ISO 999912 (ISO, 2002 apud OMS, 2004): "qualquer produto, instrumento, equipamento ou sistema técnico utilizado por uma pessoa incapacitada, especialmente produzido ou geralmente disponível, que se destina a prevenir, compensar, monitorizar, aliviar ou neutralizar a incapacidade".

Nesse mesmo capítulo, a CIF (OMS, 2004) fornece um esquema de codificação para sistemas de informação em saúde a respeito de "produtos e tecnologias de apoio destinados a facilitar a mobilidade e o transporte pessoal em ambientes interiores e exteriores" (OMS, 2004, p. 155), incluindo "equipamentos, produtos e tecnologias adaptados ou especialmente concebidos para ajudar as pessoas a se deslocarem dentro e fora dos edifícios, tais como, dispositivos para mobilidade pessoal, [...] e dispositivos para deslocações de um local para outro" (OMS, 2004, p. 155), identificando e classificando o que estes itens podem interferir nos processos de reabilitação e funcionalidade das pessoas.

Aguiar (2010, p. 24) também aponta que um dos pontos mais importantes verificados na CIF é o aspecto que mostra a maneira como a deficiência depende do ambiente ao qual está ligada e também, da estrutura do corpo do indivíduo. Recomendando-se que estudos adicionais sejam realizados por profissionais e pesquisadores de diversas disciplinas e setores, ressaltam Farias e Buchalla (2005, p. 192):

até o presente, apesar do interesse pela adoção do modelo da CIF, existem poucos estudos em curso sobre a avaliação do seu impacto na atenção à saúde. Isso decorre de ser uma classificação recente, complexa e que apresenta certo grau de dificuldade em sua utilização.

${ }^{12}$ A ISO 9999 classifica as ajudas técnicas para pessoas com incapacidade. 


\subsubsection{Estatísticas}

A deficiência visual é uma das causas mais comuns de incapacidade em todo o mundo. Segundo os dados da OMS, em 2014, considerando a população mundial, mais de 161 milhões de pessoas apresentam alguma deficiência visual, dos quais 124 milhões têm baixa visão e 37 milhões são cegos. Estes dados estariam distribuídos da seguinte forma (OMS, 2014):

Por idade: Mais de $82 \%$ das pessoas deficientes visuais tem idade igual ou superior a 50. No entanto esse número só representa $19 \%$ da população mundial. Globalmente, aproximadamente 1.4 milhões de pessoas com idade abaixo de 15 anos são deficientes visuais.

Por gênero: Em todas as regiões do mundo, as mulheres, independentemente da idade, têm significativamente mais risco de apresentar deficiência visual em relação aos homens.

Geograficamente: Mais de $90 \%$ da população mundial de deficientes visuais vivem em países em desenvolvimento, dos quais $17 \%$ se situam no continente africano, $26 \%$ estão localizados na região oeste do pacífico e $27 \%$ no sudeste da Ásia.

No Brasil, durante o Censo Demográfico mais recente, em 2010, em uma compilação de 2012, 45.606.048 milhões de pessoas declararam ter pelo menos um tipo de deficiência, correspondendo a 23,9\% da população brasileira (IBGE, 2012). Dessa porcentagem prevalece a deficiência visual, com 18,8\% da população, enquanto que a deficiência motora, a deficiência auditiva e a deficiência mental/intelectual representam 7\%, 5,1\% e 1,4\%, respectivamente, conforme Gráfico 2.1.

Gráfico 2.1 - Porcentagem de pessoas com deficiências, por tipo

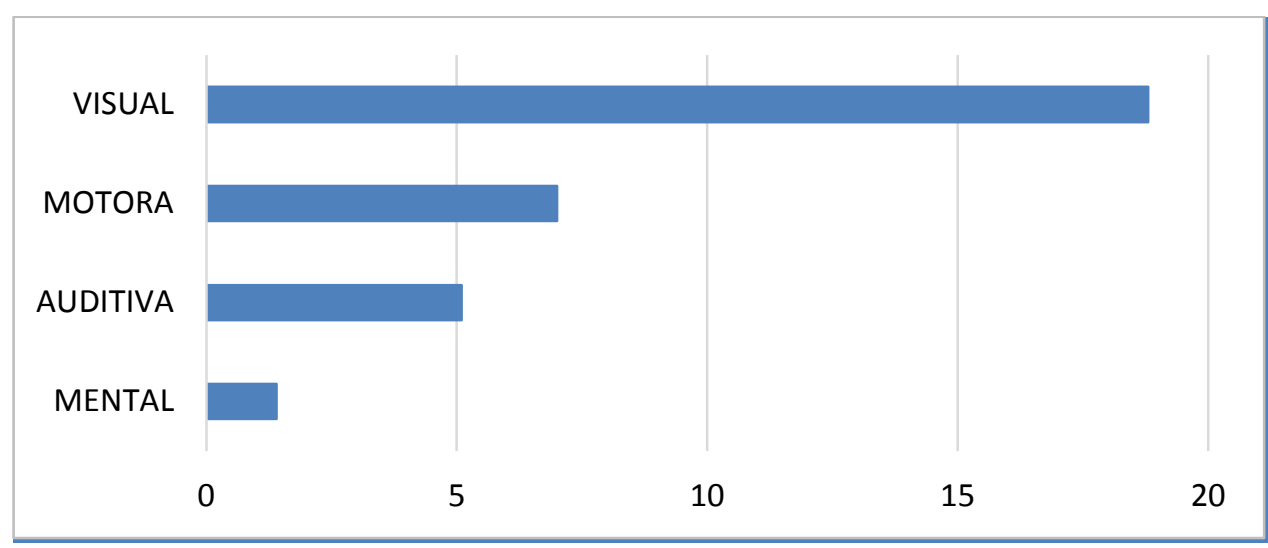

Fonte: Elaborado com base nos dados de IBGE, 2012.

Somados os valores individuais respectivos a cada tipo de deficiência, será ultrapassado o total de 23,9\%; isso se dá em função de que existem pessoas que possuem mais do que 
uma deficiência declarada. 0 Censo também identificou separadamente o número de pessoas que declararam ter nenhuma capacidade ("não consegue de modo algum"), "grande dificuldade" ou "alguma dificuldade", dentro de cada tipo de deficiência. 0 Gráfico 2.2 ilustra os valores declarados.

Gráfico 2.2 - Divisão por grau de dificuldade, dentro de cada tipo de deficiência.

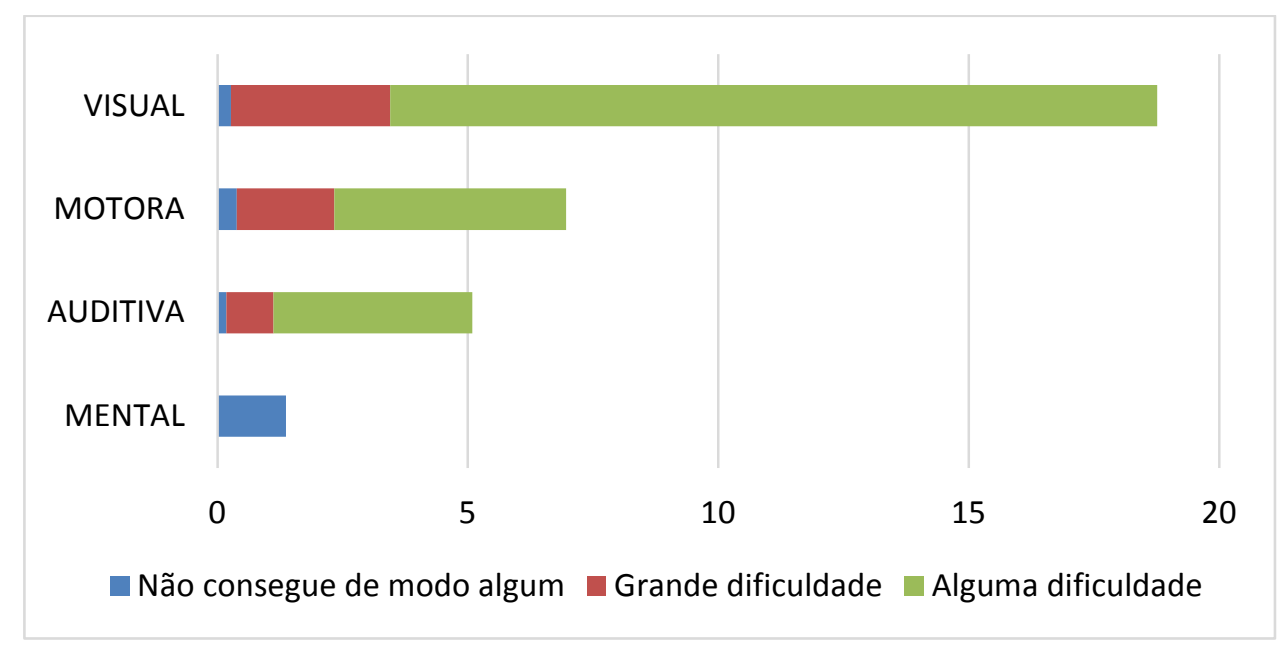

Fonte: Elaborado com base nos dados de IBGE, 2012.

O número obtido com a soma dos valores referentes a "não consegue de modo algum" e "grande dificuldade" do Gráfico 2.2 refere-se às deficiências severas, e é utilizado geralmente para concessão de benefícios legais, como pensão ou gratuidade, porém na prática observa-se que o número de pessoas a serem consideradas nos projetos de adequações à acessibilidade é bem maior, especialmente com relação à deficiência visual. ${ }^{13}$

Dentre as pessoas identificadas com deficiência visual pelo Censo, temos o Gráfico 2.3 ilustrando os grupos de idade, o qual demonstra que a maioria dessas pessoas possui mais de 40 anos de idade.

13 O Censo Demográfico 2010, (INSTITUTO BRASILEIRO DE GEOGRAFIA E ESTATÍSTICA, 2012), informa que foi pesquisado se a pessoa tinha dificuldade permanente de enxergar (avaliada com o uso de óculos ou lentes de contato, no caso de a pessoa utilizá-los), de acordo com a seguinte classificação:

- Não consegue de modo algum - para a pessoa que declarou ser permanentemente incapaz de enxergar;

- Grande dificuldade - para a pessoa que declarou ter grande dificuldade permanente de enxergar, ainda que usando óculos ou lentes de contato;

- Alguma dificuldade - para a pessoa que declarou ter alguma dificuldade permanente de enxergar, ainda que usando óculos ou lentes de contato; ou

- Nenhuma dificuldade - para a pessoa que declarou não ter qualquer dificuldade permanente de enxergar, ainda que precisando usar óculos ou lentes de contato. 
Gráfico 2.3 - Grupos de idade de pessoas com deficiência visual - números absolutos.

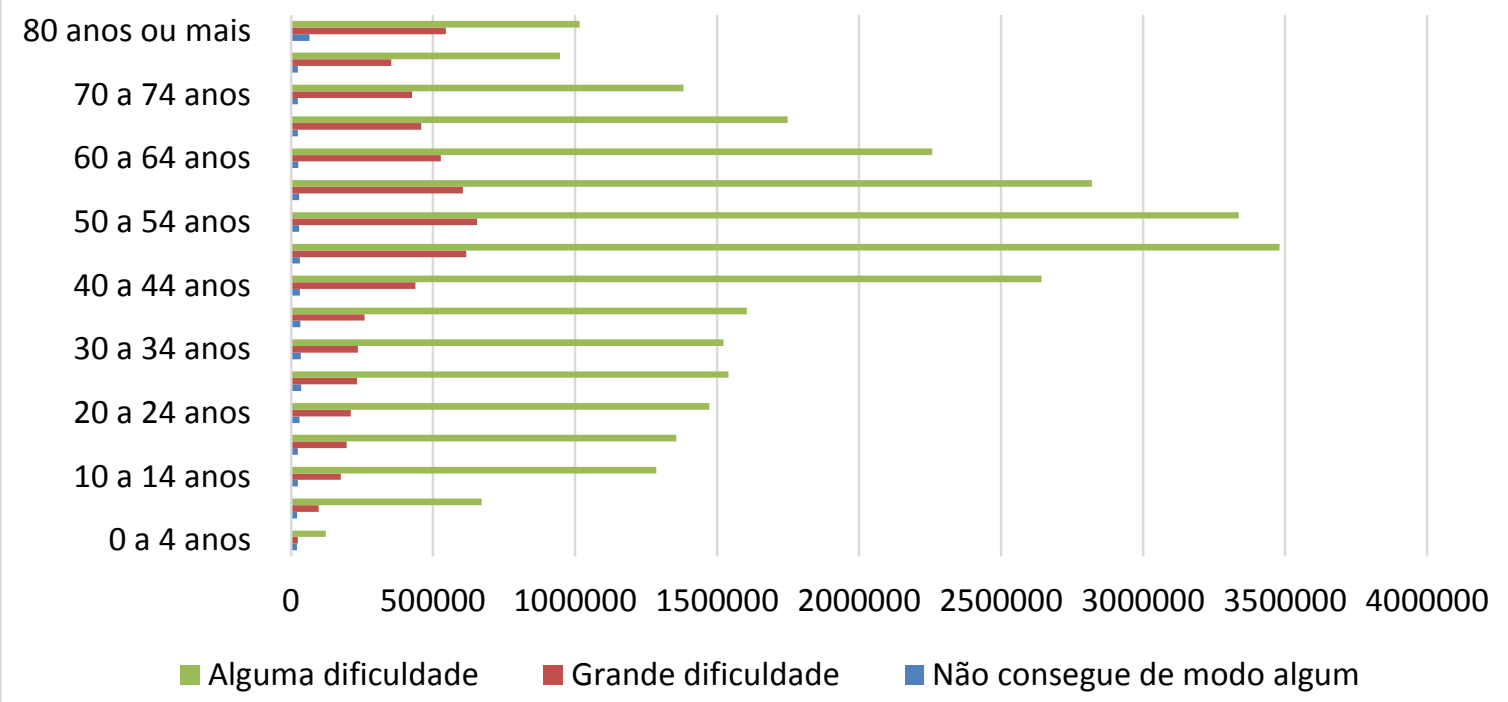

Fonte: Elaborado com base nos dados de IBGE, 2012.

Com relação aos rendimentos, o Censo apresentou uma tabela com número de pessoas com 10 anos ou mais de idade, ocupadas na semana de referência da pesquisa, e o valor de seus rendimentos. No Gráfico 2.4 estão apresentados estes dados, computados em porcentagem dentro de cada tipo de dificuldade de deficiência visual, evidenciando-se que a grande maioria recebe de 0,5 a 2 salários mínimos, qualquer que seja a dificuldade visual. Este dado pode ser útil na análise de custos ao consumidor final de auxílios tecnológicos. 
Gráfico 2.4 - Rendimento mensal em salários mínimos - porcentagem dentro de cada grupo.

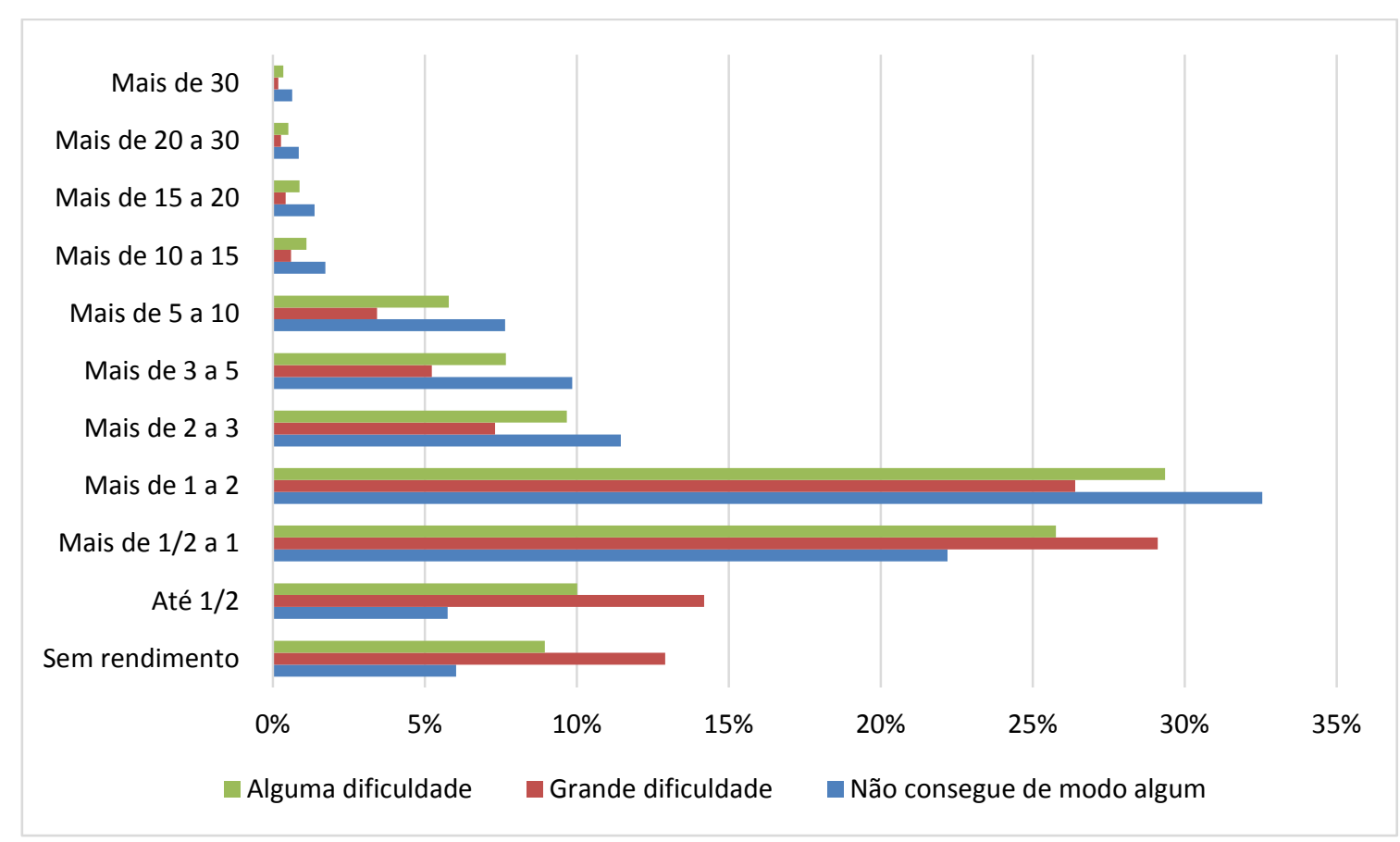

Fonte: Elaborado com base nos dados de IBGE (2012).

\subsubsection{Legislação brasileira}

Um importante referencial que fomentou a necessidade de adequação de espaços e transportes públicos, ainda que indiretamente, foi a promulgação da Lei de Cotas de contratação de pessoas com deficiência nas empresas, Lei № 8.213 de 24 de julho de 1991 (BRASIL, 1991), que dispõe sobre percentuais de destino de cargos para empregados com deficiência em empresas e sobre os planos de benefícios da previdência.

Desde meados da década de 2000, a Lei de Cotas vem sendo fiscalizada com rigor pelo Ministério Público, que aplica multas para os estabelecimentos que não estão cumprindo-a, ou estão cumprindo-a de forma indevida (SARRAF, 2013). Essa questão influenciou diretamente os sistemas de transporte, pois essas pessoas inseridas no mercado de trabalho necessitam se deslocar de suas casas até seus postos.

Em 2000 foram sancionadas duas importantes leis para a promoção da acessibilidade: a Lei No 10.048, de 8 de novembro de 2000 (BRASIL, 2000a), que dá prioridade de atendimento às pessoas com deficiência, aos idosos com idade igual ou superior a 60 anos, às gestantes, às lactantes e às pessoas acompanhadas por crianças de colo, e a Lei 
No 10.098, de 19 de dezembro de 2000 (BRASIL, 2000b), que estabelece normas gerais e critérios básicos para a promoção da acessibilidade das pessoas com deficiência ou com mobilidade reduzida, além de outras providências.

Em 2004, essas leis foram revisadas e incluídas no Decreto Federal no 5.296 (BRASIL, 2004), que regulamentou as leis de 2000. O Decreto Federal no 5.296 passou a ser a principal referência legal às questões de acessibilidade. 0 Decreto define que devem ser atendidas as normas brasileiras de acessibilidade, dando poderes legais às normas técnicas da ABNT.

A Associação Brasileira de Normas Técnicas - ABNT, associação civil sem fins lucrativos, fundada em 1940, é o órgão responsável pela normalização técnica no país. No quesito acessibilidade, a NBR 9050 redigida em 1985 (ABNT, 1985) foi a primeira norma brasileira que dispôs sobre os requisitos básicos de acessibilidade. Em 1994, ocorreu sua primeira revisão, com o objetivo de torná-la mais compreensível para os profissionais que a colocariam em prática (ABNT, 1994), porém a versão mais abrangente e completa foi a versão de 2004 (ABNT, 2004), que teve como objetivo estabelecer critérios e parâmetros técnicos que devem ser observados quando do projeto, construção, instalação e adaptação de edificações, mobiliário, espaços e equipamentos urbanos às condições de acessibilidade.

Além da NBR 9050, existem normas complementares específicas, como a NBR 14021 (ABNT, 2005), que define parâmetros de acessibilidade nos sistemas de trens urbanos e metropolitanos, abordando as condições dos trens, das estações, e das situações de emergência. Sistemas de transporte também devem atender à NBR 15599 (ABNT, 2008), que trata da acessibilidade na comunicação na prestação de serviços.

Apesar da grande abordagem sobre acessibilidade, estas normas não definem quais as soluções a serem utilizadas para suprir informações não perceptíveis por pessoas com problemas de visão, como por exemplo, a comunicação visual. Chegam a mencionar que deve haver comunicação alternativa, e chega-se até a algumas definições, mas não esclarecem a respeito de soluções para navegação de pessoas com deficiência visual.

Complementando a legislação brasileira voltada à promoção da acessibilidade no Brasil, tem-se o Decreto no 6.949 (BRASIL, 2009), que promulgou a Convenção Internacional 
sobre os Direitos das Pessoas com Deficiência e seu Protocolo Facultativo redigido pela ONU, assinados em 2007. Com essa lei, o Brasil se comprometeu a fazer valer todas as diretrizes e direitos garantidos às pessoas com deficiência em termos mundiais.

Um reforço do Governo Federal na promoção da acessibilidade foi o lançamento da Política Nacional de Mobilidade Urbana, em 2012, por meio da promulgação da Lei № 12.587, de 3 de janeiro de 2012 (BRASIL, 2012), com o objetivo de integrar os diferentes modos de transporte e a melhoria da acessibilidade e mobilidade das pessoas e cargas no território dos municípios.

Existem também diversas outras leis federais que abordam a questão da acessibilidade; algumas delas são: Lei $n^{\circ}$ 7.405, de 1985 - Torna obrigatória a colocação do "Símbolo Internacional de Acesso" em todos os locais e serviços que permitam sua utilização por pessoas com deficiência; Lei $n^{\circ}$ 7.853, de 1989 - Dispõe sobre o apoio às pessoas com deficiência, sua integração social, sobre a Coordenadoria Nacional para Integração da Pessoa Portadora de Deficiência - CORDE, institui a tutela jurisdicional de interesses coletivos ou difusos dessas pessoas, disciplina a atuação do Ministério Público, define crimes, e dá outras providências; Lei no 8.899, de 1994 - Concede passe livre às pessoas com deficiência no sistema de transporte coletivo interestadual e Lei no $11.126 / 05$ dispõe sobre o direito da pessoa com deficiência visual de ingressar e permanecer em ambientes de uso coletivo acompanhado de cão-guia.

Em 2012, a Organização Mundial de Saúde - OMS e o Banco Mundial lançaram o Relatório Mundial da Deficiência (OMS, 2012), documento redigido para proporcionar evidências a favor de políticas e programas inovadores capazes de melhorar a vida das pessoas com deficiência e facilitar a aplicação da Convenção das Nações Unidas sobre os Direitos das Pessoas com Deficiência. Esse tratado internacional reforçou a prioridade de direitos humanos e de desenvolvimento. 
Analisando-se o escopo legal, observa-se um aumento na conscientização de gestores públicos municipais quanto à importância de se prever projetos de acessibilidade e inclusão nas políticas públicas e locais. Mas ainda há muito a ser feito para que os municípios brasileiros ponham em prática um planejamento específico para as necessidades de cada cidade no que diz respeito a essa área. Conforme citado por Gonçalves et al. (2013, p. 3),

observa-se nos diversos ambientes das cidades que existe, ainda, um longo caminho a ser trilhado na garantia desses princípios e direitos e na construção de espaços sem barreiras, que promovam a inclusão de todos no acesso aos serviços básicos e à urbanidade.

\subsubsection{Cognição e percepção espacial}

Cognição diz respeito à compreensão e à capacidade de manipular a informação. 0 tratamento da informação se dá por meio das atividades mentais. É preciso se entender cognição para compreensão a respeito de percepção espacial de pessoas com deficiência visual. Neste trabalho foram considerados estudos sobre percepção do ambiente e sobre os diferentes canais sensoriais de pessoas com e sem a deficiência.

Percepção, no sentido da psicologia e das ciências cognitivas, refere-se a "como a informação é assimilada do ambiente pelos diferentes órgãos sensitivos [...]. A visão é o sentido mais dominante, seguido pela audição e pelo tato" (ROGERS; SHARP; PREECE, 2013, p. 71). Quando falta a visão, faz-se necessária a compensação deste sentido, para poder se orientar e conseguir se locomover de forma autônoma e segura. Outras percepções sensoriais, como a audição, o sistema háptico ou tato ativo ${ }^{14}$, a cinestesia ${ }^{15}$, a memória muscular, o sentido vestibular ou labiríntico, o olfato e o aproveitamento máximo de qualquer grau de visão que possa ter, podem ser utilizados para percepção dos ambientes e locomoção (LORA, 2003).

A percepção pode ser descrita como a forma como vemos o mundo à nossa volta, o modo segundo o qual o indivíduo constrói em si a representação e o conhecimento que possui

\footnotetext{
${ }^{14}$ Sistema háptico ou tato ativo é o responsável pela percepção de formas, dimensões e proporções dos objetos manipulados. Também é responsável pela percepção de peso e consistência desses objetos (SCHIFFMAN, 2005).

${ }^{15}$ Cinestesia é a percepção dos movimentos espaciais das partes corporais, dos movimentos musculares (SCHIFFMAN, 2005). "Com a ajuda do sentido cinestésico (memória muscular), é possível subir uma escada automaticamente, sem a preocupação de medir com os pés a altura de cada degrau." (VALENTINI, 2012, P. 3).
} 
das coisas, pessoas e situações (SERRANO, 2004). Os estímulos são captados pelos órgãos dos sentidos, que os envia ao cérebro, realizando um processo por meio do qual um indivíduo seleciona, organiza e interpreta estímulos. Este processo pode ser decomposto em duas fases distintas: a sensação, mecanismo fisiológico por meio do qual os órgãos sensoriais registram e transmitem os estímulos externos; e a interpretação que permite organizar e dar um significado aos estímulos recebidos (SERRANO, 2004).

Segundo Vasconcelos (2004), a percepção, antes de qualquer coisa, depende das condições físicas e psicológicas do observador, da capacidade do ambiente de proporcionar informações e do contexto social e cultural em que a relação pessoaambiente está inserida. Enfim, torna-se fundamental, para entender o processo da percepção, compreender como o ser humano percebe o ambiente por meio de seus canais sensoriais.

A audição fornece uma espacialização no domínio temporal que, investida de atenção, assume uma grande importância na localização e no deslocamento. É possível encontrar uma fonte sonora pela audição com base na ordem temporal em que os sons são ouvidos. Para isso, muitas vezes as pessoas com deficiência visual posicionam uma de suas orelhas alinhada com a fonte sonora para maximizar a diferença temporal da chegada do som às duas orelhas (HATWELL16, 2003 apud DAVID; ANTUNES; GURGEL, 2009). Essas autoras relatam que:

\footnotetext{
Para um deficiente visual, que precisa da audição para se orientar no espaço, torna-se muito difícil discernir um som pertinente de um som desconexo, em meio a todo o ruído característico dos centros urbanos. Isso acontece, por exemplo, quando o alerta sonoro de uma garagem se abrindo é mascarado pelo tráfego intenso. (DAVID; ANTUNES; GURGEL, 2009, p. 88).
}

Um dos recursos utilizados pelas pessoas com deficiência visual também por meio da audição é a denominada "sombra sonora": uma referência a uma área de relativo silêncio atrás de um objeto que filtra a emissão de som, permitindo que estas pessoas percebam a presença de paredes e outros elementos, dependendo da habilidade desenvolvida nessa percepção.

Dischinger (2000) comenta que outros elementos que diferenciam um lugar de outros ambientes próximos, como um cheiro característico ou determinado som, podem atuar

${ }^{16}$ HATWELL, Y. Psychologie cognitive de la cécité precoce. Paris: Dunod, 2003. 
como referenciais dinâmicos. Entretanto, Bins Ely (2004b) alerta que "os referenciais permanentes, por permanecerem por longo período de tempo em um lugar sem transformações em suas características, são mais confiáveis para a orientação do que os referenciais dinâmicos".

Para Dischinger (2005), é a combinação da noção do tempo de deslocamento, ou ritmo de movimento, produzido pelo sistema de orientação, com a informação constante sobre as posições do corpo produzida pelo sistema háptico do indivíduo que fornecem o controle do deslocamento pelo espaço. 0 sistema de orientação é aquele que fornece as sensações de subida e descida, respondendo pela manutenção da posição vertical do equilíbrio (SILVA, 2009). 0 sistema háptico pode ser compreendido se for relacionado com a sensação que se tem por vezes ao caminhar distraído, ou ao dirigir, e se sente que já se deveria ter chegado a determinado local, ou que talvez já a se tenha passado sem notar. Por estar distraído, perde-se os referenciais usuais (geralmente visuais), e a percepção do tempo de movimento é que passa a transmitir as informações. Assim é o referencial tempo: muito utilizado pelas pessoas com deficiência visual.

Para as pessoas em geral, o mapa mental cognitivo espacial de seu entorno é fonte de informação para a tomada de decisão e possibilidade de deslocamento independente (OKAMOTO, 2002; CARLIN, 2004). Em seu trabalho, Carlin (2004, p. 54) relata que:

A orientação espacial diz respeito à habilidade de uma pessoa em representar
mentalmente as características espaciais de um arranjo físico e a habilidade em
situar-se dentro desta representação. Esta representação mental, denominada
de "mapa cognitivo" ou "mapa mental", é composta de uma série de visões que
as pessoas fazem do ambiente, integrando num todo aquilo que é percebido em
partes.

Gibson define "as affordances do ambiente [como] aquilo que oferece ao animal, o que providencia ou fornece, ou para o bem ou para o mal. [...] refere tanto para o ambiente quanto para o animal [...] implica na complementariedade entre animal e ambiente" (GIBSON17, 1979/1986, p. 127, itálico no original, apud GÜNTHER, 2003). Criado nos anos 1970, o conceito de affordance se refere ao que é oferecido pelo ambiente ao organismo que com ele interage. 0 autor inclui entre as affordances: o meio (por exemplo, o ar); as substâncias (por exemplo, água e matéria sólida); as superfícies e seus

17 GIBSON, J. J. (1979/1986). The ecological approach to visual perception. Hillsdale, New Jersey: Lawrence Erlbaum. 
traçados; os objetos e outras pessoas e animais. Afirma ainda que "as mais ricas e mais elaboradas affordances do ambiente são dadas pelos outros animais e, para nós, pelas outras pessoas" (GIBSON17, 1979/1986, p. 135, itálico no original, apud GÜNTHER, 2003).

Carlin (2004, p. 51) relata que:

\begin{abstract}
Gibson esclarece que o Sistema de Orientação é responsável por detectar a organização estável do ambiente e por manter a posição ereta e de balanço do corpo, e coopera com todos os outros canais sensoriais servindo-lhes de base. Já o Sistema Háptico consiste em diversos receptores localizados em tecidos e ligamentos que trabalham em conjunto na percepção dos estímulos externos ao corpo humano, tornando todo o organismo um órgão ativo de percepção.
\end{abstract}

Ressalta-se a importância das affordances no processo cognitivo das pessoas com deficiência visual, porque estas características do ambiente físico condicionarão suas expectativas, desejos e sonhos com relação ao meio no qual procuram se locomover, e devem ser levadas em consideração para orientação do caminhar nos espaços, podendo favorecer suas habilidades, suas competências motoras e sua sensação de segurança.

Dischinger (2000) comenta que, dos sistemas perceptivos descritos por Gibson, para as pessoas cegas, o sentido de orientação é de fundamental importância, pois na ausência de informações auditivas, hápticas, e olfativas, o sentido de orientação é o único capaz de providenciar informação sobre a postura do corpo no espaço e seus eixos de referência (vertical/horizontal, direita/esquerda, frente/costas) assim como a sensação de movimento próprio (velocidade, distância, ritmo e direção).

Para Gibson ${ }^{17}$ (1979/1986, apud OLIVEIRA; RODRIGUES, 2006), o aspecto fundamental para se auxiliar pessoas com deficiência é entender quais informações disponíveis para o observador são efetivamente percebidas e contribuem na regulação de suas atividades. É importante citar que cada sistema perceptivo registra informações que diferem em seu tipo e qualidade, mesmo que a associação de várias informações forneça um único sentido final ao objeto percebido.

De acordo com o filósofo Merleau-Ponty (1945) a percepção baseada em informações visuais não é a mesma que a baseada em outras informações sensoriais. Ver uma árvore não é o mesmo que tocar o seu tronco, escutar o ruído de suas folhas em movimento, 
sentir seu cheiro, ou mesmo desfrutar de sua sombra, mesmo que todas estas informações possam transmitir tratar-se de uma árvore, e possibilitem a sua integração constituindo a "imagem" do que é uma árvore para quem não pode vê-la. As contribuições da fenomenologia da percepção de autores como Merleau-Ponty foram importantes para estudo da espacialidade do corpo, a motricidade e a percepção, fenômenos intimamente relacionados que se modificam e são afetados pelas características e competências motoras das pessoas.

Para outro referenciado autor, Vygotsky (1994), a percepção de objetos reais surge em idade muito precoce. Para ele, "o mundo não é visto somente em cor e forma, mas também, como um mundo com sentido e significado" (VYGOTSKY, 1994, p. 37). Em outra obra, esse autor assegura que o defeito está na sociedade e não na pessoa com deficiência visual (VYGOTSKY, 1997). Para ele, a "cegueira" como fator psicológico não existe para o sujeito que a possui. 0 pressuposto de que pessoas cegas vivem nas trevas é errôneo, ingênuo e uma tentativa falsa de se penetrar na psicologia destas pessoas que, por sua vez, em geral nem percebem a sua deficiência como um infortúnio. Mas esta condição se converte como tal no meio social, de modo que o sujeito só percebe sua deficiência indiretamente, como resultado da experiência social.

Okamoto (2002) define que a percepção humana é a resposta aos estímulos captados por meio dos sentidos humanos, e esse processo acontece na superfície e no interior do corpo. Além dos receptores externos, representados por visão, tato, olfato, audição e paladar, existe o que o autor denomina centro de sentidos internos, compostos pelo instinto de sobrevivência, sentido de equilíbrio, de movimento, entre outros, que também influenciam no comportamento (OKAMOTO, 2002). Outro aspecto alertado por este autor, é que não basta estar com os olhos abertos para ver a realidade, pois ela é percebida por meio de conceitos, símbolos, mitos e outros elementos envolvidos no processo de interpretação e produção de sentidos, o que requer uma visão mais profunda do que aquela que normalmente se tem ou que se julga ter.

A cultura também participa do processo perceptivo, segundo Tuan (1983), que enfatiza as infinitas possibilidades de perceber e avaliar o meio ambiente, influenciadas por aspectos culturais determinantes da visão de mundo dos indivíduos e dos grupos humanos. Assim, as pessoas, independente de terem alguma deficiência ou não, 
percebem e interpretam a realidade de forma tão variada quanto variados são os modos de vida.

Com relação à formação de imagens pelas pessoas com deficiência visual congênita, Leme (1998) investigou a compreensão do significado de palavras que se supõe terem uma base visual, em quatro adolescentes com cegueira congênita, cuja escolaridade correspondia às séries finais do Ensino Fundamental. Perguntou o significado de quatro adjetivos e quatro substantivos, na seguinte ordem: transparente, horizonte, abatido, pôr-do-sol, elegante, nuvem, dourado e arco-íris.

A avaliação de Leme contemplou o aspecto significado, comparado ao do dicionário, e grau de generalização/abstração, com pontuação entre zero e dois. As palavras com mais pontos para ambos os aspectos foram: abatido, pôr-do-sol, elegante e transparente. As palavras com menor pontuação foram: nuvem e horizonte, esta última sem nenhum acerto. A maioria das jovens apresentou significados corretos para a maioria das palavras, em geral com alto grau de generalização/abstração das respostas. Verificou-se, assim, que é possível que pessoas com cegueira congênita adquiram conceitos relativos ao significado de palavras com conotação predominantemente visual.

Honorato e Braviano (2012, p. 17), ao concluírem uma pesquisa que comparou desenhos realizados por pessoas com e sem cegueira, afirmam que "a análise realizada apontou para a semelhança na capacidade que pessoas com deficiência visual têm para construir imagens mentais, em relação àquelas sem deficiência visual".

Com relação à memória de imagens pelos que ficaram cegos depois de adultos, Barbosa (2015, p. 36) explica: "o adulto atingido pela deficiência visual tem perdas relacionadas aos aspectos físico, psíquico, social e econômico, sendo que seus efeitos implicam também a reorganização e o estabelecimento de novos esquemas de interação.".

Sacks (2010) apresenta relatos sobre a memória visual de pessoas que ficaram cegas após idade suficiente para terem memória de imagens a respeito do mundo. Esses relatos demonstram que nem sempre as pessoas guardam estas imagens. Em um desses relatos de Sacks, seu paciente denominado Hull conta que ficou impressionado a propósito de como sua memória visual foi se atenuando gradualmente, até a extinção 
total, até entrar em um estado em que ele (Hull) chamou de "cegueira profunda". Relata Sacks (2010, p. 204):

Dois anos depois de se tornar totalmente cego, Hull parecia tão desprovido de imagens e de memória visual quanto um cego congênito. Estudos comparáveis com cegos congênitos ou pessoas que ficaram cegas com pouca idade mostram que algumas áreas do córtex visual podem ser realocadas e usadas para processar sons e sensações do tato.

\subsubsection{Treinamento em Orientação e Mobilidade (OM)}

Para orientar-se em um ambiente e mover-se de maneira rápida, eficiente e independente, as pessoas com deficiência visual dependem de um processo cognitivo, que inclui percepção, codificação, aprendizagem e memória da informação ambiental (ESPINOSA et al., 1998). Para isso, (BINS ELY, 2004b) para isso, as pessoas devem estar orientadas por informações sobre a arquitetura e mensagens adicionais proporcionadas pelo ambiente, tratadas em um processo cognitivo complexo, o que se torna um problema quando envolve pessoas com deficiência visual, pois as limitações desse público podem implicar em sensação de insegurança, desconforto e até de incapacidade.

Para que as pessoas com deficiência visual possam partilhar de uma vida mais independente e segura, são oferecidos programas de reabilitação ou habilitação dos sentidos remanescentes. Para que essas pessoas aprendam a se orientar e se locomover sem o sentido da visão, ou com o que lhes é remanescente, existem técnicas de aprendizagem sistemática, que são denominadas como Orientação e Mobilidade (OM).

A Orientação e Mobilidade constitui uma série de técnicas específicas de proteção e exploração para que a pessoa possa se locomover com acessibilidade, ou seja, com autonomia e segurança. Conforme Weishaln (199018 apud MAZZAR0, 2003, p. 17): “Orientação é o processo de utilizar os sentidos remanescentes para estabelecer a própria posição e o relacionamento com outros objetos significativos no meio ambiente. Mobilidade é a habilidade de locomover-se com segurança, eficiência e conforto no meio ambiente, por meio da utilização dos sentidos remanescentes".

Santos (2004, p. 3), afirma: “[...] que o corpo é reconhecido na orientação espacial a partir da sua consciência corporal, tendo assim consciência da existência de si, de outras

${ }^{18}$ WEISHALN, R. Orientation and mobility in the blind children. New York: Englewood Cliffs, 1990. 
pessoas e outros objetos". A definição que Santos (2004, p. 3) apresenta para OM é: "Orientação é um processo que o cego usa através de outros sentidos para o estabelecimento de suas posições em relação com todos os objetos significativos do meio circundante; e mobilidade é a capacidade de deslocamento do ponto em que se encontra o indivíduo para alcançar outra zona do meio circundante".

Diversos autores, como Hoffmann (1998), Borges (2004) e Maia (2004), compartilham da opinião de que $\mathrm{OM}$ é uma atividade que, mais do que prover autonomia na locomoção, proporciona também melhoria da autoconfiança e da autoestima, proporcionando sua integração social e melhor qualidade de vida, devido aos benefícios psicológicos, físicos e sociais que traz.

Felippe e Felippe (1997) relatam que foi em 1955 que as técnicas de Orientação e Mobilidade tiveram início no Brasil, quando Ernest Harold Getliff, superintendente da Royal School of Industries for the Blind (Escola Real das indústrias para Cegos) foi recomendado para prestar serviços junto à Fundação do Livro do Cego no Brasil. Ele analisou e sugeriu medidas para diversos problemas da pessoa com deficiência visual. Getliff enviou ao Brasil um consultor da Repartição Internacional do Trabalho para ajudar as autoridades na estruturação das oficinas e planejamento de outros serviços.

Assim, em fevereiro de 1957, chegou ao Brasil Joseph Albert Ansejo para ministrar aulas de técnicas sobre o uso da bengala longa, também conhecida como "bengala Hoover", concebida pelo médico estadunidense Richard Hoover. A bengala é utilizada para detecção dos desníveis para cima ou para baixo, como buracos e elevações no solo.

Como um dos elementos mais antigos e usuais para exploração do espaço, a bengala torna possível, a partir da percepção tátil, que se obtenha informações antecipadas acerca de objetos presentes em seu caminho. Estudos mencionam que os participantes (pessoas com deficiência visual) apontaram a importância da bengala em dois sentidos:

\footnotetext{
no sentido prático, propicia ritmo, referência dos sons emitidos pelo seu movimento e proteção ao bater em algum objeto, possibilitando que a pessoa desvie. E no sentido psicológico, propicia liberdade, segurança, amparo e reconhecimento dos videntes de sua condição física. (PARANHOS, 2008, p. 29)
}

A bengala é utilizada por meio de diversas técnicas que permitem verificar a presença de objetos, declives do terreno, tipos de solo, entre outros. Todavia, de acordo com DAVID, 
ANTUNES e GURGEL (2009, p.87), o alcance da bengala é muito restrito, de forma que essas informações são muito limitadas, não garantindo completa segurança à mobilidade.

A locomoção com a bengala é facilitada pelo uso de linhas-guia de orientação, que em uma cidade pode ser um muro, um meio fio ou linhas de pisos táteis estrategicamente instaladas. Uma linha-guia funciona como um referencial constante pelo qual a pessoa se orienta; para poder utilizá-la é necessário treinamento para reconhecimento e memorização do percurso, pois podem existir bifurcações em uma linha, as quais conduzem a destinos distintos. Conforme Almeida (2008, p. 14):

as informações horizontais, quando existem, são geralmente pisos com textura diferenciada, sem informações adicionais indicando o 'porquê' e 'para onde' estão levando, caso decidam serem guiados por elas, além de não oferecerem opções de rotas.

A Figura 2.2 demonstra uma série de derivações de um conjunto de pisos táteis, sinalização para pessoas com deficiência visual que, quando existem, são geralmente pisos com textura diferenciada, sem informações adicionais indicando o "porquê" e "para onde" estão levando, caso decidam serem guiados por elas, além de não oferecerem opções de rotas, o que obriga a pessoa com deficiência visual a procurar treinamento para familiarização e posteriormente a utilizar a memória de conhecimento prévio do caminho para tomar uma decisão. Além destes inconvenientes, pode haver outros, como interrupções ou modificações inesperadas da linha-guia. 
Figura 2.2 - Derivações nas linhas de pisos táteis que podem gerar dúvida quanto à rota a seguir.

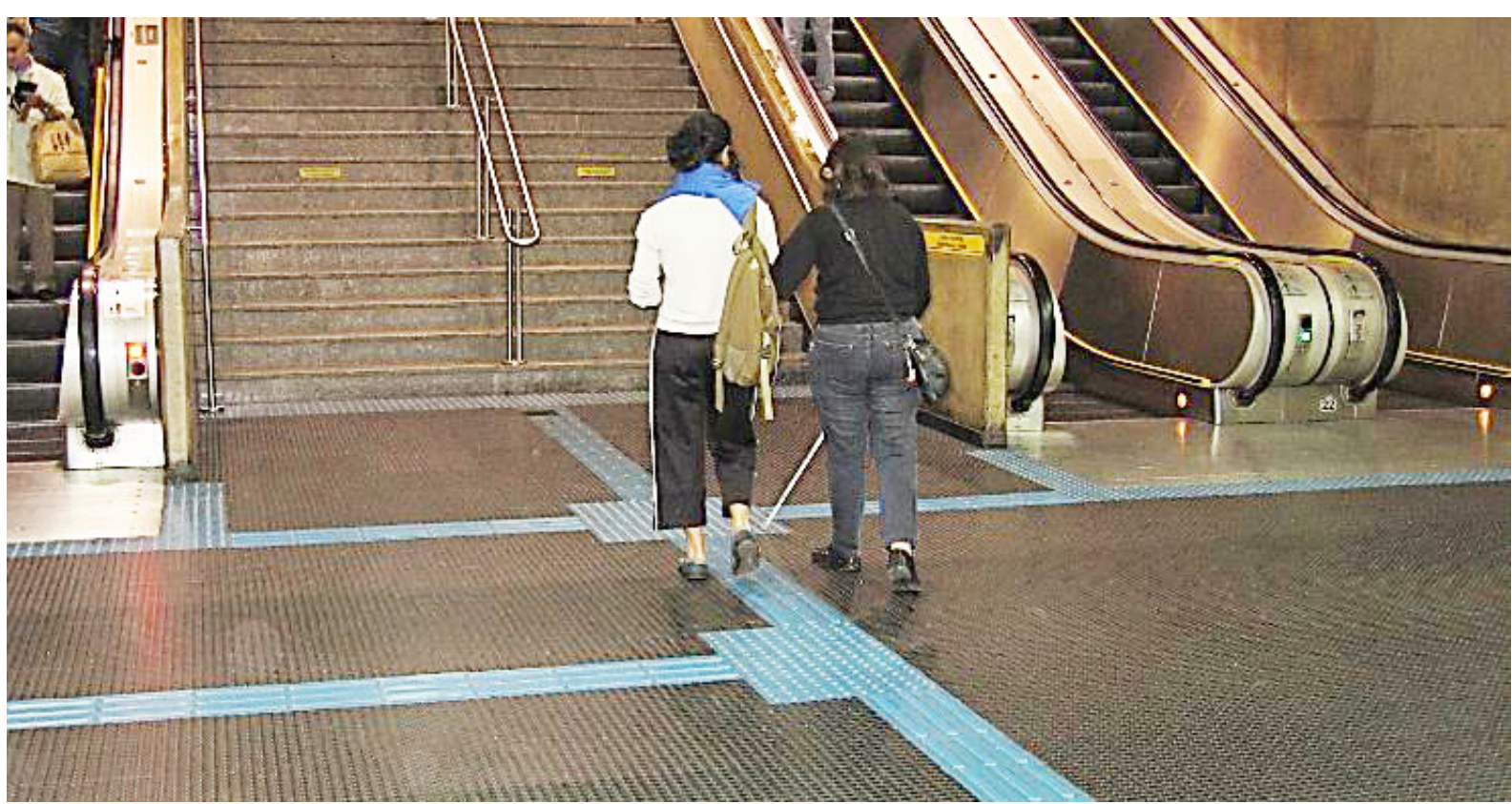

Crédito: MARIANI, E., 2013.

Borges (2004) da Sociedade de Assistência aos Cegos - SAC, define que, para desenvolvimento do treinamento em $\mathrm{OM}$, a pessoa com deficiência deverá compreender o seu meio ambiente, familiarizar-se com novos ambientes, usar informações por meio de outros sentidos, especialmente a audição, obter informação verbal, utilizar-se de guia com visão, técnicas protetoras (proteção superior, proteção inferior, proteção combinada e proteção social), utilizando-se para isso os sentidos remanescentes, tais como: tato, olfato, audição, percepção vestibular, visão residual, pontos de referência, pistas no decorrer do trajeto, bengala longa, cão-guia etc.

O profissional elabora, inicialmente, um plano de acordo com o nível de orientação e mobilidade do aluno, onde, em cada sessão, ele será avaliado de acordo com seu desenvolvimento. O programa de treinamento divide-se em várias etapas, que inicialmente são trabalhadas em ambientes internos da instituição. Os aspectos fundamentais do desenvolvimento são, resumidamente, aspectos cognitivos, psicomotores, emocionais, treinamento dos sentidos remanescentes, técnicas com guia vidente, técnicas de autoproteção, desenvolvimento da orientação, técnicas com bengala longa (que são: varredura, técnica diagonal, detecção de objetos, passagem por portas, rastreamento com técnica diagonal, subir e descer escadas, técnicas de toque, técnica de 
toque e deslize, técnica de deslize, rastreamento com técnica de toque e rastreamento em três pontos).

Ao final desta etapa em ambiente internos, o aluno já terá o domínio dessas diversas técnicas, e receberá agora instruções em ambientes externos, onde colocará em prática seus conhecimentos. Nas áreas externas, o aluno deverá seguir as mesmas regras das áreas internas, com habilidades de planejar e alternar traçados, bem como experimentar novas situações, como atravessar ruas, calçadas, subir e descer escadas rolantes, passar por portas giratórias, além de considerar a presença de pedestres para conseguir ajuda, quando se fizer necessário (MOTA, 2003).

\subsubsection{O uso do cão-guia nos deslocamentos urbanos}

O cão-guia representa um dos recursos para locomoção de pessoas com deficiência visual, mas mesmo utilizando-se de um cão-guia, Ramos $(2009$, p. 31) ressalta que a pessoa com deficiência visual deve estar habilitada nas técnicas de Orientação e Mobilidade, sendo este um pré-requisito para a obtenção de um cão-guia.

Conforme relata Giacomini (2008, p. 17), os primeiros cães treinados como guias para cegos foram os cães que serviram de mensageiros durante a Primeira Guerra Mundial. 0 cão-guia ${ }^{19}$ é utilizado como uma das formas de locomoção, porém é utilizado raramente, talvez, por se tratar de alternativa pouco difundida, de difícil acesso e aceitação social (SÁ, 2005).

No Brasil, a grande maioria desses animais é importada, e exige o conhecimento de língua estrangeira, na qual o animal foi treinado, para dar-lhe os comandos de voz. Outra forma é adquirir um cão treinado no Brasil, porém a espera é por tempo indeterminado.

Importante ressaltar que todo cão-guia tem que receber orientações para poder guiar seu usuário, não sendo capaz de orientá-lo em espaços que não conhece, sem receber comandos, mas apenas protegê-lo. Dessa forma, um sistema complementar de informação pode ser útil para a navegação desse tipo de usuário.

${ }^{19}$ Em São Paulo, a Lei Municipal № 12.492 (SÃO PAULO, 1997) assegura o acesso e trânsito de cães-guia em ambientes públicos. 


\subsubsection{0 sistema Braille e seu uso em referenciais espaciais}

A criação do sistema Braille no século XIX na França foi, sem dúvida, a primeira grande revolução para as pessoas com deficiência visual. Ele permitiu que estas pessoas tivessem acesso à informação. Conforme relatado por Silva (2013), o método Braille de escrita surgiu como ferramenta alternativa para que os indivíduos com deficiência visual pudessem aprender a ler e a escrever, evitando-se assim sua exclusão do processo de aprendizagem e consequentemente a segregação social. Durante muito tempo, este método foi sinônimo de interação entre essas pessoas e o mundo.

Para a alfabetização, o sistema Braille é utilizado por extenso, isto é, escrevendo-se as palavras letra por letra, com acentuações e pontuação nas frases. Por isso é tão importante que crianças com deficiência visual sejam alfabetizadas com o uso da escrita em Braille, para poderem saber como se escrevem as palavras e os textos, o que não é possível somente com leitores em áudio. O sistema Braille também "aplica-se à estenografia, à música e às notações científicas em geral, sendo de extraordinária universalidade, pelo fato de poder exprimir diferentes idiomas e escritas" (SONZA, 2004).

Mas nem todas as informações podem ser fornecidas pelo sistema Braille, especialmente indicações em tempo real, notadamente para deslocamentos em ambientes públicos de ampla circulação, como estações e trens de metrô. Neste contexto, o sistema Braille não é suficiente para transcrever tudo. As perspectivas espaciais são impossíveis de serem representadas eficientemente pelo Braille. Linhas retas e curvas, formas geométricas, contornos de objetos e mapas de localização são exemplos de representações gráficas não representáveis pelo Braille (ALMEIDA; LOCH, 2005, p. 5).

Além disso, a proporção de pessoas que leem Braille é muito pequena, A ACAPO (2013b, p. 3) afirma de maneira enfática que “o braille ${ }^{20}$ não é o remédio para todos os males", e complementa:

Muitos alunos e alguns designers, ao pensar nas necessidades das pessoas com deficiência visual, chegam muito cedo à conclusão que o braille vai resolver os problemas de comunicação com os utentes que não conseguem ler os ícones ou distinguir as diversas cores dos comandos. [...]. No entanto, este sistema de leitura e escrita tem limitações práticas - tem um tamanho fixo, por exemplo -

\footnotetext{
${ }^{20}$ Grafado com "b” minúsculo no original.
} 
que não permitem a sua aplicação em muitos produtos. Para além disso, é preciso notar que um grande número de pessoas com deficiência visual não sabe ler braille.

Isso é compreendido quando se observa a quantidade de pessoas com deficiência visual congênita (e que teoricamente foram alfabetizadas em Braille) em face à quantidade de pessoas que adquiriram a deficiência depois de adultas (com muito mais resistência ou dificuldade para aprender a escrita Braille).

\subsection{ESTUDOS SOBRE NAVEGAÇÃO}

Com relação a pessoas se deslocando por ambientes construídos, o termo navegação sugere a capacidade de se mover nesses ambientes, composto por duas etapas: mobilidade e orientação. Mobilidade se refere ao movimento em si, sem considerar o ambiente, e orientação existe quando há o conhecimento do ambiente e o caminho a ser percorrido (HARPER, 1998). Segundo esse autor, a forma como uma pessoa é orientada é crucial para um deslocamento bem-sucedido. "Informações sobre a posição, direção, local desejado, rota, planejamento de rotas etc., tudo está ligado ao conceito de orientação" (HARPER, 1998, p. 14 - tradução nossa).

Para Brentzen (1979), Farmer (1979), Harper e Green (2000) e Hersh e Johnson (2008), orientação refere-se ao conhecimento das relações espaciais básicas entre os objetos dentro do ambiente. Hersh e Johnson (2008) elaboraram o diagrama da Figura 2.3 para explicar as tarefas normalmente realizadas dentro da atividade de locomoção e apresentaram o diagrama elaborado por Brambring (198521, apud HERSH e JOHNSON, 2008) da Figura 2.4 para mostrar as tarefas adicionais realizadas por pessoas com deficiência visual para sua locomoção.

\footnotetext{
${ }^{21}$ BRAMBRING, M., Mobility and orientation processes of the blind, in electronic spatial sensing for the blind: contributions from perception, rehabilitation and computer vision, proceedings of the NATO Advanced Research Workshop. In: WARREN D.H.; STRELOW E. R. (Editors), Electronic spatial sensing for the blind, Dordrecht, The Netherlands, Nijhoff, 1985. p. 493-508.
} 
Figura 2.3 - Atividades de locomoção de pessoas com visão normal.

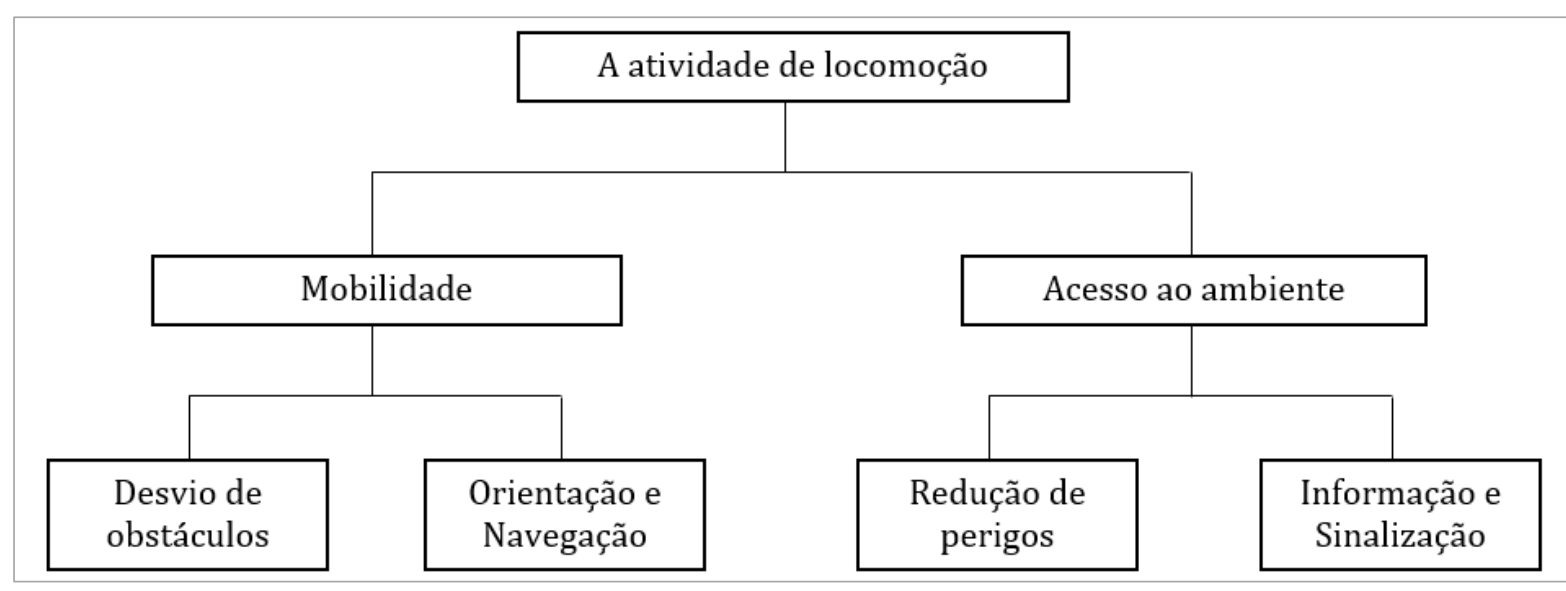

Fonte: Hersh e Johnson (2008, p. 169 - tradução nossa).

Figura 2.4 - Atividades de locomoção de pessoas com deficiência visual.

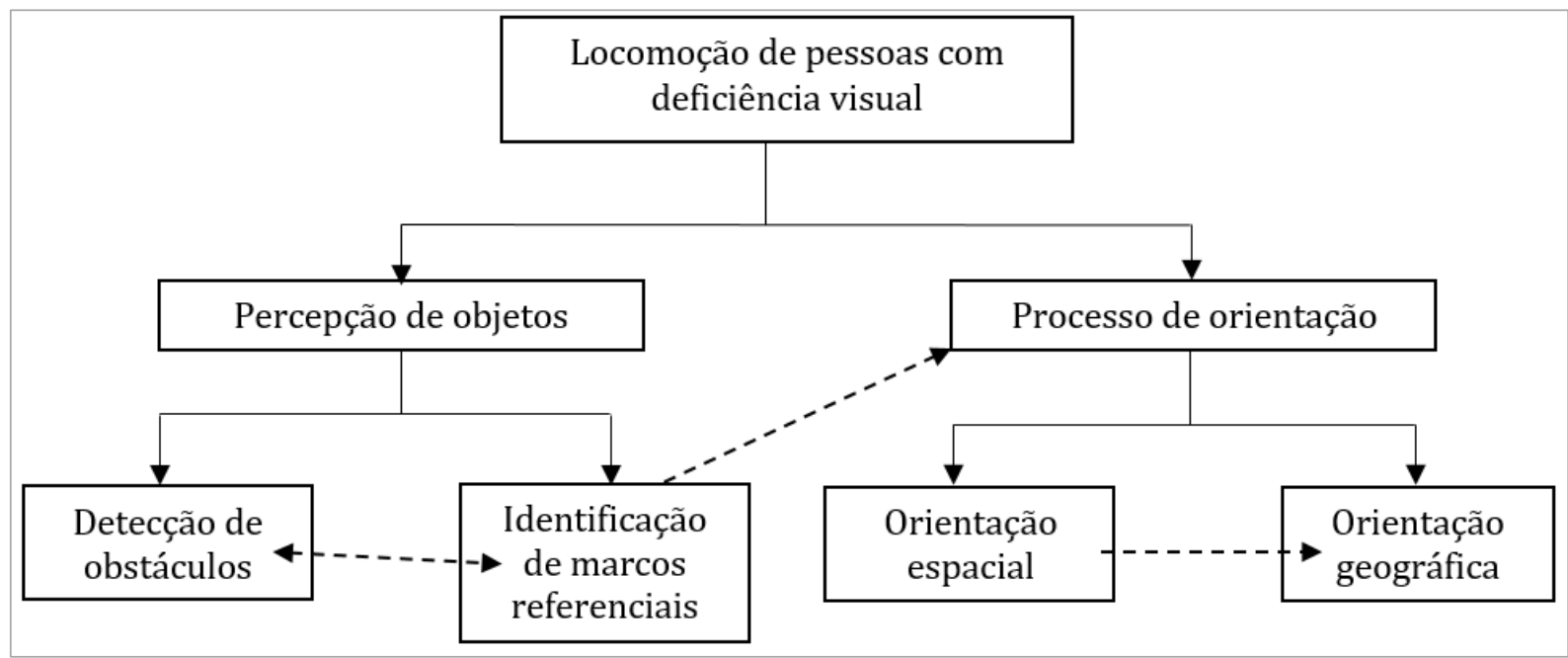

Fonte: Brambring17 (apud HERSH; JOHNSON, 2008, p. 172 - tradução nossa).

\subsubsection{Formas de se projetar a navegação}

Na linha do treinamento de orientação e mobilidade, Felippe e Felippe (1997) apontam os princípios da orientação, que são as seguintes questões: (a) "onde estou?"; (b) "onde está meu objetivo?"; e (c) “como chego lá?". Isso desencadeia um processo cognitivo que interliga:

a) percepção pelos canais sensoriais para captar as informações presentes no ambiente;

b) análise e organização dos dados percebidos em função de confiança, familiaridade etc.; 
c) seleção dos dados analisados e escolha daqueles mais importantes que satisfaçam as necessidades de orientação;

d) planejamento, que define uma ação por meio dos dados selecionados; e

e) execução, que coloca em prática a ação planejada.

Um interessante conceito relevante para a orientação espacial em ambientes construídos é o wayfinding, cuja tradução literal para o português seria "encontrando o caminho" (BINS ELY, 2004b), definido pelos cognitivistas nos anos 1970, incorporando os processos humanos de percepção, de cognição e de tomada de decisão. 0 wayfinding, que também pode ser entendido como "movimento orientado" trata de como os indivíduos se deslocam nos ambientes, ou como encontram os caminhos até seu destino, mesmo em um espaço desconhecido.

O processo de orientação envolve não apenas a construção de mapas cognitivos, mas uma série de processos mentais com o objetivo de resolver questões operacionais de como chegar a determinado lugar. Este processo de orientação foi explorado pelo arquiteto Romedi Passini em seu livro "Wayfinding in Architecture", de 1984, contemplando três estágios, a serem considerados quando se deseja prover mobilidade:

a) 0 processo da informação (estágio 1): entendido, de forma geral, como composto pela percepção do ambiente e pela cognição;

b) A tomada de decisão (estágio 2): desenvolvimento de planos de ação para alcançar um determinado destino. 0 número de decisões em um plano vai determinar o grau de complexidade da operação, já que cada decisão requer esforço mental e risco de erro; e

c) A execução da decisão (estágio 3): a transformação do plano de ação em um comportamento físico no tempo e no lugar correto ao longo de um percurso. As decisões são compostas por comportamentos e locais característicos. Se o local característico é percebido no ambiente, o comportamento é executado, mas se ocorrer algum imprevisto que interfira na ação, o comportamento não pode ser executado e a decisão se torna uma tarefa para a qual um novo plano deve ser desenvolvido.

Fazendo-se uma analogia aplicável ao objeto deste estudo, Carlin (2004) relata que estes conceitos foram estudados por Arthur e Passini (1992) que sugerem, para facilitar o 
entendimento de edifícios complexos, que as informações podem ser divididas em duas partes: (a) cinco zonas principais (estacionamento ou garagem; entrada do edifício; hall de distribuição; sanitários, cafeterias etc.; e componentes do edifício); e (b) três sistemas de circulação (sistema de circulação vertical, como elevadores, escadas ou rampas; sistema de circulação horizontal, como corredores etc.; e sistema de rota de fuga do edifício, como sinalização de emergência, saídas de emergência, alarmes etc.). Os autores sugerem que dentro de cada componente, o ambiente deve oferecer algum tipo de informação confiável para sua localização por visitantes cegos e com baixa visão.

Outro conceito que também pode ser utilizado neste estudo é o que foi apresentado pela primeira vez pelo arquiteto norte-americano Kevin Lynch, em seu livro "A imagem da cidade", de 1960. Lynch (1960) identificou cinco elementos construtivos básicos de um mapa mental, que torna as cidades legíveis por meio desses elementos: marcos referenciais, nós, caminhos, limites/bordas e distritos/zonas funcionais.

Se as cidades são legíveis em termos dos elementos identificados por Lynch, elas também podem ser facilmente mapeadas. Portanto, acredita-se que tais conceitos e argumentos também podem ser rebatidos para as edificações, podendo-se utilizar elementos semelhantes em sistemas de orientação a pessoas com deficiência visual. Passini (1984) descreveu em sua obra como as pessoas dependem de marcos referenciais, e como tentam impor ou imaginar alguma organização no ambiente, ainda que não faça muito sentido.

Marcos referenciais podem servir tanto como um conceito organizador do espaço como para auxiliar a navegação. Para a navegação, podem servir para identificar pontos de tomada de decisão, onde as escolhas são feitas, além de fornecer verificação dos progressos realizados na rota e influenciar as expectativas, dando pistas de orientação para o retorno (SORROWS; HIRTLE, 1999). Em uma abordagem interpretativa de textos de Sorrows e Hirtle (1999) e Loomis, Klatzky e Golledge (2001), marcos referenciais podem ser físicos, eletrônicos ou associados. 


\subsubsection{Formas de se prover a navegação}

A navegação propriamente dita é feita sobre um mapeamento dos ambientes, por onde a pessoa é guiada por comandos, que podem ser sonoros, táteis ou combinados. Os sonoros podem ser vozes ou sinais de áudio ("beeps"). Como táteis compreende-se as vibrações, também consideradas como comandos hápticos. Ross e Blash (200022 apud YATANI; BANOVIC; TRUONG, 2012) descobriram que a interface de comunicação mais eficaz é a que combina informações sonoras e táteis (ou hápticas); entretanto, os autores afirmam que são necessários estudos para se identificar as preferências de estilos de comunicação, para serem aplicados.

A comunicação tátil (ou háptica) por meio de vibração, além de poder substituir, em determinadas condições, as informações sonoras, também é muito útil para reforçar e/ou confirmar a execução de um comando por teclas em dispositivos eletrônicos, especialmente no uso de telas touch (YATANI; BANOVIC; TRUONG, 2012). Ross e Blasch (op. cit.) verificaram que pessoas com deficiência visual, de maneira geral, realizaram tarefas de navegação mais rápido e com menor número de erros quando foi acrescentada a interface tátil logo a seguir dos comandos de áudio.

Bradley e Dunlop (2005) fazem diversas críticas a respeito de sistemas de navegação para pessoas com deficiência visual que utilizam a saída de voz como a principal, senão a única forma de transmissão de informações para o usuário e informam que Ross e Blasch $^{23}$ (2000 apud BRADLEY; DUNLOP, 2005) constataram em suas pesquisas que a melhor interface é a que combina uma boa saída de voz com reforços táteis (vibrações, por exemplo).

Rogers, Sharp e Preece (2013, p. 72) afirmam que os sons do tipo "beep" "devem ser claros e compreensíveis, de forma que os usuários entendam o que eles querem representar"; a saída de voz "deve permitir que os usuários façam distinção entre o conjunto de palavras faladas e sejam capazes de compreender seu significado"; e "o feedback tátil utilizado em ambientes virtuais deve permitir que os usuários reconheçam o significado das várias sensações de toque" que estão sendo emitidas.

22 ROSS, D. A., BLASCH, B. B. Wearable interfaces for orientation and wayfinding. ASSETS 2000, ACM (2000), 193-200.

${ }^{23}$ ROSS, D. A., BLASCH, B.B. Evaluation of Orientation Interfaces for Wearable Computers. ISWC'00. 2000. 
Quando utilizada voz artificial, deve-se ter cuidado para se acentuar a sua entonação, pois são mais difíceis de entender do que a voz humana.

Com relação à forma de apresentação das instruções de navegação, todas as pessoas têm preferências que variam quando se trata de obter direções de viagem, e isso também se refere às pessoas com deficiência visual. Hersh e Johnson (2008) estudaram duas formas diferentes de essas pessoas receberem as instruções:

a) a primeira forma utiliza o som que é emitido pela fonte do objeto de referência. Por exemplo, para encontrar uma pessoa em uma sala, uma pessoa cega pode seguir o som da voz da pessoa. A este tipo os pesquisadores chamaram de som 3D;

b) a outra forma de informação direcional é em forma de instrução por direções. Por exemplo, "a pessoa que você procura está à sua frente, oito passos de distância”, ou "a pessoa que você procura está a 12 horas, oito metros de distância”, e variações semelhantes. A esse tipo os pesquisadores chamaram de linguagem espacial, porque utilizam a linguagem para descrever onde um objeto está localizado.

Hersh e Johnson (2008) relatam que pesquisas da Universidade da Califórnia verificaram que o som 3D e a linguagem espacial são aproximadamente comparáveis em sua eficácia como interface auditiva. Para guiar uma pessoa ao longo de uma rota, o som 3D emitido por um elemento acústico no ambiente levou a um desempenho um pouco melhor e também melhor na avaliação dos usuários do que a linguagem espacial utilizada nas pesquisas (LOOMIS; KLATZKY; GOLLEDGE, 2001). Ressalta-se que ambas as maneiras de transmissão da informação sofrem influência do ambiente e dos equipamentos utilizados, entretanto é importante que se considerem as duas formas de comunicação em estudos para projetos de sistemas de navegação.

A navegação de pessoas com deficiência visual exige o máximo de precisão de localização e de pontos de informação. Almeida (2008, p. 110), com base em Harper (1998) e Harper e Green (2000), resume alguns conceitos relacionados à navegação sem visão, dos quais se destacam para este estudo:

a) a descrição de uma rota para uma pessoa com visão é bem diferente da descrição de uma rota para uma pessoa cega. Para a primeira pode-se dizer "cruze a faixa de pedestre e siga até o posto de gasolina”, enquanto que, para a pessoa cega deve-se dizer "ande mais ou menos uns dez passos numa direção de $45^{\circ}$ para a esquerda"; 
b) deve-se usar mais terminologias temporais do que ambientais para orientação;

c) a rota a ser seguida deve ser seccionada em um número maior de estágios do que aquela descrita para uma pessoa com visão;

d) informações sobre obstáculos devem ser também mais detalhadas: sempre que possível, deve-se prover informações sobre objetos ou obstáculos próximos, orientando-se quanto a degraus, arestas, escadas etc.;

e) apesar da necessidade de maior quantidade de informação, estas devem ser simples e objetivas.

Em seus estudos, Harper (1998) faz uma decomposição do que ele chama de "tarefa de navegação", conforme Figura 2.5. 
Figura 2.5 - Decomposição da tarefa de navegação.

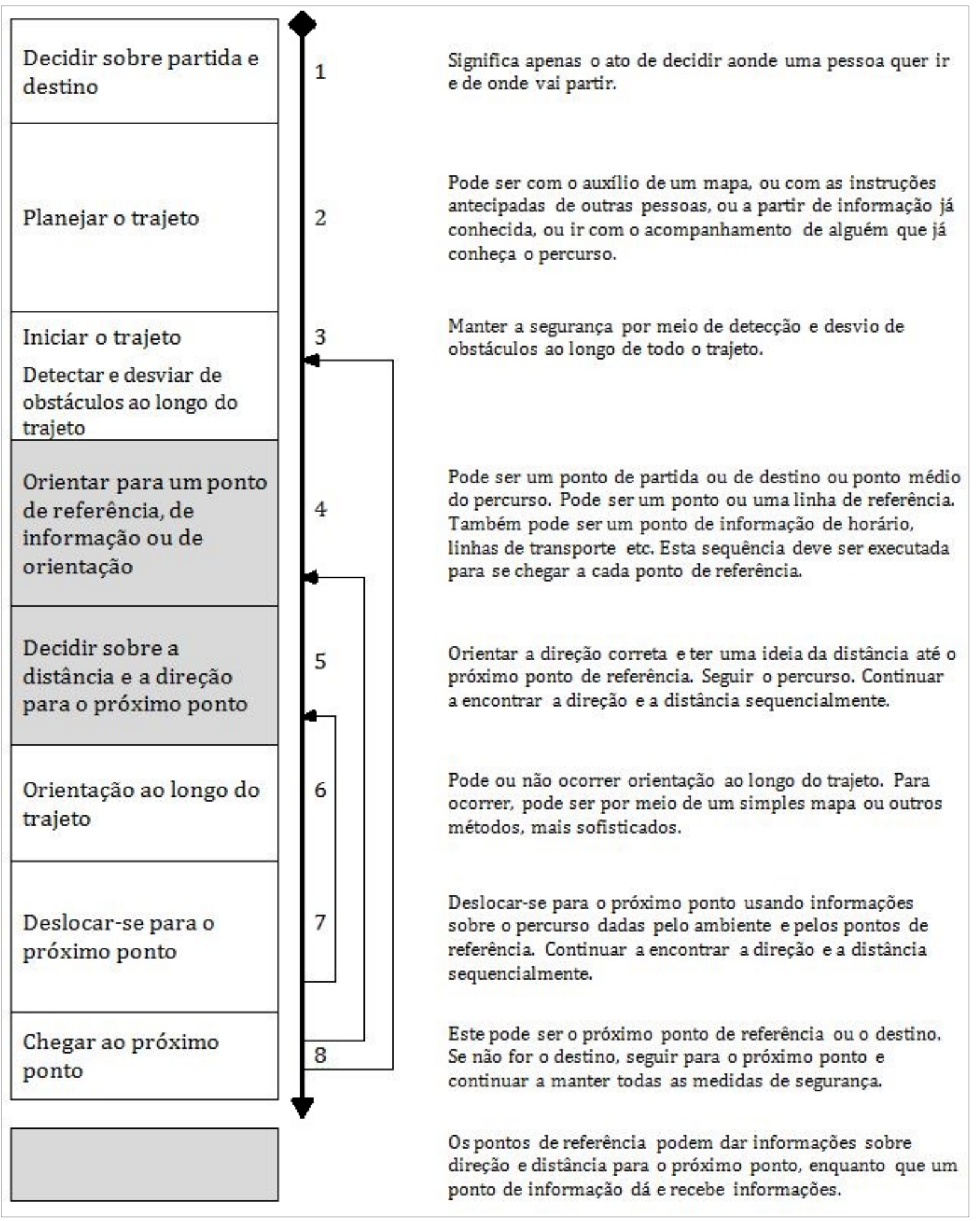

Fonte: Harper (1998, p. 20 - tradução nossa).

Resumidamente, a tarefa de navegação apresentada na figura 2.5 consiste em um número de ações simples (HARPER; GREEN, 2000):

a) planejamento da rota: a viagem é planejada, e uma rota é escolhida de antemão, com base em um mapeamento e/ou conhecimento prévio do percurso; 
b) detecção/desvio de obstáculos: objetos suspensos, não detectáveis pela bengala longa, devem ser evitados durante o percurso;

c) orientação e pontos de referência: o percurso pode ser dividido em seções com base em pontos de linhas de referência. Os pontos de referência são elementos que permitem aos usuários que se orientem pontualmente, e linhas de referência são elementos como muros ou paredes, que podem ser seguidos por um período durante o deslocamento;

d) pontos de informação: pontos de informação são locais onde estão disponíveis informações sobre o percurso, tais como horários, próximo ônibus etc.);

e) orientação ao longo do trajeto: orientações a serem solicitadas ou carregadas de alguma forma pelo usuário, como por exemplo, um mapa.

Bradley e Dunlop (2005), realizaram estudos para investigar diferenças de informações para navegação entre as pessoas com visão normal e as pessoas com deficiência visual, utilizando mapeamento cognitivo. As descrições do percurso de ambos os estudos foram categorizadas, resultando em 11 classes de informações referenciais, mostradas na Tabela 2.2, com indicação das expressões mais utilizadas em descrições de rota pelas pessoas participantes, com visão normal e com deficiência visual em vários graus.

Pode-se observar que algumas referências utilizadas pelas pessoas com deficiência visual, tais como as sensoriais e de movimento, nunca são utilizadas por pessoas sem deficiência, enquanto que referências como as textuais são muito utilizadas por pessoas sem deficiência visual e pouco utilizadas pelas que possuem deficiência ${ }^{24}$ (Gráfico 2.5).

\footnotetext{
${ }^{24}$ As referências utilizadas pelas pessoas com deficiência visual baseiam-se em conhecimento adquirido ao longo de suas experiências de vida e de treinamentos em Orientação e Mobilidade que tenham realizado. Boa parte das referências possui cunho visual devido às percepções das pessoas com baixa visão, que conseguem perceber cores e contrastes entre claro e escuro, por exemplo.
} 
Tabela 2.2 - Classes de informações referenciais usadas por pessoas com visão normal e pessoas com deficiência visual para a navegação.

\begin{tabular}{llcc}
\hline $\begin{array}{l}\text { Classe de informação } \\
\text { referencial }\end{array}$ & \multicolumn{1}{c}{ Exemplo } & $\begin{array}{c}\text { \% de uso } \\
\text { (visão } \\
\text { normal) }\end{array}$ & $\begin{array}{c}\text { \% de uso } \\
\text { (visão com } \\
\text { deficiência) }\end{array}$ \\
\hline 1. Direcional & esquerda/direita, Norte/Sul & 37,4 & 30,1 \\
\hline 2. Estrutural & estrada, monumento, igreja & 11,5 & 20,1 \\
\hline 3. Ambiental & montanha, rio, árvore & 1,6 & 2,9 \\
\hline 4. Textual - estrutural & livraria ..., loja ..., banco ... & 9,9 & 1,2 \\
\hline 5. Textual - local & rua ..., praça ... & 15,6 & 2,7 \\
\hline 6. Numérica & primeira, segunda, 100 metros & 5,0 & 7,5 \\
\hline 7. Descritiva & íngreme, alto, vermelho & 10,8 & 23,8 \\
\hline 8. Temporal/distância & caminhe até encontrar ..., pouco antes de ... & 8,2 & 5,1 \\
\hline 9. Sensorial & som de carros passando, cheiro de padaria & 0 & 4,4 \\
\hline 10. Movimento & carros passando, portas abrindo & 0 & 0,8 \\
\hline 11. Relação social & perguntando às pessoas ou usando um cão-guia & 0 & 1,4 \\
\hline
\end{tabular}

Fonte: Bradley e Dunlop (2005, p. 4 - tradução nossa).

Gráfico 2.5 - Comparação das classes de informações referenciais usadas por pessoas com visão normal e pessoas com deficiência visual para a navegação.

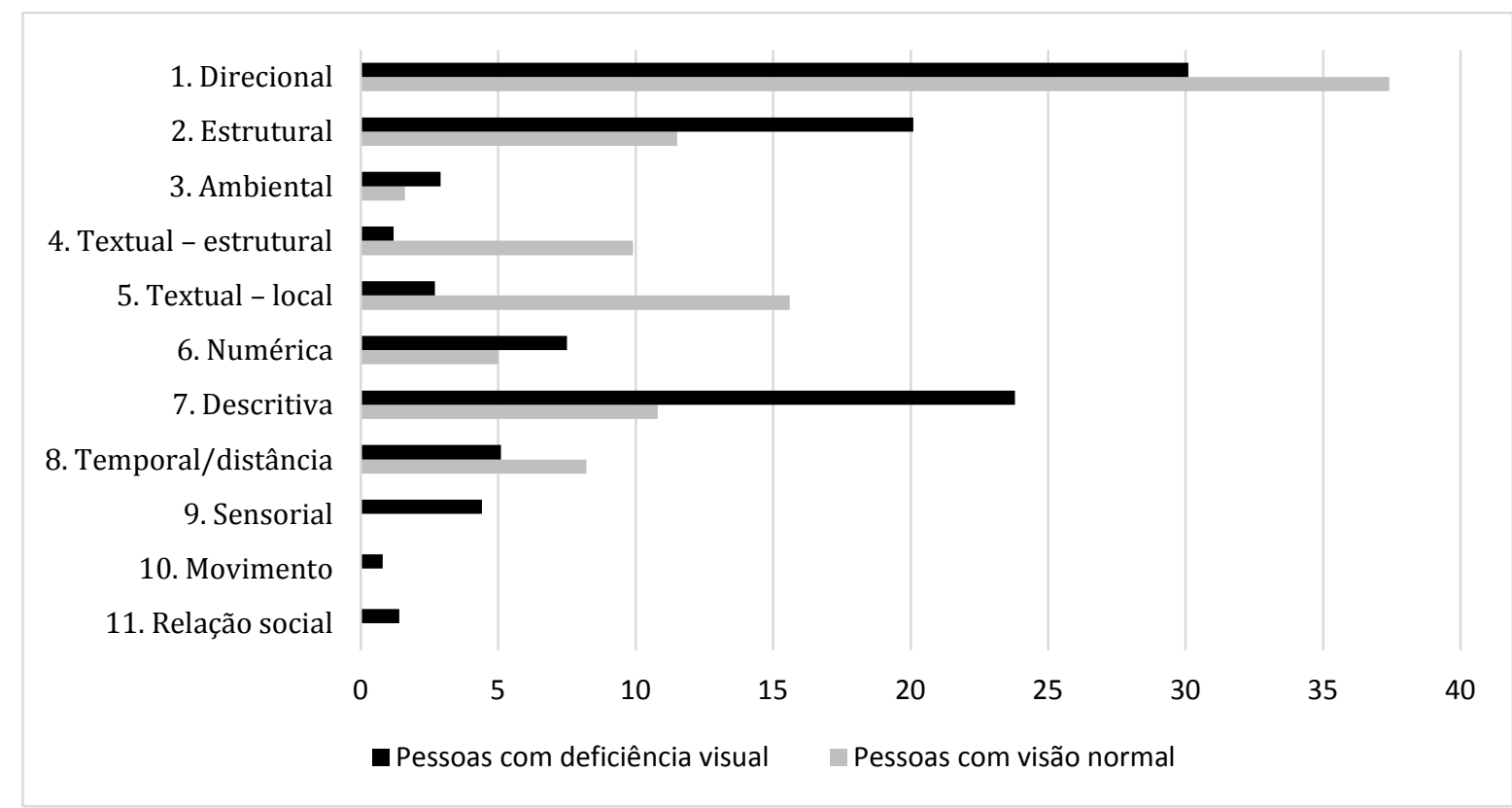

Fonte: Elaborado com base na Tabela 2.2.

Gedawy (2011) realizou estudos sobre instruções de navegação, com base na avaliação das necessidades das pessoas com deficiência visual, e ressalta que algumas das instruções podem ser formuladas de diferentes maneiras, pois o texto a ser escolhido pode depender da preferência do usuário. Esta autora também chama a atenção para a necessidade de se utilizar sinônimos dependendo do dialeto do usuário. Mesmo em uma 
região onde não se pratique diferentes dialetos, sempre existe a possibilidade de que o usuário se refira a um mesmo local de diferentes formas.

Complementando as questões de funcionamento e das instruções de navegação, é necessário que se considere a usabilidade dos dispositivos e/ou sistemas para a navegação. Para tanto é importante o envolvimento de designers de produto no processo de desenvolvimento (HERSH; JOHNSON, 2008). Por exemplo, devem ser analisadas as maneiras sobre como as informações serão enviadas e recebidas, facilidade de uso, privacidade, se será possível optar por omissão ou repetição da informação em alguns momentos, entre outras.

Um recurso que não é de navegação, mas que também pode ser usado para auxiliar nos deslocamentos é o recurso da audiodescrição ${ }^{25}$, que recentemente tem sido oferecido como uma narrativa de obras de arte, cenas de filmes e de peças de teatro, entre outras, permitindo às pessoas com deficiência visual que, mesmo não conseguindo enxergar estas situações, pelo menos as compreendam e vivenciem de alguma forma. A audiodescrição também pode ser útil na descrição de ambientes, especialmente se fornecida em tempo real.

A audiodescrição de ambientes se assemelha à técnica de $\mathrm{OM}$ denominada guia vidente, onde uma pessoa que enxerga informa à pessoa com deficiência visual as características do ambiente, tanto para situá-la quanto ao seu posicionamento, como para onde e por onde deve seguir, fornecendo dados para que tome decisões quanto ao percurso a ser realizado, com a vantagem de que esta descrição pode ser gravada e transmitida eletronicamente, sem a necessidade da presença de uma pessoa. A gravação pode ser feita a partir de dados da internet, gravados em um dispositivo móvel, por exemplo (HERSH; JOHNSON, 2008).

0 recurso da audiodescrição pode ser especialmente útil às pessoas com deficiência visual congênita, pois muitas têm dificuldade de compreender a sua posição no ambiente a partir de informações espaciais, como por exemplo, a partir de mapas táteis,

25 "O recurso da audiodescrição consiste na descrição clara e objetiva de todas as informações que compreendemos visualmente e que não estão contidas nos diálogos, como, por exemplo, expressões faciais e corporais que comuniquem algo, informações sobre o ambiente, figurinos, efeitos especiais, mudanças de tempo e espaço, além da leitura de créditos, títulos e qualquer informação escrita na tela." Disponível em <http://audiodescricao.com.br/ad/o-que-e-audiodescricao/>. Acesso em 26 ago. 2014. 
mesmo não existindo nenhuma perda significativa da mobilidade (HARPER; GREEN, 2000).

Passini26 (1994, apud ALMEIDA, 2008, p. 46) "quando se refere a informações de design de orientação espacial, afirma que elas devem ser acessíveis, completas, estruturadas hierarquicamente e devem corresponder às decisões de orientação dos usuários e enfatiza sua importância.". ALMEIDA (2008, p. 46-47) conclui que "o conteúdo informacional deve ser passado de forma clara, objetiva, correta e sem ambiguidade e sua organização deve ser estruturada de forma familiar ao usuário, facilitando a transmissão da informação.".

Esta outra determinação de Padovani ${ }^{27}$ (2006, apud ALMEIDA, 2008, p. 46), de que "o sistema deve prover toda informação necessária à realização de cada atividade da tarefa no momento em que ela é realizada, além de evitar prover informação desnecessária, que sobrecarregue a carga cognitiva do usuário ou desvie a atenção do mesmo", permite que se chegue à inferência de que não se deve misturar informações de navegação com informações de cunho comercial, como propagandas, por exemplo. Essa posição é compartilhada por Rogers, Sharp e Preece (2013) que recomendam que se evite sobrecarregar a interface com muita informação, as quais acabam por distrair e incomodar o usuário, ao invés de auxiliá-lo a prestar atenção nas informações relevantes.

A Fundação ONCE (2003) recomenda que se use diferentes botões para diferentes funções, ao invés de se usar um mesmo botão para diversas funções, com opções na tela, pois este último é mais confuso para uma pessoa com deficiência visual. Ainda que resulte em uma grande quantidade de botões, se forem dispostos de maneira lógica será melhor do que botões com multi-funções ou sub-menus e menus que rolam na tela e que são particularmente difíceis para estas pessoas, assim como selecionar ou arrastar alguma opção na tela. Textos intermitentes (que "piscam") na tela podem chamar a atenção, mas são difíceis de ler, assim como textos em movimento.

${ }^{26}$ PASSINI, R. Graphics and architecture for wayfinding. School of Architecture University of Montreal. Proceedings of Public GRAPHICS, LUNTEREN, sept. 1994.

27 PADOVANI, S. Apostila de aula do curso de pós-graduação de ensino em design, nível: pós-graduação. Disciplina ministrada: ergonomia informacional. Recife: Universidade Federal de Pernambuco, UFPE, 2006. 
A ONCE também recomenda que aparelhos de telefones celulares ou smartphones que não possuam um sistema de leitura de tela devem considerar menus simplificados, com cores contrastantes, fontes devidamente escolhidas e síntese de fala como solução viável. Se houver informação sonora, deve ser possível regular o volume e ser possível utilizar fones de ouvido.

Ferreira e Freitas (2012, p. 4) relatam que "os sistemas de diálogo falado permitem que os utilizadores dialoguem com o computador, de forma mais natural quanto possível, utilizando a sua própria voz como entrada e saída para controlar o sistema", condição favorável à usabilidade, especialmente para pessoas com deficiência visual. De acordo com estes autores, o diálogo é possível devido à tecnologia de reconhecimento de fala, que permite que o computador identifique os sons falados pelas pessoas, em conjunto com a reprodução artificial da voz humana, ou síntese de voz, emitida pelo computador.

Quando o menu de interação for por meio de informação verbal, deve ser devidamente estudada a sequência e o tempo de resposta, considerando-se a diversidade de usuários, desde o principiante até o experiente. Algumas pessoas gostam de receber todas as informações ao mesmo tempo e outros gostam que sejam feitos avisos ao longo do percurso; algumas pessoas com deficiência visual são treinadas para usar a memória quando se trata de indicações de rota (HERSH; JOHNSON, 2008).

Hersh e Johnson (2008) recomendam ainda que o sistema de navegação deva ter a flexibilidade de fornecer informações para atender ao usuário em todas as situações. Como exemplos podem ser citados: as informações de rota podem ser silenciadas até que o usuário se aproxime do destino ou de algum ponto significativo; ou as informações podem ser configuradas para repetir a cada 10 segundos, dando uma continuidade de avisos sobre os próximos pontos ou distâncias restantes para o destino. Anúncios automáticos poupam o usuário de ter que interagir manualmente com o dispositivo, condição especialmente útil se as mãos estiverem ocupadas carregando alguma coisa.

Pode-se concluir que o ideal é que a interface seja passível de reconfiguração, com os comandos funcionando de forma mais avançada, tanto em relação à sequência a ser operada como em relação ao tempo de resposta. Um usuário experiente tende a interagir de maneira mais direta e ágil com um determinado sistema do que um usuário principiante. Além disto, para um usuário experiente, acostumado com a interação 
básica com o sistema, pode-se ir aumentando o número de opções de uso, como por exemplo, compra de bilhetes on-line, linha direta com a operadora etc.

Rogers, Sharp e Preece (2013, p. 85) recomendam que se "forneça informações adicionais que fiquem escondidas, mas que sejam fáceis de acessar para os que desejarem saber mais a respeito de como realizar uma atividade com mais eficiência". Essas autoras também recomendam que a interface de dispositivos seja tal que encoraje sua exploração, restrinjam e guiem os usuários na seleção das ações mais adequadas. Elas complementam que os menus e

as instruções de comando por voz devem ser mínimos, pois as pessoas consideram difícil lidar com menus que apresentam mais de três ou quatro opções, assim como lembrar de instruções com mais do que algumas partes.

No entanto é importante se observar que a evolução do diálogo deve ser feita gradualmente. De acordo com Simon ${ }^{28}$ (1982, apud BOOCH et al., 2007, p. 14 - tradução nossa) "sistemas complexos evoluem a partir de sistemas simples muito mais rapidamente se existem formas intermediárias estáveis", e Gall ${ }^{29}$ (1986, apud BOOCH et al., 2007, p. 14 - tradução nossa) afirma "em termos mais dramáticos", que "um sistema complexo projetado a partir do zero nunca funciona e não pode ser remendado para funcionar."

\subsection{TECNOLOGIAS ELETRÔNICAS PARA GUIAR PESSOAS COM DEFICIÊNCIA VISUAL}

A interdisciplinaridade arquitetura/tecnologias eletrônicas tem sido usada com diversas finalidades. Do ponto de vista de um arquiteto, as novas tecnologias frequentemente fornecem novas formas de acrescentar valor ao espaço arquitetônico: "A luz eléctrica, por exemplo, torna as salas mais versáteis e valorizáveis à noite. As tecnologias da sociedade em rede não são excepção. Em geral, elas produzem espaço de fusão - espaço arquitectónico no qual as tecnologias digitais electrónicas permitem novas e socialmente valorizáveis combinações de pessoas e actividades.” (MITCHELL, 2005, p. 338).

\footnotetext{
${ }^{28}$ SIMON, H. The Sciences of the Artificial. Cambridge, MA: The MIT Press, 1982, p. 209.

${ }^{29}$ GALL, J. Systemantics: How systems really work and why they fail. Ann Arbor, MI.: General Systemantics Press, 1986, p. 65.
} 
Almeida et al. (2007) realizaram estudos na área de engenharia de produção a respeito da possibilidade de aplicação de equipamentos eletrônicos para orientação e mobilidade, com resultados muito favoráveis à sua aplicação, mesmo considerando-se o pouco uso de equipamentos eletrônicos de navegação na época, em relação à atualidade. 0 Gráfico 2.6 demonstra os resultados obtidos com 15 pessoas com deficiência visual, das quais, dez haviam recebido treinamento em orientação e mobilidade, sendo cinco com cegueira total e cinco com baixa visão; as demais estavam em processo de treinamento, sendo três com cegueira total e duas com baixa visão.

Gráfico 2.6 - Respostas em relação à suposta utilização de equipamentos eletrônicos para orientação e mobilidade de pessoas com deficiência visual.

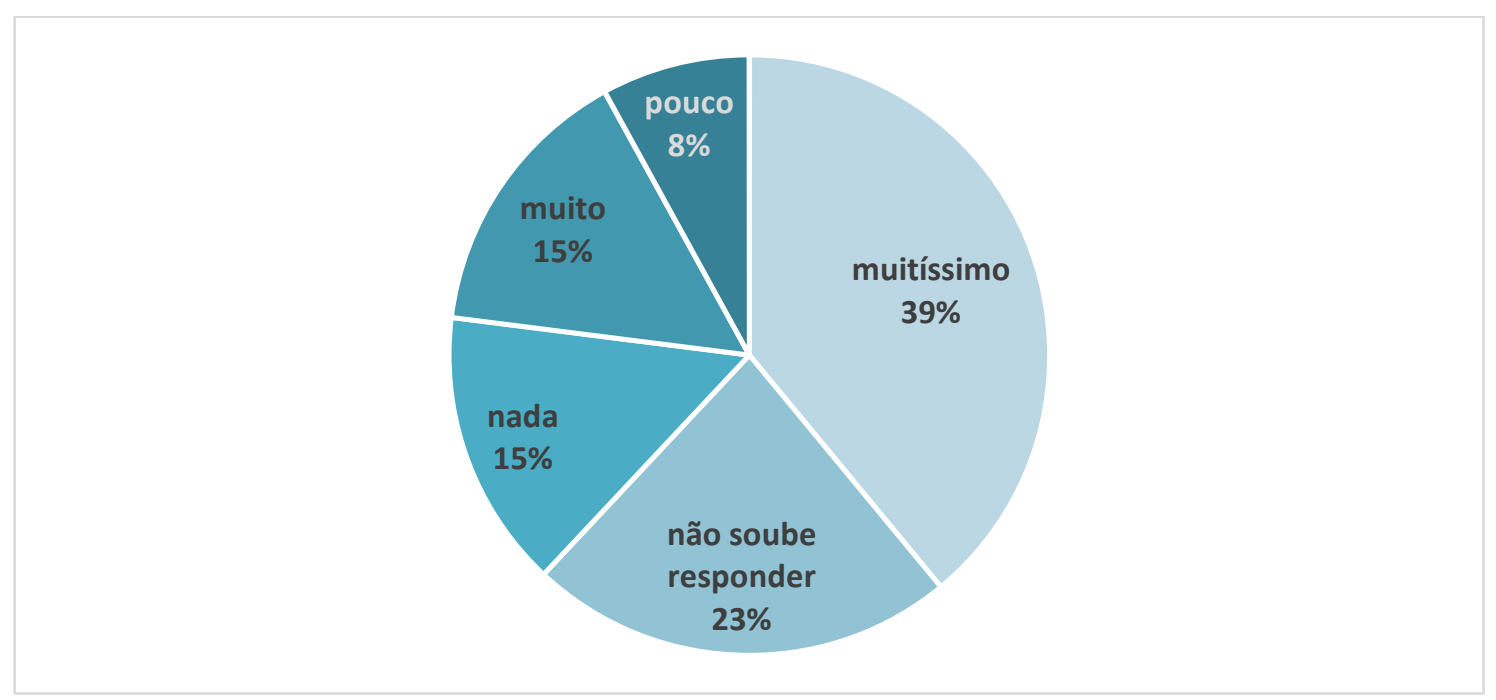

Fonte: adaptado de Almeida et al. (2007, p. 8).

\subsubsection{Breve histórico}

Os avanços tecnológicos modificaram a configuração das empresas e o modelo de empregos. Nas últimas décadas surgiram novas atividades ligadas às novas tecnologias, enquanto que desapareceram outras, de modelos que caíram em desuso. A tecnologia de computação não somente criou novos empregos, como também permitiu às pessoas com deficiência visual desenvolverem-se muito bem nos postos em que a ferramenta de trabalho fundamental é o computador.

Na década de 1980 começou a ser introduzido em algumas empresas o uso de computadores, a partir do sistema operacional MS-DOS, para otimizar as operações. No entanto, até 1990 havia poucos lugares a serem adaptados para o trabalho de pessoas 
com deficiência visual, considerando-se que as principais profissões dessas pessoas foram, por anos, telefonista, fisioterapeuta e músico.

Foi a partir do desenvolvimento de aplicativos de escritório para computadores que houve uma grande mudança nas atividades de trabalho. De acordo com Giacaglia (1998, p. 12) "quando surgiram os primeiros computadores, a interação com os usuários se dava apenas por meio da linguagem de máquina o que se constituía em um dos fatores que limitavam a complexidade dos sistemas que podiam ser desenvolvidos". Com a introdução generalizada do sistema operacional Windows, como a definição mais utilizada, e o enorme sucesso de algumas aplicações desenvolvidas pela Microsoft, muitas pessoas com deficiência se beneficiaram com seu uso, obtendo as devidas adaptações para o trabalho com computadores.

Em geral, todas as profissões foram influenciadas em maior ou menor grau, pela introdução do uso de computadores no ambiente de trabalho. Assim, a partir de então, aumentaram as profissões a serem exercidas por pessoas com deficiência visual, cujas funções são realizadas principalmente por meio do uso de dispositivos de informática ou de tecnologia adaptada.

\subsubsection{Conceitos básicos}

O entendimento de que seja um sistema de informação e navegação surgiu durante as pesquisas, em função da complexidade de projeto e de componentes que fazem parte de seu funcionamento, necessários para oferecer autonomia e segurança de fato.

Um requisito básico desse sistema é que as comunicações com o usuário sejam feitas de maneira wireless. Partindo disso, as principais questões a serem exploradas são:

a) segurança e confiabilidade na informação;

b) foco no objetivo desejado, para informar o necessário de forma eficaz ao usuário;

c) conforto, para viabilizar a utilização.

0 principal aspecto relativo à segurança e confiabilidade é garantir o próximo passo do usuário. A ausência ou redução da visão transforma todos os ambientes em locais de risco, em maior ou menor grau. A questão mais complexa para um sistema de assistência 
à navegação para pessoas com deficiência visual é determinar o posicionamento espacial instantâneo e exato do usuário (HERSH; JOHNSON, 2008; DUARTE, 2014).

Definir esse posicionamento é um processo complexo devido às seguintes razões (HERSH; JOHNSON, 2008): (a) a referência é adquirida a partir de sensores, e isso acarreta que muitos dispositivos heterogêneos precisam se comunicar uns com os outros, possivelmente utilizando tecnologias diferentes; (b) a referência é dinâmica, isto é, pode sofrer mudanças devido a novas construções e objetos que causam interferências no projeto inicial; e (c) a interpretação dos dados de referência de informação pode ser bastante complicado. Durante as pesquisas, verificou-se que as atuais tecnologias de sensoriamento e de localização espacial são as mais promissoras no sentido de se criar um sistema de informação e auxílio à navegação de pessoas com deficiência visual em redes de metrô.

Para realização da análise do quesito foco no objetivo desejado, para informar o necessário de forma eficaz ao usuário, realizou-se pesquisa bibliográfica para identificar as diversas possibilidades para efetuar a comunicação entre dispositivos que possam compor um sistema com base nas telecomunicações, onde o sistema é composto por transmissores (instalados nos ambientes, estações e trens) e receptores portados pelos usuários. A existência ou não de uma central de monitoramento, de informação ou comunicação, de banco de dados e processamento de informações independe das questões deste estudo, focado nos ambientes públicos de redes de metrô. Foram encontradas diversas tecnologias para este fim, destacando-se aquelas significativas para este estudo.

\subsubsection{Tecnologias de comunicação via rádio}

a) GNSS - Sistema de Navegação Global por Satélite

A nomenclatura GNSS é adotada para se referir a sistemas de navegação por satélite que possuam a capacidade de oferecer posicionamento em qualquer ponto da superfície terrestre. Atualmente estão em funcionamento dois sistemas GNSS: (i) o estadunidense Global Position System - GPS; e (ii) o russo Globalnaya navigatsionnaya sputnikovaya sistema - GLONASS. 
Um sistema GNSS é um sistema de navegação baseado em satélite que fornece a um dispositivo receptor móvel a posição do mesmo, desde que o receptor se encontre no campo de visão de pelo menos quatro de seus satélites.

Devido à concepção de sistemas GNSS, existem algumas restrições que o impedem de ser utilizado em sistema para orientação de pessoa com deficiência visual em uma rede de metrô ${ }^{30}$, tais como: (i) somente pode ser utilizado em ambientes externos, pois os sinais dos satélites precisam chegar ao receptor por meio de visada direta com o céu, sem obstáculos, e isso não é possível nesses ambientes, geralmente internos e subterrâneos; (ii) sua precisão de 15 a 20 metros de raio (LOOMIS; GOLLEDGE; KLATZKY, 2001; TREUILLET et al., 2007) é insuficiente para o uso de pedestres, especialmente se tiverem deficiência visual e necessitarem ter certeza a respeito do próximo passo; e (iii) recebe interferência de sinais eletromagnéticos e corpos se movimentando, existentes em profusão em ambientes de metrô ${ }^{30}$.

Além destas condições, ressalta-se que os sistemas GPS e GLONASS não possuem garantia de operação, podendo ser bloqueados ou alterados conforme interesse político ou militar dos países controladores. Existem novos sistemas em estudo, como o europeu Galileo, que promete garantias de operação.

b) Wi-Fi - redes computacionais sem fio de alta velocidade e fidelidade

Nome comercial formado pela junção das palavras "Wireless" e "Fidelity", propondo a transmissão de dados por ondas de rádio em alta fidelidade. Possui a capacidade de transmissão e recepção a médias distâncias em alta velocidade. A tecnologia de triangulação ${ }^{31}$ por Wi-Fi tem se tornado bastante comum, sendo base para se obter o posicionamento do usuário em ambientes internos, ou indoor. (MATTOS, 2006)

Sua principal vantagem é poder ser utilizado com aparelhos de mercado para a triangulação, mas também possui restrições para o uso em ambientes de metrô: (i) utiliza cinco canais por faixa de transmissão, o que limita o uso simultâneo a cinco aparelhos Wi-Fi para triangulação, tornando a navegação imprecisa; (ii) sua

\footnotetext{
30 Informação verbal obtida por meio de entrevista ao funcionário do metrô e designer de produtos de ajudas técnicas Jaldomir da Silva Filho, realizada conforme capítulos 4 e 5.

31 Triangulação de sinais é uma abordagem matemática que usa as propriedades dos triângulos para encontrar pontos de intersecção, e obter informação quanto ao posicionamento espacial. (DUARTE, 2014).
} 
frequência varia em função da densidade do meio que atravessa, sofrendo interferência de intensidade de sinal e velocidade até mesmo quando pessoas circulam no ambiente; (iii) em campo aberto, seu alcance não pode ser limitado, podendo interferir em outros dispositivos $\mathrm{Wi}-\mathrm{Fi}$, inclusive dispositivos do próprio sistema de navegação instalados em locais próximos; (iv) por ser formado por ondas de rádio, recebe interferência de outras fontes de rádio. 3032

c) Bluetooth - redes computacionais sem fio de velocidade e fidelidade limitada

Nome comercial de sistemas de transmissão e recepção de dados por meio de ondas de rádio, utilizando um sistema dedicado que possui curto alcance de transmissão e baixa velocidade de transferência de dados. 0 Bluetooth é uma tecnologia pensada inicialmente para a comunicação de baixo custo, baixo consumo e alta segurança por meio de ondas de rádio, sendo ideal para transmissão de pequeno volume de dados entre smartphones entre si, computadores entre si, e intercambiados.

O sinal Bluetooth possui as mesmas características eletromagnéticas do Wi-Fi, diferenciando-se somente no protocolo de comunicação (a linguagem) utilizada, que é mais segura por permitir a conexão fechada somente entre dois aparelhos. Mas por utilizar a mesma frequência do $\mathrm{Wi}$-Fi, pode sofrer interferências nesta faixa de comunicação, assim como também ser produtor de interferências.

O Bluetooth também apresenta como problema para o uso foco deste trabalho, não ser possível se garantir a precisão de distância, como o posicionamento do usuário, por exemplo (DUARTE, 2014). A evolução da tecnologia Bluetooth ocorreu para que fosse possível se atingir raios cada vez maiores com o sinal, não se destinando ao uso como localizadores de precisão. 3032

d) Beacon - dispositivo emissor de sinal Bluetooth, de pequeno porte

Beacons são pequenos aparelhos que emitem sinais de rádio utilizando tecnologia Bluetooth, apresentando as mesmas características descritas para esse sinal. Duarte afirma em seus estudos, que "a precisão obtida com o sinal Bluetooth não é suficiente para o uso de triangulação de algoritmos, os quais são necessários para obtenção do

32 Informação verbal obtida por meio de entrevista ao professor da FEUP, Diamantino Freitas, realizada conforme capítulos 4 e 5 . 
posicionamento [de usuários] em sistemas indoor" (DUARTE, 2014, p. 48 - tradução nossa). Essa mesma autora afirma também que pretende, em trabalhos futuros, "explorar abordagens para melhorar a localização indoor, diante da incerteza gerada pelas limitações da tecnologia de beacons” (DUARTE, 2014, p. 47 - tradução nossa).

e) RFID - Identificador de Frequência de Rádio

"Radio-Frequency IDentification", é uma tecnologia que transmite dados a partir da sua passagem por uma área previamente delimitada por um chip inserido em uma etiqueta (conhecida como tag). Este tipo de dispositivo de rádio realiza uma comunicação bilateral entre dois dispositivos, permitindo a identificação do objeto ou local. Não possui capacidade de triangulação e seu sinal é de curto alcance, podendo sofrer interferências eletromagnéticas. ${ }^{30}$ Seu projeto não prevê a transmissão de dados dinâmicos, somente informações fixas. (MAU et al., 2008)

f) NFC - Conexão de Campo Próximo

Near Field Communication é uma evolução do RFID. É uma tecnologia de concepção relativamente nova, utilizada para comunicação de baixa velocidade entre aparelhos próximos, como os utilizados para pagamentos online. Seu alcance é considerado extremamente curto, da ordem de poucos centímetros, e sua concepção não foi pensada para localização. Normalmente os aparelhos precisam estar encostados ou extremamente próximos, e se manterem imóveis um em relação ao outro. Também pode sofrer interferência eletromagnética, assim como produzi-la, apesar de não possuir potência de transmissão suficiente para alcançar além de alguns centímetros. ${ }^{30}$

\subsubsection{Tecnologias de comunicação via luz}

a) Infravermelho - sinal luminoso imperceptível aos olhos humanos

Infravermelho, também denominado infrared, foi descoberto em 1800 por Willian Herschel, e é uma faixa de onda do espectro eletromagnético não visível ao olho humano, pois sua frequência está abaixo da gama da luz visível. Muitos componentes 
eletrônicos ópticos podem trabalhar nesta faixa de frequência, permitindo transmissões de dados sem a interferência com a visão humana.

A radiação infravermelha é uma radiação eletromagnética não ionizante, com características muito positivas para utilização para a navegação em questão: (i) por estar abaixo da luz visível, não interfere com a visualização de outros aparelhos que se utilizam de luz; (ii) pode ser interrompida ou refletida com a colocação de objetos fixos ou móveis em seu campo de dispersão; (iii) pode ser detectada por sensores de baixo custo; (iv) pode ser isolada de outros sinais luminosos, reduzindo ou anulando interferências de outras radiações luminosas; (v) transmite dados em alta velocidade. ${ }^{30}$ Como cuidado é necessário que se tome medidas para evitar obstáculos entre o emissor e receptor, para não cortar a comunicação (ONCE, 2003).

b) Li-Fi - redes computacionais sem fio de alta velocidade e fidelidade

Nome comercial formado pela junção das palavras "Light" e "Fidelity", propondo a transmissão de dados por luz visível, emitida por LEDs. Possui a capacidade de transmitir comunicações em velocidade muito superior à atualmente utilizada Wi-Fi (COETZEE, 2014), com vantagens e desvantagens sobre esta, dependendo do uso: (i) as ondas de luz não podem atravessar objetos; (ii) o Li-Fi é apto para uso em áreas sensíveis às ondas eletromagnéticas, como estações e trens de metrô, pois não causam nem sofrem interferência eletromagnética (THE ECONOMIST, 2012). Apresenta características que demonstram possível utilização no tema desta pesquisa, porém não foi possível uma investigação mais detalhada, por encontrar-se ainda em fase de estudos.

c) Laser - faixa de luz amplificada, com foco e frequência restritos e grande alcance Sigla em inglês para Amplificação da Luz por Emissão Estimulada de Radiação. É uma radiação eletromagnética não ionizante, produzida artificialmente por meio de dispositivos que restringem sua frequência e amplificam sua intensidade, criando um foco luminoso extremamente restrito e que, portanto, pode ser emitido a grandes distâncias.

Principais características: (i) pode ser utilizado para transmitir a grandes distâncias; (ii) grandes amplificações causam o aquecimento do ponto focal e podem causar 
danos à retina humana (BRANDALIZE; PHILIPS, 2002); (iii) pode trabalhar com toda a faixa de frequência de luz, desde o infravermelho até o ultravioleta, passando pela faixa de luz visível; (iv) pode ser interrompida ou refletida com a colocação de objetos fixos ou móveis ao longo de sua faixa de transmissão; (v) pode ser detectada por sensores de baixo custo; (vi) transmite dados com alta velocidade. 0 Laser pode ser utilizado em conjunto com qualquer tecnologia de transmissão luminosa, para levar a informação a pontos distantes em ambientes indoor, possibilitando a transmissão da informação por meio de reflexão em paredes e portas. ${ }^{30}$

\subsubsection{Tecnologias de comunicação via som}

a) Som audível - sinal sonoro com frequências dentro da faixa audível por humanos

A utilização de dispositivos sonoros é praticamente unanimidade em aparelhos voltados ao uso de pessoas com deficiência visual, sendo reconhecido como uma das formas mais eficientes de comunicação com essas pessoas. Os sons emitidos por vozes e alarmes ("beeps") transmitem semanticamente significados como calma, alerta e atenção, compostos basicamente por tons sonoros simples ou compostos, vocais ou não. ${ }^{30}$

b) Ultrassom - sinal sonoro com frequências acima do percebido pelos ouvidos humanos

Outra utilização do som em comunicação é a que se obtém por meio de dispositivos ultrassônicos. 0 som, por propagar-se em ondas com frequência e velocidade mais baixa que a velocidade da luz, pode ser utilizado na medição de distâncias, com relativa precisão. Existem no mercado diversos componentes e aparelhos utilizando esta tecnologia, tais como o sensor de estacionamento de veículos, que indica a distância entre o para-choques e um possível obstáculo. Verificou-se que o ultrassom tem sido utilizado com certa frequência em projetos de bengalas eletrônicas para detecção de obstáculos aéreos, com relativo sucesso, apesar do custo elevado (SANTOS et al., 2012). ${ }^{30}$ 


\subsubsection{Tecnologias de comunicação via vibração}

a) Vibração - percepção de situações por meio de sinais táteis vibratórios

Do ponto de vista de dispositivos eletrônicos, as informações por vibração podem ser transmitidas pelos aparelhos ao usuário por meio do sistema háptico ${ }^{12}$. As vibrações podem ser contínuas ou intermitentes, e pode-se utilizar também receptores acoplados ao vestuário. As vibrações geralmente são produzidas por micromotores elétricos com eixos excêntricos, podendo ser instalados em aparelhos de pequeno porte, facilmente transportáveis. ${ }^{30}$

b) Infrassom - utilização de frequências sonoras baixas que causam sensações táteis

Os sinais de infrassom, que poderiam estar na categoria "Som", não podem ser percebidos pela audição humana, mas sim pelo sistema háptico, devido à vibração que produzem, mesmo sem contato físico, pois causam vibrações no ar e nos corpos, causando sensações táteis e térmicas. Por trabalhar em frequências abaixo de $20 \mathrm{~Hz}$, a utilização de infrassom demanda de equipamentos que possam produzir este comprimento de onda de forma eficiente. O dispositivo mais conhecido para produzir este tipo de onda é o subwoofer, um tipo de alto-falante de dimensões e peso inviáveis para equipamentos portáteis. ${ }^{30}$

\subsubsection{Considerações a respeito das tecnologias de comunicação}

As ondas de rádio são as principais formas de comunicação utilizadas nos estudos de dispositivos de navegação. No entanto, a tecnologia de triangulação por rádio sofre com a possibilidade de erros da ordem de alguns metros (FURUKAWA; BRUNO, 2006; PEREIRA; MOURA, 2011), o que pode significar riscos para uma navegação de usuário com deficiência visual em um ambiente de metrô. Assim, a tecnologia por ondas de rádio pode ser usada apenas de forma complementar ao sistema, como por exemplo, transmitindo dados de diagnóstico do sistema e/ou transmitindo informação de texto e voz, sendo de grande valia para a efetivação da compreensão da informação pelo usuário. 
Com relação à comunicação por luz, existem vários pontos positivos a seu favor, pois, por não desviar sua trajetória, a luz pode ser transmitida em ângulos precisos. Além disso, a luz não recebe interferência de ondas de rádio, assim como não gera interferência em ondas de rádio, muito presentes em ambientes de metrô. A interferência à luz somente pode se apresentar com a obstrução de sua passagem, o que é, de fato, desejável em alguns aspectos, pois permite suprimir o sinal em uma direção específica, bastando utilizar um anteparo para obter a supressão necessária, possibilitando que a informação seja direcional, o que é muito difícil de ser obtido com os demais tipos de sinais. 0 único inconveniente da comunicação por luz é que esta pode sofrer interferência de outras fontes luminosas, inconveniente este que pode ser contornado com filtros de luz infravermelha e sinais emitidos em frequência específica.

A comunicação sonora também é útil para a comunicação com o usuário, em forma de sons vocais e sons de "beeps", para orientá-lo quanto a ações a serem tomadas, ou para fornecer-lhe orientações sobre o ambiente, ou ainda para fornecer-lhe qualquer outra informação pertinente, devendo ser estudado seu uso para não haver interferências com os sons ambientes, tanto para os usuários com deficiência visual, como para os demais usuários (FERREIRA, 2012).

Quanto à questão do conforto, verificou-se que os dispositivos portados pelos usuários devem ser transportados facilmente, ser leves e, qualquer que seja a solução adotada, é importante ressaltar que o dispositivo não deve ocupar de maneira permanente as mãos do usuário durante a navegação, como por exemplo, a obrigatoriedade de segurar na mão um dispositivo, porque, considerando-se que uma delas já está ocupada com a bengala longa, é necessário que a outra esteja livre para outras interações (ONCE, 2003).

Uma opção de dispositivo que a princípio parece interessante é o uso de aplicativos em smartphones, por serem, atualmente, amplamente utilizados por todas as pessoas, inclusive por pessoas com deficiência visual, pois a maioria desses aparelhos possui recursos que permitem seu uso por essas pessoas.

Uma questão relacionada tanto ao conforto como à segurança é a audição. A audição exerce importante papel na segurança das pessoas, de maneira geral. A localização de sons no espaço permite encontrar ou evitar eventos sonoros. Para o ser humano, qualquer som diferente, destoante, principalmente se provindo de trás ou dos lados, 
torna a pessoa tensa e insegura (OKAMOTO, 2002). Este mecanismo de defesa é muito importante para as pessoas com deficiência visual, pois quando a visão não está disponível, a audição é um dos sentidos que auxiliam na segurança e interação social da pessoa, e isto deve ser respeitado quando do projeto de equipamentos de ajuda à navegação (HERSH; JOHNSON, 2008, p. 278).

O ouvido também está ligado ao sentido de equilíbrio (OKAMOTO, 2002), interferindo diretamente nesta questão para pessoas com deficiência visual. Interfaces de navegação em áudio têm sido geralmente estudadas utilizando fones de ouvido, principalmente para locais de grande ruído ambiente. No entanto, muitos dos potenciais usuários ficam hesitantes em adotar essas tecnologias se isso as obriga a reduzir a sua capacidade de ouvir os sons ambientes por meio do uso de fones de ouvido. Para se conciliar as necessidades, existem algumas possíveis soluções, das quais se destacam:

a) utilizar apenas um fone em um ouvido, deixando o outro ouvido livre (HERSH; JOHNSON, 2008), sem prejuízo da compreensão do todas as informações recebidas pelos dois, pois, em uma "situação de estimulação dicótica, isto é, estímulos diferentes em cada ouvido, o sujeito saberá relatar a informação fornecida a cada ouvido separadamente. Além disso, poderá concentrar-se, isto é, prestar atenção à estimulação recebida em cada ouvido separadamente." (ALMEIDA, 2008, p. 77); e

b) utilizar fone de condução óssea, ou fone de ouvido externo, que se apoia nos ossos da face e transmitem os sons por meio de vibração diretamente ao canal do ouvido, sem tampá-lo, sem impedir a captação do ruído exterior (Figura 2.6). Walker e Lindsay (2005) realizaram estudos para verificar a eficácia destes dispositivos em pessoas com deficiência visual e concluíram que é realmente possível navegar usando fones de condução óssea, pois foi possível a todos os participantes concluírem suas tarefas auditivas utilizando estes dispositivos - tarefas tradicionalmente realizadas usando fones de ouvido convencionais. 
Figura 2.6 - Exemplo de fone de ouvido externo (ou de condução óssea).

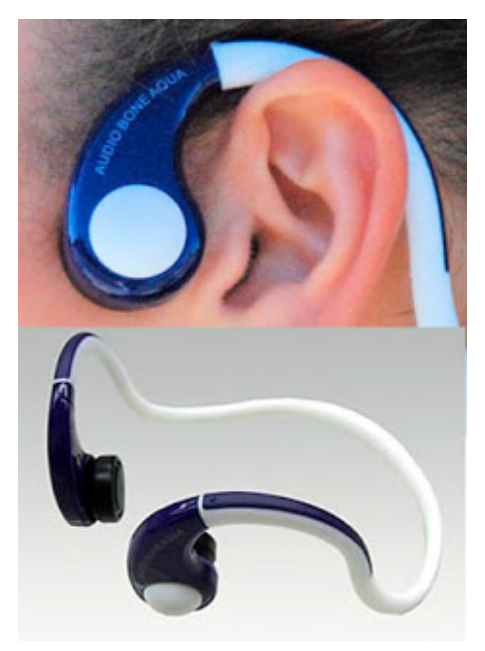

Fonte: [Internet] Disponível em <http://psy323sensationperception.blogspot.com.br/2011/11/advancements-in-hearing-technologybone.html>. Acesso em: 12 out. 2015.

\subsubsection{Estudos relacionados}

Na pesquisa por material bibliográfico e documental sobre tecnologias eletrônicas para informação e navegação de pessoas com deficiência visual, foram encontrados muitos dispositivos que fornecem informações básicas a seus usuários, por exemplo, sobre se existe ou não um obstáculo, e poucos estudos sobre dispositivos ou sistemas mais complexos que possam dar ao usuário uma visão geral do ambiente. No rol dos dispositivos de informações básicas estão as bengalas eletrônicas.

Cabe lembrar que desde os anos 1950 são estudados e desenvolvidos dispositivos eletrônicos de auxílio às pessoas com deficiência visual (HARPER, 1998, p. 23; ACAPO, 2013b, p. 6). Na Figura 2.7, um exemplo de bengala eletrônica, denominada UltraCane, concebida pela empresa Sound Foresight em conjunto com cientistas da Universidade de Leeds, do norte da Inglaterra (ECOS, 2005, p. 68), em 1998. A UltraCane, assim como as demais bengalas eletrônicas, baseia-se em sistemas de ecolocalização ${ }^{33}$ para orientação no escuro, recorrendo a ultrassons para advertência da presença de possíveis obstáculos.

\footnotetext{
33 Ecolocalização é a detecção de objetos ou obstáculos por intermédio da percepção do retorno do som
} refletido nesses objetos. 
Figura 2.7 - Bengala eletrônica UltraCane, criada em 1998.

(a) - Realização de testes.

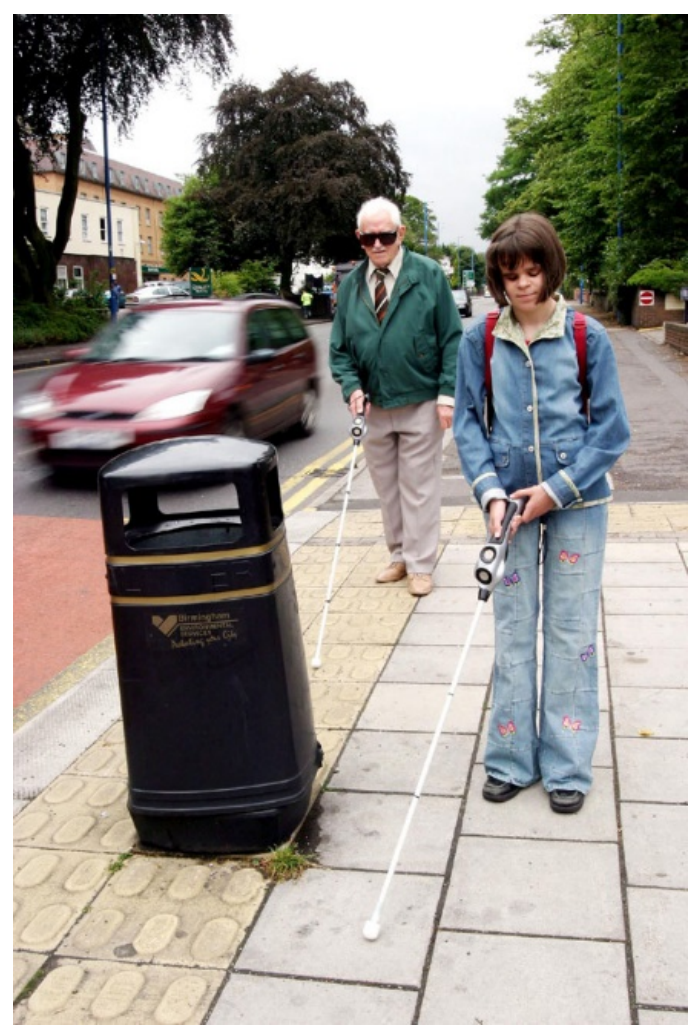

(b) - Esquemas de alcances.

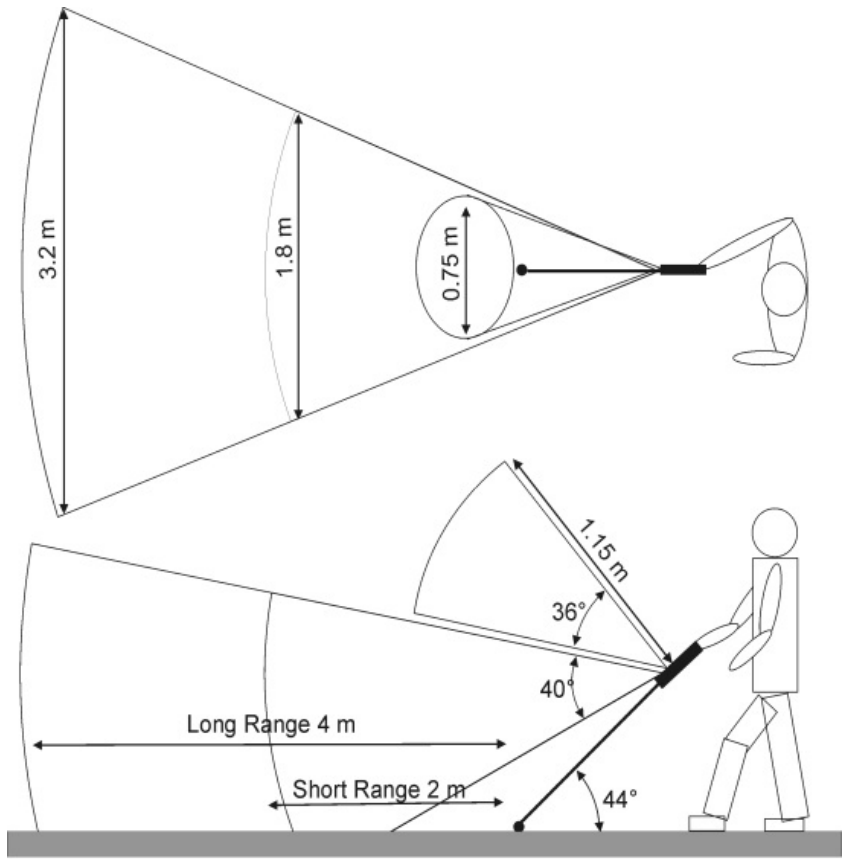

Fonte: [Internet] (a) Disponível em

<http://www.ideaholic.co.kr/Review/view.asp?ct1=AA\&boardno=1086>. Acesso em: 18 set. 2015; (b) Manual de treinamento UltraCane ${ }^{34}$ (2015).

Com relação aos dispositivos ou sistemas mais complexos, os trabalhos significativos mais antigos, com pesquisas que remontam aos anos 1970, apresentam importantes conceitos e experiências de utilização de sistemas para navegação pessoal em transportes públicos. Estes trabalhos referem-se a um sistema que utiliza sinal infravermelho para criar as "RIAS" - Remote Infrared Auditory Signage, utilizadas na concepção do sistema Talking Signs ${ }^{\mathrm{TM}}$, que basicamente fornece referências do ambiente e de direção a seguir, voltadas às pessoas com dificuldades visuais (Figura 2.8).

34 Disponível em: <http://www.ultracane.com/user_manuals>. Acesso em 12 out. 2015. 
Figura 2.8 - Sistema Talking Signs ${ }^{\mathrm{TM}}$, desenvolvido nos anos 1970 .

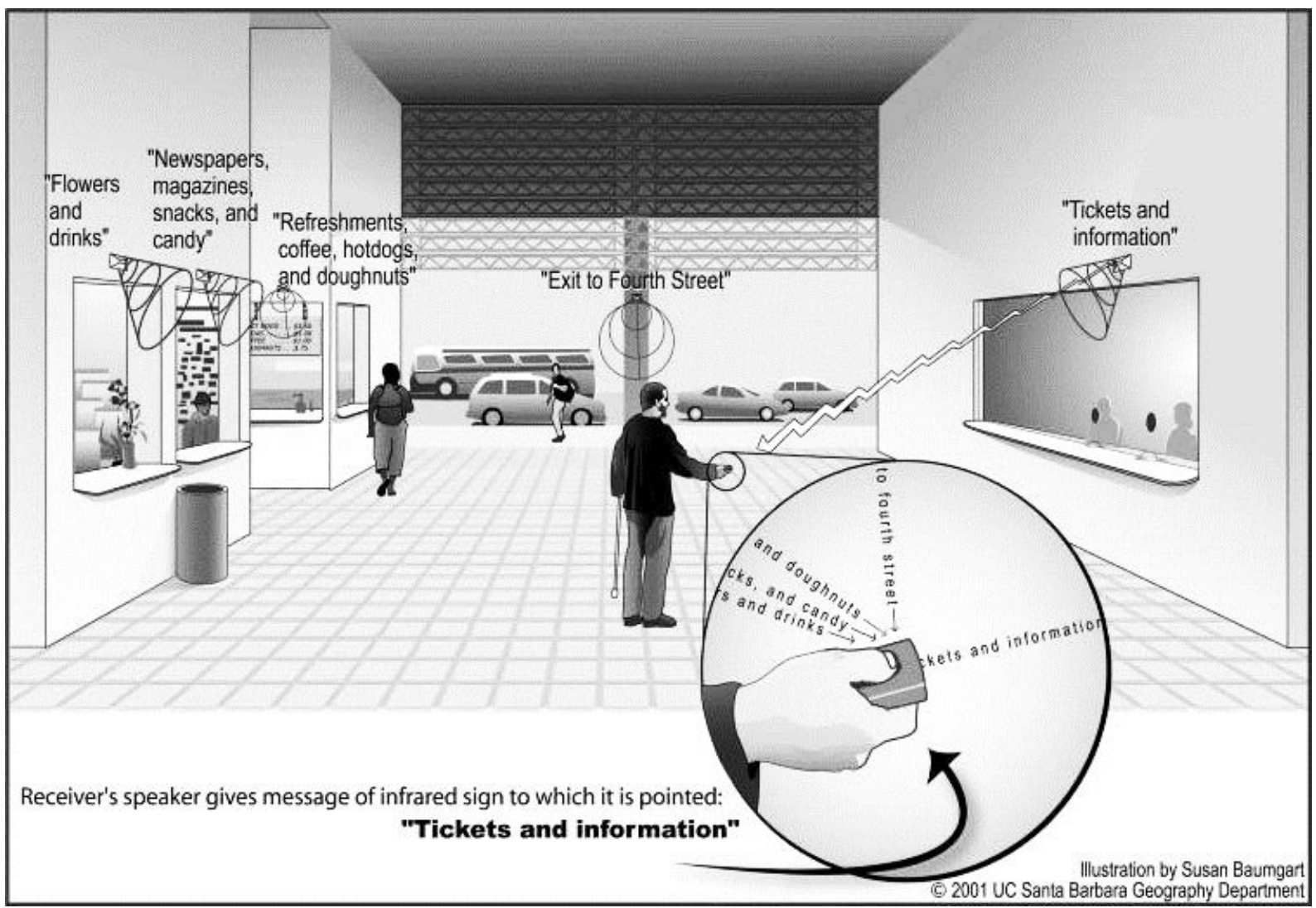

Fonte: [Internet] Disponível em: <http://www.geog.ucsb.edu/ marstonj/DIS/CH2_4.html>. Acesso em: 15 set. 2014.

O desenvolvimento do Talking Signs ${ }^{\mathrm{TM}}$ começou no Centro de Pesquisa de Engenharia de Reabilitação da Smith-Kettlewell em 1978, por William Loughborough, um engenheiro especializado em reabilitação (CRANDALL et al., 1995). Por meio de experimentos, os engenheiros da Smith-Kettlewell concluíram que raios infravermelhos codificados com informações podem ser emitidos por transmissores e acessados a partir de uma distância, sendo localizados por dispositivo com alto-falante, projetado para reproduzir as falas dos sinais. O protótipo do dispositivo foi criado em 1979 e teve a sua primeira instalação no College Community em San Diego, Califórnia, em 1984.

Outro pesquisador que se utiliza também dos sinais por infravermelho é James Marston, do Departamento de Geografia da Universidade da Califórnia em Santa Barbara. Ele iniciou suas pesquisas em 1992 sobre o uso do Talking Signs ${ }^{\mathrm{TM}}$. Um transmissor emite continuamente um feixe de sinal infravermelho que pode ser captado por um pequeno aparelho receptor, portado pelo usuário, e que faz a varredura do ambiente e intercepta 
o feixe de infravermelho contendo uma mensagem informativa e a transmite pelo altofalante do receptor (MARSTON, 2002). ${ }^{35}$

O Talking Signs ${ }^{\mathrm{TM}}$, porém, apresentou problemas devido à necessidade de o usuário apontar o receptor diretamente para o transmissor da informação sonora, o que é muito difícil de ser realizado por uma pessoa que não enxerga. Mas, mesmo apresentando problemas na aplicação, o conteúdo das pesquisas realizadas nesse campo mostrou-se muito útil nos estudos para esta dissertação.

Alguns pesquisadores do Talking Signs ${ }^{\mathrm{TM}}$ realizaram estudos de acréscimo do sistema GPS para indexação geográfica, com informações armazenadas no receptor pessoal (CRANDALL et al., 1995). Não foram encontrados relatos de sucesso dessa utilização, provavelmente porque o uso de GPS por pedestres para posicionamento espacial apresenta diversos inconvenientes.

De acordo com Loomis, Golledge e Klatzky (2001) e Duarte (2014), existem três inconvenientes no uso de GPS para pedestres, principalmente para pedestres com deficiência visual: o primeiro é que a precisão dos receptores GPS disponíveis comercialmente é limitada a um raio de 20 metros; o segundo inconveniente é a possível perda de visibilidade por satélite quando nas proximidades de edifícios ou vegetação densa bloqueando uma parte substancial do céu e o terceiro envolve as distorções resultantes de reflexões do sinal de GPS a partir de estruturas vizinhas. ${ }^{36}$

A imprecisão de localização de sistemas GPS também é explorada nos estudos dos franceses Treuillet et al. (2007). Eles exploram a questão mais desafiadora dos sistemas de auxílio à navegação de pessoas com deficiência visual, que é a localização espacial instantânea e exata do usuário. Eles abordam que a maioria dos sistemas propostos baseados em sensores de GPS têm precisão claramente insuficiente para o uso de pedestres, além de só atuarem ao ar livre e sofrerem interferências na área urbana.

\footnotetext{
35 Marston também imaginava o uso de GPS em conjunto com o Talking Signs ${ }^{\mathrm{TM}}$ para complementar informações nas áreas externas (MARSTON, 2002).

36 A ideia de se usar GPS para auxiliar na navegação de deficientes visuais remonta aos anos 1970 (COLLINS, 1985; LOOMIS, 1985 apud LOOMIS; GOLLEDGE; KLATZKY, 2001). 0 primeiro estudo de GPS para esta finalidade foi realizado por Strauss e seus colegas. Porém, como suas pesquisas ocorreram durante a fase inicial de consolidação do GPS, a imprecisão do posicionamento disponível para pedestres impedia estudos práticos com deficientes visuais (BRUSNIGHAN et al., 1989 apud LOOMIS; GOLLEDGE; KLATZKY, 2001) - situação que se verifica até a atualidade (2016).
} 
Rodrigues (2006, p. 41) relata que um dos primeiros sistemas de auxílio à navegação foi desenvolvido por Loomis et al. (1994). Eles criaram o Personal Guidance System (PGS), composto de um GPS, usado para determinar a posição e a orientação do usuário, um $\mathrm{SIG}^{37}$, para armazenar dados espaciais e uma interface sonora com o usuário. 0 planejamento da rota era feito pelo computador carregado por ele, e as instruções de como se locomover de um lugar a outro era fornecida ao usuário por meio de instruções ou descrições verbais, geradas por um sintetizador de voz.

O PGS introduziu inovações técnicas que posteriormente foram incorporadas a novos sistemas de navegação. Mesmo assim, o PGS apresentou diversos problemas operacionais. Um deles foi a sua total dependência do sinal GPS. Mas o que mais chamou a atenção para os problemas do PGS foi que as instruções verbais eram muito "complicadas", segundo o autor, difíceis de serem seguidas, reforçando a importância de se realizar estudos sobre as melhores formas de prover a comunicação de sistemas de navegação (GOLLEDGE; LOOMIS; KLATZKY, 2001).

Trabalhos mais recentes, como os realizados pelos espanhóis López-de-Ipiña, Lorido e López (2011 a 2013), referem-se a cidades inteligentes, trazendo inovações das tecnologias da informação no sentido de auxiliar idosos ou pessoas com deficiências em suas atividades diárias. Com estudos centrados no usuário, eles realizam pesquisas com aparelhos celulares de baixo custo combinando leitor de radiofrequência (RFID) na extremidade de uma bengala longa. Também pesquisaram aparelho para reconhecimento de produto que utiliza códigos $\mathrm{QR}$ em relevo e câmera de comunicação móvel, com gerenciamento por meio de rede Internet para configurar o sistema. Mesmo tendo como principal objetivo a compra e venda de produtos, os estudos desses pesquisadores apresentam importantes considerações sobre o uso de tais tecnologias, relevantes para este estudo.

Também podem ser considerados válidos os trabalhos de du Buf, José, Farrajota e Rodrigues (2007 a 2013), portugueses que desenvolveram o projeto SmartVision,

\footnotetext{
37 SIG - Sistema de Informações Geográficas (GIS - Geographic Information System), é "um sistema de suporte à decisão que envolve a integração de dados referenciados espacialmente em um ambiente para a solução de problemas" (COWEN, 1988, p.1555 - tradução nossa). Um SIG pode ou não estar integrado a um sistema de GNSS, cuja única função é fornecer, por meio de triangulação de satélites, sua posição geográfica terrestre. Exemplos de SIG: (1) um conjunto de informações sobre condições climáticas; (2) aparelhos de navegação utilizados por condutores de veículos, popularmente chamados "GPS", mas que, de fato, são GIS que fazem uso do GPS.
} 
buscando um sistema pequeno, portátil, inteligente e confiável para ajudar as pessoas com deficiência visual durante a navegação autônoma, tanto indoor como outdoor. Eles discutem o protótipo executado, seu design e seus diferentes módulos que integram um SIG com GPS, Wi-Fi, etiquetas RFID e tecnologia da informação.

O protótipo desses autores trata de navegação global, seguindo marcos conhecidos, navegação local com rastreamento do caminho, buscando o reconhecimento de objetos, para se evitar obstáculos. Em suas pesquisas também demonstraram interesse pelo uso de interfaces fáceis e intuitivas, como é necessário no atendimento de pessoas com deficiência, especialmente em ambientes públicos. Essa diretriz também é compartilhada por Rogers, Sharp e Preece (2013, p. 81) que indicam: "não sobrecarregue a memória dos usuários com procedimentos complicados para a realização de tarefas; projete interfaces que promovam o reconhecimento, em vez de recordação, utilizando menus, ícones e objetos posicionados de forma consistente”.

Instituições voltadas ao atendimento de pessoas com deficiência visual, como a Fundação ONCE (ORGANIZACIÓN NACIONAL DE CIEGOS ESPAÑOLES) e U.T.L.A.I. (USUARIOS DE TIFLOTECNOLOGÍA PARA EL LIBRE ACCESO A LA INFORMACIÓN) ${ }^{38}$, ambos da Espanha, realizam estudos frequentes sobre a evolução e o uso de tecnologias auxiliares. Em 1985 a Unidade Tiflotécnica da ONCE (UTT) foi criada para atender às necessidades técnicas dos filiados à Organização que começaram a usar computadores em seus postos de trabalho e, portanto, estes equipamentos precisavam ser adaptados em conformidade. Em uma primeira fase, a UTT importou a tecnologia específica necessária para o uso de computadores e outros dispositivos para melhorar o desempenho no trabalho; mais tarde, o foco passou a ser o desenvolvimento de seus próprios instrumentos de alta tecnologia adaptados. Desta forma é possível se encontrar diversos estudos e propostas nesta área em seus anais.

Virtanen e Koskinen (2014), da Finlândia, apresentam conceitos e experiências de utilização de sistemas de navegação pessoal em transportes públicos, como o caso de

\footnotetext{
38 Tiflotecnologia é um termo utilizado principalmente em países como Espanha e Portugal para designar tecnologia assisitiva, que são dispositivos, funcionalidades ou aplicações técnicas que ajudam uma pessoa cega a realizar as suas atividades autonomamente nas diferentes situações quotidianas. Tiflos quer dizer "cego" em grego. Caparrós (1994, p. 307) entende por Tiflotecnologia "[...] o conjunto de técnicas, conhecimentos e recursos destinados a procurar para os cegos ou deficientes visuais os meios capazes para uma correta utilização da tecnologia, com o fim de favorecer a autonomia pessoal e plena integração social, laboral e educativa".
} 
informações em tempo real para ajudar pessoas com deficiência visual a entrar e sair dos ônibus na parada certa. O sistema fornece informações ininterruptas de viagem, utilizando bases de dados de informações comerciais e de serviços por rede Internet, tentando garantir que as pessoas com deficiência visual obtenham as mesmas informações que as demais pessoas.

No Brasil existe o DPS2000, um sistema eletrônico que auxilia pessoas com deficiência visual a utilizar o transporte público. Desenvolvido em parceria com a Universidade Federal de Minas Gerais e Secretaria do Direito da Pessoa, está em funcionamento na cidade de Jaú desde 2010. 0 sistema é composto de um dispositivo portátil que fica com o usuário e um receptor que fica instalado no ônibus, comunicando-se por meio de sinais de rádio. Quando o usuário seleciona no dispositivo a linha de ônibus que deseja usar são emitidos sinais em um raio de 100 metros. Ao se aproximar do ponto, o motorista recebe sinais luminosos e sonoros para parar no ponto seguinte. A pessoa que está esperando no ponto localiza a porta de embarque por meio de um alto-falante ali instalado. (G1, 2012)

Em São Carlos também está em funcionamento um sistema semelhante ao de Jaú, mas que utiliza um aplicativo instalado no aparelho celular do usuário. De uma maneira simplificada, alguns aplicativos também facilitam a identificação da chegada de ônibus pelas pessoas com deficiência visual, como o CittaMobi e o Bus Alert, bastando que a pessoa tenha um smartphone e que o veículo também esteja equipado com algum tipo de transmissor dessa informação (LOPES, 2010).

Para navegação indoor, foi divulgado em 2015 o sistema denominado ViaVoz, desenvolvido por uma equipe técnica brasileira e instalado na Biblioteca da UNESC e na Assembleia Legislativa de Santa Catarina. Trata-se de um sistema de navegação interna onde a pessoa, portando um aparelho celular, recebe informações por meio de beacons. Conforme abordado anteriormente, os beacons não oferecem precisão de posicionamento, sendo complementado, neste caso, pelo funcionamento da bússola interna do aparelho, para que seja possível a sua localização, sendo necessário que a pessoa caminhe com o smartphone na mão, em uma posição perpendicular ao corpo, apontado para o ambiente (Figura 2.9). Devido ao inconveniente de se caminhar com o aparelho desta maneira, especialmente em locais públicos de grande movimento de 
pessoas, a equipe técnica do ViaVoz informou estar pesquisando uma alternativa mais adequada. (UNESC, 2015)

Figura 2.9 - Sistema ViaVoz instalado em Santa Catarina, ano 2015.

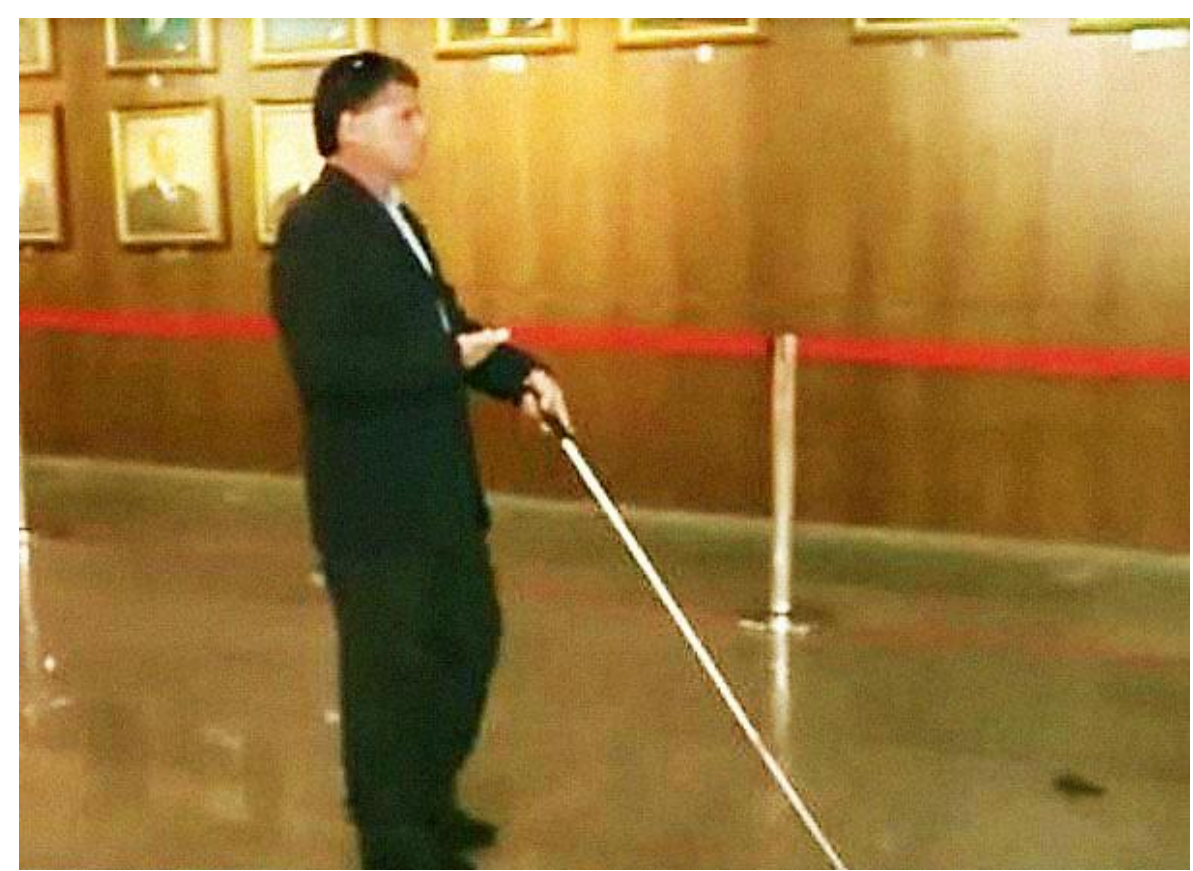

Fonte: Imagem extraída de vídeo disponível em: <https://www.youtube.com/watch?v=YFuhXDmtCnM>. Acesso em 30 dez. 2015.

Uma equipe multidisciplinar de alunos e professores da USP idealizou em 2011 um sistema colaborativo que utiliza mensagens de áudio georreferenciadas para auxiliar no deslocamento de pessoas com deficiência visual em ambientes urbanos, o Smart Audio City Guide. Em princípio, este sistema foi concebido como uma rede social baseada em sistemas de voz integrados a bases de georreferenciamento e dispositivos móveis para auxiliar os usuários na locomoção urbana.

O princípio do projeto do Smart Audio City Guide é que qualquer usuário possa colaborar, fornecendo informações de áudio a serem adicionadas ao sistema, a respeito de qualquer local da cidade, de forma que outros usuários possam utilizá-las e assim sucessivamente. Seus idealizadores intencionam desenvolver um sítio na internet e um aplicativo para smartphone, o qual, por meio da utilização de sinais GPS, possa identificar a localização do usuário para obter informações sobre o que está registrado nas redondezas e promover uma maior integração das pessoas com deficiência visual com a sociedade. (VALENTE; REGANATI, 2013) 
Apesar dos diversos estudos encontrados, tanto nacionais como estrangeiros, verifica-se que a maioria não avança, no sentido de ser comercialmente produzido e utilizado, talvez porque a maioria dos equipamentos e sistemas propostos não funciona de maneira satisfatória. Por exemplo, sistemas que exigem o uso de fones em ambos os ouvidos limitam o principal sentido de percepção e defesa de uma pessoa com deficiência visual, que é a audição; outra inviabilidade é quando o sistema depende de linha telefônica, de operadoras de telefonia móvel, e assim sucessivamente.

Além disso, foi constatado que na maioria dos estudos não houve pesquisa adequada que validasse o uso do sistema ou dispositivo projetado; pesquisa que deve considerar seu uso pelas mais diferentes pessoas, em diferentes ambientes públicos, a médio ou longo prazo, o que aponta a importância de se estudar melhor o assunto (BRADLEY; DUNLOP, 2005). Estes autores também chamam a atenção para os perigos de se realizar pesquisas com pessoas sem deficiência visual, pedindo que utilizem vendas nos olhos e "se comportem como se estivessem temporariamente cegas", pois este tipo de abordagem não considera as condições e habilidades mentais dos indivíduos que realmente irão utilizar os experimentos, por exemplo, seus conhecimentos espaciais May $^{39}$ (2000 apud BRADLEY; DUNLOP, 2005).

Para Hersh e Johnson (2008, p. 173), as possíveis razões para que muitos sistemas fracassem são:

a) complexidade excessiva, tornando dispositivos difíceis de se aprender a usar, combinado com falta de treinamento;

b) aparência imprópria do dispositivo portado pelo usuário;

c) dispositivo incômodo ou pesado para carregar;

d) não atender às necessidades dos usuários;

e) não fornecer significativamente maior funcionalidade do que a bengala longa já fornece.

${ }^{39}$ MAY, M. Accessible GPS Navigation and Digital Map Information for Blind Consumers. ICWC 2000. 


\section{REDES DE METRÔ, ACESSIBILIDADE E NAVEGAÇÃo ELETRÔNICA}

Este capítulo trata do sistema de transporte conhecido como metrô, o qual representa o modal com a mais alta capacidade, em relação à quantidade de passageiros transportados por hora/sentido. Denominado tecnicamente RRT - Rapid Rail Transit, geralmente utiliza trens elétricos de alta capacidade de transporte de passageiros por hora/sentido.

De acordo com o especialista em transporte Vuchic (2005), o conceito de RRT na verdade representa uma ampla gama de variações nas suas características físicas e operacionais, tais como escolhas diferentes em relação aos métodos construtivos, tipos de estações, tipos de material rodante (trens) e desempenho para atender a uma variedade de condições locais. No entanto, essas variações não interferem no objeto deste estudo.

Para atender às exigências de mínimo intervalo entre trens, as linhas de metrô devem ser totalmente segregadas, entre outras características. As redes de metrô convencional geralmente são subterrâneas, formadas por túneis, de maneira a não sofrer interferências do meio externo, para garantir a oferta de trens. Devido a fatores como desníveis do terreno e interferências do subsolo, também podem ser elevadas ou em nível; nestes casos, mesmo se construídas em vias segregadas, podem sofrer interferência de intempéries, como a chuva, que pode obrigar que a velocidade dos trens diminua devido às condições de frenagem.

Redes de transporte consideradas regionais ou trens de subúrbio, como as linhas operadas pela Companhia Paulista de Trens Metropolitanos - CPTM em São Paulo, e mesmo redes de metrô leve, como o metrô do Porto, também podem ter trechos com características de RRT - segregados, alta capacidade, pequenos intervalos entre trens.

O meio de transporte conhecido como metrô leve utiliza vias segregadas de uso exclusivo em boa parte de seu percurso, o que permite que sua velocidade comercial aumente e, consequentemente, também aumente a sua capacidade, ainda que em outros trechos compartilhe a via com outros modos de transporte e inclusive com os pedestres (VUCHIC, 2005; BUGARÍN, 2006). 
O Gráfico 3.1 foi elaborado por Vuchic (1981, apud BUGARÍN, 2006, p. 25) baseando-se no estudo de sistemas de transporte de diferentes cidades. Como pode ser observado, a capacidade de transporte por automóveis é muito pequena, da ordem de 2.000 a 3.000 passageiros/hora e sentido tanto no viário urbano como nas vias de alta capacidade. A mancha formada pelos sistemas de baixa capacidade, como ônibus, BRT e bonde, tem um limite de aplicação prático entre 10.000 a 12.000 passageiros/hora e sentido. Já os sistemas de alta capacidade, como metrô convencional e trem de subúrbio, chegam à capacidade de 40.000 a 50.000 passageiros/hora e sentido, ou mais. Entre estas duas manchas situam-se os sistemas de capacidade intermediária, como sistema ferroviário leve ou mais conhecido como metrô leve (BUGARÍN, 2006).

Gráfico 3.1 - Capacidade de diferentes modais de transporte.

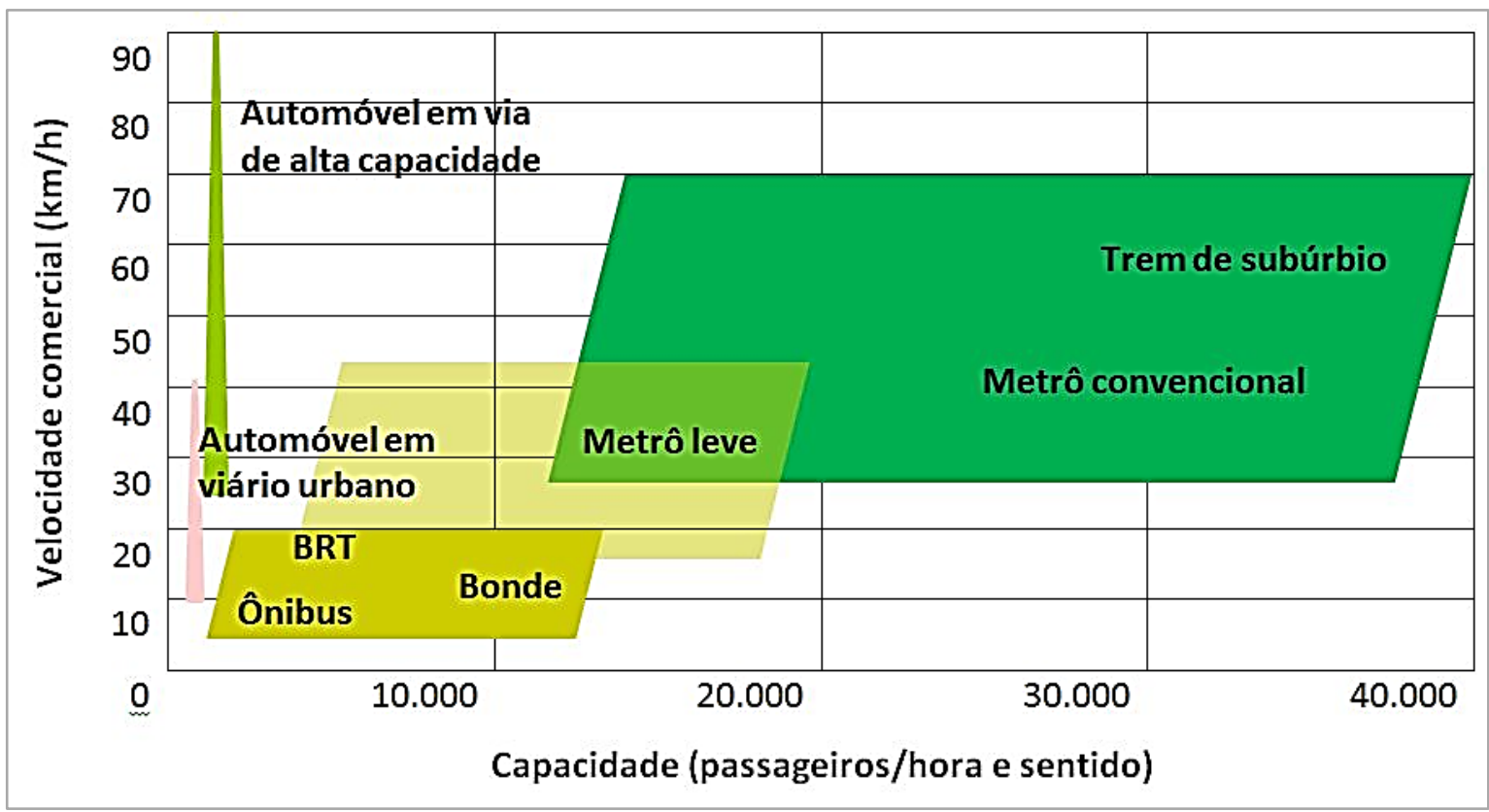

Fonte: Vuchic (1981, apud BUGARÍN, 2006, p. 25 - tradução nossa).

\subsection{CONFIGURAÇÕES DE ESTAÇÕES E TRENS DE METRÔ}

Este trabalho aborda as áreas públicas das redes de metrô, que são acessadas pelo público-alvo, notadamente as áreas públicas das estações e trens. A configuração dessas áreas nem sempre é igual entre si, mesmo em uma mesma linha, devido a diversos fatores, conforme explica Barbosa (2015, p. 56):

O planejamento e a definição do traçado de uma linha de metrô têm início a partir da análise dos deslocamentos de pessoas na cidade, dos principais fluxos e vetores - dados obtidos a partir de pesquisas de origem e destino das viagens. 
As informações sobre a demanda subsidiam o projeto funcional e o projeto básico, incluindo a quantificação dos equipamentos e dos sistemas, o dimensionamento das estações e dos terminais, a capacidade dos veículos, os intervalos entre trens e o dimensionamento das frotas.

Estações de metrô diferem de edifícios comuns em diversos aspectos. Uma estação de metrô comporta um grande número de pessoas e, se considerarmos a quantidade total de pessoas que por ali circulam durante seu horário comercial será possível se imaginar como as questões de fluxo são muito importantes no seu projeto. Uma estação de metrô dificilmente se mantém igual em termos de ocupação espacial e direcionamento de fluxo, variando ao longo do tempo, em função de estratégias operacionais, alterações de leiaute, de painéis de propaganda, de máquinas e quiosques de venda de produtos, alterações de piso tátil etc.

Ao utilizar o metrô, por mais familiarizadas que estejam, as pessoas sempre necessitam de pontos de informação ou de referência, para poderem adquirir títulos, validá-los e se dirigir à plataforma de embarque, onde entrarão em um trem que as levará ao seu destino. Muitos dos comportamentos durante a realização desse percurso interferem na circulação e até na segurança das pessoas com deficiência visual, notadamente pessoas correndo para pegar o trem, pessoas que não esperam os usuários desembarcarem para somente depois embarcar, e pessoas andando distraídas com seus smartphones. Conforme relata Barbosa (2015, p. 147):

Justamente por isso as referências espaciais ganham outra dimensão: todas as percepções se dispersam, ficam díspares e confusas muitas vezes porque o que se escuta não é o que se vê. A amplitude espacial compromete a percepção e a compreensão do espaço pelas pessoas com deficiência visual uma vez que está mais relacionada à visão do que aos outros sentidos. Os cheiros e os ruídos de balizamento se dispersam, não há penumbra, e existe contraste de iluminação. Mais do que outros referenciais da edificação, a sinalização tátil no piso é essencial para orientar o fluxo e continua sendo a única alternativa considerada no projeto.

Outra questão importante a ser considerada, é a respeito dos sistemas instalados, necessários para o funcionamento da rede de metrô, nem sempre visíveis às pessoas que circulam pelas áreas públicas. Os principais são: sistemas de alimentação elétrica da estação e dos trens; sistemas eletrônicos de controle de movimentação dos trens; sistema de ventilação, necessários para se garantir a circulação de ar nas estações enterradas; sistemas hidráulicos que impedem que a estação seja inundada por águas do 
subsolo; sistemas de controle de arrecadação e de venda de títulos ${ }^{40}$ de viagem; e sistemas de telecomunicações (telefonia, Circuito Fechado de Televisão - CFTV, sonorização de estação, radiocomunicação, cronometria, gravação das comunicações e sistema de transmissão de dados).

O sistema de CFTV permite a visualização de áreas públicas das estações, como apoio às operações de embarque/desembarque. 0 sistema de sonorização permite às estações e ao Centro de Controle a transmissão de comunicados aos usuários e empregados situados nas estações. O sistema de radiocomunicação permite a comunicação instantânea do Centro de Controle com os trens, estações, equipes de segurança e de manutenção próximas às vias. A cronometria tem por finalidade fornecer aos usuários e empregados informação horária precisa nas diversas dependências operacionais. 0 sistema de transmissão de dados é o responsável pela transmissão de alarmes, sinalizações e comandos entre os equipamentos das estações e os do Centro de Controle (CMSP, 2015c).

Os Centros de Controle também não são visíveis aos usuários, mas possuem papel essencial na operação de redes de metrô. Geralmente chamados de Centro de Controle Operacional, ou CCO, esses locais "são fruto da evolução técnica dos dispositivos de comando que passaram a permitir que sistemas fossem comandados/controlados remotamente" (RESENDE, 2011, p. 91), e de maneira centralizada. Os CCO possuem sistemas de comando, dotados de dispositivos de vigilância, com profissionais que atuam para garantir o equilíbrio do sistema, o qual, por mais automatizado que seja, é passível de falhas. Para garantir a oferta, a execução e a operação dos serviços é realizado um conjunto de atividades regidas por procedimentos, mecanismos e roteiros (BARBOSA, 2015).

Apesar de diferenças na configuração, estações de metrô, tanto subterrâneas como elevadas, possuem alguns aspectos semelhantes entre si, com acessos que convergem para um saguão de distribuição, comumente chamado mezanino. No mezanino geralmente se localiza a venda de títulos e a linha de bloqueios ou somente validadores (Figura 3.1).

40 Título é a forma atual de se referir às diversas maneiras de se efetuar a validação ou pagamento da tarifa de viagem, englobando bilhetes, cartões magnéticos etc. 
Figura 3.1 - Exemplo de um mezanino de metrô.

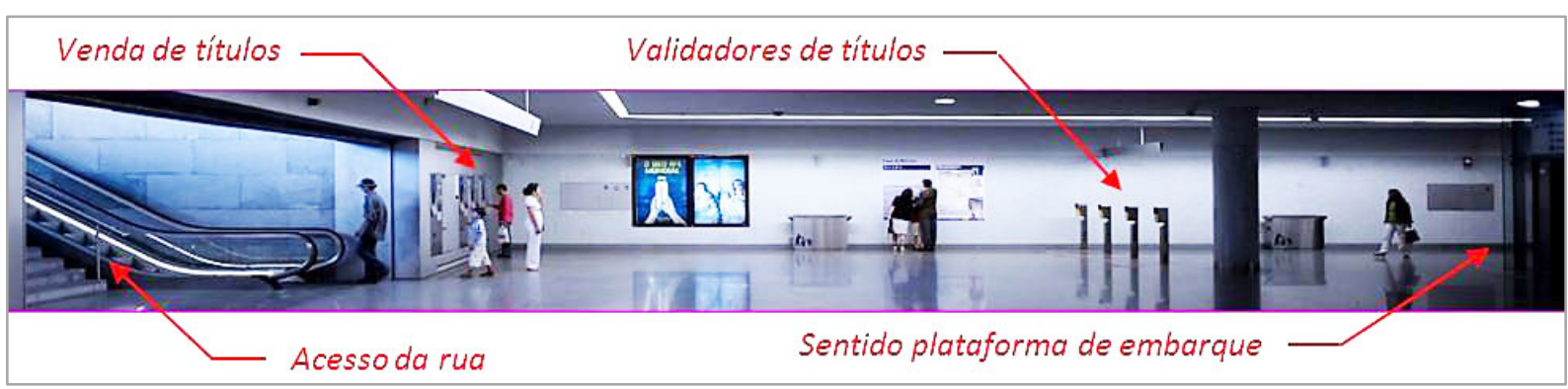

Fonte: Elaborado a partir de Metro do Porto, 2015.

Ao se ultrapassar esta linha, caminha-se para as plataformas de embarque, que podem ser laterais (Figura 3.2), centrais (Figura 3.3) ou mistas (Figura 3.4), cujo comprimento varia em função do comprimento dos trens que servem àquela linha.

Figura 3.2 - Exemplos de plataforma lateral.

(a) Estação Casa da Música - metrô do Porto.

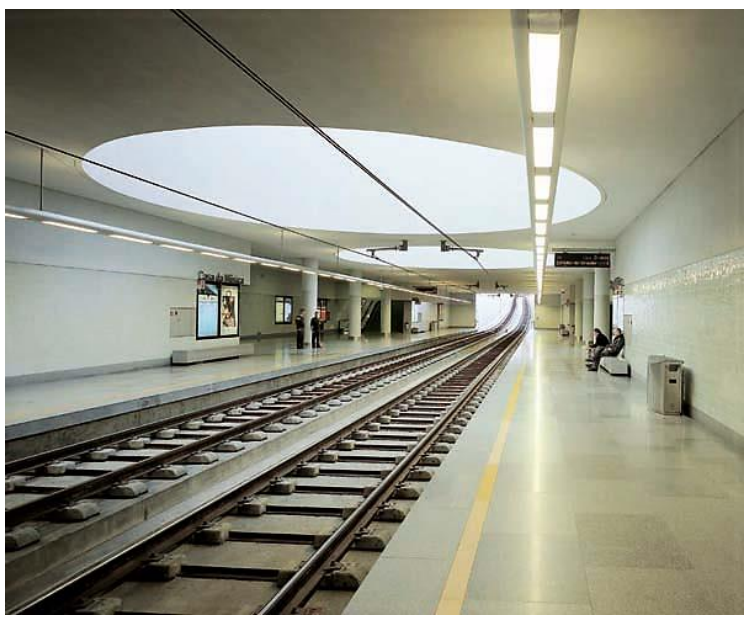

Crédito: MARIANI, E., 2015. (b) Estação Náměstí Republiky - metrô de Praga.

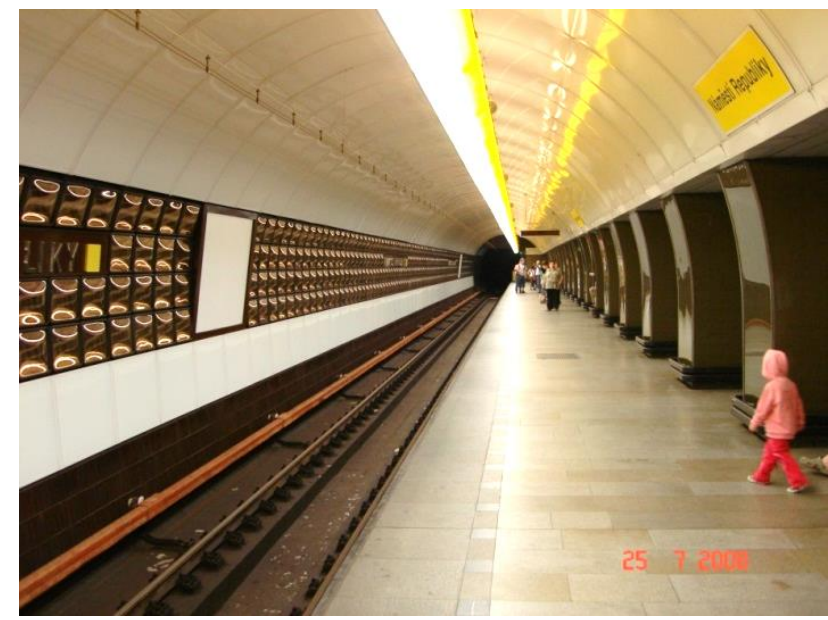

Crédito: HAGA, A., 2008. 
Figura 3.3 - Exemplos de plataforma central.

(a) Estação Carrão - metrô de São Paulo.

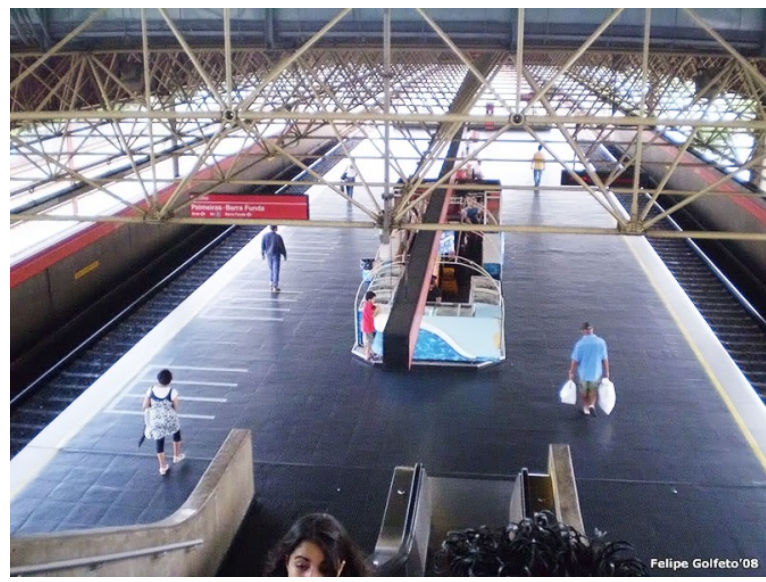

Crédito: GOLFETO, F., $2008^{41}$. (b) Estação Kelenföld vasútállomás- metrô de Budapeste.

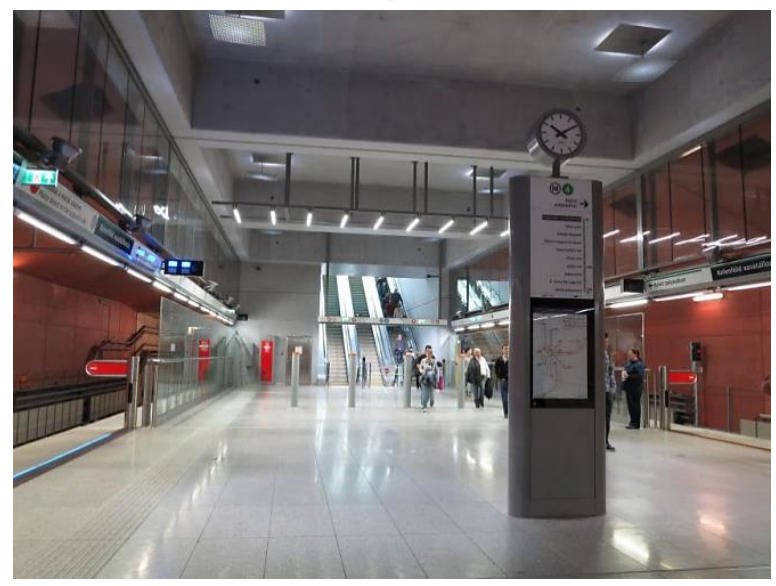

Crédito: SCHWANDL, R., 201442 .

Figura 3.4 - Exemplos de plataforma mista.

(a) Estação Estádio do Dragão - metrô do Porto.

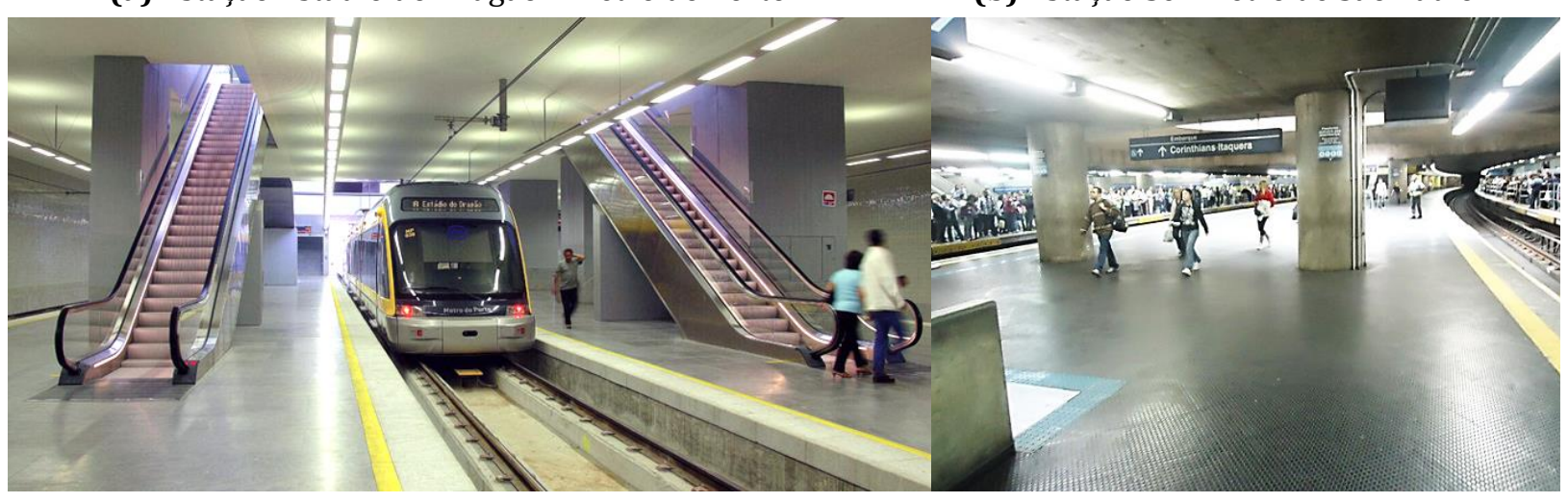

Fonte: Metro do Porto, 2015.

Crédito: MARTINI, F. P., 2012.

Ainda com relação às estações, pode variar a existência ou não de lojas, cafeterias, sanitários, salas de apoio à operação, e com relação à operação em si, pode variar a quantidade de funcionários efetivos e maneira de atuação, assim como de comunicação com os passageiros.

A configuração dos trens pode variar de frota para frota, mas geralmente possuem uma pequena quantidade de assentos, para que seja transportado um maior número de pessoas (em pé). Também é praticamente comum a existência de assentos preferenciais a pessoas com deficiência ou mobilidade reduzida (Figura 3.5) e áreas reservadas para

\footnotetext{
${ }^{41}$ Fonte: <http://www.skyscrapercity.com/showthread.php?t=690630>. Acesso em: 20 jun. 2014.

42 Fonte: <http://urbanrail.net/eu/hu/budapest/budapest-line4.htm>. Acesso em: 20 jun. 2014.
} 
pessoas em cadeira de rodas. Avisos luminosos alertando para o fechamento iminente das portas (Figura 3.6) são especialmente úteis a pessoas com deficiência auditiva.

Figura 3.5 - Assentos preferenciais na cor azul claro em trem do metrô de São Paulo.

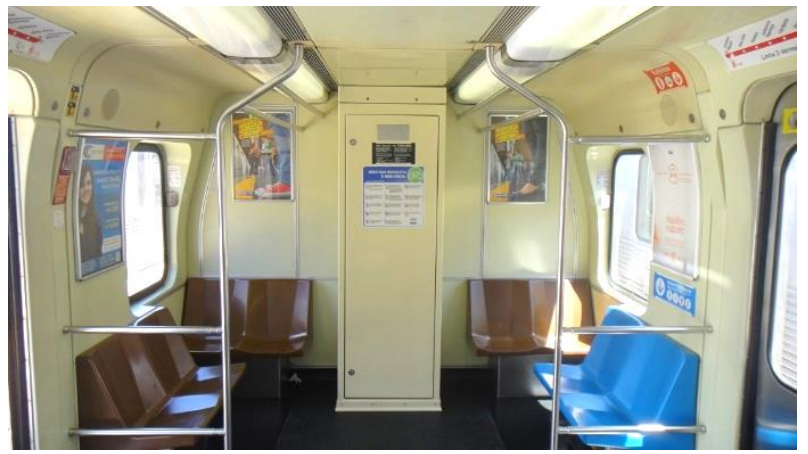

Crédito: ROSE, T. B., 2014.
Figura 3.6 - Aviso luminoso de fechamento de portas em trem no metrô de Shanghai.

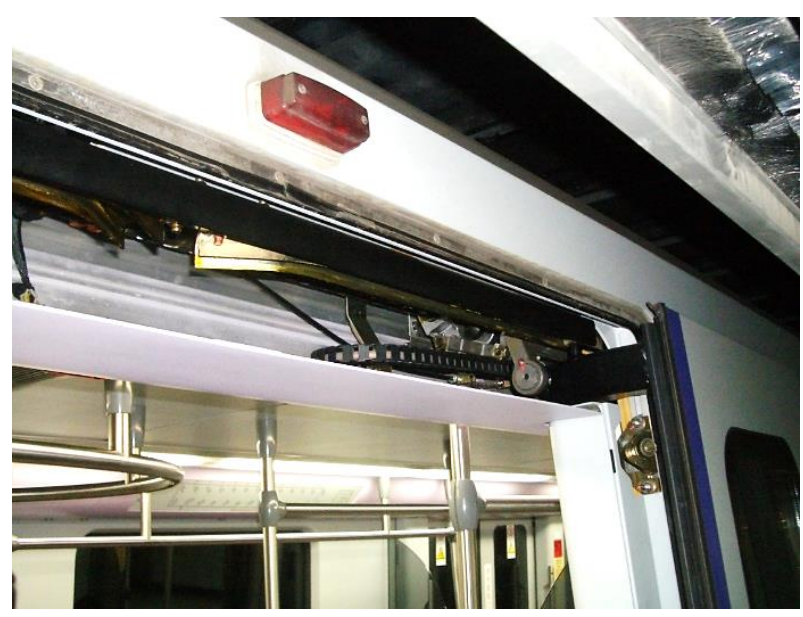

Crédito: FREITAS, J. H. Z., 2008.

Para pessoas com deficiência visual é muito útil o aviso sonoro com o nome da próxima estação, especialmente se for por meio de mensagem pré-gravada automatizada, e também se for acrescentada a informação de lado do desembarque da próxima estação. Também é desejável que haja sinalização em Braille com indicação do número do carro/trem, aviso sonoro indicando a iminência do fechamento das portas e mensagens sonoras informando a respeito de alguma anormalidade no percurso. Apoios de mão de cores contrastantes (Figura 3.7) também auxiliam pessoas com baixa visão, e o vão entre os trens e a plataforma deve ser reduzido a um mínimo, para segurança (Figura 3.8). 
Figura 3.7 - Apoios de mão de cor contrastante em trem do metrô de Hong Kong.

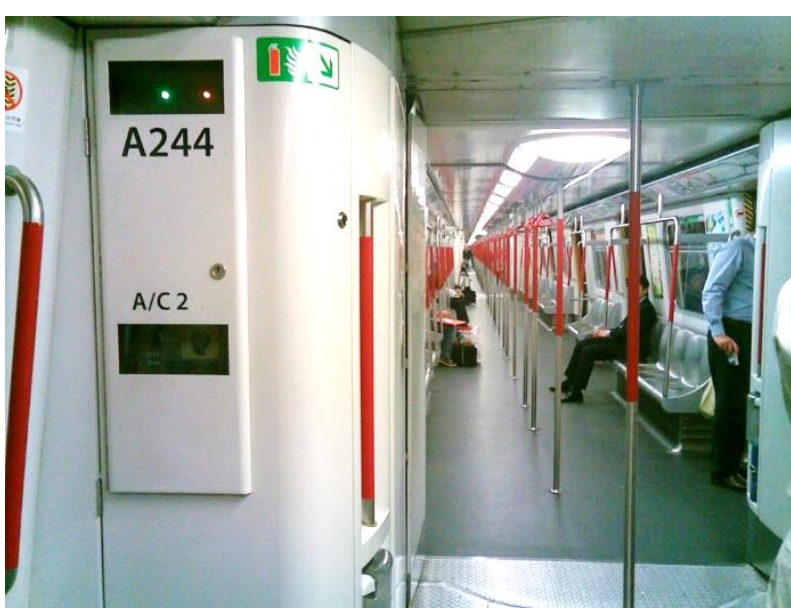

Crédito: FREITAS, J. H. Z., 2006.
Figura 3.8 - Redutor de vão entre o trem e a plataforma em estação do metrô de Hong Kong.

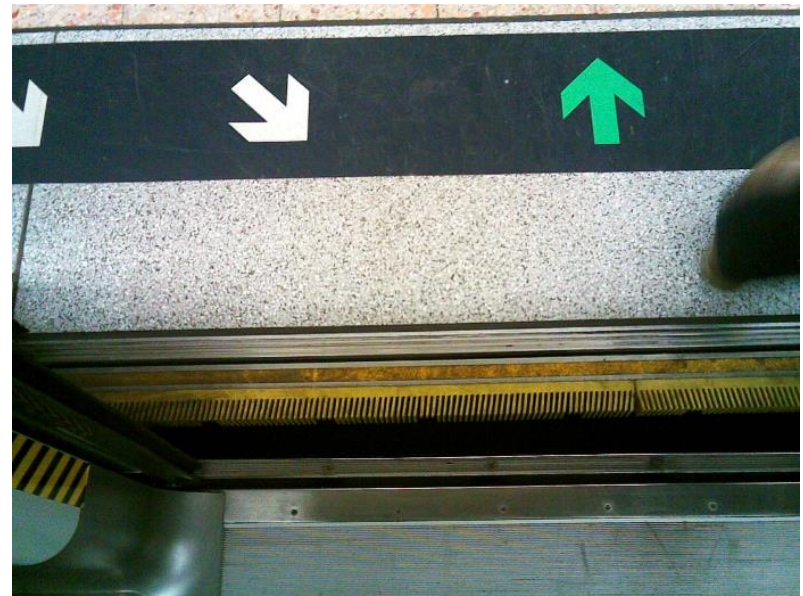

Crédito: FREITAS, J. H. Z., 2006.

Presentes em muitas das estações mais modernas, as chamadas portas de plataforma (Figura 3.9) são painéis instalados ao longo do limite entre a plataforma e a via, contendo portas sincronizadas com o sistema eletrônico de controle dos trens, o que permite a abertura e o fechamento simultâneo das portas de plataforma com as portas do trem. Sua instalação é bastante vantajosa, pois permitem que os trens circulem com maior velocidade, devido à proteção que oferecem.

Figura 3.9 - Exemplos de portas de plataforma.

(a) Estação Westminster do metrô de Londres.

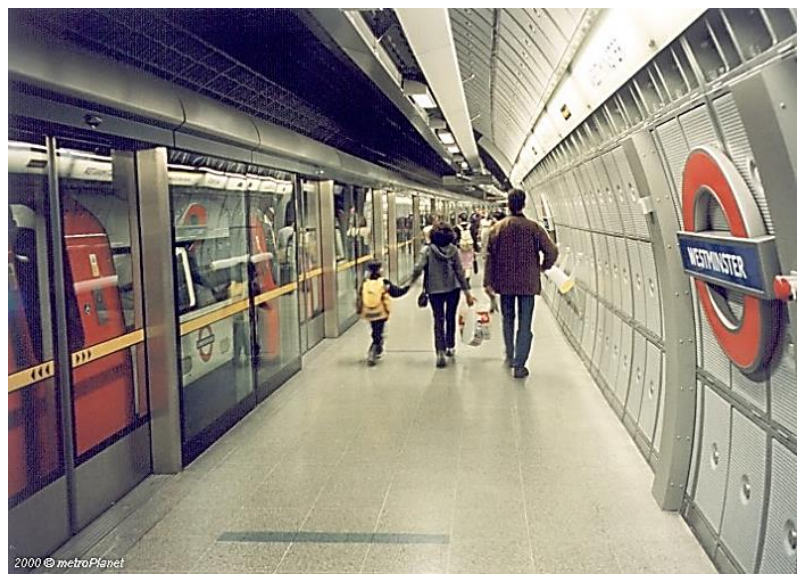

Fonte: Disponível em:

<https://tfl.gov.uk/tube/stop/940GZZLUWSM/westmin ster-underground-station>. Acesso em 13 ago. 2015. (b) Estação Tamanduateí do metrô de São Paulo.

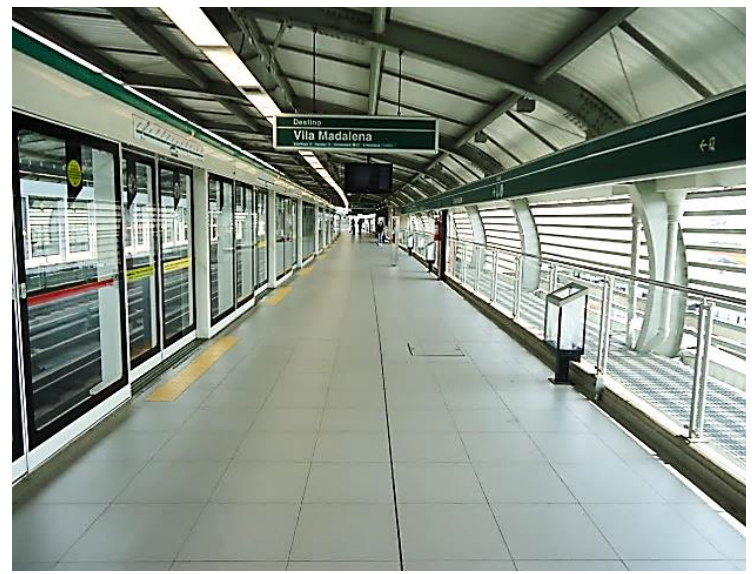

Crédito: MARTINI, F. P., 2012.

A instalação dos painéis em estações mais antigas é relativamente complexa, tanto pela compatibilidade entre os sistemas eletrônicos como pelas poucas horas de intervalo que são dadas pela operação comercial para sua instalação. Dessa forma, os painéis mais 
baixos (Figura 3.10b) são recomendados para instalação em estações em operação. Tanto os painéis altos como os mais baixos são eficientes para a segurança de pessoas com deficiência visual.

Figura 3.10 - Portas de plataforma no metrô de Paris.

(a) Painéis altos nas estações novas.

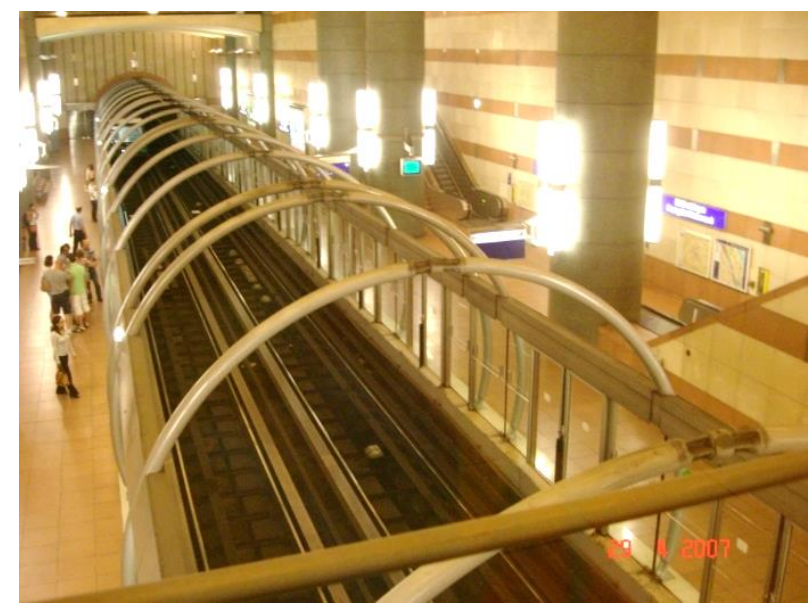

Crédito: GERBOVIC, S., 2007. (b) Painéis baixos nas estações mais antigas.

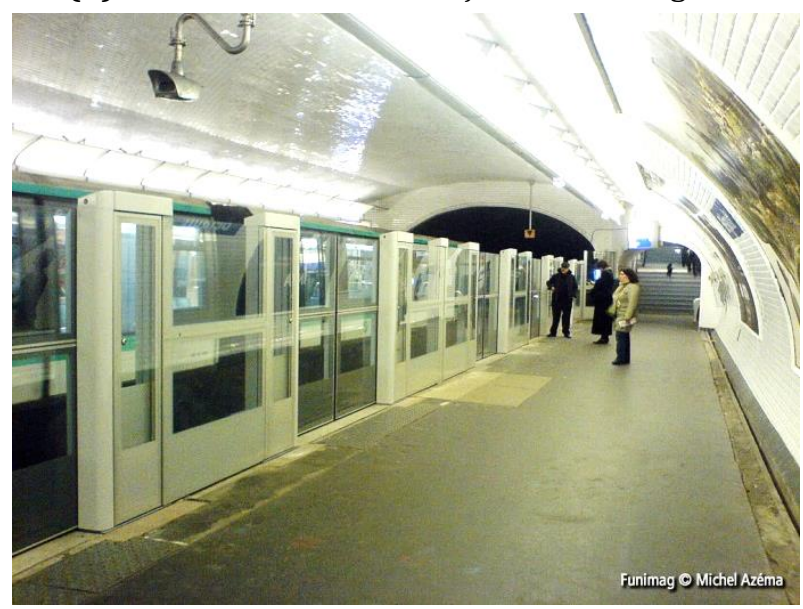

Crédito: AZÉMA, M., 2011.43

\subsection{O METRÔ DE SÃO PAULO}

A Companhia do Metropolitano de São Paulo - METRÔ começou a operar comercialmente em 1974, quando inaugurou o trecho Jabaquara - Vila Mariana. Atualmente (2015), conta com as Linhas 1-Azul (Jabaquara - Tucuruvi), 2-Verde (Vila Prudente - Vila Madalena), 3-Vermelha (Corinthians-Itaquera - Palmeiras-Barra Funda), 5-Lilás (Capão Redondo - Largo Treze) e 4-Amarela (Butantã - Luz), funcionando de domingo a sexta das $4 \mathrm{~h} 40$ à meia-noite e aos sábados das $4 \mathrm{~h} 40$ à $1 \mathrm{~h}$ de domingo.

Em 2010, foi inaugurado o primeiro trecho da Linha 4-Amarela, operada em regime de concessão pelo Consórcio ViaQuatro, e em 2014 começou a funcionar, em caráter experimental, o monotrilho da Linha 15-Prata, integrado com a Linha 2-Verde do Metrô, na estação Vila Prudente, com resultados operacionais ainda insuficientes para ser objeto deste estudo. 0 mapa parcial dos transportes metropolitanos, contemplando a rede do metrô de São Paulo está representado na Figura 3.11.

${ }^{43}$ Fonte: Disponível em: <http://www.funimag.com/photoblog/index.php/tag/subway/>. Acesso em 11 fev. 2016. 
Figura 3.11 - Mapa parcial dos transportes metropolitanos - rede do metrô de São Paulo.

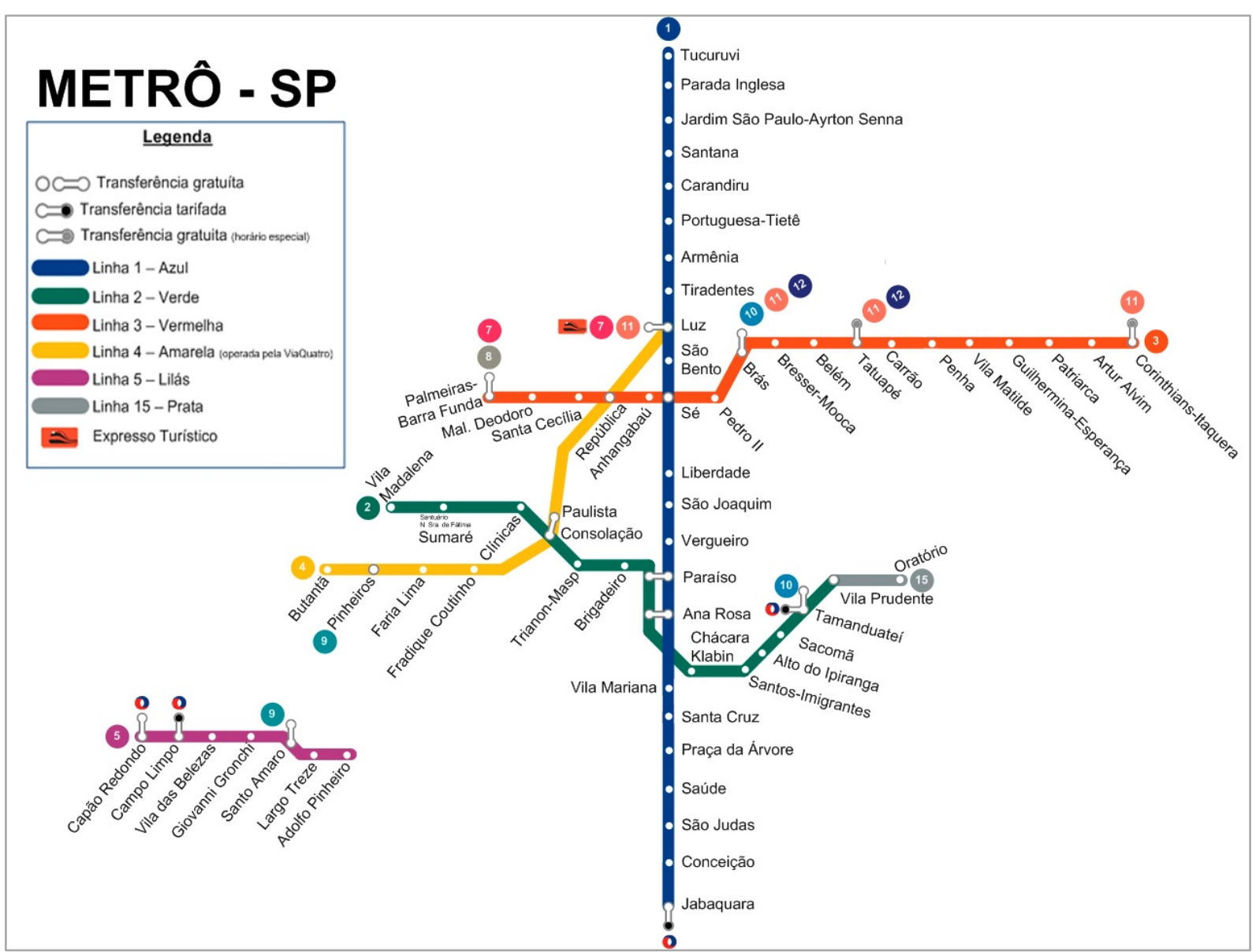

Fonte: Acervo GOP/OPT/CTV - CMSP.

A Tabela 3.1 apresenta dados das cinco linhas em operação no metrô de São Paulo.

Tabela 3.1 - Informações sobre o sistema - Situação em fevereiro de 2015.

\begin{tabular}{|c|c|c|c|c|c|c|}
\hline Linhas & $\begin{array}{c}\text { 1- } \\
\text { Azul }\end{array}$ & $\begin{array}{c}2- \\
\text { Verde }\end{array}$ & $\begin{array}{c}\text { 3- } \\
\text { Vermelha }\end{array}$ & $\begin{array}{c}4- \\
\text { Amarela }\end{array}$ & $\begin{array}{l}\text { 5- } \\
\text { Lilás }\end{array}$ & Rede \\
\hline Início da Operação Comercial & 1974 & 1991 & 1979 & 2010 & 2002 & - \\
\hline Estações ${ }^{44}$ & 23 & 14 & 18 & 7 & 7 & 62 \\
\hline Estações de conexão² & 3 & 2 & 1 & 3 & - & 6 \\
\hline $\begin{array}{l}\text { Estações de integração com a } \\
\text { CPTM }\end{array}$ & 1 & 1 & 4 & 2 & 1 & 9 \\
\hline $\begin{array}{l}\text { Estações com terminais de } \\
\text { ônibus urbanos }{ }^{2}\end{array}$ & 6 & 2 & 10 & 7 & 5 & 30 \\
\hline $\begin{array}{l}\text { Estações com terminais } \\
\text { rodoviários }\end{array}$ & 2 & - & 1 & - & - & 3 \\
\hline $\begin{array}{l}\text { Intervalo mínimo entre trens } \\
\text { (segundos) }\end{array}$ & 119 & 144 & 103 & 128 & 228 & - \\
\hline
\end{tabular}

Fonte: Elaborado com base em dados de CMSP (2015c); CMCP (2015).

${ }^{44}$ As estações de conexão estão computadas nas duas linhas que atendem, porém, uma só vez no total da rede. 
A Tabela 3.2 exibe a demanda de passageiros no ano 2014, nas cinco linhas operadas pelo Metrô ou ViaQuatro.

Tabela 3.2 - Demanda de passageiros por linha no ano 2014.

\begin{tabular}{lcccccc}
\hline $\begin{array}{l}\text { DEMANDA } \\
\text { (Milhares) }\end{array}$ & 1-Azul & 2-Verde & 3-Verm & 4-Amarela & 5-Lilás & Rede \\
\cline { 2 - 7 } Total & 311.144 & 146.724 & 357.959 & 194.356 & 79.735 & 895.561 \\
\hline $\begin{array}{l}\text { Média dos } \\
\text { dias úteis }\end{array}$ & 1.073 & 525 & 1.220 & 532 & 272 & 3.090 \\
\hline $\begin{array}{l}\text { Média dos } \\
\text { sábados }\end{array}$ & 579 & 220 & 685 & 323 & 157 & 1.641 \\
\hline $\begin{array}{l}\text { Média dos } \\
\text { domingos }\end{array}$ & 331 & 126 & 413 & 157 & 75 & 945 \\
\hline $\begin{array}{l}\text { Máxima } \\
\text { diária }\end{array}$ & 1.176 & 591 & 1.319 & 670 & 308 & 3.345 \\
\hline
\end{tabular}

Fonte: Elaborado com base nos dados da CMSP (2015d) e CMCP (2015).

A rede do metrô operada pelo Metrô ou ViaQuatro está integrada aos trens da CPTM e a outros modais de transporte da cidade de São Paulo. A rede de trens de passageiros da CPTM compartilha boa parte de suas vias com concessionárias de trens de carga circulando concomitantemente, e suas estações possuem configurações diferentes das estações operadas pelo Metrô ou ViaQuatro, o que influencia nas estratégias operacionais. A rede metroviária também possui integração com corredores de ônibus da EMTU, completando a rede dos transportes administrados pela Secretaria de Estado dos Transportes Metropolitanos - STM.

As 12 frotas do metrô ${ }^{45}$ de São Paulo integram 164 trens, com capacidade para transportar até 56 mil pessoas por hora e por sentido, nos períodos de maior procura. Cada trem é composto por seis carros, com um total de aproximadamente 130 metros de comprimento, comportando de 1500 a 1600 pessoas, dependendo da frota. A frota mais antiga data de 1974 e a mais nova de 2015 (CMSP, 2015; VIAQUATRO, 2015). Apesar da configuração do interior ter variado ao longo desse período, com redução da quantidade de assentos para aumentar a capacidade de transporte, foi mantida a quantidade de assentos preferenciais (azuis). A Figura 3.12 apresenta alguns exemplos destas mudanças.

${ }^{45}$ Linhas 1-Azul, 2-Verde, 3-Vermelha, 4-Amarela e 5-Lilás. 
Figura 3.12 - Diferenças no leiaute interno dos trens.
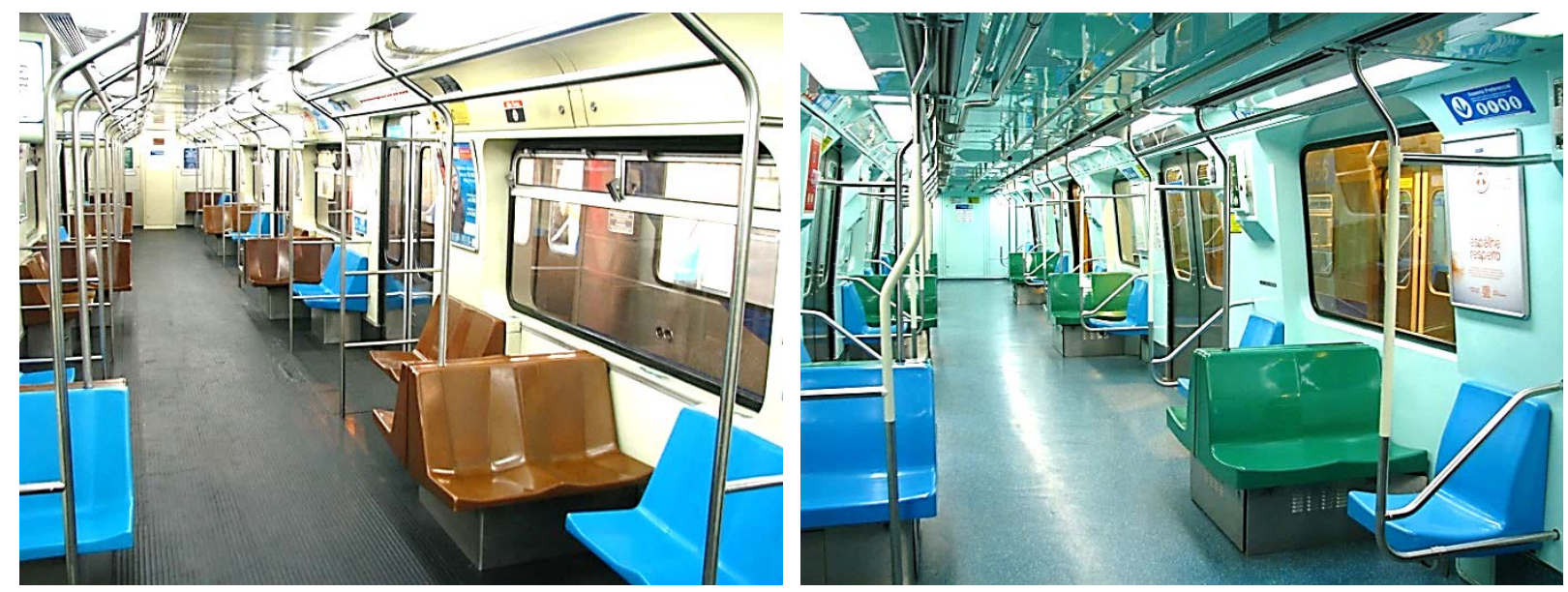

Fonte: Acervo CMSP, Gerência de Operações, OPT/CTV, 2015.

Crédito: ZAITSU, B. T., 2014.

Os carros líderes de todas as frotas (primeiro carro à frente do trem) são destinados ao uso preferencial por pessoas com deficiência ou mobilidade reduzida (CMSP, 2015), por estarem estrategicamente localizados em situação de emergência: presença mais próxima do condutor ou proximidade com abertura frontal de saída de emergência nas frotas que não possuem condutor. A sinalização existente nas estações indica que o embarque preferencial deve ser realizado no primeiro carro, conforme Figura 3.13.

Figura 3.13 - Região na plataforma de embarque preferencial.

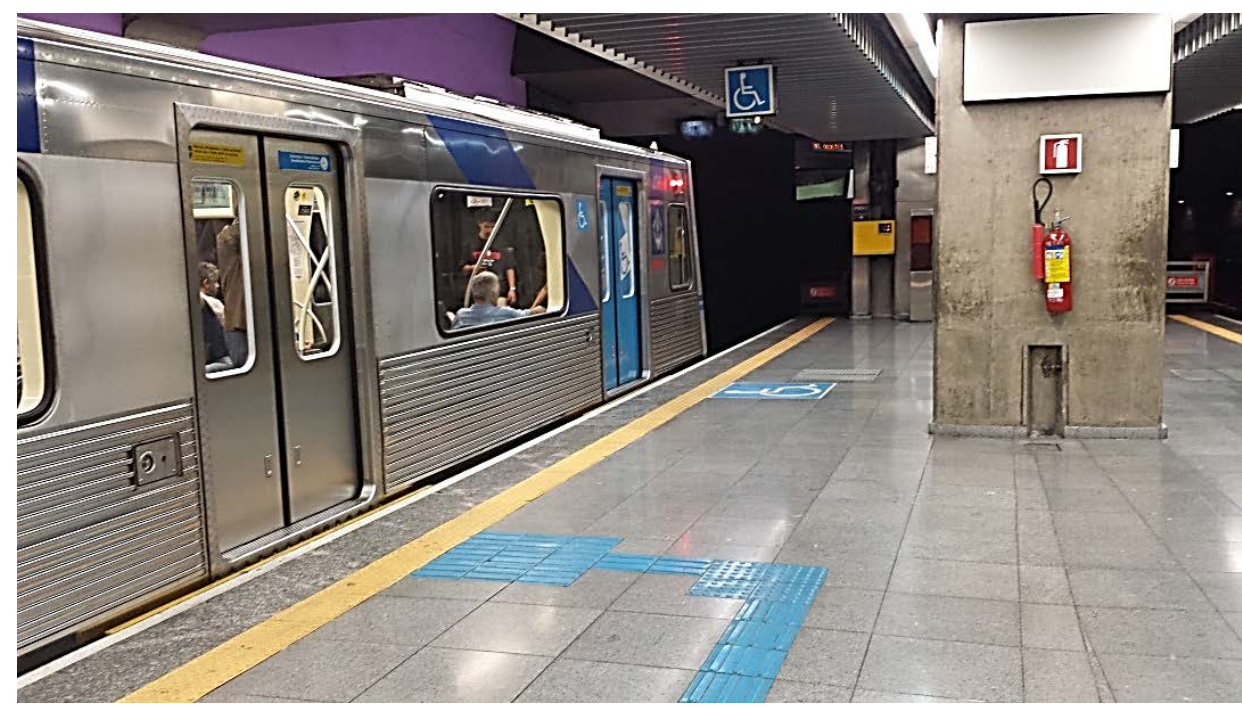

Crédito: MARIANI, E., 2016.

A região da primeira porta está sinalizada com o Símbolo Internacional de Acesso - SIA, tanto no piso como na comunicação visual suspensa. 0 piso tátil direciona a pessoa com deficiência visual para a segunda porta. 


\subsubsection{Acessibilidade}

Os principais itens de acessibilidade no metrô de São Paulo, segundo CMSP (2015a) são:

a) elevadores e rampas - Todas as estações possuem pelo menos um acesso por elevador (Figura 3.14), ou rampa (Figura 3.15), e estes acessos são interligados aos demais por meio de rota acessível. Além dos elevadores instalados nos acessos, todas as estações contam com elevadores entre o mezanino e as plataformas de embarque e desembarque. No total, existem 138 equipamentos, sinalizados visualmente e em Braille, informando os pavimentos atendidos, além de intercomunicadores internos e externos.

Figura 3.14 - Elevador.

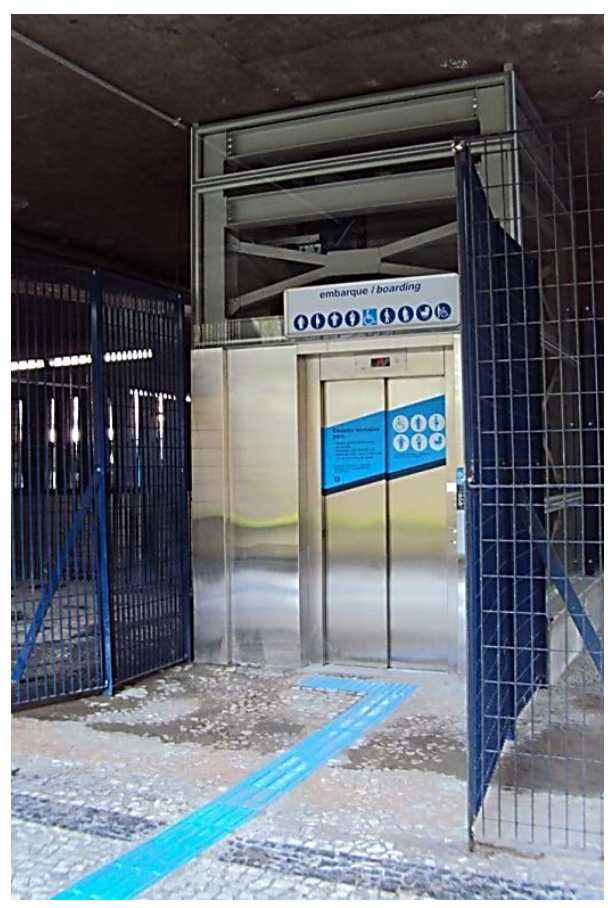

Crédito: MARIANI, E., 2010.
Figura 3.15 - Rampa.

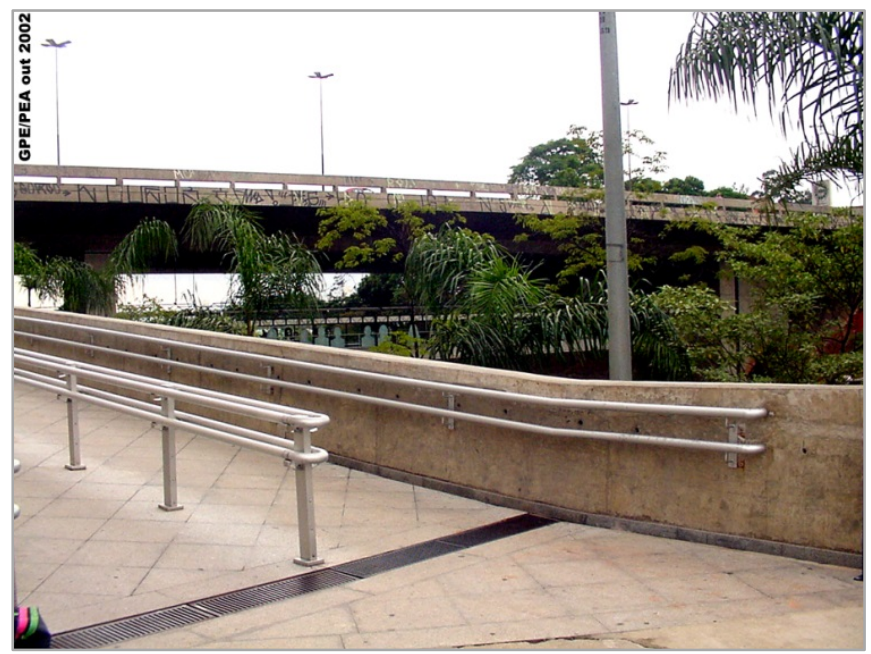

Crédito: CMSP, GPE/PEA, 2002.

b) escadas - As escadas, assim como as rampas, possuem corrimãos com configuração e dimensionamento adequados: empunhadura, prolongamento e altura de fixação (Figura 3.16). As escadas fixas dispõem de elementos antiderrapantes e sinalização visual na lateral dos degraus (Figura 3.17). 
Figura 3.16 - Corrimãos.

Figura 3.17 - Sinalização visual nos degraus.

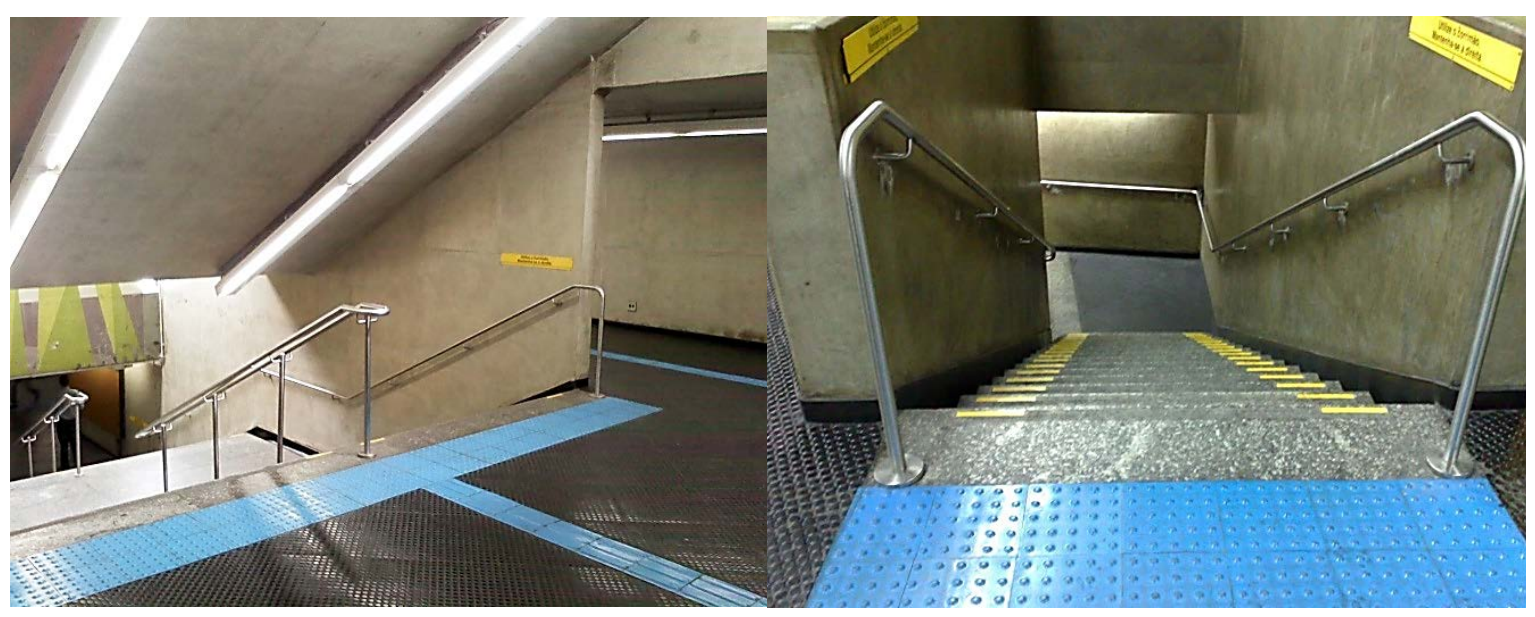

Crédito: MARIANI, E., 2010.

Crédito: MARIANI, E., 2010.

c) bloqueios e cancelas - Todas as estações dispõem de bloqueios (Figura 3.18) ou cancelas (Figura 3.19) com largura suficiente para a passagem de uma pessoa em cadeira de rodas, pessoas com carrinhos de bebê ou com malas e bicicletas.

Figura 3.18 - Bloqueio acessível.

Figura 3.19 - Cancela acessível.

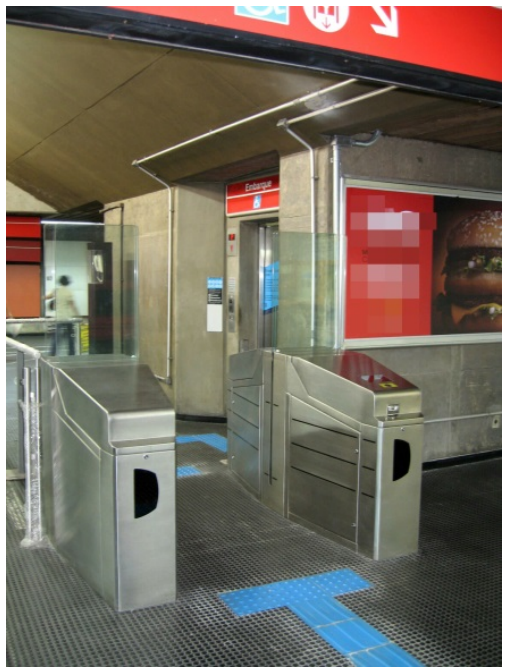

Crédito: MARIANI, E., 2010.

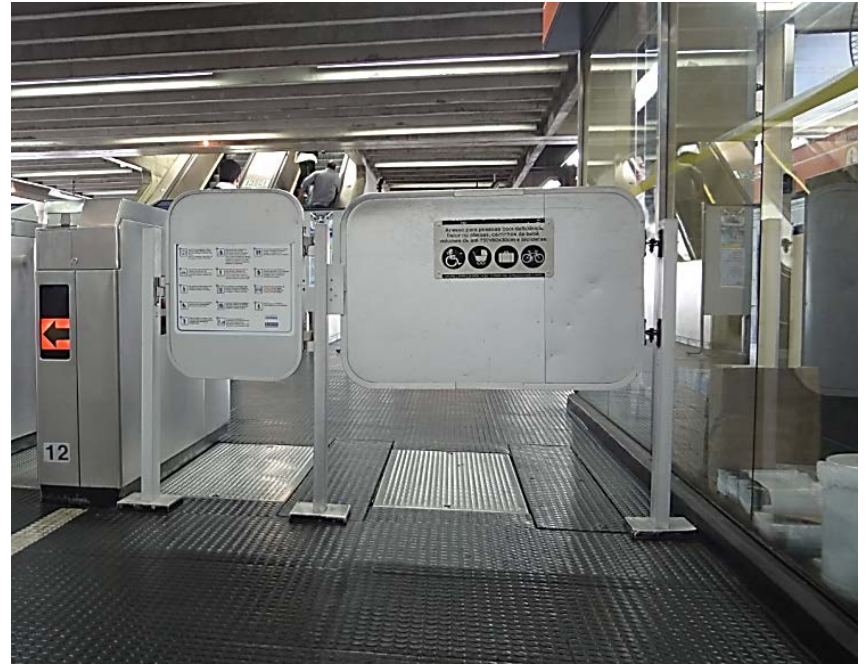

Crédito: SANTOS, D. A., 2015.

d) plataformas - As plataformas das estações dispõem de faixa tátil de alerta amarela (Figura 3.20), indicando o limite seguro entre a plataforma e a via, além de sinalização visual branca, destacando o limite físico entre a plataforma e o trem. Foram instalados elementos redutores de vão amarelos (Figura 3.20), para diminuir o espaço entre o trem e a plataforma em 13 estações, adequando-as à NBR 14021 - Transporte - Acessibilidade no sistema de trem urbano ou metropolitano (ABNT, 2005). Nas plataformas existem assentos preferenciais para 
pessoas idosas, gestantes, pessoas com crianças de colo, pessoas com mobilidade reduzida e assentos para pessoas obesas (Figura 3.21).

Figura 3.20 - Faixa tátil de alerta amarela e redutor de vão amarelo.

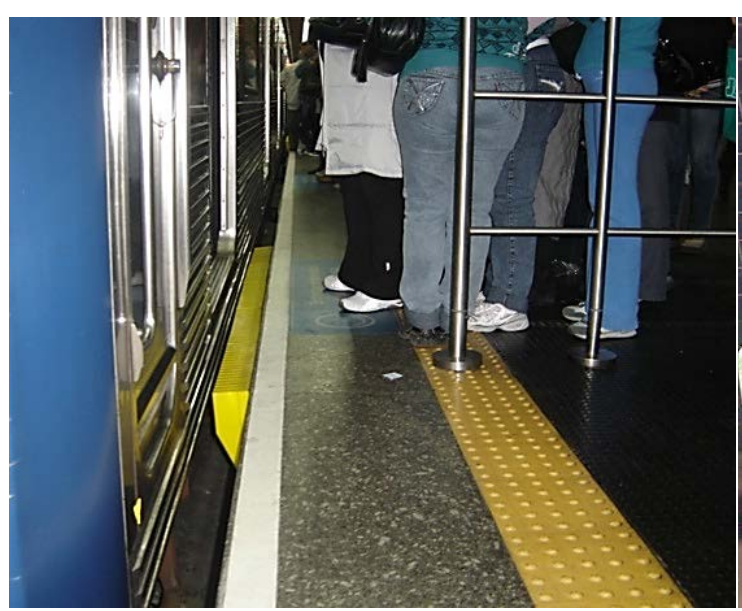

Crédito: MARIANI, E., 2010.
Figura 3.21 - Assento para pessoas obesas.

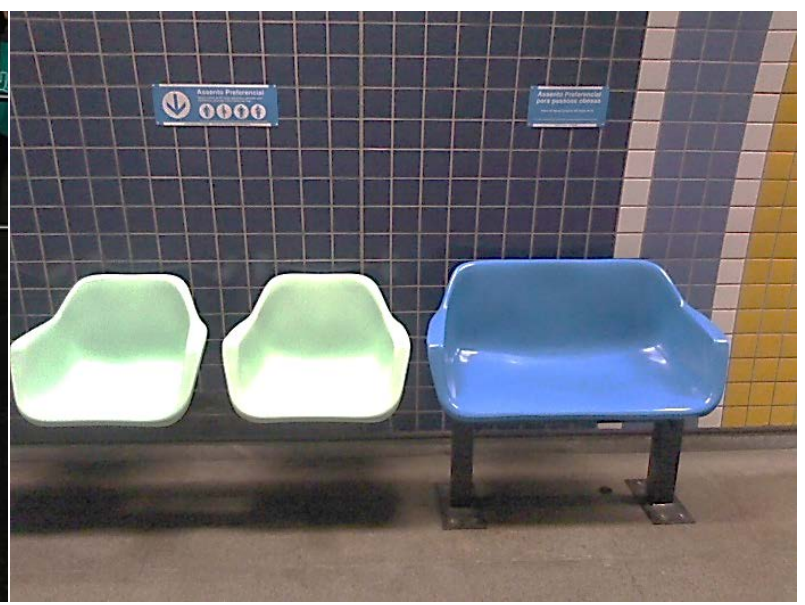

Crédito: MARIANI, E., 2010.

e) piso tátil - Exceto a faixa amarela na borda da plataforma, todos os pisos táteis das estações são azuis. Os pisos táteis de alerta são usados como sinalização de perigos iminentes a pessoas com deficiência visual, tais como escadas, elevadores e objetos suspensos. 0 piso tátil direcional indica o percurso desde cada um dos acessos da estação até os locais de embarque e desembarque nas plataformas, interligando também bilheterias, sanitários públicos, balcões de informações e conexões gratuitas com estações da CPTM ou Via Quatro.

f) comunicação visual - A comunicação visual das estações possui contraste e dimensão para leitura à distância, com boa legibilidade. Os mapas disponíveis nos conjuntos de informações possuem textos com letras dimensionadas de maneira a facilitar sua legibilidade pelas pessoas com baixa visão.

g) comunicação sonora - Nas estações e trens são veiculadas mensagens sonoras de audição pública para orientação dos usuários em geral, a respeito de serviços, normas, funcionamento do metrô, alertas de segurança ou de comportamento. Podem ser emitidas mensagens pré-gravadas, digitalizadas, com melhor qualidade de áudio, ou verbalizadas em tempo real pelos funcionários da estação, do trem ou do Centro de Controle Operacional - CCO.

h) trens (material rodante) - Todos os carros dos trens dispõem de assentos preferenciais. Todo primeiro carro de cada trem dispõe de assentos preferenciais 
em maior quantidade, além de assentos para obesos e locais para pessoa em cadeira de rodas (Figura 3.22). Os trens mais modernos contam com sinalização sonora e visual informando o nome da próxima estação, as possibilidades de conexão, o lado de desembarque, mapas eletrônicos informando o deslocamento do trem e sinalização em Braille. Nos demais trens são emitidas mensagens sonoras informando o nome da próxima estação, as possibilidades de conexão e o lado de desembarque. Além das mensagens de voz, os trens emitem um alarme sonoro para avisar quanto ao fechamento iminente das portas.

Figura 3.22 - Assento preferencial e espaço para pessoa em cadeira de rodas, no trem.

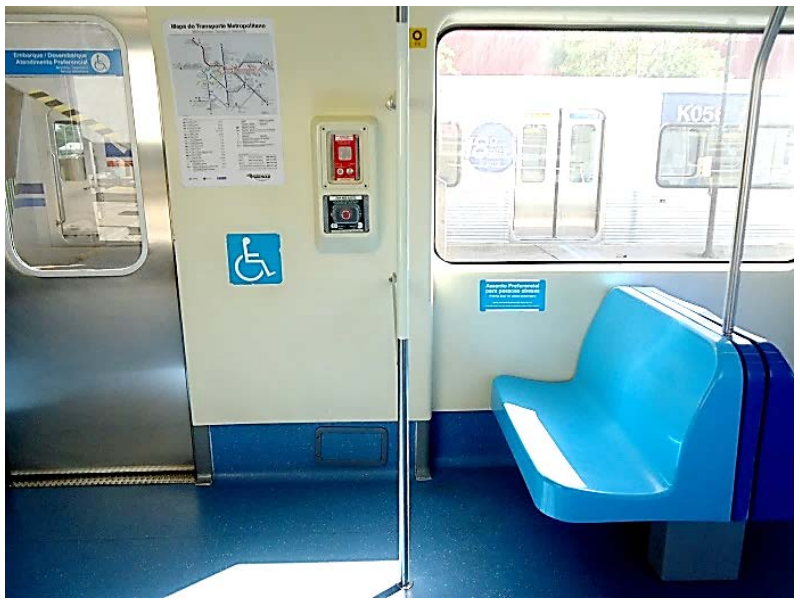

Crédito: ZAITSU, B. T., 2014.
Figura 3.23 - Sanitário acessível.

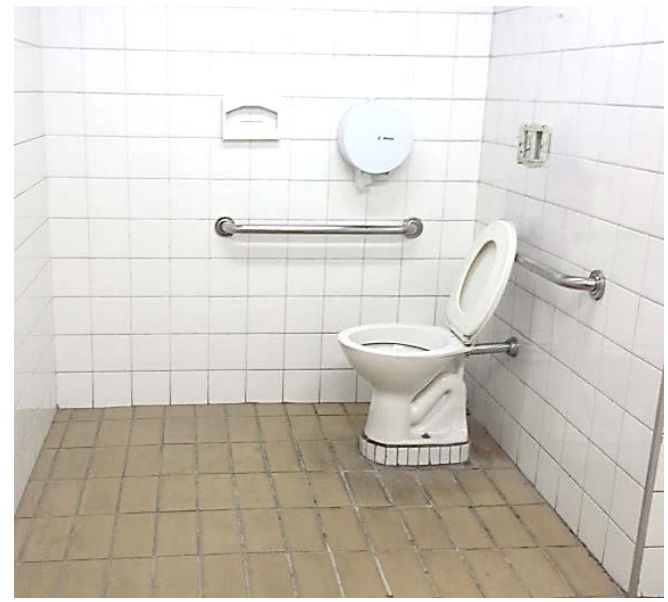

Crédito: MARIANI, E., 2014.

i) sanitários - Todos os sanitários públicos são equipados com box acessível, com acesso independente. Todas as estações contam com um sanitário interno acessível (Figura 3.23).

j) monitoração - Todas as estações dispõem de quadro de funcionários capacitados para auxílio às pessoas com deficiência ou mobilidade reduzida (Figura 3.24), acompanhando o embarque e desembarque, monitorados pelo Centro de Controle Operacional - CCO (Figura 3.25). De acordo com Barbosa (2015, p. 137-138):

O processo de monitoração tem início a partir da solicitação de auxílio pelo usuário com deficiência visual nas estações de embarque e compreende ações coordenadas envolvendo os seguintes aspectos:

- funcionário ou estagiário da estação de origem - realiza a condução do usuário até o local de embarque; comunica-se com o centro de controle por telefone antes do embarque, informando a identificação do trem onde será realizado o embarque, a estação de desembarque e o perfil do usuário (deficiência visual ou física) de forma a garantir auxílio adequado na estação de destino. Em seguida, auxilia o embarque dos usuários nos trens;

- operador do console de passageiros das diferentes linhas - registra os dados do usuário e da estação de destino no sistema de controle, que emite 
um alarme para o operador três estações antes do trem se aproximar da estação de destino, momento em que o operador entra em contato com a estação informando sobre o desembarque do usuário, seu perfil e a identificação do trem. Esses funcionários têm papel fundamental na atuação em situações de anormalidade;

- funcionário da SSO da estação de destino - recebe, por telefone, a informação sobre a chegada do usuário e informa a equipe que irá auxiliar o desembarque e garantir a continuidade do auxílio na estação de destino desde a plataforma até a saída ou embarque no trem em outra linha.

Figura 3.24 - Acompanhamento de pessoa com deficiência.

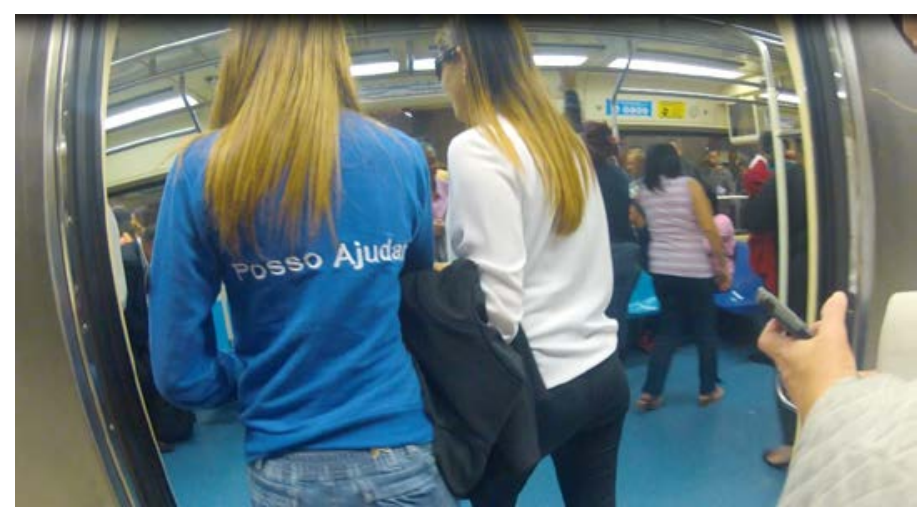

Fonte: SILVA FILHO, J., 2015.

Figura 3.25 - Centro de Controle Operacional - CCO.

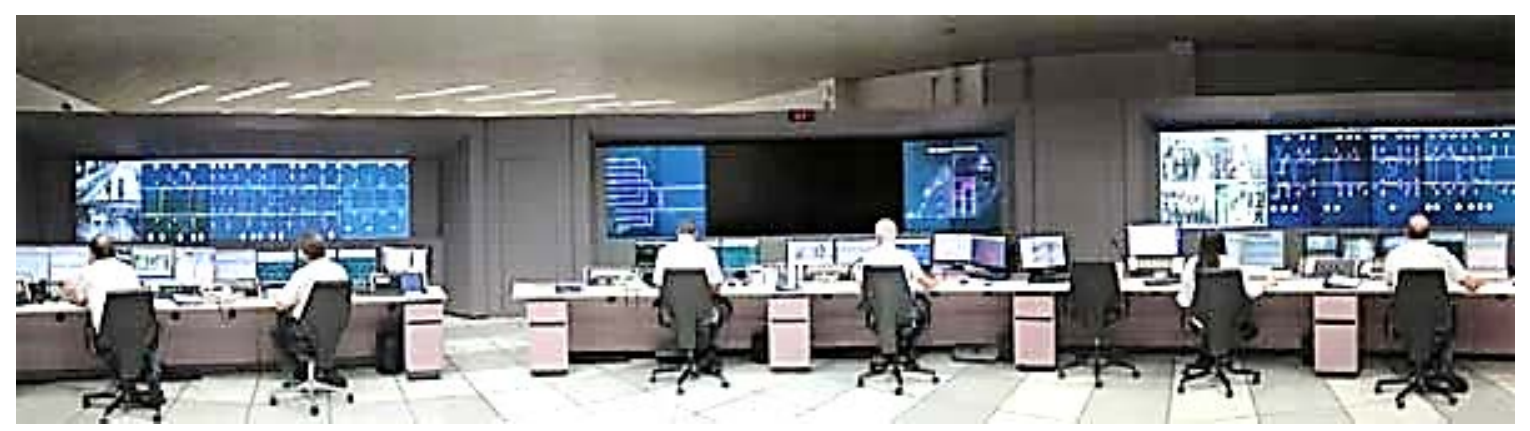

Fonte: CMSP, Departamento de Imprensa, 2015.

k) treinamentos - O Metrô de São Paulo dá acesso ao treinamento de Orientação e Mobilidade ministrado pelas entidades de reabilitação em suas instalações (Figura 3.26) e também tem oferecido este treinamento, que busca a familiarização das pessoas com deficiência visual com a estação, seu entorno, percurso seguro de embarque ou saída, localização de bilheterias, linha de bloqueios, sanitários, telefones públicos, bancos de espera e áreas comerciais. 0 treinamento também inclui orientações para o relacionamento com os demais usuários e avaliação das condições de utilização de forma autônoma ou com auxílio dos funcionários das estações. Com relação ao trem, demonstra-se o dimensionamento e a configuração 
dos carros, quantidade e funcionamento automático das portas, o vão entre o trem e a plataforma no local de embarque e desembarque e o vão entre carros (BARBOSA, 2015).

Figura 3.26- Treinamento de usuário com deficiência visual.

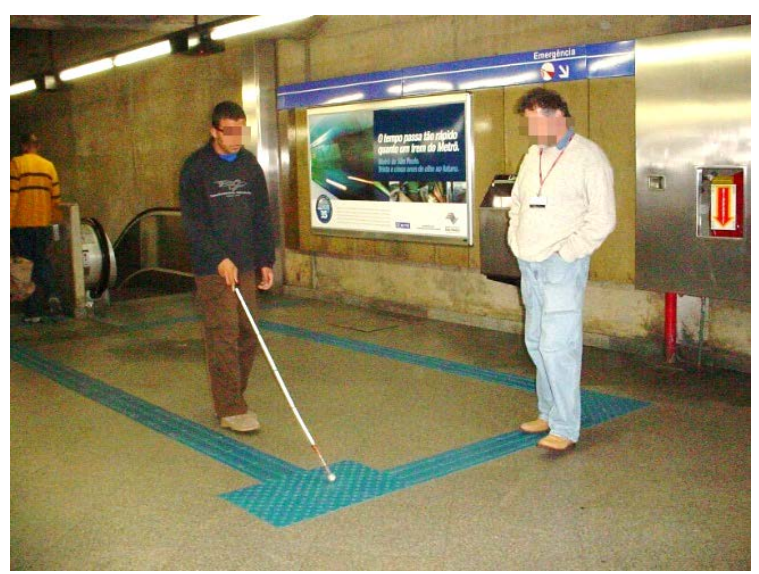

Crédito: MARIANI, E., 2004.
Figura 3.27 - Treinamento de empregado para condução de pessoa em cadeira de rodas nas escadas rolantes.

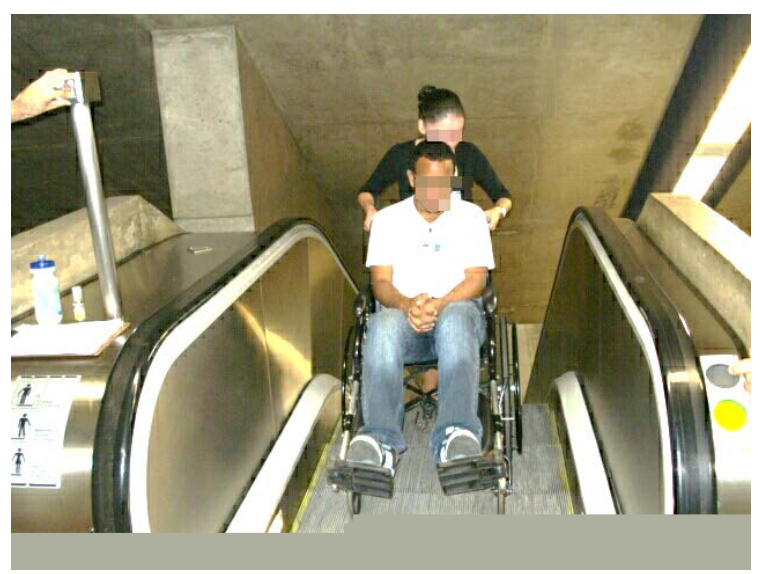

Fonte: Acervo CMSP.

1) treinamento de empregados - 0 metrô de São Paulo busca garantir a qualidade no atendimento à população, especialmente no atendimento às pessoas com deficiência ou com mobilidade reduzida por meio de treinamentos de capacitação de seus funcionários (Figura 3.27). Ao ingressarem no metrô, os funcionários das estações e os agentes de segurança são treinados na abordagem, condução e acompanhamento de pessoas com diferentes tipos e graus de deficiência ou pessoas que apresentam mobilidade reduzida, conduzindo-as até o embarque e posteriormente no desembarque, visando garantir sua segurança durante o percurso, seja em escadas rolantes, plataformas ou trens.

m) embarque / desembarque preferencial - Estratégia operacional adotada para facilitar o embarque e o desembarque de pessoas com direito assegurado por lei ao atendimento preferencial ${ }^{46}$ nos horários de maior movimento. Consiste na segregação da área da plataforma que interliga às duas primeiras portas dos trens, com acesso controlado por funcionários.

\footnotetext{
46 Lei Federal № 10.048/2000: Dá prioridade de atendimento às pessoas que especifica, e dá outras providências. (As pessoas portadoras de deficiência física, os idosos com idade igual ou superior a sessenta e cinco anos, as gestantes, as lactantes e as pessoas acompanhadas por crianças de colo terão atendimento prioritário, nos termos desta Lei.). (BRASIL, 2000a)
} 


\subsubsection{Pesquisas e indicadores}

A Tabela 3.3 e o Gráfico 3.2 mostram o total de usuários com deficiência visual monitorados nas linhas 1, 2, 3 e 5, no ano de 2014 .

Tabela 3.3 - Total de usuários com deficiência visual monitorados em 2014 no Metrô de São Paulo.

\begin{tabular}{ccc}
\hline Linha & Total & $\begin{array}{c}\text { Por milhão de passageiros } \\
\text { transportados }\end{array}$ \\
\hline 1 & 231.626 & 277 \\
\hline 2 & 58.072 & 156 \\
\hline 5 & 223.992 & 263 \\
\hline 5 & 19.438 & 122 \\
\hline
\end{tabular}

Fonte: Elaborado com base nos dados de CMSP (2014c).

Gráfico 3.2 - Porcentagens do total de monitoramentos por linha no ano 2014.

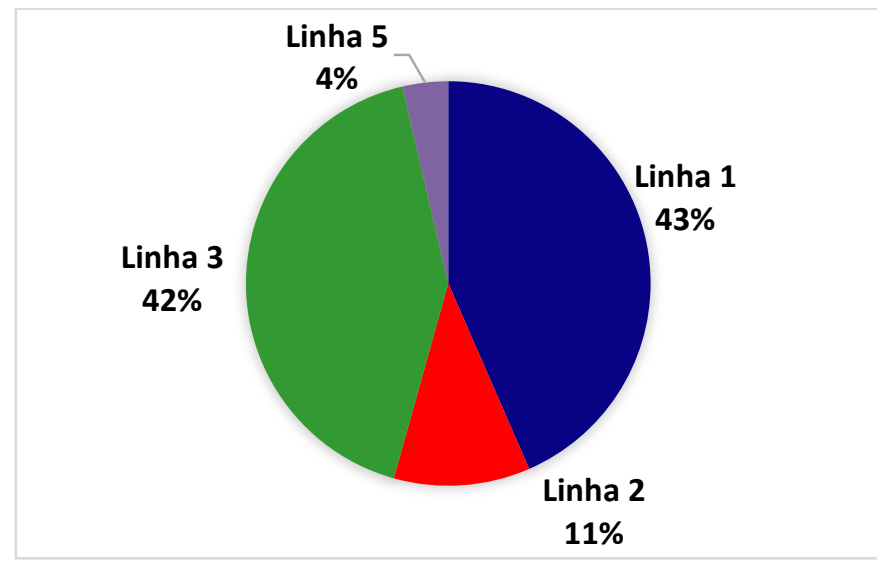

Fonte: Elaborado com base nos dados de CMSP (2014c).

A área de atendimento ao usuário recebe manifestações por meio de contatos provenientes de diversos canais de comunicação que são mantidos pelo Metrô, sendo os principais (CMSP, 2015c, p. 139): SMS-Denúncia (mensagens via celular); atendimento eletrônico (mensagens via sítio do Metrô na Internet); Telefone do Usuário; caixa de sugestões; atendimento pessoal e, de maneira mais indireta, mas também considerada, pelas manifestações nas redes sociais.

"A estratificação dos temas abordados nas manifestações resulta em indicadores de desempenho dos diversos aspectos do serviço, possibilitando um acompanhamento 
mensal e a correção dos desvios detectados" (CMSP, 2015a) para assegurar o "foco no cliente", preconizado pelo Sistema de Gestão de Qualidade da ISO-900047. A qualidade no atendimento às pessoas com deficiência ${ }^{48}$ e pessoas com restrição de mobilidade ${ }^{49}$ é medida por meio de índice de verificação denominado "Prover Atendimento". 0 Gráfico 3.3 apresenta as ocorrências nos anos de 2013, 2014 e seu respectivo acumulado, demonstrando que o número de manifestações sobre acessibilidade para pessoa com deficiência visual ou mobilidade reduzida por milhão de passageiros transportados está estabilizado.

Gráfico 3.3 - Índice de verificação "qualidade no atendimento à pessoa com deficiência ou restrição de mobilidade no sistema [Metrố ${ }^{50}$ "

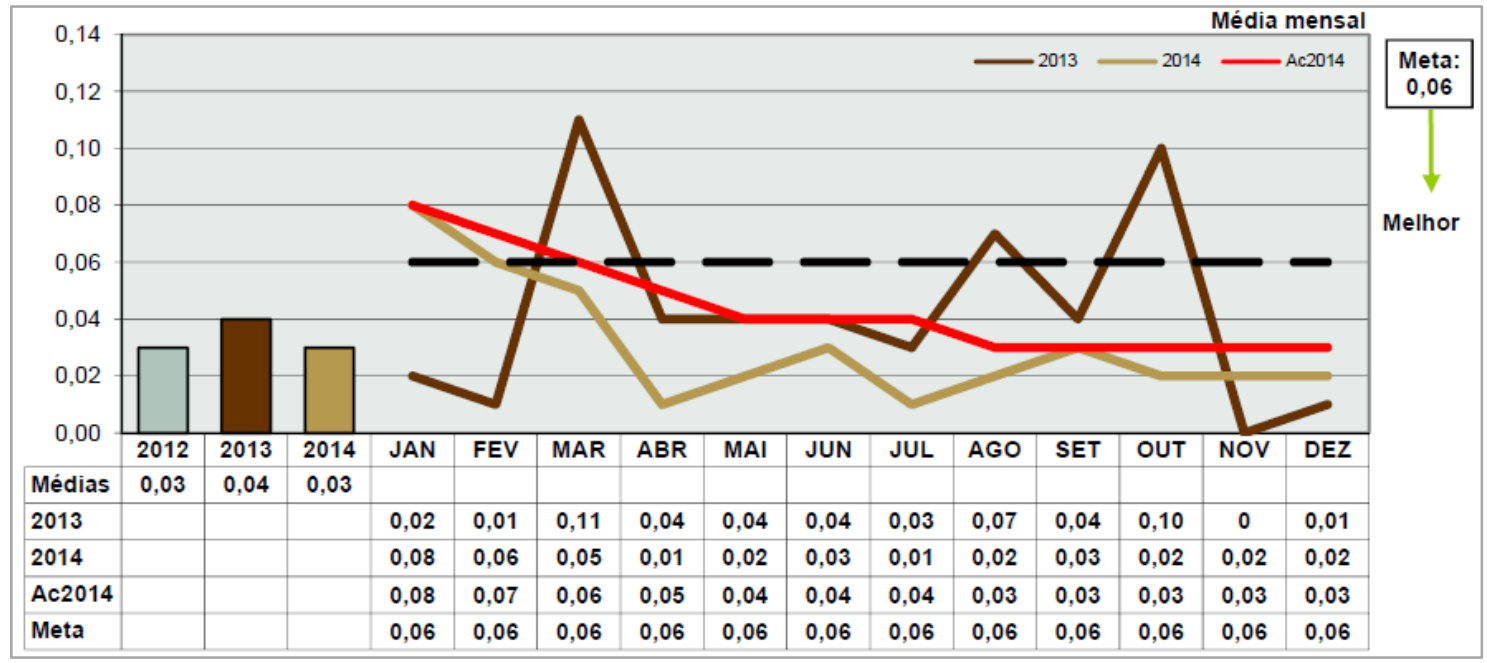

Fonte: CMSP (2014b).

O Gráfico 3.4 demonstra as manifestações relacionadas a pessoas com deficiência visual no ano 2014. Foram registradas 158 manifestações, das quais destacam-se para este estudo: (a) 85 reclamações sobre a qualidade das informações sonoras no trem, ou falta do aviso de próxima estação; e (b) 67 reclamações sobre demora na espera por funcionários, ou mau atendimento, quando solicitado acompanhamento.

\footnotetext{
${ }^{47}$ A Gerência de Operações do Metro de São Paulo possui certificação ISO 9000, entre outras certificações. 48 Todos os tipos de deficiências.

49 Idosos, pessoas com criança de colo, grávidas ou com algum tipo de doença que restrinja sua mobilidade.

50 Somente fazem parte da certificação as linhas 1, 2, 3 e 5, sob responsabilidade de operação pela Companhia do Metropolitano de São Paulo.
} 
Gráfico 3.4 - Manifestações relacionadas a pessoas com deficiência visual em 2014.

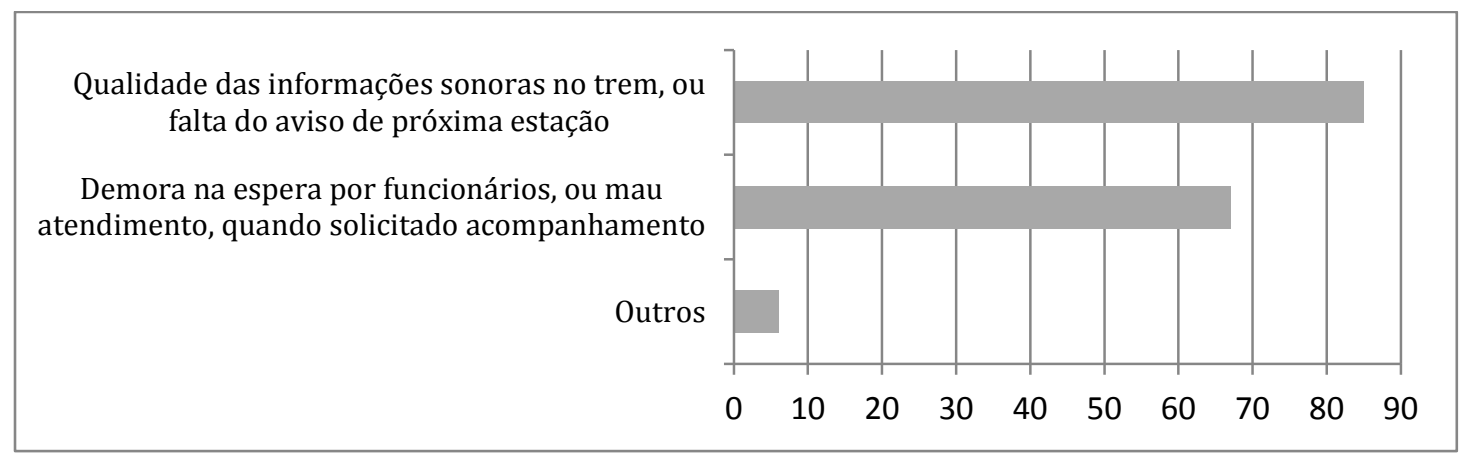

Fonte: Elaborado com base nos dados de CMSP (2014a).

A qualidade [ruim] das informações sonoras no trem, ou falta do aviso de próxima estação estão relacionadas à variação de recursos e qualidade do equipamento de informação sonora instalados nos trens, manutenção do equipamento e necessidade de fala do operador. Esta variação ocorre devido à existência de diferentes frotas de material rodante, fornecidas ao longo de 41 anos de operação, adquiridas de diferentes fornecedores, com diferentes projetos. A Companhia do Metropolitano de São Paulo busca a padronização das informações sonoras, porém existem características físicas nos trens que dificultam essa melhoria.

Nas pesquisas realizadas no Metrô de São Paulo, Barbosa (2015) analisou as manifestações de 235 respondentes, todos usuários habituais do metrô, com deficiência visual em diversos graus. A pesquisa se deu no período entre junho/2011 e junho/2012, e "teve por objetivo conhecer o perfil, os hábitos de viagem e sua opinião quanto à legibilidade dos ambientes e os desafios enfrentados na interação com o ambiente, os funcionários e os demais usuários" (BARBOSA, 2015, p. 117). Desta pesquisa extraiu-se a síntese das principais reclamações extratificadas pela autora (Tabela 3.4). 
Tabela 3.4 - Síntese das principais manifestações / reclamações verificadas na pesquisa de Barbosa (2015) com usuários do Metrô de São Paulo com deficiência visual.

\begin{tabular}{lc}
\hline $\begin{array}{c}\text { Elemento ou serviço com relação às } \\
\text { pessoas com deficiência visual }\end{array}$ & $\begin{array}{c}\text { Porcentagem do total de } \\
\text { manifestações / reclamações }\end{array}$ \\
\hline Piso tátil & $25,8 \%$ \\
\hline Atendimento pelos funcionários & $12,6 \%$ \\
\hline Informação - trem & $8,1 \%$ \\
\hline Condições das instalações & $5,2 \%$ \\
\hline Comportamento dos demais usuários & $4,9 \%$ \\
\hline Informação - estação & $3,4 \%$ \\
\hline Treinamento & $2,8 \%$ \\
\hline Proteção na plataforma & $2,6 \%$ \\
\hline Intercomunicador & $0,5 \%$ \\
\hline
\end{tabular}

Fonte: Elaborado a partir de gráfico da pesquisa de BARBOSA (2015, p. 453).

A relevância para este estudo foi identificada na análise dos relatos de insatisfação dos usuários que geraram esta síntese (BARBOSA, 2015):

a) piso tátil: falta de contraste entre o piso tátil, o piso da estação e os obstáculos; largura insuficiente do piso tátil direcional; o piso tátil não orienta o percurso para as escadas fixas e rolantes e não leva para todos os equipamentos e serviços oferecidos na estação; o percurso do piso tátil não segue o fluxo dos demais usuários, gerando confusão; dificuldade de compreensão do percurso e das mudanças de direção, principalmente nas estações de conexão; falta de diferenciação de cores para indicar diferentes destinos; o piso tátil não direciona para os pontos de parada de ônibus; nas plataformas, dificuldade de uso devido à aglomeração de pessoas, e instalado muito próximo à borda da plataforma.

b) atendimento pelos funcionários: demora na espera por funcionário para condução até o embarque e ausência de funcionário na chegada à estação de desmbarque.

c) informação - trem: falta de informação no interior do trem, como sinalização tátil, mapas, orientações ou instruções de uso dos dispositivos de emergência.

d) condições das instalações: falta de padronização da configuração das estações, dificultando a compreensão e memorização dos percursos; falta de câmeras de monitoração para auxílio imediato pelos funcionários.

e) comportamento dos demais usuários: na estação, não respeitam, permanecem sobre o piso tátil e interferem, desorientando e dificultando o deslocamento especialmente na plataforma. 
f) informação - estação: inexistência de informação sonora nas estações para orientar os percursos; falta de informação sonora ou em Braille sobre a configuração das estações, para a pessoa com deficiência visual saber usar a estação; falta de informações táteis ou sonoras indicando a localização dos bloqueios preferenciais; inadequação da sinalização tátil nos elevadores; inexistência de informações sonoras e táteis nas escadas rolantes; dificuldade de legibilidade das informações visuais em função da insuficiência do contraste de cor e do tamanho das letras nas placas de sinalização; falta de mapas táteis com descrição sonora; falta de informações sonoras ao longo do trajeto, orientando sobre a configuração e os percurso.

g) treinamento: falta de oferta de treinamento para uso das estações e trens.

h) proteção na plataforma: falta de portas de plataforma em todas as estações, especialmente nas estações com plataformas centrais.

i) intercomunicador: inoperância ou falta de intercomunicadores nas plataformas, dificultando a solicitação de auxílio no desembarque.

\subsection{O METRÔ DO PORTO}

O metrô do Porto iniciou sua operação em 2002 e constitui uma rede de transporte caracterizada como metrô leve, possuindo a maior parte de seus 67 quilômetros de extensão na superfície, ao nível das ruas. Distribuídas em seis linhas, do total de 81 estações, 14 são subterrâneas. E são os trechos em túneis e estações subterrâneas que apresentam semelhanças com sistemas de metrô, conforme abordado no início deste capítulo. 
Figura 3.28 - Localização da cidade do Porto (Portugal) e mapa ${ }^{51}$ da rede de metrô.

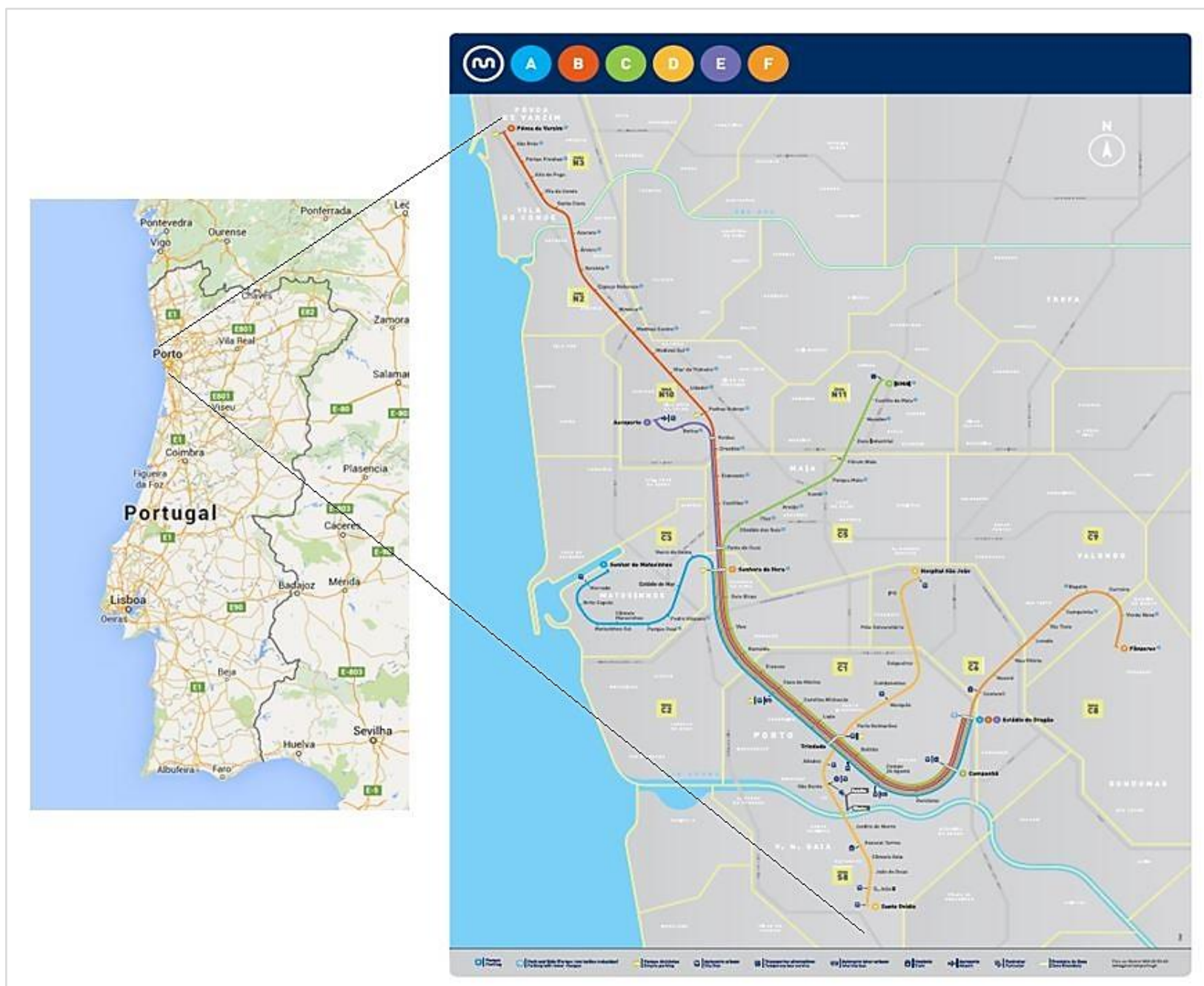

Fonte: Elaborado a partir de Google Maps, $2015^{52}$ e Metro do Porto (2015).

O metrô serve a sete municípios da região do Porto. As seis linhas do metrô do Porto são: linha A-Azul, linha B-Vermelha, linha C-Verde, linha D-Amarela, linha E-Violeta e linha F-Laranja, conforme Figura 3.28.

As estações mais próximas ao centro compartilham até cinco linhas, que se alternam por horários. Dessa forma é essencial a presença de painel de informações (Figura 3.29) e avisos sonoros nas estações, para alertar a respeito do destino do próximo trem a entrar na plataforma. Como o intervalo entre trens é em torno de 90 segundos ${ }^{53}$ nos dias úteis, e as entradas ocorrem nas plataformas de ambos os sentidos, a quantidade de avisos

${ }^{51} \mathrm{O}$ mapa da rede do metrô do Porto pode ser melhor visualizado em: <http://www.metrodoporto.pt>. Acesso em: 11 out. 2015.

52 Disponível em: <https://www.google.com/maps/d/viewer?mid=zCR7weNcynXg.k1fgZmtxwYNo\&hl=en_US>. Acesso em: 12 jun. 2015.

53 Valor verificado por meio de medições da pesquisadora, não informado pelo metrô do Porto. 
sonoros é muito grande, com poucos segundos de intervalo entre um e outro. Esta questão foi observada porque não ocorre em redes de metrô que não compartilham linhas, portanto não precisam informar o destino do próximo trem, por ser único.

Figura 3.29 - Painel instalado nas plataformas com informações sobre destino do próximo trem.

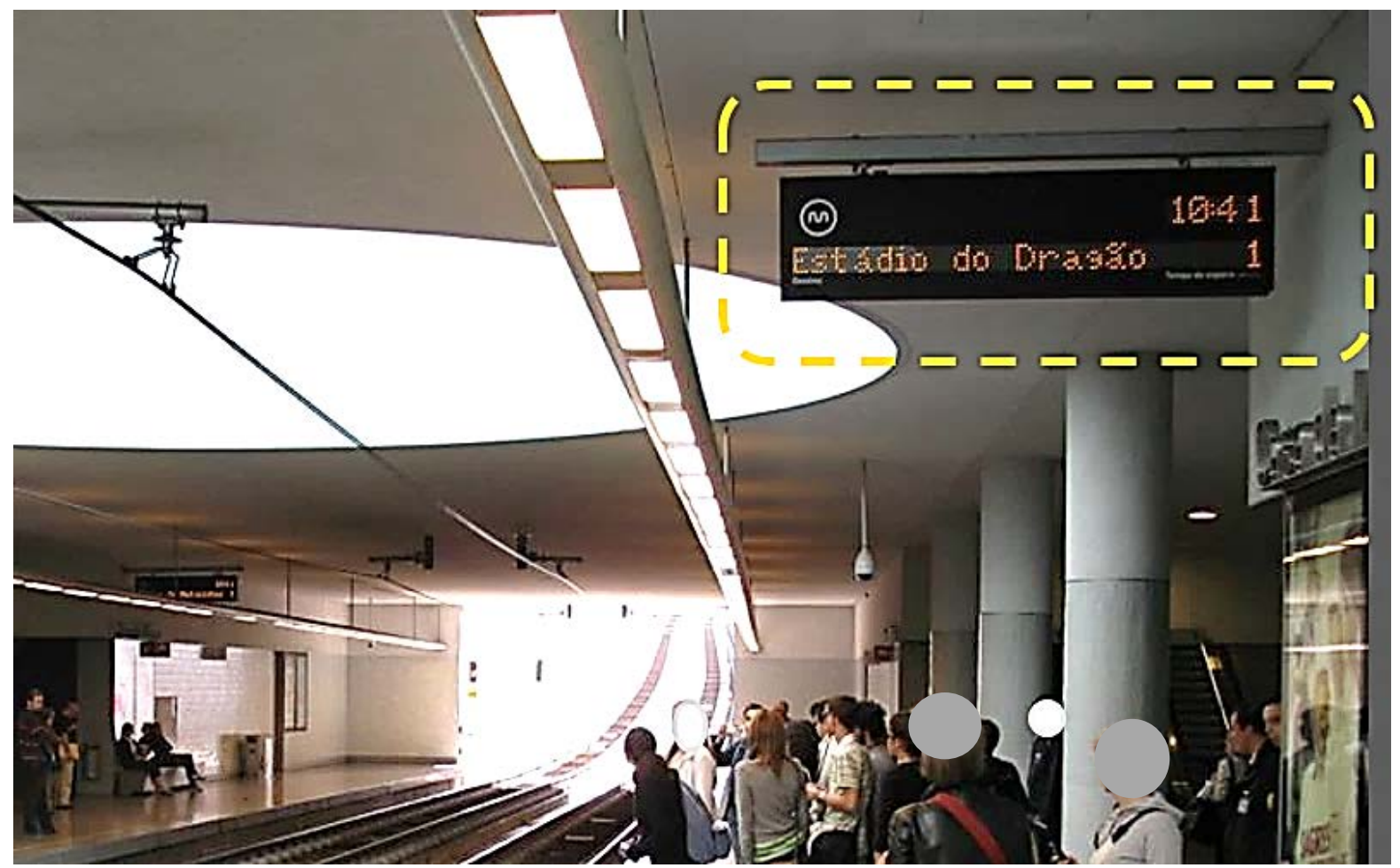

Crédito: MARIANI, E. 2015.

Atualmente, o metrô do Porto transporta um total da ordem de 200.000 passageiros por dia, conforme Tabela 3.5 e Gráfico 3.5 .

Tabela 3.5 - Relatório operacional do metrô do Porto - anos 2013 e 2014.

\begin{tabular}{lccc}
\hline Procura & $\mathbf{2 0 1 3}$ & $\mathbf{2 0 1 4}$ & $\mathbf{2 0 1 4 / 2 0 1 3}$ \\
\hline Validações & 4.566 .440 & 4.820 .774 & $5,6 \%$ \\
\hline Validações médias multiviagem (Andante) & 5,33 & 5,11 & $-4,2 \%$ \\
\hline Validações médias assinaturas (Andante) & 55,75 & 55,69 & $-0,1 \%$ \\
\hline Clientes Regulares & 69.245 & 71.926 & $3,9 \%$ \\
\hline Clientes Frequentes & 26.349 & 27.299 & $3,6 \%$ \\
\hline Passageiros / km & 22.761 .846 & 23.973 .711 & $5,3 \%$ \\
\hline Percurso médio & 4,985 & 4,973 & $-0,2 \%$ \\
\hline Vel. Comercial Passageiros & 26,30 & 26,59 & $1,1 \%$ \\
\hline Acidentes & 4 & 9 & $125,0 \%$ \\
\hline Acidentes / milhão km & 6,85 & 15,46 & $125,7 \%$ \\
\hline Taxa de ocupação & $17,00 \%$ & $17,97 \%$ & 0,97 pp \\
\hline
\end{tabular}

Fonte: Metro do Porto (2015). 
Gráfico 3.5 - Demandas do metrô do Porto - anos 2013 e 2014.

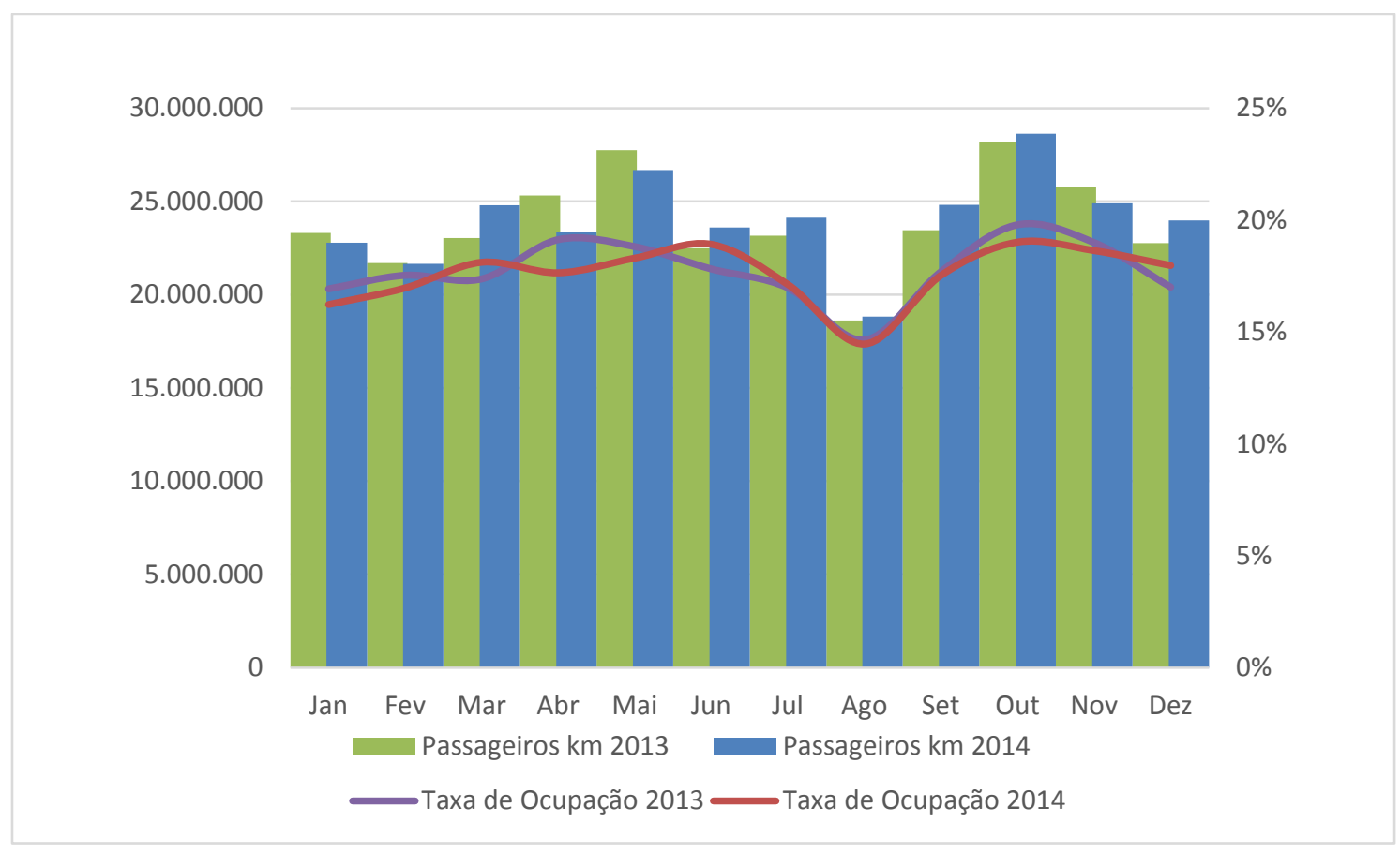

Fonte: Metro do Porto (2015).

A frota do metrô do Porto integra 102 veículos, com capacidade para transportar até 9.000 pessoas por hora e por sentido, nos períodos de maior procura. A configuração de um veículo simples tem um comprimento de 35 metros e sua capacidade é de 216 passageiros, 80 dos quais sentados. Os veículos podem ser acoplados em conjuntos de dois, formando composições duplas (METRÔ DO PORTO, 2015).

\subsubsection{Acessibilidade}

O projeto do metrô do Porto priorizou a eliminação das barreiras físicas comuns nos transportes públicos. Segundo a empresa, houve a preocupação de ouvir as opiniões e adaptar as recomendações de diversas associações representativas de cidadãos com deficiência, sendo possível, desta forma, corresponder ao máximo às necessidades específicas destas pessoas. Utilizando o conceito de que "o que está bem para a pessoa com mobilidade reduzida, está bem para todos" (METRÔ DO PORTO, 2015) foram construídas estações onde praticamente não existe desnível entre o trem e a plataforma.

Nas estações subterrâneas, o acesso desde a superfície até os níveis mais baixos pode ser vencido por elevadores, e nas estações de superfície existem rampas de acesso à plataforma. As máquinas de venda e carregamento de títulos foram posicionadas a uma 
altura adequada, permitindo a sua utilização por pessoas em cadeira de rodas ou de baixa estatura. Armários e equipamentos de informação e publicidade foram embutidos nas paredes; bancos, coletores de lixo e máquinas de venda de produtos foram criteriosamente localizados; e todas as placas suspensas de comunicação visual foram instaladas a alturas acima de 2,20 metros (Figura 3.30).

Figura 3.30 - Elementos embutidos e coletor localizado fora das regiões de fluxo.

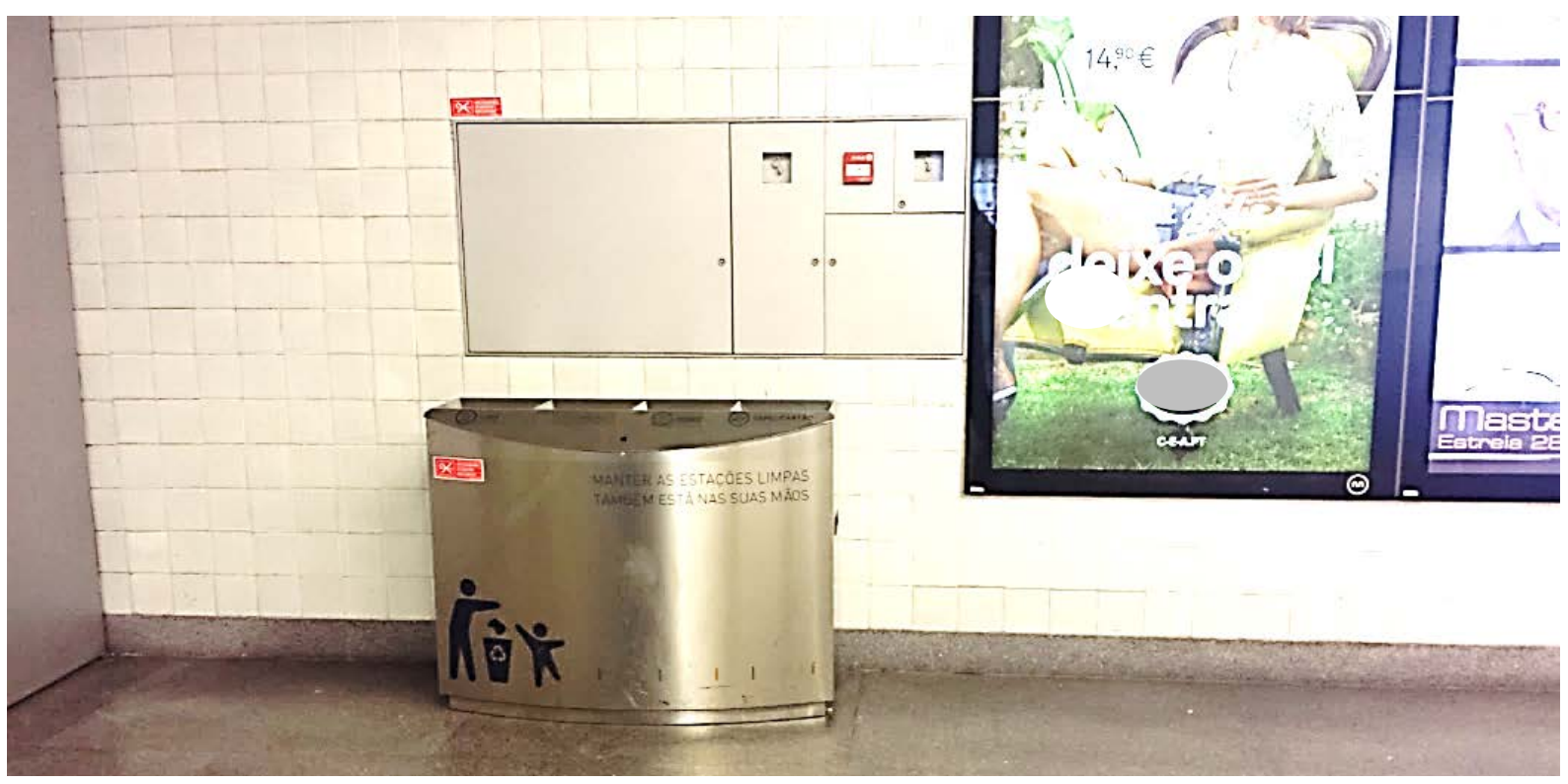

Crédito: MARIANI, E., 2015.

Especificamente à acessibilidade das pessoas com deficiência visual, o metrô do Porto optou pela instalação de pisos táteis somente como alerta no início e no final de escadas fixas e nas bordas das plataformas, não havendo pisos táteis direcionais.

Para auxiliar nos deslocamentos dentro das estações e prover informações como horários, destinos, tarifas etc., a empresa operadora está desenvolvendo em parceria com a FEUP - Faculdade de Engenharia da Universidade do Porto, e com o financiamento do POSC - Programa Operacional da Sociedade do Conhecimento, um projeto inovador, em formato de áudio, que poderá ser acessado local ou remotamente por meio do telefone celular do próprio usuário, denominado Navmetro ${ }^{\circledR}$.

\subsubsection{O sistema Navmetro ${ }^{\circledR}$}

O sistema Navmetro ${ }^{\circledR}$ - informação e navegação assistida na rede do metrô do Porto para pessoas com deficiência visual - está disponível desde dezembro de 2009, na 
estação Trindade. Trata-se um sistema que conduz os usuários com deficiência visual de maneira autônoma em várias situações: escolha de título, validação e encaminhamento no interior da estação, disponibilizando também informações gerais sobre o metrô: linhas, horários, títulos etc.

Desenvolvido pela empresa Metro do Porto em conjunto com a FEUP - Faculdade de Engenharia da Universidade do Porto, e com a ACAPO - Associação dos Cegos e Amblíopes de Portugal, o Navmetro ${ }^{\circledR}$ é uma inovação tecnológica, resultado de pesquisa e desenvolvimento, trabalho de uma equipe de técnicos, pesquisadores e acadêmicos.

Tanto o serviço de informação como o de navegação se iniciam com uma ligação telefônica efetuada pelo usuário, de um aparelho celular comum. Essa ligação é recebida por um sistema de atendimento geral, de diálogo automático baseado em voz sobre protocolo de rede Internet (VOIP) com fala sintética e reconhecimento de fala. Se a pessoa deseja somente informações (a respeito de linhas, horários etc.), é direcionada para o menu de informações desejado. A Figura 3.31 demonstra o funcionamento do sistema de informação. 
Figura 3.31 - Diagrama do funcionamento do sistema de informação do Navmetro ${ }^{\circledR}$

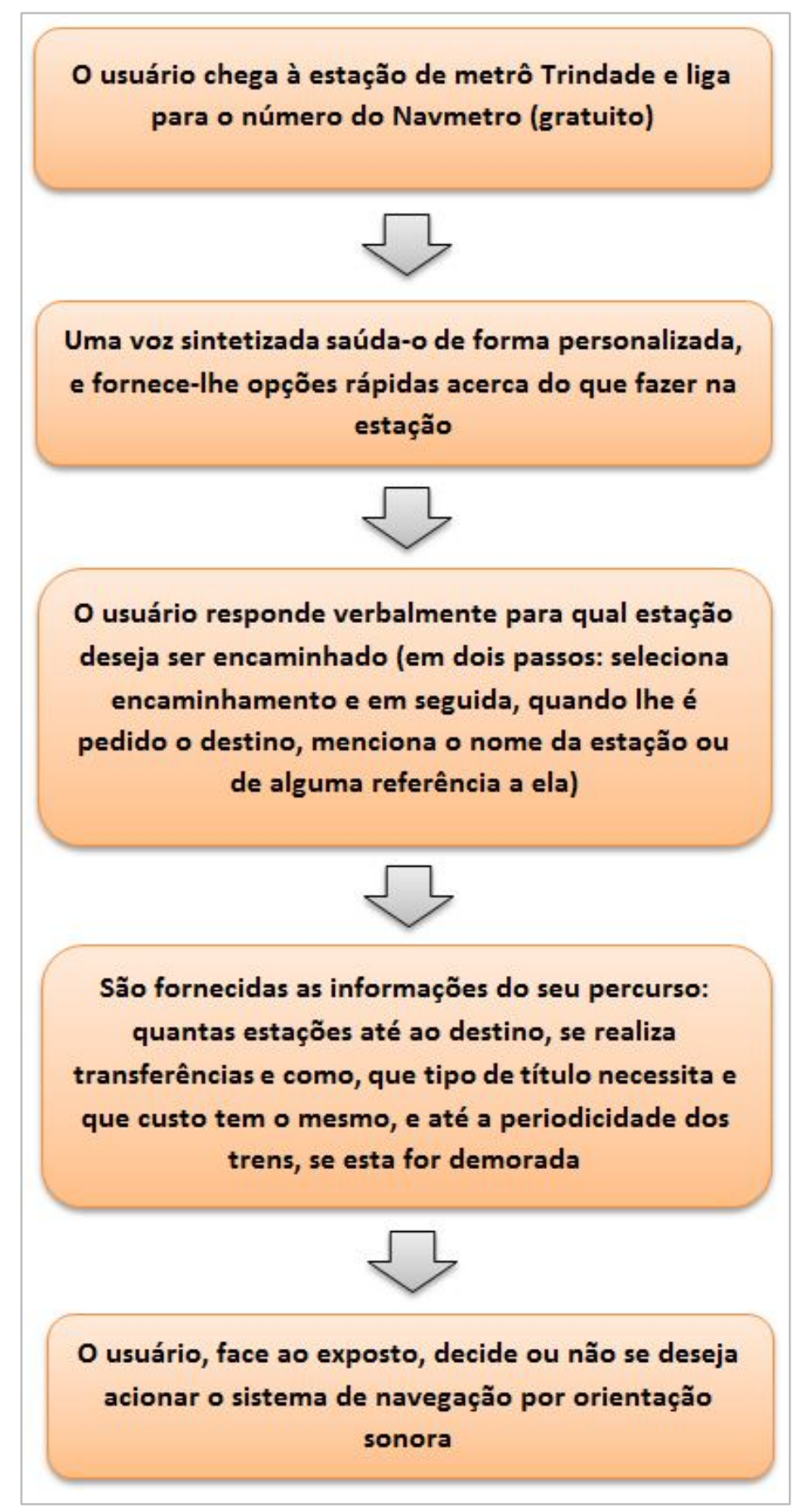

Fonte: Elaborado com base em Moutinho (2009, p. 114).

Por meio do sistema de informação, o usuário pode se programar para a realização de viagens, pois poderá saber qual a estação mais próxima para embarcar no metrô, o tipo de título a adquirir, o preço, o tempo de viagem, as características da estação (se é de superfície ou subterrânea, se possui café, sanitário etc.) e o número de paradas até o destino final. 0 sistema de informação pode ser acessado de qualquer localidade. 
Porém, se o objetivo é a navegação, a chamada obrigatoriamente tem de ser feita estando o usuário dentro da estação, que é dividida em zonas, para efeito do som. Após o atendimento automático, a pessoa escolhe o destino pretendido, tal como: determinada estação, saída da estação, sanitário, bar, loja ou máquinas de aquisição de títulos de viagem e máquinas de alimentação.

Na sequência o sistema solicita que o usuário diga em que piso se encontra, se está na plataforma, piso intermediário ou superior. Após a resposta, o sistema emite sons sequenciais por três diferentes alto-falantes, e o usuário informa qual foi o som ouvido mais próximo. Desta forma, o sistema passa a saber onde o usuário está na estação, e a partir de então passa a guiá-lo ao destino desejado.

Por meio da conversa mantida pelo celular são dadas as orientações e em seguida é emitido um som de pássaro pelo alto-falante que está no sentido a ser seguido pelo usuário. Os diversos alto-falantes foram estrategicamente instalados, de maneira a ser possível que o usuário, em qualquer posição na estação, possa seguir um caminho até seu destino.

Ao ouvir o som do pássaro, o usuário deve dirigir-se em sua direção e informar quando chegar ao ponto esperado. 0 sistema emitirá novamente o som do pássaro, repetindo-se a sequência, até o destino final. Se o usuário mudar de direção em algum momento, deverá ser feita nova localização e encaminhamento. A Figura 3.32 demonstra a sequência do diagrama da Figura 3.31.54

${ }^{54} \mathrm{O}$ funcionamento do sistema de navegação do NAVMETRO ${ }^{\circledR}$ pod de ser melhor compreendido pelo vídeo disponível na página de internet: <http://paginas.fe.up.pt/ mdi11018/wordpress>. Acesso em: $11 \mathrm{fev}$. 2015. 
Figura 3.32 - Diagrama do funcionamento do sistema de navegação do Navmetro ${ }^{\circledR}$

Após a sequência de atendimento do sistema de informação, se o usuário optar por seguir com o sistema de navegação, deve marcar esta opção no aparelho telefônico

Após informar em que piso se encontra da estação, o sistema aciona as boias sonoras deste piso, que emitem em seguintes sons: "primeira", "segunda" e "terceira", nesta sequência, em posições diferentes, e o usuário deve dizer ao telefone qual foi aquela que ele ouviu mais próximo de si, para que o sistema localize onde ele está

É disparado então, repetidamente, o som de um pássaro, pela boia sonora mais próxima que está no sentido para onde o usuário deve se dirigir, e solicitado que ele marque o número 8 ao chegar lá, de maneira a monitorar a sua localização.

Após marcar o número 8 , o sistema pode acionar nova boia sonora com som de pássaro, para que ele prossiga caminhando neste piso, ou lhe informa que está próximo a uma escada, e deve descê-la ou subi-la, devendo marcar o número 8 novamente ao chegar ao fim

\section{ॠ}

A sequência anterior é repetida sucessivamente até que o usuário chegue ao ponto desejado na estação, que pode ser plataforma de embarque ou saída.

\subsection{SISTEMAS ELETRÔNICOS DE NAVEGAÇÃO EM OUTROS METRÔS}

Outros metrôs realizaram pesquisas para uso de sistemas eletrônicos auxiliares à informação e navegação.

\subsubsection{Londres}

O metrô de Londres apresentou em 2015 o sistema Wayfindr, destinado a permitir que pessoas com deficiência visual naveguem de maneira autônoma em suas dependências. 
As pessoas recebem os comandos de voz por meio de seus smartphones, os quais, por sua vez, recebem sinais de uma rede de beacons de sinal Bluetooth instalada ao longo do percurso, desde o acesso até a plataforma. 0 metrô divulgou um vídeo de demonstração do uso desse sistema na estação Pimlico, sintetizado na Figura 3.33.

Comparando-se as informações do vídeo com a distribuição espacial da estação Pimlico, (a qual pode ser verificada na perspectiva constante da Figura 3.34), verifica-se que o sistema foi instalado em uma estação cujo percurso a ser realizado é relativamente simples, sem opções que possam confundir o usuário, o que nem sempre é possível. Devido à imprecisão do sistema, as mensagens de comando na realidade acabam sendo informações para tomada de decisão pelo próprio usuário, não constituindo exatamente uma navegação.

Como exemplo, ao chegar na base da plataforma (Figura 3.33g), a mensagem é genérica, qualquer que seja o destino do usuário. Este fato ocorre porque o sistema não consegue saber a posição exata do usuário e também porque se fossem emitidos dois sinais diferentes nesse local, um para cada destino, haveria interferência entre eles, por consequência, não sendo possível essa diferenciação com este tipo de sistema. 
Figura 3.33 - Sequência de uso do Wayfindr na estação Pimlico - metrô de Londres.

(a) Preparando-se para utilizar o sistema, com fones de ouvido.

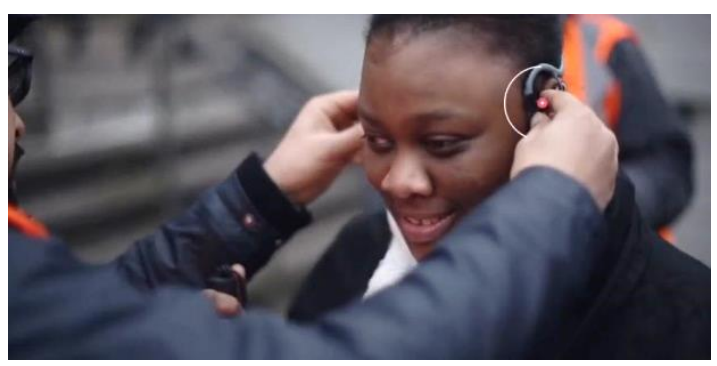

(c) 0 beacon no corredor de entrada, enviando mensagem de boas vindas e comando para seguir até o final da rampa.

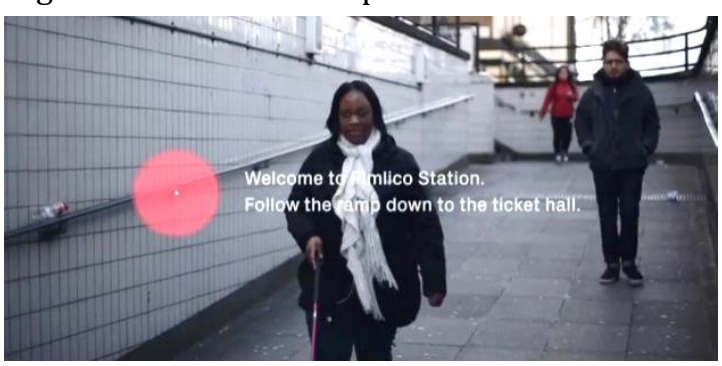

(e) Beacon indicando para virar à direita e seguir em frente, em direção aos bloqueios. No vídeo não aparece a passagem pelo bloqueio.

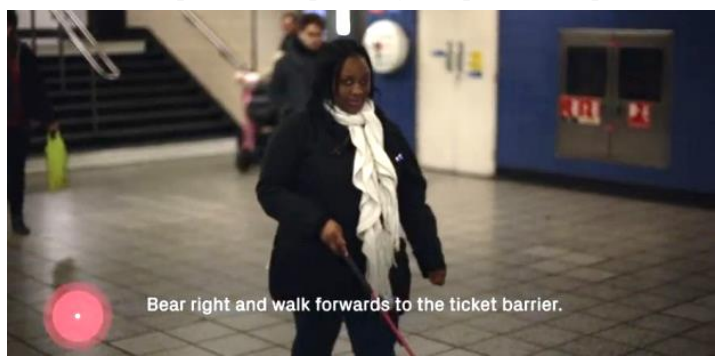

(g) No final do corredor, uma mensagem indica virar à esquerda, para um dos destinos finais, e à direita, para o sentido final oposto.

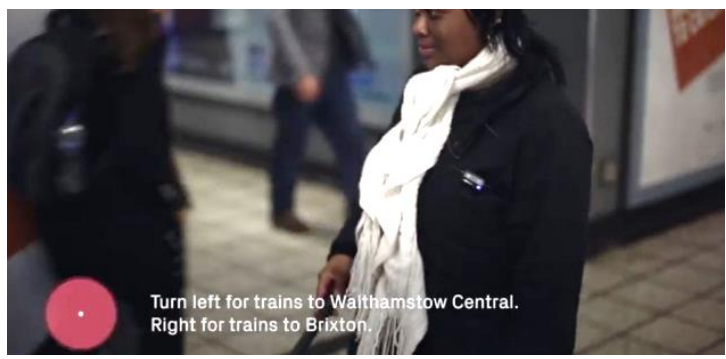

Fonte: Elaborado a partir de vídeo disponível em: $<$ https://www.youtube.com/watch?v=mc3KmbfxuUQ>. Acesso em: 27 ago. 2015. (b) Beacon instalado para localização do acesso da estação.

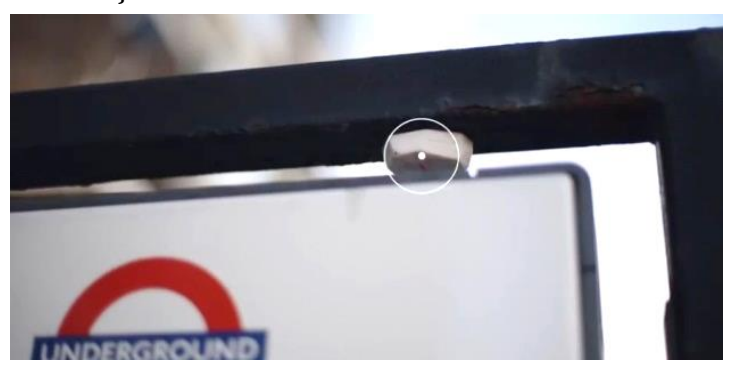

(d) Beacon no mezanino enviando comando para virar à esquerda e descer a escada. 0 sistema avisa que são nove degraus.

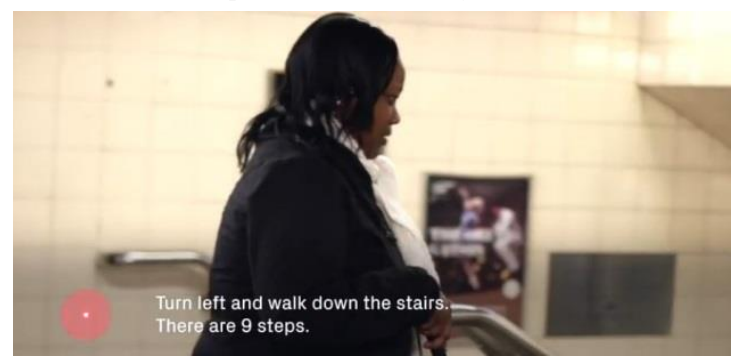

(f) Após os bloqueios e descidas pelas escadas rolantes, um beacon envia o comando para seguir em frente até o final do corredor.

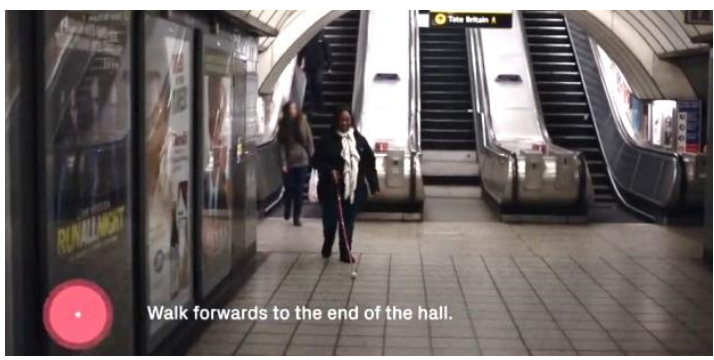

(h) Ao virar para o lado do destino desejado, é enviada uma mensagem de que a usuária se encontra na plataforma, e finalizada a navegação

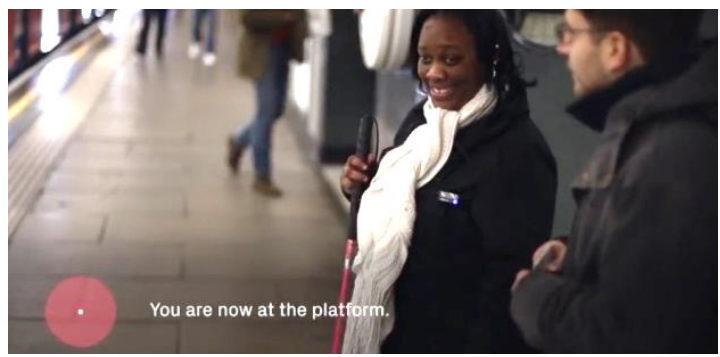


Figura 3.34 - Perspectiva espacial da estação Pimlico, com indicação do percurso realizado no vídeo sintetizado na Figura 3.32.

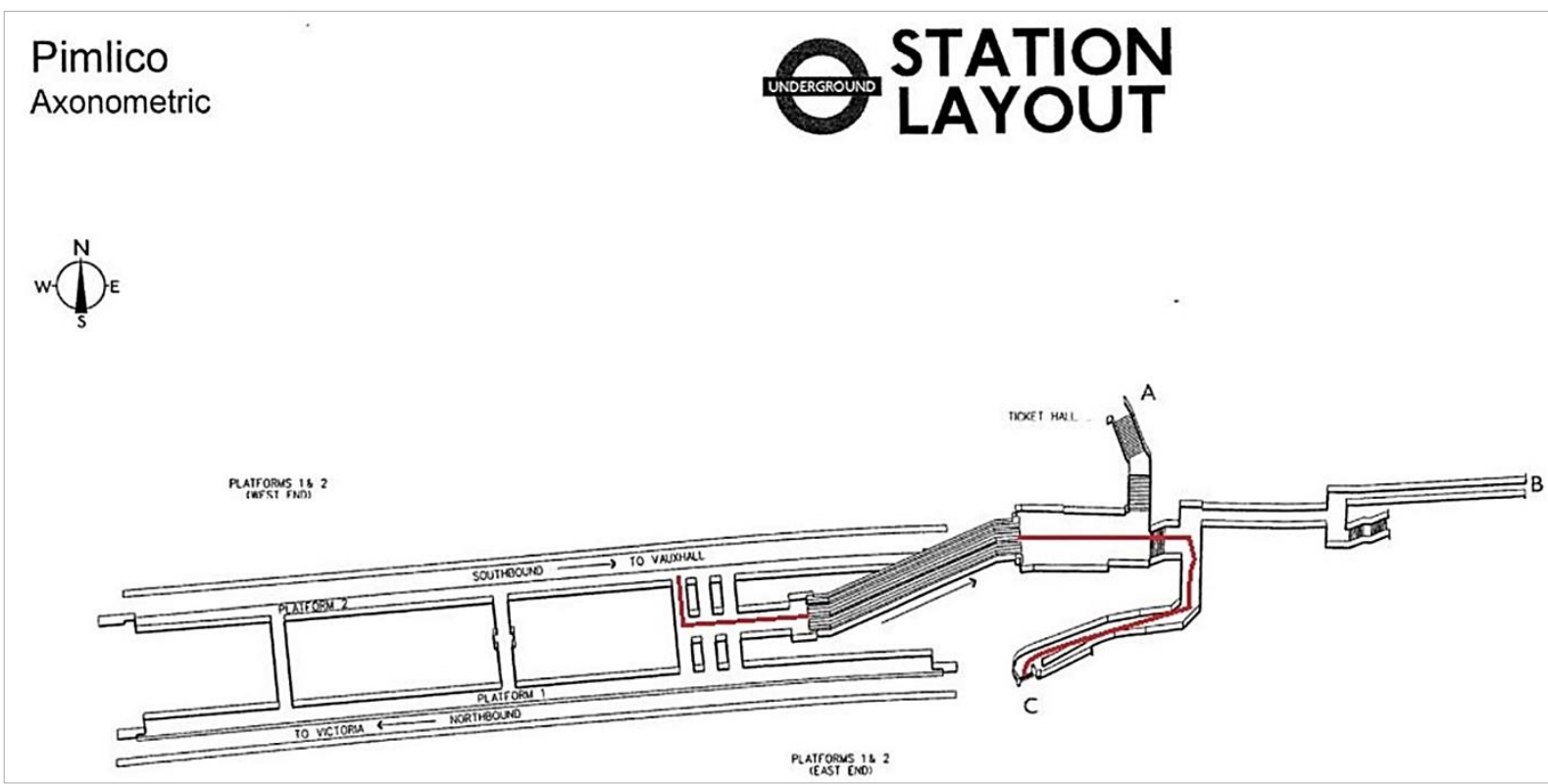

Fonte: Percurso em vermelho elaborado a partir de desenho da estação Pimlico ${ }^{55}$.

\subsubsection{Paris - RATP}

A empresa francesa de transporte público RATP realizou em 2006 um teste com 25 usuários utilizando o sistema BlueEyes, uma tecnologia sem fio para guiar pessoas com deficiência visual, estudada pela associação francesa faberNovel. A experiência ocorreu na estação de metrô Franklin Roosevelt, consistindo em uma rede de beacons de sinal Bluetooth, instalada nas dependências da estação. Os usuários recebem comandos de voz por meio de um aplicativo instalado em seus smartphones, os quais, por sua vez, recebem sinais da rede de beacons (Figura 3.35).

${ }^{55}$ Disponível em: <http://www.ianvisits.co.uk/blog/2015/07/12/3d-maps-of-every-undergroundstation-nopqrs/>. Disponível em 04 jan. 2016. 
Figura 3.35 - Usuário durante o teste no metrô de Paris, 2006, utilizando o sistema BlueEyes.

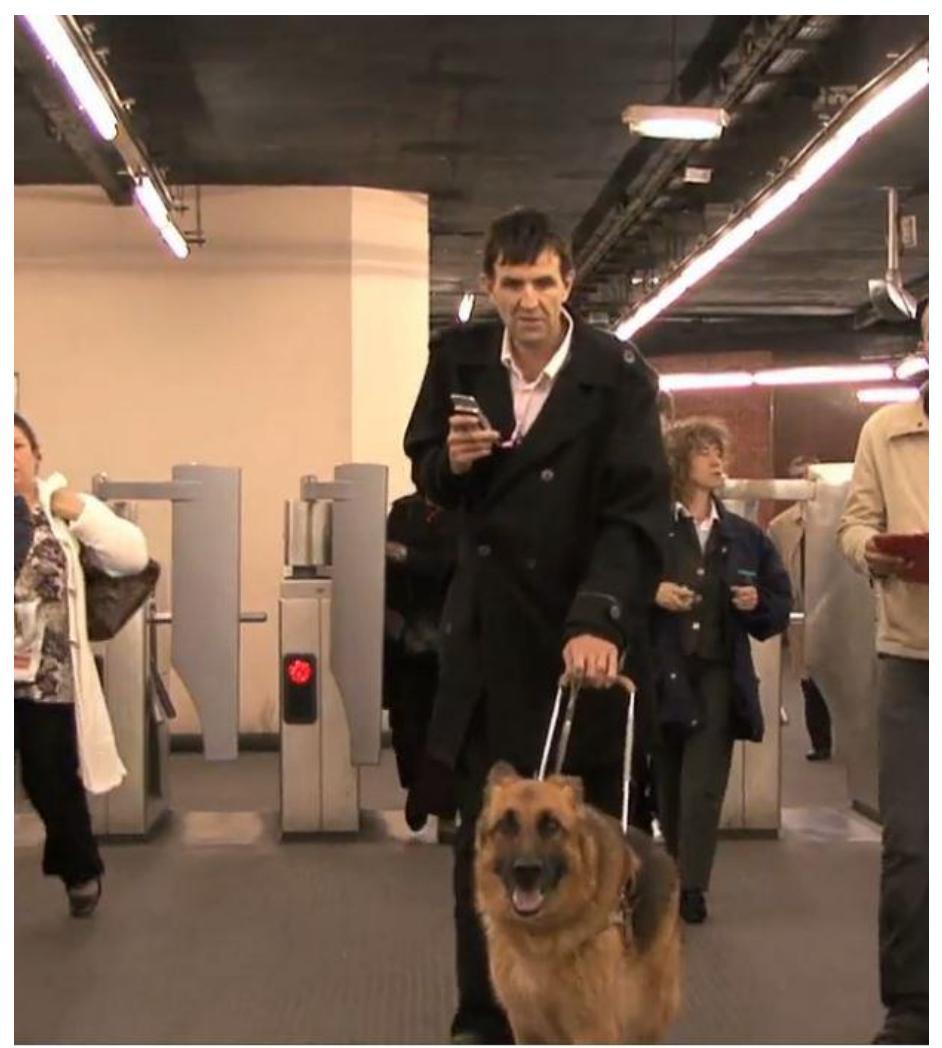

Fonte: Imagem extraída de vídeo disponível em: <https://vimeo.com/9042132>. Acesso em: 10 fev. 2016.

Para programar a viagem, o usuário acessa a base de dados BlueEyes por meio de conexão à internet. Ao entrar na estação, o sistema detecta a sua presença conforme ele vai passando pelos sinais de Bluetooth emitidos pelos beacons, que têm alcance entre 3 e 15 metros, para que o sistema consiga estimar a sua posição e direção, a fim de fornecerlhe informações adequadas para guiá-lo.

A RATP (2010) informou que estava aguardando financiamento para desenvolvimento do projeto. Apesar de a RATP manter atualmente a informação em sua página na internet, de que existe o serviço BlueEyes, a mesma não fornece mais informações a esse respeito, mesmo após ter ocorrido contato direto, por meio de consulta ao CoMET e Nova ${ }^{56}$. A empresa mantém em sua página na internet (RATP, 2015) a informação de disponibilidade do serviço BlueEyes, mas, por operar diversos serviços de transporte em

56 O CoMET e o Nova são grupos de benchmarking de metros do mundo, possuindo um programa abrangente de avaliação corporativa metroferroviária urbana internacional. Atualmente, os dois consórcios são constituídos de 30 grandes e médios sistemas de metrô, de 30 cidades ao redor do mundo. Os grupos são de propriedade conjunta e dirigido pelos membros, com gerenciamento de projetos, administração e pesquisa realizada pelo Railway and Transport Strategy Centre (RTSC), do Imperial College London. O CoMET e o Nova são bastante utilizados pelos seus membros quando se deseja obter informações pertinentes aos demais sistemas, por meio de um forum. 
Paris, como ônibus, metrô e trens, não fica claro em qual destes estaria disponível. A informação disponível é:

RATP está usando novas tecnologias para desenvolver novos serviços que promovam a acessibilidade. BlueEyes é uma dessas tecnologias testadas. Ele usa telefones celulares e tecnologia sem fio Bluetooth para oferecer soluções que ajudem as pessoas com mobilidade reduzida a viajar de forma independente na rede de transportes públicos. ${ }^{57}$

\subsubsection{França - SNCF}

A SNCF, empresa responsável pelos trens de longa distância na França, realiza melhorias na acessibilidade de suas estações e trens desde 2006, quando instituiu seu Laboratório de Acessibilidade, com a participação da Confédération Française pour la Promotion Sociale des Aveugles et Amblyopes - CFPSAA, utilizando a estação Montparnasse como local das experiências, tendo obtido alguns resultados significativos para esta pesquisa, apesar de estações e trens possuírem algumas características diferentes de estações e trens de metrôs. (SNCF, 2015)

Uma das soluções que chama a atenção é o sistema denominado Flèche Sonore, destinado à navegação de usuários com deficiência visual, que começou a ser testado em 2010 e está sendo instalado em grandes estações, com previsão de ampliação a partir de 2016. O sistema consiste em uma série de balizas instalada em uma rede aérea a três metros de altura, acompanhando o piso tátil direcional. 0 usuário caminha pelo piso tátil e ativa o sistema por meio de controle remoto universal, que na França também é utilizado para acionamento de semáforos de travessia de rua. Uma vez ativado o sistema, as balizas transmitem mensagens de localização de um serviço ou equipamento da estação, ou ainda, mensagens de direcionamento, orientando a pessoa com deficiência visual a chegar ao seu destino.

A SNCF (SNCF, 2011a) informa que o sistema emite diferentes sons que permitem sua compreensão nos grandes espaços públicos das estações. A ideia surgiu a partir do princípio de que dois pontos conectados por uma linha reta formam uma direção, e que duas mensagens sonoras curtas transmitidas a partir desta linha, a poucos metros de

57 Tradução nossa de "RATP is using new technologies to develop new services that promote accessibility. BlueEyes is one such technology tested. It uses mobile phones and Bluetooth wireless technology to offer solutions that help people with limited mobility to travel around independently on the public transport network." 
distância uma da outra, são uma maneira de informar o sentido de deslocamento, podendo guiar a pessoa. A SNCF também informa que, como o sistema Flèche Sonore transmite em diversas bandas de áudio, pode ser utilizado por várias pessoas simultaneamente, sem sobreposição de mensagens, e isto independe do sentido que se deseja seguir.

A Figura 3.36 demonstra os princípios do sistema Flèche Sonore: uma sucessão de balizas que emitem informações sonoras são ativadas ao mesmo tempo, mas cada uma transmite sua mensagem de maneira sincronizada, em uma sequência de sons e intervalos se silêncio, para criar um sistema de "flechas sonoras", facilitando a tomada de decisões para se chegar ao local desejado na estação.

Figura 3.36 - Sistema Flèche Sonore - SNCF - França.

(a) - Esquema básico de funcionamento.

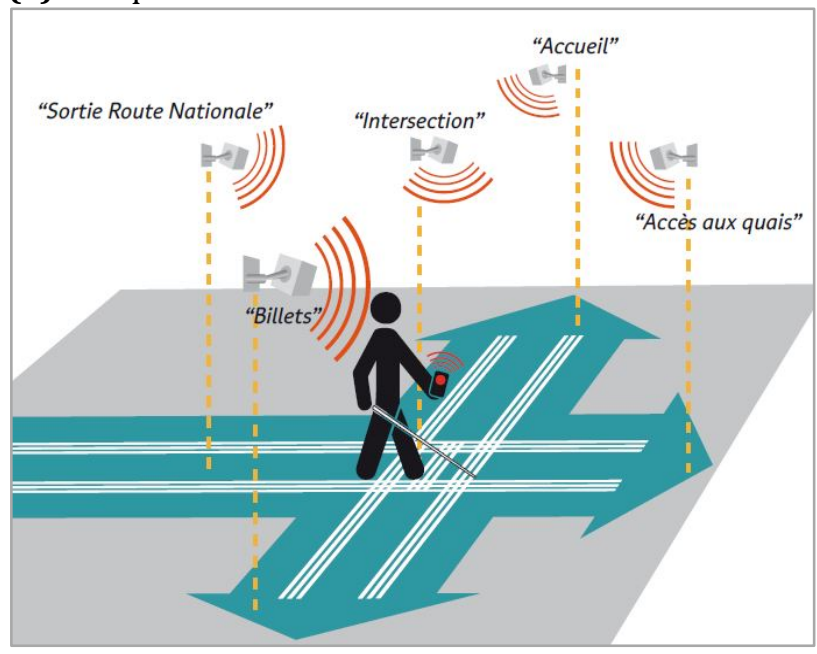

Fonte: SNCF (2011a, p. 65). (b) - Pessoa utilizando o sistema.

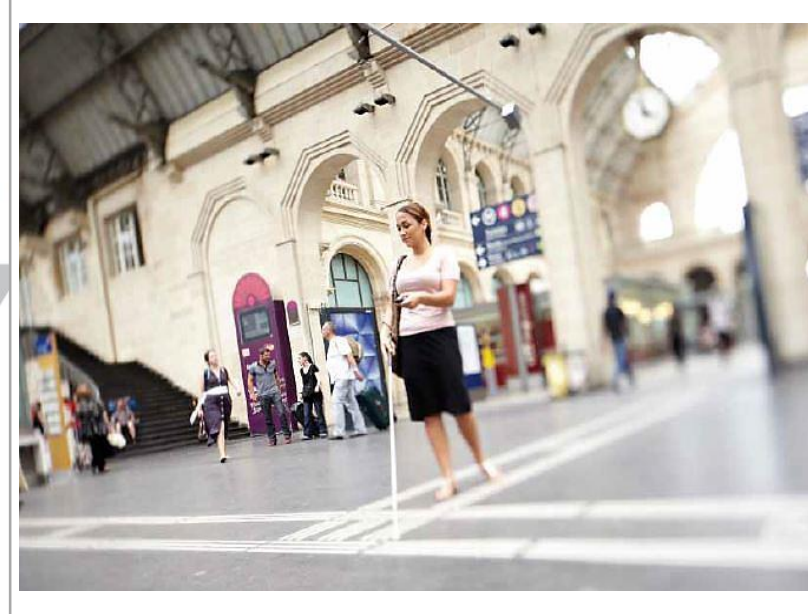

Fonte: SNCF (2015).

Em estações menores são instaladas apenas balizas de localização, posicionadas acima do acesso principal, sobre os validadores e nas plataformas, transmitindo sucessivamente a sua mensagem, para auxiliar que os usuários com deficiência visual os localizem. Este sistema é chamado de versão simples do Flèche Sonore. (SNCF, 2011b)

A SNCF relata que os usuários têm aprovado o Flèche Sonore, mas que, no entanto, eles observaram que poderiam ser efetuadas melhorias, especialmente sobre a qualidade do som e volume, bem como a clareza das mensagens. 0 Laboratório de Acessibilidade da SNCF realizou reuniões para que os usuários pudessem contribuir, opinando a respeito 
de sequências de mensagens emitidas, dependendo do caminho desejado - o que pode representar um exemplo a ser seguido por outros operadores.

Outro aspecto relevante do sistema é a sua associação ao piso tátil direcional, conferindo-lhe maior segurança. Essa associação vem de encontro a solicitações de usuários de metrôs, que desejam poder saber em tempo real, e sem necessidade de treinamento, para qual direção seguir, quando se chega a uma bifurcação ou intersecção dos pisos táteis. Se houver um sistema de informação sonora associado ao percurso, sempre que tiver dúvida, o usuário poderá acionar a orientação, por meio de seu controle remoto universal. De uma maneira geral, pode-se considerar que qualquer que seja o sistema eletrônico para guiar usuários com deficiência visual, se for associado ao piso tátil haverá ganhos, podendo servir como uma das proposições desta pesquisa.

\subsubsection{Santiago - Chile}

Em 2015, o metrô de Santiago disponibilizou o sistema BipReader em 11 estações, para auxiliar no percurso dos usuários, entre outras funções. Para utilizá-lo, é necessário que os interessados possuam um smartphone com o sistema Android 3.0 ou acima, de maneira que consigam estabelecer conexão por meio de placas NFC58. Em seu desenvolvimento foram envolvidos o Serviço Nacional de Deficiência, o Centro de Transtornos de Movimentação e fabricantes. O sistema fornece informações sobre os pontos-chave das estações, desde o acesso até o nível da plataforma, guiando o usuário. Foi necessário desenvolver um aplicativo para o smartphone do usuário, para que houvesse a conexão e transmissão das informações, assim como estudar as mensagens que cada placa apresenta. Para ouvir a mensagem, o usuário deve estar em frente a uma placa, que vai ser usada como referência para guia-lo até a próxima placa. 0 uso do sistema é gratuito e requer atualizações. (TRANSANTIAGO, 2015)

58 NFC - Near Field Communication, ou "conexão de campo próximo" é uma tecnologia utilizada para comunicação de baixa velocidade entre aparelhos próximos, como os utilizados para pagamentos online. Normalmente os aparelhos precisam estar encostados ou extremamente próximos, e se manterem imóveis um em relação ao outro (Seção 2.4.2 desta dissertação). 


\section{METODOLOGIA}

Este capítulo relata a teoria e os métodos utilizados para obtenção e análise dos dados. Minayo (2014, p. 44) considera que teoria e método são dois termos inseparáveis, "devendo ser tratados de maneira integrada e apropriada quando se escolhe um tema, um objeto, ou um problema de investigação". A autora considera o conceito de Metodologia "de forma abrangente e concomitante" (MINAYO, 2014, p. 44) tais como a "criatividade do pesquisador", expressão utilizada pela autora para definir a marca pessoal e específica do pesquisador na forma de articular teoria, métodos, achados experimentais, observacionais ou qualquer outro tipo específico de resposta às indagações específicas. Desta forma, será relatado o percurso da investigação e a justificativa dos métodos adotados, com foco nos objetivos deste trabalho.

\subsection{REFERENCIAL TEÓRICO}

Como estratégia de pesquisa, foram utilizados dados de referencial teórico, com o objetivo de aprofundar os conhecimentos sobre os temas relacionados e subsidiar a análise dos dados e proposições. Iniciou-se com o estudo de documentação e bibliografia nacionais e estrangeiras buscando-se referências que fizessem relação entre deficiência visual e recursos eletrônicos de navegação.

Com relação a estudos para se compreender a pessoa com deficiência visual e sua maneira de se relacionar com o mundo, visando à sua locomoção, pouco foi encontrado, o que levou a autora a buscar por referenciais teóricos e práticos que pudessem juntos delinear os referenciais utilizados por essas pessoas para se locomoverem por espaços públicos, considerando suas estruturas perceptual e cognitiva.

\subsection{PESQUISAS DE CAMPO - INSTRUMENTOS DE COLETA DE DADOS}

O uso de um sistema de transporte é uma atividade socialmente organizada, onde muitas vezes o comportamento real difere de como é descrito por quem o faz e, dessa forma, é importante confiar tanto nas entrevistas quanto nas observações das pessoas em questão, no próprio local objeto do estudo. 0 ponto de partida foi, pois, saber de sua 
experiência perceptiva, conforme recomenda Masini (2003). Foram então definidos os seguintes objetivos da pesquisa prática: (a) identificar e analisar quais os sentidos e os referenciais utilizados pelas pessoas com deficiência visual ao se locomoverem por estações e trens de metrô; (b) compreender como elas percebem o espaço, os trens em movimento e as demais pessoas, para poder orientar-se; (c) observar como é a experiência de uma pessoa com deficiência visual que utiliza um sistema de informação e navegação para se deslocar em uma estação.

Para atender a esses objetivos, as ferramentas da pesquisa qualitativa foram muito importantes, com suas abordagens em geral focadas na identificação das necessidades de cada projeto, assegurando o conhecimento das características e necessidades de cada indivíduo.

$\mathrm{Na}$ busca por melhor compreender os significados e características das situações vivenciadas pelos usuários, a grande maioria das pesquisas de campo foram realizadas no metrô de São Paulo, por meio de observações participantes, não-participantes, entrevistas e questionários. Para a observação prática da experiência da utilização de um sistema de informação e navegação para se deslocar em uma estação, optou-se por realizar uma pesquisa no metrô da cidade do Porto, em Portugal, a respeito do sistema Navmetro ${ }^{\circledR}$. A Figura 4.1 ilustra, em resumo, os instrumentos utilizados para as pesquisas de campo.

Figura 4.1 - Instrumentos utilizados nas pesquisas de campo.

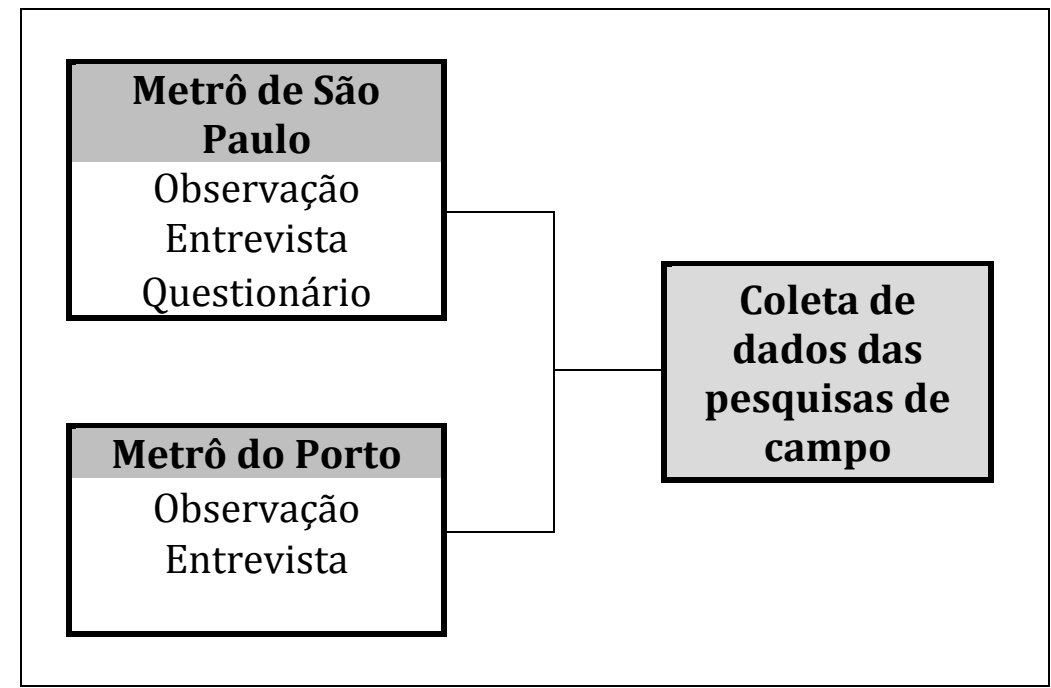




\subsubsection{Justificativas}

A utilização de métodos de abordagem qualitativa justifica-se por intermédio de diversos autores. De acordo com Flick (2009a, p. 16), a pesquisa qualitativa "usa o texto como material empírico (ao invés de números) parte da noção da construção social das realidades em estudo, está interessada nas perspectivas dos participantes, em suas práticas do dia a dia e em seu conhecimento cotidiano em relação ao estudo." Oliveira (2002) afirma que a pesquisa qualitativa proporciona a investigação de situações complexas ou particulares às pessoas com deficiência visual, pois:

As pesquisas que se utilizam da abordagem qualitativa possuem a facilidade de poder descrever a complexidade de uma determinada hipótese ou problema, analisar a interação de certas variáveis, compreender e classificar processos dinâmicos experimentados por grupos sociais, apresentar contribuições no processo de mudança, criação ou formação de opiniões de determinado grupo e permitir, em maior grau de profundidade, a interpretação das particularidades dos comportamentos ou atitudes dos indivíduos. (OLIVEIRA, 2002, p.117)

Para Flick (2009a) a pesquisa qualitativa é indicada para melhor interpretar e identificar as necessidades dos usuários, que muitas vezes não são nem reconhecidas pelos próprios, e identificar peculiaridades que nem sempre podem ser encontradas em livros, revistas ou trabalhos acadêmicos:

a pesquisa qualitativa usa o texto como material empírico (em vez de números), parte da noção da construção social das realidades em estudo, está interessada nas perspectivas dos participantes, em suas práticas do dia a dia e em seu conhecimento cotidiano relativo à questão em estudo. Os métodos devem ser adequados àquela questão e devem ser abertos o suficiente para permitir um entendimento de um processo ou relação. (FLICK, 2009a, p. 16)

Segundo Moresi (2003), a pesquisa qualitativa deve ser usada quando se deseja entender detalhadamente porque um indivíduo possui determinado comportamento. "A pesquisa qualitativa é especialmente útil em situações que envolvem o desenvolvimento e aperfeiçoamento de novas ideias" (MORESI, 2003, p. 69-70).

As pesquisas tradicionais (quantitativas) podem ser inadequadas "quando não existe um produto atual no mercado que integre, ao menos de forma primitiva, o novo produto, os usuários não possuem fundamentos sobre os quais formular suas opiniões" (DANTAS; SOUSA, 2013). A subjetividade de tal sistema levou à realização de pesquisa qualitativa. 
Optou-se pela realização de pesquisa qualitativa básica, que neste estudo demonstrou ser particularmente útil como ferramenta para determinar o que é importante como informação e referência para orientar o percurso de pessoas com deficiência visual em estações e trens de metrô, identificando-se padrões recorrentes na forma de temas e categorias.

A realização de pesquisa qualitativa também se deu por influência de Angrosino (2009), que recomenda este tipo de pesquisa quando se tem interesse em ter acesso a experiências em seu contexto natural, como foi parte deste trabalho.

\subsubsection{Observação}

A utilização da ferramenta observação conduzida no próprio ambiente do usuário no decorrer de rotinas normais diárias teve como objetivo chegar à cognição social, conforme Taylor, Peplau e $\operatorname{Sears}^{59}$ (2006, apud Rodrigues et. al, 2010, p. 53), pois, também de acordo com estes autores, “[...] é o estudo de como as pessoas formam inferências com base nas informações sociais fornecidas pelo ambiente". A utilização das observações foi muito importante, porque "as práticas apenas podem ser acessadas por meio da observação, uma vez que as entrevistas e as narrativas somente tornam acessíveis os relatos das práticas e não as próprias práticas" (FLICK, 2009b, p.203). 0 instrumento observação foi favoravelmente utilizado nos estudos de Cohen (2006), Valentini (2012), Queiroz (2014) e Barbosa (2015), servindo de orientação para esta pesquisa.

Com o objetivo de familiarização e identificação descritiva e qualitativa dos ambientes, foram feitas visitas exploratórias antes das observações, nas estações e trens de metrô a serem pesquisados. Foram verificados fluxos de usuários ao longo do dia, leiautes das estações e trens e sistema de comunicação com esses usuários. Esse reconhecimento permitiu melhor comparação entre as observações que compuseram este experimento e melhor análise dos resultados.

59 TAYLOR, S. E.; PEPLAU, L. A.; SEARS, D. O. Social Psychology. Pearson/Prentice Hall, 2006. 


\subsubsection{Entrevista}

Utilizou-se a técnica de entrevista por ser um dos instrumentos que têm desempenhando importante papel nos estudos científicos. Por terem natureza interativa, as entrevistas individuais de profundidade permitem tratar de temas complexos que dificilmente poderiam ser investigados por meio de questionários.

Neste trabalho optou-se pelas entrevistas individuais semiestruturadas (KOSKINEN; MATTELMÄKI; BATTARBEE, 2003; FLICK, 2009b; BAUER; GASKELL, 2010), sem uma ordem rigidamente estabelecida para as perguntas, assemelhando-se muito a uma conversa, onde o entrevistador faz perguntas específicas, mas também deixa que o entrevistado responda em seus próprios termos, buscando-se obter informações sobre "o que as pessoas sabem, crêem, esperam, sentem ou desejam, pretendem fazer, fazem ou fizeram [...]” (SELLTIZ60, 1967, apud GIL, 1999, p. 117). Segundo Lüdke e André (198661, apud OLIVEIRA, 2012, p. 3), a grande vantagem dessa técnica “é que ela permite a captação imediata e corrente da informação desejada, praticamente com qualquer tipo de informante e sobre os mais variados tópicos".

A técnica da entrevista em grupo também foi utilizada neste trabalho, para realização das entrevistas no metrô do Porto. Esta técnica é sugerida quando a pesquisa, "pressionada pelo tempo, é muito mais rápido fazer um pequeno número de entrevistas com grupos focais do que entrevistar o mesmo número de pessoas individualmente" (GASKELL, 2003, p. 73). Devido ao tempo disponibilizado pelos profissionais a serem entrevistados, foi considerado que seria mais produtivo unir os dois em uma única entrevista.

Embora existam muitas semelhanças entre entrevistas individuais e em grupo, no caso do metrô do Porto a ideia não foi "fazer um conjunto de perguntas padronizadas ou esperar que o entrevistado traduza seus pensamentos em categorias específicas de resposta" (GASKELL, 2003, p. 73), mas sim unir os relatos dos profissionais quanto ao histórico do desenvolvimento do sistema Navmetro ${ }^{\circledR}$, para se obter esclarecimentos e acréscimos em pontos importantes.

\footnotetext{
60 SELLTIZ, C. et al. Métodos de pesquisa nas relações sociais. 2. ed. São Paulo: EPU, 1987. v. 3.

61 LÜDKE, M., ANDRÉ, M. E. D. A. Pesquisa em educação: abordagens qualitativas. São Paulo: EPU, 1986.
} 
A técnica de entrevista foi favoravelmente utilizada nos estudos de Cohen (2006), Valentini (2012), Queiroz (2014) e Barbosa (2015), servindo de orientação para esta pesquisa.

Neste trabalho a pesquisadora elaborou as perquntas, mas algumas questões foram sendo acrescentadas, dependendo das respostas. Foi dada liberdade aos entrevistados e a possibilidade de surgir novos questionamentos não previstos pela pesquisadora, ocasionando uma melhor compreensão do objeto em questão.

\subsubsection{Questionário}

O intuito de se aplicar um questionário a um grande número de usuários do metrô com deficiência visual, combinando-se métodos quantitativos e qualitativos foi o de proporcionar uma base contextual mais rica para interpretação e validação dos resultados, de acordo com o proposto por Kaplan e Duchon (1988), capaz de aumentar a compreensão da realidade desses indivíduos. De acordo com Freitas, Janissek-Muniz e Moscarola (2005), o uso de técnicas qualitativas associadas a quantitativas permite estabelecer conclusões mais significativas a partir dos dados coletados. A técnica de entrevistas foi favoravelmente utilizada nos estudos de Queiroz (2014) e Barbosa (2015) servindo de orientação para esta pesquisa.

O questionário nesta pesquisa foi elaborado com questões semiabertas, onde, além da pessoa responder às questões pelas alternativas propostas, ela também teve a opção de comentar a resposta. As questões foram elaboradas de maneira que pudessem ser respondidas sem maiores dificuldades, conforme recomendam Kronberger e Wagner (2010), procurando-se que fossem: (a) claras, concretas, precisas; (b) possibilitassem uma única interpretação; (c) se referissem a uma única ideia de cada vez; e (d) “evitassem o constrangimento”, conforme sugerido por Bardin (1979, p. 173). 


\subsection{PESQUISA NO METRÔ DE SÃO PAULO}

A pesquisa no metrô de São Paulo teve início com uma pesquisa piloto.

\subsubsection{Pesquisa piloto}

Como técnica para separar o problema em diversos níveis de abstração, utilizou-se o método da Escada da Abstração (ou "Ladder of Abstraction"), um conceito que serve para descrever a maneira pela qual a mente humana pode conceber as coisas em diversos níveis distintos de abstração, proposto por Owen (1992).

Definindo-se como "degrau" central da escada a questão: "Como as pessoas com deficiência visual circulam pelo sistema metrô de São Paulo?", aplicou-se a pergunta "por quê?" sucessivamente, cujas respostas indicaram, no sentido ascendente da Escada, os objetivos da pesquisa. Aplicando-se a pergunta "como?", sucessivamente, no sentido descendente da Escada, as respostas indicaram os métodos para a pesquisa, conforme Figura 4.2. 
Figura 4.2 - Escada da abstração.

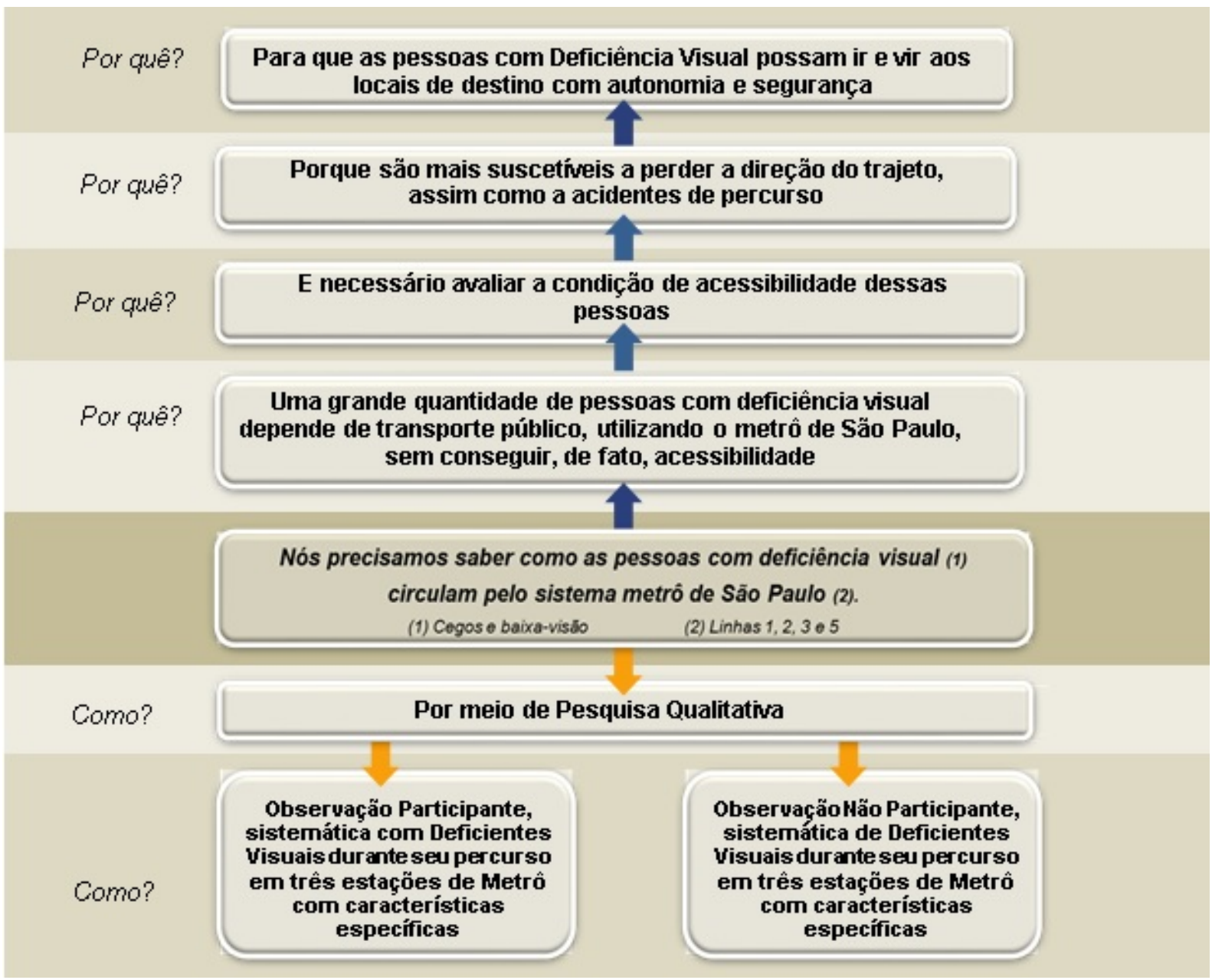

Fonte: MARIANI, E; DUTRA, D. N. M; DAYÈ, C. (2013).

0 mapeamento de stakeholders ${ }^{62}$, ou "partes interessadas" realizado nesta pesquisa teve como objetivo definir pessoas ou grupo de pessoas que afetam ou são afetadas pelas decisões do projeto ou serviço relacionado aos usuários com deficiência visual. 0 mapeamento é um diagrama que indica essas prováveis pessoas ou grupos, sendo utilizado para guiar o planejamento para pesquisa com os usuários. A Figura 4.3 mostra o mapeamento dos stakeholders identificados como envolvidos no processo.

${ }^{62}$ Apesar de ter sido utilizado desde os anos 1960, foi por intermédio da publicação em 1984 de um texto referindo-se ao termo stakeholder, que Richard E. Freeman recebeu o crédito pela sua criação. A definição tradicional de stakeholder é "qualquer grupo ou indivíduo que pode afetar ou é afetado pela realização dos objetivos da organização" (FREEMAN, 1984 apud FONTAINE et al.; 2006, tradução nossa).

De acordo com Bryson (2004), o termo stakeholder refere-se a pessoas, grupos ou organizações que devem, de alguma forma, ser levados em conta por líderes e analistas, tendo passado de termo originalmente utilizado na área de administração, para o uso comum, devido à noção de que, atender às principais partes interessadas gera "bons lucros" (BRYSON, 2004, p. 22 - tradução nossa), e entre os acadêmicos, por gerar bons resultados (FONTAINE et al.; 2006). 
Figura 4.3 - Mapeamento dos stakeholders.

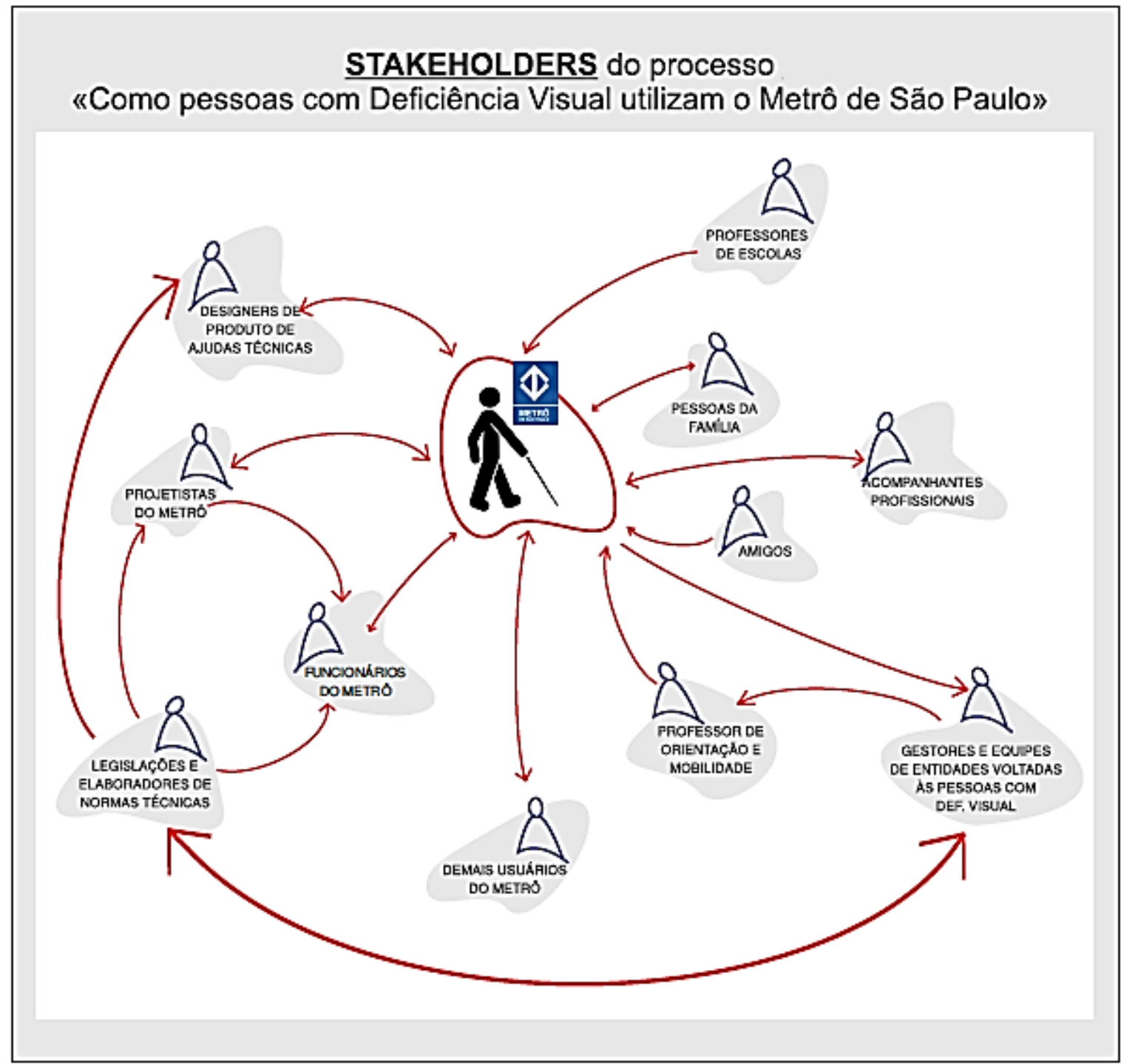

Fonte: MARIANI, E; DUTRA, D. N. M; DAYÈ, C. (2013).

Dentre os stakeholders identificados na Figura 4.3, destacam-se para esta pesquisa:

a. usuários do metrô com deficiência visual: pessoas diretamente envolvidas no tema da pesquisa;

b. demais usuários do metrô: interferem na circulação dos usuários com deficiência visual;

c. funcionários do metrô: responsáveis por auxílio na circulação e na segurança dos usuários;

d. professores de Orientação e Mobilidade: responsáveis pelo treinamento dos usuários com deficiência visual; 
e. designers de produtos de ajudas técnicas: responsáveis por projetos auxiliares nos deslocamentos de pessoas com deficiência visual, entre outros;

f. projetistas do metrô: responsáveis pelos projetos das estações, trens e mobiliário do metrô, que podem ajudar ou atrapalhar no percurso dos usuários com deficiência visual.

Decidiu-se que a pesquisa piloto poderia ser realizada apenas com um tipo de stakeholder, devendo-se avançar na sequência com pesquisas com os demais stakeholders destacados. Dentro de cada grupo de stakeholders foram identificadas as pessoas-chave que seriam submetidas à pesquisa. Essas pessoas serão apresentadas ao longo deste capítulo.

Quanto ao método utilizado na pesquisa piloto, realizou-se análise dos diversos métodos de pesquisa qualitativa, optando-se por observações sistemáticas: (a) observação de campo: permite a percepção do pesquisador sobre os fatos, sem intermediação; (b) sistemática: considera a elaboração prévia de plano de trabalho. Esta opção baseou-se em estudos de Rampazzo (2005) e Flick (2013), que afirmam que nesse contexto, pesquisadores têm acesso a informações inacessíveis via métodos de pesquisa orientados.

Neste piloto foram experimentados dois tipos de observação sistemática:

a. Observação participante: a observação participante geralmente considera que o pesquisador esteja engajado na vida do grupo ou na situação, porém, neste caso a posição da pesquisadora foi a de "participante observador". Conforme Gold 63 (1958 apud OLIVEIRA, 2012, p. 8):

no papel de participante como observador, ao contrário do participante completo, o pesquisador teve o prévio consentimento por parte da comunidade a ser observada. Os sujeitos, neste caso, sabem do caráter científico do estudo, podendo haver acordos, algumas obrigações e promessas, discutidas antes do início da pesquisa. (Grifo nosso)

Além da observação em si, em algumas ocasiões durante o trajeto os observados foram discursando sobre suas percepções do ambiente e também dando depoimentos espontâneos a respeito da acessibilidade no metrô.

${ }^{63}$ GOLD, R. L. Roles in Sociological Field Observations. Social Forces, 36: 217-223, 1958. 
b. Observação não-participante, na qual "o observador deve manter distância dos eventos observados a fim de evitar influenciá-los, caracterizando assim o 'observador completo'” (GOLD63, 1958 apud FLICK, 2009b, p. 204).

Devido à inexperiência com este método, a pesquisadora realizou uma visita prévia a uma das estações escolhidas, conversou com dois funcionários da estação que trabalham na linha de frente, em contato direto com os usuários, perguntando a respeito da frequência de pessoas com deficiência visual. Enquanto realizava esta visita, surgiu uma dessas pessoas, com traços aparentes de deficiência visual. A pesquisadora então aproveitou a oportunidade para realizar uma prévia de observação, acompanhando a pessoa até seu destino sem se manifestar, e percebeu, a interferência dos demais usuários durante a realização desse percurso, alguns oferecendo auxílio, outros cruzando rápido pelo caminho, chegando a pisar na bengala. Este fato chamou a atenção para a necessidade de que durante as observações a serem realizadas com usuários com deficiência visual fossem incluídas observações a respeito das interferências com os stakeholders "demais usuários do metrô", e isto foi acrescentado no protocolo de observação.

Diante das definições dos stakeholders e do método, decidiu-se começar a pesquisa piloto observando-se os "usuários do metrô com deficiência visual". Para escolha das pessoas-chave, de acordo com Moresi (2003, p. 69), "é importante trabalhar com uma amostra heterogênea de pessoas enquanto se conduz uma pesquisa qualitativa". Desta forma foram colocadas as condições (DEMO, 1995) para observação de diferentes pessoas com deficiência visual: (a) congênita; ou (b) adquirida depois de adulta; (c) todos com os sentidos remanescentes preservados, para não haver contaminação da pesquisa; (d) não utilizam cão-guia; (e) utilizam diferentes estações, de diferentes linhas.

A exclusão inicial de pessoas com cão-guia foi devido ao pressuposto de que essas pessoas não seriam beneficiadas com sistemas eletrônicos de informação e navegação em redes de metrô. Mais tarde, após a evolução dos trabalhos, percebeu-se a importância de se aprofundar a pesquisa incluindo-se pessoas com cães-guia, para se verificar a confirmação desse pressuposto.

Ficou definida a observação de quatro usuários, considerando-se que inicialmente devese observar um pequeno número de unidades amostrais - neste caso, pessoas com 
deficiência visual - do grupo envolvido. Os pequenos números não constituem uma característica inalienável da pesquisa qualitativa. Conforme Moresi (2003, p. 70) "nada há que determine que a pesquisa qualitativa tenha que ser conduzida com pequenos números. Mas as grandes quantidades de dados densos que os métodos qualitativos tendem a gerar propiciam uma razão de ordem prática para que se limite o tamanho da amostra.".

Diante destas condições, foram selecionados participantes aleatoriamente, dentro de um grupo heterogêneo de pessoas adultas com deficiência visual, que atendessem às condições previamente colocadas, para melhor representatividade.

Para a observação participante, foram convidadas duas pessoas, uma com cegueira adquirida ("R.") e outra com cegueira congênita ("I."). "R." foi selecionado por ser usuário frequente do metrô, que sempre se manifesta à empresa Metrô buscando treinamento, reivindicando melhorias e oferecendo-se como voluntário para pesquisas. “I.” também é usuária frequente do metrô e possui características diferentes de "R.", tanto com relação à deficiência (um já enxergou, o outro não) como com relação à forma como ambos se deslocam no ambiente público (utilização ou não de pisos táteis, autonomia, conhecimento do Braille, treinamento). Foi feito o convite a cada uma dessas pessoas, informando-as de que seriam observadas e filmadas durante seu percurso, previamente combinado como sendo uma viagem habitual, sem alteração de comportamento, de maneira a interferir o mínimo possível nos resultados.

Para a observação não-participante, definiu-se que seriam observadas pessoas com deficiência visual ${ }^{64}$ escolhidas aleatoriamente em duas estações distintas. Como regra do método, não seria feito nenhum contato com elas, de maneira a não interferir nos resultados. As pessoas selecionadas receberam a denominação de "X" e "Y".

No início foi pensado na seleção de estações do metrô de diferentes linhas, com demandas e características arquitetônicas diferentes entre si, porém as observações participantes deveriam ocorrer por estações e linhas normalmente utilizadas pelos convidados. Mesmo com esta exigência, a pesquisa realizou-se dentro de uma diversidade: (1) “R." entrou pela estação Artur Alvim e desembarcou na estação Tatuapé, ambas da linha 3-Vermelha; (2) "I." entrou na estação Vergueiro da linha 1-Azul, fez

64 Pessoas que apresentassem traços evidentes de deficiência visual. 
conexão com a linha 3-Vermelha na estação Sé, e desembarcou na estação Marechal Deodoro.

Para as observações não-participantes foram escolhidas as estações Marechal Deodoro, da linha 3-Vermelha e Vila Prudente, da linha 2-Verde. A escolha da estação Marechal Deodoro se deu por ser esta uma estação que recebe um grande número de pessoas com deficiência visual, pela sua proximidade com uma instituição voltada às pessoas com deficiência visual. A estação Vila Prudente foi escolhida por ser uma estação das mais novas da rede.

A pessoa escolhida aleatoriamente para ser observada na estação Marechal Deodoro, "X", desembarcou na estação Artur Alvim da linha 3-Vermelha. A observação de "Y" realizada a partir da estação Vila Prudente teve que ser descartada devido a evidências de contaminação. Mas este fato não causou interferência nos resultados, de forma que a pesquisa piloto com os três usuários que completaram a observação foi considerada válida.

Para padronizar as observações estipulou-se como protocolo a observação das pessoas com deficiência visual de acordo com a amostra estabelecida, utilizando o metrô, desde a calçada do acesso de uma estação, ao longo de todo o trajeto, até a saída ou conexão com outro modal, inclusive dentro dos trens do metrô. Também foi observado o comportamento dos demais usuários durante o percurso. Ao final do percurso, solicitouse a cada pessoa observada que participasse de uma breve entrevista semiestruturada, a respeito de sensação de insegurança no percurso realizado; sua interação com smartphones e Internet; e sugestões de tecnologias e/ou equipamentos para melhorar a circulação de pessoas com deficiência visual na rede de metrô.

As primeiras observações ocorreram na seguinte ordem: (a) "R." no dia 18/10/2013, sexta-feira, das 16h às 18h; (b) "I." no dia 28/10/2013, segunda-feira, das 17h às 18h15; e (c) "X" no dia 25/10/2013, sexta-feira, das 18h às $19 \mathrm{~h} 15$.

0 registro dos comportamentos e das falas das observações foi feito por meio de gravações de vídeo de todo o percurso, fotografias e anotações por escrito.

Os dados obtidos foram transcritos em arquivos de textos e posteriormente organizados, de acordo com as etapas de análise. 


\subsubsection{Alterações propostas}

$\mathrm{Na}$ avaliação das experiências realizadas na pesquisa piloto buscou-se identificar, ainda que com apenas três usuários, padrões de conduta, semelhanças e diferenças comportamentais em relação à execução dos percursos, e foi possível se identificar, além dos padrões, itens de comportamento desconhecidos pela pesquisadora. No entanto a pesquisa piloto apontou alguns itens a serem alterados na pesquisa final.

A primeira medida tomada foi descartar a observação não-participante devido ao procedimento padrão do Metrô de São Paulo que, para maior segurança das pessoas com deficiência visual, disponibiliza funcionários para acompanhamento desses usuários, descaracterizando sua eventual circulação autônoma65. A respeito da monitoração, destaca-se um depoimento feito pela ACAPO, a Associação de Cegos e Amblíopes de Portugal:

Também é essencial mostrar o respeito pela autonomia: não devem impedir os clientes de realizar o que sabem e conseguem fazer sozinhos. Caso contrário, podem considerar o seu comportamento paternalista, o que prejudicará a imagem do serviço prestado. Por outro lado, uma pessoa com deficiência visual pode ter dificuldade em circular num espaço que não conhece e pode precisar do seu apoio como guia para chegar à saída, ao elevador ou a outro ponto dentro do vosso estabelecimento. (ACAPO, 2013a, p. 5)

Outro motivo que também contribuiu para o descarte da observação não-participante foi o fato de que, mesmo para observação de pessoas com deficiência visual que circulam de maneira totalmente autônoma, o fato de não se manifestarem verbalmente prejudica o entendimento a respeito de suas percepções e decisões.

Procedeu-se à observação participante dos usuários com deficiência visual, mas manteve-se os ganhos da observação não-participante, anônima, em relação aos demais usuários, os quais interferem no caminhar daqueles com deficiência visual. 0 acompanhamento foi feito de maneira discreta, misturando-se como usuária do metrô, sem chamar a atenção. Essa condição significou para esta pesquisa, de acordo com

650 metrô disponibiliza funcionário para fazer o acompanhamento de pessoa com deficiência até o embarque no trem, e funcionário aguardando no desembarque de outra estação, para dar mais segurança a essas pessoas. No entanto, não são todas pessoas que solicitam esse acompanhamento e também, eventualmente, pode acontecer de o funcionário não estar presente no momento do desembarque, devido à grande demanda de usuários, o que pode causar desagrado na pessoa que desce do trem e tem que ficar esperando pelo funcionário. 
Angrosino (2009, p. 9), "ter aceso a experiências, interações [...] em seu contexto natural, e de uma forma que dê espaço às suas particularidades e aos materiais nos quais são estudados".

Outra alteração ocorrida em relação à pesquisa piloto, conforme mencionado em 4.3.1, foi incluir a observação de usuário com cão-guia.

Os problemas apontados nas reclamações feitas pelos usuários que constam no Gráfico 3.4, no capítulo 366, geraram discussões internas na empresa Companhia do Metropolitano de São Paulo no primeiro semestre de 2015, com a participação da pesquisadora, para se propor uma solução satisfatória e segura, e a discussão se voltou para a possibilidade de se instalar um sistema eletrônico auxiliar de informação e navegação. Nestas reuniões ficou decidido, entre outras medidas, que deveria ser realizada pesquisa qualitativa/quantitativa com usuários do metrô com deficiência visual a respeito de suas dificuldades, expectativas e conhecimento a respeito do uso do metrô, das monitorações e de aparelhos de navegação.

Para completar a lista dos stakeholders a serem pesquisados, decidiu-se pela realização de entrevistas individuais de profundidade com funcionários das estações e trens do metrô, com professores do orientação e mobilidade, com designers de produtos de ajudas técnicas e com projetistas do metrô.

\subsubsection{Observação complementar}

Definidas as alterações, foram realizadas observações complementares com usuários no metrô de São Paulo.

Seguindo-se as mesmas condições da pesquisa piloto, foram selecionados participantes aleatoriamente, dentro de um grupo de pessoas adultas com deficiência visual que atendessem às condições propostas nas alterações, para serem observadas em seus percursos pelo metrô.

Foram convidadas três pessoas, sendo que todas utilizam o metrô diariamente: (a) "G.", uma pessoa com cegueira total congênita que utiliza cão-guia; (b) "V.", uma pessoa com

660 Gráfico 3.4 faz referência às reclamações sobre demora no acompanhamento de funcionário e reclamações sobre a qualidade das informações sonoras no trem. 
cegueira total adquirida aos 19 anos; e (c) "M", uma pessoa com baixa visão congênita. Como na pesquisa piloto, foi feito o convite a cada uma delas, informando-as de que seriam observadas e filmadas durante seu percurso, previamente combinado como sendo uma viagem habitual, sem alteração de comportamento, de maneira a interferir o mínimo possível nos resultados.

Da mesma forma que na pesquisa piloto, as observações participantes ocorreram por estações e linhas normalmente utilizadas pelos participantes. 0 primeiro deles, com o cão-guia, entrou na estação Pedro II e desembarcou na estação Palmeiras-Barra Funda, ambas da linha 3-Vermelha. 0 segundo embarcou pela estação Fradique Coutinho da linha 4-Amarela, fez conexão com a linha 3-Vermelha na estação República e desceu na estação Vila Matilde, também da linha 3-Vermelha. 0 terceiro embarcou pela estação São Bento da linha 1-Azul, fez conexão com a linha 4-Amarela na estação Luz e desceu na estação Pinheiros, desta mesma linha.

0 protocolo a ser seguido foi o mesmo elaborado para a pesquisa piloto. As observações complementares ocorreram na seguinte ordem: (a) "G." no dia 26/08/2015, quartafeira, das 17h45 às 18h45; (b) "V." no dia 03/09/2015, quinta-feira, das 17h50 às 19h; e (c) “M.” no dia 23/09/2015, quarta-feira, das 17h10 às 18h20.

0 registro dos comportamentos e das falas das observações foi feito por meio de gravações de vídeo de todo o percurso, fotografias e anotações. Os dados obtidos foram transcritos em arquivos de textos e posteriormente organizados, de acordo com as etapas de análise.

\subsubsection{Entrevistas com funcionários e projetistas do metrô}

Para pesquisa com os stakeholders "funcionários do metrô" e "projetistas do metrô" foram realizadas entrevistas semiestruturadas, individuais, presenciais, com pessoaschave que foram identificadas e selecionadas, no período de agosto a outubro de 2015.

Para o quesito "funcionários do metrô", foram selecionados oito profissionais como pessoas-chave: (a) chefe do departamento de segurança operacional; (b) 2 supervisores de estações; (c) coordenador da equipe de monitoração de manifestações em redes sociais; (d) responsável pela monitoração das manifestações nos canais de comunicação 
(exceto redes sociais); (e) responsável pelo treinamento de funcionários para condução de pessoas com deficiências e treinamento de orientação a usuários com deficiência visual; (f) coordenadora de área de pesquisas de atendimento ao cliente; e (g) supervisor do Centro de Controle Operacional.

Para o quesito "projetistas do metrô", identificou-se dois funcionários como pessoaschave para as entrevistas: (a) responsável pela área de projeto civil e arquitetura; e (b) responsável pela área de projeto de sistemas.

Foi realizada uma abordagem prévia via e-mail enviado a cada um deles para informação a respeito dos propósitos da pesquisa e convite para participar. Em seguida foram marcados horário e local das entrevistas por meio de ligação telefônica ou via email.

O conteúdo de cada entrevista foi elaborado, de acordo com Barbosa (2015, p. 133) "abrangendo questões preparadas a partir do perfil, da função, do conhecimento e da experiência dos entrevistados e, consequentemente, da expectativa da resposta sobre os temas abordados". Os roteiros das entrevistas realizadas (APÊNDICES A, B, C, D, E, F, G, $\mathrm{H}, \mathrm{I})$ foram semiestruturados, onde constam perguntas direcionadas de modo que os entrevistados pudessem discorrer e expressar suas experiências, opiniões e reflexões sobre os temas abordados.

As entrevistas foram realizadas individualmente no edifício do Centro de Controle Operacional (CCO) do Metrô de São Paulo. A cada conversa a pesquisadora fazia uma introdução para deixar o entrevistado mais à vontade para falar sobre o assunto foco da entrevista, após o que, pedia licença para gravar a conversa, sempre relembrando a confidencialidade do conteúdo. As entrevistas foram gravadas ou feitas anotações, conforme autorização de cada entrevistado. Posteriormente as gravações e anotações foram transcritas para arquivo de texto. 0 Quadro 4.1 apresenta a relação e o protocolo das entrevistas. 
Quadro 4.1 - Pessoas-chave e temas abordados nas entrevistas.

\begin{tabular}{|c|c|c|}
\hline \multicolumn{3}{|c|}{ Entrevistas individuais presenciais } \\
\hline Pessoas-chave & $\begin{array}{l}\text { Data da } \\
\text { realização }\end{array}$ & Temas abordados \\
\hline \multicolumn{2}{|c|}{ Em comum a todos } & $\begin{array}{l}\text { - Dados pessoais: nome; formação; função } \\
\text { atual; histórico de funções na área de } \\
\text { deficiência visual; tempo de atuação; } \\
\text { - } \text { aspectos a serem melhorados, visando a } \\
\text { possibilidade de que um sistema de } \\
\text { informação e navegação possa suprir parte } \\
\text { das dificuldades existentes; } \\
\text { - características de um possível sistema } \\
\text { eletrônico de informação e navegação. }\end{array}$ \\
\hline $\begin{array}{l}\text { Chefe do departamento de } \\
\text { segurança operacional }\end{array}$ & $\begin{array}{l}\text { 07/08/2015 } \\
\text { Duração aprox.: } \\
1 \mathrm{~h}\end{array}$ & $\begin{array}{l}\text { - ocorrências de furtos e roubos relacionados } \\
\text { a pessoas com deficiência visual; } \\
\text { características do treinamento do corpo de } \\
\text { seguranças. }\end{array}$ \\
\hline $\begin{array}{l}\text { Supervisor de Estações (2 } \\
\text { supervisores) }\end{array}$ & $\begin{array}{l}\text { 07/08/2015 } \\
\text { Duração aprox.: } \\
\text { 50min. } \\
\text { e } \\
\text { 10/08/2015 } \\
\text { Duração aprox.: } \\
1 \mathrm{~h}\end{array}$ & $\begin{array}{l}\text { - aspectos positivos e negativos relacionados } \\
\text { ao deslocamento das pessoas com } \\
\text { deficiência visual, incluindo a avaliação e o } \\
\text { impacto dos fluxos dos demais usuários; } \\
\text { - o preparo dos empregados para auxiliar as } \\
\text { pessoas com deficiência. }\end{array}$ \\
\hline $\begin{array}{l}\text { Coordenador da equipe de } \\
\text { monitoração de } \\
\text { manifestações em redes } \\
\text { sociais }\end{array}$ & $\begin{array}{l}\text { 12/08/2015 } \\
\text { Duração aprox.: } \\
1 \mathrm{~h}\end{array}$ & $\begin{array}{l}\text { - principais solicitações manifestadas nas } \\
\text { redes sociais, a respeito de uso do metrô } \\
\text { por pessoas com deficiência visual; } \\
\text { - aspectos da mobilidade dessas pessoas na } \\
\text { cidade. }\end{array}$ \\
\hline $\begin{array}{l}\text { Responsável pela } \\
\text { monitotação de } \\
\text { manifestações nos canais de } \\
\text { comunicação (exceto redes } \\
\text { sociais) }\end{array}$ & $\begin{array}{l}\text { 13/08/2015 } \\
\text { Duração aprox.: } \\
1 \mathrm{~h}\end{array}$ & $\begin{array}{l}\text { - principais solicitações manifestadas nos } \\
\text { canais de comunicação, a respeito do uso do } \\
\text { metrô por pessoas com deficiência visual. }\end{array}$ \\
\hline $\begin{array}{l}\text { Responsável pelo } \\
\text { treinamento de funcionários } \\
\text { para condução de pessoas } \\
\text { com deficiências e } \\
\text { treinamento de orientação a } \\
\text { usuários com deficiência } \\
\text { visual }\end{array}$ & $\begin{array}{l}\text { 03/09/2015 } \\
\text { Duração aprox.: } \\
1 \mathrm{~h}\end{array}$ & $\begin{array}{l}\text { - dificuldades de uso do metrô pelas pessoas } \\
\text { com deficiência visual; } \\
\text { - dificuldades no treinamento de orientação } \\
\text { nas estações e trens do metrô às pessoas } \\
\text { com deficiência visual; } \\
\text { - dificuldades no preparo dos funcionários } \\
\text { das estações na condução destas pessoas. }\end{array}$ \\
\hline $\begin{array}{l}\text { Responsável pela área de } \\
\text { pesquisas }\end{array}$ & $\begin{array}{l}\text { 13/08/2015 } \\
\text { Duração aprox.: } \\
1 \text { h10 }\end{array}$ & $\begin{array}{l}\text { - principais solicitações manifestadas nas } \\
\text { pesquisas a respeito do uso do metrô por } \\
\text { pessoas com deficiência visual. }\end{array}$ \\
\hline $\begin{array}{l}\text { Supervisor do Centro de } \\
\text { Controle Operacional (CCO) }\end{array}$ & $\begin{array}{l}\text { 25/09/2015 } \\
\text { Duração aprox.: } \\
1 \mathrm{~h}\end{array}$ & $\begin{array}{l}\text { - descrição do serviço de monitoração das } \\
\text { pessoas com deficiência visual; } \\
\text { - } \text { aspectos do serviço de monitoração das } \\
\text { pessoas com deficiência visual, em relação } \\
\text { aos funcionários das estações e aos } \\
\text { funcionários do Centro de Controle. }\end{array}$ \\
\hline
\end{tabular}


(Conclusão)

\begin{tabular}{|c|c|c|}
\hline \multicolumn{3}{|c|}{ Entrevistas individuais presenciais } \\
\hline Pessoas-chave & $\begin{array}{c}\text { Data da } \\
\text { realização }\end{array}$ & Temas abordados \\
\hline $\begin{array}{l}\text { Responsável pela área de } \\
\text { projeto civil e arquitetura }\end{array}$ & $\begin{array}{c}\text { 15/10/2015 } \\
\text { Duração aprox.: } \\
50 \mathrm{~min} .\end{array}$ & $\begin{array}{l}\text { - aspectos civis e arquitetônicos das estações } \\
\text { do metrô: método construtivo, influências, } \\
\text { execução etc.; } \\
\text { - dificuldades para atendimento a normas e } \\
\text { leis de acessibilidade; } \\
\text { - pesquisas que estão sendo realizadas para } \\
\text { melhoria das condições de acessibilidade } \\
\text { das pessoas com deficiência visual. }\end{array}$ \\
\hline $\begin{array}{l}\text { Responsável pela área de } \\
\text { projeto de sistemas }\end{array}$ & $\begin{array}{c}\text { 15/10/2015 } \\
\text { Duração aprox.: } \\
\text { 50min. }\end{array}$ & $\begin{array}{l}\text { - } \text { aspectos construtivos e de leiaute das } \\
\text { diversas frotas de trens, bem como das } \\
\text { razões de se ter tão variada frota; } \\
\text { - dificuldades para atendimento a normas e } \\
\text { leis de acessibilidade; } \\
\text { - } \text { pesquisas que estão sendo realizadas para } \\
\text { melhoria das condições de acessibilidade } \\
\text { das pessoas com deficiência visual. }\end{array}$ \\
\hline
\end{tabular}

As entrevistas encerraram-se sempre que os assuntos se esgotavam. Por se tratar de perguntas abertas, que teoricamente requerem um tempo razoável para as respostas, houve o cuidado de não dispersar a conversa fora de seus objetivos e manter-se dentro do tempo previamente determinado, tendo a maioria a duração aproximada de uma hora, sendo dada a oportunidade e amplo espaço para ouvir as experiências e impressões dos entrevistados. Todos eles demonstraram estar dispostos a passar as informações, tecer comentários e fazer sugestões.

Seguindo orientações de Bauer e Gaskell (2010), ao finalizar cada entrevista fez-se uma consideração positiva a respeito da conversa, demonstrando ter sido de grande valia, agradecendo ao entrevistado e garantindo a ele a confidencialidade das informações. Nas entrevistas gravadas, ao desligar o gravador, era perguntado se ele gostaria de fazer mais alguns comentários agora que o gravador estava desligado - e alguns acabaram por tecer considerações muito importantes, discretamente anotadas pela pesquisadora e consideradas na análise.

\subsubsection{Entrevistas com professores de Orientação e Mobilidade}

Para pesquisa com os stakeholders "professores de Orientação e Mobilidade", em relação ao metrô de São Paulo, foram realizadas entrevistas individuais de 
profundidade, semiestruturadas, com pessoas-chave que foram identificadas e selecionadas, em setembro de 2015.

Foi realizada uma abordagem inicial via e-mail a três professores de treinamento em Orientação e Mobilidade em instituições voltadas para pessoas com deficiência visual, para esclarecimento dos propósitos da pesquisa. Após a anuência de cada um, foi enviado o roteiro de perguntas também via e-mail. Uma professora preferiu responder por escrito e devolver via e-mail. 0 outro professor manifestou-se por escrito, via e-mail, e também de maneira presencial. 0 roteiro de perguntas foi enviado no dia 09/09/2015 e devolvido nos dias 21/09/2015 e 22/09/2015. A entrevista presencial se deu no dia 25/09/2015. 0 terceiro convidado não se manifestou.

O intuito destas entrevistas foi saber a opinião dos professores, sob os aspectos da Orientação e Mobilidade, (a) melhor compreensão das observações realizadas com os usuários em campo; (b) investigação de situações complexas e particulares relacionadas à percepção e orientação das pessoas com deficiência visual; e (c) identificação da possibilidade de contribuição e aspectos a respeito de sistema eletrônico de informação e navegação para a autonomia e segurança de pessoas com deficiência visual ao utilizarem redes de metrô.

0 roteiro das entrevistas realizadas consta do Apêndice J. Os temas foram abordados de acordo com os seguintes módulos: (a) Questões 1 e 2: dados pessoais: nome; formação; função atual; histórico de funções na área de deficiência visual; tempo de atuação; (b) dificuldades na circulação de pessoas com deficiência visual no metrô de São Paulo e em outros metrôs, com sugestões de melhoria; (c) aspectos do treinamento de Orientação e Mobilidade no metrô de São Paulo; e (d) características de um possível sistema eletrônico para informação e navegação em redes de metrôs.

\subsubsection{Entrevista com designers de produtos de ajudas técnicas}

Para pesquisa com os stakeholders "designers de produtos de ajudas técnicas", em relação ao metrô de São Paulo, foi realizada entrevista individual de profundidade, semiestruturada, presencial, com pessoa-chave que foi identificada e selecionada, em setembro de 2015. 
Trata-se de um profissional da área de tecnologia da informação no Metrô de São Paulo, mestrando da Fauusp em "Projeto, processo e linguagens em design", que desenvolve pesquisas de produtos de ajudas técnicas voltados a pessoas com deficiência visual, principalmente para uso em redes de metrôs. Foi realizada uma abordagem inicial por meio de ligação telefônica para esclarecimento dos propósitos da pesquisa. Em seguida foram marcados horário e local da entrevista por meio de ligação telefônica. A entrevista ocorreu em 21/09/2015, das $15 \mathrm{~h}$ às 16h30, no edifício do Centro de Controle Operacional (CCO) do Metrô de São Paulo.

O intuito desta entrevista foi saber deste profissional: (a) o que já foi pensado a respeito de sistemas de informação e navegação para pessoas com deficiência visual; (b) interferências e outras dificuldades relacionadas ao uso desses equipamentos em estações de metrô; (d) no que consiste eventuais sistemas já pesquisados e projetados por ele; (e) resultados de testes práticos; e (f) questões de patentes. 0 roteiro da entrevista realizada consta do Apêndice K.

Os dados obtidos em todas as entrevistas foram transcritos em arquivos de textos e posteriormente organizados, de acordo com as etapas de análise.

\subsubsection{Questionário}

Como parte das investigações realizadas pelo Metrô de São Paulo para dirimir os problemas com a autonomia e segurança dos usuários com deficiência visual, conforme vem sendo relatado neste trabalho, foi preparada pela equipe responsável pelas pesquisas dessa empresa uma pesquisa qualitativa/quantitativa com uma amostra de 67 destes usuários. 0 questionário foi elaborado com a participação da autora desta dissertação, incluindo-se questões com base no que foi descoberto nas observações participantes realizadas neste trabalho.

A empresa Metrô relata que "mesmo com o investimento em acessibilidade, os usuários com deficiência visual reivindicam melhorias nesse processo e no atendimento propriamente dito. $\mathrm{O}$ fato de o Metrô ter sempre prestado um atendimento especial às pessoas com deficiência, gera um nível de exigência bastante elevado por parte destes usuários." (CMSP, 2015d), o que justifica o investimento em melhorias constantes. 
Para a pesquisadora o principal objetivo da aplicação do questionário foi fornecer indicações sobre como a acessibilidade no metrô é sentida pelas pessoas com deficiência visual, com relação ao uso de sistema eletrônico complementar de informação e navegação no ambiente das estações e trens do Metrô de São Paulo. Para tanto, foram inseridas questões a respeito da forma de utilização deste meio de transporte, necessidade de acompanhamento de funcionários, desejo de autonomia, e também sobre a interação desses usuários com equipamentos eletrônicos.

A abordagem dos usuários com deficiência visual para participação na pesquisa foi feita pelos funcionários do Metrô, durante o acompanhamento deste público nas estações das linhas 1-Azul, 2-Verde, 3-Vermelha e 5-Lilás ${ }^{67}$, sendo solicitada sua contribuição para responder à pesquisa, explicando-lhes os objetivos. As pessoas que aceitaram contribuir responderam via telefone, de maneira anônima. Adotou-se esse sistema tendo em vista que a realização das entrevistas pessoalmente nas estações demandaria um tempo bastante longo para a coleta das informações, interferindo no tempo de viagem.

A coleta dos dados ocorreu entre os dias 08/07/2015 e 21/07/2015, feita por uma pesquisadora autônoma especializada em entrevistas em profundidade, com duração média de 30 minutos por entrevista. As respostas foram lançadas no formulário, tomando-se o cuidado para serem anotados os termos exatos utilizados nas respostas às questões abertas.

O teor da análise foi mais qualitativo, apesar de ter sido usado software estatístico para processar principalmente as questões fechadas, relacionadas ao perfil dos entrevistados. Cada questionário recebeu um número de identificação, de 1 a 67. A tabulação dos dados das perguntas abertas consistiu na digitação das respostas e posterior divisão em grupos para efeito de análise e interpretação dos resultados. Depois de concluída a codificação, foi realizado o processamento por meio do software SPSS (Statistical Package for Social Sciences).

O formulário (APÊNDICE V) que serviu de guia para a pesquisa foi formado por 30 questões, distribuídas conforme o Quadro 4.2.

\footnotetext{
${ }^{67}$ A aplicação do Questionário foi realizada somente nas linhas de metrô administradas pela CMSP.
} 
Quadro 4.2 - Temas abordados no questionário.

\begin{tabular}{cl}
\hline Questões & \multicolumn{1}{c}{ Temas abordados } \\
\hline $\mathbf{1}$ a $\mathbf{4}$ & Perfil do usuário: nome, sexo, idade e escolaridade \\
\hline $\mathbf{5}$ a $\mathbf{8}$ & $\begin{array}{l}\text { Interação do usuário com as novas tecnologias eletrônicas (computador, leitores de } \\
\text { tela, internet, smartphones etc.) }\end{array}$ \\
\hline $\mathbf{1 0}$ a $\mathbf{1 2}$ & Informações sobre a frequência e finalidade de uso do metrô \\
\hline $\mathbf{1 3}$ e 14 & Maneira de chegar às estações \\
\hline $\mathbf{1 5}$ a 19 & Maneira de se locomover nas estações \\
\hline $\mathbf{1 9}$ a $\mathbf{2 1}$ & $\begin{array}{l}\text { Avaliação do atendimento dos funcionários e tolerância admissível de espera para ser } \\
\text { acompanhado por funcionário }\end{array}$ \\
\hline $\mathbf{2 2}$ & Sugestões para agilizar sua locomoção nas estações \\
\hline $\mathbf{2 3}$ a $\mathbf{2 5}$ & Opinião sobre a possibilidade atual de locomoção pelas estações e trens \\
\hline $\mathbf{2 6}$ & $\begin{array}{l}\text { Opinião sobre o uso de tecnologias eletrônicas para auxiliar na locomoção } \\
\text { independente }\end{array}$ \\
\hline $\mathbf{2 7}$ & Comparação entre o metrô e outros espaços da cidade com relação à acessibilidade \\
\hline $\mathbf{2 8}$ & Relação de áreas das estações e insegurança \\
\hline $\mathbf{2 9}$ & Diferenças nas dificuldades de uso entre as diversas estações \\
\hline $\mathbf{3 0}$ & Sugestões de melhoria \\
\hline
\end{tabular}

Fonte: Elaborado a partir de questionário do Apêndice V.

\subsection{PESQUISA NO METRÔ DO PORTO}

A pesquisa no metrô do Porto foi realizada no período entre 01 e 05/03/2015, organizada pela equipe do Gabinete de Projetos do Metro do Porto, com o objetivo de conhecer e coletar dados para análise de sistema de informação e navegação denominado Navmetro ${ }^{\circledR}$. Também foi possível observar aspectos da arquitetura das estações, trens, sistema de comunicação visual e sonora, bem como estratégias de operação das linhas.

\subsubsection{Visitas exploratórias}

Para melhor compreender os espaços percorridos pelos usuários do metrô do Porto foram realizadas visitas exploratórias pelas áreas públicas de diversas estações da rede e pelos dois tipos de trens. A primeira visita ocorreu no dia 02/03/2015 no horário da manhã, pelas estações Casa da Música e Estádio do Dragão, onde foram fotografados os 
ambientes públicos e vivenciada a experiência de aquisição de título, validação, familiarização com sistema de informação sobre as linhas, por meio de painel eletrônico nas plataformas, e a viagem propriamente dita.

A segunda visita ocorreu no dia 03/03/2015 no horário da manhã, desta vez por estações da linha D-Amarela, na região de Vila Nova de Gaia, onde as estações são de superfície. Foram visitadas as estações Jardim do Morro, Câmara Gaia, João de Deus e Santo Ovídio, além de acompanhamento de todo o percurso dos trens circulando no mesmo nível de pedestres, automóveis e outros modais de transporte. Ainda no dia 3 de março foram visitados, no período da tarde, os trechos das linhas ao norte da cidade do Porto utilizando-se a linha A-Azul até a estação Senhor de Matosinhos, a linha E-Violeta até a estação Aeroporto e linha B-Vermelha até Póvoa do Varzim.

No dia 05/03/2015 foram visitadas as estações subterrâneas próximas ao centro do Porto, como Aliados, Salgueiros e Trindade, esta última, onde seria realizada a pesquisa de observação. Também foi visitada a estação São Bento, que teve seu projeto elaborado pelo arquiteto português Álvaro Siza, com características de acabamento um pouco diferente das demais.

Os dados obtidos foram transcritos em arquivos de textos e posteriormente organizados, de acordo com as etapas de análise. Foram registradas fotografias de aspectos significativos do percurso.

\subsubsection{Entrevistas}

Mesmo já tendo havido interação por meio de contatos anteriores entre a pesquisadora e a equipe do metrô do Porto, foi durante as entrevistas com esses profissionais que se deu a familiarização com o Navmetro ${ }^{\circledR}$. Foram entrevistados em grupo dois arquitetos que participaram desde o início do desenvolvimento do Navmetro ${ }^{\circledR}$ os quais, com uma base semiestruturada de itens a serem abordados (APÊNDICE L), fizeram relatos que foram gravados, fotografados e foram feitas anotações por escrito. A entrevista foi realizada de forma presencial.

- Data da entrevista: 02/03/2015, das $9 \mathrm{~h} 30$ às $13 \mathrm{~h} 30$, incluindo-se o tempo para demonstração do sistema de informações do Navmetro ${ }^{\circledR}$. 
- Local da entrevista: Gabinete de Projetos do Metrô do Porto - Av. Fernão Magalhães, 1862, 9o piso, Porto, Portugal.

- Temas abordados: 0 sistema Navmetro ${ }^{\circledR}$ : histórico e questões técnicas de seu desenvolvimento, objetivos de sua instalação, como funciona o sistema de informação e o sistema de navegação, painel atual de sua utilização e perspectivas para o futuro.

Entrevistou-se também o professor da Faculdade de Engenharia da Universidade do Porto - FEUP, responsável pela proposta e desenvolvimento do Navmetro ${ }^{\circledR}$, com uma base semiestruturada de itens a serem abordados (APÊNDICE M). A entrevista foi realizada de forma presencial.

- Data da entrevista: 04/03/2015, das 9h30 às $12 \mathrm{~h} 30$.

- Local da entrevista: Gabinete de Projetos do Metrô do Porto - Av. Fernão Magalhães, 1862, 9o piso, Porto, Portugal.

- Temas abordados: 0 sistema Navmetro ${ }^{\circledR}$ : histórico e desenvolvimento do projeto, inconvenientes e pontos de melhoria.

Os dados obtidos em todas as entrevistas foram transcritos em arquivos de textos e posteriormente organizados, de acordo com as etapas de análise.

\subsubsection{Observação}

A pesquisa de campo foi realizada na estação Trindade, por meio de observação participante, pública, sistemática, em uma situação natural, no dia 06/03/2015, das 10h às 13h. Por intermédio da ACAPO - Associação de Cegos e Amblíopes de Portugal foi convidado um usuário cadastrado no serviço Navmetro ${ }^{\circledR}$, que está habituado utilizar o metrô e o Navmetro ${ }^{\circledR}$, aqui denominado “F.”.

A estação Trindade é a maior do metrô do Porto, por onde passam as seis linhas, possuindo dois níveis de via férrea: o superior, por onde passam as linhas A, B, C, E e F, e um inferior, por onde passa a linha D. Entre esses dois níveis existe um piso intermediário, de distribuição. Todas as plataformas são laterais às vias.

Foi combinado que "F." realizaria um percurso desde o acesso da estação Trindade até uma de suas plataformas da linha D utilizando o Navmetro ${ }^{\circledR}$, sem auxílio ou intervenção 
de terceiros, de maneira a se comportar o mais natural possível, como está acostumado. Depois de simular um embarque no trem seria feito o percurso inverso, da plataforma até a saída da estação. Como o Navmetro ${ }^{\circledR}$ não é utilizado nos trens, houve somente observação na estação.

"F." foi informado de que seria observado e filmado durante seu percurso, e que sua identidade seria preservada, expondo-se somente observações relevantes de seu comportamento que pudessem ser motivo de análise, visando melhorar a mobilidade de pessoas com deficiência visual.

Foram feitos registros por meio de gravações de vídeo de todo o percurso, fotografias e anotações por escrito. Além da observação em si, durante o trajeto, "F." foi fazendo depoimentos espontâneos, eventuais, sobre suas compreensões e/ou dificuldades com o sistema Navmetro ${ }^{\circledR}$ e percepções do ambiente.

Logo em seguida à observação de "F.", a pesquisadora submeteu-se a uma experiência de utilizar o sistema Navmetro ${ }^{\circledR}$. O professor Diamantino ofereceu-lhe um telefone celular local, e foram seguidos todos os passos da simulação anterior, na estação Trindade. Durante o teste prático a pesquisadora teve a oportunidade de coletar dados complementares para a análise do sistema Navmetro ${ }^{\circledR}$.

Os dados obtidos foram transcritos em arquivos de textos e posteriormente organizados, de acordo com as etapas de análise. Foram elaborados mapas sintéticos com localização espacial e fotografias de eventos significativos do percurso.

\subsection{TERMOS DE AUTORIZAÇÃO}

Considerando-se os aspectos éticos, elaborou-se um Termo de Consentimento Livre e Esclarecido - TCLE (APÊNCIDE N), bem como um Termo de Autorização de Uso de Imagem e Depoimentos (APÊNDICE O), relativos à autorização das pessoas com deficiência visual que participaram das observações durante uma viagem utilizando o metrô, tanto para as pesquisas realizadas no metrô de São Paulo, como no metrô do Porto. 
O TCLE elaborado contempla informações sobre a pesquisadora e a pesquisa. Foi informado que não seria necessária nenhuma alteração em sua rotina de uso do metrô e que, portanto, seria a pesquisadora que iria até ele, na estação e no horário por ele utilizado e iria acompanhá-lo, procurando interferir o mínimo possível, para poder identificar informações referentes à sua percepção espacial e sua relação com o ambiente e com os demais usuários durante esse percurso.

Foi ressaltado no TCLE que a pesquisa não apresentaria riscos, pois não haveria interferência à sua rotina, no entanto, ao consentir em sua participação neste estudo, ele teria a liberdade de se recusar a fazer quaisquer partes da pesquisa, assim como também encerrar sua participação, sem qualquer prejuízo. 0 termo também esclarece que, pela sua participação neste estudo, ele não teria nenhuma despesa, bem como nada seria pago pela sua participação.

O termo de autorização de uso das imagens feitas durante a observação foi necessário porque se evidenciou que os rostos dos participantes não poderiam ser descaracterizados para não se perder importantes informações transmitidas por suas expressões faciais. Este termo esclarecia que o uso de suas imagens e depoimentos seriam utilizados somente para fins científicos e de estudos (livros, artigos, slides) em favor da pesquisadora, obedecendo ao que está previsto nas Leis que resguardam os direitos das pessoas com deficiência, como o Decreto № 3.298/1999, alterado pelo Decreto № 5.296/2004 (BRASIL, 2004).

Devido à deficiência visual dos participantes, adotou-se como estratégia para garantir a leitura e a segurança na hora de assinar os termos, o envio por e-mail destes em forma de arquivo de texto, que poderia ser lido utilizando-se um leitor de tela de computador. Em seguida, se estivesse de acordo, ele deveria imprimir os termos e assiná-los, entregando-os à pesquisadora no momento da pesquisa. 0 e-mail enviado aos participantes, informando-os quanto ao teor da pesquisa consta do Apêndice P. 


\subsection{ANÁLISE E INTERPRETAÇÃO}

$\mathrm{Na}$ análise e interpretação realizadas neste trabalho procurou-se estabelecer relações entre os dados obtidos em campo, os objetivos da pesquisa e o embasamento teórico realizado na revisão da literatura, realizando-se um ir e vir sucessivo entre essas partes.

Para a análise dos resultados obtidos utilizou-se, de acordo com Angrosino (2009): (a) análise descritiva e (b) análise teórica (análise de conteúdo; análise da conversação e da fala; análise do discurso).

A análise descritiva foi feita com a leitura sistemática dos dados para buscar por padrões, regularidades ou temas emergentes dos dados (ANGROSINO, 2009) que pudessem ser organizados em categorias para a análise. Os padrões compartilhados entre os observados foram sistematizados.

Neste trabalho, a análise de conteúdo se deu pela leitura das falas, realizada por meio das transcrições de entrevistas, depoimentos e protocolos de observação, transformadas em textos. Este material foi resumido após tratamento e classificação. As inferências ${ }^{68}$ serviram para a interpretação final. De acordo com Bardin $(1979$, p. 81): "É certo que o gênero de resultados obtidos pelas técnicas de análise de conteúdo não pode ser tomado como prova inelutável. Mas constitui, apesar de tudo, uma ilustração que permite corroborar, pelo menos parcialmente, os pressupostos em causa.".

Primeiramente foi feita uma leitura flutuante, até que começasse a emergir os contornos de suas primeiras unidades de sentido, conforme indicado por Gerhardt e Silveira (2009), guiando a pesquisadora na busca das informações contidas no texto. Este procedimento controlou a sua própria subjetividade para, na sequência, efetuar-se a organização, sistematização, objetividade e generalização dos resultados obtidos, conforme proposto por Gerhardt e Silveira (2009). Procedimento semelhante foi aplicado às imagens em movimento, de acordo com Rose (2010), de maneira a contribuir na categorização dos resultados.

68 Inferência é a "operação lógica, pela qual se admite uma proposição em virtude da sua ligação com outras proposições já aceites como verdadeiras” (BARDIN, 1979, p.39). 
Devido à tendência negativa da análise de conteúdo focalizar somente a frequência e perder outros dados importantes, durante todo o processo houve cuidado para não se descuidar do que é raro e ausente, conforme alertado por Bauer (2010).

A análise da conversação e da fala foi aplicada na análise formal de situações cotidianas, manifestações espontâneas. Foi realizada com base em Flick (2009b, p.300), iniciando-se com a investigação de como determinadas conversações/interações foram iniciadas e encerradas; procedeu-se sequencialmente, onde nada do que foi dito depois foi utilizado para explicar algo que veio antes; analisou-se somente em relação ao contexto local no qual a interação foi produzida.

A análise do discurso foi utilizada tanto nas conversas cotidianas, mas principalmente nos dados das entrevistas. Considerou-se o contexto interpretativo pois, como alertado por Gill (2010), todo discurso é circunstancial.

Para análise das entrevistas realizadas foram utilizados procedimentos que levaram a relacionar estruturas semânticas (significantes) com estruturas sociológicas (significados) dos discursos com fatores psicossociais, contexto cultural e processos de produção de mensagem. Esse conjunto analítico visou a dar consistência interna às operações, conforme recomenda Minayo (2014).

Durante as entrevistas foi possível perceber nitidamente o que é mencionado por Minayo (2014, p. 262), onde a autora diz que a entrevista fornece informações que tratam da reflexão do próprio sujeito sobre a realidade que vivencia, constituindo-se de “ideias, crenças, maneira de pensar; opiniões, sentimentos, maneiras de sentir; maneiras de atuar; condutas; projeções para o futuro; razões conscientes ou inconscientes de determinadas atitudes e comportamentos".

Com relação aos dados obtidos com a aplicação do questionário, para efeito de análise e interpretação dos resultados dividiu-se a amostra de 67 pessoas com deficiência em três grupos, referentes à maneira de circular pelas estações e trens do metrô: (a) o grupo que não quer ser autônomo; (b) o grupo que deseja ser autônomo; e (c) o grupo que é autônomo. Os dados foram cruzados pelo grau de deficiência visual que a pessoa apresenta. 


\section{RESULTADOS}

Este capítulo apresenta os resultados das pesquisas de campo que foram aplicadas e as considerações feitas durante a análise e interpretação dos dados obtidos, de acordo com a metodologia explicitada no capítulo sobre os métodos.

\subsection{OBSERVAÇÕES PARTICIPANTES NO METRÔ DE SÃO PAULO}

Neste estudo foram sistematizados os padrões reconhecidos considerando-se as declarações e as observações dos participantes das pesquisas. Para os padrões relativos às declarações feitas pelas pessoas observadas, considerou-se se foram feitas espontaneamente ou obtidas por meio da condução em uma entrevista, assim como se essas declarações foram feitas em público ou em particular à pesquisadora. Para os padrões relativos às observações das atividades considerou-se se aconteceram em grupo ou individualmente, assim como se as atitudes foram espontâneas ou provocadas. Essas considerações foram importantes para a análise dos dados obtidos com as observações, pois:

Em geral, as declarações e as ações públicas têm maior probabilidade de refletir o comportamento ideal do grupo do que as de caráter privado. As declarações e as atividades que ocorrem espontaneamente ou que são dadas voluntariamente pelas pessoas na comunidade têm maior probabilidade de ser partes de um modelo compartilhado do que aquelas provocadas pelo pesquisador. (ANGROSINO, 2009, p. 90)

\subsubsection{Protocolo de observação}

O protocolo de observação a ser seguido pela pesquisadora durante as observações foi estabelecido de acordo com o exposto na seção 4.3, organizado no Quadro 5.1. 
Quadro 5.1 - Protocolo de observação.

\begin{tabular}{|c|c|}
\hline \multicolumn{2}{|r|}{ Protocolo de observação } \\
\hline \multicolumn{2}{|r|}{ Usuário com deficiência visual } \\
\hline $\begin{array}{l}\text { Entrevista aberta, de } \\
\text { caráter informal, } \\
\text { realizada como preparo } \\
\text { para observação } \\
\text { participante }\end{array}$ & $\begin{array}{l}\text { (Utilizar somente para as observações participantes) } \\
\text { Grau da deficiência. Congênita ou não. } \\
\text { Recebeu treinamento de Orientação e Mobilidade? } \\
\text { Motivo e frequência de uso do metrô. } \\
\text { Há quanto tempo utiliza o metrô. } \\
\text { Utiliza auxílio de um funcionário? Por quê? }\end{array}$ \\
\hline $\begin{array}{l}\text { Local de partida da } \\
\text { observação }\end{array}$ & $\begin{array}{l}\text { Data, horário, local; descrição sucinta da entrada da estação, fluxo de pessoas; } \\
\text { a pessoa observada chegou sozinha ou acompanhada, entrou na estação } \\
\text { sozinha ou acompanhada. }\end{array}$ \\
\hline $\begin{array}{l}\text { Caracterização da } \\
\text { pessoa observada }\end{array}$ & $\begin{array}{l}\text { Utiliza bengala, de que tipo, segura a bengala com qual das mãos; porta itens } \\
\text { tais como bolsa, mochila; segura algo nas mãos (além da bengala). }\end{array}$ \\
\hline $\begin{array}{l}\text { O percurso na estação } \\
\text { de entrada }\end{array}$ & $\begin{array}{l}\text { Deslocamento passo a passo, desde a entrada até a espera pelo trem; uso de } \\
\text { piso tátil, escadas, elevadores; recebeu auxílio de pessoas; ocorrência da } \\
\text { estratégia de embarque preferencial }{ }^{69} \text {; fatos e ocorrências, como por exemplo, } \\
\text { esbarrar em objetos ou pessoas; se busca referências no ambiente, físicas, } \\
\text { visuais, sonoras ou outras. }\end{array}$ \\
\hline A viagem no trem & $\begin{array}{l}\text { Entra sozinho ou alguém o acompanha; trem cheio ou vazio; uso de assentos; } \\
\text { auxílio; o que faz e ocorre até desembarcar do trem. }\end{array}$ \\
\hline $\begin{array}{l}\text { O percurso de conexão } \\
\text { (quando houver) }\end{array}$ & $\begin{array}{l}\text { Deslocamento passo a passo desde o desembarque do primeiro trem até o } \\
\text { local de espera do próximo trem. }\end{array}$ \\
\hline $\begin{array}{l}\text { A viagem no segundo } \\
\text { trem (quando houver) }\end{array}$ & Idem ao primeiro trem. \\
\hline $\begin{array}{l}\text { O percurso na estação } \\
\text { de destino }\end{array}$ & $\begin{array}{l}\text { Deslocamento passo a passo desde o desembarque do trem até a saída para a } \\
\text { rua ou conexão com outro modal; para onde se dirige; segue sozinho ou } \\
\text { acompanhado. }\end{array}$ \\
\hline Tempo & $\begin{array}{l}\text { Tempo físico ao percorrer cada fase da observação: entrada estação / } \\
\text { embarque trem; trajeto do trem; conexão (quando houver); saída. }\end{array}$ \\
\hline $\begin{array}{l}\text { Sentimentos e } \\
\text { impressões }\end{array}$ & $\begin{array}{l}\text { Registro de emoções ou referências manifestadas: tranquilidade, pressa, } \\
\text { irritabilidade, segurança, confiança etc. }\end{array}$ \\
\hline Outras observações & Ocorrências relevantes \\
\hline $\begin{array}{l}\text { Entrevista } \\
\text { semiestruturada } \\
\text { realizada no final da } \\
\text { observação } \\
\text { participante }\end{array}$ & $\begin{array}{l}\text { Quais os locais das estações que você se sente mais inseguro? } \\
\text { Você utiliza smartphone? } \\
\text { Você acessa à Internet? } \\
\text { Que tecnologias/equipamentos poderiam ajudar os usuários com deficiência } \\
\text { visual a se deslocar de forma independente no metrô? } \\
\text { Gostaria de fazer alguma sugestão para melhorar o serviço do metrô para } \\
\text { pessoas com deficiência visual? }\end{array}$ \\
\hline \multicolumn{2}{|r|}{ Demais usuários } \\
\hline Comportamento & $\begin{array}{l}\text { Interferências no caminhar do usuário com deficiência; procuram auxiliar; } \\
\text { atrapalham. }\end{array}$ \\
\hline
\end{tabular}

${ }^{69}$ Estratégia de embarque ou desembarque preferencial (ocorre no metrô de São Paulo): local sinalizado e controlado nas plataformas, na região do primeiro carro, de determinadas estações, em horários de maior demanda de usuários. (Fonte: Metrô Boa Viagem - Disponível em <http://metro.sp.gov.br> Acesso em 14 abr. 2015.) (CMSP, 2015). 


\subsubsection{Características das pessoas observadas}

\section{a) “R."}

Sexo masculino, 50 anos, arquiteto que foi adquirindo a cegueira aos poucos, após os 36 anos, até ficar totalmente cego aos 41 anos. Não teve treinamento em orientação e mobilidade, não conhece Braille, mas caminha de maneira autônoma, por diversas regiões da cidade. Sempre morou em São Paulo. A escolha se deu devido ao fato de que "R." é um usuário frequente do metrô, assim como de outros modos de transporte público.

\section{b) "I."}

Sexo feminino, 30 anos, jornalista, cega congênita que consegue perceber clarões. Recebeu treinamento em orientação e mobilidade na infância, domina o Braille, mas não caminha de maneira totalmente independente, não utiliza piso tátil e não reconhece as diferenças entre piso tátil de alerta e piso tátil direcional. Mesmo assim vai ao trabalho e frequenta cursos sozinha, contando com a ajuda de funcionários das empresas de transporte ou transeuntes. Nasceu e morou em uma cidade do interior paulista, tendo se mudado para São Paulo depois de formada. A escolha se deu pelo fato de que "I." também é usuária frequente do metrô e possui características diferentes de "R." com relação à deficiência (um já enxergou, o outro não) e com relação à forma como ambos se relacionam com o ambiente público (utilização ou não de pisos táteis, autonomia, utilização do sistema Braille, treinamento).

\section{c) "X"}

Sexo masculino, aproximadamente 25 anos, dados desconhecidos por ter sido feita observação não-participante, sem nenhuma abordagem.

\section{d) “G."}

Sexo masculino, 29 anos, analista de sistemas, cego congênito. Teve treinamento de orientação e mobilidade, domina o Braille, e utiliza cão-guia há três anos. "G." foi selecionado por utilizar a rede de metrô com auxílio de seu cão-guia diariamente para ir trabalhar e eventualmente para lazer e estudos; eles costumam servir de voluntários para pesquisas e campanhas publicitárias de divulgação de uso do cão-guia, e até foi criada uma página em uma rede social para contribuir com essa divulgação. A escolha de pessoa que faz uso do cão-guia foi muito importante para se compreender quais as 
necessidades destes usuários e possível utilidade de um sistema eletrônico de navegação a eles.

e) "V."

Sexo feminino, 36 anos, começou a perder a visão aos sete anos, até chegar ao ponto de conseguir perceber somente clarões, aos 19 anos. Depois disso interessou-se em aprender o Braille, fez faculdade de letras e pós-graduação em marketing e comunicação. Atualmente exerce funções administrativas no trabalho, buscando promover a acessibilidade em estabelecimentos comerciais. "V." foi uma das pessoas que participaram de um movimento para pedir ao Metrô mais segurança, após um acidente com um colega que também era deficiente visual; ela utiliza o metrô diariamente para ir trabalhar e frequentemente para estudar e a lazer.

\section{f) “M.”}

Sexo masculino, 44 anos, possui baixa visão congênita. "M." fez faculdade de letras e atualmente trabalha como programador de PABX (telefonia). Ele utiliza o metrô do trabalho para casa todos os dias, e é usuário habitual há tempos, desde muito jovem. É um aficionado pelo tema metrô, e procura estudar e se informar a respeito de seu funcionamento, construção e demais informações.

\subsubsection{Percursos realizados}

A Tabela 5.1 apresenta dados dos percursos realizados durante as observações de campo, conforme seção 4.3. 
Tabela 5.1 - Atividades de campo - observações.

\begin{tabular}{cccccc}
\hline $\begin{array}{c}\text { Pessoa } \\
\text { observada }\end{array}$ & $\begin{array}{c}\text { Horário início } \\
\text { da observação }\end{array}$ & $\begin{array}{c}\text { Estação de } \\
\text { entrada }\end{array}$ & $\begin{array}{c}\text { Estação de } \\
\text { conexão }\end{array}$ & $\begin{array}{c}\text { Estação de } \\
\text { saída }\end{array}$ & $\begin{array}{c}\text { Horário final } \\
\text { da observação }\end{array}$ \\
\hline “R." & $16 \mathrm{~h} 00$ & Artur Alvim & Não houve & Tatuapé & $18 \mathrm{~h} 00$ \\
\hline “I." & $17 \mathrm{~h} 00$ & Vergueiro & Sé & $\begin{array}{c}\text { Marechal } \\
\text { Deodoro }\end{array}$ & $18 \mathrm{~h} 15$ \\
\hline "X" & $18 \mathrm{~h} 00$ & $\begin{array}{c}\text { Marechal } \\
\text { Deodoro }\end{array}$ & Não houve & Artur Alvim & $19 \mathrm{~h} 15$ \\
\hline “G." & $17 \mathrm{~h} 45$ & Pedro II & Não houve & $\begin{array}{c}\text { Palmeiras- } \\
\text { Barra Funda }\end{array}$ & $18 \mathrm{~h} 45$ \\
\hline "V." & $17 \mathrm{~h} 50$ & $\begin{array}{c}\text { Fradique } \\
\text { Coutinho }\end{array}$ & República & Vila Matilde & $19 \mathrm{~h} 00$ \\
\hline “M." & $17 \mathrm{~h} 10$ & São Bento & Luz & Pinheiros & $18 \mathrm{~h} 20$ \\
\hline
\end{tabular}

Fonte: Elaborado a partir dos registros de campo.

\subsubsection{Características das estações}

O Apêndice Q apresenta as características e serviços relevantes para este estudo, das 13 estações utilizadas nas observações de campo.

\subsubsection{Características dos trens}

Foram utilizados trens (material rodante) de diferentes modelos durante os percursos das pessoas com deficiência visual observadas na pesquisa. Apesar das semelhanças entre os modelos, os trens que circulam pela rede do metrô de São Paulo apresentam diferenças de localização e dimensionamento de assentos, barras e apoios de mão horizontais e verticais dificultando sua compreensão pelos usuários com deficiência visual (APÊNDICE R). Devido a necessidades operacionais e de manutenção, diferentes modelos circulam em uma mesma linha, de forma que o usuário não consegue estabelecer um padrão para uso dos trens.

\subsubsection{Registros dos comportamentos e falas nas observações}

Foram elaboradas as sínteses das observações realizadas com essas pessoas, e que constam do Apêndice S. De acordo com Cohen (2006, p. 3) "partiu-se da hipótese que as características físicas dos ambientes urbanos ou suas affordances influenciam nas 
competências motoras, nas sensações e na habilidade de lidar com o meio, condicionando ou reforçando a deficiência." Essas sínteses relatam não somente destaques do que foi observado à luz do objetivo "investigar as formas como as pessoas com deficiência visual utilizam e interagem em seus percursos por estações e trens de metrô", mas também pontos de melhorias que possam ser realizadas por sistemas eletrônicos de informação e navegação, conforme vem sendo estudado.

\subsubsection{Categorias identificadas nas observações}

Identificou-se cinco categorias entre as pessoas observadas, detalhadas nos Quadros 5.2 a 5.6 e Figuras 5.1 a 5.8:

a) maneira de encontrar o acesso à estação;

b) maneira de caminhar dentro da estação;

c) maneira de caminhar na plataforma e de embarcar/desembarcar do trem;

d) comportamento dentro do trem;

e) interferência dos demais usuários.

Quadro 5.2 - Maneira de encontrar o acesso à estação.

\begin{tabular}{cl}
\hline & \multicolumn{1}{c}{ Categoria (a): Maneira de encontrar o acesso à estação } \\
\hline “R." & $\begin{array}{l}\text { Depois de descer sozinho da van, "R.", utilizando sua bengala orienta-se pela } \\
\text { mureta, em direção ao acesso da estação Artur Alvim. (Figura 5.1a) }\end{array}$ \\
\hline “I." & $\begin{array}{l}\text { "I." caminha pela rua Vergueiro sozinha, utilizando sua bengala, orientando-se } \\
\text { pela mureta do Centro Cultural São Paulo, que fica próximo ao seu local de } \\
\text { trabalho. Ao chegar à estação Vergueiro existem grandes contêineres de coleta } \\
\text { seletiva de lixo próximo à entrada, e ela os utiliza como referência. (Figura 5.1b) }\end{array}$ \\
\hline "X" & $\begin{array}{l}\text { "X" chegou à estação sozinho, caminhando pela calçada de um dos acessos da } \\
\text { estação Marechal Deodoro. Ele utiliza sua bengala e caminha rapidamente, } \\
\text { orientando-se pelos muros e edifícios. Ao chegar à frente da estação existe um } \\
\text { recuo que ele percebe com a bengala, seguindo diretamente para a porta. }\end{array}$ \\
\hline “G." $\quad \begin{array}{l}\text { "G." chegou à estação Pedro II com seu cão-guia Julia, pela rampa de conexão do } \\
\text { Expresso Tiradentes. Julia o conduz ao acesso do metrô, levando-o diretamente } \\
\text { para os bloqueios (catracas). }\end{array}$ \\
$\begin{array}{l}\text { "V." chegou à estação Fradique Coutinho acompanhada de uma colega de } \\
\text { trabalho. Ela informou que sempre pede que colegas de trabalho a acompanhem } \\
\text { até a estação porque no caminho existem muitas interferências que a } \\
\text { atrapalham. (Figura 5.1c) }\end{array}$ \\
$\begin{array}{l}\text { "M." chegou sozinho à estação São Bento, utilizando sua bengala. Ele caminha } \\
\text { rapidamente e localiza o acesso facilmente. (Figura 5.1d) }\end{array}$ \\
\hline “M."
\end{tabular}


Figura 5.1 - Maneira de encontrar o acesso à estação.

(a) - "R."

(b) - "I."

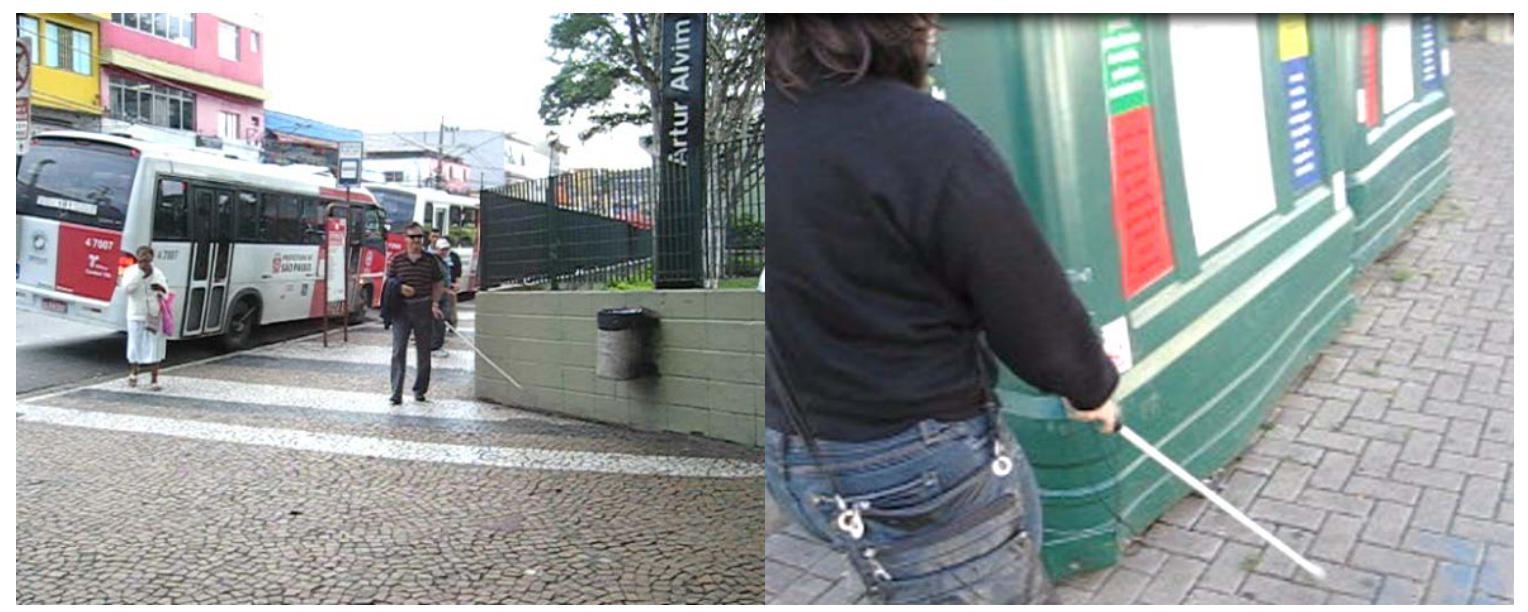

Crédito - MARIANI, E., 2013.

Crédito - MARIANI, E., 2013.

(c) - "V."

(d) - "M."

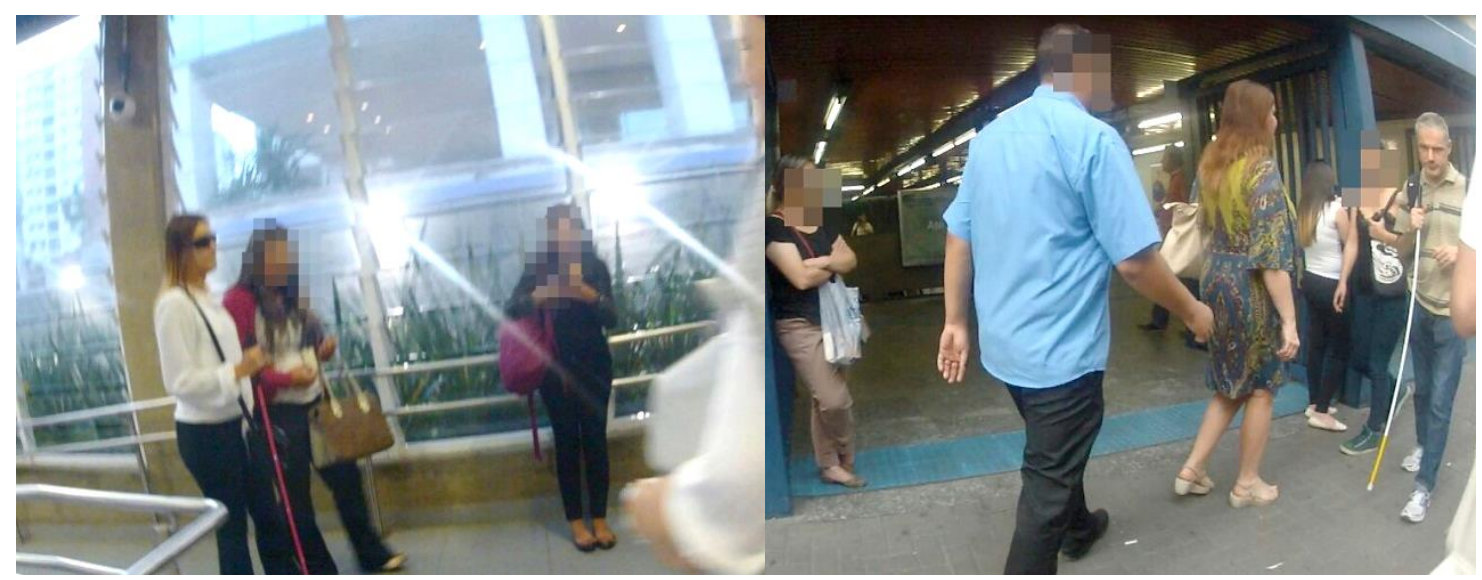

Crédito - SILVA FILHO, J., 2015.

Crédito - SILVA FILHO, J., 2015. 
Quadro 5.3 - Maneira de caminhar dentro da estação.

\section{Categoria (b): Maneira de caminhar dentro da estação}

“R." "R." utiliza e demonstra conhecer a sinalização com pisos táteis. Não quer o auxílio oferecido pelos funcionários do metrô nas estações que já conhece. (Figura 5.2a)

“I." I." não utiliza os pisos táteis e geralmente pede auxílio a um funcionário para ser conduzida para embarque e desembarque. Ela afirma que não consegue perceber a diferença entre as texturas dos pisos com a bengala. Mas admite que são úteis a muitas pessoas com deficiência visual. (Figura 5.2b) Ela também afirma que prefere as escadas rolantes por se sentir mais segura, com os dois pés fixados, sem pessoas a empurrá-la. Esta declaração foi totalmente nova para a pesquisadora, que sempre teve a informação de que a preferência pelas escadas rolantes às escadas fixas seria pelo conforto.

"X" $\quad$ Durante o percurso entre a porta da estação e as catracas "X" não utiliza o piso tátil. Ao chegar às catracas existem várias filas formadas para entrar, e " $\mathrm{X}$ " é auxiliado por um usuário comum, que o conduz a um funcionário do metrô. A partir deste ponto não foi possível se avaliar se ele teria utilizado o piso tátil (lembrando tratar-se da única observação secreta). (Figura 5.2c)

"G." G." é guiado o tempo todo pelo cão-guia Julia, que obedece aos seus comandos. A cada etapa do percurso, "G." entrega uma recompensa à Julia, em forma de biscoitos caninos. (Figura $5.2 \mathrm{~d}$ )

"V." $\quad$ "V." realiza todo o percurso com o auxílio de uma colega de trabalho ou um funcionário da estação. Ela utiliza sempre os elevadores. No entanto, ela afirma que, na ausência de funcionário, ela "dá um jeito" de se deslocar na estação. (Figura 5.2e)

"M." "M." tem baixa visão e é autônomo, nunca pede auxílio aos funcionários do metrô. Ele só utiliza o piso tátil nos trechos onde o percurso é mais direto, onde "dá menos voltas", e em estações que não conhece. (Figura 5.2f) 
Figura 5.2 - Maneira de caminhar dentro da estação.

(a) - "R." utiliza o piso tátil e elevador.

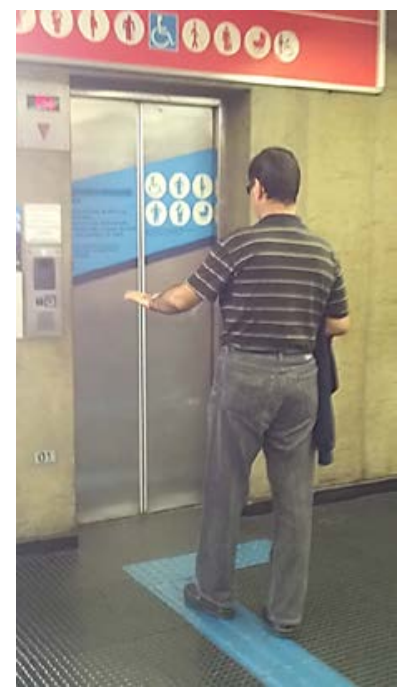

Crédito: MARIANI, E., 2013.

(c) - "X" pede auxílio a um funcionário.

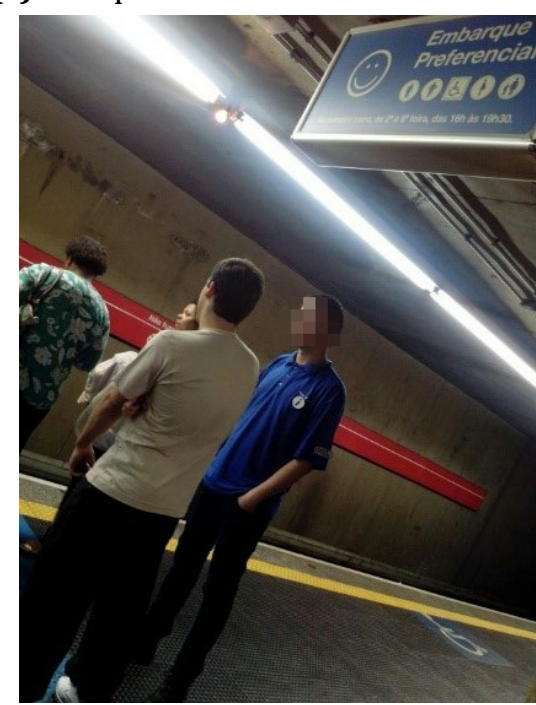

Crédito: DUTRA, D. N. M., 2013.

(e) - "V." pede auxílio a um funcionário ou colega de trabalho.

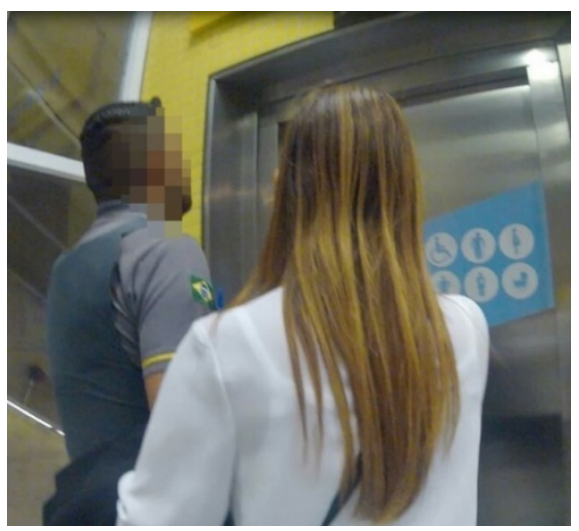

Crédito: SILVA FILHO, J., 2015. (b) - "I." prefere ser acompanhada por um funcionário ou amigo, e prefere as escadas rolantes.

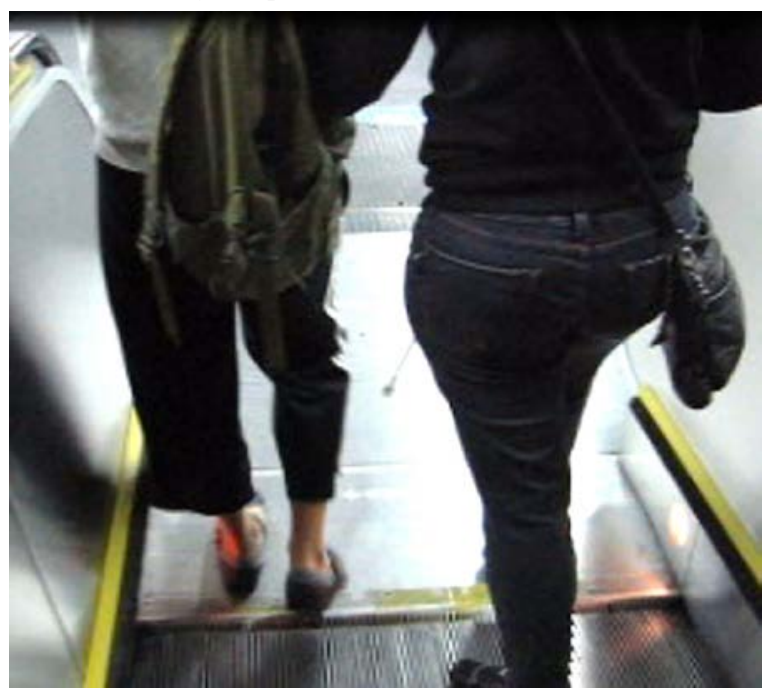

Crédito: MARIANI, E., 2013.

(d) - G." utiliza um cão-guia.

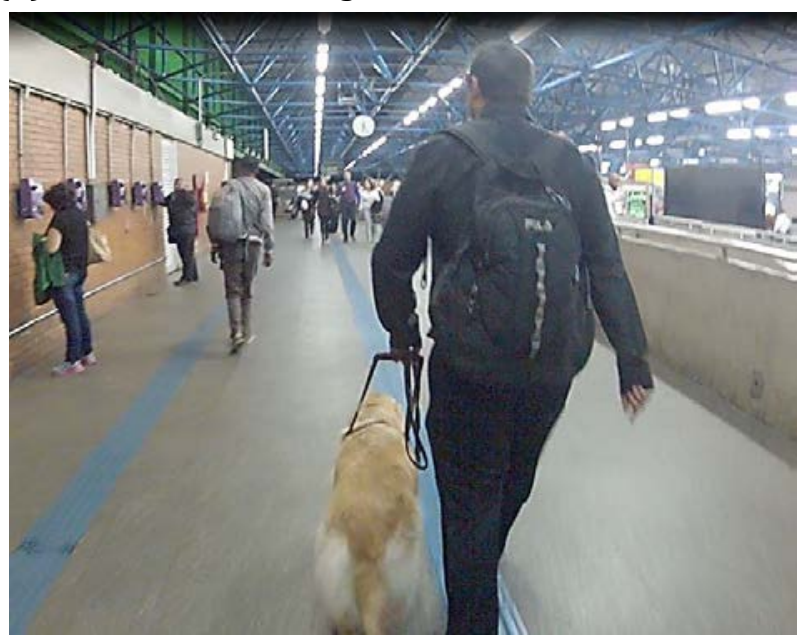

Crédito: SILVA FILHO, J., 2015.

(f) - "M." é autônomo e utiliza o piso tátil somente em alguns trechos.

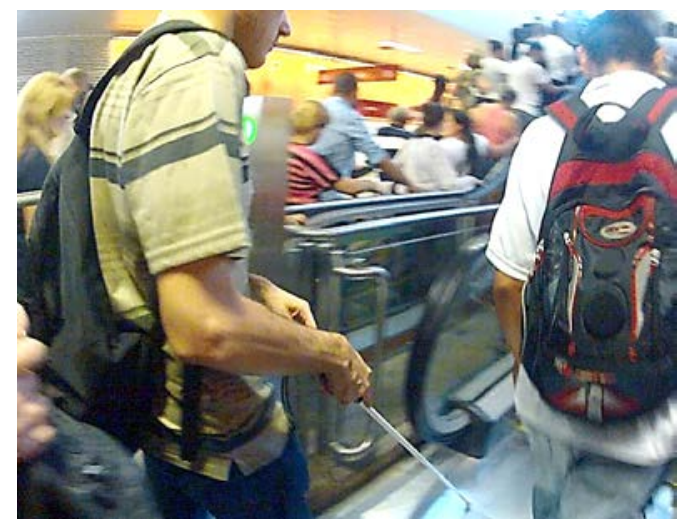

Crédito: SILVA FILHO, J., 2015. 
Destaque para a maneira de ocupar as mãos (Figura 5.3): chegando ao bloqueio, "I." apoia sua bengala com sua mão direita (a) e na sequência apoia sob o braço direito enquanto abre a bolsa para retirada do título a ser validado (b); em seguida procura o validador com a mão esquerda enquanto encosta o cartão no local de validação com a mão direita, em uma evidente ocupação frequente das mãos, dado importante para projeto de qualquer sistema que utilize dispositivo portátil para comunicação com o usuário.

Figura 5.3 - Sequência de ocupação das mãos para validação de título no bloqueio.
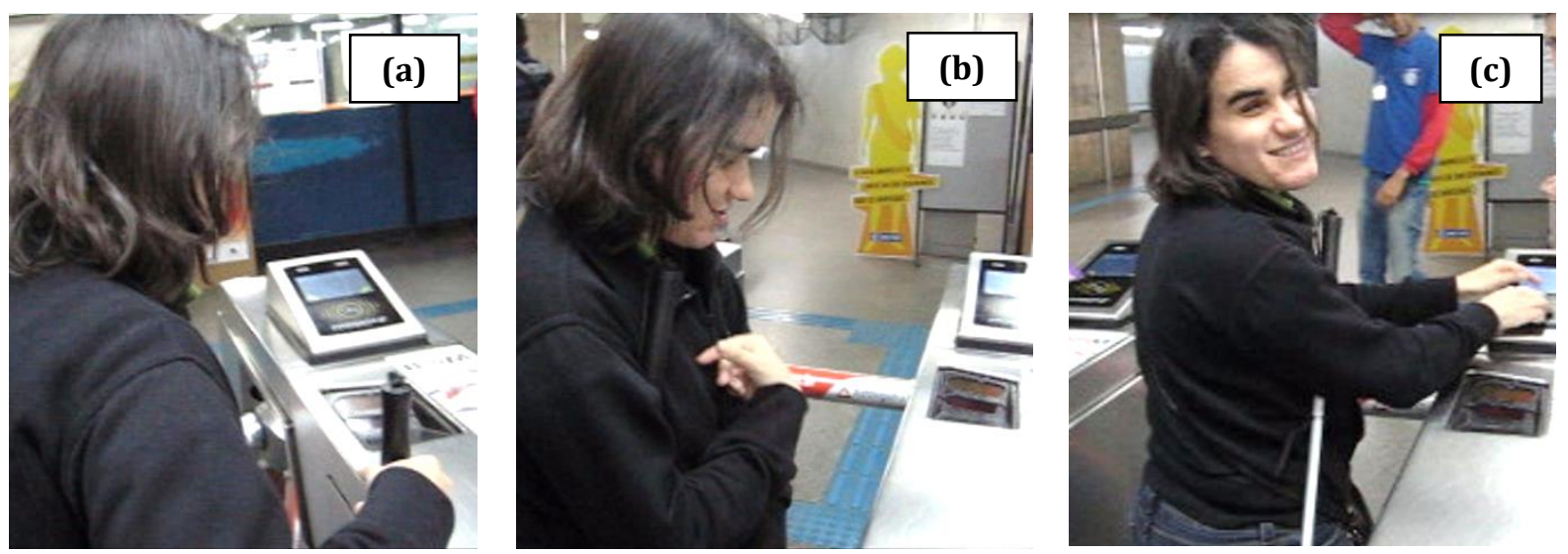

Crédito: MARIANI, E., 2013. 
Quadro 5.4 - Maneira de caminhar na plataforma e embarcar/desembarcar do trem.

\section{Categoria (c): Maneira de caminhar na plataforma e embarcar/desembarcar do trem}

“R." $\quad$ "R." caminha tranquilo pela plataforma, mas ao ouvir a chegada do trem, ele para e vira-se de frente para o fluxo, permanecendo parado até que a plataforma esvazie. Quando o próximo trem chega, ele já não para, pois sabe que está no contra fluxo e dessa forma é visível para as pessoas, que desviam dele. E conta que sabe de que lado vêm as pessoas porque "os primeiros vêm gritando". (Figura 5.4a)

“I." I." pede o acompanhamento de um funcionário para caminhar na plataforma, pois afirma ter muito medo de que alguém apressado a empurre. (Figura 5.4b)

"X" "X" utilizou o acompanhamento de um funcionário, mas durante todo este percurso pareceu tranquilo, seguro, inclusive utilizando o telefone celular para efetuar uma chamada de voz.

"G." "G." é guiado pela plataforma por Julia, seu cão-guia, até o ponto em que foi treinado para aguardar o trem. Ao chegar a este ponto, afastado aproximadamente um metro da borda, Julia para na frente de "G." e o impede de continuar, mantendo-o seguro de cair na via. Ao chegar o trem, Julia o conduz para o embarque. (Figura 5.4c)

"V." "V." caminha pela plataforma com a condução de um funcionário do metrô, que permanece até seu embarque no trem (Figura 5.4d). Ao descer na estação República, um outro funcionário a espera, devido à estratégia de acompanhamento, e a conduz até o trecho da linha 3-Vermelha, onde uma funcionária a conduz pela plataforma utilizada para desembarque dos demais usuários, onde não há aglomeração, até o local reservado para o embarque preferencial (Figura 5.4e).

“M." "M." caminha de modo independente, sem pedir auxílio, mas ao chegar à plataforma da linha 1, aguarda o trem afastado da borda, por segurança. Está acostumado com o local onde o trem para e onde se localiza a porta para entrar, mas ele diz que o resíduo visual que possui o ajuda a perceber onde realmente está a porta, caso o trem pare fora. $\mathrm{Na}$ linha 4 , ele se mantém mais tranquilo devido às portas de plataforma. (Figura 5.4f) 
Figura 5.4 - Maneira de caminhar na plataforma e embarcar/desembarcar do trem.

(a) - "R." caminha tranquilo pela plataforma mas para com a aproximação do trem.

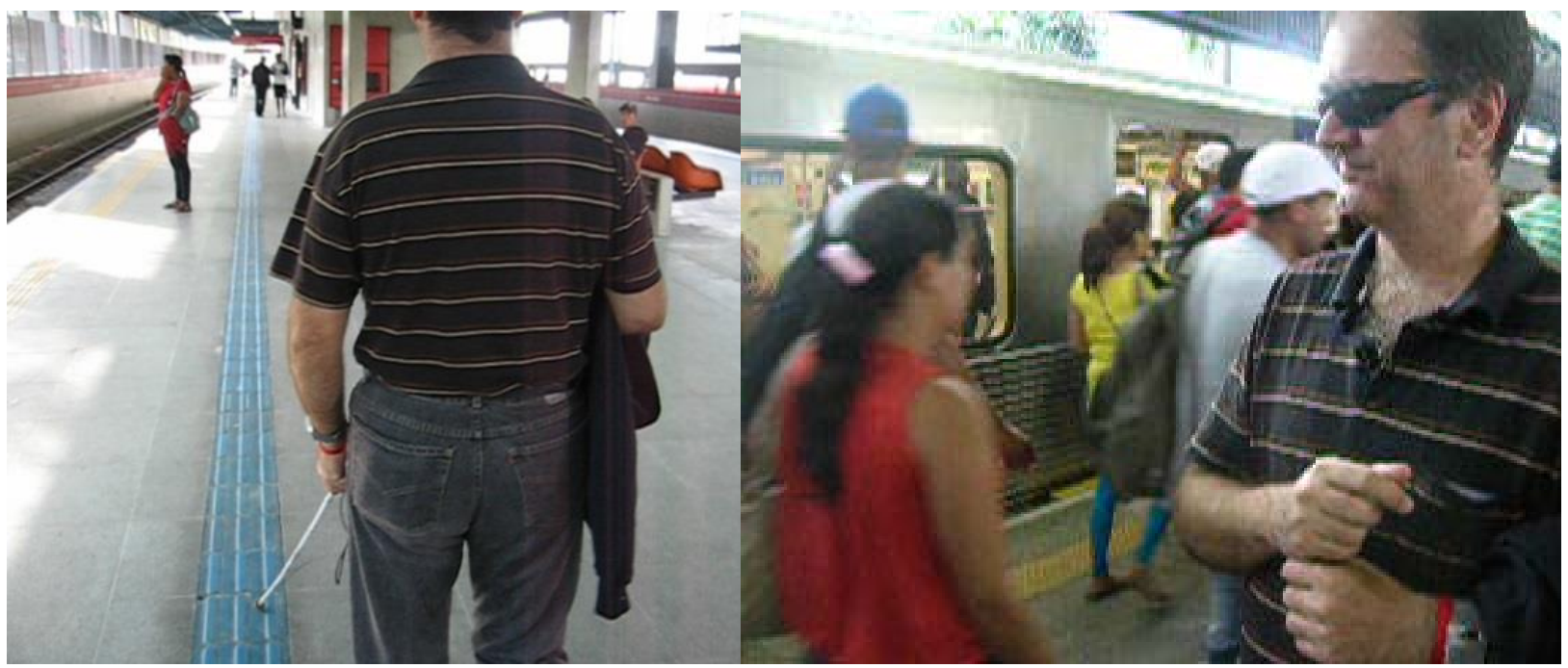

Crédito: MARIANI, E., 2013.

(b) - "I." tem medo de caminhar na plataforma antes do trem chegar, mas é ágil ao desembarcar.

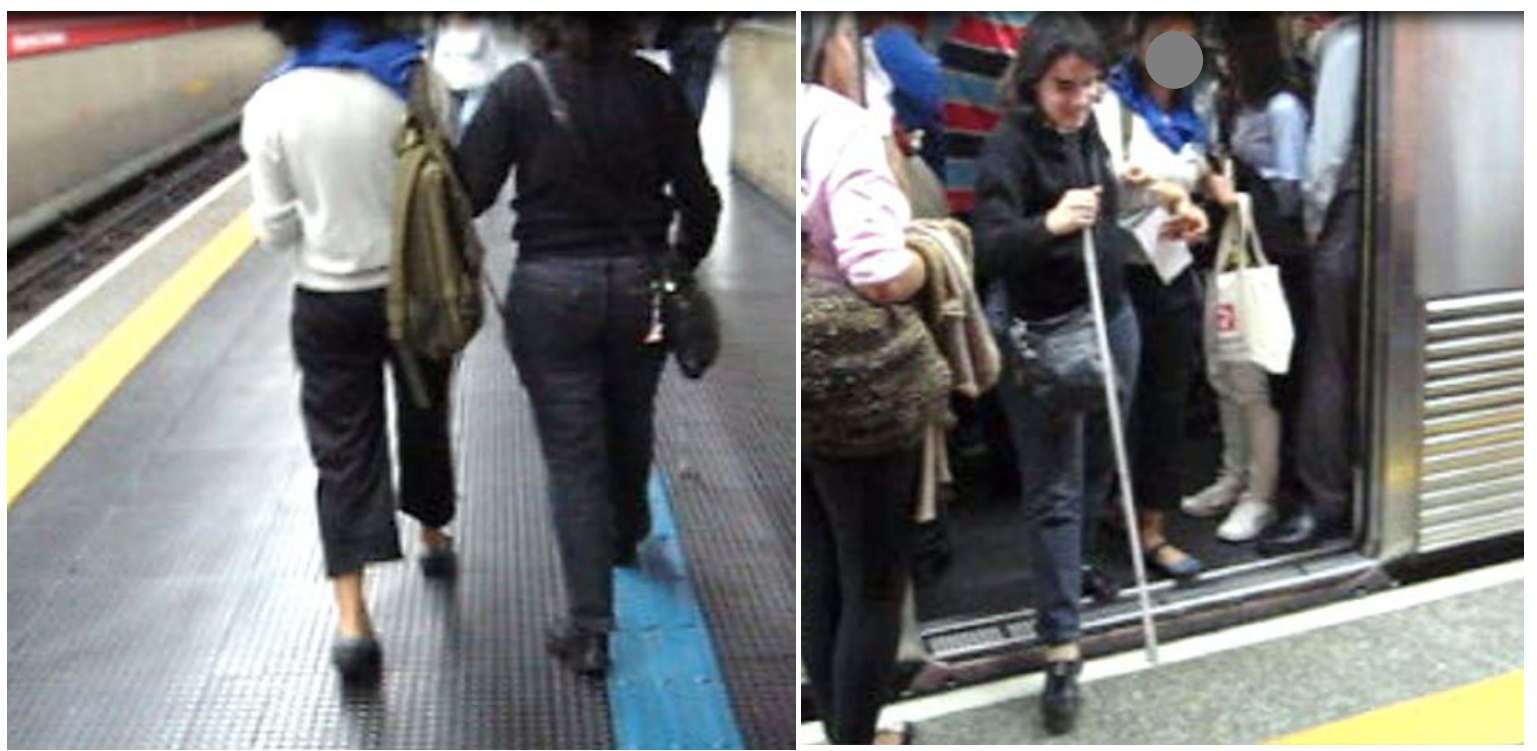

Crédito: MARIANI, E., 2013. 
(c) - "G." e Julia, seu cão-guia, que o mantém seguro na plataforma e o orienta para entrar no trem.
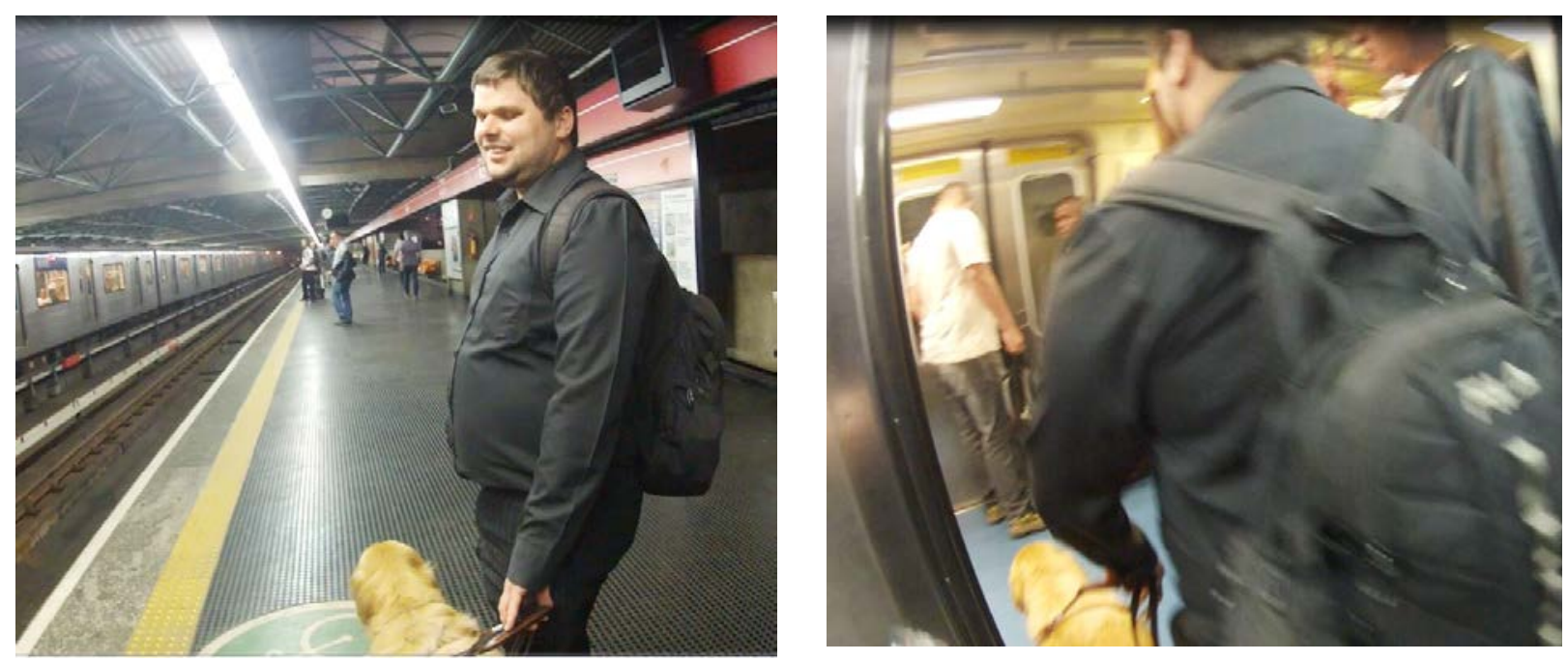

Crédito: SILVA FILHO, J., 2015.

(d) - "V." é orientada por um funcionário da linha 4-Amarela.
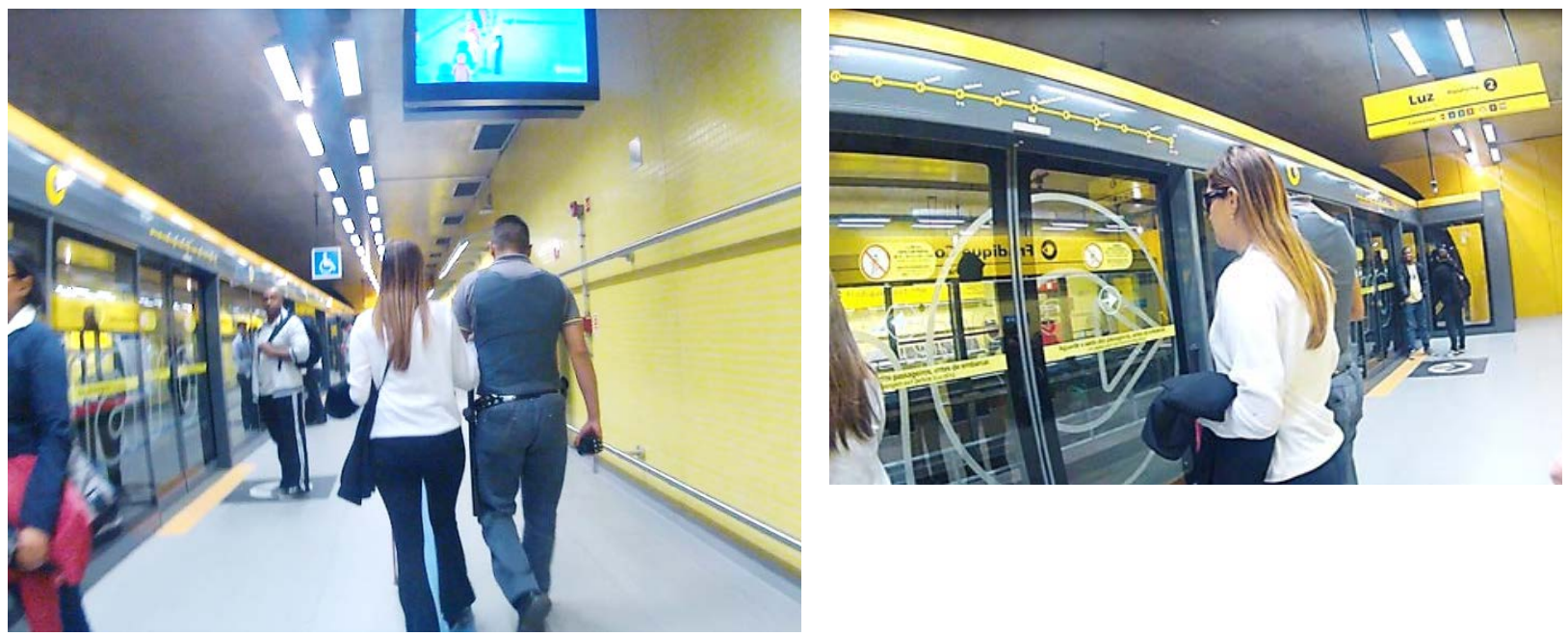

Crédito: SILVA FILHO, J., 2015.

(e) - "V." é encaminhada à área reservada para o embarque preferencial na linha 3-Vermelha.

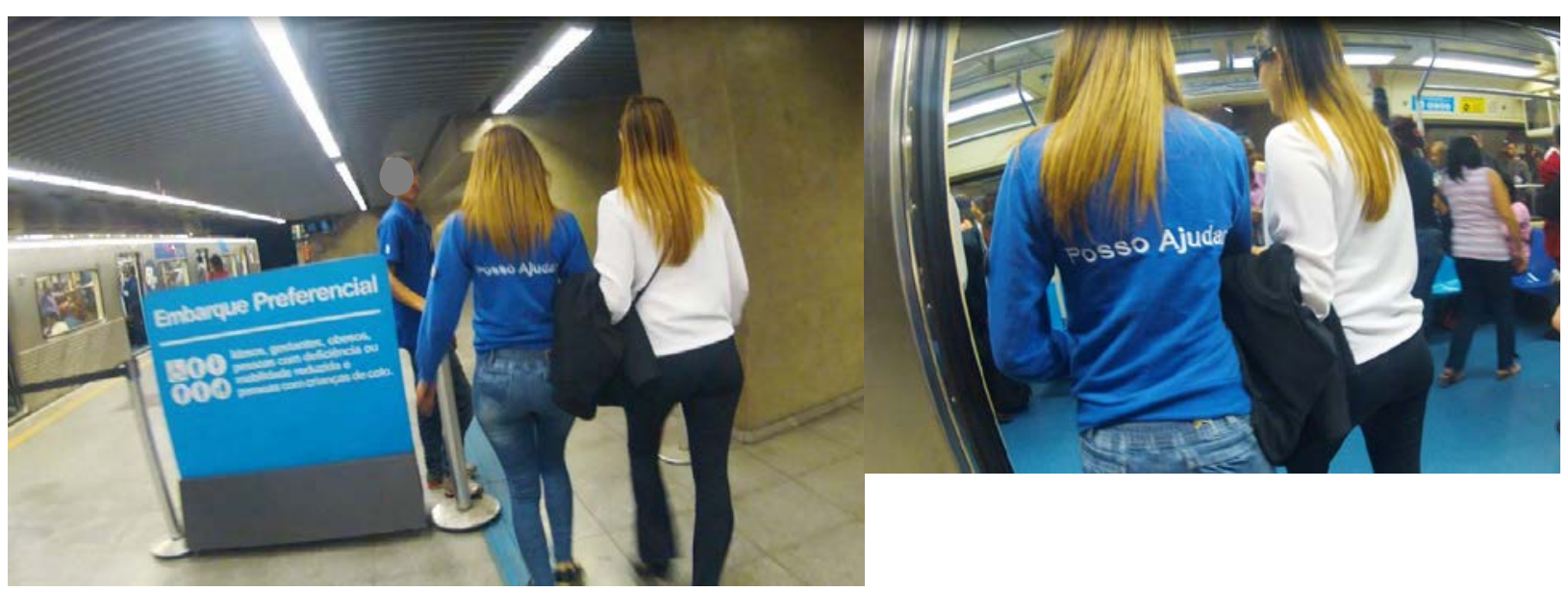

Crédito: SILVA FILHO, J., 2015. 
(f) - "M." se mantém afastado da borda da plataforma na linha 1, e mais tranquilo na linha 4, onde existem portas de plataforma.
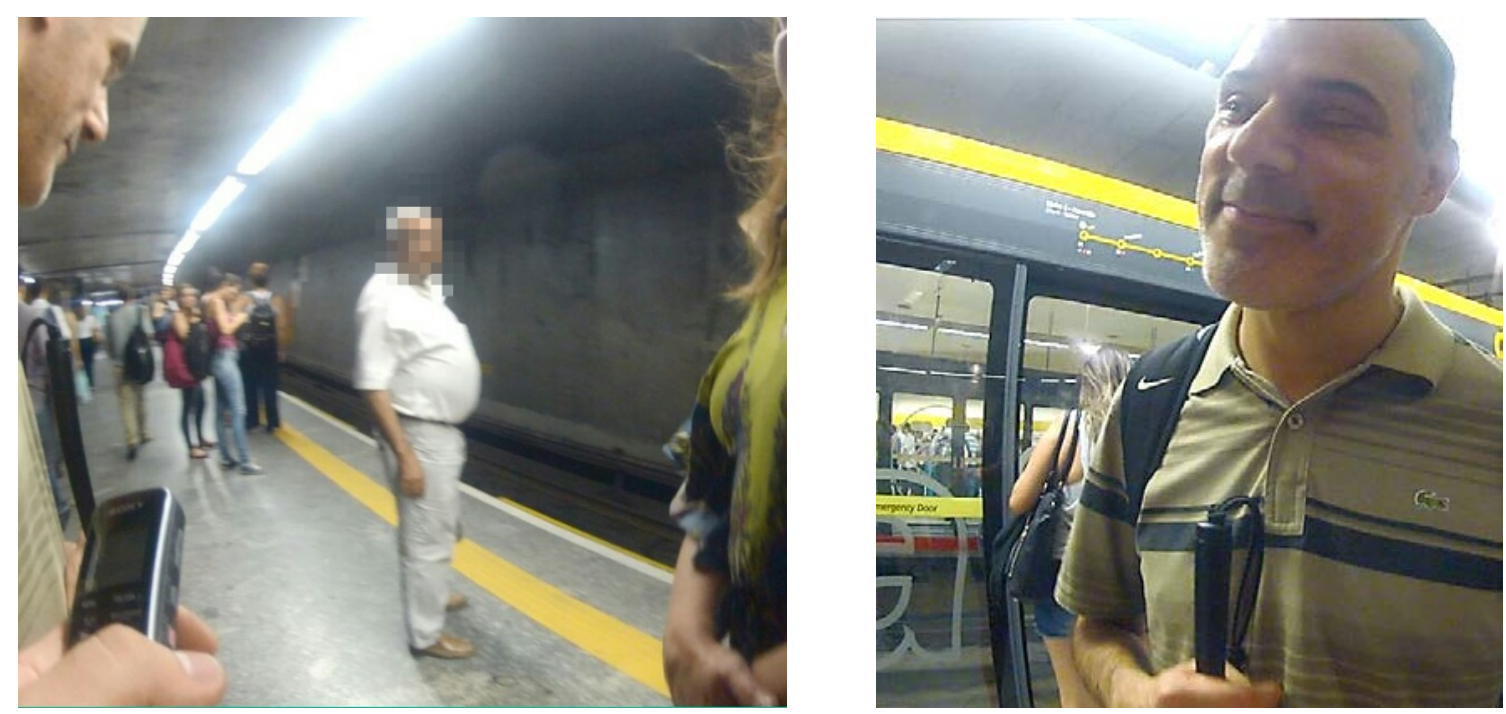

Crédito: SILVA FILHO, J., 2015. 
Quadro 5.5 - Comportamento dentro do trem.

\section{Categoria (d): Comportamento dentro do trem}

“R." $\quad$ Ao entrar no trem do metrô, "R." já sabe que o assento preferencial está à sua direita, e percebe com a bengala que o mesmo está vago (Figura 5.5a). Na sequência, senta-se e dobra a bengala, que abre novamente logo que é anunciada por mensagem sonora o nome da estação de destino.

“I." Depois de entrar no trem, "I." demonstra tranquilidade, estando familiarizada com o percurso. 0 trem está lotado (Figura 5.5b), ela permanece em pé o tempo todo, e não procura sentar-se. Mesmo tendo prioridade, ela diz que já sabe que os assentos devem estar ocupados por pessoas que precisam mais deles do que ela. Logo que é anunciada a estação de destino, ela se posiciona em frente à porta e desce segura. Ela relata que, quando o trem está na estação não tem medo de caminhar na plataforma, porque a própria presença do trem constitui uma barreira segura para não cair na via.

"X" $\quad 0$ tem está cheio e "X" permanece em pé, sem ser abordado pelas demais pessoas (Figura 5.5c). Os assentos preferenciais estavam ocupados. Ao longo do percurso o trem foi ficando muito cheio, e " $\mathrm{X}$ " permaneceu em pé, tranquilo. Com o esvaziar do trem vaga um assento junto ao corredor, e " $\mathrm{X}$ " percebe e se senta. Mais adiante passa para o assento preferencial ao seu lado que ficou vago. Ao ouvir o nome da estação de destino ele abre a bengala e se posiciona para descer, fazendo tudo com segurança.

"G." $\quad$ Por meio da condução do cão-guia Julia, "G." direciona-se a um assento preferencial que estava desocupado. 0 trem não está muito cheio, algumas pessoas em pé olham para "G." e Julia, admirando-os. "G." consulta mensagens em seu telefone (iPhone), sempre tranquilo (Figura 5.5d). Ao se aproximar da estação de destino, Julia começa a se movimentar, para que ele perceba que estão chegando, até que "G." se levanta para o desembarque.

"V." "V." encontra o assento preferencial vazio, à sua esquerda depois de ser embarcada pela funcionária do metrô (Figura 5.5e). Ela permanece sentada o tempo todo, conversando com a pesquisadora, segurando sua bengala longa rosa, uma cor diferenciada, pois a maioria é branca. 0 trem acaba ficando lotado e mesmo tendo esvaziado um pouco ao longo do percurso, ela sabe que ao desembarcar ainda tem muitas pessoas em pé, por isso se antecipa um pouco para garantir o desembarque.

"M." "M." entra no trem da linha 4-Amarela praticamente vazio, e percebe com o resíduo de sua visão que o assento preferencial está vazio, sentando-se e permanecendo tranquilo, conversando com a pesquisadora o tempo todo da viagem. (Figura 5.5f) 
Figura 5.5 - Comportamento dentro do trem.

(a) - "R."

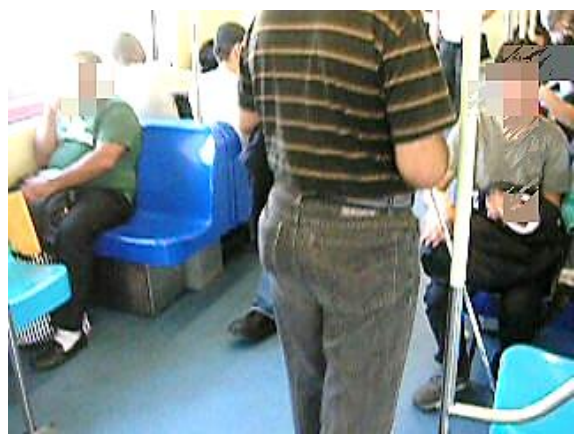

Crédito: MARIANI, E., 2013.

(d) - "G."

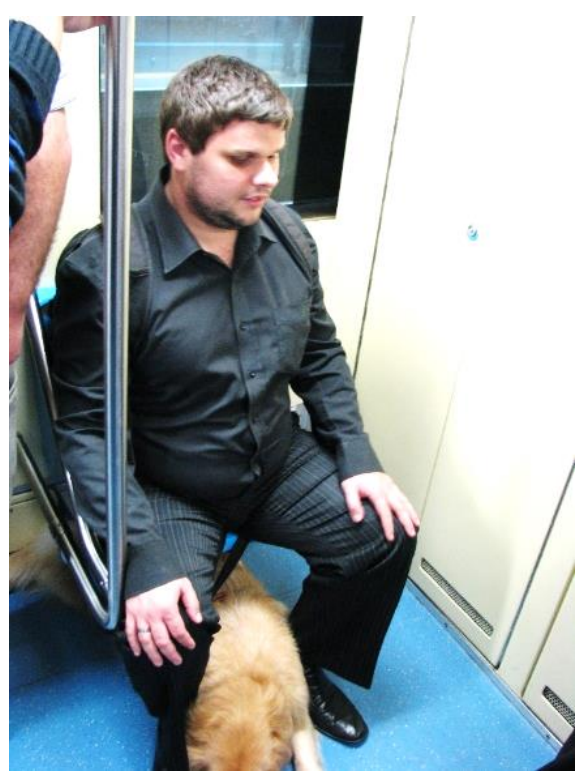

Crédito: SILVA FILHO, J., 2015. (b) - "I."

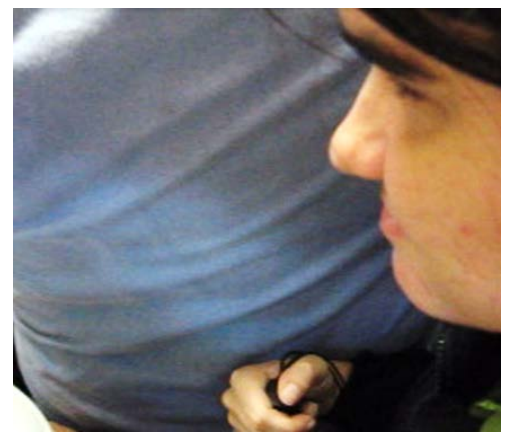

Crédito: MARIANI, E., 2013.

(e) - "V."

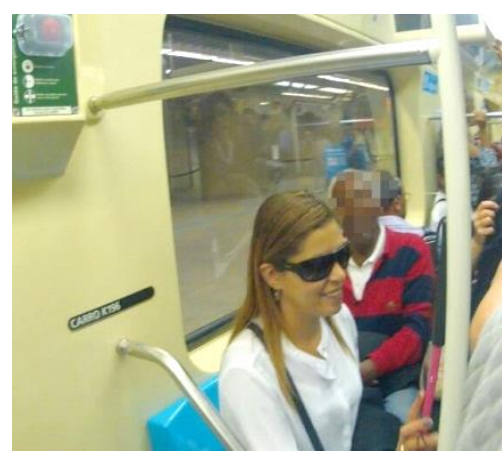

Crédito: SILVA FILHO, J., 2015. Crédito: SILVA FILHO, J., 2015.

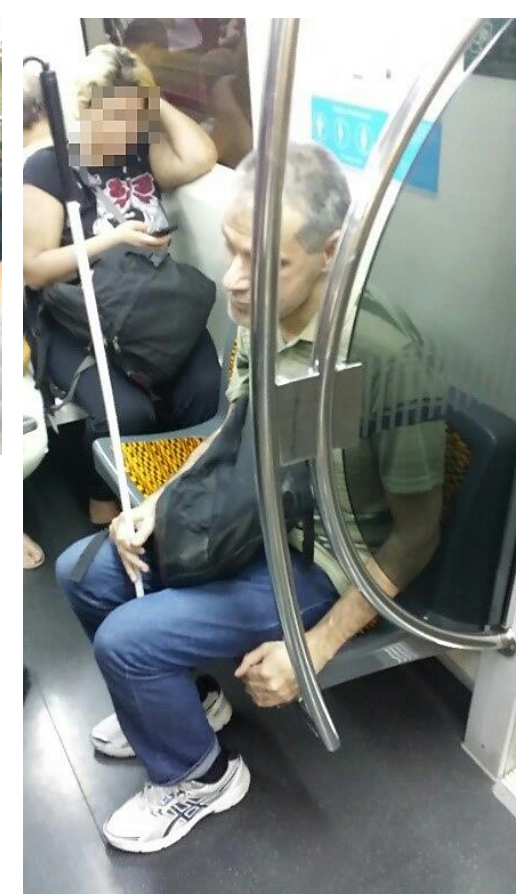

(c) - "X"

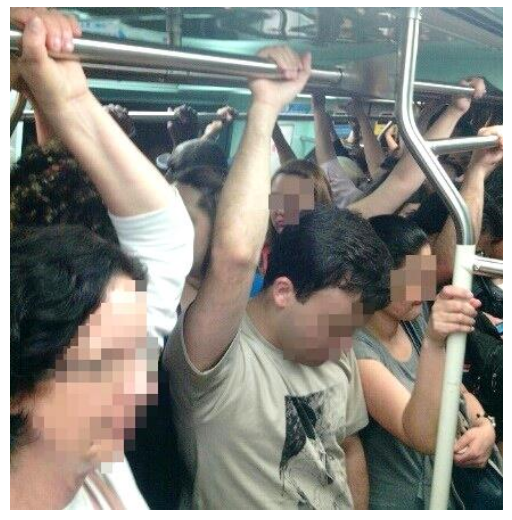

Crédito: DUTRA, D. N. M., 2013.

(f) - "M." 
Quadro 5.6 - Interferência dos demais usuários.

\begin{tabular}{|c|c|}
\hline \multicolumn{2}{|r|}{ Categoria (e): Interferência dos demais usuários } \\
\hline “R." & $\begin{array}{l}\text { "R." demonstrou que lida com a interferência de usuários de maneira tranquila, } \\
\text { virando-se de frente para o fluxo de pessoas quando estas estão cruzando seu } \\
\text { caminho temporariamente, como no desembarque na plataforma. Ele faz isso } \\
\text { para que as demais pessoas identifiquem que ele é uma pessoa com deficiência } \\
\text { visual e desviem. }\end{array}$ \\
\hline "I." & $\begin{array}{l}\text { Mesmo com acompanhamento da pesquisadora, usuários apressados tropeçam e } \\
\text { pisam na bengala de "I." (Figura 5.6a) }\end{array}$ \\
\hline “X” & $\begin{array}{l}\text { "X" praticamente não sofreu interferência dos demais usuários, apenas um } \\
\text { senhor que o abordou para conduzi-lo até um funcionário do metrô, que fez seu } \\
\text { acompanhamento. }\end{array}$ \\
\hline “G." & $\begin{array}{l}\text { Foi o que sofreu menos interferência dos demais usuários, pois seu cão-guia } \\
\text { desviou de todos. Além disso, por não utilizar bengala, sofre menos } \\
\text { interferências. (Figura 5.6b) }\end{array}$ \\
\hline “V." & $\begin{array}{l}\text { "V." praticamente não sofreu interferência física dos demais usuários, pois foi } \\
\text { conduzida o tempo todo por funcionários (Figura 5.6c), porém relatou sofrer com } \\
\text { a interferência dos comentários dos demais usuários quando está em pé no trem, } \\
\text { os assentos estão todos ocupados e as pessoas não lhe oferecem lugar. }\end{array}$ \\
\hline “M." & $\begin{array}{l}\text { "M." foi o que mais sofreu interferência dos demais usuários, tanto apressados, } \\
\text { tropeçando e pisando em sua bengala (Figuras 5.6d e 5.7), como tentando auxiliá- } \\
\text { lo (Figura 5.8). }\end{array}$ \\
\hline
\end{tabular}


Figura 5.6 - Interferência dos demais usuários.

(a) - "I." sofre interferência de usuários.

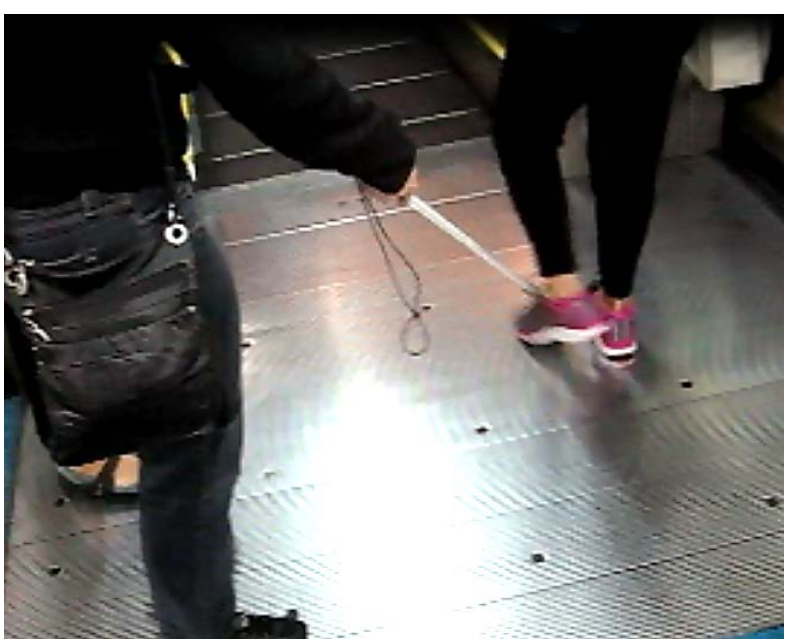

Crédito: MARIANI, E., 2013.

(c) - "V." não sofre interferência porque é conduzida para a área de embarque preferencial.

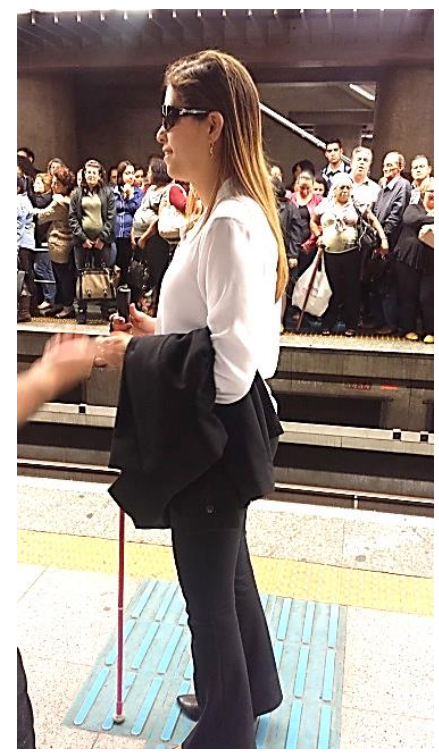

Crédito: MARIANI, E., 2015. (b) - "G." é desviado dos usuários por Julia.

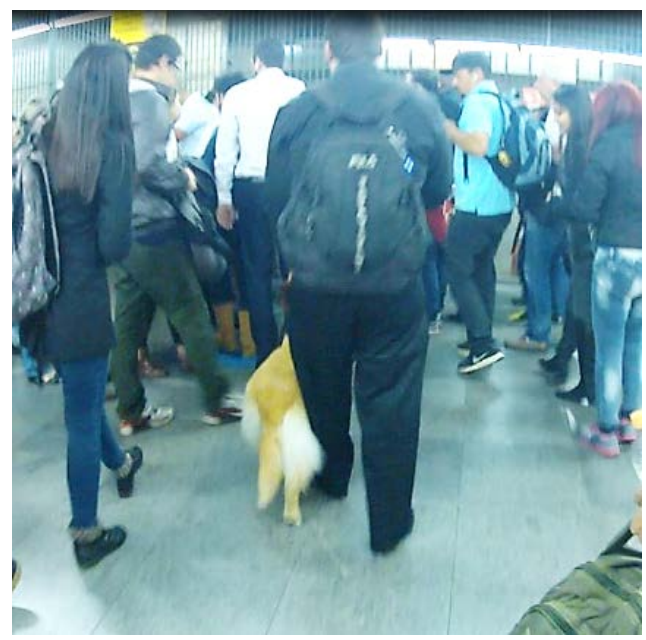

Crédito: SILVA FILHO, J., 2015.

(d) - "M." sofre bastante interferência de usuários apressados e distraídos.

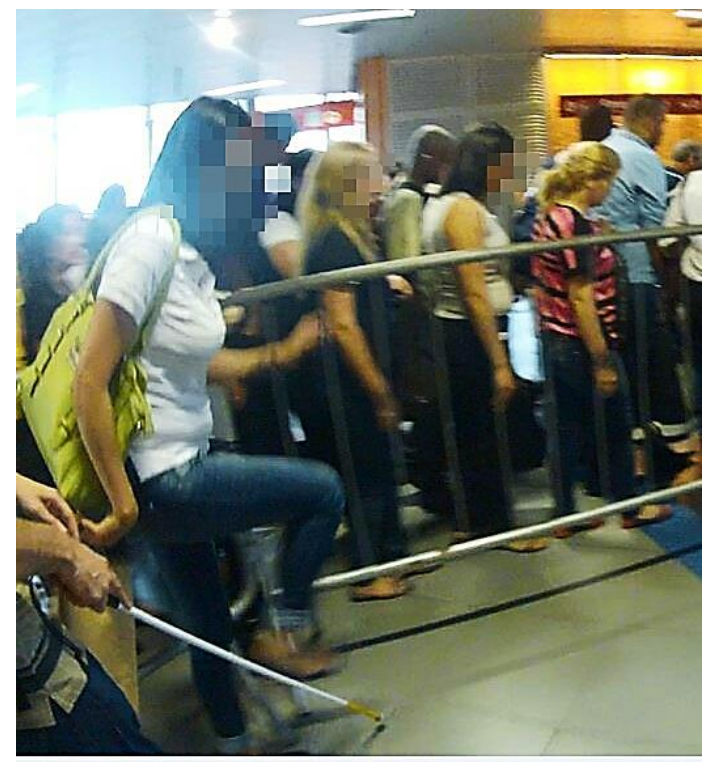

Crédito: SILVA FILHO, J., 2015. 
Figura 5.7 - Sequência de interferência de uma usuária.

(a) - Usuária andando apressada, olhando para o lado, distraída.

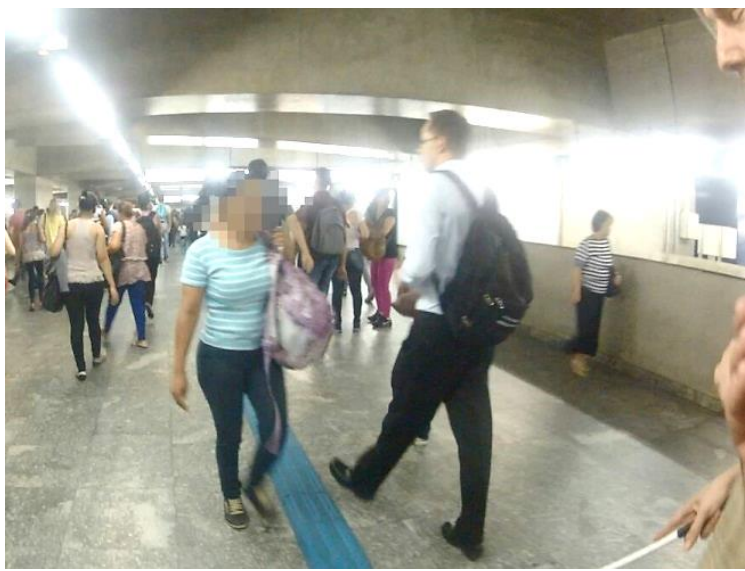

(c) - 0 encontro com a bengala de "M.", que rastreia o piso tátil.

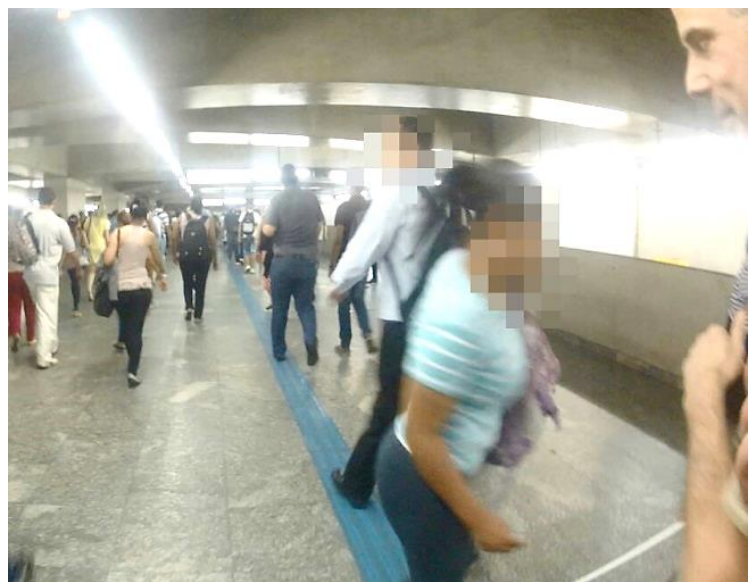

Crédito: SILVA FILHO, J., 2015. (b) - Ela cruza a linha do piso tátil sem nem ao menos olhar para a frente.

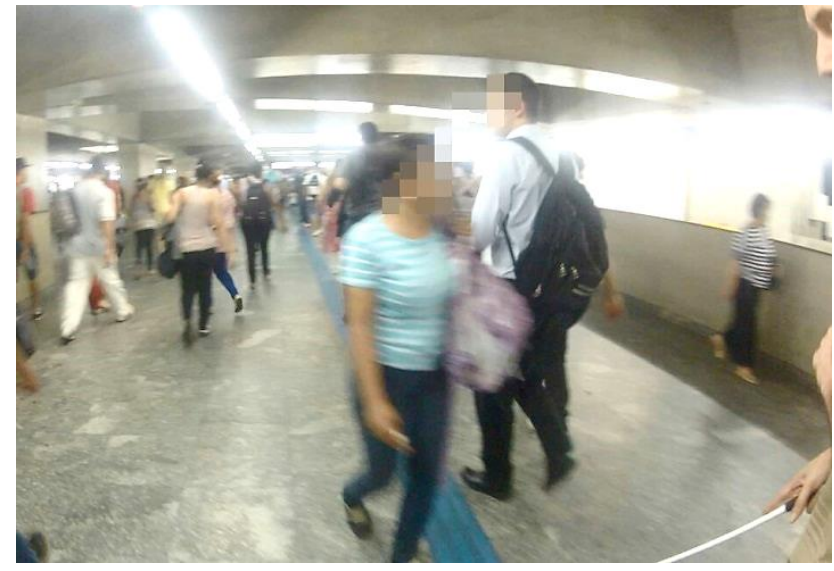

(d) - A usuária tropeça e quase cai, causando leve dano à bengala.

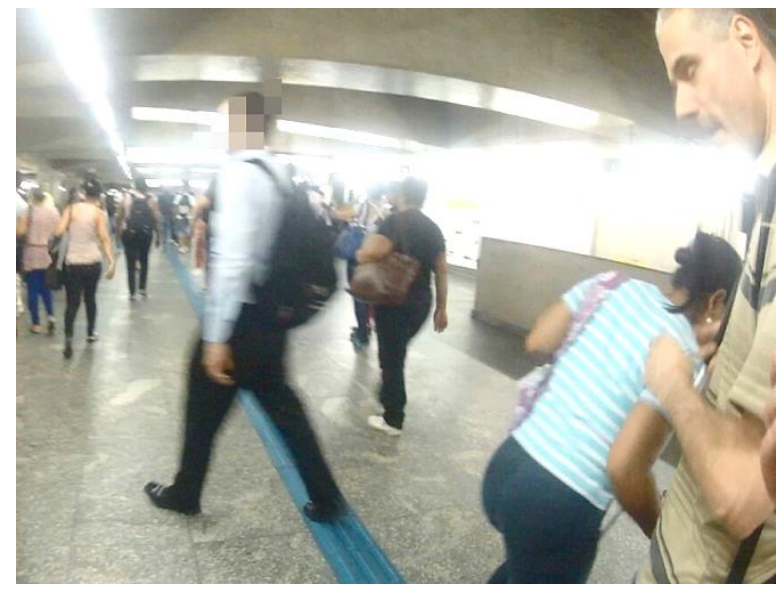

Figura 5.8 - Sequência de abordagem de "M." por um usuário para auxiliá-lo.
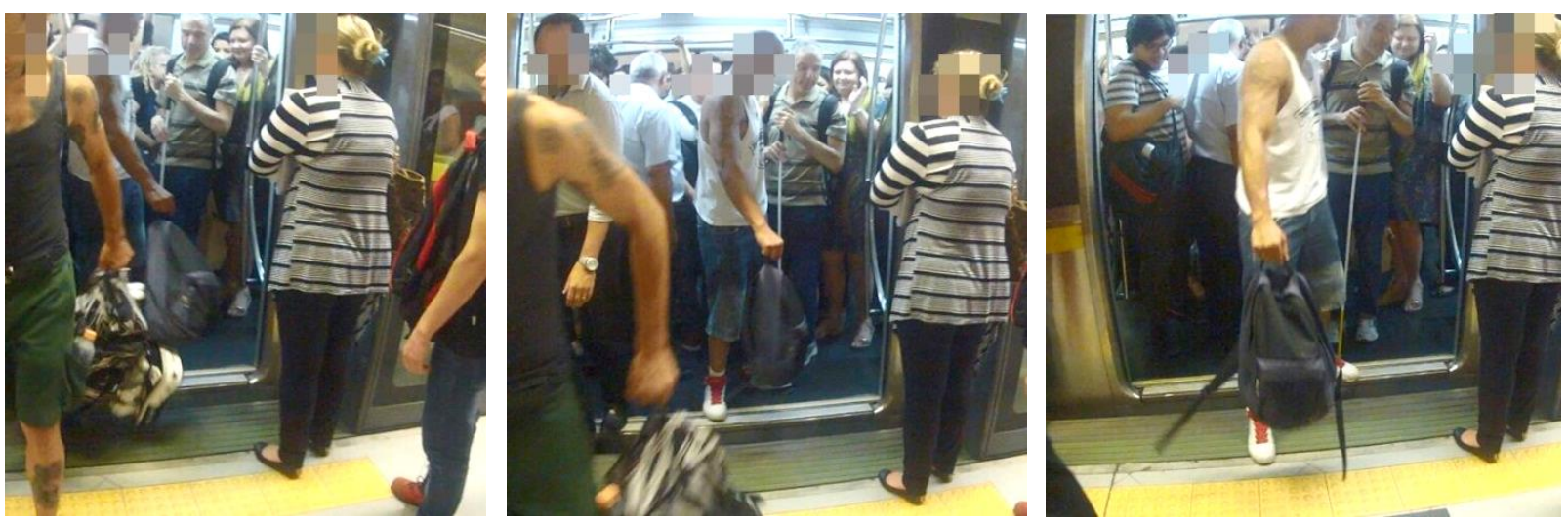

Crédito: SILVA FILHO, J., 2015. 


\subsubsection{Padrões identificados nas observações}

As observações de campo realizadas no metrô de São Paulo permitiram a constatação de diferentes perfis psicológicos e de habilidades entre os usuários com deficiência visual. Mas, mesmo com diferenças entre si, diante de situações semelhantes oferecidas pelo ambiente metrô, foi possível se identificar cinco padrões entre as pessoas observadas:

a) uso de bengala 70 ;

b) ritmo e velocidade no andar;

c) contorno de obstáculos de maneira tranquila;

d) percepção de chegada da estação de destino dentro do trem e lado de saída que deve usar;

e) sofrem grande interferência por parte dos demais usuários.

\subsection{ENTREVISTAS NO METRÔ DE SÃO PAULO}

Foram realizadas 12 entrevistas relativas ao metrô de São Paulo, sendo nove funcionários do metrô, dois professores de Orientação e Mobilidade e um designer de produto de ajudas técnicas. 0 roteiro das entrevistas semiestruturadas foi estabelecido de acordo com o exposto no capítulo dos métodos. A síntese das entrevistas consta do Apêndice T.

\subsubsection{Temas identificados nas entrevistas}

Foram identificados seis temas no discurso dos entrevistados:

a) a falta de informação a respeito das pessoas com deficiência visual: uma maior e melhor divulgação sobre essas pessoas, principalmente sobre suas capacidades, atividades e motivo de uso do metrô (a trabalho e estudo) poderia melhorar a interação entre funcionários e demais usuários com relação a essas pessoas;

b) existem diferentes grupos de pessoas com deficiência que utilizam o metrô: (i) aqueles que são autônomos, só pedem auxílio em estações grandes e de conexão

\footnotetext{
70 Considerou-se também o usuário com cão-guia porque ele mantém uma bengala guardada consigo para usar quando o cão apresentar problemas de saúde, e já utilizou bengala no passado.
} 
entre linhas; (ii) aqueles que não são autônomos, sempre pedem auxílio; (iii) aqueles que não pedem auxílio porque querem ser autônomos, mas este último grupo é o mais problemático, porque a maioria precisa de auxílio, acabam se arriscando; e (iv) o grupo que é autônomo porque utiliza cão-guia;

c) o uso de aplicativos em smartphones utilizados pelos usuários para auxiliar de alguma forma no uso do metrô deveria ser fomentado;

d) mais informações sonoras, tais como descrição da estação e informação sobre arredores, poderiam auxiliar, se disponibilizadas de alguma forma;

e) a instalação de painéis de portas de plataforma em todas as estações forneceria mais segurança a todos;

f) a associação de um guia eletrônico à instalação de pisos táteis direcionais apresenta diversas vantagens, sendo a principal, elucidar o caminho a seguir.

\subsection{QUESTIONÁRIO NO METRÔ DE SÃO PAULO}

Na pesquisa por meio do instrumento questionário, apesar de ter sido utilizado software estatístico para processar as questões fechadas, relacionadas ao perfil dos usuários, o teor da análise foi mais qualitativo, devido às questões abertas e a fatores inerentes ao tema.

O questionário foi aplicado conforme método proposto e Apêndice $\mathrm{V}$, a uma amostra de 67 usuários do metrô ${ }^{71}$ com deficiência visual, composta de 42 homens e 25 mulheres, a maioria (58) possui treinamento de orientação e mobilidade. Os dados foram estratificados em três grandes grupos: (a) pessoas com baixa visão; (b) pessoas com cegueira adquirida; e (c) pessoas com cegueira congênita (desde o nascimento ou que se tornaram cegos antes do processo de alfabetização).

Quanto à frequência de uso, 82\% utilizam o metrô cinco ou mais dias por semana (Gráfico 5.1), principalmente para trabalhar (Gráfico 5.2).

${ }^{71}$ Foram considerados os usuários das linhas 1,2 ,3 e 5, administradas pela CMSP. 
Gráfico 5.1 - Frequência de uso do metrô.

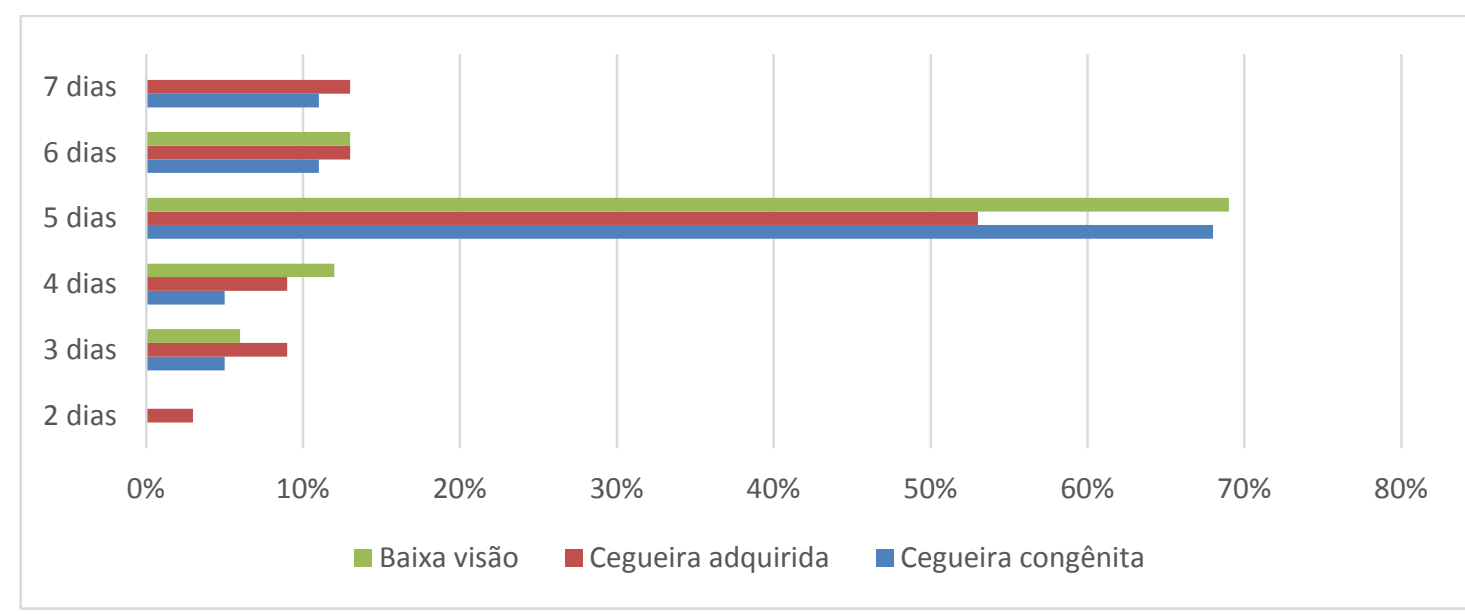

Fonte: Elaborado a partir das respostas ao questionário - Apêndice V.

Gráfico 5.2 - Motivo de uso do metrô.

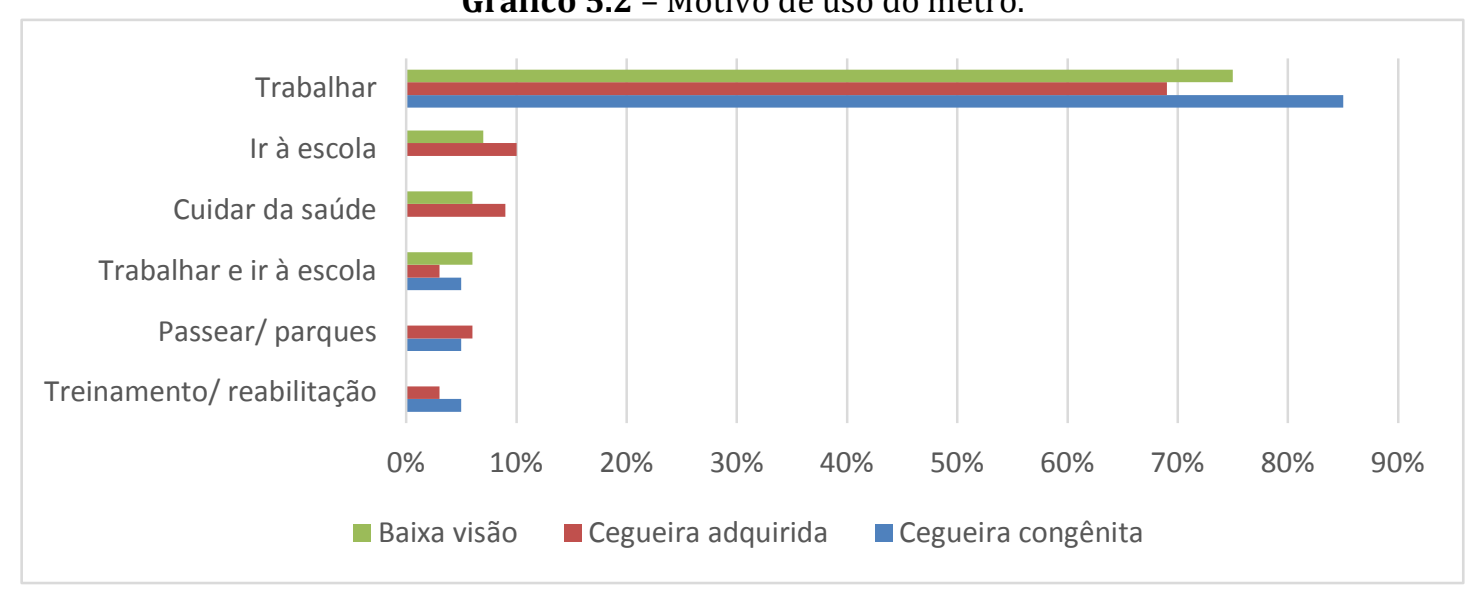

Fonte: Elaborado a partir das respostas ao questionário - Apêndice V.

Quanto à forma de chegar às estações do metrô, a maioria chega de ônibus ou a pé (Gráfico 5.3), e sozinho (Gráfico 5.4).

Gráfico 5.3 - Meios de transporte utilizados para chegar ao metrô.

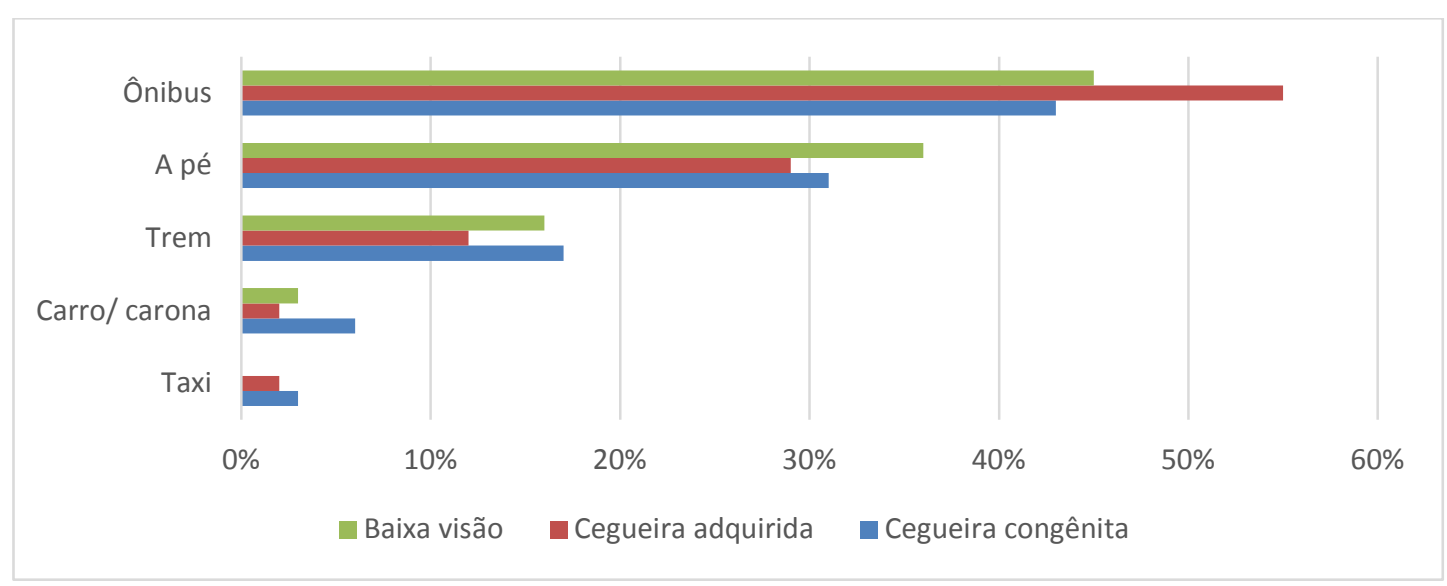

Fonte: Elaborado a partir das respostas ao questionário - Apêndice V. 
Gráfico 5.4 - Como costuma chegar às estações do metrô.

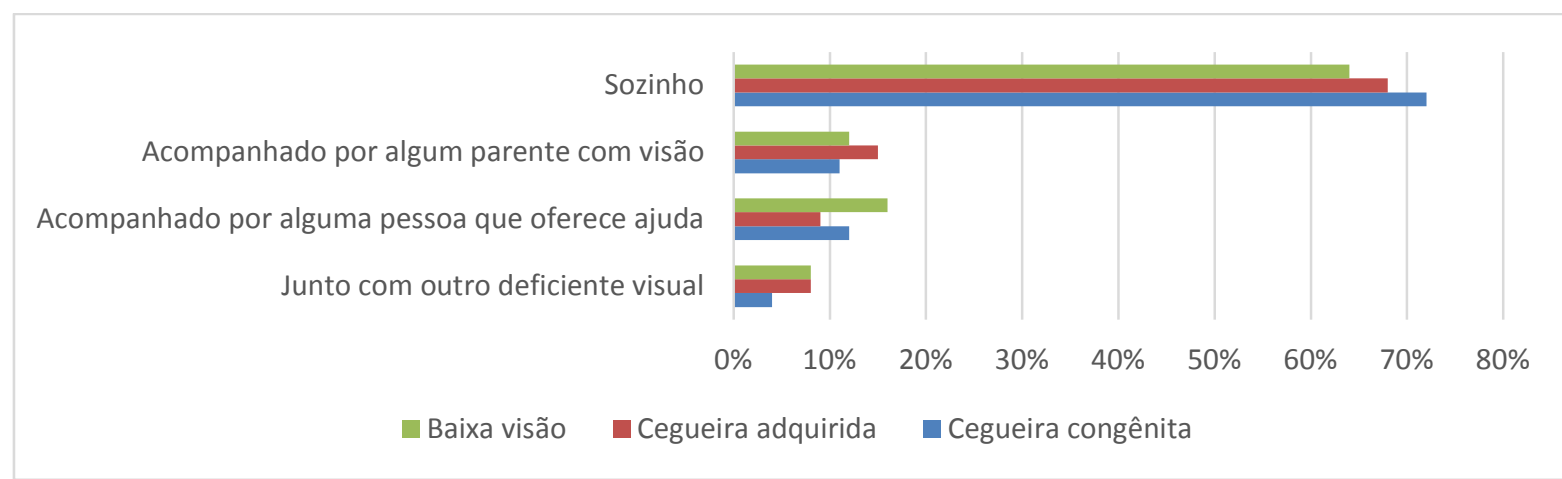

Fonte: Elaborado a partir das respostas ao questionário - Apêndice V.

0 que se destaca no Gráfico 5.4 é o fato de que a maioria chega ao metrô desacompanhado, de maneira autônoma, inclusive por meio de outros meios de transporte que utilizam sozinhos, no entanto, ao entrarem nas estações, a maioria quer ser acompanhada por um funcionário (Gráfico 5.5).

Gráfico 5.5 - Pede auxílio para utilizar o metrô?

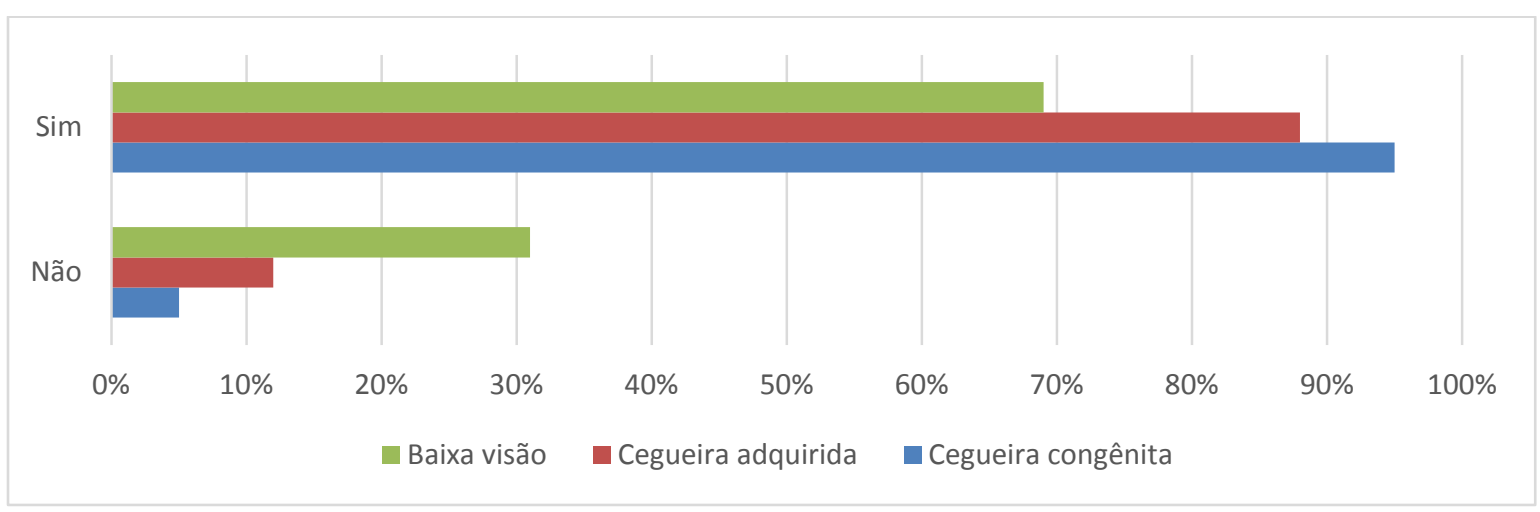

Fonte: Elaborado a partir das respostas ao questionário - Apêndice V.

Uma possível explicação para o resultado do Gráfico 5.5 tem por referência CMSP (2015d):

A explicação mais razoável é que o Metrô sempre ofereceu auxílio para pessoas com deficiência se deslocar no interior de suas estações e continua oferecendo, mesmo depois que tornou seus espaços acessíveis. 0 atendimento é muito mais seguro e cômodo para os usuários com deficiência visual que têm receio de se acidentar. Além disso, a aglomeração de pessoas e o fluxo rápido imposto pelo sistema metroviário faz com que esse sentimento aumente, principalmente nas plataformas onde há o risco de queda na via.

De fato, os principais motivos alegados para solicitação de auxílio de funcionário em seus deslocamentos pelas estações constam do Gráfico 5.6. 
Gráfico 5.6 - Qual o motivo para solicitação de auxílio de funcionário no metrô?

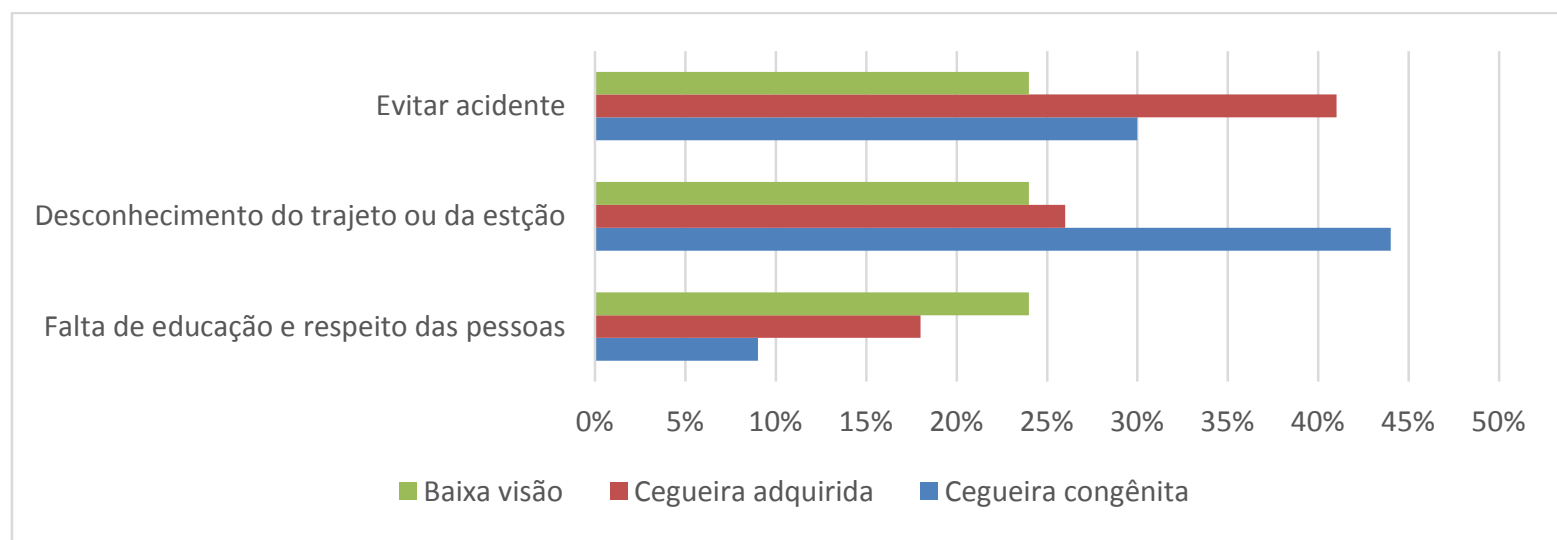

Fonte: Elaborado a partir das respostas ao questionário - Apêndice V.

Mesmo com alegações diferentes, pode-se interpretar que todas possuem o mesmo fundamento: o receio de se acidentar, principalmente o de cair na via, como aponta o Gráfico 5.7, indicando que o maior medo está nas plataformas.

Gráfico 5.7 - "Qual o local das estações onde se sente mais inseguro?"

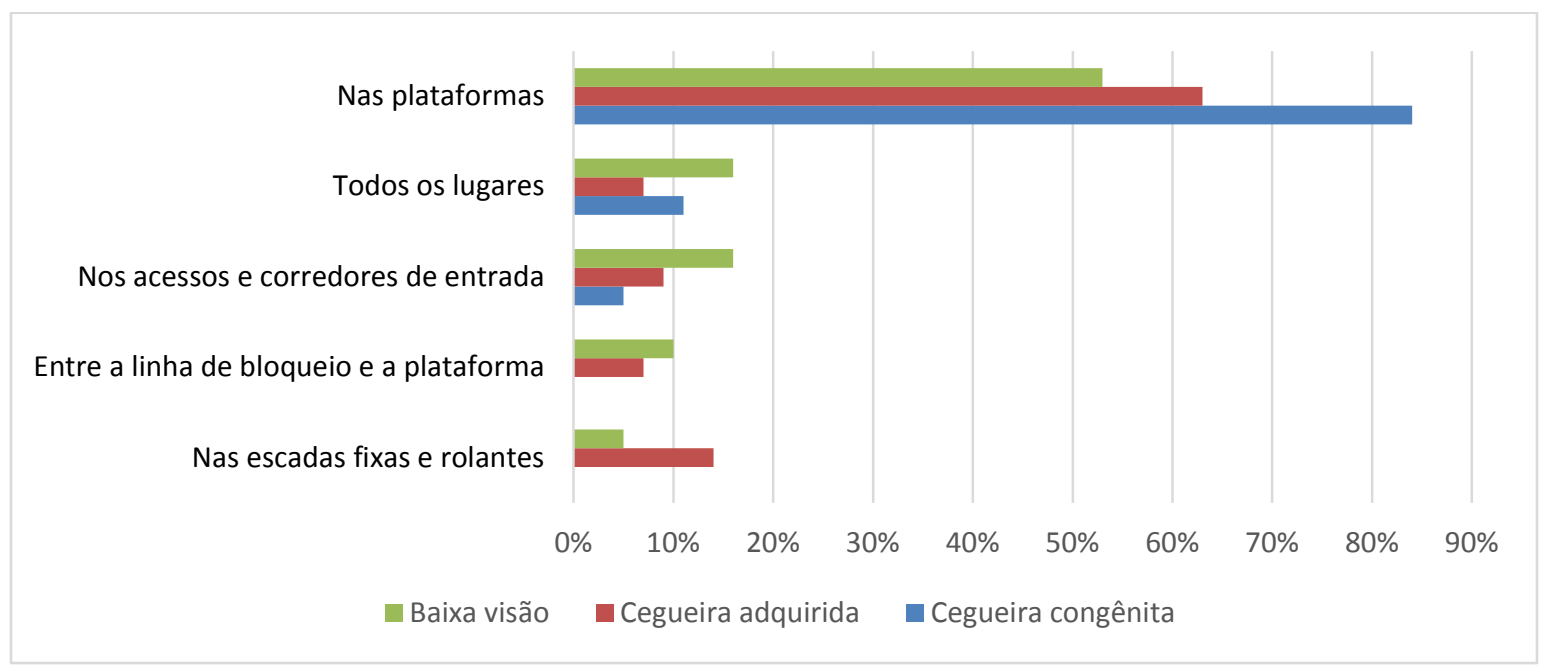

Fonte: Elaborado a partir das respostas ao questionário - Apêndice V.

No entanto, mesmo com os motivos alegados, a maioria que hoje pede auxílio gostaria de se deslocar de maneira independente dentro do metrô também (Gráfico 5.8). 
Gráfico 5.8 - "Gostaria de se deslocar de maneira independente no metrô (sem necessidade de auxílio dos funcionários)?"

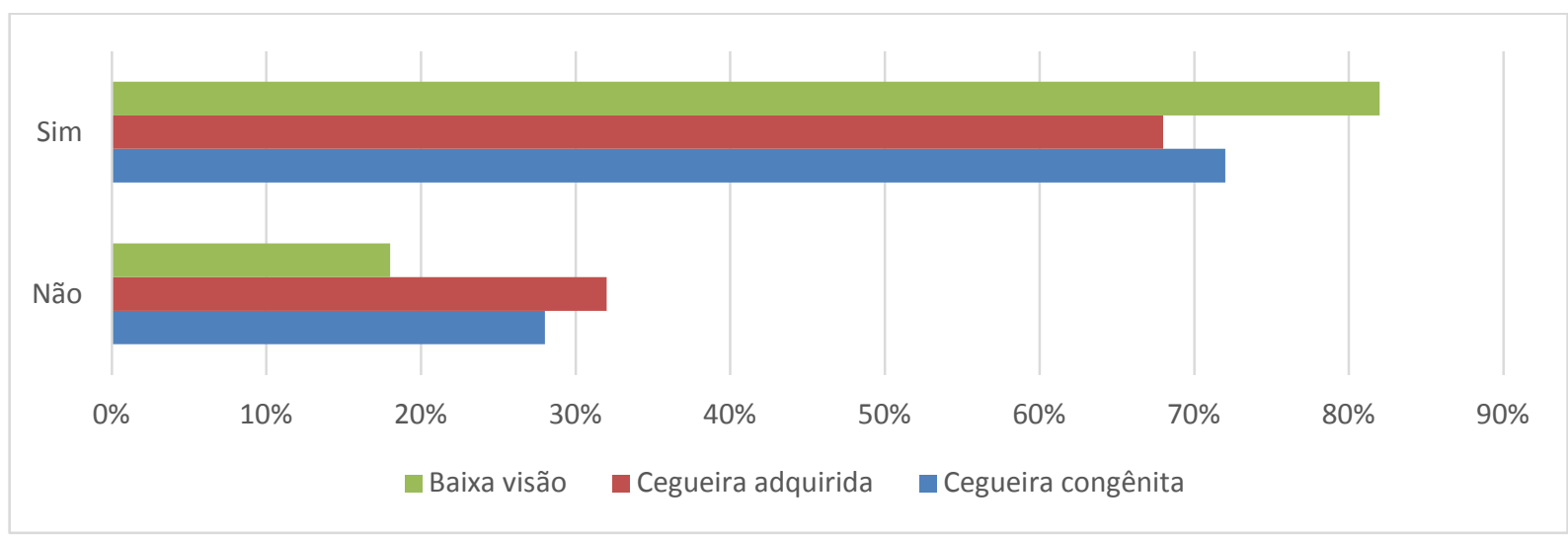

Fonte: Elaborado a partir das respostas ao questionário - Apêndice V.

Diante da constatação de que a maioria que hoje pede auxílio gostaria de se deslocar de maneira independente, coube uma investigação mais detalhada sobre o assunto, um dos objetivos deste trabalho: "Investigar as formas como as pessoas com deficiência visual utilizam e interagem em seus percursos por estações e trens de metrô para subsidiar uma possível utilização de sistemas eletrônicos para informação e auxílio à navegação, à luz das variáveis cognitivas dos futuros usuários.”.

Nas respostas para a questão "o que o metrô dispõe hoje é suficiente para uma pessoa com deficiência visual se deslocar sozinha?", o "não" foi bastante significativo, porém surgiu um meio termo entre o "sim" e o "não", que foi "em algumas estações sim, em outras não”, conforme Gráfico 5.9.

Gráfico 5.9 - "O que o metrô dispõe hoje é suficiente para uma pessoa com deficiência visual se deslocar sozinha?"

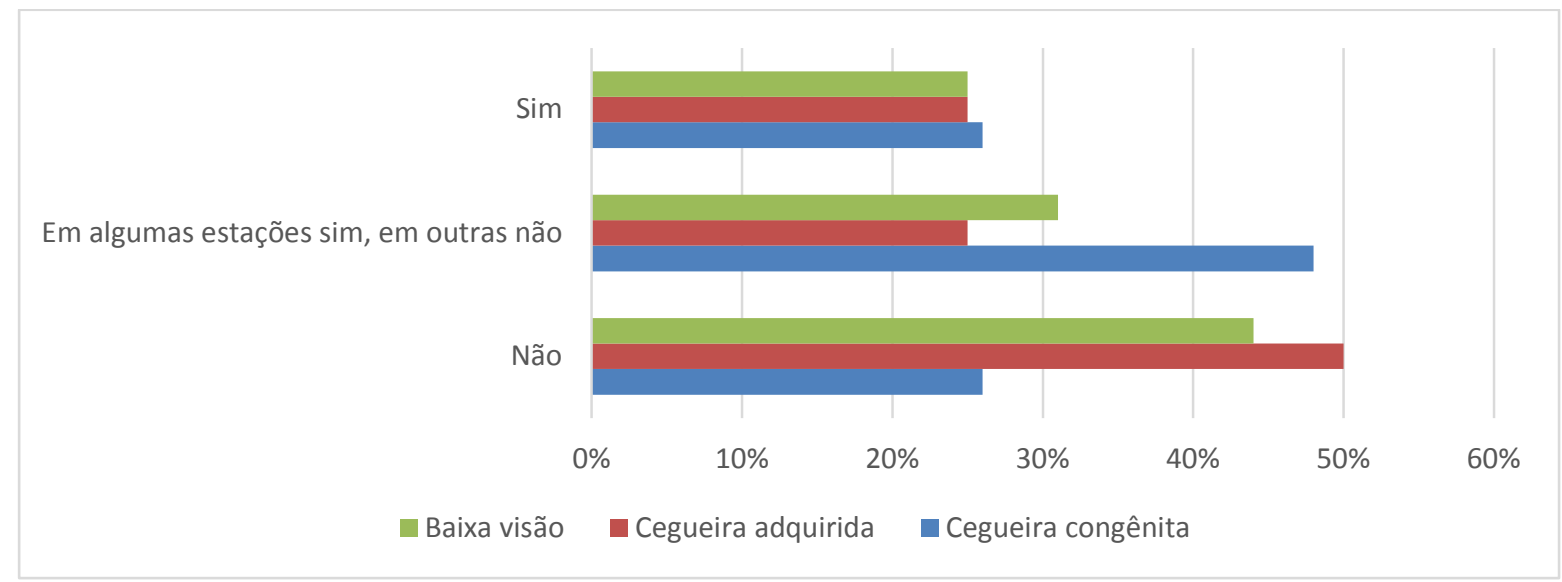

Fonte: Elaborado a partir das respostas ao questionário - Apêndice V. 
Para aqueles que responderam "não", foi solicitado que informassem qual o motivo ou o que poderia ser feito para melhorar essas condições. O Gráfico 5.10 apresenta os principais resultados.

Gráfico 5.10 - Para quem respondeu "não" na questão do Gráfico 5.9 - principais resultados.

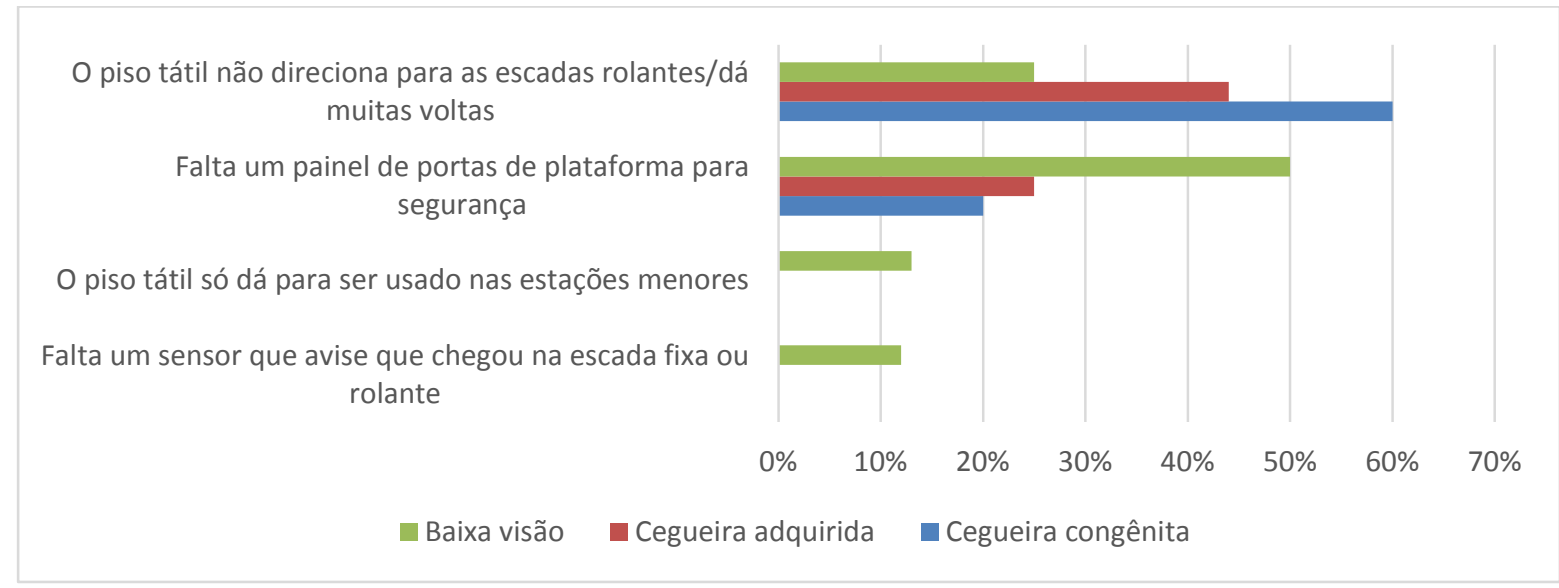

Fonte: Elaborado a partir das respostas ao questionário - Apêndice V.

Também foi solicitado que as pessoas que responderam "em algumas estações sim, em outras não" fornecessem o motivo ou uma sugestão. O Gráfico 5.11 apresenta os principais resultados.

Gráfico 5.11 - Para quem respondeu "em algumas estações sim, em outras não" na questão do Gráfico 5.9 - principais resultados.

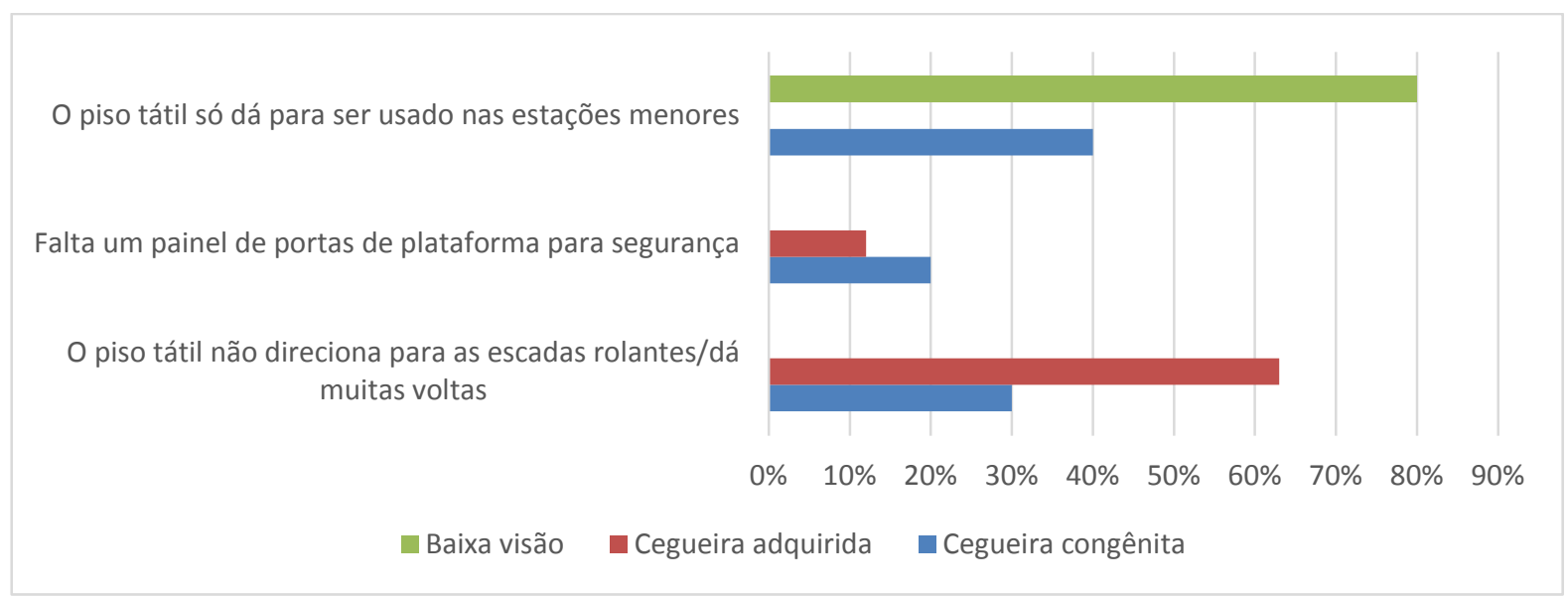

Fonte: Elaborado a partir das respostas ao questionário - Apêndice V.

Finalmente, dentre as questões mais significativas para este trabalho, tem-se os resultados para "em sua opinião, quais tecnologias ou equipamentos poderiam ajudar as pessoas com deficiência visual a se deslocarem de forma independente no metrô?" (Gráfico 5.12). 
Gráfico 5.12 - Para quem respondeu "em algumas estações sim, em outras não" na questão do Gráfico 5.9 - principais resultados.

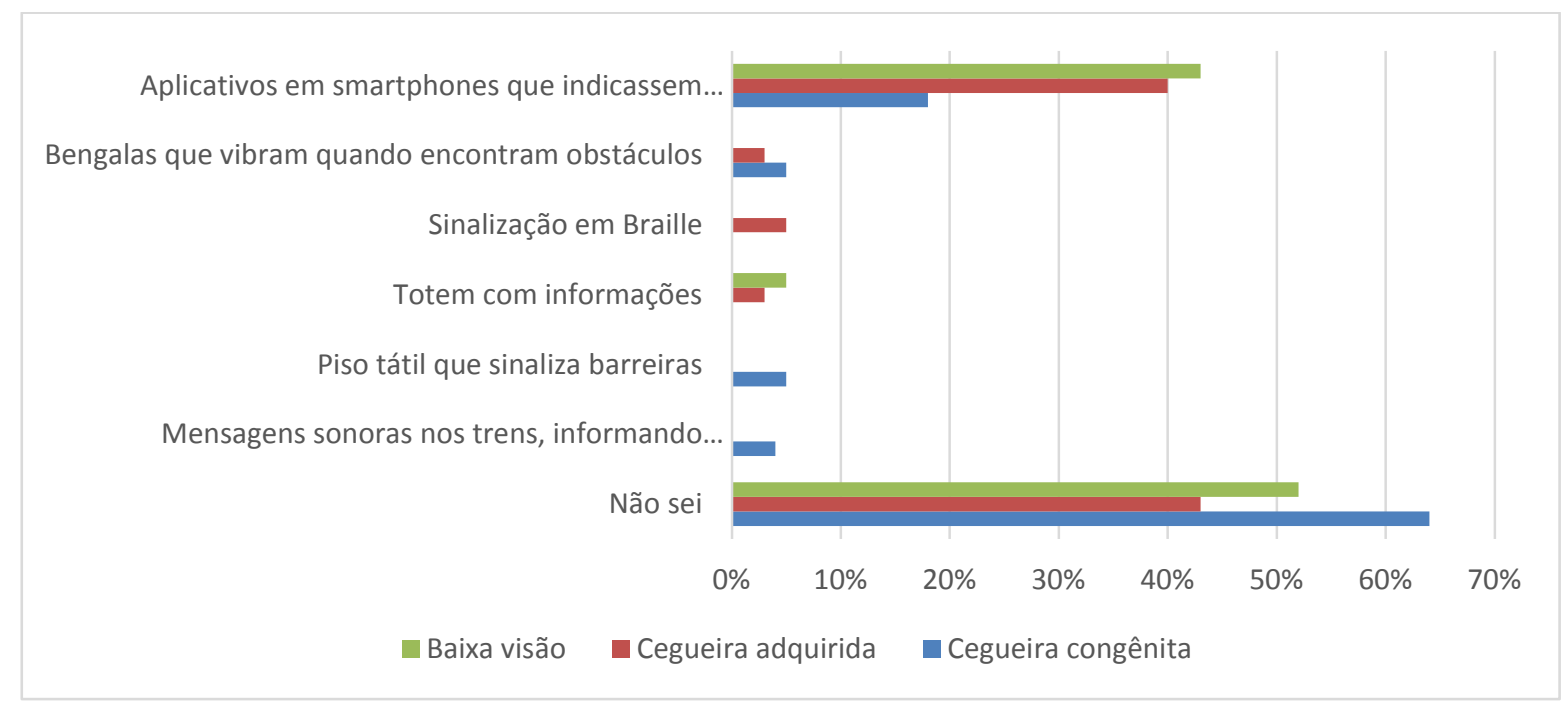

Fonte: Elaborado a partir das respostas ao questionário - Apêndice V.

Dentre as respostas apresentadas no Gráfico 5.12, destaca-se a possibilidade de uso de aplicativos em smartphones para orientar a rota, demonstrando a tendência à aceitação e facilidade de uso de tecnologias eletrônicas para auxiliar a navegação. Nota-se que houve também uma grande quantidade de pessoas que responderam "não sei", o que já era esperado, pois o fato de uma pessoa ter deficiência visual não significa que ela conheça todas as possíveis soluções para seu problema.

Essa tendência ao uso de tecnologias eletrônicas é fortemente reforçada quando analisamos os resultados para a questão "Costuma acessar a internet", obtendo-se valores significativos para a resposta "sim" (Gráfico 5.13).

Gráfico 5.13 - "Costuma acessar a internet?".

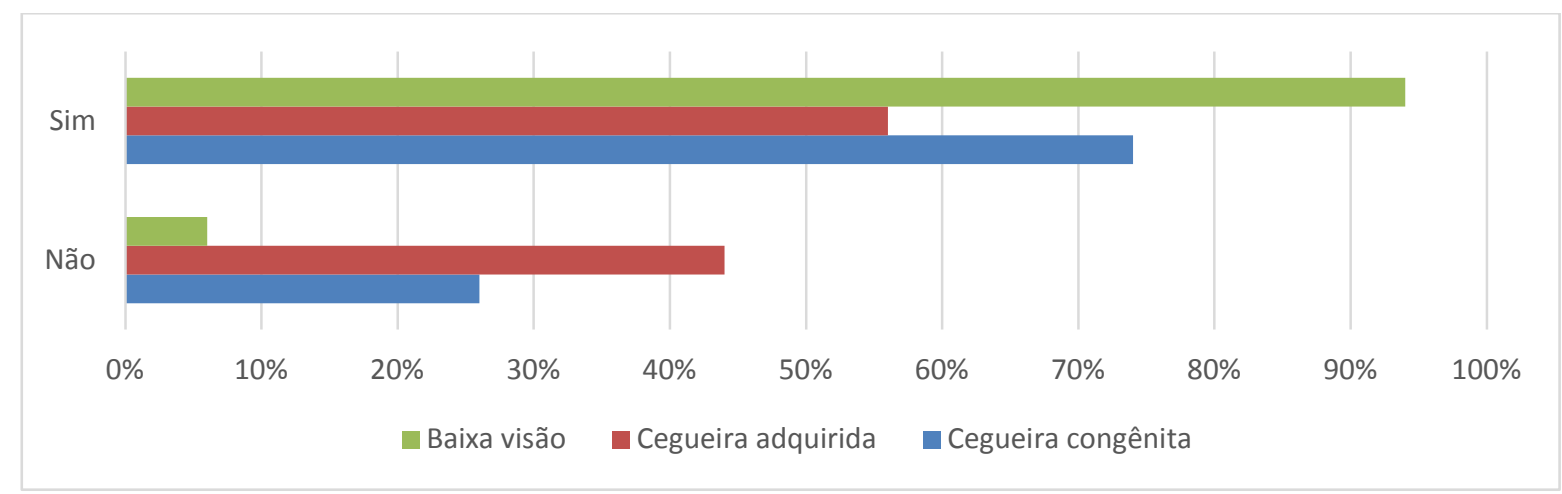

Fonte: Elaborado a partir das respostas ao questionário - Apêndice V. 


\subsection{CONSIDERAÇÕES SOBRE A PESQUISA NO METRÔ DE SÃO PAULO}

A pesquisa realizada no metrô de São Paulo, compreendendo as observações de campo, entrevistas e aplicação de questionário, apresentou resultados que confirmaram a fundamentação teórica e acrescentaram dados significativos a este trabalho, de maneira a contribuir para a elaboração das proposições no capítulo 6.

Constatações como a dificuldade de circulação por estações em horários de grande movimento, com grande interferência dos demais usuários, dificultando a utilização dos sentidos remanescentes das pessoas com deficiência visual para a percepção espaçotemporal do ambiente, especialmente nas estações maiores e de conexão entre linhas, podem significar a necessidade de se manter o serviço de acompanhamento por funcionários ou até de ser intensificado, mesmo com a viabilização de melhorias sugeridas, como auxílios eletrônicos para informação e navegação de pessoas com deficiência visual e melhor divulgação à população sobre essas pessoas.

Mesmo com as dificuldades identificadas, e com um grande número de pessoas com deficiência visual que hoje solicita o auxílio de funcionários (85\%), o número dessas mesmas pessoas que hoje pede auxílio, mas que deseja ser independente, também é grande (72\%), chamando a atenção para que sejam realizadas investigações e estudos a respeito.

A necessidade de instalação de portas de plataformas em todas as estações foi enfatizada pela maioria das pessoas pesquisadas, no entanto sua instalação não é simples e pode até ser inviável em alguns locais, conforme apresentado no referencial sobre redes de metrô. É preciso se pensar em soluções alternativas. 0 acompanhamento por funcionários é uma solução paliativa, que nem sempre funciona, em função da grande quantidade de pessoas a serem atendidas, o que vem crescendo a cada ano, principalmente em função da legislação, a qual passou a favorecer o estudo e o trabalho de pessoas com deficiência em geral.

Sistemas de monitoração, informação e navegação eletrônicos podem auxiliar favoravelmente, principalmente considerando-se que as novas gerações possuem grande facilidade em lidar com smartphones e em absorver novas tecnologias. 
Também é imprescindível maior atenção à adequação e manutenção dos sistemas de comunicação sonora, tanto nas estações como nos trens, especialmente quanto ao anúncio com o nome da próxima estação. No entanto, é difícil a padronização do leiaute interno dos trens, em função da aquisição de veículos de diferentes fornecedores, implicando em diferentes estruturas e mecanismos.

\subsection{VISITAS EXPLORATÓRIAS NO METRÔ DO PORTO}

Nas visitas exploratórias em busca das affordances dos ambientes, caminhou-se pelas estações conforme síntese apresentada no Apêndice U, fotografando-se as áreas públicas e vivenciando-se a experiência de se obter títulos por meio de máquina automática de venda de títulos de viagem, pois no metrô do Porto não existem bilheterias, com a figura humana vendendo títulos, somente máquinas automáticas. Outro fato a notar foi a ausência de bloqueios com validadores, impedindo o acesso de quem não possui títulos, mas somente uma série de validadores estrategicamente distribuídos na passagem para acesso às plataformas. A multa, caso o usuário não valide o título, vai de 10 a 100 vezes o preço da passagem.

As estações próximas ao centro do Porto são subterrâneas, incluindo-se a estação Trindade, onde foi realizada a pesquisa de observação de usuário do Navmetro ${ }^{\circledR}$. Na visita pelas estações da linha D-Amarela, na região de Vila Nova de Gaia, onde as estações são de superfície, foi realizado o acompanhamento de todo o percurso dos trens circulando no mesmo nível de automóveis e outros modais de transporte, assim como também a circulação de pedestres.

As estações de superfície também foram exploradas durante visita aos trechos das linhas ao norte da cidade do Porto, utilizando-se a linha A-Azul até a estação Senhor de Matosinhos, a linha E-Violeta até a estação Aeroporto e linha B-Vermelha até Póvoa do Varzim.

Com relação ao material rodante, a frota de trens do metrô do Porto é formada por dois tipos de veículos: Eurotram e Flexity Swift, com dois carros por composição. 0 tempo de parada nas estações de término é de 30 segundos, e nas demais, 20 segundos. Observouse durante os percursos que, para entrar ou sair dos trens, é necessário apertar um 
botão localizado em cada uma de suas portas, o que é desfavorável às pessoas com deficiência visual quando estão sozinhas.

\subsection{ENTREVISTAS NO METRÔ DO PORTO}

\subsubsection{Funcionários do metrô}

Foram entrevistados os arquitetos Joana Baptista e Manuel Paulo Teixeira ${ }^{72}$. Com base nas anotações de campo, foram identificados os seguintes temas, em relação ao sistema Navmetro $^{\circledR}$ : (a) histórico da execução; (b) objetivos; (c) funcionamento do sistema de informação; (d) funcionamento do sistema de navegação; (e) questões técnicas de seu desenvolvimento; (f) situação atual; e (g) perspectivas.

Foram identificados os seguintes temas:

\section{a) histórico da execução}

Os entrevistados relataram que o metrô do Porto foi concebido com acessibilidade física satisfatória; os veículos eram o estado da arte e a equipe de arquitetos das estações e dos espaços urbanos foi extremamente atenta a este requisito. 0 resultado foi a criação de uma rede livre de barreiras arquitetônicas. Entretanto, quando estavam desenvolvendo a comunicação visual e informações gerais aos usuários (placas com comunicação visual direcional, horários, tarifários, mapas de rede etc.), perceberam que essas informações não iriam chegar aos passageiros com deficiência visual, surgindo a necessidade de se resolver esta lacuna de comunicação.

Os arquitetos contam que a primeira ideia que lhes surgiu para solucionar este problema foi a de se fazer réplicas de todas as informações visuais em Braille. No entanto, perceberam que há informações que se tornam praticamente impossíveis de se reproduzir dessa maneira. Decidiram procurar especialistas, e o desafio de conseguir que os passageiros com deficiência visual conseguissem utilizar a rede do metrô do Porto com total autonomia, tal como os demais usuários foi então exposto à ACAPO

720 arquiteto João Paulo Teixeira participou ativamente de todo o processo de desenvolvimento do Navmetro ${ }^{\circledR}$, no entanto não estava mais trabalhando na empresa. Ele fez questão de participar da entrevista. 
(Associação de Cegos e Amblíopes de Portugal), que lhes sugeriu que o ideal seria disponibilizar toda a informação em áudio.

Para auxiliar os técnicos do metrô do Porto a disponibilizar em áudio todas as informações, foram procurados pela FEUP, na pessoa do professor Diamantino Freitas, em 1998, que expôs a sua ideia para viabilizar a informação e o encaminhamento dos usuários com deficiência visual, tendo disponibilizado o Laboratório de Sinais e Sistemas da FEUP para estudos e desenvolvimento.

Em 2000 foi celebrado um Protocolo entre a empresa Metro do Porto, FEUP e ACAPO, com o principal objetivo de reunir em torno do projeto, as entidades com os conhecimentos necessários para que o Navmetro ${ }^{\circledR}$ pudesse efetivamente resultar em uma ferramenta de utilização diária para as pessoas com deficiência visual.

Foram feitos testes com "práticos" (pessoas acostumadas a circular pelo metrô) e "principiantes", com acompanhamento de professor de Orientação e Mobilidade.

\section{b) objetivos}

Disponibilizar toda a informação relativa à operação do metrô em modo áudio, em telefones celulares comuns, e fácil de ser utilizado, por meio de uma organização lógica dos menus, e ainda suportada por um software com reconhecimento de voz.

Criar um sistema de orientação sonora dentro das estações subterrâneas, de maneira a auxiliar a navegação, proporcionando autonomia a pessoas com deficiência visual circulando por essas estações.

\section{c) funcionamento do sistema de informação}

O Navmetro ${ }^{\circledR}$ possui dois tipos de funcionamento: o primeiro, disponibiliza em formato áudio, por ligação telefônica, toda a informação de operação existente nas estações em painéis de comunicação visual e que permite ter informação suficiente para realização de uma viagem. (Por ex.: esquema das linhas, nome das estações, horários, tarifários etc.). Para efeito deste trabalho, será utilizada a expressão "sistema de informação", como referência a esse primeiro funcionamento.

O nome que é dado atualmente a este sistema de informação é a linha de atendimento “Olá Metro!” e não é necessário que se instale nenhum aplicativo no telefone, pois utiliza 
somente o teclado comum do aparelho, podendo ser utilizado por qualquer tipo de telefone celular GSM.

Atualmente o serviço de informação pode ser utilizado de forma simultânea por até dez pessoas, e isso tem-se mostrado suficiente, no entanto é possível aumentar esse número, com expansão do sistema, se necessário.

Os entrevistados consideraram que, apesar da boa aceitação, o diálogo precisa ser melhorado, pois existem muitos "confirme", tornando sua utilização desagradável para algumas pessoas, especialmente àquelas que já utilizam o sistema de informação de maneira frequente (avançada).

\section{d) informações adicionais sobre o sistema de navegação}

0 segundo tipo de funcionamento do Navmetro $^{\circledR}$, e o mais importante para esta pesquisa, disponibiliza um sistema compatível com as funções da audição, permitindo a sua orientação dentro do espaço físico de uma estação, em substituição à comunicação visual e demais informações visuais utilizadas para seu encaminhamento. Esse sistema consegue traçar uma rota na estação, após o usuário haver especificado o seu destino, por recurso ao diálogo com o sistema de informação do Navmetro ${ }^{\circledR}$, e guiá-lo até seu embarque ou saída. Para efeito deste trabalho, será utilizada a expressão "sistema de navegação", como referência a esse segundo funcionamento.

Atualmente a utilização do serviço de orientação pessoal só pode ser realizada por um usuário de cada vez, em cada piso, devido às interferências sonoras que podem ocorrer no que os técnicos chamam de espaço acústico. Porém, eles informam que o sistema vem sendo aprimorado, de forma a possibilitar maior flexibilidade no uso compartilhado deste serviço.

Os entrevistados informam que, em termos práticos, ao chegar à estação, seja pelo acesso da rua ou pelo desembarque nas plataformas, o usuário liga para a central de atendimento e informa seu destino. 0 sistema então utiliza mecanismos para obter sua localização no espaço da estação, e leva o usuário a seguir um conjunto de boias sonoras que estão estrategicamente posicionadas no teto da estação, e cujo acionamento sequencial permite criar todas as rotas possíveis dentro daquele espaço. 0 som escolhido para as boias sonoras, foi o som produzido por um pássaro estrategicamente escolhido por meio de pesquisa técnica, por ser um som que se distinguia bem de toda a 
cacofonia típica de um espaço público, e também por ser facilmente identificado, por ser um som inusitado em um espaço subterrâneo.

Da mesma maneira que ocorre com o sistema de informação, para se usar o sistema de navegação não é necessário que se instale nenhum aplicativo no telefone, pois utiliza somente o teclado comum do aparelho, podendo ser utilizado com qualquer tipo de telefone celular GSM.

\section{e) questões técnicas do desenvolvimento}

As dificuldades para o desenvolvimento do Navmetro ${ }^{\circledR}$ foram de várias ordens, mas destacam-se as dificuldades técnicas surgidas ainda na fase de projeto, tais como, conceber um sistema que teria obrigatoriamente que ser de fácil utilização, compatível com qualquer telefone celular de mercado e cujo sistema de orientação sonora nas estações fosse de interação pacífica com os demais sistemas de informação aos usuários.

Um dos principais desafios foi estruturar toda a informação existente e criar os diálogos possíveis com os utilizadores, organizando a informação de maneira bastante lógica.

Definiu-se a necessidade de o sistema compreender não somente a fala do usuário, mas também a variação de sotaques, que é bem grande em Portugal, e também interpretar seu destino a partir de nomes comumente referenciados à determinada estação que não o seu nome próprio. Por exemplo, para referir-se à estação Estádio do Dragão a pessoa pode falar somente "Dragão", ou "Porto" (em referência ao estádio do Porto Futebol Clube, localizado junto à estação) ou ainda "Antas" (em referência ao nome do bairro onde se localiza esta estação); de todas essas formas o sistema fará a interpretação de que o destino é Estádio do Dragão.

\section{f) situação atual}

Na opinião dos arquitetos, as ferramentas do Navmetro ${ }^{\circledR}$, principalmente o sistema de informação, demonstraram ser bastante úteis, levando a empresa Metro do Porto a decidir pela sua disponibilização a todos os usuários, e também ampliação para serviços de Achados e Perdidos. Por meio de sua linha de atendimento “Olá Metro!", o serviço de informações efetuou em torno de 17.000 atendimentos no último ano. O serviço de informação para pessoas com deficiência visual efetuou em torno de 1.000 atendimentos no último ano. 
Já no que se refere ao sistema de navegação, conta-se com 56 usuários, o que é significativo considerando-se que está instalado apenas na estação central da Trindade. Tanto o serviço de informação como o de navegação não são tarifados pelo metrô; apenas é cobrado o valor de uma ligação local pela operadora de telefonia móvel escolhida pelo usuário, como em uma ligação comum. Pessoas com deficiência visual cadastradas são isentas também do custo da ligação. Vale lembrar que no metrô do Porto, pessoas com deficiência não têm isenção no valor dos títulos de viagem.

\section{g) perspectivas}

Os arquitetos informam que já está pronto o projeto de expansão do sistema de navegação para a estação Campo 24 de Agosto, estagnado pela crise econômica na Europa. Porém estão otimistas, porque o Navmetro ${ }^{\circledR}$ foi integrado no núcleo dos sistemas de ajuda e informação, de fornecimento obrigatório, em todas as futuras estações da rede.

Vale lembrar que o sistema de informação é um recurso disponível para todas as estações, necessitando apenas de atualização de dados quando houver expansão da rede, com novas estações.

Finalmente eles relatam que o Navmetro $^{\circledR}$ já possui patente nacional e internacional, havendo manifestações de interesse de sua aplicação em outros edifícios públicos, como centros de compras, por exemplo.

\subsubsection{Professor da FEUP}

Foi entrevistado o professor Diamantino Freitas, docente do Departamento de Engenharia Eletrotécnica e de Computadores da FEUP - Faculdade de Engenharia da Universidade do Porto. Com base nas anotações de campo, foram identificados os seguintes temas, em relação ao sistema Navmetro ${ }^{\circledR}$ : (a) histórico do projeto; (b) desenvolvimento do projeto; (c) inconvenientes e pontos de melhoria.

Foram identificados os seguintes temas:

\section{a) histórico do projeto}

Nos anos 1990 ocorreu o avanço da digitalização nas telecomunicações, porém percebeu-se que as novas tecnologias não serviam diretamente às pessoas com 
deficiência visual. Nessa mesma época foi criada a COST, agência de investigação científica e técnica da cooperação europeia, que passou a desenvolver, entre outras, pesquisas na área de acessibilidade, com o apoio do Programa Operacional Sociedade do Conhecimento (POSC). Por meio desses trabalhos, visualizou-se uma oportunidade de negócio, e a Portugal Telecom foi sensibilizada, passando a investir mais no reconhecimento e síntese de voz.

No ano 2000 o professor entrevistado participou de um congresso de telecomunicações no Rio de Janeiro, no qual se identificou sistemas de transportes (de maneira geral) como tendo muitas informações "a negro", ou seja, não legíveis a pessoas com deficiência visual. Nessa época, o sistema de comunicação GSM ainda era limitado para determinados usos, mas ganhava força e desenvolvimento.

Em 2005, após algumas tentativas de se propor algo nessa área aos operadores de transporte de Portugal, tentativas frustradas por mudanças na política nacional, finalmente representantes da FEUP, dentre eles o professor Diamantino, decidiram procurar o metrô do Porto, que aceitou a ideia, convidando a ACAPO, como representante das pessoas com deficiência visual, a fazer parte do processo.

Em 2007 começaram a trabalhar nos dois projetos: de informação e de navegação. Conseguiram financiamento para trabalhar no protótipo, do qual foi feita uma demonstração pública em 2008. Ele relata que houve certa resistência por parte de consultores da ACAPO, mas que finalmente foi executado na estação Trindade.

\section{b) desenvolvimento do projeto}

Desde o início do desenvolvimento do projeto foi pensado em se utilizar a comunicação auditiva com as pessoas com deficiência visual, e procedeu-se a pesquisas e estudos de maneira a realizar essa comunicação. Havia um importante componente necessário para o funcionamento do sistema, que constituía uma grande dificuldade: a identificação do posicionamento do usuário no espaço da estação.

A primeira ideia para se gerar essa localização foi por meio de uma rede de sinal Bluetooth, porém, mesmo com o acréscimo de recursos técnicos, a imprecisão e a lentidão inviabilizaram o uso desse tipo de recurso. 0 raciocínio seguinte foi o de se utilizar rede com sinal Wi-Fi, e inclusive chegaram a adquirir e instalar um sistema de localização via Wi-Fi, porém teve de ser abandonado devido às interferências 
eletromagnéticas (como a circulação dos trens, por exemplo) e a principal falha, o cruzamento de sinais entre plataformas, de maneira que o sistema poderia confundir se o usuário estava na Plataforma 1 ou Plataforma 2.

Finalmente surgiu a ideia de "boias sonoras", utilizando-se os próprios alto-falantes da estação, constituindo o sistema inaugurado em 3 de dezembro de 2009, em funcionamento até hoje. Para localização das boias sonoras foram realizados testes minuciosos para identificação dos ângulos de captação do som (azimutais), chegando-se a um erro máximo de 4 graus de direção.

No estudo dos tipos de sons a serem emitidos, houve consenso de que não poderia ser um som que incomodasse aos demais usuários nem que lhes causasse pânico, como sons de alarme. Verificou-se que sons metálicos são facilmente percebidos pelo ouvido humano, assim como chilros de pássaros, tendo-se optado por um destes chilros.

\section{c) inconvenientes e pontos de melhoria}

Um inconveniente identificado pelo entrevistado é que o sistema utiliza operadoras de rede GSM, ficando suscetível ao seu funcionamento adequado.

Um aspecto a ser melhorado, em sua opinião, é a respeito da maneira de se efetuar a localização do usuário dentro da estação, para uso do sistema de navegação. Ele informa que já realizaram estudos para uma nova maneira de localização do usuário, já que este é atualmente um dos pontos de insatisfação dos clientes. Nestes novos estudos, ao realizar a ligação telefônica, é emitido na estação um som inaudível às pessoas, mas que é captado pelo microfone do aparelho celular, o que permite que o sistema localize automaticamente a posição do usuário.

Outro ponto de melhoria é a respeito do diálogo. Mesmo com todos os estudos para se criar uma lógica de diálogo por meio de telefone celular, ainda é necessário que sejam feitas melhorias na forma de diálogo disponibilizada, como, por exemplo, criação de atalhos para usuários que já dominam o sistema.

\subsubsection{Análise de conteúdo}

$\mathrm{Na}$ análise de conteúdo das entrevistas com os representantes do metrô do Porto e com o professor da FEUP, observa-se o foco a respeito das pesquisas já realizadas e das 
pesquisas em andamento pelas equipes, a respeito do Navmetro ${ }^{\circledR}$, com relação aos sons de pássaros, para navegação no interior das estações e para incrementar o sistema de informação geral. Também se nota com grande frequência a menção à continuidade dos estudos para melhoria do sistema, especialmente com relação à localização do usuário na estação e à lógica da comunicação pelo telefone celular.

\subsection{OBSERVAÇÃO PARTICIPANTE NO METRÔ DO PORTO}

A pessoa com deficiência visual que participou da observação foi "F.", um senhor de 72 anos de idade que ficou totalmente cego aos 19. Não recebeu treinamento de orientação e mobilidade, apenas o incentivo de uma irmã, que o orientou e estimulou para circular com autonomia pelas ruas da cidade do Porto. "F." exerceu a profissão de telefonista a partir desta idade, e está aposentado há alguns anos. Boa parte de sua vida foi auxiliado por cães-guia. Quando o último faleceu, há cerca de quatro anos, "F." abriu mão deste recurso, passando a se utilizar somente de bengala. Habituado a caminhar pelas ruas do Porto, "F." mantém seus sentidos remanescentes preservados e não se intimida em utilizar sozinho o metrô e outros modais de transporte.

Para a observação foi elaborado o protocolo de pesquisa, conforme Quadro 5.7. 
Quadro 5.7 - Protocolo de observação adotado.

\begin{tabular}{|c|c|}
\hline \multicolumn{2}{|r|}{ Protocolo de observação - Estação Trindade } \\
\hline \multicolumn{2}{|r|}{ Usuário com deficiência visual } \\
\hline $\begin{array}{l}\text { Entrevista aberta, de } \\
\text { caráter informal, } \\
\text { realizada como } \\
\text { preparo para } \\
\text { observação } \\
\text { participante }\end{array}$ & $\begin{array}{l}\text { Grau da deficiência. Congênita ou não. } \\
\text { Recebeu treinamento de orientação e mobilidade? } \\
\text { Motivo e frequência de uso do metrô. } \\
\text { Há quanto tempo utiliza o metrô. } \\
\text { Utiliza auxílio de um funcionário? Por quê? }\end{array}$ \\
\hline $\begin{array}{l}\text { Local de partida da } \\
\text { observação }\end{array}$ & $\begin{array}{l}\text { Data, horário, local; descrição sucinta da entrada da estação, fluxo de } \\
\text { pessoas; a pessoa observada chegou sozinha ou acompanhada, entrou na } \\
\text { estação sozinha ou acompanhada. }\end{array}$ \\
\hline $\begin{array}{l}\text { Caracterização da } \\
\text { pessoa observada }\end{array}$ & $\begin{array}{l}\text { Utiliza bengala, de que tipo, segura a bengala com qual das mãos; porta } \\
\text { itens tais como bolsa, mochila; segura algo nas mãos (além da bengala). }\end{array}$ \\
\hline $\begin{array}{l}\text { O percurso da entrada } \\
\text { até a espera pelo trem } \\
\text { na linha } D \text {, utilizando } \\
\text { o Navmetroß: }\end{array}$ & $\begin{array}{l}\text { Observá-lo: efetuar a ligação telefônica, perceber os sinais emitidos pelos } \\
\text { alto-falantes (boias sonoras), dar o retorno ao sistema, perceber se o } \\
\text { sistema conseguiu localizá-lo, seguir na direção do som do pássaro até o } \\
\text { próximo ponto, dar o retorno ao sistema, seguir na direção do som do } \\
\text { pássaro até o próximo ponto, e assim sucessivamente, até chegar ao local } \\
\text { de destino. Observar também se ele utiliza escadas, elevadores, se esbarra } \\
\text { em objetos ou pessoas, se busca referências físicas, além dos sons das boias } \\
\text { sonoras. }\end{array}$ \\
\hline $\begin{array}{l}\text { O percurso da } \\
\text { plataforma até a saída }\end{array}$ & $\begin{array}{l}\text { Deslocamento passo a passo desde o desembarque do trem até a saída para } \\
\text { a rua, nos moldes da alínea "c". }\end{array}$ \\
\hline Tempo & $\begin{array}{l}\text { Tempo físico ao percorrer cada fase da observação; entrada estação/nível } \\
\text { intermediário/plataforma, e plataforma/nível intermediário/saída. }\end{array}$ \\
\hline $\begin{array}{l}\text { Sentimentos e } \\
\text { impressões }\end{array}$ & $\begin{array}{l}\text { Registro de emoções ou referências manifestadas: tranquilidade, pressa, } \\
\text { irritabilidade, segurança, confiança etc. }\end{array}$ \\
\hline Outras observações & Ocorrências relevantes \\
\hline \multicolumn{2}{|r|}{ Demais usuários } \\
\hline Comportamento & $\begin{array}{l}\text { Interferências no caminhar do usuário com deficiência; procuram auxiliar; } \\
\text { atrapalham. }\end{array}$ \\
\hline
\end{tabular}

"F." chegou à estação Trindade pela plataforma superior, no nível do acesso, e realizou um percurso de embarque na plataforma inferior, passando pelo nível intermediário. A Figura 5.9 representa um corte transversal à estação, no qual se pode identificar os seus vários níveis. 
Figura 5.9 - Corte da estação Trindade.

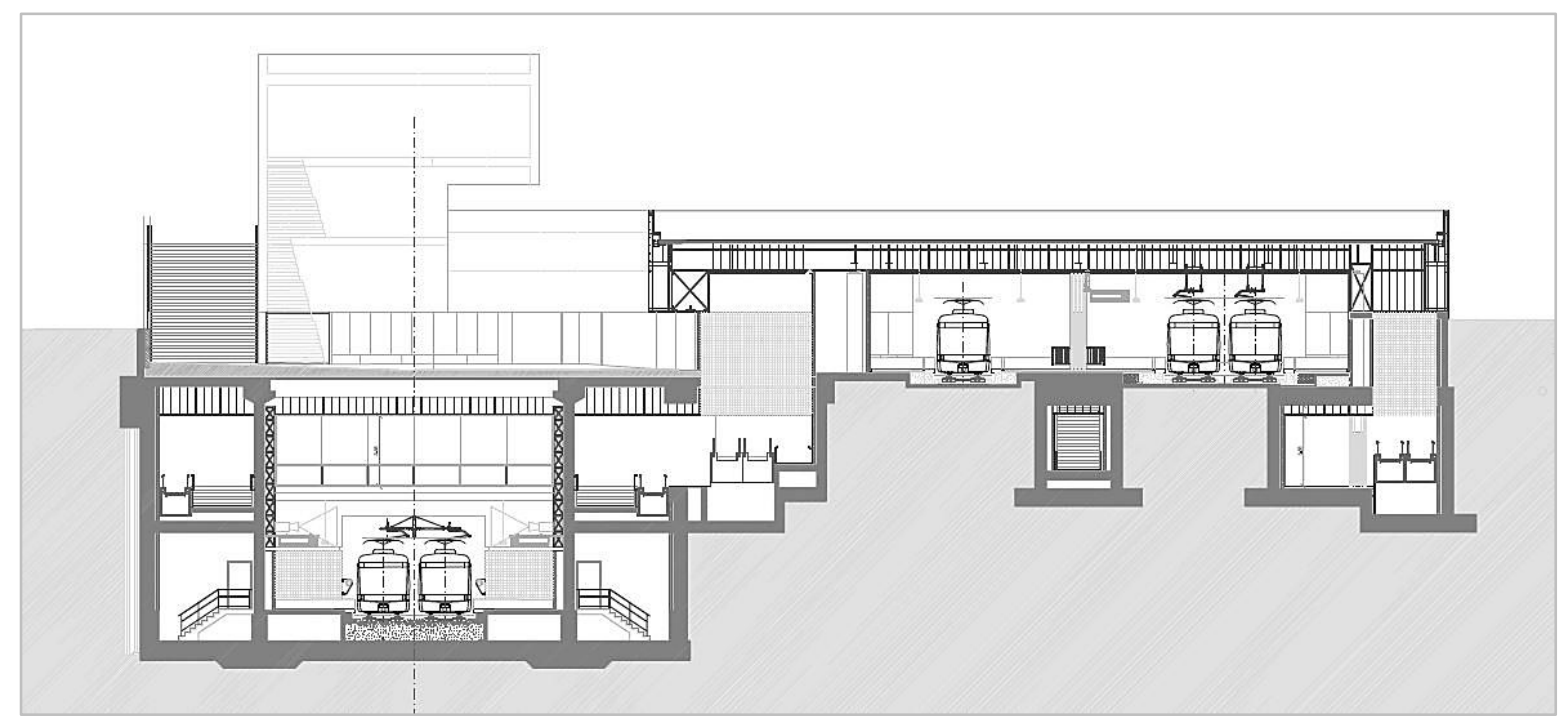

Fonte: Metro do Porto (2015).

A Figura 5.10 representa a planta do nível acesso e plataformas das linhas A, B, C, E e F, com indicação do percurso inicial de embarque de "F." em amarelo.

Figura 5.10 - Planta do nível acesso e plataformas linhas A, B, C, E e F da estação Trindade - embarque.

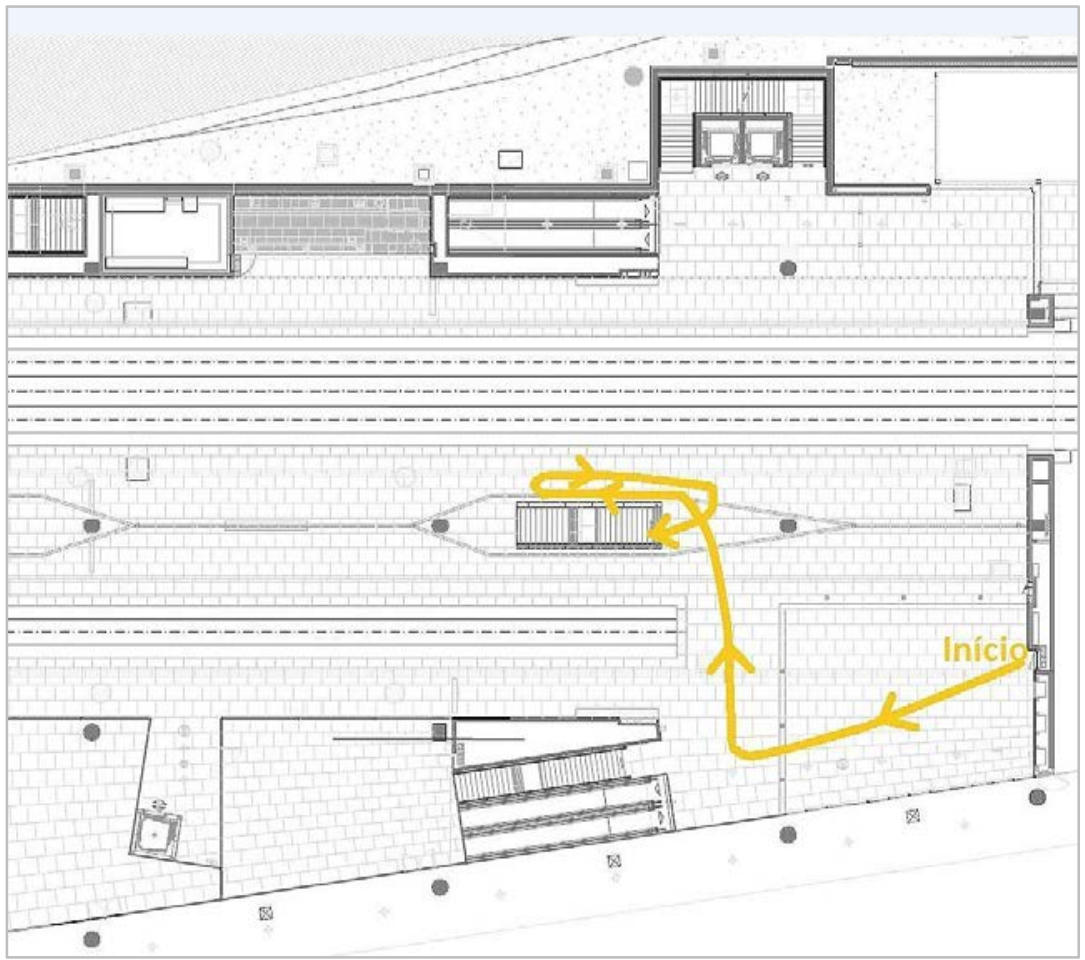

Fonte: Elaborado sobre documento fornecido pelo Metro do Porto(2015).

A Figura 5.11 representa a planta do nível intermediário, com indicação da sequência do percurso de embarque de "F." em amarelo. 
Figura 5.11 - Planta do nível intermediário da estação Trindade - embarque.

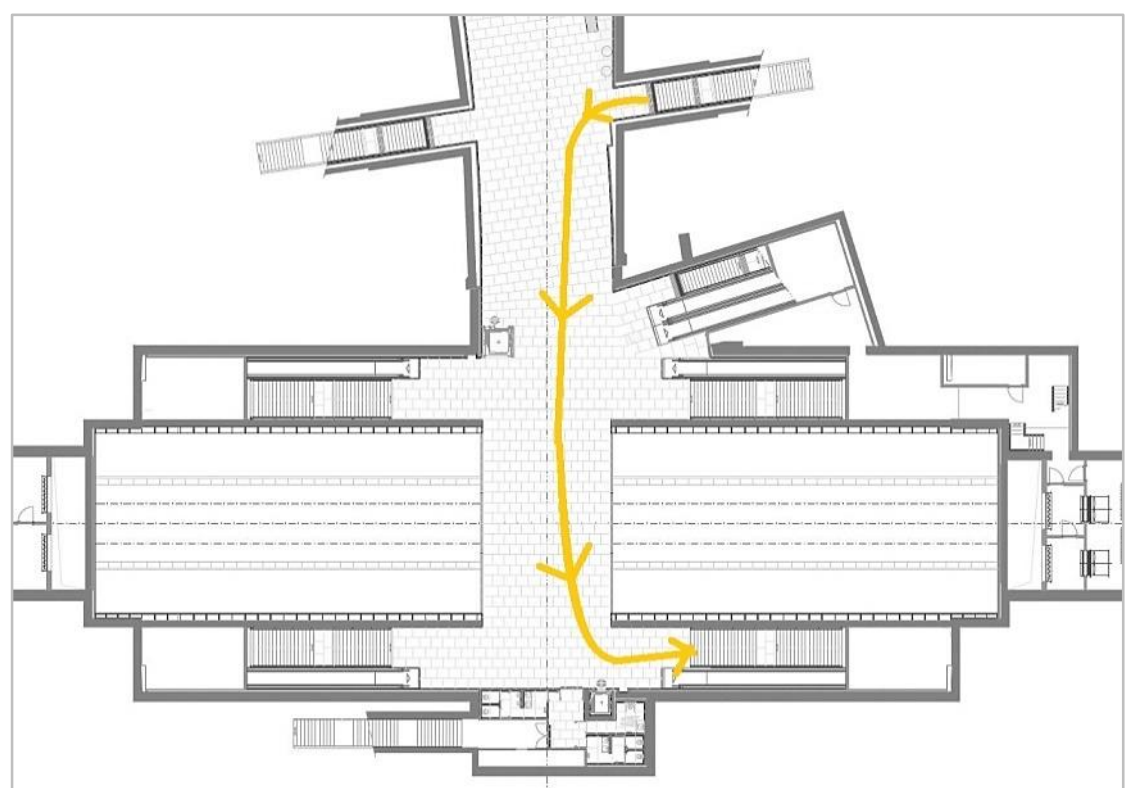

Fonte: Elaborado sobre documento fornecido pelo Metro do Porto (2015).

A Figura 5.12 representa a planta do nível plataforma da linha D, com indicação da sequência do percurso de embarque de "F." em amarelo, até o destino final na plataforma, simulando-se seu embarque no trem. Na sequência, em azul, consta o retorno de "F.", com indicação do seu percurso de desembarque e saída da estação.

Figura 5.12 - Planta da plataforma da linha D da estação Trindade - embarque e saída.

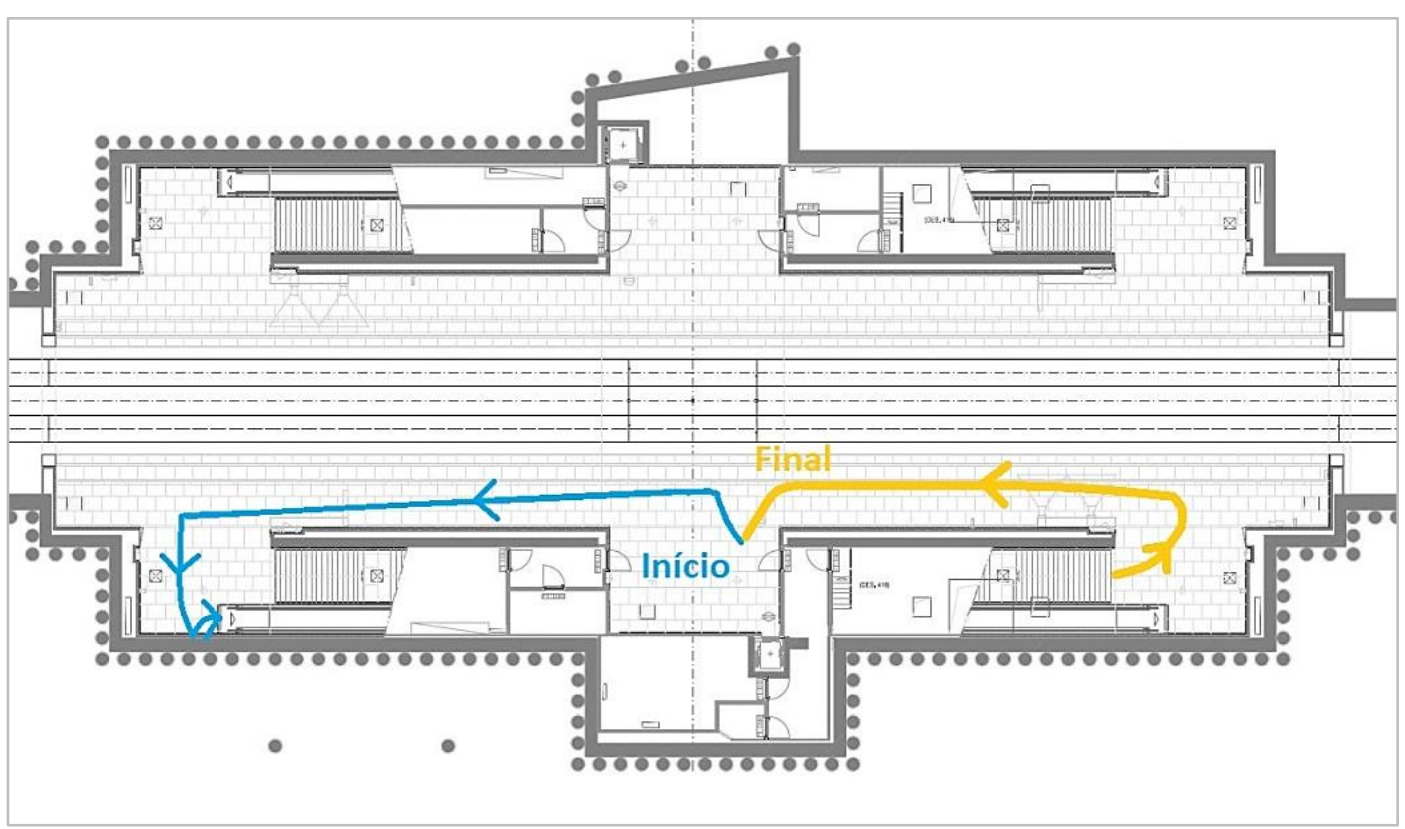

Fonte: Elaborado sobre documento fornecido pelo Metro do Porto (2015). 
A Figura 5.13 representa a planta do nível intermediário, com indicação da sequência do percurso de saída de "F." em azul.

Figura 5.13 - Planta da plataforma da linha D da estação Trindade - saída.

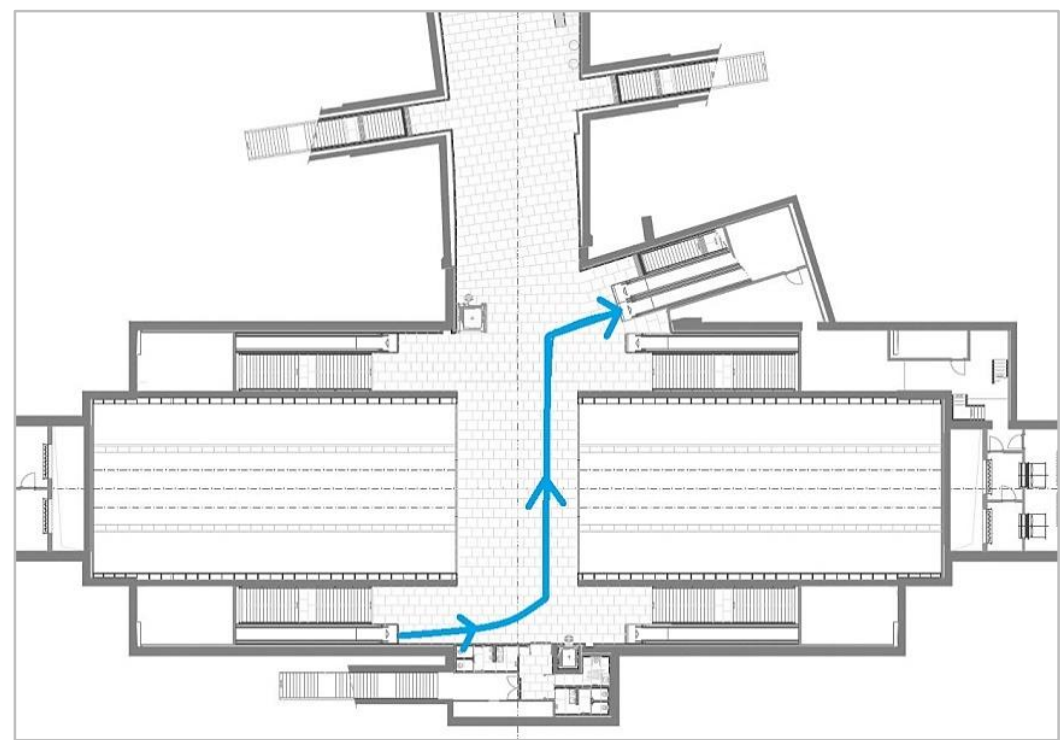

Fonte: Elaborado sobre documento fornecido pelo Metro do Porto (2015).

A Figura 5.14 representa a planta do nível do acesso, com indicação do trecho final do percurso de "F." em azul.

Figura 5.14 - Planta do nível acesso e plataformas das linhas A, B, C, E e F da estação Trindade - saída.

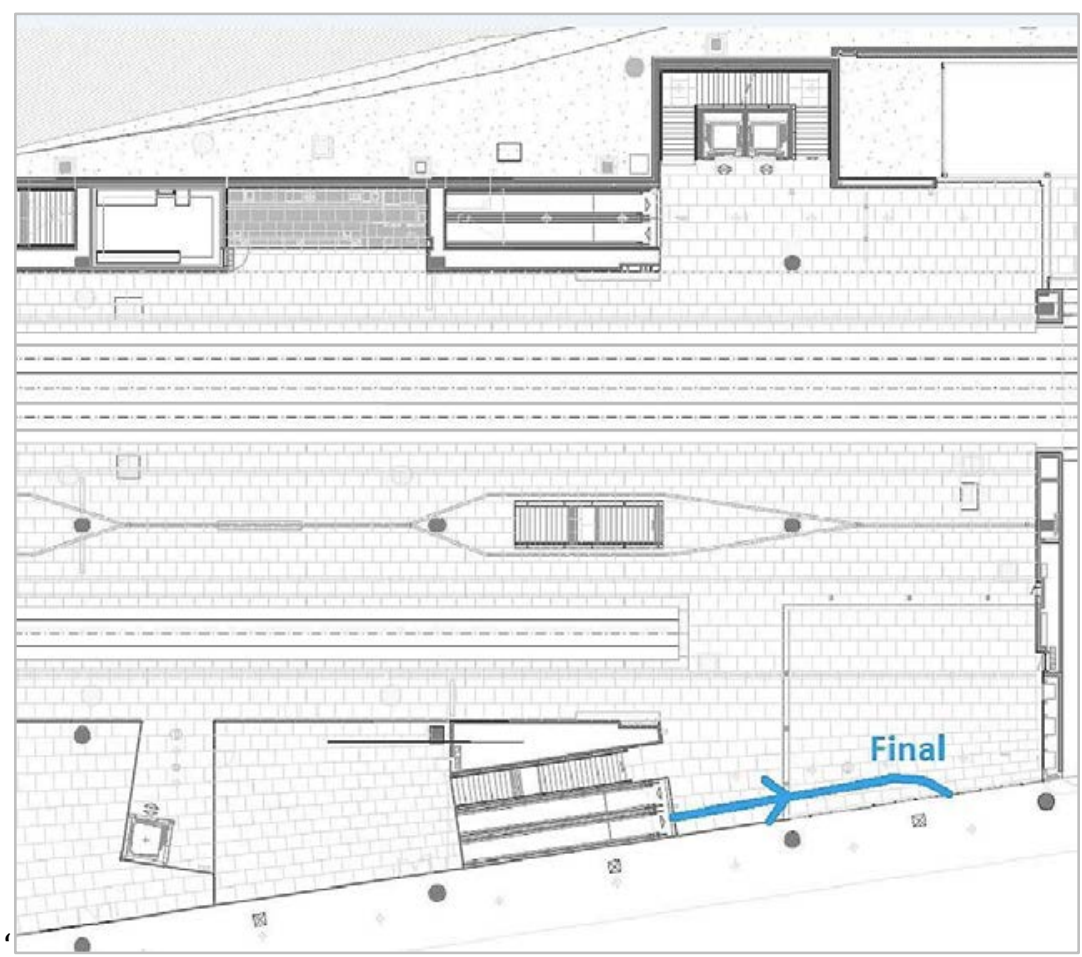

Fonte: Elaborado sobre documento fornecido pelo Metro do Porto (2015). 


\subsubsection{Síntese da observação de “F."}

"F." chegou à estação Trindade pelo trem na plataforma superior (Figura 5.15) e foi recebido pelo professor Diamantino Freitas da FEUP, que também acompanhou os testes, assim como a arquiteta Joana Baptista, da empresa Metro do Porto.

Figura 5.15 - Vista da chegada pelo acesso da praça à estação Trindade.

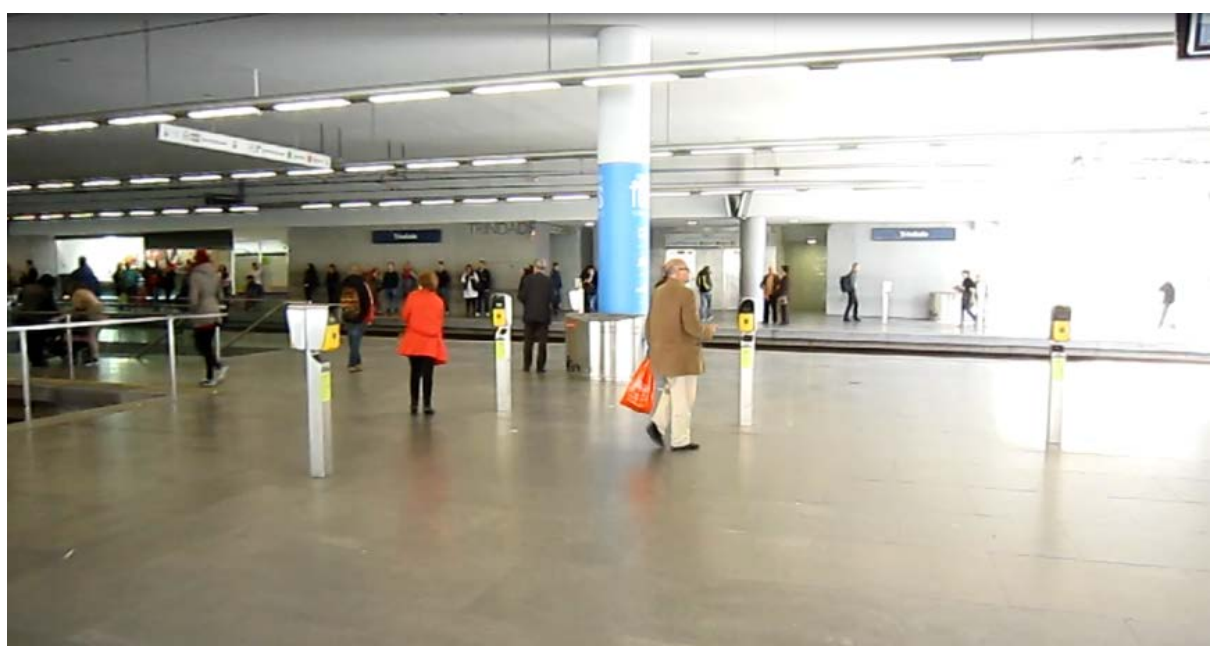

Crédito: MARIANI, E., 2015.

Após as apresentações, a pesquisadora informou que o percurso seria gravado e relembrou que o trajeto e suas ações deveriam ocorrer da maneira mais natural possível, como em uma viagem que ele normalmente faz. "F." iniciou realizando a ligação de seu próprio telefone celular para o Navmetro ${ }^{\circledR}$ (Figura 5.16) informando que desejava ir para a estação Marquês da linha D-Amarela. Como estava no piso superior, significou que o sistema deveria guiá-lo até a plataforma no piso inferior, passando pelo piso intermediário. 
Figura 5.16 - "F." efetuando a ligação para dar início à orientação pelo Navmetro ${ }^{\circledR}$

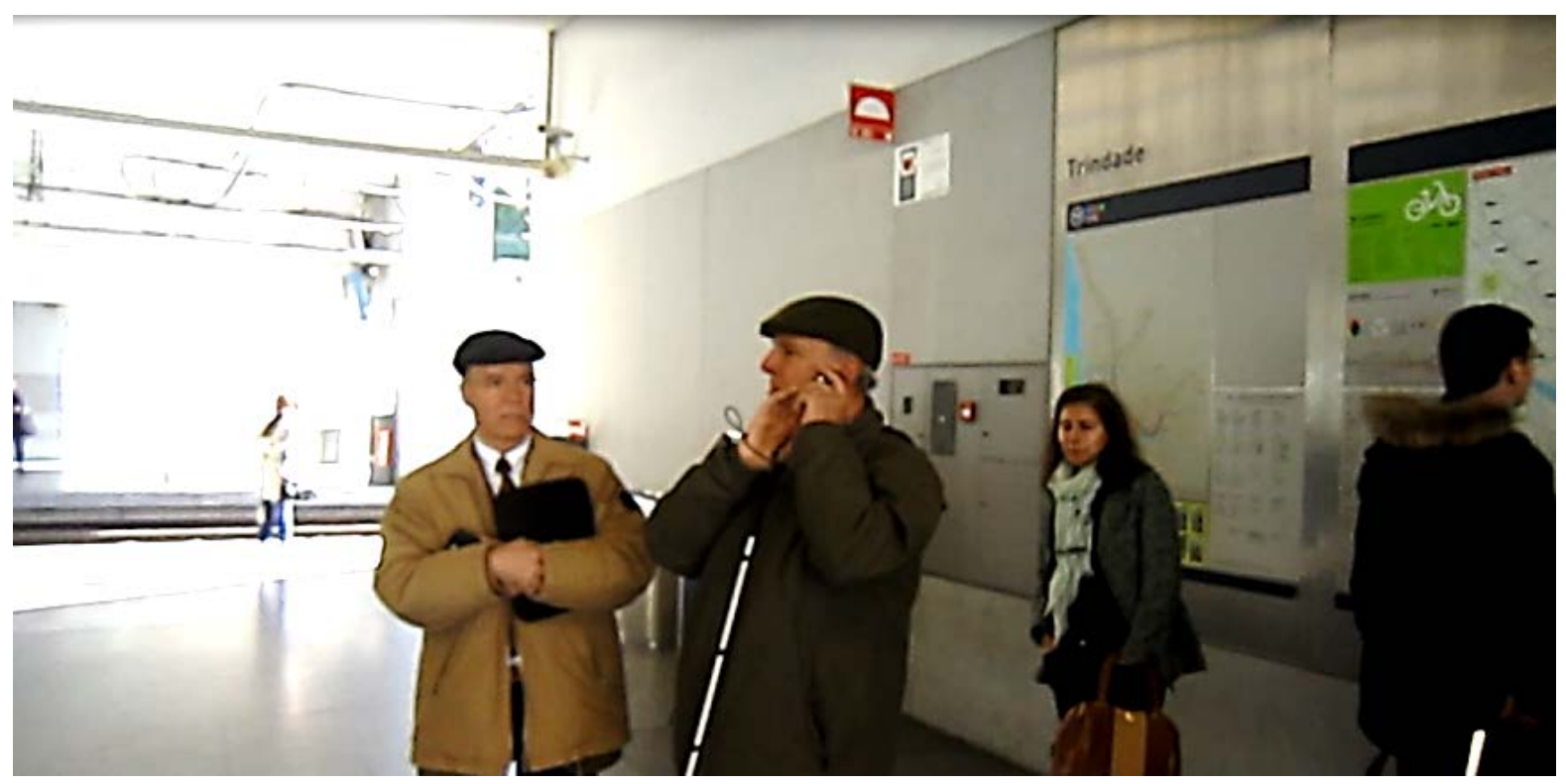

Crédito: MARIANI, E., 2015.

O sistema acionou as boias sonoras deste piso, que emitiram os seguintes sons: "primeira", "segunda" e "terceira", nesta sequência, em posições diferentes dentro da estação, e "F." falou "segunda", ao telefone, que foi o som que ele ouviu mais próximo. Desta forma o sistema pode identificar a região onde ele se encontrava na estação, e começou a emitir repetidamente o som de um pássaro na direção de uma escada que o levaria para a plataforma inferior. "F." seguiu na direção desse som, tranquilo, utilizando a bengala com uma das mãos e segurando o telefone junto ao ouvido com a outra (Figura $5.17)$. 
Figura 5.17 - Após ser identificado pelo sistema, "F." seguiu na direção do som do pássaro.

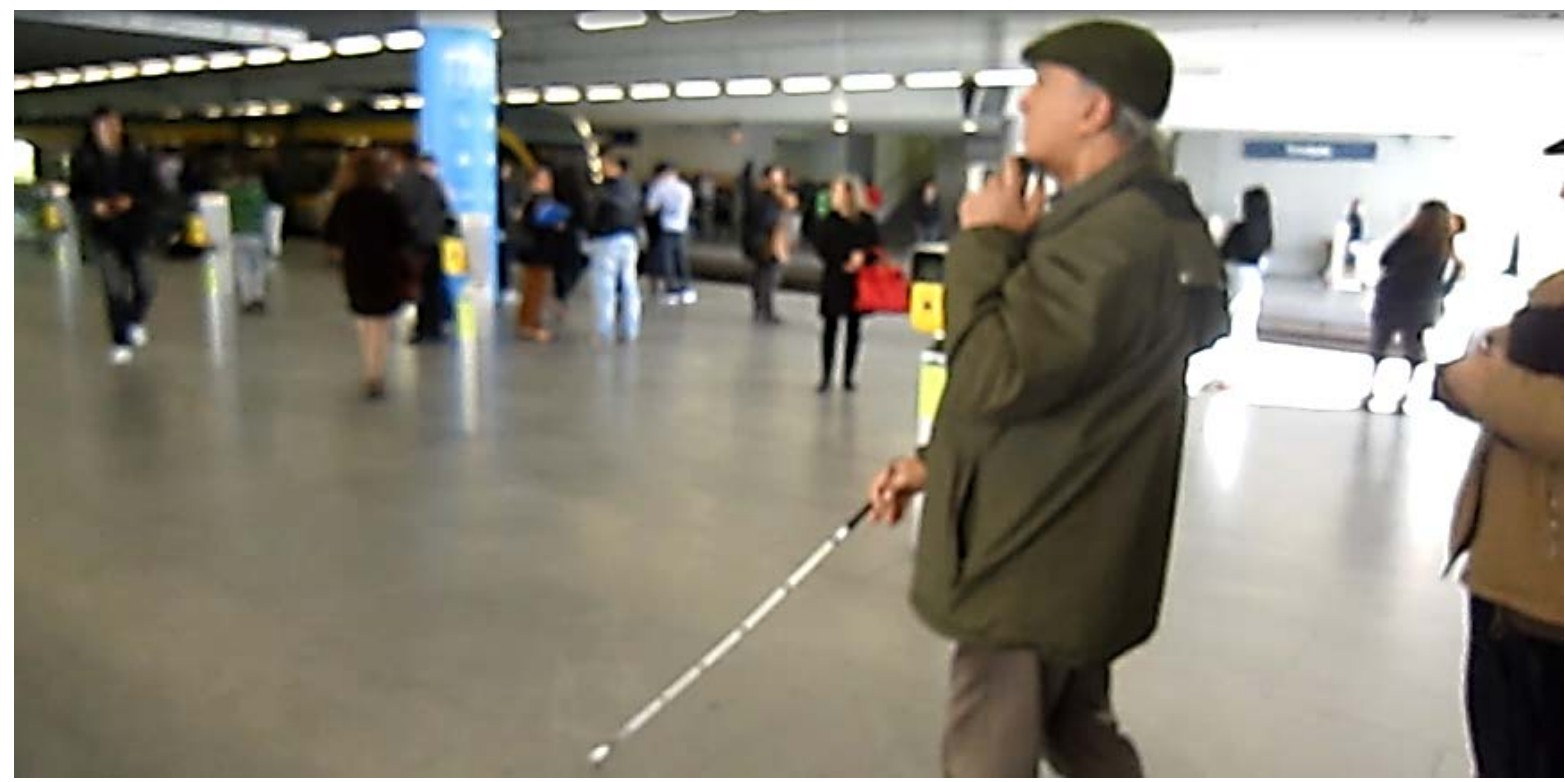

Crédito: MARIANI, E., 2015.

Observou-se ao longo de todo o percurso, que muitos usuários ofereceram auxílio (Figura 5.18) e que estas abordagens causavam interferência na concentração de "F.".

Figura 5.18 - Usuária oferecendo auxílio a "F.".

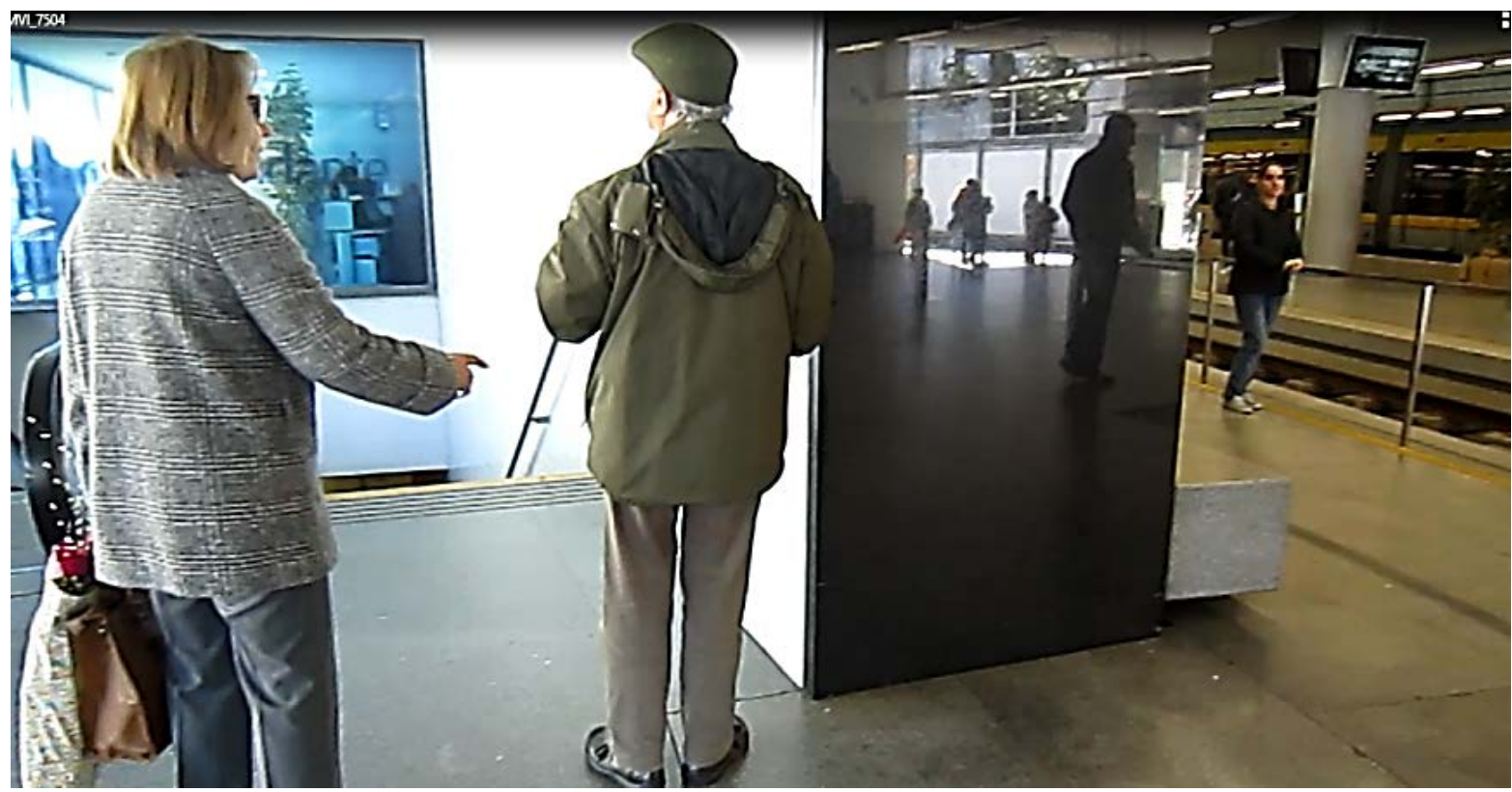

Crédito: MARIANI, E., 2015.

Mais à frente "F." teve dúvida se estava na direção certa, e decidiu reiniciar o atendimento, finalizando a ligação e ligando novamente, repetindo todo o processo de localização pelas boias sonoras. Aqui se notou uma atitude que veio a se repetir durante todo o trajeto: o barulho natural da estação interfere na informação que lhe está sendo 
dada pelo telefone, pois sempre que ele não estava falando, cobria o microfone do celular com a mão, buscando ouvir melhor. Outra observação importante, é que todas as vezes em que ele necessitou ouvir o som das boias sonoras do ambiente, foi necessário afastar o telefone do ouvido, podendo acarretar na perda de alguma instrução (Figura 5.19).

Figura 5.19 - "F." ouvindo a comunicação via celular e ouvindo os sons das boias sonoras do ambiente.
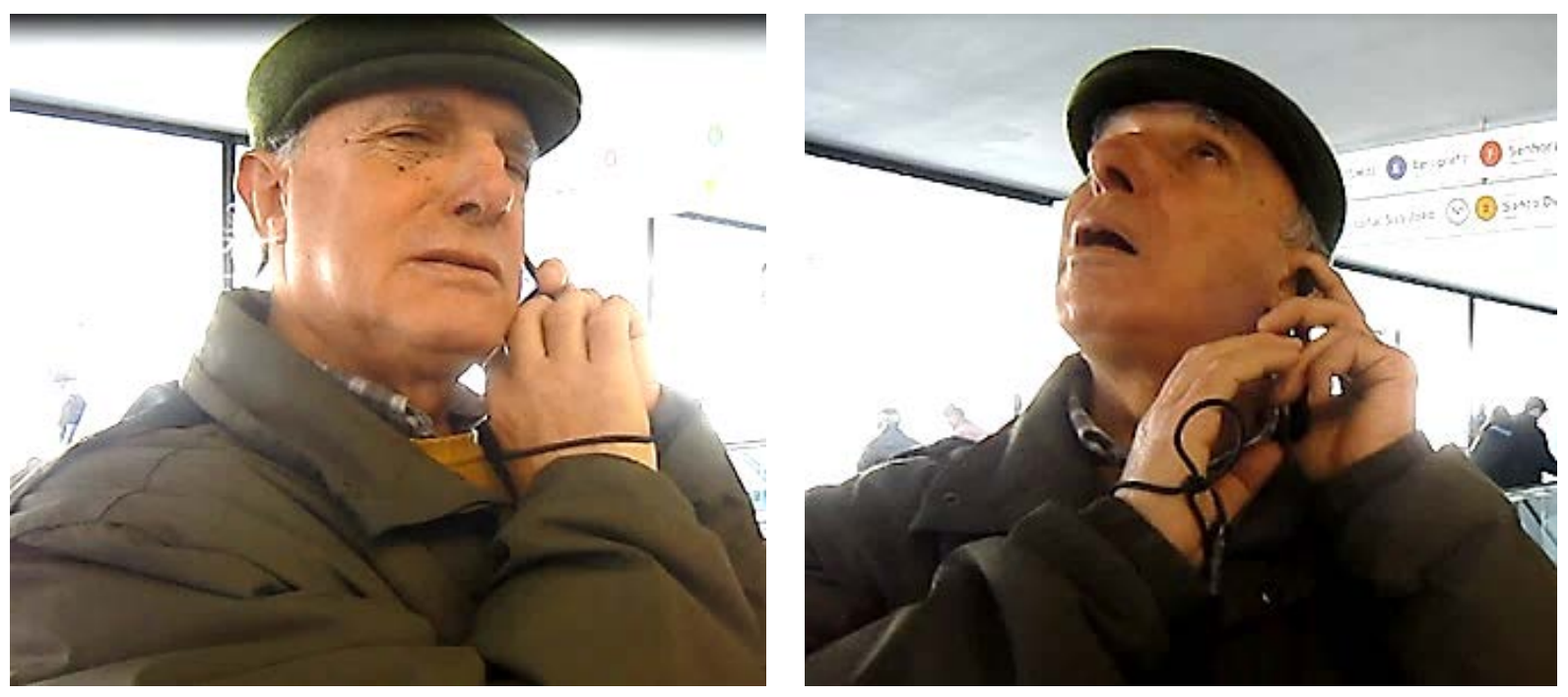

Crédito: MARIANI, E., 2015.

Repetida a operação, finalmente ele seguiu na direção da escada (Figura 5.20).

Figura 5.20 - "F." em direção à escada.

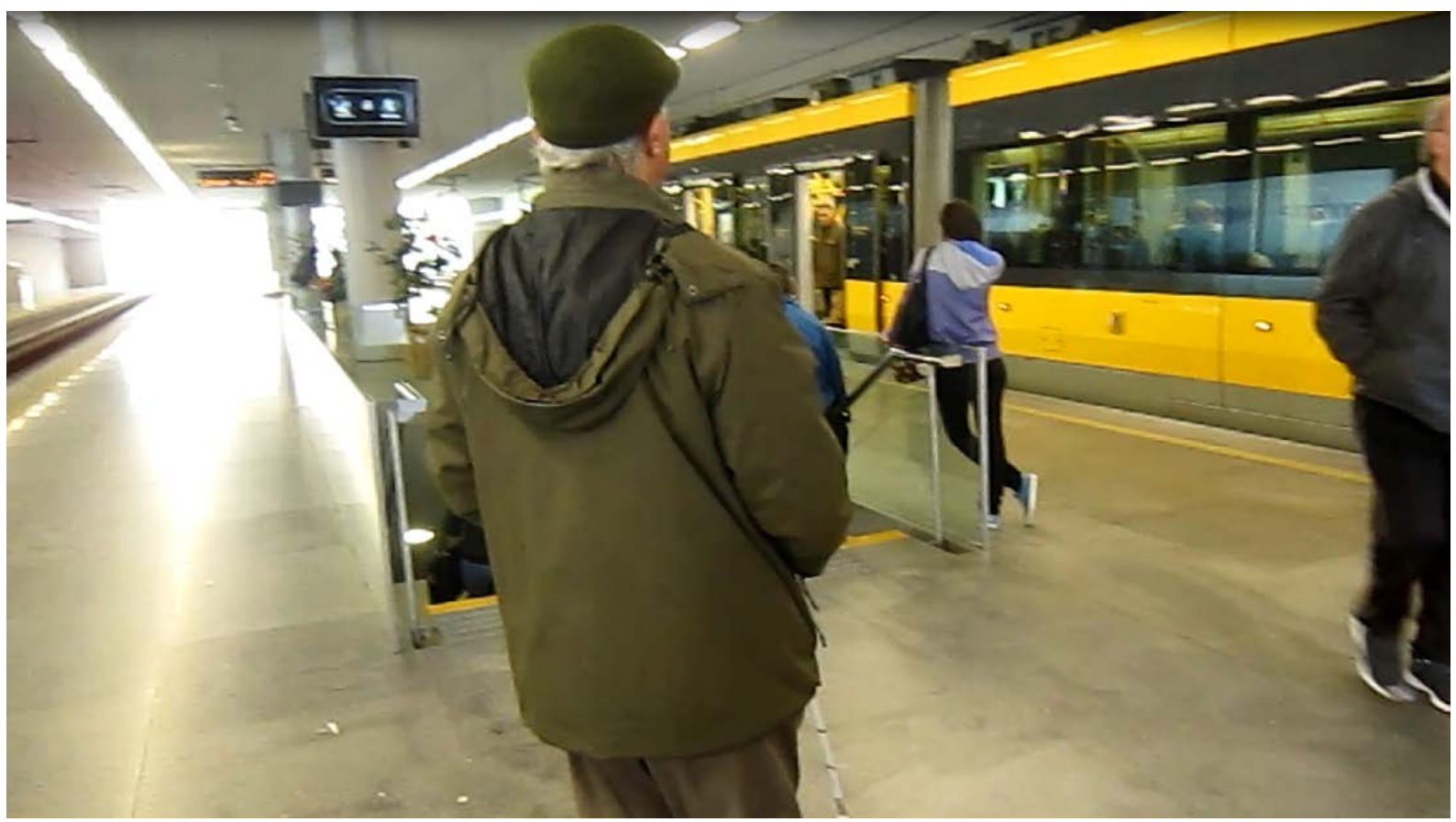

Crédito: MARIANI, E., 2015. 
Mas acabou por ultrapassar a escada (Figura 5.21). Ao perceber que estava na lateral da escada, ele retornou (Figura 5.22). Observa-se nas figuras que durante esta parte do trajeto ele não estava ouvindo as orientações dadas pelo sistema via telefone, o que pode ter interferido na localização da escada. Isto significa que o usuário deve ficar o tempo todo conectado ao celular.

Figura 5.21 - "F." ultrapassa a escada.

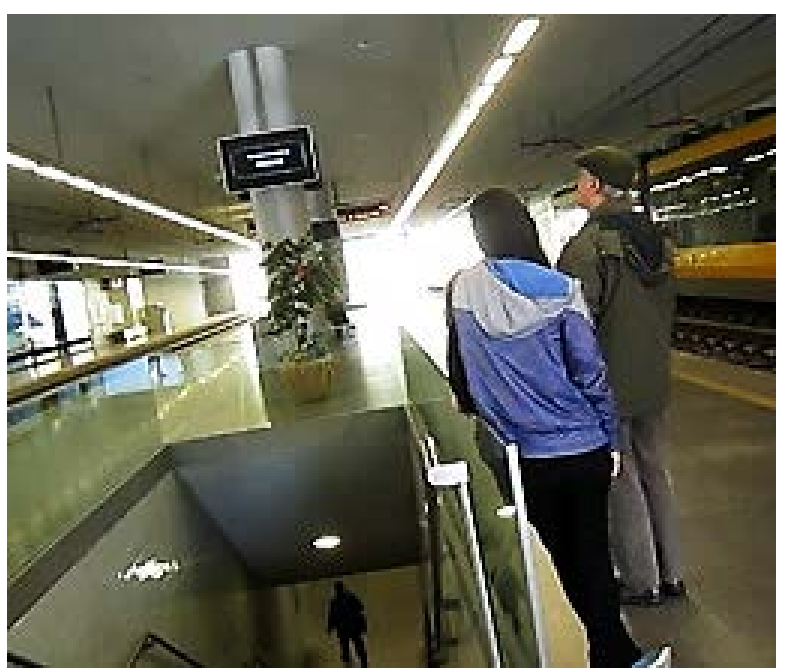

Crédito: MARIANI, E., 2015.
Figura 5.22 - "F." retorna ao perceber o erro.

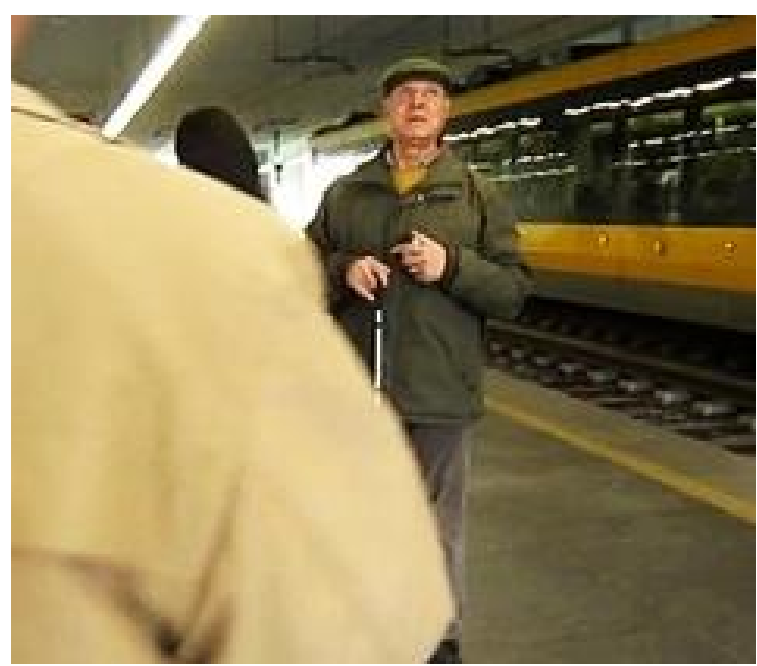

Crédito: MARIANI, E., 2015.

Após ouvir as instruções (Figura 5.23) ele finalmente localizou a escada (Figura 5.24) e desceu em direção ao piso intermediário (Figura 5.25).

Figura 5.23 - "F." ouvindo as instruções novamente.

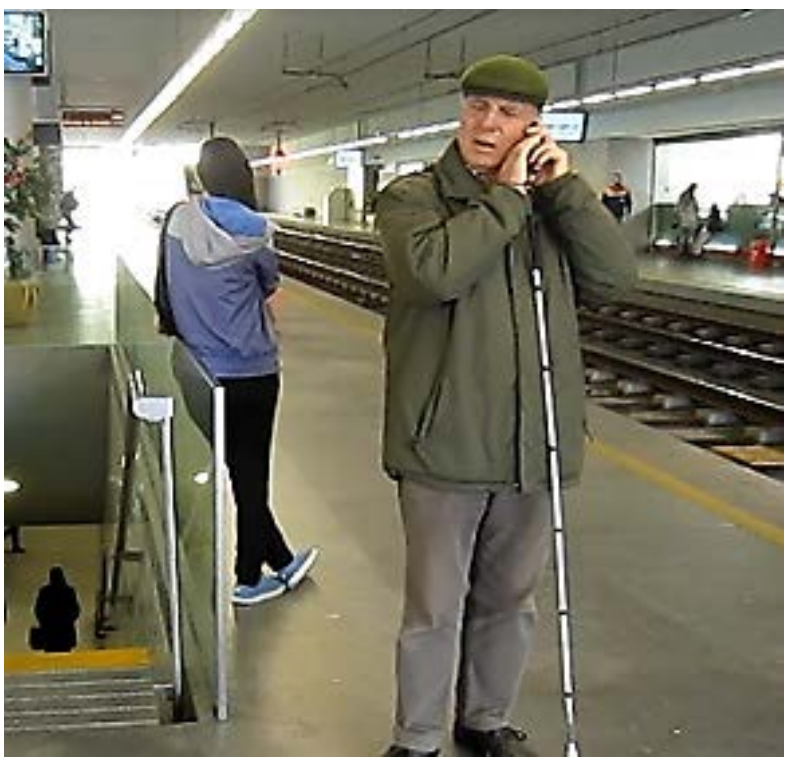

Crédito: MARIANI, E., 2015.
Figura 5.24 - "F." localiza a escada.

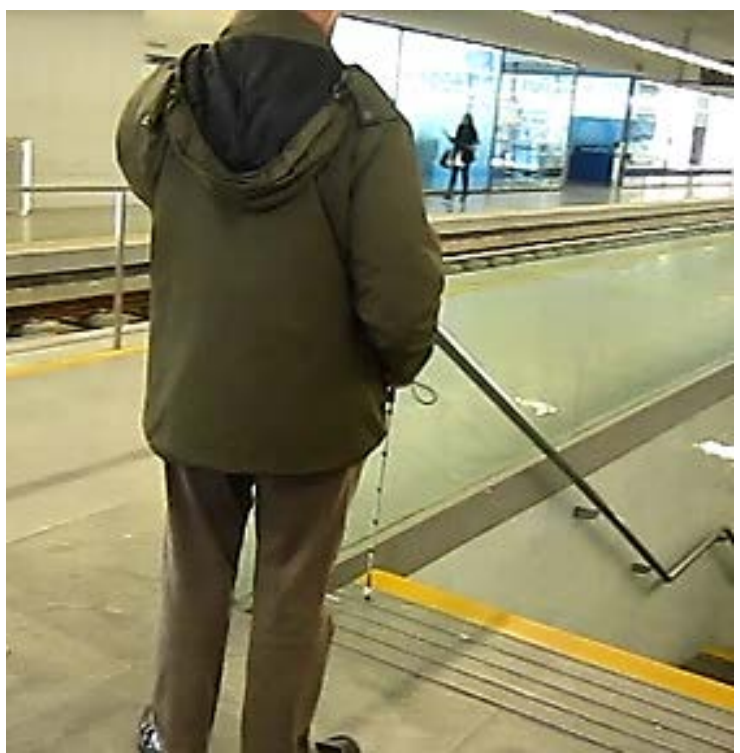

Crédito: MARIANI, E., 2015. 
Figura 5.25 - "F." descendo em direção ao piso intermediário.

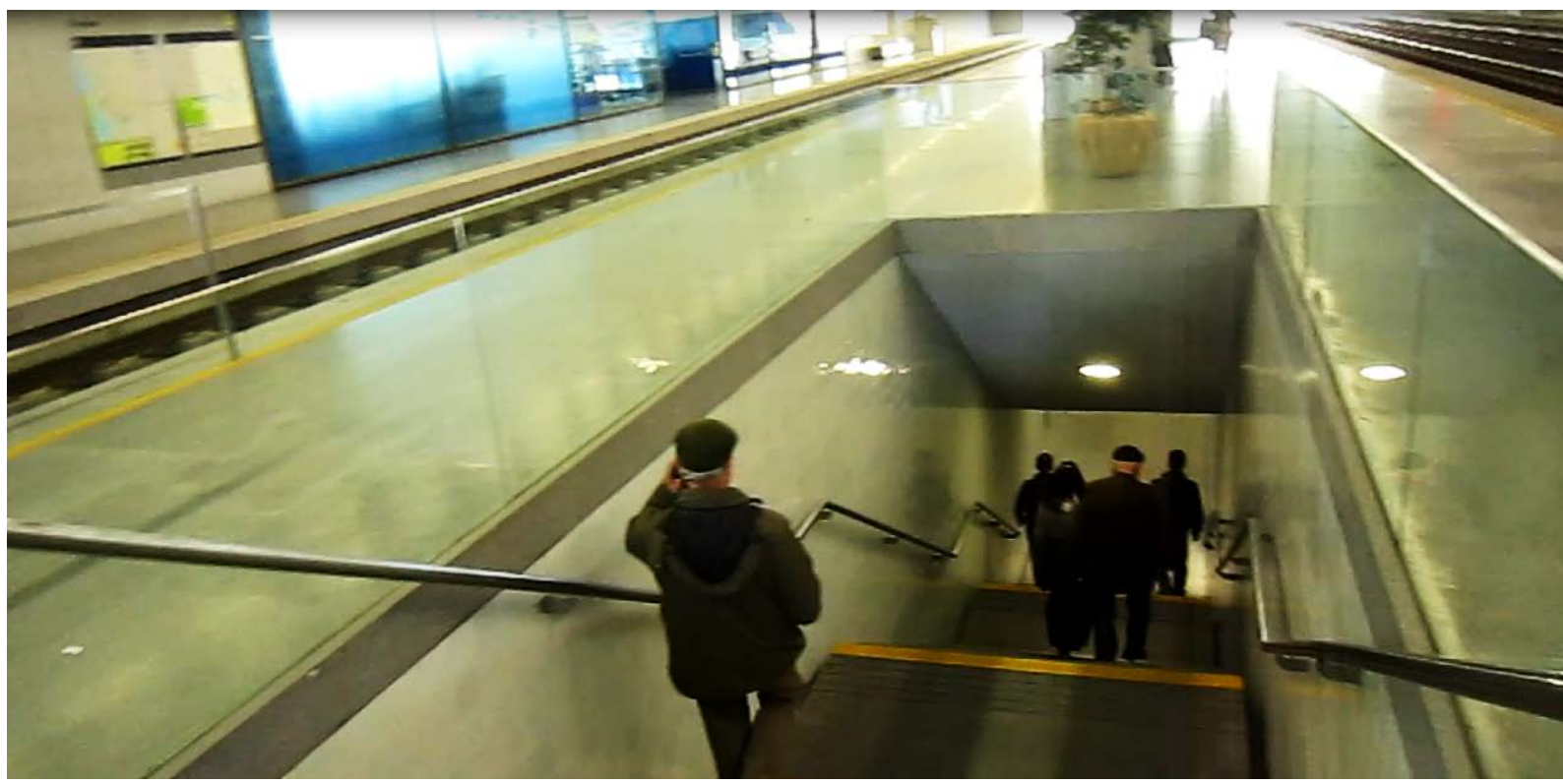

Crédito: MARIANI, E., 2015.

Ao chegar ao piso intermediário ele marcou o número 8 no telefone, e o sistema prosseguiu disparando o som do pássaro na direção da escada de acesso à plataforma, para onde ele se dirigiu, sem intercorrências. A Figura 5.26 mostra "F." no piso intermediário, com o telefone afastado do ouvido.

Figura 5.26 - "F." no piso intermediário.

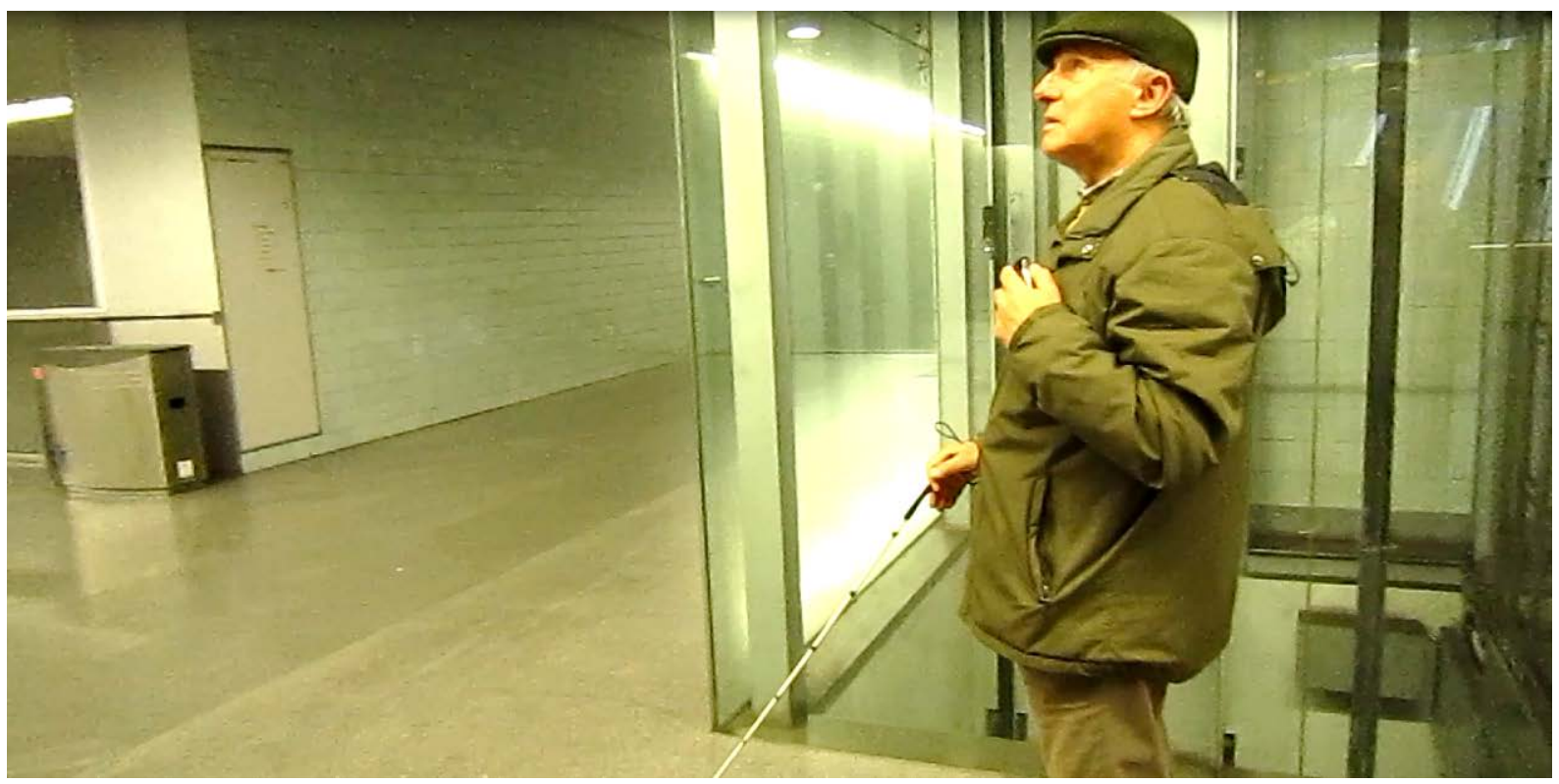

Crédito: MARIANI, E., 2015. 
Após chegar à plataforma, "F." simulou um embarque no trem e finalizou a ligação. Neste ponto a pesquisadora aproveitou para realizar uma breve entrevista, perguntando-lhe sobre suas impressões, e ele informou que o sistema era bom, que lhe dava autonomia, mas que o incomodava ter de lembrar-se de marcar o número 8 ao chegar aos pontos intermediários, de tomada de decisão, e também "lembrar-me de ouvir o telefone".

Finalizada a entrevista, decidiu-se executar o percurso de volta, como se ele tivesse acabado de desembarcar nesta plataforma, e ele repetiu a ligação e todas as instruções necessárias para ser guiado pelo sistema. Nota-se na Figura 5.27 a dificuldade para ouvir, tanto o que era falado pelo telefone, como os sons emitidos pelas boias sonoras. Ao ruído da circulação dos trens somam-se os avisos sonoros que são dados normalmente pela operação de metrôs em geral, porém no caso do metrô do Porto a quantidade de avisos sonoros aumenta na região das plataformas, para serem informadas as diferentes linhas que passam pelo mesmo viário. Esse "conflito sonoro" torna a plataforma o local de utilização mais difícil do sistema. A Figura 5.27 demonstra a expressão de "F." buscando ouvir a comunicação.

Figura 5.27 - "F." tentando ouvir o sistema na plataforma.
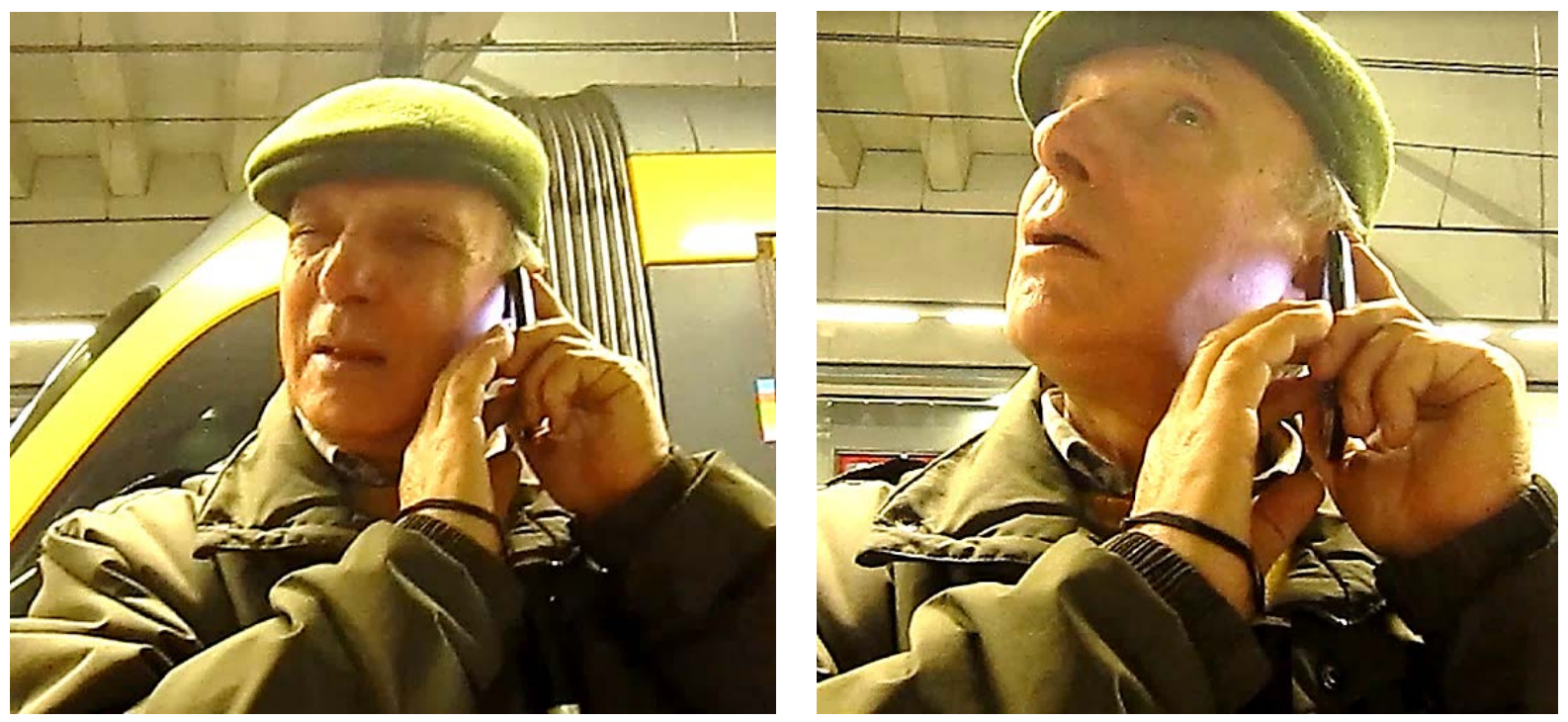

Crédito: MARIANI, E., 2015.

Após conseguir se localizar, "F." seguiu pela plataforma na direção das escadas para saída, podendo perceber mais facilmente desta vez, por serem escadas rolantes, com som do motor em funcionamento (Figura 5.28). 
Figura 5.28 - Após simulação de desembarque na plataforma, "F." utiliza o Navmetro ${ }^{\circledR}$ em direção à saída.
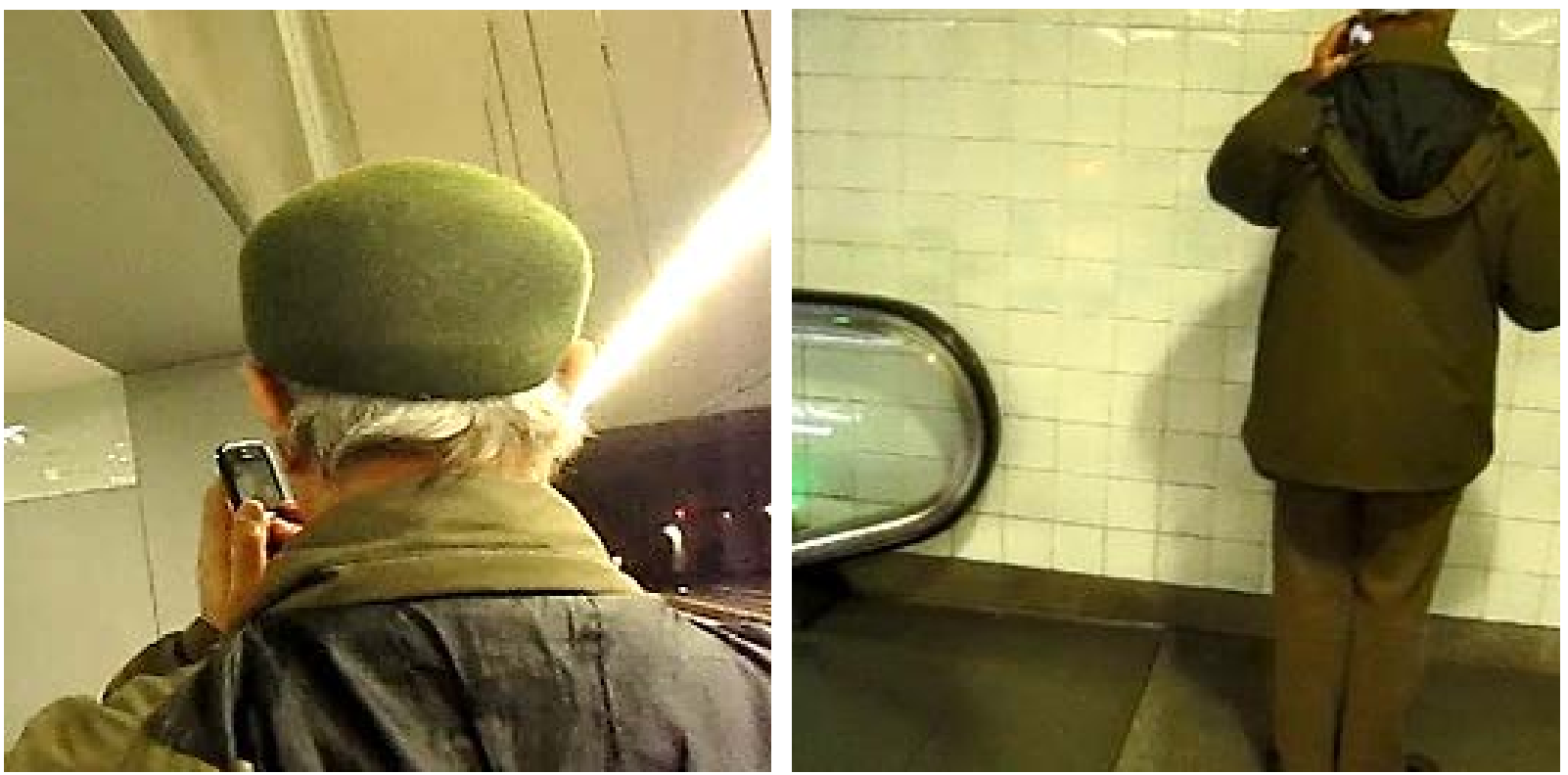

Crédito: MARIANI, E., 2015.

Ao localizar a escada, ele subiu em direção ao piso intermediário (Figura 5.29) onde prosseguiu utilizando as instruções (Figura 5.30). A pesquisadora perguntou à representante do metrô do Porto se as escadas rolantes não teriam seu sentido invertido ao longo do dia, em função de fluxos diferentes, o que poderia atrapalhar seu uso por pessoas com deficiencia visual, e ela respondeu que as escadas lá nunca são invertidas.

Figura 5.29 - "F." utiliza a escada rolante para se dirigir ao piso intermediário, em direção à saída.
Figura 5.30 - Chegando ao piso intermediário, "F." ouve as instruções pelo celular.

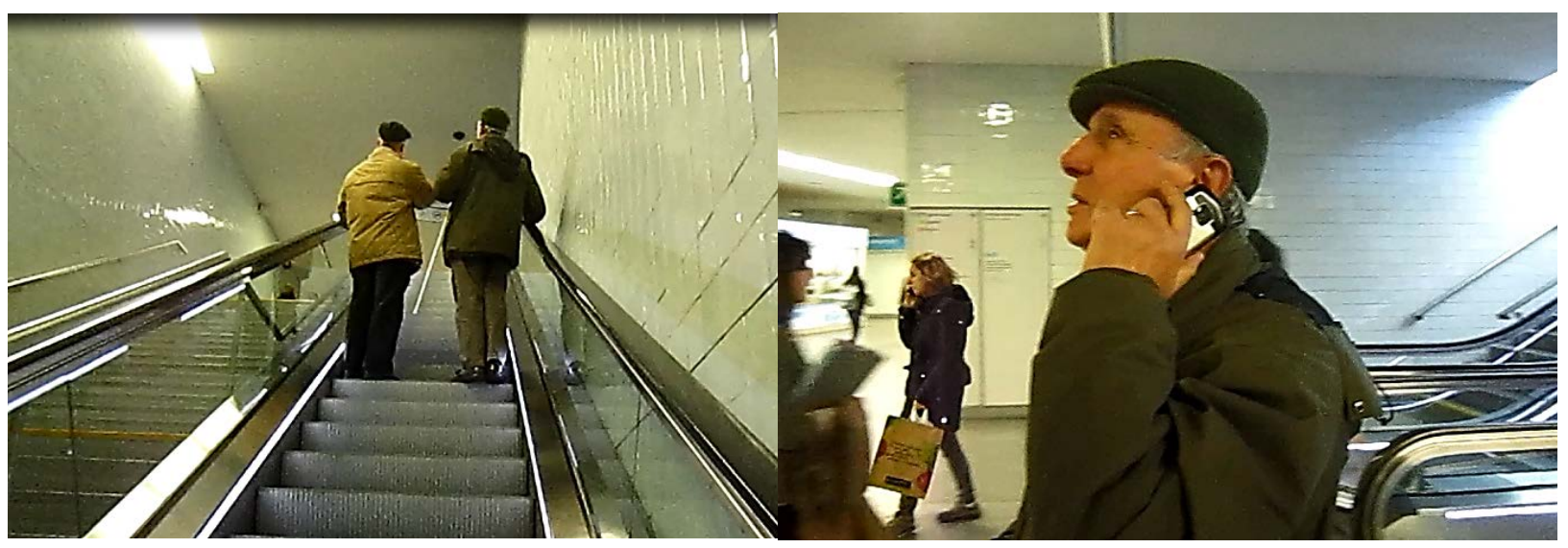

Crédito: MARIANI, E., 2015.

Ao chegar no nível superior, na região das portas do acesso, finalizou-se a observação (Figura 5.31). 
Figura 5.31 - Final da observação de “F.”.

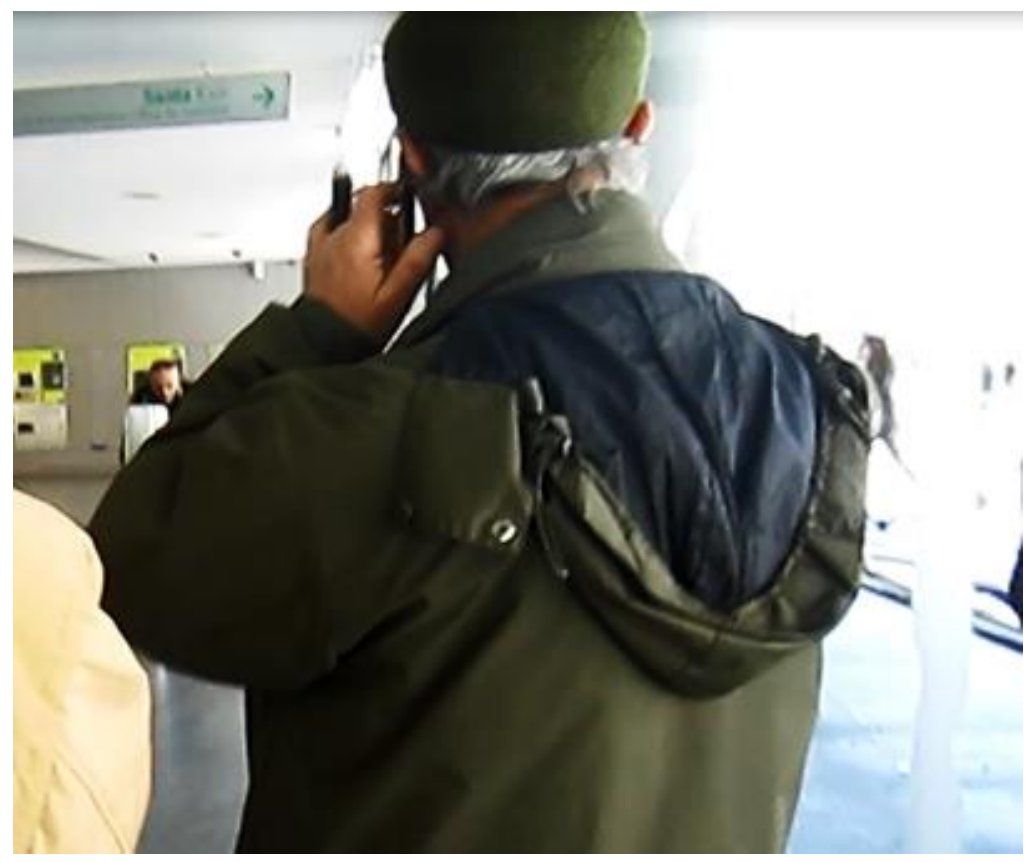

Crédito: MARIANI, E., 2015.

\subsubsection{Teste prático realizado pela pesquisadora}

Após a realização da observação de "F.", a pesquisadora realizou um teste prático, utilizando os mesmos recursos. Realizou a ligação telefônica e procedeu às orientações que lhe foram dadas e solicitadas.

O objetivo de repetir a simulação foi para conhecer a interação do usuário com o sistema, ouvir as orientações e avaliar sua lógica e eficácia, pois, enquanto realizava a observação de "F." não estava ouvindo o que lhe era dito pelo telefone.

Ao realizar a experiência de utilizar o Navmetro ${ }^{\circledR}$ a pesquisadora pode confirmar o que já havia constatado a respeito das interferências auditivas do ambiente com as instruções dadas pelo telefone. Observou também que a lógica do menu de diálogo não oferece boa interação com o usuário, e não existe diferencial para usuário novato ou experiente.

No entanto, a pesquisadora constatou que o som do pássaro realmente se destaca no ambiente, sendo bem claro e funcional, além de não incomodar os demais usuários, chegando a ser até agradável. 0 único local de algum conflito foi realmente na região das plataformas, conforme já abordado. 


\subsection{CONSIDERAÇÕES SOBRE A PESQUISA NO METRÔ DO PORTO}

O contato direto com profissionais que estudaram um sistema de auxílio à informação e navegação em funcionamento em uma estação de metrô permitiu a aproximação quanto aos detalhes de seu desenvolvimento, suas dificuldades, erros e acertos. A realização da observação de campo de um usuário com deficiência visual utilizando o sistema Navmetro ${ }^{\circledR}$, seu depoimento e a própria experiência da pesquisadora com o uso do sistema permitiram complementar os dados para a análise de sua consistência e confirmação dos dados teóricos e das entrevistas.

A pesquisa sobre o sistema Navmetro ${ }^{\circledR}$ não significou chegar a uma conclusão se há ou não pontos de melhoria de sua usabilidade, mas sim obter dados que pudessem ser comparados com os das demais pesquisas deste trabalho, fundamentando a análise e proposições.

Como um dos principais dados obtidos, que pode ser útil no desenvolvimento de projetos semelhantes, tem-se: o problema apresentado no uso de Wi-Fi, relatado pelos desenvolvedores; a imprecisão de localização utilizando-se sistemas por meio de aparelhos que emitem sinais de rádio com tecnologia Bluetooth, tornando seu uso limitado; a possibilidade de se utilizar sons diferenciados, que se destaquem no ambiente, sem incomodar aos demais usuários, como o som de pássaros.

Também se evidenciou que a interação entre o usuário e o sistema de comunicação por meio de menus sucessivos exige estudos cuidadosos quanto à sua lógica, destacando-se também: a importância de se diferenciar usuários experientes de novatos; o resultado positivo na utilização de aparelhos celulares de todos os tipos, do próprio usuário; a necessidade de se considerar as diferentes maneiras de se referir aos locais; a dificuldade de se ter que segurar o celular com as mãos, sem fone de ouvido durante a navegação. 


\section{PROPOSIÇÕES}

Este capítulo aborda um dos objetivos desta dissertação, que é propor diretrizes a serem adotadas em projetos de sistemas eletrônicos para guiar pessoas com deficiência visual nas estações e trens de metrô de maneira autônoma e segura.

Para chegar às proposições que contribuirão para o delineamento do sistema, foi estratificado o conteúdo teórico e prático abordado nesta dissertação, respondendo-se a questões como: (a) quem deverá ser atendido ou poderá utilizá-lo; (b) o quê deve ser disponibilizado pelo sistema; (c) locais da rede de metrô onde deve haver cobertura pelo sistema; (d) quando o sistema deve atuar; (e) como o usuário acessa ou recebe o sistema.

Figura 6.1 - Quem deve ser atendido pelo sistema.

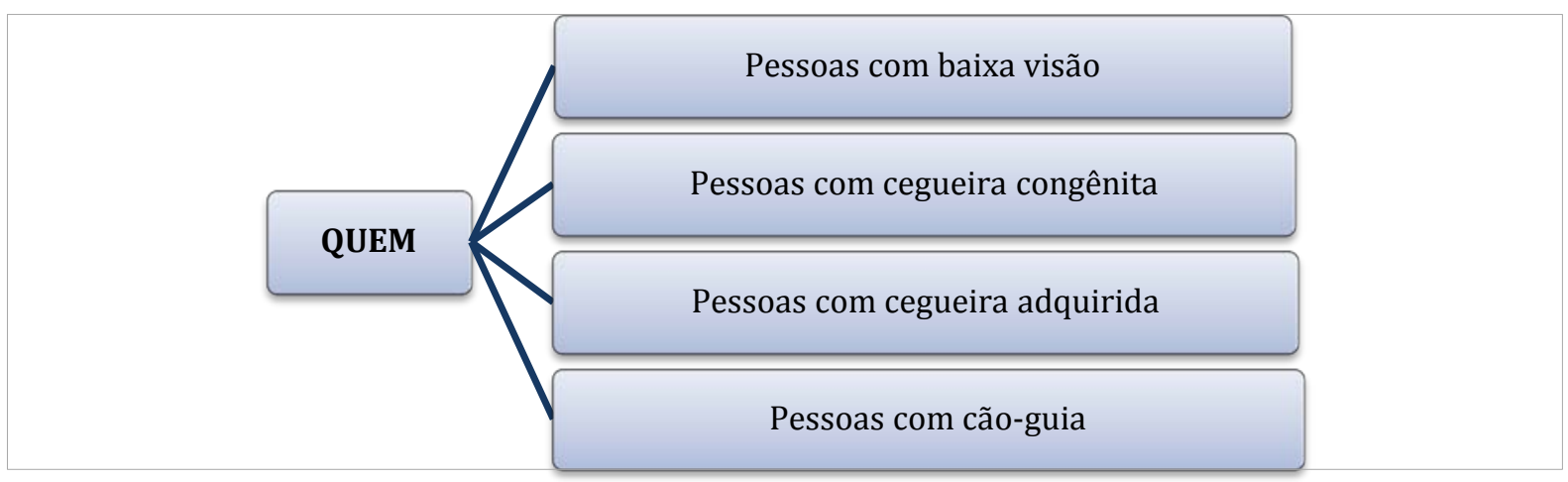

Começando pelas pessoas a serem atendidas ou que poderão utilizar o sistema em referência, considera-se que deverão ser atendidas: (a) pessoas com baixa visão; (b) pessoas com cegueira congênita; (c) pessoas com cegueira adquirida; e (c) pessoas com cão-guia (Figura 6.1).

Figura 6.2 - 0 quê deve ser disponibilizado pelo sistema.

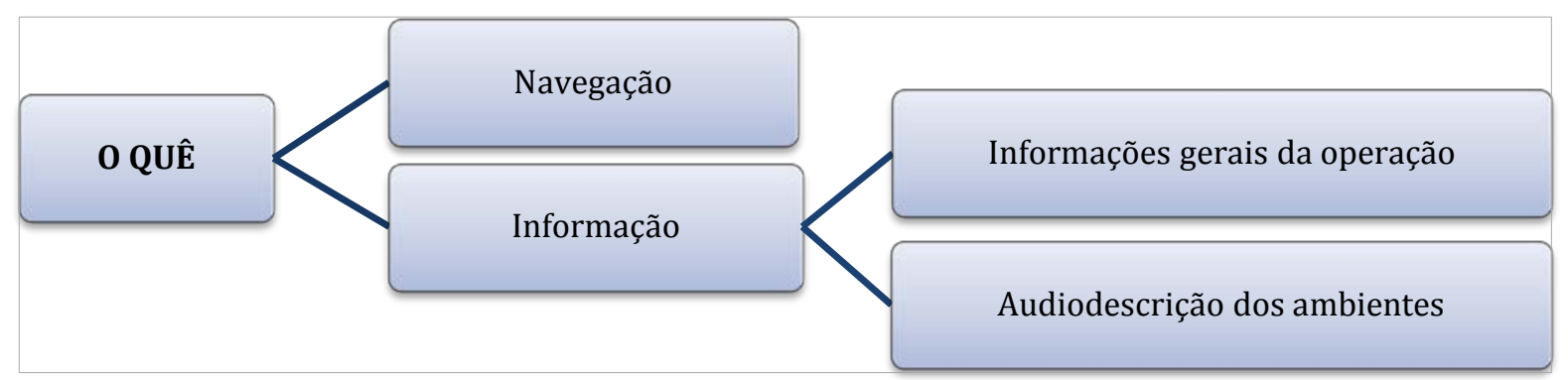


Com relação a o quê deve ser disponibilizado pelo sistema, chega-se à essência deste estudo: a navegação de pessoas com deficiência visual pelos ambientes de estações e trens de metrô, assim como obtenção de informações gerais da operação da rede e também informações sobre o ambiente por meio de audiodescrição (Figura 6.2).

As informações gerais a serem fornecidas referem-se a horários, estações, linhas e demais dados disponibilizados conforme a necessidade. A audiodescrição dos ambientes pode ser pré-gravada, obtida por meio de página da empresa operadora na internet, ou obtida em tempo real.

Figura 6.3 - Onde deve haver cobertura pelo sistema.

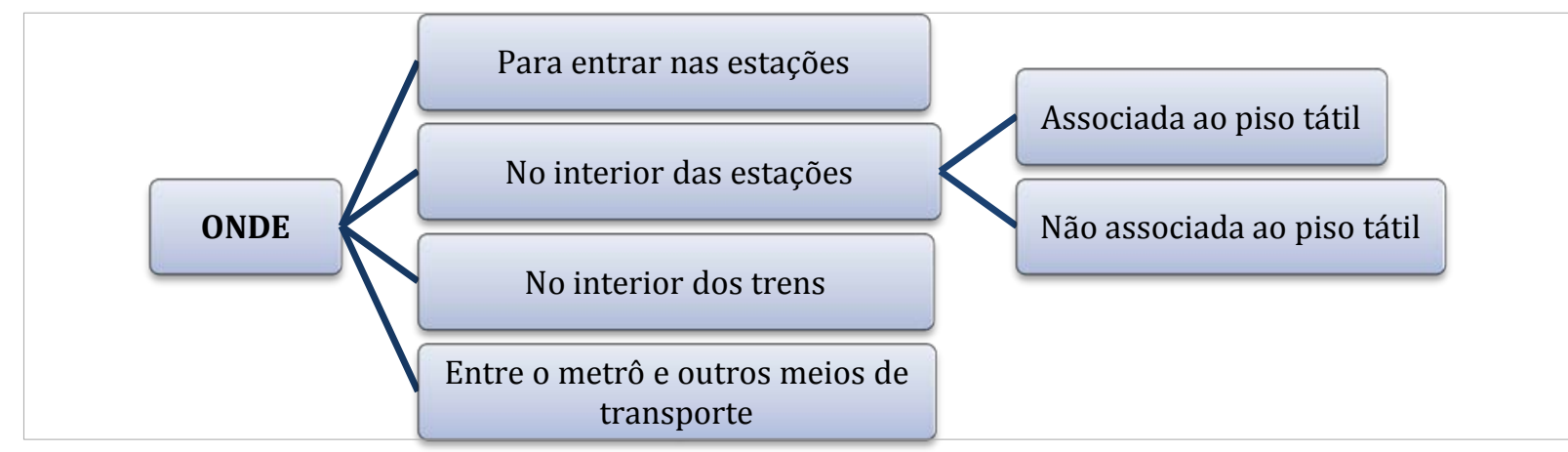

Com relação aos locais onde deve haver cobertura pelo sistema, pode-se definir que seja para localizar o acesso à estação, no interior das estações, no interior dos trens e entre o metrô e outros meios de transporte (Figura 6.3). Pode haver estações onde já exista o piso tátil direcional, ao qual se deseja associar o sistema eletrônico, especialmente para orientação quando do encontro de diversas linhas, e o usuário não sabe qual direção tomar. Mas também pode haver estações sem existência de piso tátil direcional ${ }^{73}$, nas quais seja delegado ao sistema eletrônico cumprir sozinho a função de navegação.

\footnotetext{
73 Depende de exigências da legislação. No Brasil é obrigatória a instalação de pisos táteis, tanto de alerta como direcionais, de acordo com ABNT (2005) e Brasil (2004).
} 
Figura 6.4 - Quando deve atuar o sistema.

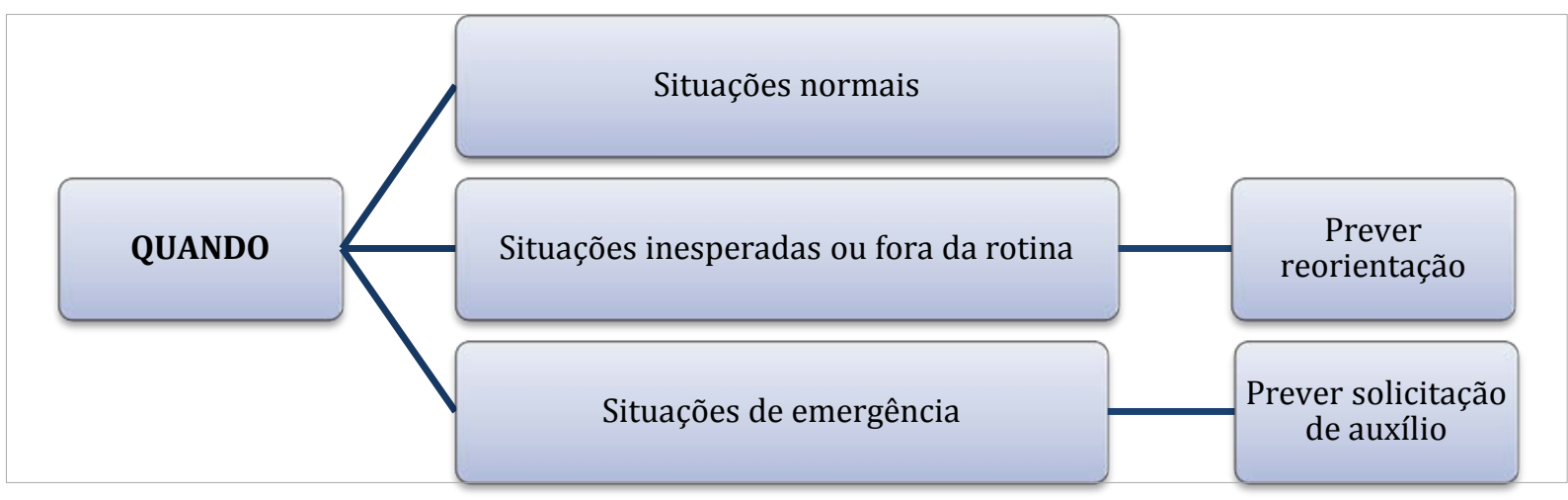

Quanto à questão sobre quando o sistema deve atuar, além das situações consideradas normais, tem-se as seguintes situações (Figura 6.4):

a) situações inesperadas ou fora da rotina: quando o usuário erra a rota ou sai fora propositalmente, por algum motivo, como por exemplo, preferência pessoal ou existência de objeto interferindo no percurso. Neste caso deve-se prever algum modo de reorienta-lo para que chegue em segurança ao destino;

b) situações de emergência: quando o usuário está com algum problema que não permite que ele prossiga, como por exemplo, dúvida na operação do dispositivo, pânico, mal súbito ou qualquer situação em que ele não se sinta seguro para prosseguir a rota. Neste caso deve-se prever algum modo de solicitação de auxílio, pelo próprio usuário, ou por alguém que esteja próximo e deseja ajudar.

Para situações de emergência externas, tais como fechamento inesperado da estação, interrupção do serviço de trens, incêndio, tumulto etc., deverá ser estudada a possibilidade de atendimento por meio do guia eletrônico, ou se haverá procedimento operacional específico para atuar junto a esses usuários. 
Figura 6.5 - Como o usuário acessa ou recebe o sistema.

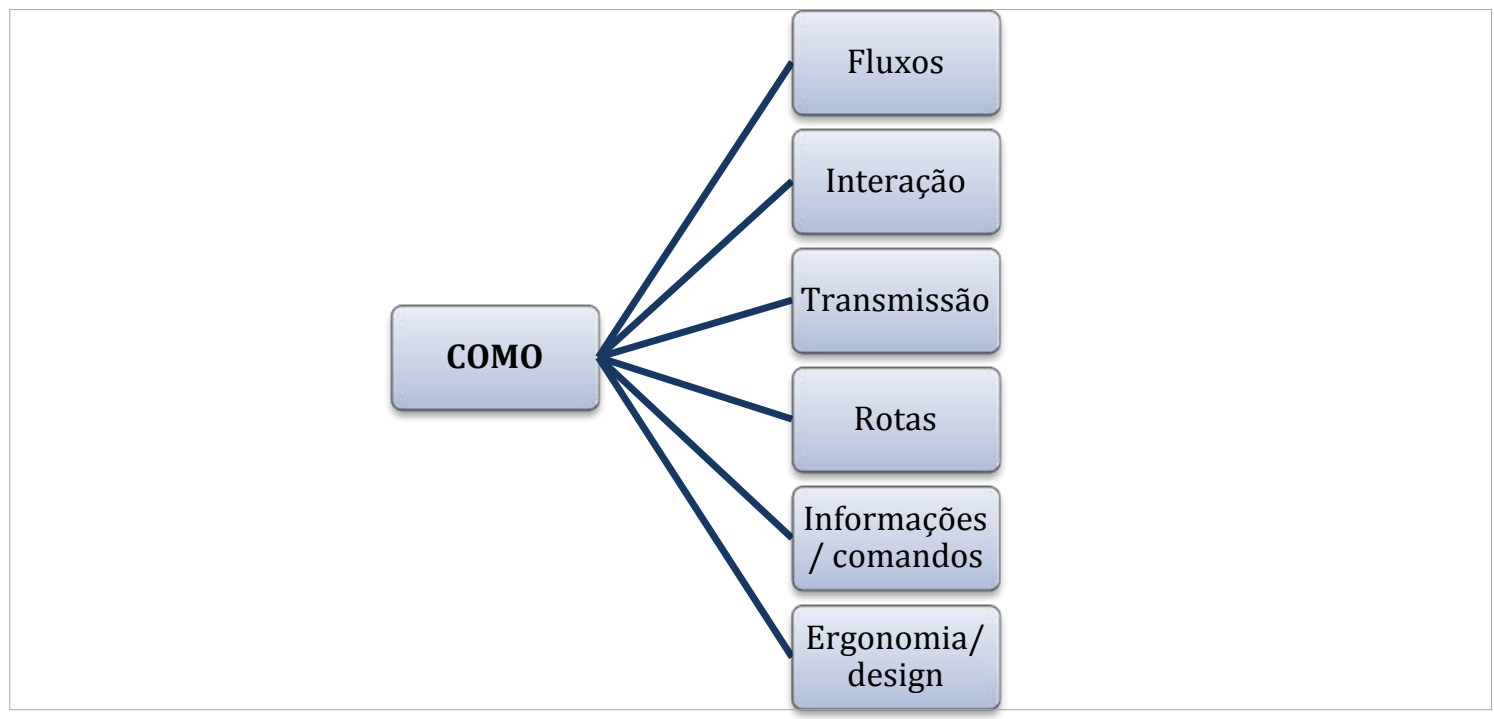

Para definições sobre como o usuário acessa ou recebe o sistema, abre-se um leque de requisitos (Figura 6.5) que incidirão diretamente no seu desempenho, dentre eles, fluxos, interação, transmissão, rotas, informações/comandos e ergonomia/design.

\section{$6.1 \quad$ FLUXOS}

Mesmo diante da complexidade e diversidade de estações, trens e procedimentos operacionais contidos em uma rede de metrô, elaborou-se um diagrama geral de fluxos com diferentes possibilidades de circulação de pessoas, desde sua entrada até a saída, aplicável à maioria das redes de metrô, conforme Figura 6.6. 
Figura 6.6 - Diagrama de fluxos para viagem em redes de metrô.

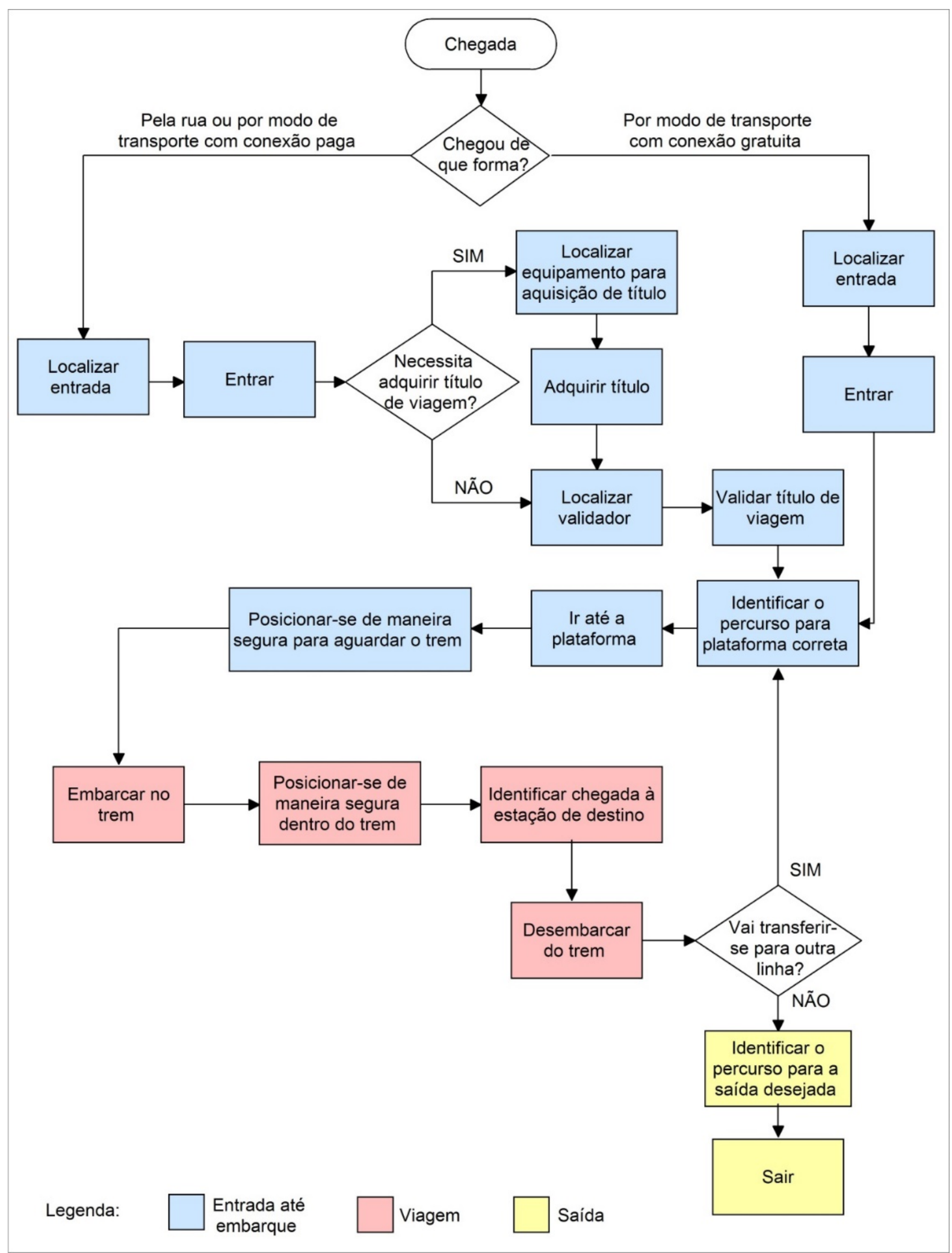

Conforme o diagrama proposto na Figura 6.6, as pessoas podem chegar à estação de metrô: (1) pela rua ou por modo de transporte de conexão paga; (2) por modo de 
transporte de conexão gratuita. 0 Quadro 6.1 relaciona as ações do diagrama de fluxos da Figura 6.6 com as condições a serem atendidas por ele.

Quadro 6.1 - Etapas do diagrama de fluxos para pessoas com deficiência visual.

\begin{tabular}{|c|c|c|}
\hline & AÇÃo & CONDIÇÃO \\
\hline \multirow{9}{*}{ 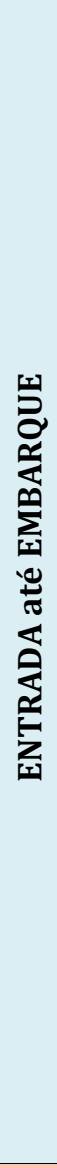 } & Localizar entrada & $\begin{array}{l}\text { As pessoas chegam à estação de diversos modos: a pé, por outros } \\
\text { meios de transporte ou de "carona". Deve-se prever que todos os } \\
\text { acessos da estação sejam identificáveis também para pessoas com } \\
\text { deficiência visual. }\end{array}$ \\
\hline & Entrar & $\begin{array}{l}\text { A pessoa deve conseguir entrar e caminhar pelo interior da estação de } \\
\text { maneira clara e segura. Ao entrar na estação, deverá tomar uma } \\
\text { decisão a respeito do título de viagem: (a) necessita adquiri-lo ou (b) } \\
\text { não necessita adquiri-lo. }\end{array}$ \\
\hline & $\begin{array}{l}\text { Localizar equipamento } \\
\text { para aquisição de título }\end{array}$ & $\begin{array}{l}\text { Se houver necessidade de adquiri-lo, o deve haver orientação/modo } \\
\text { para que consiga caminhar e localizar os equipamentos de venda de } \\
\text { títulos. }\end{array}$ \\
\hline & Adquirir título & $\begin{array}{l}\text { Os equipamentos de venda de títulos devem permitir que ela adquira } \\
\text { o título de maneira clara e segura. }\end{array}$ \\
\hline & Localizar validador & $\begin{array}{l}\text { Deve haver orientação/modo para que consiga caminhar e localizar } \\
\text { os equipamentos validadores de títulos. }\end{array}$ \\
\hline & Validar título de viagem & $\begin{array}{l}\text { Os equipamentos validadores de títulos devem permitir que ela valide } \\
\text { o título de maneira clara. }\end{array}$ \\
\hline & $\begin{array}{l}\text { Identificar o percurso para } \\
\text { a plataforma correta }\end{array}$ & $\begin{array}{l}\text { Deve haver orientação/modo para que consiga localizar o percurso } \\
\text { para a plataforma por onde passará o trem que o levará ao destino. }\end{array}$ \\
\hline & Ir até a plataforma & $\begin{array}{l}\text { A pessoa deve conseguir caminhar pela plataforma de maneira clara e } \\
\text { segura. }\end{array}$ \\
\hline & $\begin{array}{l}\text { Posicionar-se de maneira } \\
\text { segura para aguardar o } \\
\text { trem }\end{array}$ & $\begin{array}{l}\text { Deve haver orientação/modo para que consiga localizar a posição na } \\
\text { plataforma onde poderá aguardar o trem de maneira segura e que } \\
\text { permita fácil embarque. }\end{array}$ \\
\hline \multirow{4}{*}{$\sum_{\substack{5 \\
5}}^{5}$} & Embarcar no trem & A pessoa deve conseguir embarcar no trem de maneira clara e segura. \\
\hline & $\begin{array}{l}\text { Posicionar-se de maneira } \\
\text { segura dentro do trem }\end{array}$ & $\begin{array}{l}\text { Deve haver orientação/modo para que consiga posicionar-se de } \\
\text { maneira segura dentro do trem. }\end{array}$ \\
\hline & $\begin{array}{l}\text { Identificar chegada à } \\
\text { estação de destino }\end{array}$ & $\begin{array}{l}\text { Deve haver informação para que a pessoa identifique a chegada à } \\
\text { estação de destino. }\end{array}$ \\
\hline & Desembarcar do trem & $\begin{array}{l}\text { A pessoa deve conseguir desembarcar do trem de maneira clara e } \\
\text { segura. Ao desembarcar, deverá tomar uma decisão a respeito do } \\
\text { prosseguimento: (a) necessita transferir-se para outra linha, para } \\
\text { chegar ao destino ou (b) já chegou à estação de destino. }\end{array}$ \\
\hline \multirow{2}{*}{ 尝 } & $\begin{array}{l}\text { Identificar o percurso para } \\
\text { a saída }\end{array}$ & $\begin{array}{l}\text { A pessoa deve conseguir identificar o percurso e caminhar pelo } \\
\text { interior da estação de maneira clara e segura até a saída correta. }\end{array}$ \\
\hline & Sair & A pessoa deve conseguir sair da estação de maneira segura. \\
\hline
\end{tabular}

O diagrama da Figura 6.6 se aplica a estações subterrâneas, em nível ou elevadas e a diferentes formas de aquisição de título e validação. Independe de sistema de plataforma central, laterais ou mista, assim como da existência de painéis de portas de plataforma e 
também do tipo de veículo de transporte. Inclui conexões entre linhas da própria rede e também entre modos de transporte.

Para se prover acessibilidade na realização de uma viagem completa (desde a entrada até a saída) é necessário que pessoas com deficiência visual consigam executar todas as etapas indicadas no diagrama de maneira autônoma e segura. Para isso, deve-se pensar em cada uma dessas ações e se prever de que maneira será possível serem realizadas por pessoas com deficiência visual, e em que momentos o sistema eletrônico de informação e navegação poderá contribuir. Nesses estudos deverão ser analisados os fluxos internos às estações e trens, porém deverá ser lembrado que muitos dos dados coletados em levantamentos de estações e trens de metrô variam constantemente, pela própria dinâmica do sistema.

Também deverá se considerar que as pessoas podem necessitar consultar o balcão de informações, utilizar o sanitário, ou ainda ir a uma loja ou algum ponto de interesse na estação, devendo haver opção para direcionamento a esses locais. Para tanto, o sistema deverá considerar pelo menos dois aspectos: (a) quando esses locais existem na estação onde se está; e (b) quando esses locais não existem naquela estação:

a) para os casos em que o local desejado encontra-se naquela estação, o sistema deverá prover direcionamento até lá e, na sequência, até o próximo local de interesse, que pode ser a plataforma de embarque ou saída, por exemplo;

b) para os casos em que o local desejado não se econtra naquela estação, o sistema deverá prover informação suficiente para guiar a pessoa com deficiência visual até o local, que poderá estar em outra estação, ou guiá-la até um funcionário que poderá acompanhá-la ao local, ou fornecer informações adicionais.

\subsection{INTERAÇÃO}

A interação entre o usuário e o sistema pode se dar de diferentes formas. De maneira geral, deve-se prever formas para que as informações sobre o ambiente a ser percorrido cheguem até os usuários com deficiência visual, ou que os usuários com deficiência visual sejam conduzidos de alguma forma e não precisem receber diretamente essas informações. 
Uma das formas de se prover a orientação é por meio de sons ambientes, emitidos por alto-falantes estrategicamente instalados ao longo do percurso. Outra forma de orientação é por meio de dispositivos portados pelo usuário. Em ambos os casos a interação deve se dar de maneira a não tomar toda a atenção do usuário, que precisa continuar percebendo informações do ambiente.

O sistema poderá utilizar aparelhos dedicados para este uso específico ou aplicativos instalados em telefones celulares/smartphones, tendo sido constatada a preferência por estes últimos. Se a opção for por telefones celulares/smartphones, o sistema deverá ser adequado ao uso de aparelhos adquiridos com facilidade no mercado. Consequentemente, deve-se prever seu funcionamento em diferentes sistemas operacionais e compatibilização com diferentes operadoras de telefonia móvel.

A comunicação entre o usuário e o sistema pode se dar por meio de comandos de fala (sistema de diálogo falado) ou por meio de comandos por botões físicos do dispositivo (aparelho dedicado ou smartphone), entre outros modos. Qualquer que seja a forma, deve ter preferencialmente uso intuitivo, com o mínimo necessário de instruções de uso. Todos os seus mecanismos devem ser simples, eficientes e ágeis aos usuários, de forma a não desencorajar o seu uso.

Para receber os comandos o ideal é por meio da audição com reforço de vibração. Por comandos sonoros entende-se vozes e/ou sinais de áudio ("beeps"). A vibração é muito útil para confirmar comandos e também como reforço para melhor e mais rápida compreensão destes, como por exemplo, quando a orientação é para virar à esquerda ou direita. Um aparelho junto ao corpo do usuário que vibre do lado esquerdo ou direito, conforme o comando, acelera sua tomada de decisão (confundir direita com esquerda em uma navegação rápida é problema de muitas pessoas, mesmo daquelas sem deficiência visual). Além disto, muitas pessoas com deficiência congênita não conhecem direita/esquerda, pois não foram estimuladas a isto durante sua vida.

\subsection{TRANSMISSÃO}

A transmissão pode ser entendida aqui como envio e captação de sinais entre dispositivos portados pelos usuários e emissores localizados no ambiente ou à distância. 
Podem ser combinados diferentes tipos de transmissão para a execução correta do percurso, devendo-se focar na captação e orientação da posição do usuário nos ambientes, permitindo sua navegação. A tolerância de erro técnico de identificação do posicionamento do usuário precisa garantir que este não irá entrar em risco ao empreender o próximo passo. É essencial a precisão de localização.

Foram identificadas diversas formas de transmissão de sinais que poderão fazer parte do projeto do sistema de informação e navegação. A escolha dentre elas deverá considerar a precisão na captação do sinal, para que o usuário receba os comandos de maneira a não haver erros na sua execução, como por exemplo, tomar caminhos errados, passar do ponto de tomada de decisão ou ainda falhas mais graves que possam causar acidentes e até queda na via. Também deve prever o realinhamento da rota quando houver erros no percurso ou em situações inesperadas, conforme já abordado.

A transmissão deve atuar em ambientes internos e não pode causar ou receber interferências dos sistemas preexistentes nas estações e trens, para não colocar em risco a operação.

\subsection{ROTAS}

Rotas são os percursos pré-definidos a serem realizados pelos usuários com deficiência visual para chegarem aos destinos desejados utilizando o sistema eletrônico de informação e navegação.

Os percursos devem ser definidos junto à empresa operadora e preferencialmente com a participação de pessoas com deficiência visual, professores de orientação e mobilidade ou profissionais especializados na área, sempre se considerando o conjunto formado pelas demais variáveis do sistema: fluxos, interação, transmissão e comandos.

Uma rota poderá estar associada ou não a um percurso de piso tátil direcional, dependendo de definições da empresa operadora e questões legais. No Brasil é obrigatório o uso de pisos táteis direcionais em áreas de ampla circulação, como estações de metrô ${ }^{74}$. A associação de um sistema eletrônico de navegação aumenta a

\footnotetext{
74 Também é obrigatória a instalação de pisos táteis de alerta nos locais com potencial de perigo, como escadas, bordas de plataformas e obstáculos.
} 
segurança e o entendimento do percurso a ser seguido, especialmente nos cruzamentos com diversas opções de destino. No entanto esta associação não é obrigatória, ficando a cargo de definição de projeto.

A rota a ser seguida deve ser seccionada em tantos estágios quantos forem necessários para haver o máximo de precisão de localização e de pontos de informação. Poderão ser considerados os elementos de wayfinding propostos por Lynch (1960), por serem consagrados para compreensão de áreas edificadas: (a) marcos referenciais; (b) nós; (c) caminhos; (d) limites/ bordas; e (e) distritos/zonas funcionais.

\subsection{INFORMAÇÕES/ COMANDOS}

As informações ou comandos de navegação enviados ao usuário devem utilizar termos simples, de conhecimento geral da população. Devem ser explícitas, evitando-se mensagens ambíguas, contraditórias ou demasiado restritas, com terminologia ou vocabulário erudito, pouco comum ou inadequado à maioria da população. Se utilizar sinais de áudio ("beeps") deve estar claro o seu significado.

As mensagens preferenciais são do tipo "ande cerca de dez passos numa direção de 45 graus para a esquerda”. As terminologias mais comuns às pessoas com deficiência visual são das seguintes ordens ${ }^{75}$ :

a) Direcional: esquerda/ direita; Norte/ Sul;

b) Descritiva: íngreme, alto, vermelho;

c) Estrutural: estrada, monumento, igreja;

d) Numérica: primeira, segunda, 100 metros;

e) Temporal/ distância: caminhe até encontrar...; um pouco depois de...;

f) Sensorial: som de carros passando, trem chegando.

\footnotetext{
${ }^{75}$ Conforme exposto no referencial teórico, as referências utilizadas pelas pessoas com deficiência visual baseiam-se em conhecimento adquirido ao longo de suas experiências de vida e de treinamentos em Orientação e Mobilidade que tenham realizado. Referências pouco utilizadas para o caminhar de pedestres videntes, como Norte/Sul e XX graus, são utilizadas por pessoas cegas que recebem treinamento e, muitas vezes, não possuem outro referencial. Da mesma forma, boa parte das referências possui cunho visual devido às percepções das pessoas com baixa visão, que conseguem perceber cores e contrastes entre claro e escuro, por exemplo.
} 
Deve-se dar preferência por frases menores, poupando o usuário de efetuar paradas obrigatórias em todos os pontos de informação. Também se deve evitar prover informação desnecessária, que sobrecarregue a carga cognitiva do usuário ou desvie a sua atenção. Não colocar propaganda entre as informações.

Algumas pessoas gostam de receber todas as informações de uma vez, ao passo que outras gostam que sejam feitos avisos ao longo do percurso. Prever que muitas pessoas não têm paciência de esperar explicações, devendo-se pensar em diferentes configurações para o recebimento de informações, caso necessário. É essencial manter a perspectiva de que a pessoa com deficiência visual faz parte de uma população determinada pela especificidade de sua condição, no entanto cada pessoa é única e preserva sua própria identidade.

Cada usuário pode se referir a um mesmo local de formas diferentes, como nome completo da estação, nome popular da estação, nome do bairro, nome de algum ponto de interesse conhecido da região da estação, como hospitais, escolas, igrejas etc., e isto deve ser considerado no projeto do sistema. A sequência e tempo de resposta dos diálogos devem considerar desde o principiante até o experiente. Considerar que o novato vai se tornando experiente, e a interação vai mudando. Esta condição se aplica tanto no uso sistema de informação e navegação quanto no uso da rede de metrô, podendo-se utilizar opções de filtros e opções avançadas, por exemplo.

Outra importante característica do sistema é a possibilidade de se optar por omissão ou repetição da informação ou comando, conforme preferência do usuário.

\subsection{ERGONOMIA/ DESIGN}

Os dispositivos portados pelo usuário, seja aparelho dedicado, smartphone ou ambos ${ }^{76}$, devem ser leves e não podem ocupar sua mão em tempo integral durante a navegação, lembrando que uma delas provavelmente já está ocupada pela bengala longa ou pelo arreio do cão-guia.

\footnotetext{
${ }^{76}$ Eventualmente, devido a limitações tecnológicas, pode ser necessário que o usuário porte mais do que um dispositivo, para usar o sistema.
} 
Usar diferentes botões para diferentes funções. Se resultar em uma grande quantidade de botões, devem ser dispostos de maneira lógica para pessoa com deficiência visual. Também não se deve utilizar funções "selecionar" ou "arrastar" na tela. Evitar textos que fiquem piscando ou se movimentando na tela.

Nas informações em áudio deve ser possível regular o volume, usar fone de ouvido ou, se for emitido som por alto-falantes, este deve ser facilmente audível pelo usuário, mesmo em ambientes ruidosos como estações de metrô, sem, no entanto, incomodar ou confundir os demais usuários. Deve-se prever a variação de sons ambientes para adequação do volume da informação/ comando. Deve-se evitar o uso de sons que possam gerar alarme desnecessário.

Para o uso de fones de ouvido não deve ser exigido que se utilizem os dois ouvidos, para manter a sua percepção do ambiente. Preferencialmente, utilizar fones de ouvido de condução óssea, que deixam os ouvidos livres ao mesmo tempo em que fazem a comunicação.

Se forem utilizados aparelhos dedicados, deve-se dimensionar sua eletrônica de maneira que não acabe a bateria durante o percurso. Esta mesma exigência cabe ao aplicativo a ser utilizado no smartphone, que não deve fazer uso excessivo de bateria. Além disso, o aplicativo deve informar o tempo estimado de bateria, e avisar quando estiver abaixo de certa carga.

\subsection{ILUSTRAÇÕES}

A quantidade de exemplos de situações que podem ocorrer é muito grande, em função da quantidade de variáveis que podem compor um sistema. Os exemplos apresentados a seguir têm como objetivo ilustrar os principais conceitos abordados neste trabalho. No Exemplo 1 a pessoa deseja se deslocar do ponto A para o ponto B. A Figura 6.7 demonstra o percurso a ser realizado. 
Figura 6.7 - Percurso a ser realizado - Exemplo 1.

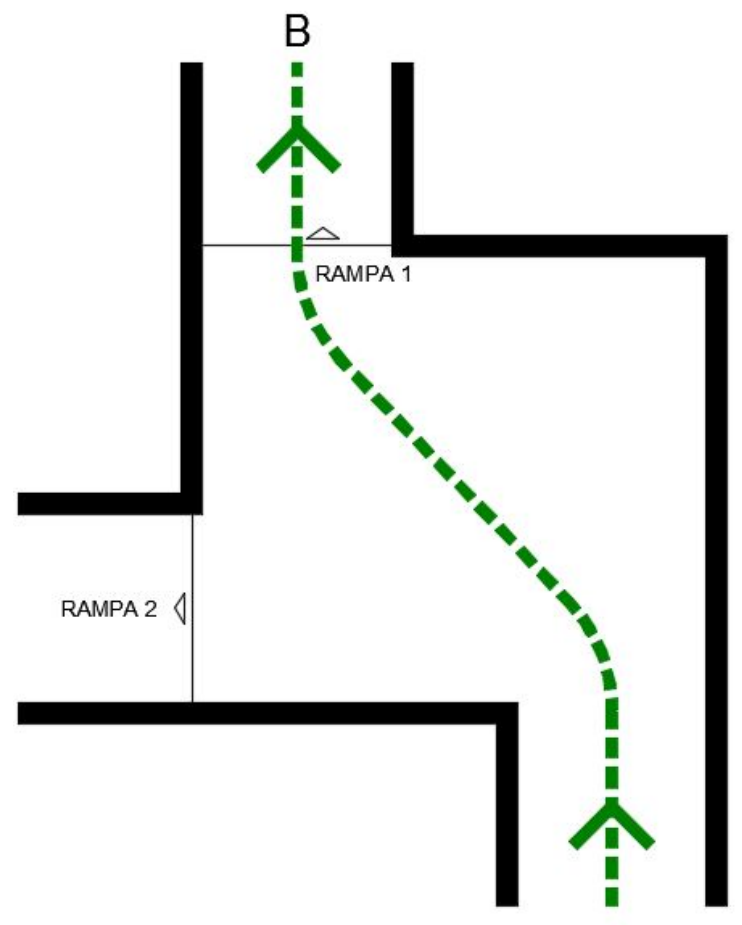

A

Para que uma pessoa com deficiência visual possa atingir este objetivo, instalou-se um sistema hipotético de navegação (Figura 6.8). A pessoa parte do ponto A com destino ao ponto $\mathrm{B}$ e recebe o sinal emitido pelo transmissor frontal (a) com a mensagem "Rampa à esquerda".

Figura 6.8 - Orientação inadequada/insuficiente para a navegação.

(a)

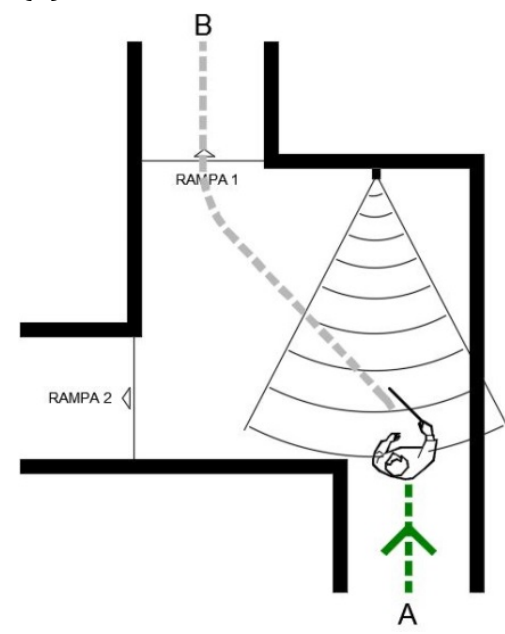

(b)

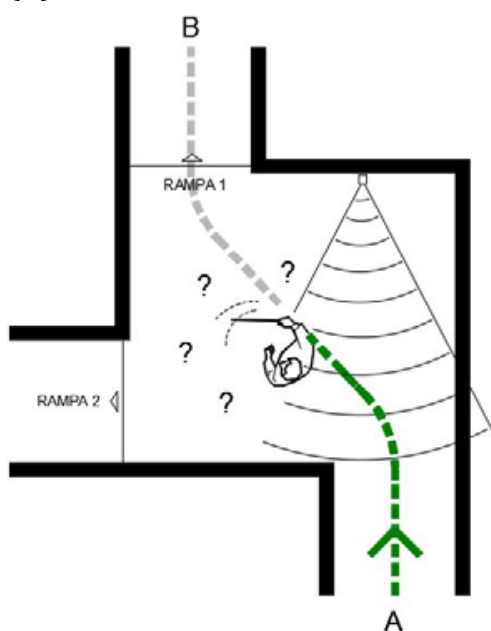

(c)

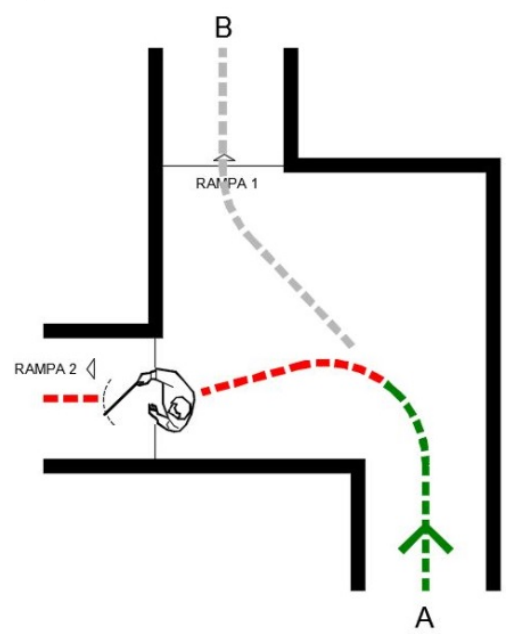


A pessoa avança um ou dois passos no percurso "à esquerda", conforme o comando, mas não encontra a rampa e fica confusa (b), pois a rampa 1, onde está o ponto $B$, está distante do ponto em que ela recebeu o sinal, o que, conjugado à informação dada, não foi suficiente para orientá-la corretamente, podendo até incorrer no erro de encontrar a rampa 2, que também está à esquerda, acreditando estar no caminho certo (c).

Uma possível solução poderia ser a mudança da mensagem de comando para "Caminhe cerca de cinco passos a 45 graus à esquerda e encontre a rampa". Esta mensagem está de acordo com a linguagem a ser utilizada, no entanto, trata-se de uma mensagem muito longa para uma navegação em estações de metrô, pois obriga a pessoa a parar para ouvila, o que pode ser indesejável em um local onde todos, inclusive o próprio usuário com deficiência, caminham de maneira apressada.

Uma solução mais adequada pode envolver o acréscimo de mais um transmissor, com mensagens complementares, por exemplo (Figura 6.9). A pessoa parte do ponto A em direção ao ponto $\mathrm{B}$ e recebe o sinal emitido pelo transmissor frontal (a) com a mensagem "Caminhe a 45 graus, à esquerda". Ao avançar dois ou três passos nesta direção receberá a mensagem do transmissor lateral (b) com a mensagem "Rampa a três passos", e provavelmente chegará ao local desejado (c). Ainda para este exemplo, podem haver outras soluções, dependendo do tipo de sinal da transmissão, tipo de equipamento utilizado, interferências etc.

Figura 6.9 - Orientação adequada para a navegação.

(a)

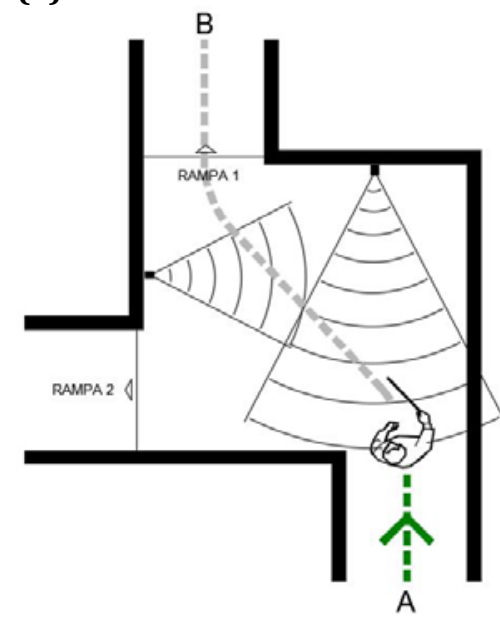

(b)

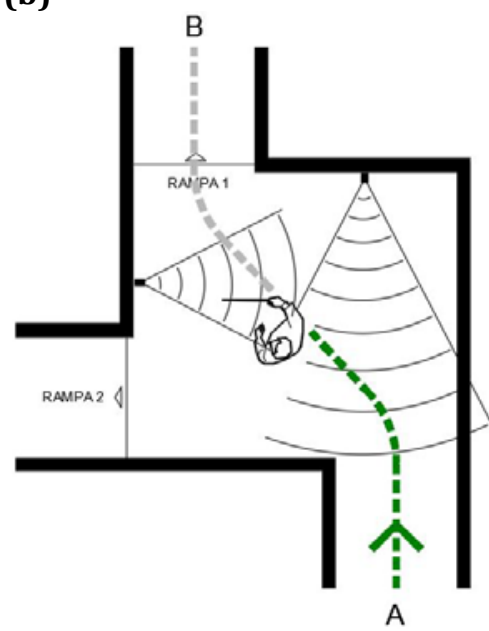

(c)

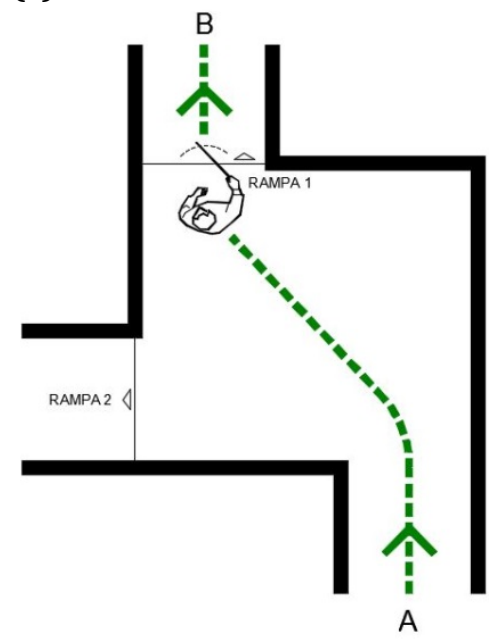


O Exemplo 2 (Figura 6.10) ilustra uma dificuldade complementar a projetistas: os percursos geralmente são de ida e volta, passando pelos mesmos ambientes (a), o que exige comandos diferentes ou genéricos, quando possível. Quando se utiliza transmissores direcionais, por exemplo, é possível haver controle de direcionamento de diferentes rotas (b), porém quando o transmissor é de amplo alcance (c) não é possível se garantir detalhamento do percurso.

Figura 6.10 - Percursos a serem realizados - Exemplo 2.

(a)

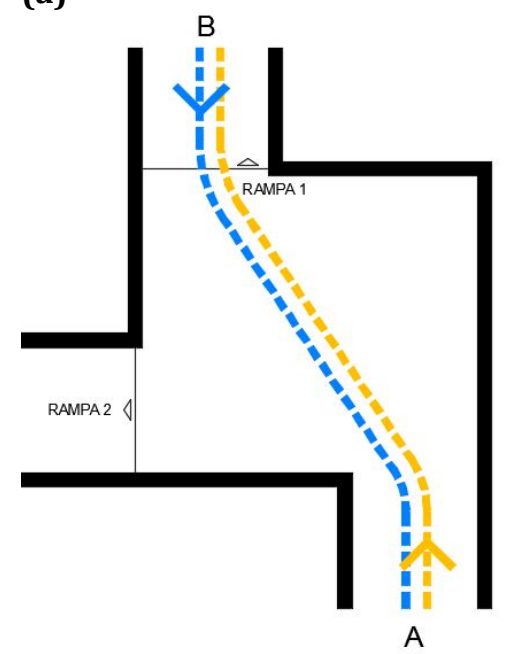

(b)

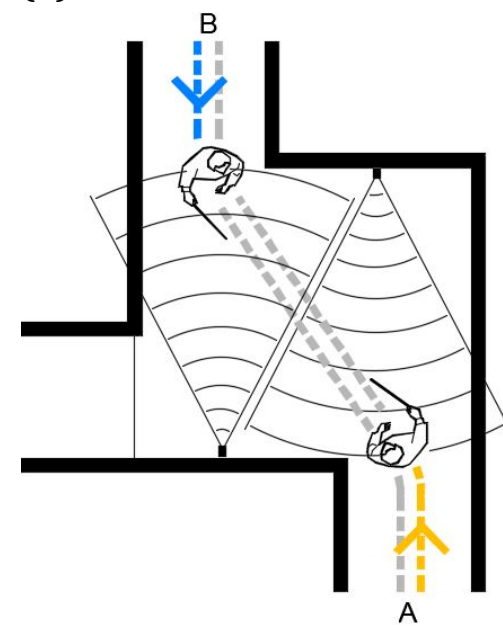

(c)

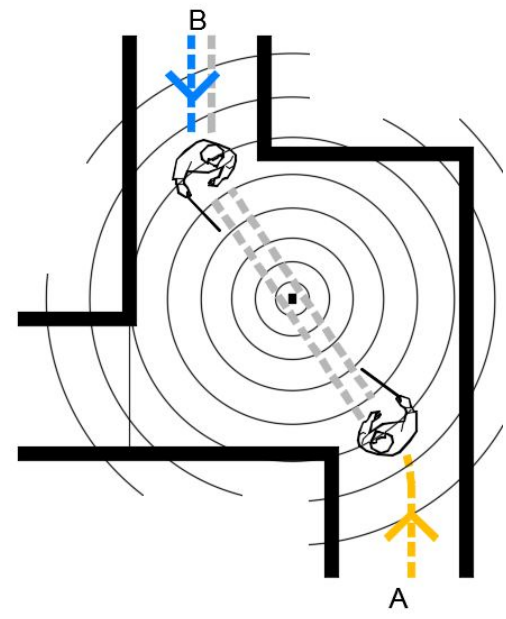

\subsection{CONDIÇÕES GERAIS}

Além da questão da segurança, já abordada, deve-se considerar as seguintes condições:

a) o funcionamento do sistema não deve perturbar a operação normal da estação, tampouco os demais usuários;

b) o uso de um sistema eletrônico para informação e navegação não elimina a utilização das técnicas de Orientação e Mobilidade, especialmente as técnicas de autoproteção ${ }^{77}$ e técnicas com bengala longa ${ }^{78}$;

c) o sistema deve ser capaz de uso simultâneo, em quantidade suficiente para atender à demanda;

\footnotetext{
77 Técnicas de autoproteção: proteção superior, proteção inferior, proteção combinada e proteção social. 78 Técnicas com bengala longa: varredura, técnica diagonal, detecção de objetos, passagem por portas, rastreamento com técnica diagonal, subir e descer escadas, técnicas de toque, técnicas de toque e deslize, técnica de deslize, rastreamento com técnica de toque e rastreamento em três pontos
} 
d) deve-se prever como e quando serão feitas as manutenções do sistema. Deve-se prever como será realizado o tratamento de falhas no sistema, avisando-se tanto à operadora como aos usuários;

e) no caso de falha do sistema, deve haver solução alternativa para que o usuário prossiga até chegar seguro ao seu destino;

f) conforme a ONCE (2003), dada à rapidez com que se aperfeiçoam os meios técnicos, se recomenda avaliação, planejamento e renovação permanente do sistema e seus dispositivos.

\subsection{PROPOSIÇÕES COMPLEMENTARES}

$\mathrm{Na}$ pesquisa realizada por Barbosa (2015) são propostos requisitos a serem incorporados nas normas técnicas vigentes, relacionados a melhorias para o uso de sistemas de metrô por pessoas com deficiência visual. Analisando-se os requisitos propostos, é possível se identificar que muitos deles podem se beneficiar ou mesmo considerar o uso de sistemas eletrônicos de informação e navegação, conforme Quadro 6.2, de acordo com essa mesma autora:

A impossibilidade de padronizar soluções implica a existência de referências e de um sistema de informação, de comunicação e de orientação que torne legível, simultaneamente, os macro e os microambientes destinados à mobilidade, e possibilite a orientação dos deslocamentos coletivos em meio às necessidades individuais. Facilitar a percepção e a compreensão dos ambientes é essencial para orientar os deslocamentos, seja em ambientes de uso habitual ou eventual. (BARBOSA, 2015, p. 2) 
Quadro 6.2 - Proposições complementares de melhorias.

\begin{tabular}{|c|c|}
\hline Requisitos propostos por Barbosa (2015) & $\begin{array}{l}\text { Solução complementar com o uso de sistema } \\
\text { eletrônico de informação e navegação }\end{array}$ \\
\hline $\begin{array}{l}\text { Requisitos para configuração dos espaços de } \\
\text { conexão de forma a garantir uma rota acessível } \\
\text { entre diferentes modos de transporte. }\end{array}$ & $\begin{array}{l}\text { O sistema instalado de maneira integrada entre } \\
\text { os modos de transporte poderá orientar quanto à } \\
\text { rota acessível. }\end{array}$ \\
\hline $\begin{array}{l}\text { Posicionamento dos recursos de circulação } \\
\text { vertical de forma a facilitar a sua visualização, } \\
\text { legibilidade e compreensão do espaço. }\end{array}$ & $\begin{array}{l}\text { O sistema poderá direcionar e indicar a } \\
\text { localização dos recursos de circulação vertical, } \\
\text { sem necessidade de visualização e compreensão } \\
\text { do espaço. }\end{array}$ \\
\hline $\begin{array}{l}\text { Arquivo sonoro contendo audiodescrição dos } \\
\text { ambientes das estações disponibilizados por meio } \\
\text { da internet, para auxiliar o planejamento dos } \\
\text { deslocamentos. }\end{array}$ & $\begin{array}{l}\text { Além das informações a serem disponibilizadas } \\
\text { por meio da internet, o sistema poderá fornecer } \\
\text { audiodescrição dos ambientes das estações e } \\
\text { trens em tempo real, além da opção de navegação, } \\
\text { que talvez seja mais adequada para algumas } \\
\text { pessoas. }\end{array}$ \\
\hline
\end{tabular}

Mapas táteis com recursos sonoros para orientar deslocamentos na estação, posicionados nos pontos de tomada de decisão (acesso/saída, mezanino área paga, mezanino área livre, local de embarque e desembarque preferencial).

Mapas táteis com recursos sonoros para orientar deslocamentos na rede, posicionados nos pontos de tomada de decisão (no mezanino área paga e no local de embarque e desembarque preferencial).

Mapas táteis com recursos sonoros para orientar deslocamentos na entre diferentes sistemas de transporte, posicionados nos pontos de tomada de decisão (acesso/saída, mezanino área paga).

Contraste de cor entre piso, parede, portas, Além do contraste de cor entre os elementos da corrimão, pilares, painéis de informação e estação e do trem, o sistema poderá fornecer equipamentos da estação e do trem.

O sistema eletrônico de navegação poderá ser uma alternativa mais eficaz a todos os mapas táteis. audiodescrição dos ambientes das estações e trens em tempo real, além da opção de navegação, que poderá orientar o percurso e fornecer as informações necessárias.

Piso tátil direcional para elevadores e escadas.

Piso tátil ao longo das rampas, evitando-se terminar junto aos corrimãos.

Percursos diagonais e em curva pouco acentuadas em substituição aos percursos ortogonais.

O sistema eletrônico de navegação poderá ser complementar aos pisos táteis, de maneira a permitir a realização de percursos personalizados, conforme a preferência do usuário.

Distribuição de mapas e folhetos com tipos 0 sistema poderá fornecer informações em áudio. ampliados. 
(Conclusão)

Requisitos propostos por Barbosa (2015)

Requisitos para sinalização dos ambientes de acessível entre diferentes modos de transporte.

Requisitos de sinalização tátil, visual e sonora integradas para máquinas e equipamentos de autoatendimento, incluindo intercomunicadores, bilheterias, dispositivos para leitura de cartões, bloqueios, elevadores e escadas rolantes.

Tempo máximo de espera para auxílio nos deslocamentos. espaços de conexão de forma a garantir uma rota

Solução complementar com o uso de sistema eletrônico de informação e navegação

O sistema instalado de maneira integrada entre os modos de transporte poderá orientar quanto à rota acessível.

Além da integração entre a sinalização tátil, visual e sonora dos elementos citados, integrar também o sistema de informação e navegação.

O sistema eletrônico de informação e navegação poderá contribuir para a autonomia de muitas pessoas com deficiência visual, reduzindo o número de usuários que esperam pelo auxílio de um funcionário. 0 quadro de funcionários poderá ser otimizado.

Requisitos para veiculação das mensagens sonoras no interior dos trens e mensagens visuais nos painéis eletrônicos e mapas dinâmicos.

Requisitos para veiculação das mensagens sonoras e visuais no interior dos trens.
O sistema poderá fornecer as informações de maneira clara e personalizada a cada usuário, de acordo com o percurso programado e preferências pessoais, como por exemplo, o volume do áudio.

Fonte: Elaborado com base em proposta de Barbosa (2015, p.476). 


\section{CONSIDERAÇÕES FINAIS}

A pesquisa partiu do princípio da mobilidade independente, onde as pessoas com deficiência visual são capazes de viajar de maneira autônoma. Enquanto ajudas tradicionais, como uso de bengala longa e treinamento de Orientação e Mobilidade, constituem importantes ferramentas para a identificação de pontos de orientação e detecção de obstáculos no ambiente, também podem ser insuficientes para a locomoção em estações e trens de metrô, pelas suas características específicas.

Pode-se afirmar que as mudanças tecnológicas ocorridas nas últimas décadas modificaram não somente a configuração das empresas e o modelo de empregos, mas também permitiu às pessoas com deficiência desenvolverem-se profissionalmente, sobretudo utilizando o computador como ferramenta de trabalho. Mas, mesmo com esse avanço, e das conquistas legalmente instituídas pela legislação, ainda existe uma lacuna no que tange à acessibilidade nos meios de transporte, utilizados na maioria de seus deslocamentos.

Esta pesquisa buscou elementos que pudessem subsidiar a utilização de sistemas eletrônicos complementares para informação e auxílio à navegação de pessoas com deficiência visual em redes de metrô, a partir de uma abordagem centrada no usuário, a fim de propor diretrizes de projeto. Para se atingir essa meta foi necessário realizar estudos integrando várias áreas de conhecimento e pesquisa, uma tarefa multidisciplinar.

Pesquisas iniciais demonstraram a existência de tentativas de utilização nos anos 1970, em estações metroferroviárias, de dispositivos que emitem sinais eletrônicos de infravermelho, localizados por dispositivos com alto-falante projetado para reproduzir as falas dos sinais, limitados pela tecnologia disponível na época, mas um exemplo válido dessa possibilidade. O rápido avanço de tecnologias fez surgirem novos meios de transmissão de diversos tipos de sinais e de dispositivos, no entanto, pouco se encontrou de bibliografia que tivesse a finalidade de propor um sistema de informação e navegação para guiar pessoas com deficiência visual. 
Diante da dificuldade de se encontrar compilações de dados significativos para projetistas e usuários, a fundamentação teórica apresentada nesta dissertação buscou reunir as informações multidisciplinares específicas para pesquisadores e demais interessados no assunto . Para chegar às conclusões deste estudo e fazer as proposições que aqui constam, fez-se necessário um mapeamento cognitivo do usuário, investigar as tecnologias disponíveis e as características pertinentes a redes de metrô, além de sistemas de informação e navegação para pessoas com deficiência visual.

Para o mapeamento cognitivo do usuário com deficiência visual foi necessária a investigação em diversas disciplinas, como a psicologia ambiental, a fenomenologia, a antropologia, a sociologia, o urbanismo e a educação, entre outros, gerando os dados aqui reunidos. Também foram investigados e realizado cruzamento de requisitos para a informação e navegação de pessoas com deficiência visual, requisitos de tecnologias eletrônicas de comunicação e requisitos de redes de metrô.

Com relação aos dados sobre pessoas com deficiência visual, destaca-se a informação de que entre $70 \%$ e $80 \%$ dessas pessoas não são totalmente cegas, possuindo alguma visão útil, o que influencia na sua interação com os espaços de circulação pública. Outro dado relevante, é que indivíduos com cegueira congênita (que adquiriram a deficiência até aproximadamente cinco anos de idade) apresentam mais dificuldade para acompanhar a sua posição no ambiente do que aqueles que adquiriram a deficiência mais tarde, e essa dificuldade deve ser considerada no planejamento de dispositivos de auxílio à mobilidade, os quais devem atender a todos.

Esta pesquisa também esclarece que não é verdade que todas as pessoas com deficiência visual são fluentes em Braille, não podendo ser este um recurso único para fornecimento de informações. O Braille é a única forma de alfabetização para pessoas que adquiriram a deficiência visual antes de serem alfabetizadas, as quais representam apenas $6,4 \%$ do total de pessoas com deficiência visual, enquanto as demais têm muito mais dificuldade ou resistência para aprender esta forma de escrita.

Complementar à maneira como se dá a relação de seu corpo com o ambiente urbano, surgem questões a respeito das particularidades intrínsecas aos seres humanos, à necessidade de se rever conceitos negativos de "deficiência", tais como "incapacidade" e 
“desvantagem", conforme conceito proposto pela CIF79, que considera a deficiência não como um problema da pessoa, mas "como um problema criado socialmente e basicamente como uma questão de interação plena do indivíduo com a sociedade" (TEIXEIRA, 2013, p. 29). Dessa forma, na pesquisa foi considerado também o conceito de affordance, o qual se refere ao que é oferecido pelo ambiente ao organismo que com ele interage.

Para compreensão a respeito de percepção espacial, foram considerados estudos sobre percepção do ambiente e sobre os diferentes canais sensoriais de pessoas com e sem a deficiência, suas condições físicas e psicológicas, a capacidade do ambiente de proporcionar informações e o contexto social e cultural em que a relação pessoaambiente está inserida. Como boa parte da realidade é percebida por meio da visão, as pessoas com deficiência visual utilizam outras percepções sensoriais, como a audição, o sistema háptico, a cinestesia, a memória muscular, o sentido vestibular ou labiríntico, o olfato e o aproveitamento máximo de qualquer grau de visão que possa ter.

O conceito de navegação, contemporaneamente utilizado também como determinação de curso de pessoas por caminhos terrestres e ambientes construídos é explorado neste estudo com importância significativa, pois a forma como uma pessoa é orientada é crucial para um deslocamento bem sucedido. Basicamente, a tarefa de navegação consiste em um número de ações simples: (a) planejamento da rota; (b) orientação em pontos de referência; (c) orientação ao longo do trajeto; e (d) detecção/ desvio de obstáculos. A tarefa de navegação foi explorada sob diferentes óticas e o cruzamento entre elas permitiu se chegar às proposições no final do trabalho.

A pesquisa demonstrou que uma viagem envolve muitos e complexos desafios em tempo real, mas que, por meio de estudos envolvendo a divisão do trajeto relacionando-os aos conceitos de Orientação e Mobilidade, foi possível a formulação de um número de diferentes elementos significativos para o usuário, úteis para o planejamento de sistemas de navegação. A tarefa de navegação é uma sequência muito complexa de etapas onde grande quantidade de informações sobre o ambiente e mudanças de direção são constantemente transmitidas, recebidas e atualizadas, trabalho que envolve,

${ }^{79}$ A Classificação Internacional de Funcionalidade, Incapacidade e Saúde - CIF publicada pela Organização Mundial da Saúde - OMS em maio de 2001 e traduzida para a língua portuguesa em 2003, apresenta um modelo que analisa as diversas condições de saúde do ser humano, em associação aos aspectos ambientais. (CIF, 2004) 
obviamente, muito mais do que o desenvolvimento de um aplicativo para aparelhos de telefonia móvel, como os atuais smartphones.

A dissertação também abordou a audiodescrição, um recurso conceitualmente novo, que começou a ser explorado e tomou força para transmitir informações visuais de filmes, programas de televisão e peças de teatro às pessoas que não enxergam, como expressões corporais, figurinos, efeitos especiais e informações sobre o ambiente. Devido a esta última possibilidade, a audiodescrição também pode ser muito útil na descrição de ambientes a serem percorridos na realidade, podendo ser pré-gravada ou obtida em tempo real, permitindo mais autonomia nos deslocamentos. Este recurso pode ser especialmente útil às pessoas com deficiência visual congênita, pois muitas têm dificuldade de compreender a sua posição no ambiente a partir de informações espaciais, como por exemplo, a partir de mapas táteis.

Complementando as questões de informação e navegação, o texto aborda importantes itens sobre as questões de usabilidade dos dispositivos e sistemas, alertando para a necessidade da participação de designers de produto no processo de desenvolvimento.

Com relação aos requisitos de tecnologias eletrônicas a serem utilizadas, foram investigados sistemas criados com este objetivo, seus usos e seus avanços. 0 entendimento de que seja um sistema de informação e navegação surgiu durante as pesquisas, em função da dificuldade para se oferecer autonomia e segurança de fato, tendo sido exploradas as questões de: (a) segurança e confiabilidade na informação; (b) foco no objetivo desejado, para informar o necessário de forma eficaz ao usuário; e (c) conforto, para viabilizar a utilização.

Foram analisadas as possibilidades de utilização de transmissores de sinais por ondas de rádio (GNSS, ERB, Wi-Fi, Bluetooth, RFID, NFC e VHF); luz (infravermelho, Laser e luz visível); som (som audível e ultrassom); e vibração (vibração e infrassom). Estas explorações, trazidas à luz da possibilidade de integração à arquitetura para prover a autonomia na circulação de pessoas em redes de metrô poderão servir de base para compreensão do tema por parte da comunidade de desenvolvedores interessados no assunto. 
Verificou-se que muitos pesquisadores tiveram sua atenção voltada para o projeto de equipamentos para auxiliar a caminhada de pessoas com deficiência visual, mas, o que chama a atenção é que a maioria não chega a ser desenvolvida comercialmente. As razões para que isso ocorra podem estar ligadas à falta de investimento, mas frente aos estudos insípidos, sem o cuidado adequado na realização das pesquisas, pode-se entender porque na maioria dos casos os usuários perdem o interesse em utilizá-los. Isto alerta para a necessidade de realização de pesquisa adequada, que considere o uso do sistema e seus equipamentos pelas mais diferentes pessoas, nos diferentes ambientes de redes de metrô, em especial com relação à precisão de localização espacial.

A investigação também apontou que estações de metrô diferem de edifícios comuns em vários aspectos, com interferências diretas nos projetos. Uma estação de metrô comporta um grande número de pessoas circulando, gerando fluxos que variam ao longo do dia, e que podem variar bastante ao longo dos anos, por isso as questões de fluxo são muito importantes nos projetos. Além das questões de fluxos de pessoas e de trens, estações de metrô possuem sistemas nem sempre visíveis aos seus usuários, mas que podem causar ou sofrer interferência a novos sistemas, devendo-se haver compatibilização entre esses. Aliadas às características peculiares dos ambientes de metrô encontra-se a diversidade de usuários, o que exige que os desenvolvedores tomem conhecimento das necessidades de ambos os lados para poderem chegar a um produto eficiente.

A complementação da pesquisa teórica se deu com a pesquisa de campo, por meio da utilização de diferentes métodos, principalmente qualitativos: observações nãoparticipantes e participantes, entrevistas e questionários. A pesquisa de campo assumiu grande importância para a estruturação da análise e proposições deste trabalho. As observações práticas nas estações do metrô de São Paulo e metrô do Porto, em Portugal, foram fundamentais para o entendimento sobre como as pessoas com deficiência visual atualmente fazem para saber itinerários do metrô, onde é a entrada, a saída, como fazem quando devem ir a uma estação que não conhecem, como é a ambientação, a localização espacial e temporal, quais os termos mais conhecidos e mais utilizados, entre outras questões, visando à utilização de sistemas eletrônicos para auxílio a essas pessoas. 
A pesquisa no metrô do Porto permitiu o contato direto com profissionais desenvolvedores e usuários de um serviço já instalado e em funcionamento desde 2009, de informação e navegação assistida a pessoas com deficiência visual. O sistema denominado Navmetro ${ }^{\circledR}$ visa proporcionar de forma gratuita aos usuários com deficiência visual, acesso a informações referentes ao transporte, tais como linhas, horários e títulos, bem como um serviço para auxílio na orientação dessas pessoas dentro das estações.

No sistema Navmetro ${ }^{\circledR}$, a interação com o usuário se faz por meio da fala utilizando-se um telefone celular comum e orientação sonora por sons de pássaros. Para esta dissertação foi realizada observação de campo com usuário deficiente visual na estação Trindade, além de entrevistas com pesquisadores do metrô do Porto e engenheiro da FEUP - Faculdade de Engenharia da Universidade do Porto, responsável pela equipe de pesquisadores, acadêmicos e de desenvolvimento.

Dentre os resultados válidos para esta pesquisa obtidos no metrô do Porto, pode-se destacar: a necessidade e a dificuldade para criação de um sistema que obtenha a localização exata do usuário, para poder guia-lo; a possibilidade de se utilizar sons diferenciados, que se destaquem no ambiente, sem incomodar aos demais usuários, como o som de pássaros; a importância da interação entre o usuário e o sistema, como por exemplo, a lógica da comunicação; a dificuldade de se utilizar sinais Wi-Fi e Bluetooth em ambientes de metrô, tanto pela imprecisão de localização, como pelas interferências que sofrem e que causam na operação. Também se evidenciou a importância de se realizar pesquisas científicas para desenvolvimento de produtos dessa complexidade.

A pesquisa no metrô de São Paulo permitiu a observação de usuários com deficiência visual utilizando um metrô que é reconhecido como um sistema de alta capacidade e articulador do transporte público na Região Metropolitana de São Paulo, destacando-se mundialmente pelo serviço de transporte sobre trilhos de milhões de passageiros diariamente. Os usuários com deficiência visual que participaram da pesquisa realizaram viagens habituais, sem alteração de percurso ou de comportamento, pelos mais diversos horários e estações de diferentes configurações. 
Em paralelo ocorreram entrevistas com profissionais do metrô e profissionais de Orientação e Mobilidade, as quais permitiram uma visão complementar para análise dos dados obtidos. Finalmente, a aplicação de questionário qualitativo/quantitativo a 67 usuários com deficiência visual foi decisiva para a consolidação das análises e proposições.

Foram feitas análises descritivas das observações e análise de conteúdo da fala dos participantes, identificando-se que fatores tais como a complexidade espacial e a grande quantidade de usuários nas estações interferem diretamente na autonomia dos deslocamentos de usuários e que, mesmo que muitos sistemas disponibilizem funcionários para acompanhar pessoas com deficiência, esta solução é passível de falhas e/ou descontentamento por parte dessas.

Ainda com relação ao acompanhamento por funcionários, pode-se destacar a confirmação de que, ainda que a maioria dos usuários com deficiência visual deseje ser autônoma, a maioria solicita auxílio de funcionários do metrô para se deslocar nas estações, por desconhecimento dos percursos e/ou medo de acidentes.

As pesquisas demonstraram que a região das estações de metrô onde as pessoas com deficiência visual têm mais medo de caminhar sozinhas é nas plataformas de embarque e desembarque, por consistirem em ambientes que oferecem riscos para quem não está preparado para perceber o limite do desnível entre a plataforma e a via por onde circulam os trens, potencializados pela presença de outros usuários. Mesmo treinada, a pessoa pode confundir-se ou sofrer alguma vertigem por estar muito próxima do trem em movimento, e a melhor solução, que é a instalação de portas de plataforma, é de difícil execução, especialmente nas estações mais antigas.

As entrevistas com os professores de Orientação e Mobilidade mostraram opiniões favoráveis à proposta de uso de sistemas eletrônicos como auxiliares à informação e navegação de pessoas com deficiência visual. Esses profissionais fizeram declarações no âmbito do ensino das técnicas de $\mathrm{OM}$, a respeito de percepção espacial e cognição das pessoas em questão; declarações não encontradas em bibliografias e também não identificadas durante as observações e entrevistas, porém úteis a esta pesquisa. 
A pesquisa gerou uma grande quantidade de dados que permitiram propor diretrizes a serem utilizadas em projetos de desenvolvimento desses sistemas, além de uma grande quantidade de dados que poderão ser úteis a outras pesquisas, pois este estudo concentra informações específicas às áreas de deficiência visual, sistemas eletrônicos para informação, sistemas eletrônicos para navegação, redes de metrô, e a interligação entre os assuntos, apresentados de uma maneira pouco encontrada em trabalhos acadêmicos atualmente.

Destaca-se também a informação de que entre 70\% e 80\% das pessoas com deficiência visual não são totalmente cegas, possuindo alguma visão útil, o que influencia na sua interação com os espaços de circulação pública. Outro dado relevante, é que indivíduos com cegueira congênita (que adquiriram a deficiência até aproximadamente os cinco anos de idade) apresentam mais dificuldade para acompanhar a sua posição no ambiente do que aqueles que adquiriram a deficiência mais tarde assim como para interpretar mapas, e esta dificuldade deve ser considerada no planejamento de dispositivos de auxílio à mobilidade, os quais devem atender a todos.

Pode-se chegar a duas importantes conclusões: a primeira é que ainda não existe um consenso a respeito de como deve ser esse sistema (o que justifica estudos para isso) e a segunda é que, independentemente das características físicas e operacionais de cada sistema de metrô, a instalação de recursos eletrônicos para auxiliar pessoas com deficiência visual em áreas públicas será cada vez mais utilizada.

A presente pesquisa buscou contribuir para a ampliação do campo teórico de temas relacionados a tecnologias para auxílio na locomoção de pessoas com deficiência visual, frente à relevância acadêmica do tema, às lacunas existentes e às possibilidades de novas contribuições para profissionais da área e acima de tudo para a autonomia das pessoas com deficiência visual.

Em virtude do surgimento, no final do mestrado, de novos sistemas que se propõem a guiar pessoas com deficiência visual em redes de metrô, como por exemplo, o Wayfindr, no metrô de Londres, não foi possível avaliá-los com mais profundidade, em função do tempo. Sugere-se, como encaminhamento para trabalhos futuros, estudos de sistemas instalados em outros metrôs para avaliação de seu desempenho. 
Sugere-se a ampliação deste estudo de maneira a atender outros usuários que também possam se beneficiar de sistemas eletrônicos de informação e navegação em redes de metrô. Existem diversos tipos de dificuldades que as pessoas apresentam, e que podem ser supridas com esse tipo de auxílio, destacando-se: auxiliar na comunicação e alerta de perigos a pessoas com deficiência auditiva; auxiliar idosos na comunicação, alerta de perigos e navegação; auxiliar de diversas formas pessoas com deficiências ou dificuldades de comunicação e compreensão em geral, como pessoas com déficit de atenção, pessoas com déficit de inteligência e autistas. 


\section{REFERÊNCIAS}

AGUIAR, F. de O. Acessibilidade relativa dos espaços urbanos para pedestres com restrições de mobilidade. 2010. Tese de Doutorado em Ciências, Engenharia de Transportes. Escola de Engenharia de São Carlos, Universidade de São Paulo, São Carlos, 2010.

ALMEIDA, A.; ORDUÑA, P.; CASTILLEJO, E.; LÓPEZ-DE-IPIÑA, D. SACRISTAN, M. Imhotep: an approach to user and device conscious mobile applications. Personal and

Ubiquitous Computing (Journal), 2011. v. 15, n. 4, p. 419-429.

ALMEIDA, L. C.; LOCH, R. E. N. Mapa tátil: passaporte para a inclusão. Extensio - Revista Eletrônica de Extensão n. 3, ano 2005 - Universidade Federal de Santa Catarina, 2005.

ALMEIDA, M. F. X. M. Auxílios à navegação de pedestres cegos através de mapa tátil. 2008. Dissertação de Mestrado em Design. Universidade Federal de Pernambuco, Recife, 2008.

ALMEIDA, M. F. X. M.; RIBEIRO, G. S.; SANTOS, V. M. V.; MARTINS, L. B. Avaliação ergonômica dos recursos utilizados na orientação e mobilidade de pessoas com deficiência visual. XXVII Encontro Nacional de Engenharia de Produção. Foz do Iguaçu, 2007.

AMARAL, A. L. Pensando a deficiência como diferença. In: III Congresso Brasileiro sobre Educação Especial, 1999, Curitiba/ PR. Anais... Curitiba, 1999. p. 234-242.

AMIRALIAN, M. L. T. M. Compreendendo o cego. Uma visão psicanalítica da cegueira por meio de desenhos-estórias. São Paulo: Casa do Psicólogo, Fapesp, 1997.

AMIRALIAN, M. L. T. M. Sou cego ou enxergo? As questões da baixa visão. Educar, Curitiba, n. 23, p. 15-28. Editora UFPR, 2004.

ANGROSINO, M. Etnografia e observação participante. Porto Alegre: Artmed, 2009.

ARTHUR, P.; PASSINI, R. Wayfinding: People, Signs and Architecture. Toronto: McGrawHill Ryerson, 1992.

ASSOCIAÇÃO BRASILEIRA DE NORMAS TÉCNICAS - ABNT. NBR 14021: transporte acessibilidade no sistema de trem urbano ou metropolitano. Rio de Janeiro, 2005.

ASSOCIAÇÃO BRASILEIRA DE NORMAS TÉCNICAS - ABNT. NBR 15599: acessibilidade na comunicação na prestação de serviços. Rio de Janeiro, 2008.

ASSOCIAÇÃO BRASILEIRA DE NORMAS TÉCNICAS - ABNT. NBR 9050: acessibilidade para pessoas com deficiência a edificações, mobiliário, espaços e equipamentos urbanos. Rio de Janeiro, 1994.

ASSOCIAÇÃO BRASILEIRA DE NORMAS TÉCNICAS - ABNT. NBR 9050: acessibilidade a edificações, mobiliário, espaços e equipamentos urbanos. Rio de Janeiro, 2004. 
ASSOCIAÇÃO BRASILEIRA DE NORMAS TÉCNICAS - ABNT. NBR 9050: acessibilidade a edificações, mobiliário, espaços e equipamentos urbanos. Rio de Janeiro, 2015.

ASSOCIAÇÃO BRASILEIRA DE NORMAS TÉCNICAS - ABNT. NBR 9050: Adequação das edificações e do mobiliário urbano à pessoa deficiente - Procedimento. Rio de Janeiro, 1985.

ASSOCIAÇÃO DOS CEGOS E AMBLÍOPES DE PORTUGAL - ACAPO. Recomendações sobre atendimento a pessoas com deficiência visual. Núcleo de Estudos e Investigação em Acessibilidade. Nov. 2013a. [S.I.]. Disponível em:

<http://www.acapo.pt/>. Acesso em 18 ago. 2014.

ASSOCIAÇÃO DOS CEGOS E AMBLÍOPES DE PORTUGAL - ACAPO. Recomendações sobre design de produtos que podem ser utilizados por pessoas com deficiência visual. Núcleo de Estudos e Investigação em Acessibilidade. Abr. 2013b. [S.I.]. Disponível em: <http://www.acapo.pt/>. Acesso em 18 ago. 2014.

BAKER, R. R. The human navigation and the sixty sense. New York: Simon and Schuster, 1981.

BARBOSA, M. B. P. Wayfinding na jornada da pessoa com deficiência visual no sistema metroferroviário. 2015. Tese de Doutorado em Arquitetura e Urbanismo. Faculdade de Arquitetura e Urbanismo da Universidade de São Paulo, São Paulo, 2015.

BARDIN, L. Análise de conteúdo. Tradução Luís Antero Reto e Augusto Pinheiro. Lisboa, Edições 70, 1979.

BARRAGA, N. C. Increased visual behavior in low vision children. New York: American Foundation for the Blind, 1964.

BATISTA, C. G.; ENUMO, S. R. F. Desenvolvimento humano e impedimentos de origem orgânica: o caso da deficiência visual. In: NOVO, H.A. e MENANDRO, M.C.S. (Org.). Olhares diversos: estudando o desenvolvimento humano). Vitória, E.S.: UFES, Programa de Pós-graduação em Psicologia, Capes, Proin, 2000. p. 157-174.

BAUER, M. W. Análise de conteúdo clássica: uma revisão. In: BAUER, M.; GASKELL, G. (Org.). Pesquisa qualitativa com texto, imagem e som. Um manual prático. Petrópolis: Vozes, 2010. cap. 8, p.189-217.

BAUER, M.; GASKELL, G. (Org.). Pesquisa qualitativa com texto, imagem e som. Um manual prático. Petrópolis: Vozes, 2010.

BERNARDI, N. 0 impacto do desenho universal no processo e no ensino do projeto arquitetônico: o caso de indivíduos com visão subnormal. 2007. Tese de Doutorado em Engenharia. Faculdade de Engenharia Civil, Arquitetura e Urbanismo, UNICAMP, Campinas, 2007. 
BIANCHETTI, L.; FREIRE I. M. (Org.). Um olhar sobre a diferença. Campinas: Papirus, 2000.

BINS ELY, V. H. M. Acessibilidade espacial: Condição necessária para o projeto de ambientes inclusivos. In: MORAIS, A. de. Ergodesign do ambiente construído e habitado. Rio de Janeiro, 2004a. p. 17-40.

BINS ELY, V. H. M. Orientar-se no Espaço: condição indispensável para a acessibilidade. In: Seminário Nacional Acessibilidade no Cotidiano, I., 2004, Rio de Janeiro. Anais .... Rio de Janeiro: UFRJ, 2004b.

BINS ELY, V. H. M.; DISCHINGER, M.; DAUFENBACH, K.; RAMOS, J.; BOOCH, G.; MAKSIMCHUK, R. A.; ENGLE, M. W.; YOUNG, B. J.; CONALLEN, J.; HOUSTON, K. A. Object oriented design with applications. 3. ed. Boston, Pearson Education, Inc., 2007.

BORGES, J. H. M. Orientação e Mobilidade, 2004. [S.I.]. Disponível em: <http:/www.sac.org.br/ori_mob.htm>. Acesso em: 31 mar. 2014.

BRADLEY, N. A.; DUNLOP, M. D. An experimental investigation into wayfinding directions for visually impaired people. Personal and Ubiquitous Computing, 2005.

BRANDALIZE, M. B.; PHILIPS, J. Padrões de classificação de equipamentos laser utilizados em levantamentos terrestres e aéreos. Curitiba, PUC PR, 2002.

BRAMBRING, M., Mobility and orientation processes of the blind, in electronic spatial sensing for the blind: contributions from perception, rehabilitation and computer vision, proceedings of the NATO Advanced Research Workshop. In: WARREN D.H.; STRELOW E. R. (Editors), Electronic spatial sensing for the blind, Dordrecht, The Netherlands, Nijhoff, 1985. p. 493-508.

BRASIL. Decreto No 5.296, de 2 de dezembro de 2004. Regulamenta as Leis n. 10.048, de 8 de novembro de 2000 , que dá prioridade de atendimento às pessoas que especifica, e 10.098, de 19 de dezembro de 2000, que estabelece normas gerais e critérios básicos para a promoção da acessibilidade das pessoas portadoras de deficiência, ou com mobilidade reduzida, e dá outras providências. Diário Oficial da União, Brasília, 2004.

BRASIL. Decreto No 6.949, de 25 de agosto de 2009. Promulga a Convenção Internacional sobre os Direitos das Pessoas com Deficiência e seu Protocolo Facultativo, assinados em Nova York, em 30 de março de 2007. Diário Oficial da União, Brasília, 2009.

BRASIL. Lei No 10.048, de 8 de novembro de 2000. Dá prioridade de atendimento às pessoas que especifica, e dá outras providências. Diário Oficial da União, Brasília, 2000a.

BRASIL. Lei No 12.587, de 3 de janeiro de 2012. Institui as diretrizes da Política Nacional de Mobilidade Urbana e dá outras providências. Diário Oficial da União, Brasília, 2012. 
BRASIL. Lei No 8.213, de 24 de julho de 1991. Dispõe sobre os Planos de Benefícios da Previdência Social e dá outras providências. Diário Oficial da União, Brasília, 1991.

BRASIL. Lei No 10.098, de 19 de dezembro de 2000. Estabelece normas gerais e critérios básicos para a promoção da acessibilidade das pessoas portadoras de deficiência ou com mobilidade reduzida, e dá outras providências. Diário Oficial da União, Brasília, 2000b.

BRENTZEN, B. L. Orientation Aids, in Foundations of Orientation and Mobility. Ed Welsh R. L.et al, AFB, USA, 1979.

BRUSNIGHAN, D. A.; STRAUSS, M. G.; FLOYD, J. M.; WHEELER, B. C. Orientation aidimplementing the Global Positioning System. In: BUUS, S. (Ed.), Proceedings of the weenth Annual Norrheart Bioengineering Conference. Boston: IEEE, 1989. p. 33-34.

BRYSON, J. M. What to do when stakeholders matter. Stakeholders identification and analysis techniques. Public Management Review, v. 6, Issue 12004 21-53. University of Minnesota. Routledge: Taylor \& Francis, 2004.

BUGARÍN, M. D. R. Sistemas ferroviários metropolitanos lixeiros. In: BUGARÍN, M. D. R.; DIEGO, J. S. de; FERNÁNDEZ, J. P.; ROEL, P. B. Transporte metropolitano da Coruña. Debate sobre unha proposta de CC. 00. Cadernos socioeconómicos de DEZEME, 2006/2. Santiago, Fundación 10 de Marzo de CC. 00., 2006. p. 23-35.

CAPARRÓS, J. A. E., Tiflotecnologia. In: MARTIN, M. B.; BUENO, S. T. (Org.). Deficiência Visual. Aspectos Psicoevolutivos y Educativos. Málaga, Ediciones Aljibe, 1994, p. 307318.

CARLIN, F. Acessibilidade espacial em Shopping Centers: um estudo de caso. 2004. Dissertação de Mestrado em Engenharia de Produção. Universidade Federal de Santa Catarina, Florianópolis, 2004.

CAVALCANTI, P. Desenho Universal: por uma arquitetura inclusiva. Relatório de pesquisa do Grupo PET/ARQ, Universidade Federal de Santa Catarina. Florianópolis: MEC/SeSU, 2000.

CDC. National Center for Health Statistics. Classifications of diseases and functioning \& disability. ICD-9-CM Rich text files (.rtf) via FTP: 2002. Dtab03.zip. Classification of diseases and injuries. ICD-9-CM Tabular list of diseases (FY03). 369.9 Unspecified visual loss, p. 215. Disponível em:

<http://ftp.cdc.gov/pub/Health_Statistics/NCHS/Publications/ICD9-CM/2002/>. Acesso em: 27 jun. 2015.

COETZEE, J. LiFi beats Wi-Fi with 1GB wireless speeds over pulsing LEDs. 2014. [S.I.]. Disponível em: <http://gearburn.com/2014/01/lifi-beats-wi-fi-with-1gb-wirelessspeeds-over-pulsing-leds/>. Acesso em: 04 jan. 2016. 
COHEN, R. Cidade, corpo e deficiência: percursos e discursos possíveis na experiência urbana. 2006. Tese de Doutorado em Psicossociologia de Comunidades e Ecologia Social. Instituto de Psicologia da Universidade Federal do Rio de Janeiro. Rio de Janeiro, 2006.

COLLINS, C. C. On mobility aids forthe blind. In D. H. Warren \& E. R. Strelow (Ed.). Electronic Spatial Sensing for the Blind. Dordrecht: Martinus Nijhoff, 1985. p. 35-64.

COMISSÃO DE MONITORAMENTO DAS CONCESSÕES E PERMISSÕES - CMCP. Relatório de demanda da ViaQuatro - Linha 4-Amarela. Secretaria de Estado dos Transportes Metropolitanos - STM, São Paulo, 2015.

COMPANHIA DO METROPOLITANO DE SÃO PAULO - CMSP. [S.I.]. Disponível em: <http://www.metro.sp.gov.br >. Acesso em: 04 jul. 2015.

COMPANHIA DO METROPOLITANO DE SÃO PAULO - CMSP. Diretoria de Operações. Relatório Operacional R02014. CD-ROM. CMSP, $2015 \mathrm{a}$.

COMPANHIA DO METROPOLITANO DE SÃO PAULO - CMSP. Gerência de Operações. CRM-Sugar - 2014. GOP/OPR. CMSP, 2014a.

COMPANHIA DO METROPOLITANO DE SÃO PAULO - CMSP. Gerência de Operações. Desempenho da operação - Dezembro de 2014. Relatório GOP/OPC/CTE. CMSP, 2014b.

COMPANHIA DO METROPOLITANO DE SÃO PAULO - CMSP. Gerência de Operações. Percepção da pessoa com deficiência visual sobre o deslocamento no Metrô de São Paulo. Relatório de Pesquisa GOP/OPR nº 14/2015. CMSP, 2015b.

COMPANHIA DO METROPOLITANO DE SÃO PAULO - CMSP. Gerência de Operações. Por dentro da operação - 2014. Compact-disc. CMSP, 2015c.

COMPANHIA DO METROPOLITANO DE SÃO PAULO - CMSP. Gerência de Operações. Relatório de Monitoração das pessoas com deficiência e restrição de mobilidade no Metrô de São Paulo. GOP/OPR/CAU. Dezembro, 2014. CMSP, 2014c.

COMPANHIA DO METROPOLITANO DE SÃO PAULO - CMSP. Gerência de Operações. Sistema Estatístico da Operação - SEO - 2015. São Paulo: CMSP, 2015d.

COWEN, David J. Gis versus CAD versus DBMS: what are the differences? Photogrammetric Engineering and Remote Sensing, 1986. v.55, n.11, p.1551-1555.

CRANDALL, W.; BENTZEN, B. L.; MYERS, L.; MITCHELL, P. Transit accessibility improvement through talking signs - remote infrared signage: a demonstration and evaluation. Report from the Federal Transit Act, Cooperative Agreement with the U.S. Department of Transportation, Federal Transit Administration and Project ACTION of the National Easter Seal Society. San Francisco, 1995.

DANTAS, D.; SOUSA, C. S. M. de. Quando as pesquisas tradicionais podem ser inadequadas. São Paulo, 2013. Conteúdo de aula ministrada em 27 set. 2013 no curso 
de Pós-Graduação da Faculdade de Arquitetura da Universidade de São Paulo, Disciplina AUP 5899 - Design centrado no usuário.

DAVID, J. da S.; ANTUNES, X. M.; GURGEL, V. T. Cidade acessível: igualdade de direitos e particularidades da pessoa com deficiência visual. Mnemosine, Universidade Federal do Rio de Janeiro, 2009. v. 5, n. 1, p. 80-94.

DEMO, Pedro. Metodologia científica em ciências sociais. 3. ed. São Paulo: Atlas, 1995.

DISCHINGER, M. Designing For All Senses, Accessible Spaces For Visually Impaired People, Department Of Space And Process, Chalmers University of Technology, Göteborg, Sweden. 2000. p. 69-71.

DISCHINGER, M. Onde Está Tudo Aquilo Que Não Desenhamos? Projetar 2005 - II Seminário sobre Ensino e Pesquisa em Projeto de Arquitetura. 2005. Disponível em: <http://projedata.grupoprojetar.ufrn.br/dspace/bitstream/123456789/1198/1/221\% 20DISCHINGER_M.pdf>. Acesso em: 13 jul. 2013.

du BUF, J. Improved grating and bar cell models in cortical area v1 and texture coding. Image and Vision Computing 25(6), 873-882, 2007.

du BUF, J. M. H.; BARROSO, J.; RODRIGUES, J. M. F.; PAREDES, H.; FARRAJOTA, M.; FERNANDES, H.; JOSÉ, J.; TEIXEIRA, V.; SALEIRO, M. The SmartVision navigation prototype for the blind. In: Proc. Int. Conf. on Software Development for Enhancing Accessibility and Fighting Info-exclusion, 2010. p. 167-174.

du BUF, J. M. H.; BARROSO, J.; RODRIGUES, J. M. F.; PAREDES, H.; FARRAJOTA, M.; FERNANDES, H.; JOSÉ, J.; TEIXEIRA, V.; SALEIRO, M. The SmartVision navigation prototype for blind users. JDCTA: Int. J. of Digital Content Technology and its Applications 5(5), 2011. p. 351-361.

DUARTE, K. S. SmartGuia: Shopping Assistant for Blind People. 2014. Dissertação de Mestrado em Engenharia Biomédica, Faculdade de Ciências e Tecnologia da Universidade de Coimbra. Coimbra, 2014.

ECOS de alerta. Revista Pesquisa FAPESP. Ed. 110. Abril de 20015. p. 68. Disponível em: <http://revistapesquisa.fapesp.br/2005/04/01/folheie-a-ed-110/>. Acesso em: 13 nov. 2015.

ESPINOSA, M. A.; UNGAR, S.; OCHAIATA, E.; SPENCER, M. B. C. Comparing methods for introducing blind and visually impaired people to unfamiliar urban environments. Journal of Environmental Psychology, 1998. v. 18, p. 277-287.

FARIAS, N.; BUCHALLA, C. M. A. Classificação Internacional de Funcionalidade, Incapacidade e Saúde da Organização Mundial da Saúde: Conceitos, Usos e Perspectivas. Revista Brasileira de Epidemiologia, São Paulo, 2005. v. 8, n. 2.

FARMER, L. W. Mobility Devices, in Foundations of Orientation and Mobility. Ed Welsh R. L.et al, AFB, USA, 1979. 
FELIPPE, J. A. M., FELIPPE, V. L. R. Orientação e Mobilidade. São Paulo: Laramara Associação Brasileira de Assistência ao Deficiente Visual, 1997.

FERREIRA, E. J. NAVMETRO ${ }^{\circledR}$ - avaliação de usabilidade de sistemas de interação por voz. 2012. Dissertação de Mestrado em Design Industrial. Faculdade de Engenharia da Universidade do Porto. Porto, 2012.

FERREIRA, E. J.; FREITAS, D. NAVMETRO ${ }^{\circledR}$ : estudo preliminar da aplicação de métodos de avaliação de usabilidade. Revista do Programa de Pós-Graduação em Design da UDESC. v. 1, n. 2, 2012.

FERRONI, M. C. C.; GASPARETTO, M. E. R. F. A influência das relações sociais no desenvolvimento de escolares com baixa visão. VII Encontro da Associação Brasileira de Pesquisadores em Educação Especial. ISSN 2175-960X. Londrina, 2011. p. 10921103.

FLICK, U. Desenho da pesquisa qualitativa. Porto Alegre: Artmed, 2009a.

FLICK, U. Introdução à pesquisa qualitativa. Porto Alegre: Artmed, 2009b.

FLICK. U. Introdução à Metodologia de Pesquisa: Um Guia Para Iniciantes. Porto Alegre: Penso: 2013.

FONTAINE, C.; HAARMAN, A.; SCHMID, S. The Stakeholder Theory. Stakeholder Theory of the MNC, 2006. Disponível em:

<http://www.martonomily.com/sites/default/files/attach/Stakeholders\%20theory.pdf >. Acesso em 12 out. 2014.

FRATOCCHI, A. C. G.; GUEDES, C.; SILVA, C. T.; CARDOSO, D. D.; MARIANI, E.; PONTES, F. M.; FERREIRA, G.; BORGES, M. L.; TAKESHITA, N. Ações de relacionamento inclusivas: experiências do Metrô de São Paulo. Revista Engenharia. São Paulo, ago./out. 2015. n. 626, p. 162-167.

FREEMAN, R. E. Strategic Management: A stakeholder Approach. Boston, MA: Pitman, 1984.

FREITAS, H.; JANISSEK-MUNIZ, R.; MOSCAROLA, J. Modelo de formulário interativo para análise de dados qualitativos. Revista de Economia e Administração, São Paulo, 2005. v. 4, n. 1, p. 27-48.

FURUKAWA, R. N.; BRUNO , L. C. Dispositivo remoto para controlar funcionalidades de aplicativos em um computador. XXVI ENEGEP, 2006, p. 4. [S.I.]. Disponível em: <http://www.abepro.org.br/biblioteca/ENEGEP2006_TR490329_6902.pdf>. Acesso em: 14 jan. 2015.

G1 (2012). Iniciativas facilitam a vida de deficientes visuais no interior de SP. [S.I.]. Disponível em: <http://g1.globo.com/sp/bauru-marilia/noticia/2012/01/iniciativasfacilitam-vida-de-deficientes-visuais-no-interior-de-sp.html>. Acesso em: 03 fev. 2012. 
GAIO, R. Para além do corpo deficiente: histórias de vida. Jundiaí: Fontoura, 2006.

GALL, J. Systemantics: How systems really work and why they fail. Ann Arbor, MI.: General Systemantics Press, 1986, p. 65.

GASKELL, G. Entrevistas individuais e focais. In: BAUER, M.; GASKELL, G. (Org.).

Pesquisa qualitativa com texto, imagem e som. Um manual prático. Petrópolis: Vozes, 2010. cap. 3, p. 64-89.

GASPARETTO, M. E. R. F. et al. Dificuldade visual em escolares: conhecimentos e ações de professores do ensino fundamental que atuam com alunos que apresentam visão subnormal. Arquivos brasileiros de oftalmologia, São Paulo, 2004. v. 67, n.1, p. 65-71.

GEDAWY, H. K. Designing an Interface and Path Translator for a Smart Phone-Based Indoor Navigation System for Visually Impaired Users. 2011. Thesis (Master of Science). School of Computer Science, Carnegie Mellon University, Pittsburgh, 2011.

GERHARDT, T. E.; SILVEIRA, D. T. (Org.) Métodos de pesquisa. Coordenado pela Universidade Aberta do Brasil - UAB/UFRGS e pelo Curso de Graduação Tecnológica Planejamento e Gestão para o Desenvolvimento Rural da SEAD/UFRGS. Porto Alegre: Editora da UFRGS, 2009.

GIACAGLIA, M. E. Modelagem de dados para planejamento e gestão operacional de transportes. 1998. Tese de Doutorado em Engenharia. Escola Politécnica da Universidade de São Paulo, São Paulo, 1998.

GIACOMINI, L. Análise de um programa: "passo a passo" orientação e mobilidade para pessoas surdocegas. 2008. Dissertação de Mestrado em Psicologia da Educação.

Universidade de São Paulo, São Paulo, 2008.

GIBSON, J. J. The ecological approach to visual perception. Hillsdale, New Jersey: Lawrence Erlbaum, 1979/1986.

GIL, A. C. Métodos e técnicas de pesquisa social. 6. ed. São Paulo: Atlas, 1999.

GIL, M. Deficiência Visual. Brasília: MEC, 2000.

GILL, R. Análise de discurso. In: BAUER, M.; GASKELL, G. (Org.). Pesquisa qualitativa com texto, imagem e som. Um manual prático. Petrópolis: Vozes, 2010. cap. 10, p. 244270 .

GOLD, R. L. Roles in Sociological Field Observations. Social Forces, 36: 217-223, 1958.

GOLLEDGE, R., LOOMIS, J.; KLATZKY, R. Components of a Personal Guidance System (PGS) for vision impaired travelers. Annual Meeting of the Association of Pacific Coast Geographers, Santa Barbara, 2001. v.1, p. 66-78. 
GONÇALVES, N. M.; MELLER, M. H. S.; PATRICIO, A. J. G. Educação sem barreiras: a acessibilidade em estudo. In: 19ำ Congresso Brasileiro de Transporte e Trânsito da Associação Nacional de Transporte Público - ANTP. Anais... Brasília, 2013.

GÜNTHER, H. Mobilidade e affordance como cerne dos estudos pessoa-ambiente. In: Estudos de Psicologia, 2003. p. 273-280.

HARPER, S. Standardising electronic travel aid interaction for visually impaired people. Thesis (Master of Philosophy). Institute of Science and Technology, University of Manchester, Manchester, 1998.

HARPER, S.; GREEN, P. A travel flow and mobility framework for visually impaired travellers. International Conference on Computers Helping People with Special Needs. Jun 2000.

HATWELL, Y. Psychologie cognitive de la cécité precoce. Paris: Dunod, 2003.

HERSH, M .A.; JOHNSON, M. A. (Org.). Assistive technology for visually impaired and blind people. London: Springer-Verlag, 2008.

HILDEBRANDT, L. M. Intervenção de enfermagem no sofrimento psíquico em hospital geral. Ribeirão Preto: Editora e Gráfica Escala, 1998.

HOFFMANN, S. B. Orientação e mobilidade: um processo de alteração positiva no desenvolvimento integral da criança cega congênita - estudo intercultural entre Brasil e Portugal. 1998. Dissertação de Mestrado em Ciências do Movimento Humano. Escola de Educação Física da Universidade Federal do Rio Grande do Sul, Porto Alegre, 1998.

HONORATO, S. Percepção de imagens através de frequências vibratórias captadas pelas mãos de pessoas cegas. 2013. Dissertação de Mestrado em Design e Expressão Gráfica. Universidade Federal de Santa Catarina, Florianópolis, 2013.

HONORATO, S.; BRAVIANO, G. A formação da imagem mental em deficientes visuais. Artigo elaborado como avaliação final da disciplina Seminários de Dissertação do programa Pós Design da UFSC. 2012. In: HONORATO, S. Percepção de imagens através de frequências vibratórias captadas pelas mãos de pessoas cegas. 2013. Dissertação de Mestrado em Design e Expressão Gráfica. Universidade Federal de Santa Catarina, Florianópolis, 2013.

ICO. Resolução adotada pelo Conselho Internacional de Oftalmologia. Austrália, Sidnei, abril de 2002. Disponível em: <http://www.cbo.com.br/publicacoes/jotazero/ed90/comunicado.htm>. Acesso em: 20 out. 2014.

INSTITUTO BRASILEIRO DE GEOGRAFIA E ESTATÍSTICA - IBGE. Censo demográfico 2010. Características gerais da população, religião e pessoas com deficiência. Compilação 2012. Brasil, Rio de Janeiro, 2012. Disponível em: <ftp://ftp.ibge.gov.br/Censos/Censo_Demografico_2010/Caracteristicas_Gerais_Religiao _Deficiencia/caracteristicas_religiao_deficiencia.pdf>. Acesso em: 13 jun. 2014. 
INTERNATIONAL ORGANIZATION FOR STANDARDIZATION - ISO. Assistive products for persons with disability - Classification and terminology. ISO 9999. Genève: ISO, 2011.

JACOBSON, R. D. Talking tactile maps and environmental audio beacons: an orientation and mobility development tool for visually impaired people. Institute of Earth Studies, University of Wales Aberystwyth, Ceredigion, SY23 3DB, U.K. 1999.

JOSÉ, J.; FARRAJOTA, M.; RODRIGUES, J. M. F.; du BUF, J. M. H. The SmartVision local navigation aid for blind and visually impaired persons. International Journal of Digital Content Technology and its Applications, v.5, n. 5, May 2011. Vision Laboratory, Institute for Systems and Robotics (ISR), University of the Algarve (FCT and ISE), Faro, Portugal, 2011.

JOSÉ, J.; RODRIGUES, J. M. F.; du BUF, J. M. H. Visual navigation for the blind: path and obstacle detection. In: Proc. Int. Conf. on Pattern Recognition Applications and Methods, 2012. v. 2, p. 515-519.

KAPLAN, B.; DUCHON, D. Combining qualitative and quantitative methods information systems research: a case study. Manage. Inf. Syst. Q. 12, 4, 1988. p. 571586.

KOSKINEN, I.; MATTELMÄKI, T.; BATTARBEE, K. Empathic design. Finland: IT Press, 2003.

KRONBERGER, N.; WAGNER, W. Palavras-chave em contexto: análise estatística de textos. In: BAUER, M.; GASKELL, G. Pesquisa qualitativa com texto, imagem e som. Um manual prático. Petrópolis: Vozes, 2010. cap. 17, p. 416-441.

LEME, M. E. S. Investigação de conceitos em cegos congênitos. Monografia apresentada ao Cepre-FCM-Unicamp, como requisito do curso de especialização Deficiência visual e surdez: fundamentos para a intervenção, 1998.

LOOMIS, J. M. Digital map and navigation system for the visually impaired. Unpublished mawscript. Deptmmt af Psychology, University of California, Santa Barbara, 1985.

LOOMIS, J. M., KLATZKY, R. L., GOLLEDGE, R. G. Navigating without vision: basic and applied research. Optometry and Vision Science, 2001. v. 78, n. 5, p. 282-289.

LOOMIS, J. M.; GOLLEDGE, R. G.; KLATZKY, R. L. GPS-Based navigation systems for the visually impaired. Fundamentals of Wearable Computers and Augmented Reality. Ed. Woodrow Bartfield and Thomas Caudell. Mahwah: Lawrence Erlbaum, 2001. p. 193203.

LOOMIS, J.M.; GOLLEDGE, R.G.; KLATZKY, R.L.; SPEIGLE, J.M.; TIETZ, J. Personal guidance system for the visually impaired. In: Communications of the ACM. New York, 1994. v. 2, p. 85-91. 
LOPES, N. Transporte acessível: Um direito dos cidadãos, um dever dos governantes. Livro Acessível Universal Blog. Publicado em 2010. [S.I.] Disponível em: < http://www.livroacessivel.org/blog/atencao-prefeitos-transporte-acessivel-um-direitodos-cidadaos-um-dever-dos-governantes/>. Acesso em: 23 out. 2015.

LÓPEZ-DE-IPIÑA, D.; KLEIN, B.; PÉREZ, J.; GUGGENMOS, C.; GIL, G. User-Aware Semantic Location Models for Service Provision. Proceedings of the 5th International Symposium of Ubiquitous Computing and Ambient Intelligence (UCAMI 2011). ISBN:978-84-694-9677-0. Riviera Maya, Mexico, December, 2011.

LÓPEZ-DE-IPIÑA, D.; KLEIN, B.; VANHECKE, S. Towards Ambient Assisted Cities and Citizens. Deusto Institute of Technology, DeustoTech University of Deusto Bilbao, Spain. European Software Institute, ICT Division. Zamudio, Bizkaia, SPAIN, 2013.

LÓPEZ-DE-IPIÑA, D.; LORIDO, T.; LÓPEZ, U. BlindShopping: enabling accessible shopping for visually impaired people through mobile technologies. ICOST 2011: 9th International Conference on Smart Homes and Health Telematics. LNCS6719, Toward Useful Services for Elderly and People with Disabilities, Springer. ISBN: 978-3-64221534-6, Montréal, Canada, June 2011.p. 266-270.

LÓPEZ-DE-IPIÑA, D.; LORIDO, T.; LÓPEZ, U. Indoor navigation and product recognition for blind People assisted shopping. Deusto Institute of Technology DeustoTech., University of Deusto Avda. Universidades 24, 48007 Bilbao, Spain. (Ed.): IWAAL 2011, LNCS 6693, 2011. p. 33-40.

LORA, T. D. P. Descobrindo o real papel das outras percepções, além da visão, para a orientação e mobilidade. In: MOTA, M. G. B. da. Orientação e Mobilidade: conhecimentos básicos para a inclusão da pessoa com deficiência visual. Brasília: MEC, SEESP, 2003. Disponível em: <http://portal.mec.gov.br/seesp/arquivos/pdf/ori_mobi.pdf>. Acesso em: 14 dez. 2013.

LÜDKE, M., ANDRÉ, M. E. D. A. Pesquisa em educação: abordagens qualitativas. São Paulo: EPU, 1986.

LYNCH, K. A imagem da cidade. Tradução Maria Cristina Tavares Afonso. Lisboa: Edições 70, 1999 (Texto original inglês, 1960).

MAIA, T. Orientação e mobilidade dos cegos: um mito? Uma capacidade? 2004. [S.I.]. Disponível em: <http://www.lerpraver.com>. Acesso em: 31 mar. 2014.

MARIANI, E; DUTRA, D. N. M; DAYÈ, C. A circulação de pessoas com deficiência visual no sistema metrô de São Paulo. Artigo apresentado no curso de Pós-Graduação da Faculdade de Arquitetura da Universidade de São Paulo, para conclusão da Disciplina AUP 5899 - Design centrado no usuário. São Paulo, 2013.

MARSTON, R. J. Towards an Accessible City: Empirical Measurement and Modeling of Access to Urban Opportunities for those with Vision Impairments, Using Remote Infrared Audible Signage. 2002. Dissertation (Doctor of Philosophy in Geography). University of California, Santa Barbara, 2002. Disponível em: 
<http://www.geog.ucsb.edu/ marstonj/Dissertation_of_James_R._Marston.pdf $>$. Acesso em: 12 jun. 2014.

MASINI, E. F. S. A experiência perceptiva é o solo do conhecimento de pessoas com e sem deficiências sensoriais. Maringá: Psicologia em Estudo, 2003. v. 8, n. 1, p. 39-43.

MASINI, E. F. S. A pessoa com baixa visão: desenvolvimento de sua eficiência visual. Temas Desenvolv., 1999. v. 8, n. 46, p. 28-34.

MASINI, E. F. S. 0 perceber e o relacionar-se do deficiente visual: orientando professores especializados. Brasília: Corde, 1994.

MASINI, E. F. S.; CHAGAS, P. A. C.; COVRE, T. K. M. Facilidades e dificuldades encontradas pelos professores que lecionam para alunos com deficiência visual em universidades regulares. Revista Benjamin Constant. Edição 34, Artigo 2. Agosto de 2006. Disponível em: <http://www.ibc.gov.br/?catid=4\&itemid=10043>. Acesso em: 14 out. 2013.

MATTOS, G. M. Redes de acesso em banda larga utilizando sistemas VSAT e WiFi. 2006. Dissertação de Mestrado em Engenharia Elétrica. Pontíficia Universidade Católica do Rio de Janeiro, Rio de Janeiro, 2006.

MAU, S.; MELCHIOR, N. A; MAKATCHEV, M.; STEINFELD, A. BlindAid: An Electronic Travel Aid for the Blind. The Robotics Institute Carnegie Mellon University, Pittsburgh, Pennsylvania, 2008.

\section{MAY, M. Accessible GPS Navigation and Digital Map Information for Blind} Consumers. ICWC 2000.

MAZZARO, J. L. Introdução - História de Mariana. In: MOTA, M. G. B. da. (Org.). Orientação e Mobilidade: Conhecimentos Básicos Para A Inclusão Da Pessoa Com Deficiência Visual. Brasília: MEC, SEESP, 2003. Disponível em:

<http://portal.mec.gov.br/seesp/arquivos/pdf/ori_mobi.pdf>. Acesso em: 14 dez. 2013.

MAZZOTTA, M. J. S. Educação especial no Brasil: história e política pública. São Paulo: Cortez, 1996.

MERLEAU-PONTY, M. Fenomenologia da Percepção. Tradução C. Moura. São Paulo: Martins Fontes, 1994 (Texto original francês, 1945)

METRO DO PORTO S. A. [S.I.]. Disponível em: <http://www.metrodoporto.pt/>. Acesso em: 17 jul. 2015.

MINAYO, M. C. S. 0 desafio do conhecimento. Pesquisa qualitativa em saúde. São Paulo: HUCITEC, 2014.

MITCHELL, W. e-topia: Tecnologias de Informação e Comunicação e a Transformação da Vida Urbana. In: CASTELLS, M. e CARDOSO, G. (Org.). A Sociedade em rede - do conhecimento à acção política. Anais... Conferência promovida pelo Presidente da República de Portugal. Lisboa, 2005. 
MORESI, E. (Org.) Metodologia da pesquisa. Programa de Pós-Graduação Stricto Sensu em Gestão do Conhecimento e Tecnologia da Informação. Universidade Católica de Brasília, Brasília, 2003.

MOSQUERA, C. Educação Física para deficientes visuais. Rio de Janeiro: Sprint, 2000. p. 9-24.

MOTA, M. G. B. da. (Org.). Orientação e Mobilidade: conhecimentos básicos para a inclusão da pessoa com deficiência visual. Brasília: MEC, SEESP, 2003. Disponível em: <http://portal.mec.gov.br/seesp/arquivos/pdf/ori_mobi.pdf>. Acesso em: 14 dez. 2013.

MOTTA, L. M. V. M.; ROMEU FILHO, P. (Org.) Audiodescrição: transformando imagens em palavras. São Paulo: Secretaria dos Direitos da Pessoa com Deficiência do Estado de São Paulo, 2010.

MOUTINHO, J. N. Sistema de apoio acústico à navegação pessoal. 2009. Dissertação de Mestrado Integrado em Engenharia Electrotécnica e de Computadores, Major Automação. Faculdade de Engenharia da Universidade do Porto, Porto, 2009.

NUNES, S. da S.; LOMÔNACO, J. F. B. Desenvolvimento de conceitos em cegos congênitos: caminhos de aquisição do conhecimento. Revista Semestral da Associação Brasileira de Psicologia Escolar e Educacional (ABRAPEE). v. 12, n. 1, Janeiro/Junho 2008. p. 119-138.

OKAMOTO, J. Percepção ambiental e comportamento: visão holística da percepção ambiental na arquitetura e na comunicação. São Paulo: Ed. Mackenzie, 2002.

OLIVEIRA, C. L. de. Um apanhado teórico-conceitual sobre a pesquisa qualitativa: tipos, técnicas e características. Revista Travessias. ed. 04. ISSN 1982-5935. Educação, Ciência, Linguagem e Arte, 2012.

OLIVEIRA, F. I. S.; RODRIGUES, S. T. Affordances: a relação entre agente e ambiente. Ciências \& Cognição 2006; v. 09. Disponível em: <http://www.cienciasecognicao.org/>. Acesso em 05 mar. 2014.

OLIVEIRA, S. L. de. Tratado de Metodologia Científica: projetos de pesquisas, TGI, TCC, monografias, dissertações e teses. São Paulo: Pioneira Thomson Learning, 2002.

ORGANIZAÇÃO MUNDIAL DA SAÚDE - OMS. Estimativas apresentadas pela OMS sobre a população mundial. Fact Sheet $N^{\circ} 282$. [Internet - Updated August 2014]. Disponível em: <http://www.who.int/mediacentre/factsheets/fs282/en/>. Acesso em: 15 abr. 2015.

ORGANIZAÇÃO MUNDIAL DA SAÚDE - OMS. Relatório mundial sobre a deficiência. World Health Organization; The World Bank. World report on disability 2011. Tradução Lexicus Serviços Linguísticos. São Paulo: SEDPcD, 2012. 334 p. Disponível em: <http://www.pessoacomdeficiencia.sp.gov.br/usr/share/documents/RELATORIO_MUN DIAL_COMPLETO.pdf >. Acesso em: 23 ago. 2013. 
ORGANIZAÇÃO MUNDIAL DE SAÚDE - OMS. CIF: Classificação Internacional de Funcionalidade, Incapacidade e Saúde. Tradução Amélia Leitão. Lisboa: DirecçãoGeral da Saúde, 2004.

ORGANIZACIÓN NACIONAL DE CIEGOS ESPAÑOLES - ONCE. Accesibilidad para personas con ceguera y deficiencia visual. 1. ed., Madrid: ONCE, 2003.

ORMELEZI, E.M. Os Caminhos da aquisição do conhecimento e a cegueira: do universo do corpo ao universo simbólico. 2000. Dissertação de Mestrado em Educação. Universidade de São Paulo, São Paulo, 2000.

OWEN, C. L. Context for Creativity. (Adapted from a paper given at the National Design Engineering Conference held in Chicago, Illinois on April 10, 1991. Published in: Design Studies [England] 13, n. 3 (1992), p. 216-228; and Design Processes Newsletter 4, n. 4 (1992), p. 1-6.

PADOVANI, S. Apostila de aula do curso de pós-graduação de ensino em design, nível: pós-graduação. Disciplina ministrada: ergonomia informacional. Recife: Universidade Federal de Pernambuco, UFPE, 2006.

PARANHOS, M. Apropriação de espaço por adultos com deficiência visual: estudo de casos. 2008. Dissertação de Mestrado em Psicologia Clínica. Núcleo de Psicossomática e Psicologia Hospitalar da Pontifícia Universidade Católica de São Paulo, São Paulo, 2008.

PASSINI, R. Graphics and architecture for wayfinding. School of Architecture University of Montreal. Proceedings of Public GRAPHICS, LUNTEREN, sept. 1994.

PASSINI, R. Wayfinding in Architecture. Montreal: Van Nostrand Reinhold Company, 1984.

PEREIRA, B. Os cegos e as máquinas de pagamento com tela touch. BLOG da AUDIODESCRIÇÃO. [S.I.]. Disponível em:

<http://www.blogdaaudiodescricao.com.br/2015/08/os-cegos-e-as-maquinas-depagamento-com-tela-touch.html>. Acesso em 10 dez. 2015.

PEREIRA, E. D.; MOURA, A. A. Desenvolvimento de um sistema de localização de fontes Rádio Frequência para aplicações indoor. 2011. Dissertação de Mestrado Integrado em Engenharia Electrotecnica e de Computadores. Faculdade de Engenharia da Universidade do Porto, Porto, 2011.

QUEIROZ, V. M. Acessibilidade para pessoas com deficiência visual: uma análise de parques urbanos. 2014. Dissertação de Mestrado em Arquitetura e Urbanismo.

Faculdade de Arquitetura e Urbanismo da Universidade de São Paulo. São Paulo, 2014.

RAMOS, J. J. C. Acessibilidade para a pessoa com cegueira em trilhas. 2009.

Dissertação de Mestrado em Educação Especial. Centro de Educação e Ciências Humanas da Universidade Federal de São Carlos, São Carlos, 2009. 
RAMPAZZO, L. Metodologia Científica para alunos de graduação e pós-graduação. São Paulo: Edições Loyola, 2005.

RÈGIE AUTONOME DES TRANSPORTS PARISIENS - RATP. [S.I.]. Disponível em: <http://www.ratp.fr/en/ratp/c_5087/accessibility/>. Acesso em: 10 dez. 2015.

RÈGIE AUTONOME DES TRANSPORTS PARISIENS - RATP. Accessibilité des réseaux. Le guide. 2010. Disponível em: <http://www.ratp.fr/fr/upload/docs/ application/pdf/2010-12/guideacc.pdf>. Acesso em: 10 dez. 2015.

RESENDE, A. E. Salas de controle: do artefato ao instrumento. 2011. Tese de Doutorado em Arquitetura e Urbanismo. Faculdade de Arquitetura e Urbanismo da Universidade de São Paulo. São Paulo, 2011.

RODRIGUES, A.; ASSMAR, E. M. L.; JABLANSKI, B. Psicologia Social. Petrópolis: Vozes, 2010.

RODRIGUES, C. E. M. Um dispositivo háptico de auxílio à navegação para deficientes visuais. TCC de Graduação em Ciência da Computação. Centro de Informática da Universidade Federal de Pernambuco, Recife, 2006.

ROGERS, Y.; SHARP, H.; PREECE, J. Design de interação: além da interação humanocomputador. Tradução Isabela Gasparini. 3. ed. Porto Alegre: Bookman, 2013.

ROSE, D. Análise de imagens em movimento. In: BAUER, M.; GASKELL, G. (Org.).

Pesquisa qualitativa com texto, imagem e som. Um manual prático. Petrópolis: Vozes, 2010. cap. 14, p.343-364.

ROSS, D. A., BLASCH, B. B. Evaluation of Orientation Interfaces for Wearable Computers. ISWC'00, 2000.

ROSS, D. A., BLASCH, B. B. Wearable interfaces for orientation and wayfinding. ASSETS 2000, ACM, 2000. p. 193-200.

SÁ, E. D. de. Acessibilidade: as pessoas cegas no itinerário da cidadania. In: Inclusão: Revista da Educação Especial. Secretaria de Educação Especial/MEC, v. 1, n. 1, out. 2005. p. 13-18.

SACKS, O. 0 olhar da mente. Tradução Laura Teixeira Mota. Companhia das Letras, 2010.

SANT'ANNA, L. A importância da audiodescrição na comunicação das pessoas com deficiência. In: MOTTA, L. M. V. de M.; ROMEU FILHO, P. (Org.). Audiodescrição: transformando imagens em palavras. Secretaria de Estado dos Direitos da Pessoa com Deficiência - SEDPCD. São Paulo, 2010.

SANTOS, A. 0 cego, o espaço, o corpo e o movimento: uma questão de orientação e mobilidade. 2004. [S.I.]. Disponível em: <http://www.ibcnet.org.br>. Acesso em: 15 abr. 2014 
SANTOS, J. P.; FOREST, J. D.; DUTRA, G. A.; ALMEIDA, M. Uma avaliação da bengala eletrônica para a melhoria de mobilidade dos deficientes visuais. Simpósio de Excelência e Gestão em Tecnologia. 2012.

SÃO PAULO (Município). Lei No 12.492, de 10 de outubro de 1997. Assegura o ingresso de cães guia para deficientes visuais em locais de uso público ou privado. Disponível em: <https://www.procon.sp.gov.br/texto.asp?id=2637>. Acesso em: 23 set. 2014.

SARRAF, V. P. A Comunicação dos sentidos nos espaços culturais brasileiros: estratégias de mediações e acessibilidade para as pessoas com suas diferenças. 2013. Tese de Doutorado em Comunicação e Semiótica. Pontifícia Universidade Católica de São Paulo, São Paulo, 2013.

SASSAKI, R. Inclusão - construindo uma sociedade para todos. Rio de Janeiro: WVA, 1999.

SCHIFFMAN, H. R. Sensação e percepção. Tradução Luís Antônio Fajardo Pontes, Stella Machado. 5. ed. Rio de Janeiro: LTC, 2005.

SELLTIZ, C. et al. Métodos de pesquisa nas relações sociais. 2. ed. São Paulo: EPU, 1987. v. 3.

SERRANO, D. P. Percepção e o processo de compra. 2004. [S.I.].Disponível em: <http://www.portaldomarketing.com/Artigos/Percepção.htm>. Acesso em: 15 abr. 2014.

SILVA, O. M. da. A epopéia ignorada: a pessoa deficiente na história do mundo de ontem e de hoje. São Paulo: CEDAS, 1987.

SILVA, R. F. L. da. Design de produto integrado ao projeto urbano: avaliação do projeto de tecnologia assistiva "bengala longa eletrônica" e sua contribuição para a inclusão do deficiente visual em espaço urbano aberto. 2009. Dissertação de Mestrado em Arquitetura e Urbanismo. Centro Tecnológico da Universidade Federal de Santa Catarina, Florianópolis, 2009.

SILVA, S. C. P. Deficiência visual: o seu conceito sob os pontos de vista médico e pedagógico e o sistema braile. Artigo. Red Educativa Mundial - REDEM. 2013. Disponível em: <http://redem.org/wp-content/uploads/2013/09/BREVE-HISTORICO-DADEFICIENCIA-VISUAL-E-O-SEU-CONCEITO-SOB-OS-PONTOS-DE-VISTA-MEDICO-EPEDAGOGICO.pdf.pdf > . Acesso em: 10 ago. 2013.

SIMÕES, J. F. O que é Design Universal? Entrevista de Eleine Ostroff a Jorge Falcato Simões. Design Inclusive, Cadernos de Design Anuário, Centro Português de Design, Lisboa, 2001. ano 9, n. 23/24, p. 78-80.

SIMON, H. The Sciences of the Artificial. Cambridge, MA: The MIT Press, 1982, p. 209. 
SOCIÉTÉ NATIONALE DES CHEMINS DE FER FRANÇAIS - SNCF. [S.I.]. Disponível em: $<$ http://www.accessibilite.sncf.com/la-demarche-daccessibilite/equipements/article/la-fleche-sonore>. Acesso em: 14 dez. 2015.

SOCIÉTÉ NATIONALE DES CHEMINS DE FER FRANÇAIS - SNCF. Guide Mobilité Réduite Information Voyageurs. SNCF: 2011b. Disponível em: <http://www.accessibilite.sncf.fr/IMG/pdf/guide_de_mobilite_reduite_2011-2.pdf>. Acesso em: 14 dez. 2015.

SOCIÉTÉ NATIONALE DES CHEMINS DE FER FRANÇAIS - SNCF. Le Bilan Accessibilité 2004-2011. SNCF: 2011a. Disponível em:

<http://www.accessibilite.sncf.com/IMG/pdf/SNCF-Bilan_Accessibilite_2004_2011FR_06-2-2.pdf>. Acesso em: 14 dez. 2015.

SONZA, A. P. Acessibilidade de Deficientes Visuais aos Ambientes Digitais/Virtuais. 2004. Dissertação de Mestrado em Educação. Faculdade de Educação da Universidade Federal do Rio Grande do Sul, Porto Alegre, 2004.

SORROWS, M. E.; HIRTLE, S. C. The nature of landmarks for real and electronic spaces. Conference: Spatial Information Theory: Cognitive and Computational Foundations of Geographic Information Science, International Conference COSIT '99, Stade, Germany, August 25-29, 1999.

TAYLOR, S. E.; PEPLAU, L. A.; SEARS, D. O. Social Psychology. Pearson/Prentice Hall, 2006.

TEIXEIRA, E. Projetos arquitetônicos de acessibilidade domiciliar e tecnologia assistiva: um estudo com arquitetos, terapeutas ocupacionais e usuários na cidade de São Paulo. 2013. Dissertação de Mestrado em Tecnologia da Arquitetura. Faculdade de Arquitetura e Urbanismo da Universidade de São Paulo, São Paulo, 2013.

TELFORD, C. SAWREY, J. O indivíduo excepcional. Rio de Janeiro: LCT, 1988.

THE ECONOMIST. Tripping the light fantastic: A fast and cheap optical version of Wi-Fi is coming. 2012. [S.I.]. Disponível em: <http://www.economist.com/node/21543470>. Acesso em: 04 jan. 2016.

TRANSANTIAGO. [S.I.]. Disponível em: <http://www.transantiago.cl/>. Acesso em: 12 dez. 2016.

TRANSPORT FOR LONDON. Accessibility guides. Disponível em: <https://tfl.gov.uk/forms/12387.aspx> . Acesso em: 23 ago. 2015.

TREUILLET, S.; ROYER, E.; CHATEAU, T.; DHOME, M.; LAVEST, J.M. Body mounted vision system for visually impaired - outdoor and indoor wayfinding assistance. In: Conference \& Workshop on Assistive Technologies for People with Vision \& Hearing Impairments Assistive Technology for All Ages. M.A. Hersh (ed.), 2007.

TUAN, Yi-Fu. Espaço e Lugar - A Perspectiva da Experiência. São Paulo, 1983. 
UNESC. Biblioteca da Unesc é a primeira do Brasil com guia auditivo para deficientes visuais. Publicado em set. 2015. [S.I.]. Disponível em:

<http://www.unesc.net/portal/blog/ver/213/31620>. Acesso em: 17 nov. 2015.

VALENTE, C. F.; REGANATI, G. H. O. Smart Audio City Guide. 2013. TCC - Instituto de Matemática e Estatística da Universidade de São Paulo, São Paulo, 2013.

VALENTINI, S. M. R. Os sentidos da paisagem. 2012. Tese de Doutorado em Arquitetura e Urbanismo. Faculdade de Arquitetura e Urbanismo da Universidade de São Paulo. São Paulo, 2012.

VASCONCELOS, R. T. B. Humanização de ambientes hospitalares: características arquitetônicas responsáveis pela Integração interior/exterior. 2004. Dissertação de Mestrado em Arquitetura e Urbanismo. Universidade Federal de Santa Catarina, Florianópolis, 2004.

VIAQUATRO. [S.I.]. Disponível em: <http://www.viaquatro.com.br>. Acesso em: 04 jul. 2015.

VIRTANEN, A.; KOSKINEN, S. NOPPA - Navigation and guidance system for the visually impaired. VTT Industrial Systems. Fin-33101 Tampere, Finland, 2014.

VUCHIC, V. R. Urban transit: operations, planning, and economics. New Jersey: John Wiley \& Sons, 2005.

VYGOTSKY, L. S. A formação social da mente: o desenvolvimento dos processos psicológicos superiores. São Paulo: Martins Fontes, 1994.

VYGOTSKY, L. S. Fundamentos de Defectología. Obras Completas, tomo cinco. Tradução em espanhol do original russo organizado em 1983, a partir de originais escritos até 1934. Cuba: Editorial Pueblo y Educación, 1997.

WALKER, B. N.; LINDSAY, J. Navigation performance in a virtual environment with bonephones. ICAD 05-Eleventh Meeting of the International Conference on Auditory Display, Limerick, Ireland, 2005.

WEISHALN, R. Orientation and mobility in the blind children. New York: Englewood Cliffs, 1990.

YATANI, K.; BANOVIC N.; TRUONG, K. N. SpaceSense: Representing Geographical Information to Visually Impaired People Using Spatial Tactile Feedback. University of Toronto, Department of Computer Science. Microsoft Research Asia, 2012. 


\section{BIBLIOGRAFIA}

AGRAWAL, D. G.; GUJRATHI, G. S. GPS \& GSM based Voice Alert System for Blind

Person. IJSRD - International Journal for Scientific Research \& Development. v. 1, Issue 9. Bhusawal, India, 2013.

ALAMYS. Associação Latino-americana de Metrôs e Subterrâneos. Disponível em: <http://www.alamys.or>. Acesso em: 13 out. 2014.

ALMEIDA, J. J. G.; PORTO, E. T. R. A pessoa deficiente visual: revelações sobre a atividade motora. 1999. Disponível em: <http://www.bbdigi.unicamp.br>. Acesso em: 13 abr. 2014.

AMIRALIAN, M. L. T. M. et al. A criança deficiente visual com problemas de aprendizagem: um modelo para atendimento integral. Pesquisa realizada no Lide/ IPUSP com apoio do CNPq e Capes. São Paulo, 2002.

AMIRALIAN, M. L. T. M. 0 psicólogo e as pessoas com deficiência visual. In: MASINI, E. F. S. (Org.). Do sentido, pelos sentidos, para o sentido: sentido das pessoas com deficiência sensorial. Niterói: Intertexto, 2002.

ANDRADE, N. H. S. de. A percepção visual de pacientes com retinopatia diabética segundo o referencial de Merleau-Ponty. 2008. Tese de Doutorado em Enfermagem. Universidade de São Paulo, Ribeirão Preto, 2008.

ANTP ASSOCIAÇÃO NACIONAL DE TRANSPORTES PÚBLICOS. Transporte Humano: Cidades com Qualidade de Vida. São Paulo, 1997. Disponível em:

<http://www.almg.gov.br/opencms/export/sites/default/acompanhe/eventos/hotsites /2013/mobilidade_urbana/docs/ANTP_transporte_humano.pdf $>$. Acesso em: 04 jul. 2013.

ANUÁRIO DA PRODUÇÃO DE INICIAÇÃO CIENTÍFICA - Anhanguera Educacional. Lógica matemática aplicada à definição de rotas usando dispositivos GPS. Disponível em: <http://www.sare.anhanguera.com/index.php/anuic/article/view/1672>. Acesso em: 04 jul. 2013.

ASSOCIAÇÃO DOS CEGOS E AMBLÍOPES DE PORTUGAL - ACAPO. Como caracterizar a cegueira? [S.I.]. Disponível em: <http://www.acapo.pt/>. Acesso em: 18 ago. 2014.

BALAKRISHNAN, G.; SAINARAYANAN, G.; NAGARAJAN, R.; SAZALI, Y. Wearable RealTime Stereo Vision for the Visually Impaired. Engineering Letters, 14:2, EL 1422. Advance online publication: 16 May, 2007.

BARBOSA, M. B.; ALBUQUERQUE, R. M. A. Comunicação, Sinalização e Acessibilidade. In: ORNSTEIN, S. W.; PRADO, A. R. A.; LOPES, M. E. (Org.). Desenho Universal: caminhos da acessibilidade no Brasil. São Paulo: Annablume, 2010. p. 279-290. 
BARKER, P.; BARRICK, J; WILSON, R. Building Sight: A handbook of Building and Interior Design Solutions to include the needs of Visually Impaired People. London, 1995.

BARKER, P.; HESKETH, P.; SMYTHE, S. The design and operation of accessible public transport systems. London, 1996.

BARQUEIRO, R. Emprestar o olhar. In: MOTTA, L. M. V. M.; ROMEU FILHO, P. (Org.) Audiodescrição: transformando imagens em palavras. São Paulo: Secretaria dos Direitos da Pessoa com Deficiência do Estado de São Paulo, 2010.

BASTO, L. de S. C.; GAIO, R. C. Técnicas de orientação e mobilidade para pessoas cegas: reflexões na perspectiva da educação física. Movimento \& Percepção, Espírito Santo do Pinhal, SP, v. 11, n. 16, jan./abr. 2010.

BASTOS, M. I. de S. R.. Inclusão digital e social de pessoas com deficiência: textos de referência para monitores de telecentros. Brasília, DF: UNESCO, 2007. Disponível em: <http://unesdoc.unesco.org/images/0016/001600/160012por.pdf>. Acesso em: 04 jul. 2013.

BAUMAN, Z. Modernidade Líquida. Rio de Janeiro: Jorge Zahar Editor, 2001.

BERGSON, H. 0 pensamento e o movente: ensaios e conferências. (Original publicado em 1911). São Paulo: Martins Fontes, 2006.

BEYDOUN, K; FELEA, V.; GUYENNET, H. Wireless sensor network system helping navigation of the visually impaired. ICTTA'08, IEEE int. conf. on Information and Communication Technologies: from Theory to Applications, Syria, dec. 2007.

BINS ELY, V. H. M. Ergonomia + Arquitetura: buscando um melhor desempenho do ambiente físico. In: 4o Congresso Internacional de Ergonomia e Usabilidade de Interfaces Humano - Tecnologia: Produtos, Programas, Informação, Ambiente Construído - Rio de Janeiro - RJ. Anais do 4o Ergodesign. Rio de Janeiro, PUC-Rio, 2004.

BINS ELY, V. H. M.; DISCHINGER, M. (Org.). Avaliação Pós-Ocupação em Edificações de Uso Coletivo - Beira Mar Shopping. Florianópolis: MEC/SeSU, 2000. Relatório de Pesquisa do Grupo PET/ARQ, Universidade Federal de Santa Catarina, 2000.

BISCHOFF, A. R.; HOFFMAN, L. T.; LUNKES, L. Deficiência Visual. In: CAMARGO, N. F.; GONZALEZ, S. J. Desporto Adaptado Portadores de Deficiência: natação. Porto Alegre: UFRGS, INDESP, 1996.

BRASIL. Ministério das Cidades. Brasília. Atendimento Adequado às Pessoas com Deficiência e Restrição de Mobilidade. Programa Brasileiro de Acessibilidade Urbana - Brasil Acessível - Caderno 1, 2006. Disponível em: <http://www.portalodm.com.br//publicacao/261/brasil-acessivel---caderno-1--atendimento-adequado-as-pessoas-com-deficiencia-e-restricao-de-mobilidade $>$. Acesso em: 14 dez. 2013. 
BRASIL. Ministério das Cidades. Brasília. Implantação de Sistemas de Transporte Acessíveis. Programa Brasileiro de Acessibilidade Urbana - Brasil Acessível Caderno 5, 2006. Disponível em:

<http://www.portalodm.com.br//publicacao/265/brasil-acessivel---caderno-5implantacao-de-sistemas-de-transportes-acessiveis>. Acesso em: 14 dez. 2013.

BRASIL. Portal de Ajudas Técnicas. [S.I.]. Disponível em:

<http://portal.mec.gov.br/seesp/index.php?option=content\&task=view\&id=64\&Itemid =193>. Acesso em: 24 mar. 2013.

BRITO, J. D. Sistemática para avaliação da conformidade: uma proposta para uso de cão-guia. 2009. Dissertação de Mestrado em Sistemas de Gestão. Universidade Federal Fluminense, Niterói, 2009. Disponível em: <http://hdl.handle.net/10926/1076>. Acesso em: 13 ago. 2014.

BUENO, G. A. Orientação e Mobilidade do curso de especialização (lato-sensu) da UNICID - Universidade Cidade de São Paulo. 2000. Disponível em:

<http://www.lilacs.org.br>. Acesso em 31 mar. 2014.

CADERNOS TÉCNICOS da ANTP. Sistemas Inteligentes de Transportes. Volume 8, 2012. Disponível em:

<http://www.antp.org.br/_5dotSystem/download/dcmDocument/2013/03/18/9AB9A 3EB-97DC-4711-9751-162AD361D7F0.pdf>. Acesso em: 25 jul. 2013.

CAIADO, K. R. M. Aluno deficiente visual na escola: lembranças e depoimentos. Campinas, SP: Autores Associados-PUC, 2003.

CAMBIAGHI, S. Desenho universal: métodos e técnicas para arquitetos e urbanistas. São Paulo: Editora Senac, 2007.

CARCIERI, S.; MORRIS, S.; PERRY B. RFID Technology to Aid in Navigation and Organization for the Blind and Partially Sighted - Exploring the use of RFID for the blind and visually impaired in association with the Danish Society for the Blind in Copenhagen, Denmark. Relatório do Projeto de Qualificação (Bacharel em Ciências) - Faculdade de Worcester - Instituto Politécnico, Thorkild Olesen, Danish Association of the Blind, 2009.

CARDOSO, E.; KOLTERMANN, T. L. S. Recursos para Acessibilidade em Sistemas de Comunicação para Usuários com Deficiência. Design \& Tecnologia, Porto Alegre, n. 2, UFRGS, 2010, p. 8-21. Disponível em:

<http://www.pgdesign.ufrgs.br/designetecnologia/index.php/det/article/view/18>. Acesso em: 23 out. 2014.

CARROLL, T. J. Cegueira: o que ela é, o que ela faz e como conviver com ela. Movimento \& Percepção, Espírito Santo do Pinhal, SP, v. 11, n. 16, jan./abr. 2010- ISSN 1679-8678 São Paulo: 1968.

CARVALHO, J. O. F. de. Soluções tecnológicas para viabilizar o acesso do deficiente visual à Educação a Distância no Ensino Superior. 2001. Tese de Doutorado em Engenharia. Faculdade de Engenharia Elétrica e de Computação da Universidade Estadual de Campinas, 2001. 
CARVALHO, K. M. M. et al. Visão subnormal: Orientações ao professor do ensino regular. Campinas: Unicamp, 48 p., 1994.

CASARIN, V. A mídia externa e o ambiente construído na paisagem urbana: um estudo de caso. 2007. Dissertação de Mestrado em Arquitetura e Urbanismo. Universidade Federal de Santa Catarina, Florianópolis, 2007.

CASTELlS, M.; CARDOSO, G. A Sociedade em Rede. São Paulo: Paz e Terra, 1999.

CASTRO, J. A. M. Educação Física, orientação e mobilidade de deficiência visual. Movimento - Ano III - n. 5 - 1996/2 - VIII Encontro da Associação Brasileira de Pesquisadores em Educação Especial Londrina, 2013.

CEADIS, CENTRO DE ASESORAMIENTO SOBRE DISCAPACIDAD. Manual sobre discapacidad - Método para la recepción de personas con discapacidad em espetáculos públicos, atividades turísticas, culturales y sociales em el ámbito municipal. Sevilla, 2003.

CIONE, S. L. Técnicas de orientação e mobilidade para pessoas cegas: um estudo sob a ótica da educação física. 2005. Dissertação de Mestrado em Educação Física.

Universidade Metodista de Piracicaba, 2005.

CIPINIUK, A.; PORTINARI, D. B. Sobre métodos de Design. In: COELHO, L. A. L. (Org.).

Design Método. Rio de Janeiro: Editora PUC-Rio; Teresópolis: Novas Ideias, 2006. p. 1738.

COELHO, L. A. L. (Org.). Design Método. Rio de Janeiro: Editora PUC-Rio; Teresópolis, Novas Ideias, 2006.

COMPANHIA DO METROPOLITANO DE SÃO PAULO - CMSP. Gerência de Operações. Caracterização socioeconômica dos usuários e seus hábitos de viagem - 2014 . Relatório de Pesquisa GOP/OPR no 01/2015. CMSP, 2015.

COMPANHIA DO METROPOLITANO DE SÃO PAULO - CMSP. Gerência de Operações. 0 Metrô segundo seu usuário - uma avaliação do serviço - 2a Tomada - junho de 2015. Relatório GOP/OPR/CCP. CMSP, 2015.

COMPANHIA PAULISTA DE TRENS METROPOLITANOS - CPTM. [S.I.]. Disponível em: <http://www.cptm.sp.gov.br>. Acesso em: 13 mar. 2014.

COOK, A. M.; HUSSEY, S. M. Assistive Technologies: Principles and Practice. 2. ed. St. Louis, Mosby Elsevier Inc., 2002.

COOK, A.M. \& HUSSEY, S. M. Assistive Technologies: Principles and Practices. St. Louis, Missouri. Mosby - Year Book, Inc. 1995.

CORDEIRO, A. R. Localização geográfica através de aparelho celular. 2013. TCC Faculdade de Engenharia Elétrica da Universidade Federal do Paraná, Paraná. 2013. 
Disponível em: <http://www.eletrica.ufpr.br/ufpr2/tccs/39.pdf>. Acesso em: 25 abr. 2015.

CORIAT, A. S.; (2002) Lo Urbano Y Lo Humano: Hábitat Y Discapacidad (Libreria Técnica CP67 S. A., Buenos Aires, Argentina). p.32.

CRANDALL, W. The Smith-Kettlewell RERCT; Talking Signs and Fax Reader Projects. American Society of Public Administrators Annual Conference, July 19, 1993.

CRANDALL, W.; BENTZEN, B.; MYERS, L.; STEED, D. Talking Signs - Remote Infrared Signage: A Guide for Transit System Managers. Project ACTION1, 1995.

CRANDALL, W.; GERREY, W.; ALDEN, A. Remote signage and its implications to printhandicapped travelers. Proceedings: Rehabilitation Engineering Society of North America (RESNA) Annual Conference, Las Vegas, June 12-17, 1993, p. 251-53.

CRESWELL, J. W. Investigação qualitativa e projeto de pesquisa: escolhendo entre cinco abordagens. Tradução Sandra Mallmann da Rosa. Revisão técnica Dirceu da Silva. Porto Alegre: Penso, 2014.

CROWOLF, S. A blind person's first week with their iPhone. Artigo disponível em: <http://sayencrowolf.net/2010/09/a-blind-persons-first-week-with-their-iphone/>. Acesso em: 14 mar. 2013.

CUSTÓDIO, V. S. Caminhada de pessoas com deficiência visual em áreas naturais: um estudo com auxílio do GPS (Sistema de Posicionamento Global). 2009. Tese de Doutorado em Educação Física. Faculdade de Educação Física da Universidade Estadual de Campinas, Campinas, 2009.

DAMBHARE, S.; SAKHARE, A. Smart stick for blind: obstacle detection, artificial vision and real-time assistance via GPS. 2nd National Conference on Information and Communication Technology (NCICT), 2011.

DEPRAZ, N., VARELA, F. \& VERMERSCH, P. A redução à prova da experiência. Arquivos Brasileiros de Psicologia. 58 (1). Disponível em: <http://www.psicologia.ufrj.br/abp/>. Acesso em: 15 abr. 2014.

DEPRAZ, N., VARELA, F. \& VERMERSCH, P. On becoming aware: a pragmatic of experiencing. Philadelphia-Amsterdam: Benjamin Publishing, 2003.

DEZIN, N.K. The Research Act (3. ed.). Englewood Cliffs, NJ: Prentice Hill, 1989. DIDEROT, D. Carta aos cegos para o uso dos que vêem. In: Textos escolhidos. Diderot. São Paulo: Abril Cultural, 1979.

DISCHINGER, M.; BINS ELY, M. H. V. A Importância dos Processos Perspectivos na cognição de espaços urbanos para portadores de deficiência Visual. (ABERGO, 1999). Congresso Latino - Americano de Ergonomia IX Congresso Brasileiro de Ergonomia III Seminário de Ergonomia da Bahia. 1999. 
DUTRA, D. N. M.; MARIANI, E.; DAYÉ, C. Por mais olhares no Metrô: a circulação de pessoas com deficiência visual no sistema metrô de São Paulo. In: V ENEAC Encontro Nacional de Ergonomia do Ambiente Construído e VI Seminário Brasileiro de Acessibilidade Integral, 2014, Rio de Janeiro. Anais do V ENEAC Encontro Nacional de Ergonomia do Ambiente Construído e VI Seminário Brasileiro de Acessibilidade Integral. Rio de Janeiro: Laboratório de Ergodesign e Usabilidade de Interfaces LEUI/ PUC-Rio, 2014.

EUROPEAN COMMISSION - DGXIII - Empowering Users Trought Assistive Technology, 1998. Disponível em: <http://www.siva.it/research/eustat/index.html>. Acesso em: 17 ago. 2013.

FELIPPE, J. A. M. Caminhando Juntos: manual das habilidades básicas de orientação e mobilidade. São Paulo: Laramara - Associação Brasileira de Assistência ao Deficiente Visual, 2001.

FISCHER, L. C. A implantação de comércio e serviços em estações de transporte de alta capacidade - um estudo sobre a adequação de estações metroviárias à luz dos resultados da avaliação pós-ocupação. 2013. Dissertação de Mestrado em Arquitetura e Urbanismo. Faculdade de Arquitetura e Urbanismo da Universidade de São Paulo, São Paulo, 2013.

FONTANA, M. V. L., VERGARA Nunes, E. L. Educação e Inclusão de Pessoas Cegas: da Escrita Braile à Internet. 2006. Universidade Federal de Pelotas - UFPel. Disponível em: <http://w3.ufsm.br/alemdavisao/publica/PDF/braile_internet.pdf>. Acesso em: 19 ago. 2014.

FRAGER, R. Teorias da Personalidade. São Paulo: Harbra, 1986.

FREEONI, M. C. C.; GASPARETTO, M. E. R. F. A influência das relações sociais no desenvolvimento de escolares com baixa visão. Anais do VII Encontro da Associação Brasileira de Pesquisadores em Educação Especial. Londrina, 2011. p. 1092-1103.

FREITAS, D.; RICARDO, M.; ALMEIDA, N. Sistema complementar de navegação pessoal na rede da Metro do Porto para pessoas com deficiência visual. Relatório final, Faculdade de Engenharia da Universidade do Porto, Porto, 2008.

FREITAS, M. I. C. de; BORGES, J. A. S.; VENTORINI, S. E.; FUJIOTAKANO, D.; ROSANE, A. Maquete Tátil e DOSVOX - Os desafios da Construção de um Sistema que aprimore a transmissão do conhecimento para alunos cegos e de baixa visão. Núcleo de Computação Eletrônica - UFRJ - Rio de Janeiro, 2003.

GALVÃO FILHO, T. A Tecnologia Assistiva: de que se trata? In: MACHADO, G. J. C.; SOBRAL, M. N. (Org.). Conexões: educação, comunicação, inclusão e interculturalidade. Ed. Porto Alegre: Redes Editora. Disponível em: <http://www.galvaofilho.net/assistiva.pdf>. Acesso em: 17 ago. 2013.

GARRET, J.J. The Elements of User Experience: User-Centered Design for the Web and Beyond (2. ed.). Berkeley (USA), Material, 2010. 
GASPARETTO, M. E. R. F. Visão subnormal em escolas públicas: conhecimento, opinião e conduta de professores e diretores do ensino fundamental. 2001. Tese de Doutorado em Ciências Médicas. Faculdade de Ciências Médicas da Universidade Estadual de Campinas, Campinas, 2001.

GASPARETTO, M. E. R. F.; KARA-JOSÉ, N. Entendendo a baixa visão - orientação aos pais. Projecto Nacional para Alunos com Baixa Visão - pnaBV. Secretaria de Educação Especial. Brasília, Ministério da Educação, 2000.

GOLLEDGE, R.; KLATSKY, R.; AVRAAMIDES, M., LOOMIS J., Functional Equivalence of Spatial Representations Derived From Vision and Language: Evidence From Allocentric Judgments Journal of Experimental Psychology: Learning, Memory, and Cognition v.30(4), 2004. p. 801-814.

GONÇALVES, L. B. Deficientes visuais: uma experiência clínica. Boletim Clínico. Número 7, Outubro/1999. Disponível em: <http://www.pucsp.br/clinica/boletimclinico/boletim_07/boletim_07_7.html>. Acesso em: 14 ago. 2014.

GOODWIN, K. Designing for the Digital Age: How to Create Human-Centered Products and Services Paperback. Indianapolis: Willey Publishing, Inc., 2009.

GOOSSENS, C.; CRAIN, S. S. Utilizing Switch Interfaces with Children who are Severely Phisically Challenged. Austin, Texas: Pro.ed, Inc. 1992.

HALL, E. T. A dimensão oculta. 1986. Lisboa, Portugal: Relógio D’Água Editores. 1986.

HARASZY, Z. Personalized head-related transfer function measurement for acoustic virtual reality development. U.P.B. Sci. Bull., Series C, v. 74, 2012.

HARASZY, Z.; IANCHIS, D.; TIPONUT, V. Generation of the head related transfer functions using artificial neural networks. Proceedings of the 13th WSEAS International Conference on CIRCUITS. Department of Applied Electronics POLITEHNICA University of Timisoara. Timisoara, Romania, 2010.

HOFFMANN, S. B.; SEEWALD, R. Locomoção com cães-guia. 2003. Disponível em: <http://www.bengalalegal.com/orienta>. Acesso em: 12 set. 2015.

INTERNATIONAL ORGANIZATION FOR STANDARDIZATION - ISO. Assistive products for blind and vision impaired persons - Tactile walking surface indicators. ISO/DIS 23599. Genève: ISO, 2010.

INTERNATIONAL ORGANIZATION FOR STANDARDIZATION - ISO. Ergonomics of human-system interaction - Guidance on software accessibility. ISO 9241-171. Genève: ISO, 2008.

KASTRUP, V. A invenção na ponta dos dedos: a reversão da atenção em pessoas com deficiência visual. Psicologia em Revista. Belo Horizonte, 2007. v. 13, n.1, p. 69-90.

KELLER, H. A história de minha vida. Tradução J. E. Veiga. Rio de Janeiro: José Olympio, 
1939. (Texto original em inglês s/d.)

KUMAR, A.; PATRA, R.; MAHADEVAPPA, M.; MUKHOPADHYAY, J.; MAJUMDAR, K. An embedded system for aiding navigation of visually impaired persons. Technical note. Current Science, v. 104, n. 3, 10 February 2013. p. 302-306.

KUMAR, M. N.; USHA, K. Voice Based Guidance and Location Indication System for the Blind Using GSM, GPS and Optical Device Indicator. International Journal of Engineering Trends and Technology (IJETT) - V. 4 Issue 7- July 2013.

LAHAV, O.; MIODUSER, D. Multisensory virtual environment for supporting blind persons' acquisition of spatial cognitive mapping, orientation, and mobility skills. Tel Aviv Universit Proc. 4th Intl Conf. Disability, Virtual Reality \& Assoc. Tech., Veszprém, Hungary, 2002.

LARAMARA - Associação Brasileira de Assistência à Pessoa com Deficiência Visual. [S.I.]. Disponível em: <http://laramara.org.br>. Acesso em: 13 dez. 2013.

LÉVY, P. A inteligência coletiva. São Paulo: Ed. Loyola, 1998.

LIMA FILHO, M. A.; WAECHTER, H. N. Tecnologias assistivas presentes no tablet e seu potencial para uma educação inclusiva de pessoas com deficiência visual. Revista Brasileira de Tradução Visual, Recife, n. 15, jun. 2013.

LIMA, F. J. de; SILVA, J. A. da. Algumas considerações a respeito do sistema tátil de crianças cegas ou de visão subnormal. Revista Benjamin Constant, Rio de Janeiro, RJ. Ed. 17, dez. 2000.

LOUGHBOROUGH, W. Orientation: the missing factor in 0 \& M. Proceedings: CSUN Conference on Technology and Persons with Disabilities, 1990.

LOUGHBOROUGH, W. Talking Signs - An Accessibility Solution for the Blind and Visually Impaired. 12th C.M.B.E.C. / 1st Pan Pacific Symposium, Vancouver, Canada, 1986.

LOWENFELD, B. Our Blind Children: Growing and Learning With Them Springfield, Illinois: Charles C. Thomas, 1971.

LOWNFELD, B. El niño disminuido visual em La escuela. Buenos Aires, American Foundation for Overseas Blind, 1974.

MASI, I. Conceitos - Aquisição básica para a orientação e mobilidade. In: Ministério da Educação. Secretaria de Educação Especial. Orientação e Mobilidade: conhecimentos básicos para a inclusão da pessoa com deficiência visual. Brasília: MEC, SEESP, 2003, p.38-55. Disponível em: <http://portal.mec.gov.br/seesp/arquivos/pdf/ori_mobi.pdf> Acesso em: 15 abr. 2015.

MASINI, E. F. S. (Org.). A pessoa com deficiência visual: um livro para educadores. 1. ed. São Paulo: Vetor; 2007. 
MASINI, E. F. S. Do sentido... pelos sentidos... para o sentido: o sentido das pessoas com deficiências sensoriais. São Paulo: Vetor, 2002.

MASINI, E. F. S. 0 perceber e o relacionar-se do deficiente visual: orientando professores especializados. 1990. Tese de Livre Docência. Faculdade de Educação da Universidade de São Paulo, São Paulo, 1990.

MENDES, A. B. Avaliação das condições de acessibilidade para pessoas com deficiência visual em edificações em Brasília - estudo de casos. 2009. Dissertação de Mestrado em Arquitetura e Urbanismo. Faculdade de Arquitetura e Urbanismo da Universidade de Brasília, Brasília, 2009.

MERLEAU-PONTY, M . Outrem e o mundo humano. In: A fenomenologia da percepção. São Paulo: Martins Fontes, 1994.

MEYERS, G. Análise da conversação e da fala. In: BAUER, M.; GASKELL, G. (Org.). Pesquisa qualitativa com texto, imagem e som. Um manual prático. Capítulo 11. Petrópolis: Vozes, 2010. p.271-292.

MIRANDA, A. S.; ZISSOU, A. de J. Considerações sobre Acessibilidade e Usabilidade em Ambientes Hipermídia. In: ULBRICHT, V. R.; PEREIRA, A. T. C. (Org). Hipermídia: um desafio da atualidade. Florianópolis: Pandion, 2009.

MLODINOW, L. Subliminar: como o inconsciente influencia nossas vidas. Rio de Janeiro: Zahar, 2013.

MUNSTER, M. de A.; ALMEIDA, J. J. G. de. Atividade física e deficiência visual. In: GORGATTI, M. G.; COSTA, R. F. da. (Org.). Atividade física adaptada: qualidade de vida para pessoas com necessidades especiais. Barueri: Manole, 2005.

NÓBREGA, T. P. Corpo, percepção e conhecimento em Merleau-Ponty. Revista Estudos de Psicologia 2008, 13(2), 141-148 ISSN (versão eletrônica): 1678-4669. Disponível em: <www.scielo.br/epsic>. Acesso em: 25 set. 2013.

NORMAN, D. A. 0 design do dia-a-dia. Tradução Ana Deiró. Rio de Janeiro: Rocco, 2006.

NOVI, R. M. Orientação e Mobilidade para deficientes visuais: o sol que faltava em minha vida. Londrina: Cotação da Construção, 1996.

NYE, R.D. Três Psicologias - Ideias de Freud, Skinner e Rogers. São Paulo: Pioneira Thomson Learning, 2002.

OCHAÍTA, E. Aspectos Cognitivos del Desarollo Psicológico de los Ciegos. Madrid: Centro de Publicaciones Del Ministério de Educacion y Ciência, 1993.

OCHAÍTA, E.; ROSA, A. Percepção, ação e conhecimento nas crianças cegas. In: COLL, C.; PALACIOS, J.; MARCHESI, A. (Org.). Desenvolvimento Psicológico e Educação. V. 3 - 
Necessidades educativas especiais e aprendizagem escolar. Tradução M. A. G. Domingues (original espanhol de 1993). Porto Alegre: Artes Médicas, 1995.

OLIVEIRA, R.; KARA-JOSÉ, N.; WILSON, M. Entendendo a baixa visão - orientação aos professores. Projecto Nacional para Alunos com Baixa Visão - pnaBV. Secretaria de Educação Especial. Brasília, Ministério da Educação, 2000.

OMOTE, S. Deficiência e não deficiência: recortes do mesmo tecido. Revista Brasileira de Educação Especial. Marília, 1994. v. 1, n. 2, p. 65-73.

ORNSTEIN, S. W.; PRADO, A. R. A.; LOPES, M. E. (Org.). Desenho universal: caminhos da acessibilidade no Brasil. São Paulo: Annablume, 2010.

ORNSTEIN, S.; ROMÉRO, M. Avaliação Pós-Ocupação do Ambiente Construído. São Paulo: Nobel, 1992.

PALLASMAA, J. Os olhos da pele: a arquitetura e os sentidos. Tradução Técnica Alexandre Salvaterra. Porto Alegre: Bookman, 2001.

PINHEIRO, J. Q.; GÜNTHER, H. Métodos de Pesquisa nos Estudos Pessoa-Ambiente. São Paulo: Casa do Psicólogo, 2008.

PORTUGAL. SNRIPD - Secretariado Nacional para a Reabilitação e Integração das Pessoas com Deficiência. [S.I.]. Disponível em:

<http://www.snripd.pt/default.aspx?IdLang=1>. Acesso em: 25 mar. 2013.

PRAVEEN, R. G.; PAILY, R. P. Blind navigation assistance for visually impaired based on local. International Conference on Design And Manufacturing, IConDM 2013. Depth Hypothesis from a Single Image. Dept of Electronics and Electrical Engineering, IIT Guwahati, Guwahati, India. Procedia Engineering 64, 2013. p. 351 - 360.

PRESSMAN, R. S. Engenharia de Software. Mcgraw Hill, Artmed, 2006.

RAILWAY TECHNOLOGY STRATEGY CENTRE. Nova Benchmarking Phase VI - Case Study: Passenger Incidents Management. London, 2004.

RICKERT, T. Making Access Happen - How to Promote and Plan Access for Disabled Persons and Elders to Buses, Trains, Taxis and Other Modes of Transport. Access Exchange International (AEI). San Francisco. Disponível em: < http://www.independentliving.org/mobility/rickert200302.pdf>. Acesso em: 15 out. 2013.

RICKERT, T. Movilidad para Todos - Transportación Accesible Alrededor del Mundo. Access Exchange International (AEI). San Francisco. Disponível em: <http://www.independentliving.org/movilidad/movilidad.pdf>. Acesso em: 15 out. 2013.

ROGERS, C. Sobre o poder pessoal. 4. ed. São Paulo: Martins Fontes, 2001. 
SÁ, E. D. de; CAMPOS, I. M.; SILVA, M. B.C. Atendimento Educacional Especializado: Deficiência Visual. Curitiba: Gráfica e Editora Cromos, 2007.

SACKS, O. Ver e não ver. In: Um antropólogo em Marte. São Paulo: Companhia das Letras, 1997.

SARTORETTO, M. L.; BERSCH, R. Tecnologia assistiva. [S.l.]. Disponível em: <http://www.assistiva.com.br>. Acesso em: 30 set. 2015.

SONZA, A. P.; SANTAROSA, L. M. C. Ambientes digitais virtuais: acessibilidade aos deficientes visuais. CINTED-UFRGS na Educação v. 1, n. 1, Fevereiro, 2003.

SPENCER, C.; BLADES. M. \& MORSLEY, K. The child in the physical environment: the development of spatial knowledge and cognition. Chichester: Wiley. 1989.

TANENBAUM, A. S. Redes de Computadores. 4. ed. Disponível em: <http://wwwusr.inf.ufsm.br/ rose/Tanenbaum.pdf>. Acesso em: 14 jul. 2013.

TEIXEIRA, E. ; ONO, Rosaria . Projetos arquitetônicos para acessibilidade na habitação: A prática de terapeutas ocupacionais e de arquitetos em São Paulo. In: ENEAC 2013 - IV Encontro Nacional de Ergonomia do Ambiente Construído e V Seminário Brasileiro de Acessibilidade Integral, 2013, Florianópolis. Anais do IV Encontro Nacional de Ergonomia do Ambiente Construído e V Seminário Brasileiro de Acessibilidade Integral, 2013. v. 1.

TRANSPORTS FOR LONDON. Step-Free Tube Guide. Disponível em: <http://www.tfl.gov.uk/assets/downloads/olympic-step-free-tube-guide.pdf>. Acesso em: 23 ago. 2015.

TRANSPORTS FOR LONDON. Transport Accessibility. Tube. Disponível em: <http://www.tfl.gov.uk/ gettingaround/transportaccessibility/1169.aspx>. Acesso em: 23 ago. 2015.

UNION INTERNATIONALE DES TRANSPORTS PUBLICS - UITP. The Metro: an opportunity for sustainable development in large cities. Focus - A UITP position paper, nov. 2003.

UNION INTERNATIONALE DES TRANSPORTS PUBLICS - UITP. Access to Public transport. Core Brief. Ed. Jun 2001. 4 p. Disponível em: <http://www.uitp.org/sites/default/files/cck-focus-papersfiles/01\%20ACCESS\%20T0\%20PUBLIC\%20TRANSPORT.pdf>. Acesso em: 05 abr. 2013.

UTLAI - Usuarios de Tiflotecnología para el Libre Acceso a la Información. [S.I.]. Disponível em: <http://www.utlai.org>. Acesso em: 22 mar. 2013.

VENTORINI, S. E. A experiência como fator determinante na representação espacial do deficiente visual. 2007. Dissertação de Mestrado em Geografia. Instituto de Geociências e Ciências Exatas da Universidade Estadual Paulista, Rio Claro, 2007. 
VIVEIROS, E. R. de; CAMARGO, E. P. de. Deficiência visual na perspectiva da neurociência cognitiva: delineamento de uma aplicação didática para o ensino de física. Anais da X Jornada de Educação Especial: Educação Especial e o uso das tecnologias da informação e comunicações em práticas pedagógicas inclusivas. Faculdade de Ciências da Universidade Estadual Paulista Júlio de Mesquita Filho de Bauru. Marília: Oficina Universitária, 2010. v. 1. p. 1-9.

VYGOTSKY, L. S. Pensamento e linguagem. (tradução brasileira da tradução em inglês do original russo de 1934). São Paulo: Martins Fontes, 1989.

WATAYA, R. S. Desenvolvimento de percepção em 3D para deficientes visuais: uso de realidade aumentada com o sacra. 2009. Tese de Doutorado em Educação. Pontifícia Universidade Católica de São Paulo, 2009.

WELSH R. L.; BLASH, B. Foundations of orientation and mobility. New York: American Foundation for the Blind, 1980.

WOJNACKI, D. Orientação e mobilidade para as pessoas visualmente deficientes com desvantagens adicionais. 1989. Curso de Orientación y Movilidad para personas discapacitadas visuales com impedimentos adicionales. Apostila. Viña del Mar, Chile, 1995.

WRIGHT, P.; McCARTHY, J.; CARROLL, J. Experience-Centered Design: Designers, Users, and Communities in Dialogue (Synthesis Lectures on Human-Centered Informatics). Morgan \& Claypoll, 2010.

YELAMARTHI, K.; HAAS, D.; NIELSEN, D.; MOTHERSELL, S. RFID and GPS integrated navigation system for the visually impaired. School of Engineering and Technology. Central Michigan University, 2010.

ZWIERS, M. P.; VAN OPSTAL, A. J.; CRUYSBERG, J. R. M. A spatial hearing deficit in earlyblind humans. The Journal of Neuroscience. University Medical Centre, The Netherlands, v. 21, 2001. 


\section{GLOSSÁRIO}

Acessibilidade - Possibilidade e condição de alcance, percepção e entendimento para utilização, com segurança e autonomia, de espaços, mobiliários, equipamentos urbanos, edificações, transportes, informação e comunicação, inclusive seus sistemas e tecnologias, bem como outros serviços e instalações abertos ao público, de uso público ou privado de uso coletivo, tanto na zona urbana como na rural, por pessoa com deficiência ou mobilidade reduzida. (ABNT, 2015, p. 2).

Audiodescrição - O recurso da audiodescrição consiste na descrição clara e objetiva de todas as informações que compreendemos visualmente e que não estão contidas nos diálogos, como, por exemplo, expressões faciais e corporais que comuniquem algo, informações sobre o ambiente, figurinos, efeitos especiais, mudanças de tempo e espaço, além da leitura de créditos, títulos e qualquer informação escrita na tela. (Disponível em: <http://audiodescricao.com.br/ad/o-que-e-audiodescricao/>. Acesso em: 26 ago. 2014.)

Bengala - Ver "Bengala longa".

Bengala longa - Bengala utilizada por pessoas com deficiência visual para auxiliar na sua locomoção, por meio de diversas técnicas de Orientação e Mobilidade. A bengala longa também é conhecida como "bengala Hoover", por ter sido concebida pelo médico estadunidense Richard Hoover, após a Segunda Guerra Mundial. A bengala torna possível, a partir da percepção tátil, que se obtenha informações antecipadas acerca de objetos presentes em seu caminho.

Braille - Sistema de escrita baseado na combinação de pontos em relevo, usada para a leitura e escrita de pessoas com deficiência visual.Cada letra ou número é formado por uma combinação diferente, de maneira que a pessoa lê e escreve formando as palavras por meio das letras. Por isso é tão importante que crianças com deficiência visual sejam alfabetizadas com o uso da escrita em Braille, para poderem saber como se escrevem as palavras e os textos, o que não é possível somente com leitores em áudio. 0 sistema Braille também "aplica-se à estenografia, à música e às notações científicas em geral, sendo de extraordinária universalidade, pelo fato de poder exprimir diferentes idiomas e escritas" (SONZA, 2004). 
Cão-guia - É um animal que recebe preparação e treinamento apropriado desde seu nascimento, com a finalidade de auxiliar pessoas com deficiência visual, tanto na sua condução, como na realização de tarefas. Embora os cães-guia sejam treinados para garantir a segurança de seu dono, eles somente conseguem levá-lo a um determinado destino após receberem treinamento prévio, ou orientações ao longo do percurso.

CCO - Centro de Controle Operacional. Em sistemas de metrô, o CCO atua como o cérebro de toda a operação, possuindo sistemas de comando, dotados de dispositivos de vigilância, com profissionais que atuam para garantir o equilíbrio do sistema, o qual, por mais automatizado que seja, é passível de falhas. Para garantir a oferta, a execução e a operação dos serviços é realizado um conjunto de atividades regidas por procedimentos, mecanismos e roteiros (BARBOSA, 2015).

Deficiência visual - De maneira geral, deficiência visual é um termo utilizado para referência a impedimentos orgânicos que levam a um mau funcionamento visual ou à ausência de visão. Para se referir às diferentes modalidades de deficiência visual, são utilizados os termos "cegueira" e "baixa visão". Várias formas de classificação têm sido utilizadas para descrever a extensão da perda de visão, mas, de maneira geral, a concepção de cegueira é definida como sendo a ausência total de visão, podendo-se perceber clarões. Os demais níveis de acuidade visual são denominados "baixa visão". Entre $70 \%$ e $80 \%$ das pessoas que possuem deficiência visual não são totalmente cegas, possuindo alguma visão útil (HARPER, 1998; AMIRALIAN, 2004; HONORATO, 2013). A deficiência visual desde o nascimento ou adquirida até aos cinco anos de idade é denominada deficiência visual congênita. Após isso, é considerada deficiência visual adquirida ou adventícia (ORMELEZI, 2000; NUNES; LOMÔNACO, 2008).

Desenho universal - concepção de produtos, ambientes, programas e serviços a serem usados, na maior medida possível, por todas as pessoas, sem necessidade de adaptação ou projeto específico. 0 desenho universal não exclui as ajudas técnicas para grupos específicos de pessoas com deficiência, quando necessárias. 0 conceito de desenho universal tem como pressupostos: equiparação das possibilidades de uso, flexibilidade no uso, uso simples e intuitivo, captação da informação, tolerância ao erro, mínimo esforço físico, dimensionamento de espaços para acesso, uso e interação de todos os usuários. 
Embarque/ desembarque preferencial (Metrô de São Paulo) - Estratégia operacional adotada pelo metrô de São Paulo para facilitar o embarque e o desembarque de pessoas com direito assegurado por lei ao atendimento preferencial ${ }^{80}$ nos horários de maior movimento. Consiste na segregação da área da plataforma que interliga às duas primeiras portas dos trens. O local é sinalizado e tem o acesso controlado por funcionários, na região do primeiro carro, de determinadas estações, em horários de maior demanda de usuários. (Fonte: Metrô Boa Viagem - Disponível em <http://metro.sp.gov.br> Acesso em 14 abr. 2015.)

GIS - Ver “SIG”.

GNSS - sistemas de navegação por satélite que possuam a capacidade de oferecer posicionamento em qualquer ponto da superfície terrestre. Refere-se a sistemas como o estadunidense GPS e o russo GLONASS.

Informação - Neste estudo, o termo informação está sendo usado como referência às informações estáticas e dinâmicas necessárias para realização de uma viagem de metrô, tais como horários, linhas, estações, serviços prestados e tarifas, que geralmente são fornecidas por meio de comunicação visual, restringindo seu acesso a pessoas com deficiência visual.

Mobilidade - Para a pessoa com deficiência visual, mobilidade é a habilidade de locomover-se com segurança, eficiência e conforto no meio ambiente, por meio da utilização dos sentidos remanescentes. (WEISHALN81, 1990 apud MAZZARO, 2003, p. 17).

Navegação - 0 termo navegação, por muito tempo foi usado apenas como sinônimo de determinação de curso de navios e aviões, o que se dava por meio da geometria e astronomia (BAKER, 1981, p. 4). Contudo, o sistema de navegação dos aviões modernos passou a se basear em outras tecnologias que não envolvem astronomia e, mais recentemente, o termo navegação passou a ter seu uso ampliado, como por exemplo,

\footnotetext{
${ }^{80}$ Lei Federal № 10.048/2000: Dá prioridade de atendimento às pessoas que especifica, e dá outras providências. (As pessoas portadoras de deficiência física, os idosos com idade igual ou superior a sessenta e cinco anos, as gestantes, as lactantes e as pessoas acompanhadas por crianças de colo terão atendimento prioritário, nos termos desta Lei.). (BRASIL, 2000a)

81 WEISHALN, R. Orientation and mobility in the blind children. New York: Englewood Cliffs, 1990.
} 
para a navegação de automóveis e de pessoas por caminhos terrestres e ambientes construídos.

Orientação - Para a pessoa com deficiência visual, orientação é o processo de utilizar os sentidos remanescentes para estabelecer a própria posição e o relacionamento com outros objetos significativos no meio ambiente. Weishaln ${ }^{81}$ (1990 apud MAZZARO, 2003, p. 17).

Piso tátil - piso caracterizado por textura e cor contrastantes em relação ao piso adjacente, destinado a constituir alerta ou linha-guia, servindo de orientação, principalmente às pessoas com deficiência visual ou baixa visão. São de dois tipos: piso tátil de alerta e piso tátil direcional. (ABNT, 2015, p. 5)

Rota - O termo é usado para designar um percurso específico a ser realizado. Uma rota acessível constitui-se em um "trajeto contínuo, desobstruído e sinalizado, que conecte os ambientes externos ou internos de espaços e edificações, e que possa ser utilizado de forma autônoma e segura por todas as pessoas, inclusive aquelas com deficiência e mobilidade reduzida. A rota acessível pode incorporar estacionamentos, calçadas rebaixadas, faixas de travessia de pedestres, pisos, corredores, escadas e rampas, entre outros" (ABNT, 2015, p. 5).

SIG - Sistema de Informações Geográficas (GIS - Geographic Information System), é "um sistema de suporte à decisão que envolve a integração de dados referenciados espacialmente em um ambiente para a solução de problemas" (COWEN, 1988, p.1555 tradução nossa). Um SIG pode ou não estar integrado a um sistema de GNSS, cuja única função é fornecer, por meio de triangulação de satélites, sua posição geográfica terrestre. Exemplos de SIG: (1) um conjunto de informações sobre condições climáticas; (2) aparelhos de navegação utilizados por condutores de veículos, popularmente chamados “GPS”, mas que, de fato, são GIS que fazem uso do GPS.

Smartphone - Sem termo equivalente em português, a tradução literal de smartphone como sendo "telefone inteligente", remete à combinação de telefone celular com recursos de microcumputador em um mesmo dispositivo eletrônico. As funções avançadas que possui (além da utilidade básica de comunicação por voz), permitem que desenvolvedores criem uma infinidade de programas com diversas utilidades. 
Software de leitura de tela - Os leitores de tela são uma forma de tecnologia assistiva potencialmente útil para pessoas cegas, deficientes visuais, analfabetas, ou que têm dificuldades de aprendizagem específicas. Os leitores de tela identificam e interpretam o que está sendo mostrado na tela e o apresentam ao usuário na forma de voz, ícones de som, ou em Braille utilizando um dispositivo de saída. (OMS, 2012)

Tecnologia assistiva - Conforme definido pelo Comitê de Ajudas Técnicas da Secretaria Nacional dos Direitos Humanos da Presidência da República do Brasil, em 2008, Tecnologia Assistiva (TA) é uma área do conhecimento, de característica interdisciplinar, que engloba produtos, recursos, metodologias, estratégias, práticas e serviços que objetivam promover a funcionalidade, relacionada à atividade $\mathrm{e}$ participação, de pessoas com deficiência, incapacidades ou mobilidade reduzida, visando sua autonomia, independência, qualidade de vida e inclusão social.

Tiflotecnologia - Tiflotecnologia é um termo utilizado principalmente em países como Espanha e Portugal para designar tecnologia assisitiva na forma de dispositivos, funcionalidades ou aplicações técnicas que ajudam uma pessoa cega a realizar as suas atividades autonomamente nas diferentes situações quotidianas. Tiflos quer dizer "cego" em grego. Caparrós (1994, p. 307) entende por Tiflotecnologia “[...] o conjunto de técnicas, conhecimentos e recursos destinados a procurar para os cegos ou deficientes visuais os meios capazes para uma correta utilização da tecnologia, com o fim de favorecer a autonomia pessoal e plena integração social, laboral e educativa".

Título - é a forma atual de se referir às diversas maneiras de se efetuar a validação ou pagamento da tarifa de viagem, englobando bilhetes, cartões magnéticos etc.

Vidente - termo comumente utilizado para referência a pessoa que enxerga, que não possui deficiência visual. 


\section{APÊNDICE A}

\section{Entrevista individual - roteiro semiestruturado}

\section{Chefe do departamento de segurança operacional}

- Data da entrevista

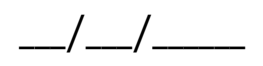

- Horário de início

- Horário de término

Introdução para esclarecer o motivo da entrevista:

Gostaria de realizar uma entrevista com você, ou com alguém de sua indicação, sobre pessoas com deficiência visual no Metrô de São Paulo. Trata-se de uma pesquisa acadêmica para meu mestrado na FAU-USP, cujo objetivo é recolher informações e ideias para melhoria das viagens dessas pessoas. Reforço que, por tratar-se de um trabalho acadêmico, as informações serão usadas estritamente para esse fim, sendo preservada a sua identidade. Também não serão divulgadas em nenhum tipo de mídia. Muito obrigada!

Dados pessoais:

1. Nome

2. Formação/Função atual e histórico de funções no Metrô/Tempo de atuação

Com relação às pessoas com deficiência visual:

3. Qual seu contato com pessoas com deficiência visual?

4. O que você identifica como maiores dificuldades na circulação dessas pessoas no metrô de SP?

5. Tem conhecimento de reclamações ou reinvindicações das pessoas com deficiência visual com relação ao metrô de SP? Qual sua opinião a respeito?

6. Em sua opinião, o que poderia ser feito para facilitar suas viagens?

7. Tem conhecimento a respeito de sistemas eletrônicos de informação e navegação para pessoas com deficiência visual? Qual sua opinião a respeito?

8. Você tem registros de furtos/roubos de pessoas com deficiência visual? Poderia falar a respeito?

9. O corpo de seguranças do Metrô é treinado para atendimento às pessoas com deficiência visual? 


\section{APÊNDICE B}

\section{Entrevista individual - roteiro semiestruturado}

\section{Supervisor de estações}

- Data da entrevista

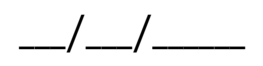

- Horário de início

- Horário de término

Introdução para esclarecer o motivo da entrevista:

Gostaria de realizar uma entrevista com você, ou com alguém de sua indicação, sobre pessoas com deficiência visual no Metrô de São Paulo. Trata-se de uma pesquisa acadêmica para meu mestrado na FAU-USP, cujo objetivo é recolher informações e ideias para melhoria das viagens dessas pessoas. Reforço que, por tratar-se de um trabalho acadêmico, as informações serão usadas estritamente para esse fim, sendo preservada a sua identidade. Também não serão divulgadas em nenhum tipo de mídia. Muito obrigada!

Dados pessoais:

1. Nome

2. Formação/Função atual e histórico de funções no Metrô/Tempo de atuação

Com relação às pessoas com deficiência visual:

3. Qual seu contato com pessoas com deficiência visual?

4. O que você identifica como maiores dificuldades na circulação destas pessoas no metrô de SP?

5. O que você identifica como maior dificuldade dos funcionários no tratamento com essas pessoas?

6. Você tem conhecimento de como as pessoas com deficiência visual circulam pelas instalações do Metrô quando não querem o auxílio dos funcionários?

7. Em geral, como é a interação usuário com deficiência visual X usuário sem deficiência?

8. Quais fatores são considerados difíceis na condução dos usuários?

9. Em sua opinião, o que poderia ser feito para facilitar suas viagens?

10. Dentre todas as questões apontadas por você, o que deveria ser priorizado? 
11. Tem conhecimento a respeito de sistemas eletrônicos de informação e navegação para pessoas com deficiência visual? Qual sua opinião a respeito?

12. Você observa se pessoas com deficiência visual utilizam telefones celulares ou aparelhos de música dentro do metrô? Se sim, sabe dizer se elas utilizam fones de ouvido?

Gostaria de acrescentar algo para contribuir com a pesquisa? 


\section{APÊNDICE C}

\section{Entrevista individual - roteiro semiestruturado}

\section{Coordenador da equipe de monitoração de manifestações em redes sociais}

- Data da entrevista

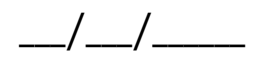

- Horário de início

- Horário de término

Introdução para esclarecer o motivo da entrevista:

Gostaria de realizar uma entrevista com você, ou com alguém de sua indicação, sobre pessoas com deficiência visual no Metrô de São Paulo. Trata-se de uma pesquisa acadêmica para meu mestrado na FAU-USP, cujo objetivo é recolher informações e ideias para melhoria das viagens dessas pessoas. Reforço que, por tratar-se de um trabalho acadêmico, as informações serão usadas estritamente para esse fim, sendo preservada a sua identidade. Também não serão divulgadas em nenhum tipo de mídia. Muito obrigada!

Dados pessoais:

1. Nome

2. Formação/Função atual e histórico de funções no Metrô/Tempo de atuação

Com relação às pessoas com deficiência visual:

3. Qual seu contato com pessoas com deficiência visual?

4. O que você identifica como maiores dificuldades na circulação destas pessoas no metrô de SP?

5. Tem conhecimento de reclamações ou reinvindicações das pessoas com deficiência visual com relação ao metrô de SP? Qual sua opinião a respeito?

6. Tem conhecimento a respeito de sistemas eletrônicos de informação e navegação para pessoas com deficiência visual? Qual sua opinião a respeito?

7. Em sua opinião, o que poderia ser feito para facilitar suas viagens?

Gostaria de acrescentar algo para contribuir com a pesquisa? 


\section{APÊNDICE D}

\section{Entrevista individual - roteiro semiestruturado}

\section{Responsável pela monitotação de manifestações nos canais de comunicação (exceto redes sociais)}

- Data da entrevista

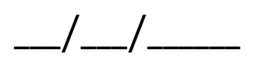

- Horário de início

- Horário de término

Introdução para esclarecer o motivo da entrevista:

Gostaria de realizar uma entrevista com você, ou com alguém de sua indicação, sobre pessoas com deficiência visual no Metrô de São Paulo. Trata-se de uma pesquisa acadêmica para meu mestrado na FAU-USP, cujo objetivo é recolher informações e ideias para melhoria das viagens dessas pessoas. Reforço que, por tratar-se de um trabalho acadêmico, as informações serão usadas estritamente para esse fim, sendo preservada a sua identidade. Também não serão divulgadas em nenhum tipo de mídia. Muito obrigada!

Dados pessoais:

1. Nome

2. Formação/Função atual e histórico de funções no Metrô/Tempo de atuação

Com relação às pessoas com deficiência visual:

3. Qual seu contato com pessoas com deficiência visual?

4. O que você identifica como maiores dificuldades na circulação destas pessoas no metrô de SP?

5. Tem conhecimento de reclamações ou reinvindicações das pessoas com deficiência visual com relação ao metrô de SP? Qual sua opinião a respeito?

6. Em sua opinião, o que poderia ser feito para facilitar suas viagens?

7. Tem conhecimento a respeito de sistemas eletrônicos de informação e navegação para pessoas com deficiência visual? Qual sua opinião a respeito?

Gostaria de acrescentar algo para contribuir com a pesquisa? 


\section{APÊNDICE E}

\section{Entrevista individual - roteiro semiestruturado}

\section{Responsável pelo treinamento de funcionários para condução de pessoas com deficiências e treinamento de orientação a usuários com deficiência visual}

- Data da entrevista

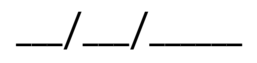

- Horário de início

- Horário de término

Introdução para esclarecer o motivo da entrevista:

Gostaria de realizar uma entrevista com você, ou com alguém de sua indicação, sobre pessoas com deficiência visual no Metrô de São Paulo. Trata-se de uma pesquisa acadêmica para meu mestrado na FAU-USP, cujo objetivo é recolher informações e ideias para melhoria das viagens dessas pessoas. Reforço que, por tratar-se de um trabalho acadêmico, as informações serão usadas estritamente para esse fim, sendo preservada a sua identidade. Também não serão divulgadas em nenhum tipo de mídia. Muito obrigada!

Dados pessoais:

1. Nome

2. Formação/Função atual e histórico de funções no Metrô/Tempo de atuação

Com relação às pessoas com deficiência visual:

3. Qual seu contato com pessoas com deficiência visual?

4. O que você identifica como maiores dificuldades na circulação destas pessoas no metrô de SP?

5. O que você identifica como maior dificuldade dos funcionários na condução destas pessoas no metrô SP?

6. Qual é a importância do treinamento dos empregados para utilização do metrô pelas pessoas com deficiência visual?

7. Como é feito o treinamento de usuários com deficiência visual? Por que o metrô aplica esse treinamento?

8. Você tem conhecimento de como as pessoas com deficiência visual circulam pelas instalações do Metrô quando não querem o auxílio dos funcionários?

9. Em sua opinião, o que poderia ser feito para facilitar suas viagens? 
10. Tem conhecimento a respeito de sistemas eletrônicos de informação e navegação para pessoas com deficiência visual? Qual sua opinião a respeito?

Gostaria de acrescentar algo para contribuir com a pesquisa? 


\section{APÊNDICE F}

\section{Entrevista individual - roteiro semiestruturado}

\section{Responsável pela área de pesquisas}

- Data da entrevista

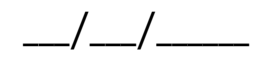

- Horário de início

- Horário de término

Introdução para esclarecer o motivo da entrevista:

Gostaria de realizar uma entrevista com você, ou com alguém de sua indicação, sobre pessoas com deficiência visual no Metrô de São Paulo. Trata-se de uma pesquisa acadêmica para meu mestrado na FAU-USP, cujo objetivo é recolher informações e ideias para melhoria das viagens dessas pessoas. Reforço que, por tratar-se de um trabalho acadêmico, as informações serão usadas estritamente para esse fim, sendo preservada a sua identidade. Também não serão divulgadas em nenhum tipo de mídia. Muito obrigada!

Dados pessoais:

1. Nome

2. Formação/Função atual e histórico de funções no Metrô/Tempo de atuação

Com relação às pessoas com deficiência visual:

3. Qual seu contato com pessoas com deficiência visual?

4. Nas pesquisas, quais são as principais reclamações ou reinvindicações das pessoas com deficiência visual com relação ao metrô de SP? Qual sua opinião a respeito?

5. Em sua opinião, o que poderia ser feito para facilitar suas viagens?

6. Tem conhecimento a respeito de sistemas eletrônicos de informação e navegação para pessoas com deficiência visual? Qual sua opinião a respeito?

Gostaria de acrescentar algo para contribuir com a pesquisa? 


\section{APÊNDICE G}

\section{Entrevista individual - roteiro semiestruturado}

\section{Supervisor do Centro de Controle Operacional (CCO)}

- Data da entrevista

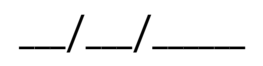

- Horário de início

- Horário de término

Introdução para esclarecer o motivo da entrevista:

Gostaria de realizar uma entrevista com você, ou com alguém de sua indicação, sobre pessoas com deficiência visual no Metrô de São Paulo. Trata-se de uma pesquisa acadêmica para meu mestrado na FAU-USP, cujo objetivo é recolher informações e ideias para melhoria das viagens dessas pessoas. Reforço que, por tratar-se de um trabalho acadêmico, as informações serão usadas estritamente para esse fim, sendo preservada a sua identidade. Também não serão divulgadas em nenhum tipo de mídia. Muito obrigada!

Dados pessoais:

1. Nome

2. Formação/Função atual e histórico de funções no Metrô/Tempo de atuação

Com relação às pessoas com deficiência visual:

3. Qual o papel do CCO na monitoração para atendimento às pessoas com deficiência visual?

4. E quando essas pessoas não querem ser monitoradas, qual a atuação do Centro de Controle?

5. O que você identifica como maiores dificuldades na circulação destas pessoas no metrô SP?

6. Em sua opinião, o que poderia ser feito para facilitar suas viagens?

7. Tem conhecimento a respeito de sistemas eletrônicos de informação e navegação para pessoas com deficiência visual? Qual sua opinião a respeito?

Gostaria de acrescentar algo para contribuir com a pesquisa? 


\section{APÊNDICE H}

\section{Entrevista individual - roteiro semiestruturado}

\section{Responsável pela área de projeto civil e arquitetura}

- Data da entrevista

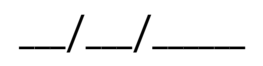

- Horário de início

- Horário de término

Introdução para esclarecer o motivo da entrevista:

Gostaria de realizar uma entrevista com você, ou com alguém de sua indicação, sobre pessoas com deficiência visual no Metrô de São Paulo. Trata-se de uma pesquisa acadêmica para meu mestrado na FAU-USP, cujo objetivo é recolher informações e ideias para melhoria das viagens dessas pessoas. Reforço que, por tratar-se de um trabalho acadêmico, as informações serão usadas estritamente para esse fim, sendo preservada a sua identidade. Também não serão divulgadas em nenhum tipo de mídia. Muito obrigada!

Dados pessoais:

1. Nome

2. Formação/Função atual e histórico de funções no Metrô/Tempo de atuação

Com relação ao seu trabalho e às pessoas com deficiência visual:

3. Quais os aspectos civis e arquitetônicos das estações do metrô: método construtivo, influências, execução etc.?

4. Quais as dificuldades para atendimento a normas e leis de acessibilidade?

5. Tem informação sobre pesquisas que estão sendo realizadas para melhoria das condições de acessibilidade das pessoas com deficiência visual?

6. Qual seu contato com pessoas com deficiência visual?

7. Em sua opinião, o que poderia ser feito para facilitar suas viagens?

8. Tem conhecimento a respeito de sistemas eletrônicos de informação e navegação para pessoas com deficiência visual? Qual sua opinião a respeito?

Gostaria de acrescentar algo para contribuir com a pesquisa? 


\section{APÊNDICE I}

\section{Entrevista individual - roteiro semiestruturado}

\section{Responsável pela área de projeto de sistemas}

- Data da entrevista

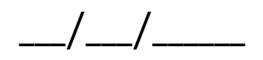

- Horário de início

- Horário de término

Introdução para esclarecer o motivo da entrevista:

Gostaria de realizar uma entrevista com você, ou com alguém de sua indicação, sobre pessoas com deficiência visual no Metrô de São Paulo. Trata-se de uma pesquisa acadêmica para meu mestrado na FAU-USP, cujo objetivo é recolher informações e ideias para melhoria das viagens dessas pessoas. Reforço que, por tratar-se de um trabalho acadêmico, as informações serão usadas estritamente para esse fim, sendo preservada a sua identidade. Também não serão divulgadas em nenhum tipo de mídia. Muito obrigada!

Dados pessoais:

1. Nome

2. Formação/Função atual e histórico de funções no Metrô/Tempo de atuação

Com relação ao seu trabalho e às pessoas com deficiência visual:

3. Como são estudados os aspectos construtivos e de leiaute das diversas frotas de trens?

4. Quais as razões de se ter tão variada, a frota de trens?

5. Quais as dificuldades para atendimento a normas e leis de acessibilidade?

6. Fale sobre o sistema sonoro de informação de próxima estação.

7. Tem informação sobre pesquisas que estão sendo realizadas para melhoria das condições de acessibilidade das pessoas com deficiência visual?

8. Qual seu contato com pessoas com deficiência visual?

9. Em sua opinião, o que poderia ser feito para facilitar suas viagens?

10. Tem conhecimento a respeito de sistemas eletrônicos de informação e navegação para pessoas com deficiência visual? Qual sua opinião a respeito?

Gostaria de acrescentar algo para contribuir com a pesquisa? 


\section{APÊNDICE J}

\section{Entrevista individual - roteiro semiestruturado}

\section{Professor de Orientação e Mobilidade (OM)}

- Data da entrevista

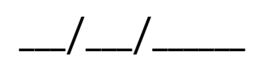

- Horário de início

- Horário de término

Introdução para esclarecer o motivo da entrevista:

Gostaria de realizar uma entrevista com você sobre treinamento de OM e pessoas com deficiência visual no Metrô de São Paulo. Trata-se de uma pesquisa acadêmica para meu mestrado na FAU-USP, cujo objetivo é recolher informações e ideias para melhoria das viagens dessas pessoas, não caracterizando nenhuma pesquisa oficial do Metrô de São Paulo. Não se trata de uma análise do serviço prestado pelo metrô, mas sim de uma pesquisa sobre modos de orientação das pessoas com deficiência visual, como por exemplo, o que é que ajuda, o que interfere etc. Reforço que, por tratar-se de um trabalho acadêmico, as informações serão usadas estritamente para esse fim, sendo preservada a sua identidade. Também não serão divulgadas internamente e em nenhum tipo de mídia.

Dados pessoais:

1. Nome

2. Formação/Função atual e histórico de funções na área de deficiência visual/Tempo de atuação

Com relação às pessoas com deficiência visual:

3. O que você identifica como maiores dificuldades na circulação de pessoas com deficiência visual no metrô de SP?

4. O que você identifica como maior dificuldade dos funcionários na condução destas pessoas no metrô de SP?

5. Em sua opinião, o que poderia ser feito para facilitar suas viagens?

6. Tem conhecimento a respeito de outros metrôs? Poderia comparar, ou comentar algo?

7. De maneira geral, as instituições oferecem treinamento de Orientação e Mobilidade para que pessoas com deficiência visual utilizem o metrô? Quais as condições? (Particular etc.) 
8. Tem conhecimento a respeito de sistemas eletrônicos de informação e navegação para pessoas com deficiência visual? Qual sua opinião a respeito?

9. Como poderiam ser aliadas técnicas de $\mathrm{OM}$ a esses dispositivos eletrônicos?

Gostaria de acrescentar algo para contribuir com a pesquisa? 


\section{APÊNDICE K}

\section{Entrevista individual - roteiro semiestruturado}

\section{Designer de produtos de ajuda técnica}

- Data da entrevista

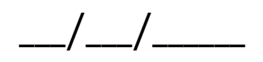

- Horário de início

- Horário de término

Introdução para esclarecer o motivo da entrevista:

Gostaria de realizar uma entrevista com você, ou com alguém de sua indicação, sobre pessoas com deficiência visual no Metrô de São Paulo. Trata-se de uma pesquisa acadêmica para meu mestrado na FAU-USP, cujo objetivo é recolher informações e ideias para melhoria das viagens dessas pessoas. Reforço que, por tratar-se de um trabalho acadêmico, as informações serão usadas estritamente para esse fim, sendo preservada a sua identidade. Também não serão divulgadas em nenhum tipo de mídia. Muito obrigada!

Dados pessoais:

1. Nome

2. Formação/Função atual e histórico de funções na área de deficiência visual/Tempo de atuação

Com relação às pessoas com deficiência visual:

3. Tem conhecimento a respeito de sistemas eletrônicos de informação e navegação para pessoas com deficiência visual, de maneira geral? Qual sua opinião a respeito?

4. Tem conhecimento a respeito destes sistemas instalados em outros metrôs? Poderia comparar, ou comentar algo?

5. Você já realizou projetos na área de produtos de ajudas técnicas para facilitar a circulação de pessoas com deficiência visual, de maneira geral? E na área de utilização em redes de metrô?

6. Como foi o processo de desenvolvimento destes produtos? Utilizou pesquisas? Em que fase estão os testes de utilização?

7. Poderia comentar a respeito de um possível desenvolvimento, produção e custos destes produtos/sistemas? 
8. O que você identifica como maiores dificuldades para o desenvolvimento deste tipo de ajuda técnica?

Gostaria de acrescentar algo para contribuir com a pesquisa? 


\section{APÊNDICE L}

\section{Entrevista em grupo - roteiro semiestruturado \\ Representantes da empresa Metro do Porto S. A. \\ Arq. Joana Baptista e Arq. Manuel Paulo Teixeira}

- Data da entrevista

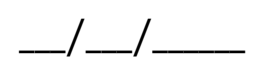

- Horário de início

- Horário de término

Introdução para esclarecer o motivo da entrevista:

Gostaria de realizar uma entrevista com a equipe de profissionais da empresa Metro do Porto que participaram do desenvolvimento e execução do sistema Navmetro ${ }^{\circledR}$. Trata-se de uma pesquisa acadêmica para meu mestrado em Arquitetura na FAU-USP, cujo objetivo é recolher informações e ideias para propor diretrizes para sistemas semelhantes. Reforço que, por tratar-se de um trabalho acadêmico, as informações serão usadas estritamente para esse fim. Também não serão divulgadas em nenhum tipo de mídia. Muito obrigada!

Dados pessoais:

1. Nome

2. Formação/Função atual e histórico de funções na área de deficiência visual/Tempo de atuação

Com relação ao sistema Navmetro ${ }^{\circledR}$ :

3. Como surgiu a ideia de criar um sistema de informação e navegação para pessoas com deficiência visual no metrô do Porto?

4. Como foi o desenvolvimento do Navmetro ${ }^{\circledR}$ ? Quais as maiores dificuldades encontradas?

5. Houve participação de pessoas com deficiência visual ou entidade voltadas a essas pessoas? Como foi sua participação?

6. Como funciona o sistema de informação?

7. Como funciona o sistema de navegação? Qual a ligação entre os dois sistemas?

8. Vocês realizaram avaliações? Qual a opinião dos usuários?

9. Quais os inconvenientes e pontos de melhoria identificados pela equipe técnica? 
10. 0 que se identifica como maiores dificuldades para o desenvolvimento deste tipo de ajuda técnica?

11. Qual a situação atual do sistema? Quais as perspectivas para o futuro?

Gostaria de acrescentar algo para contribuir com a pesquisa? 


\section{APÊNDICE M}

\section{Entrevista individual - roteiro semiestruturado \\ Professor da FEUP - Diamantino Freitas}

- Data da entrevista

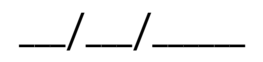

- Horário de início

- Horário de término

Introdução para esclarecer o motivo da entrevista:

Gostaria de realizar uma entrevista com o professor Diamantino Freitas, responsável pela equipe da FEUP que desenvolveu o sistema Navmetro ${ }^{\circledR}$ no metrô do Porto. Trata-se de uma pesquisa acadêmica para meu mestrado em Arquitetura na FAU-USP, cujo objetivo é recolher informações e ideias para propor diretrizes para sistemas semelhantes. Reforço que, por tratar-se de um trabalho acadêmico, as informações serão usadas estritamente para esse fim. Também não serão divulgadas em nenhum tipo de mídia. Muito obrigada!

Dados pessoais:

1. Nome

2. Formação/Função atual e histórico de funções na área de deficiência visual/Tempo de atuação

Com relação ao sistema Navmetro ${ }^{\circledR}$ :

3. Como surgiu a ideia de criar um sistema de informação e navegação para pessoas com deficiência visual no metrô do Porto?

4. Como foi o desenvolvimento do Navmetro ${ }^{\circledR}$ ? Quais as maiores dificuldades encontradas?

5. Houve participação de pessoas com deficiência visual ou entidade voltadas a essas pessoas? Como foi sua participação?

6. Como funciona o sistema de informação?

7. Como funciona o sistema de navegação? Qual a ligação entre os dois sistemas?

8. Vocês realizaram avaliações? Qual a opinião dos usuários?

9. Quais os inconvenientes e pontos de melhoria identificados pela equipe técnica?

10. 0 que se identifica como maiores dificuldades para o desenvolvimento deste tipo de ajuda técnica? 
11. Qual a situação atual do sistema? Quais as perspectivas para o futuro? Gostaria de acrescentar algo para contribuir com a pesquisa? 


\section{APÊNDICE N \\ UNIVERSIDADE DE SÃO PAULO \\ FACULDADE DE ARQUITETURA E URBANISMO}

\section{TERMO DE CONSENTIMENTO LIVRE E ESCLARECIDO}

Título da Pesquisa: Estudos de sistemas eletrônicos de informação e navegação para pessoas com deficiência visual em redes de metrô.

\section{Pesquisadora:}

Eliete Mariani

Mestranda

e-mail: emariani@usp.br

Tel.: (11) 97210-3752

\section{Orientador:}

Prof. Dr. Marcelo E. Giacaglia

e-mail: mgiacagl@usp.br

\section{Informações aos participantes:}

O objetivo desta pesquisa é investigar as formas como as pessoas com deficiência visual utilizam e interagem em seus percursos por estações e trens, a fim de sugerir melhorias nas condições de uso de metrôs.

Os ambientes públicos de sistemas de transporte ainda são frequentemente inacessíveis a pessoas com deficiência visual as quais, por não terem acesso às informações visuais que facilitam na orientação para a mobilidade, ficam limitadas a certos espaços físicos, tendo restrito seu direito à liberdade de ir e vir. Estações de metrô, por possuírem grandes espaços públicos, diferentes configurações, circulação de trens em seu interior e pessoas andando apressadas, tendem a parecer confusas e perigosas para quem não enxerga, ainda que essas estações atendam plenamente a todos os requisitos exigidos nas normas técnicas e legislação pertinente. Algumas redes de metrô disponibilizam funcionários para auxílio e monitoração, porém este serviço também apresenta problemas, como insatisfação por parte dos usuários com deficiência visual e alto custo às empresas operadoras.

Para participar da pesquisa é necessário somente que você me informe os dias e horários em que costuma utilizar o metrô e qual o percurso que geralmente realiza, que eu irei acompanhá-lo em uma dessas viagens, procurando interferir o mínimo possível, para poder identificar informações referentes à sua percepção espacial e relação com o ambiente e com os demais usuários durante este percurso. Acrescento que não se trata de uma análise do serviço prestado pelo metrô, mas sim de uma pesquisa sobre modos de orientação das pessoas com deficiência visual, como por exemplo, o que é que ajuda, o que interfere etc.

Para uma compreensão mais completa eu devo observá-lo desde a chegada a uma estação do metrô até sua saída na estação de destino. Se estiver habituado a solicitar o auxílio de funcionários do metrô ou se estiver acostumado a ser autônomo, deverá fazê-lo como de costume. Esta pesquisa não apresenta riscos, pois não haverá interferência à sua rotina, no entanto, ao consentir em sua participação neste estudo, você tem a liberdade de se recusar a fazer quaisquer partes da pesquisa, 
assim como também encerrar sua participação, sem qualquer prejuízo. Se desejar, poderá obter mais informações sobre a pesquisa através dos canais de contato fornecidos pela pesquisadora.

Para sua participação neste estudo você não terá nenhuma despesa, bem como nada será pago por sua participação. Após estes esclarecimentos, solicitamos o seu consentimento de forma livre para participar desta pesquisa. Portanto preencha, por favor, os itens que se seguem:

"Tendo em vista os itens acima apresentados, eu, confirmo que recebi e li uma cópia deste termo de consentimento e autorizo de forma livre e esclarecida a execução do trabalho de pesquisa e a divulgação dos dados obtidos neste estudo, de acordo com o Termo de Autorização de Uso de Imagem e Depoimentos, assinado em anexo."

Assinatura do participante da pesquisa

Nome e assinatura da testemunha

Declaro que obtive de forma apropriada e voluntária este Consentimento Livre e Esclarecido.

São Paulo, de de

Eliete Mariani - Pesquisadora 


\section{APÊNDICE 0 \\ UNIVERSIDADE DE SÃO PAULO \\ FACULDADE DE ARQUITETURA E URBANISMO \\ TERMO DE AUTORIZAÇÃO DE USO DE IMAGEM E DEPOIMENTOS}

Título da Pesquisa: Estudos de sistemas eletrônicos de informação e navegação para pessoas com deficiência visual em redes de metrô.

\section{Pesquisadora:}

Eliete Mariani

Mestranda

e-mail: emariani@usp.br

Tel.: (11) 97210-3752

\section{Orientador:}

Prof. Dr. Marcelo E. Giacaglia

e-mail: mgiacagl@usp.br

$\mathrm{Eu}$, RG no CPF n은 depois de conhecer e entender os objetivos, procedimentos metodológicos, riscos e benefícios da pesquisa, conforme especificados no Termo de Consentimento Livre e Esclarecido, assinado em anexo, bem como de estar ciente da necessidade do uso de minha imagem e/ou depoimento, AUTORIZO, através do presente termo, a pesquisadora Eliete Mariani a realizar gravações em vídeos, fotos e/ou colher meu depoimento sem quaisquer ônus financeiros a nenhuma das partes.

Ao mesmo tempo, libero a utilização destas fotos e/ou depoimentos para fins científicos e de estudos (livros, artigos, slides) em favor da pesquisadora, obedecendo ao que está previsto nas Leis que resguardam os direitos dos idosos (Estatuto do Idoso, Lei no 10.741/2003) e das pessoas com deficiência (Decreto no 3.298/1999, alterado pelo Decreto no 5.296/2004).

Assinatura do participante da pesquisa

Nome e assinatura da testemunha

Declaro que obtive de forma apropriada e voluntária este Termo de Autorização de Uso de Imagem e Depoimentos.

São Paulo, de de 


\section{APÊNDICE P}

\section{Mensagem enviada via e-mail aos participantes da pesquisa de observação no metrô de São Paulo, contendo os termos de autorização em anexo:}

Prezado

conforme conversamos via telefone, estou lhe encaminhando os termos da pesquisa que estou realizando com o objetivo de investigar as formas como as pessoas com deficiência visual utilizam e interagem em seus percursos por estações e trens de metrô, para minha pesquisa de mestrado na FAU-USP.

Leia atentamente os dois termos anexos: (1) Termo de Consentimento Livre e Esclarecido e (2) Termo de Autorização de Uso de Imagem e Depoimentos. Se estiver de acordo, por favor, imprima e assine-os, para me entregá-los no dia da pesquisa. Reforço que você não é obrigado a assiná-los, sem nenhum prejuízo.

Se tiver alguma dúvida, estou à disposição. Se preferir, posso ligar para conversarmos.

Muito obrigada!

Eliete Mariani emariani@usp.br Tel. (11) XXX 


\section{APÊNDICE Q}

\section{Características físicas e serviços relevantes nas estações do metrô de São Paulo}

Os Quadros Q.1 a Q.13 apresentam as características físicas e serviços relevantes para este estudo das 13 estações utilizadas pelos usuários participantes durante as observações de campo: Luz, Artur Alvim, Fradique Coutinho, Marechal Deodoro, Barra Funda, Pedro II, Pinheiros, São Bento, República, Tatuapé, Vergueiro, Sé e Vila Matilde.

Quadro Q.1 - Configuração das estações utilizadas nas observações - Luz.

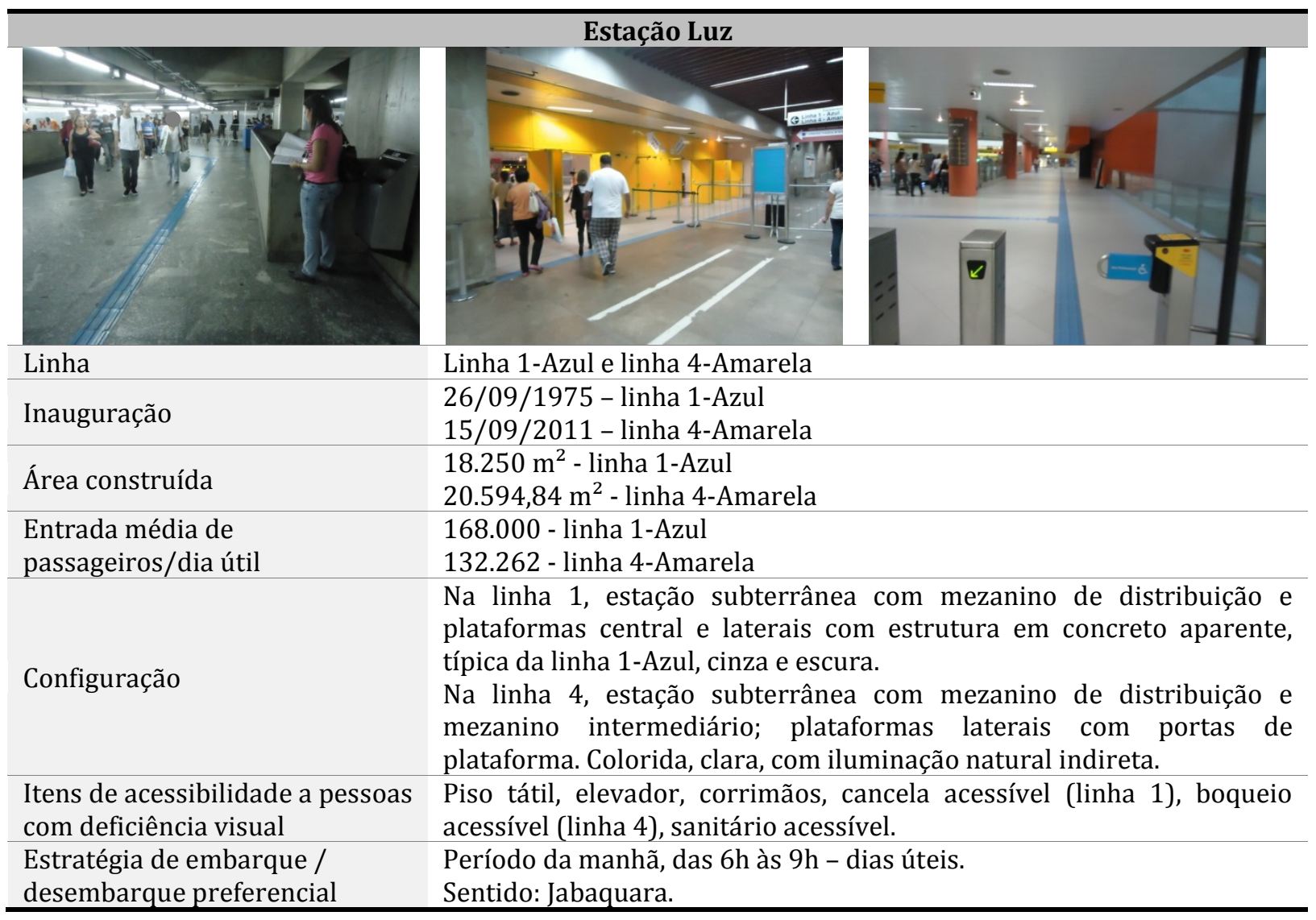

Fonte: Elaborado com base nos dados de ViaQuatro (2015), CMCP, (2015), CMSP, (2015), CMSP, (2015c). Crédito das imagens: PONTES, F. M., 2013. Acervo CMSP. 
Quadro Q.2 - Configuração das estações utilizadas nas observações - Artur Alvim.

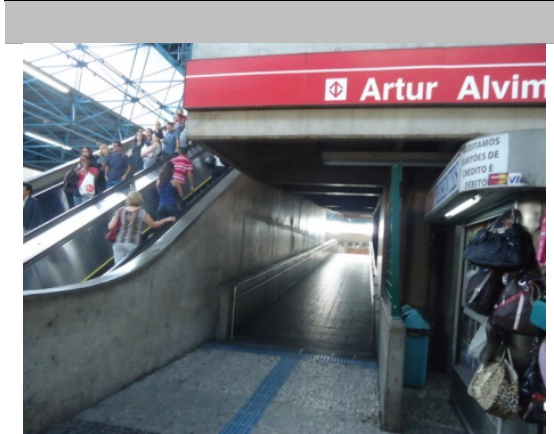

Linha

Inauguração

Área construída

Entrada média de

passageiros/dia útil

Configuração

Itens de acessibilidade

Estratégia de embarque /

desembarque preferencial

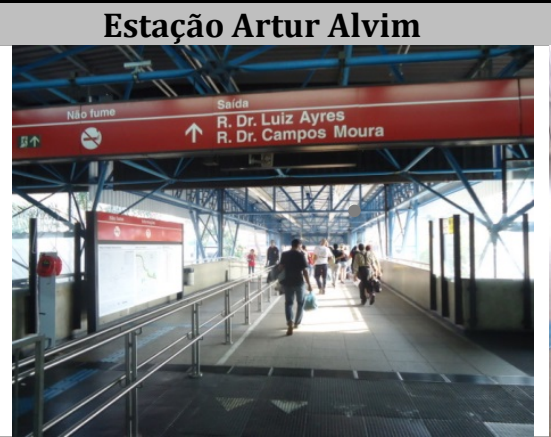

Linha 3-Vermelha

$17 / 09 / 1988$

$12.580 \mathrm{~m}^{2}$

74.000

Estação com mezanino de distribuição sobre plataforma central em superfície, estrutura em concreto aparente e cobertura espacial metálica treliçada, com testeiras coloridas, um marco referencial na paisagem.

Piso tátil, elevador, rampas, corrimãos, cancela acessível, sanitário acessível.

Período da manhã, das $6 \mathrm{~h}$ às $9 \mathrm{~h}$ - dias úteis.

Sentido: Palmeiras-Barra Funda.

Fonte: Elaborado com base nos dados de CMSP (2015) e CMSP (2015c).

Crédito das imagens: PONTES, F. M., 2013. Acervo CMSP.

Quadro Q.3 - Configuração das estações utilizadas nas observações - Fradique Coutinho.

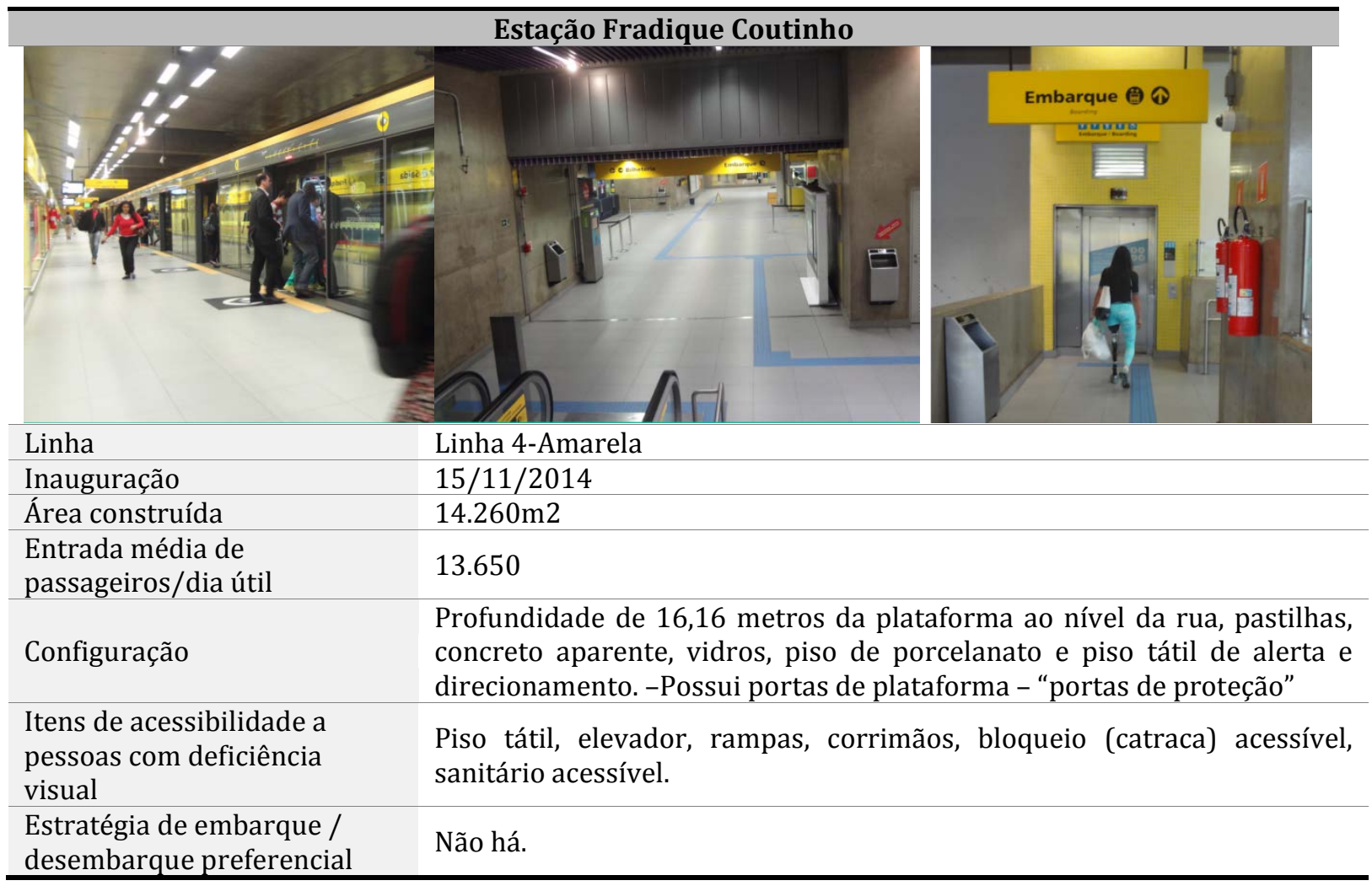

Fonte: Elaborado com base nos dados de ViaQuatro (2015) e CMCP (2015).

Crédito das imagens: SANTOS, D. A., 2015. Acervo CMSP. 
Quadro Q.4 - Configuração das estações utilizadas nas observações - Marechal Deodoro.

\begin{tabular}{|c|c|}
\hline \multicolumn{2}{|r|}{ Estação Marechal Deodoro } \\
\hline Irestins & \\
\hline Linha & Linha 3-Vermelha \\
\hline Inauguração & $17 / 12 / 1988$ \\
\hline Área construída & $12.580 \mathrm{~m}^{2}$ \\
\hline $\begin{array}{l}\text { Entrada média de } \\
\text { passageiros/dia útil }\end{array}$ & 39.000 \\
\hline Configuração & $\begin{array}{l}\text { Estação subterrânea com mezanino de distribuição e plataformas } \\
\text { laterais sobrepostas, estrutura em concreto aparente e aberturas para } \\
\text { iluminação natural. }\end{array}$ \\
\hline $\begin{array}{l}\text { Itens de acessibilidade a } \\
\text { pessoas com deficiência visual }\end{array}$ & Piso tátil, elevador, corrimãos, cancela acessível, sanitário acessível. \\
\hline $\begin{array}{l}\text { Estratégia de embarque / } \\
\text { desembarque preferencial }\end{array}$ & $\begin{array}{l}\text { Período da tarde, das } 16 \mathrm{~h} \text { às } 19 \mathrm{~h} 30 \text { - dias úteis. } \\
\text { Sentido: Corinthians-Itaquera. }\end{array}$ \\
\hline
\end{tabular}

Fonte: Elaborado com base nos dados de CMSP (2015) e CMSP (2015c).

Crédito das imagens: PONTES, F. M., 2013. Acervo CMSP.

Quadro Q.5 - Configuração das estações utilizadas nas observações - Palmeiras-Barra Funda.

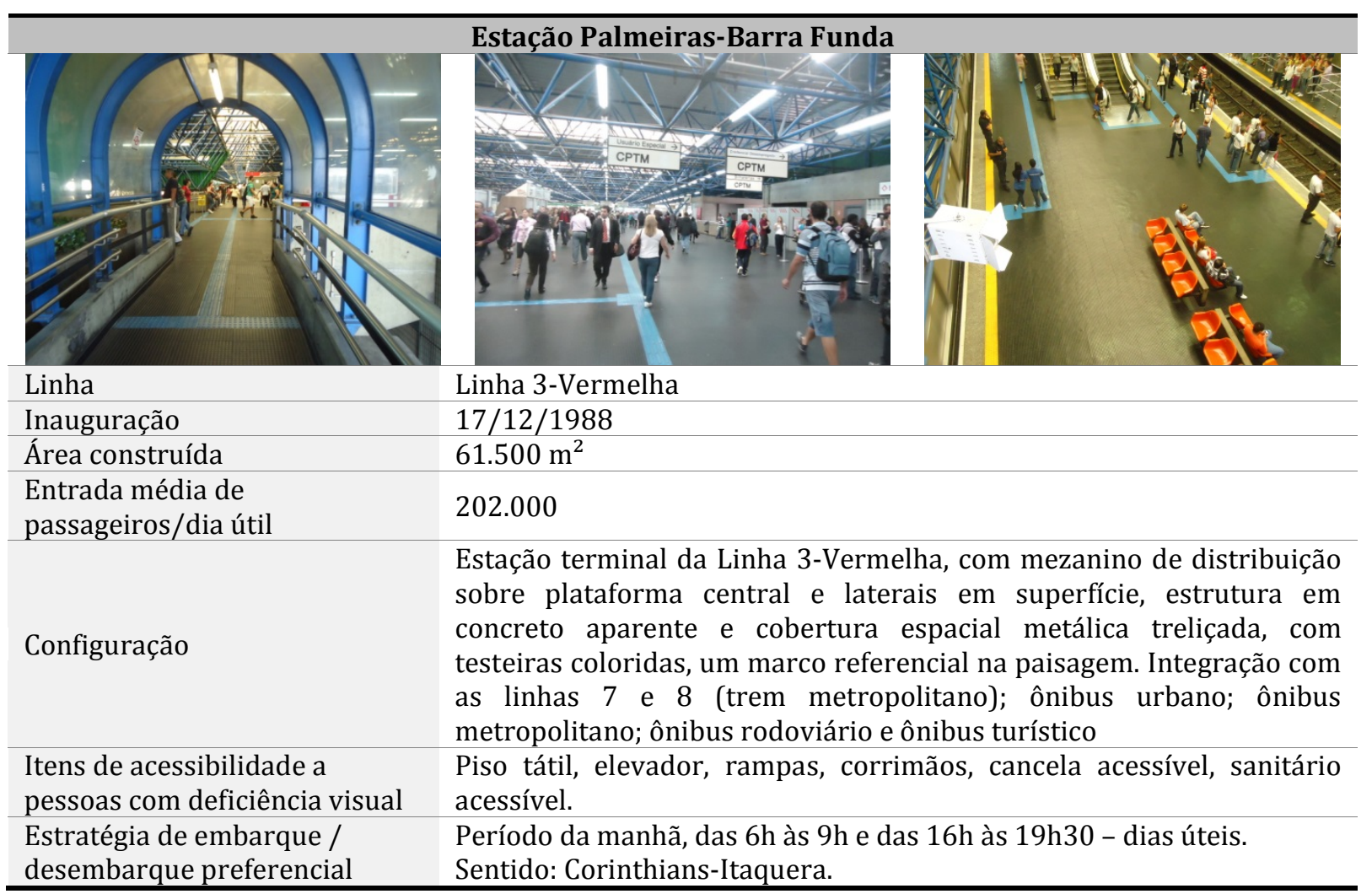

Fonte: Elaborado com base nos dados de CMSP (2015) e CMSP (2015c).

Crédito das imagens: PONTES, F. M., 2013. Acervo CMSP. 
Quadro Q.6 - Configuração das estações utilizadas nas observações - Pedro II.

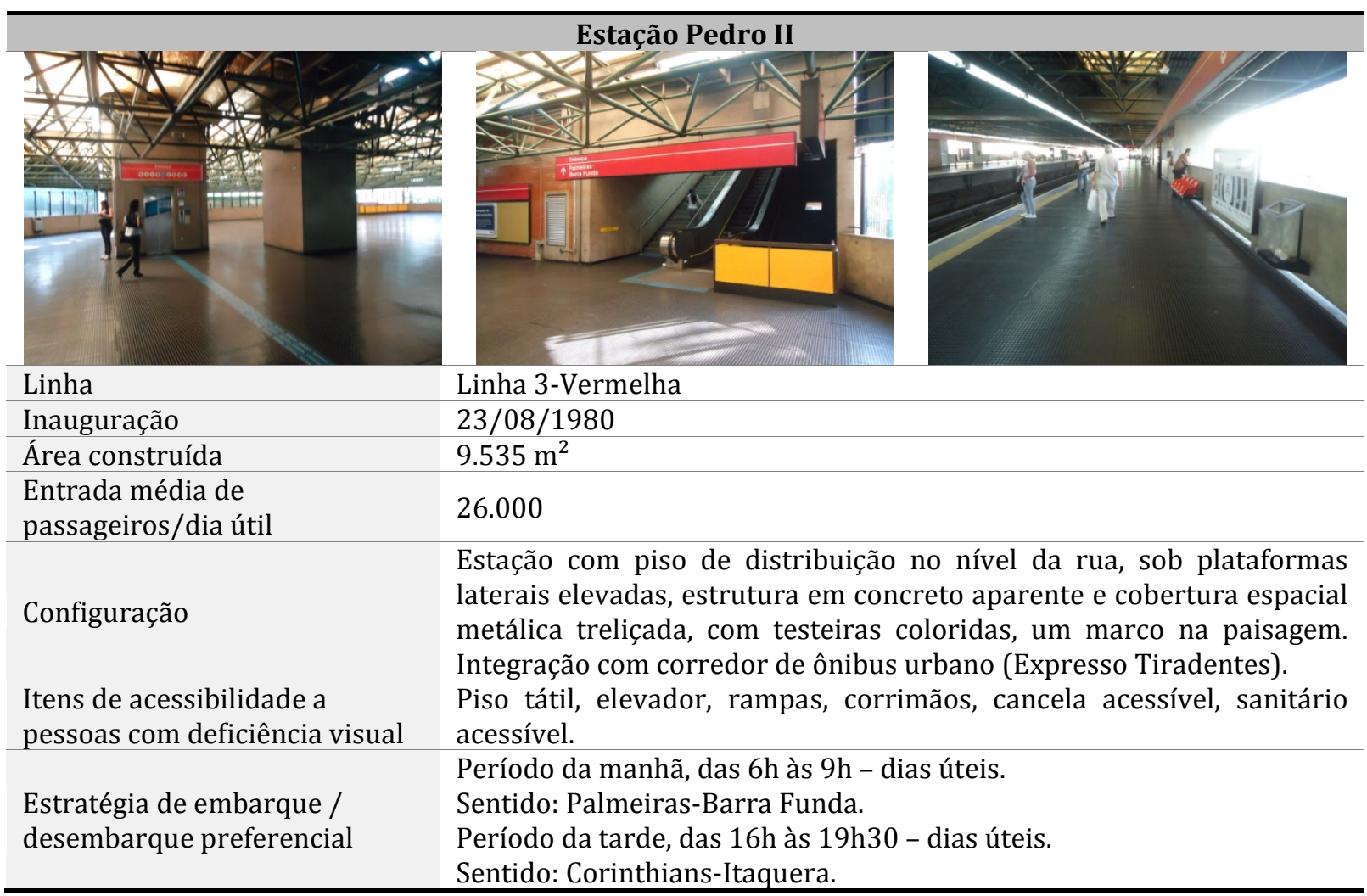

Fonte: Elaborado com base nos dados de CMSP (2015) e CMSP (2015c).

Crédito das imagens: PONTES, F. M., 2013. Acervo CMSP.

Quadro Q.7 - Configuração das estações utilizadas nas observações - Vergueiro.

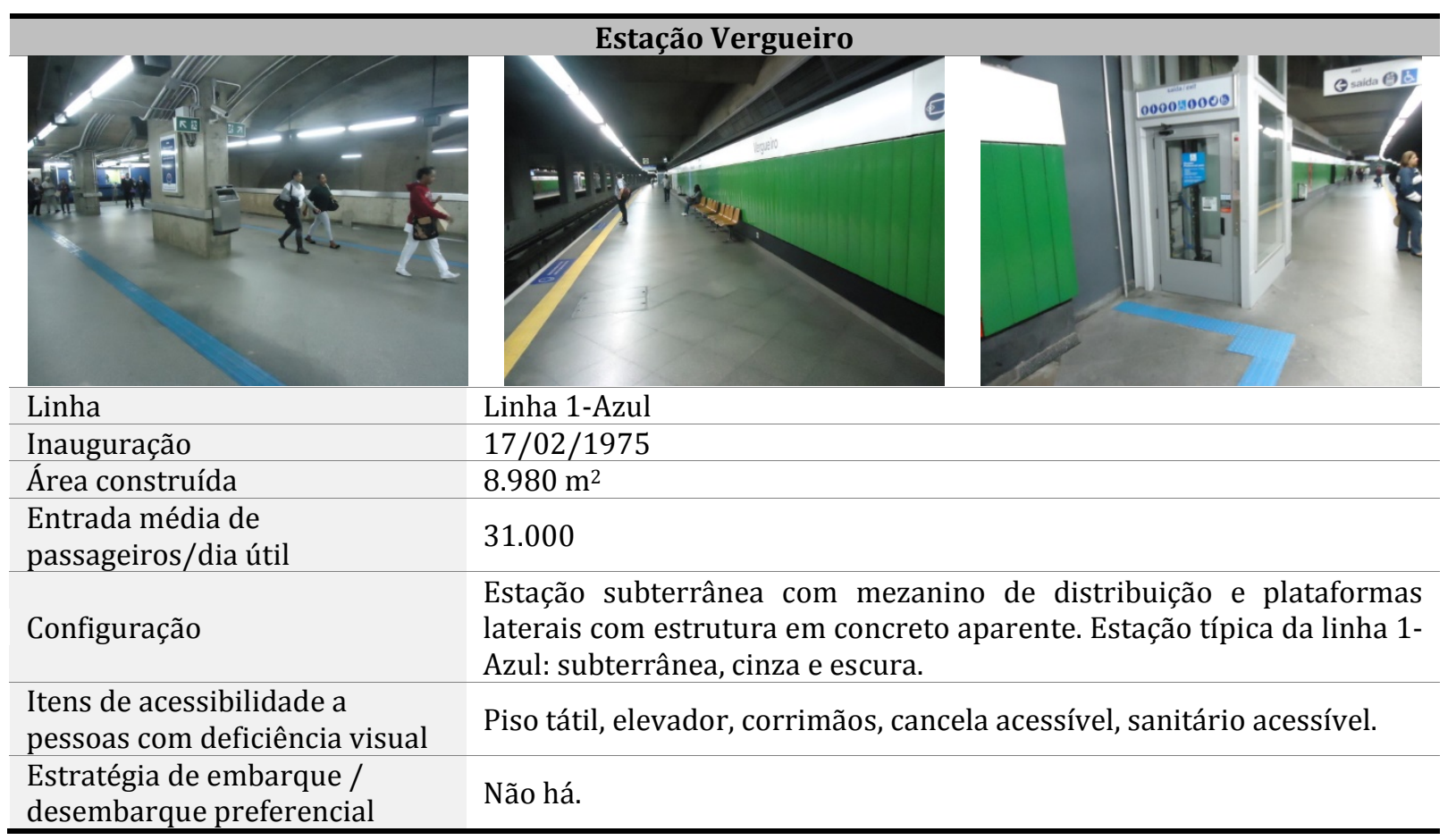

Fonte: Elaborado com base nos dados de CMSP(2015) e CMSP (2015c).

Crédito das imagens: PONTES, F. M., 2013. Acervo CMSP. 
Quadro Q.8 - Configuração das estações utilizadas nas observações - Pinheiros.
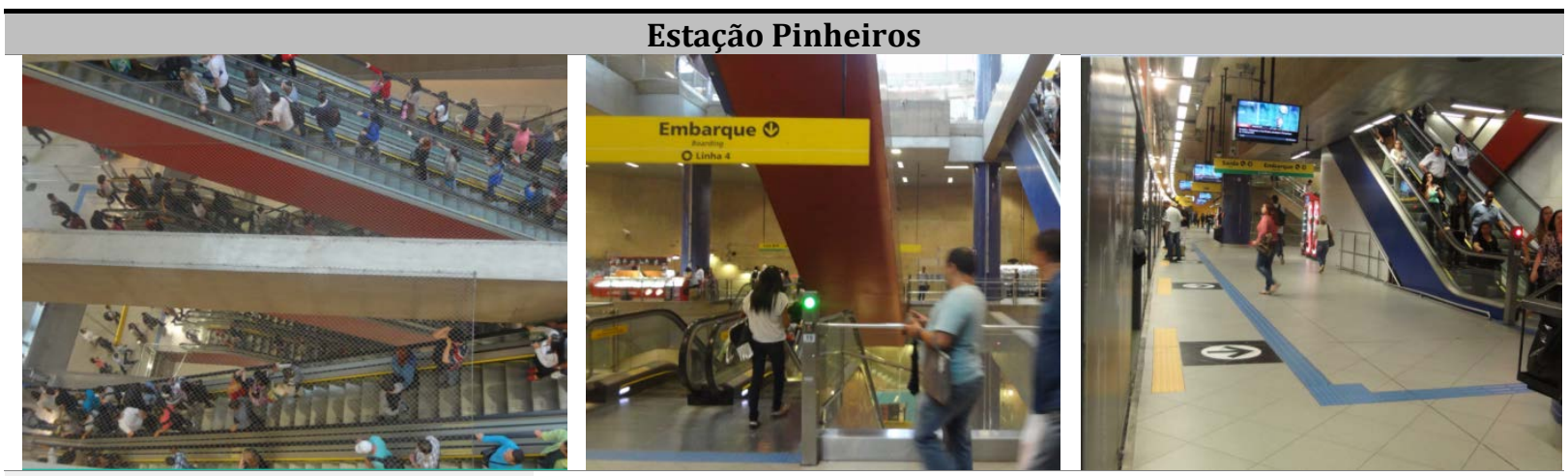

Linha

Linha 4-Amarela

Inauguração

$16 / 05 / 2011$

Área construída $15.026,51 \mathrm{~m}^{2}$

Entrada média de passageiros/dia útil

\subsection{2}

Estação subterrânea com mezanino de distribuição e mezanino

Configuração

plataforma.

Colorida, clara, com aberturas para iluminação natural. Integração com a estação Pinheiros da linha 9-Esmeralda administrada pela CPTM, por uma passarela sobre a Marginal Pinheiros.

Itens de acessibilidade a pessoas Piso tátil, elevador, rampas, corrimãos, bloqueios acessíveis, com deficiência visual Estratégia de embarque / desembarque preferencial sanitário acessível.

Não há.

Fonte: Elaborado com base nos dados de ViaQuatro (2015) e CMCP (2015).

Crédito das imagens: SANTOS, D. A., 2015. Acervo CMSP.

Quadro Q.9 - Configuração das estações utilizadas nas observações - São Bento.

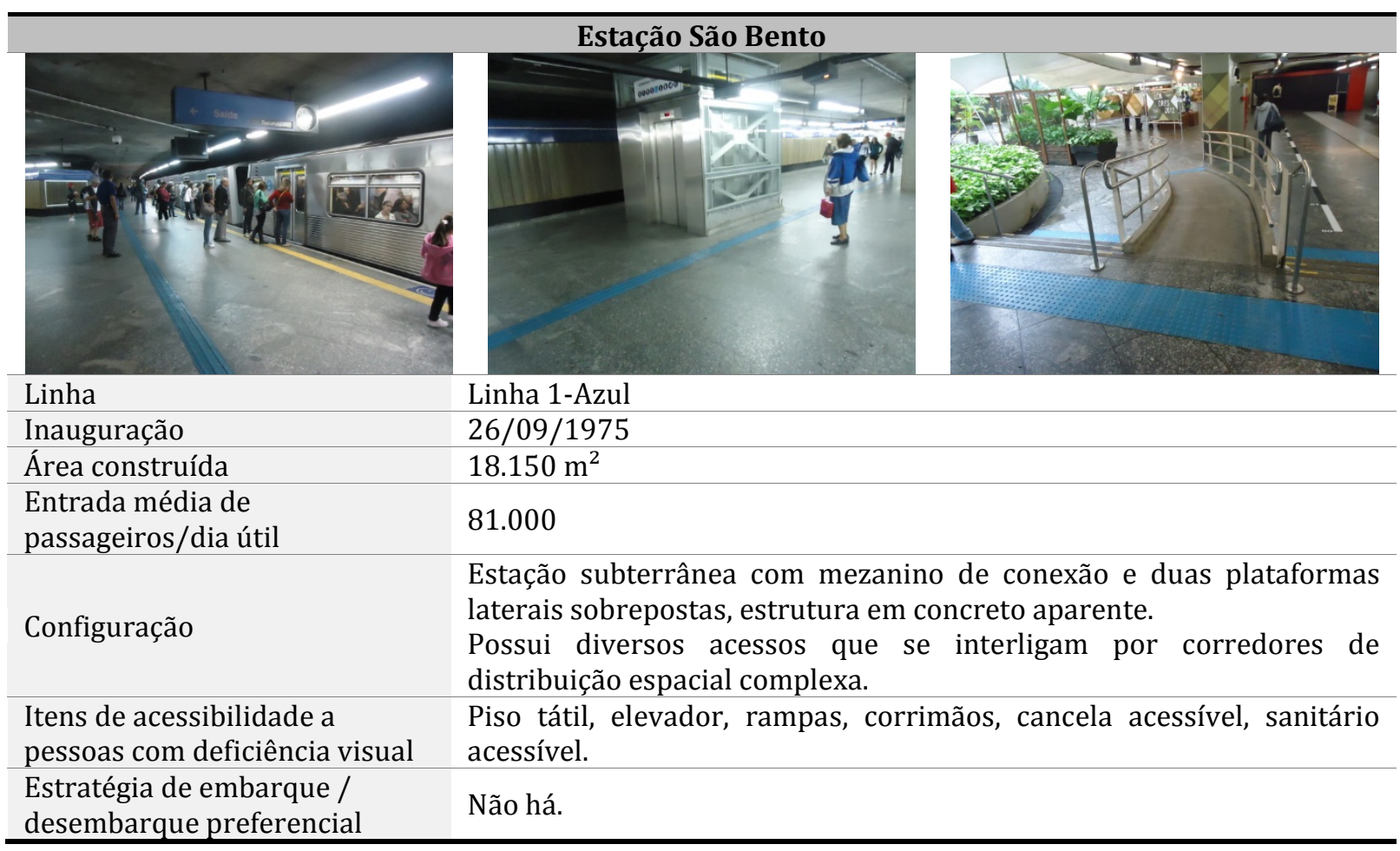

Fonte: Elaborado com base nos dados de CMSP (2015) e CMSP (2015c).

Crédito das imagens: PONTES, F. M., 2013. Acervo CMSP. 
Quadro Q.10 - Configuração das estações utilizadas nas observações - República.

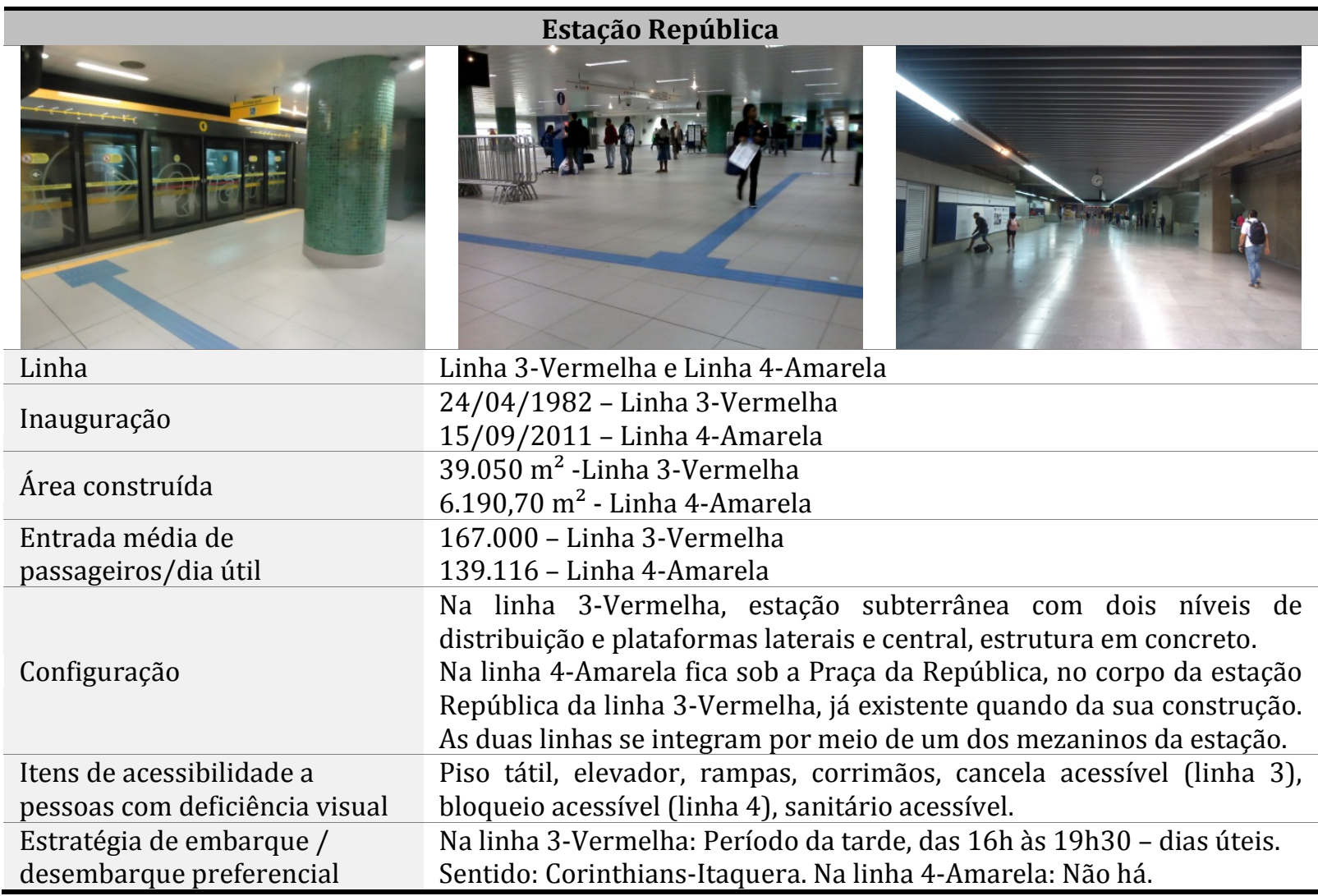

Fonte: Elaborado com base nos dados de ViaQuatro (2015), CMCP (2015), CMSP (2015) e CMSP (2015c). Crédito das imagens: PONTES, F. M., 2013. Acervo CMSP.

Quadro Q.11 - Configuração das estações utilizadas nas observações - Tatuapé.

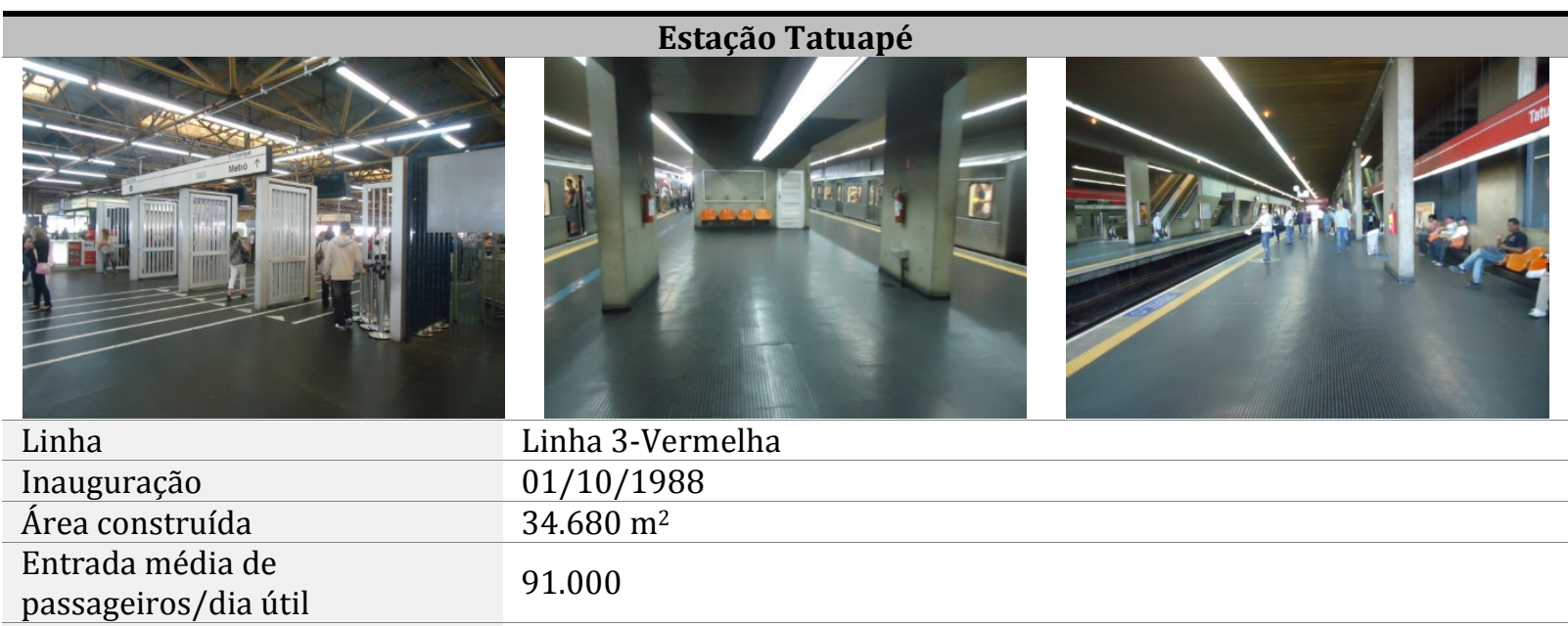

Estação com mezanino de distribuição sobre plataformas central e

Configuração laterais em superfície, estrutura em concreto aparente e cobertura espacial metálica treliçada, com testeiras coloridas, um marco referencial na paisagem. Conexão com o trem metropolitano.

Itens de acessibilidade a Piso tátil, elevador, rampas, corrimãos, cancela acessível, sanitário pessoas com deficiência visual Estratégia de embarque / acessível.

Período da manhã, das $6 \mathrm{~h}$ às $9 \mathrm{~h}$ - dias úteis.

desembarque preferencial Sentido: Palmeiras-Barra Funda.

Fonte: Elaborado com base nos dados de CMSP (2015) e CMSP (2015c).

Crédito das imagens: PONTES, F. M., 2013. Acervo CMSP. 
Quadro Q.12 - Configuração das estações utilizadas nas observações - Sé.

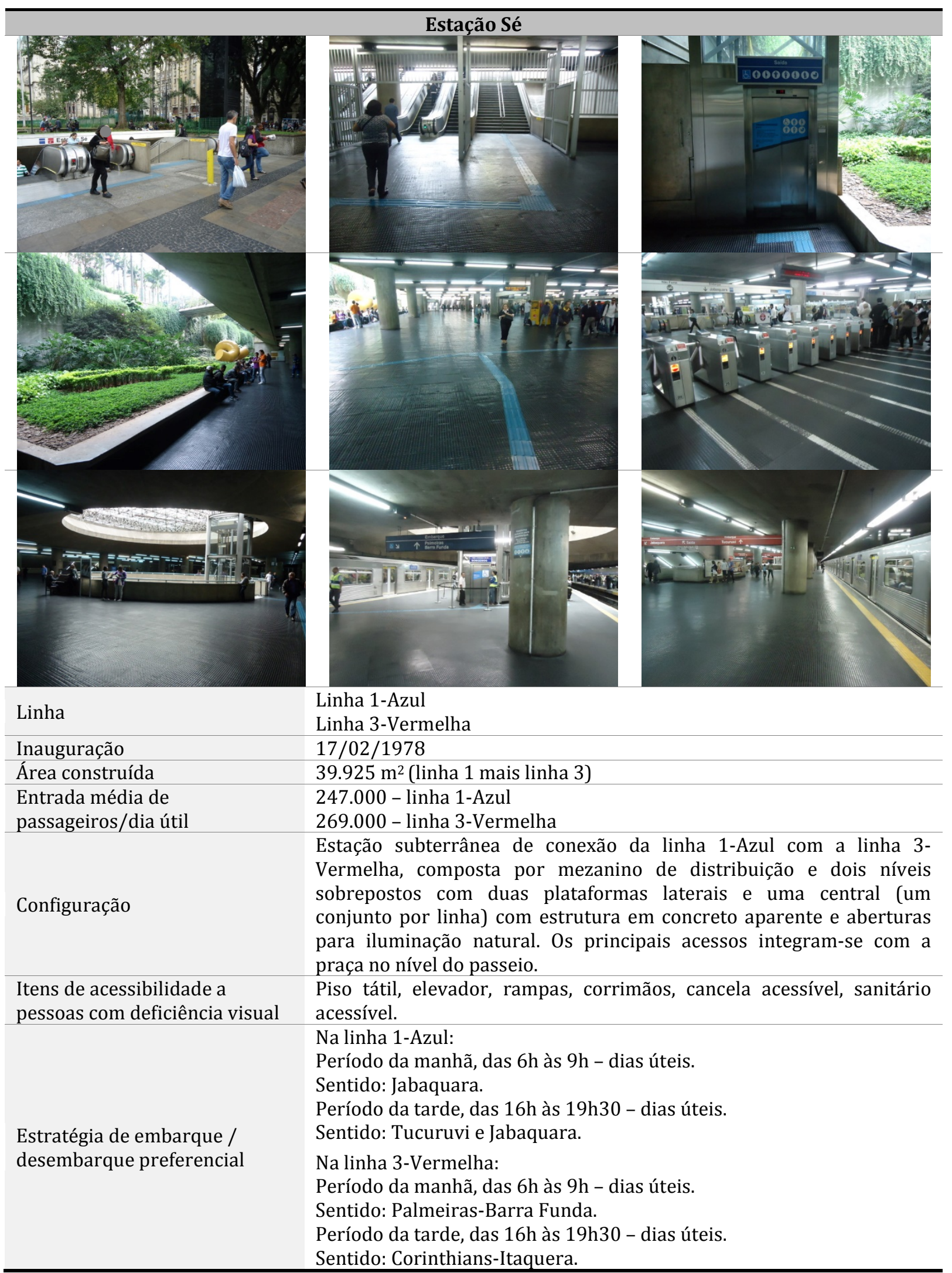

Fonte: Elaborado com base nos dados de CMSP (2015) e CMSP (2015c).

Crédito das imagens: PONTES, F. M., 2013. Acervo CMSP. 
Quadro Q.13 - Configuração das estações utilizadas nas observações - Vila Matilde.

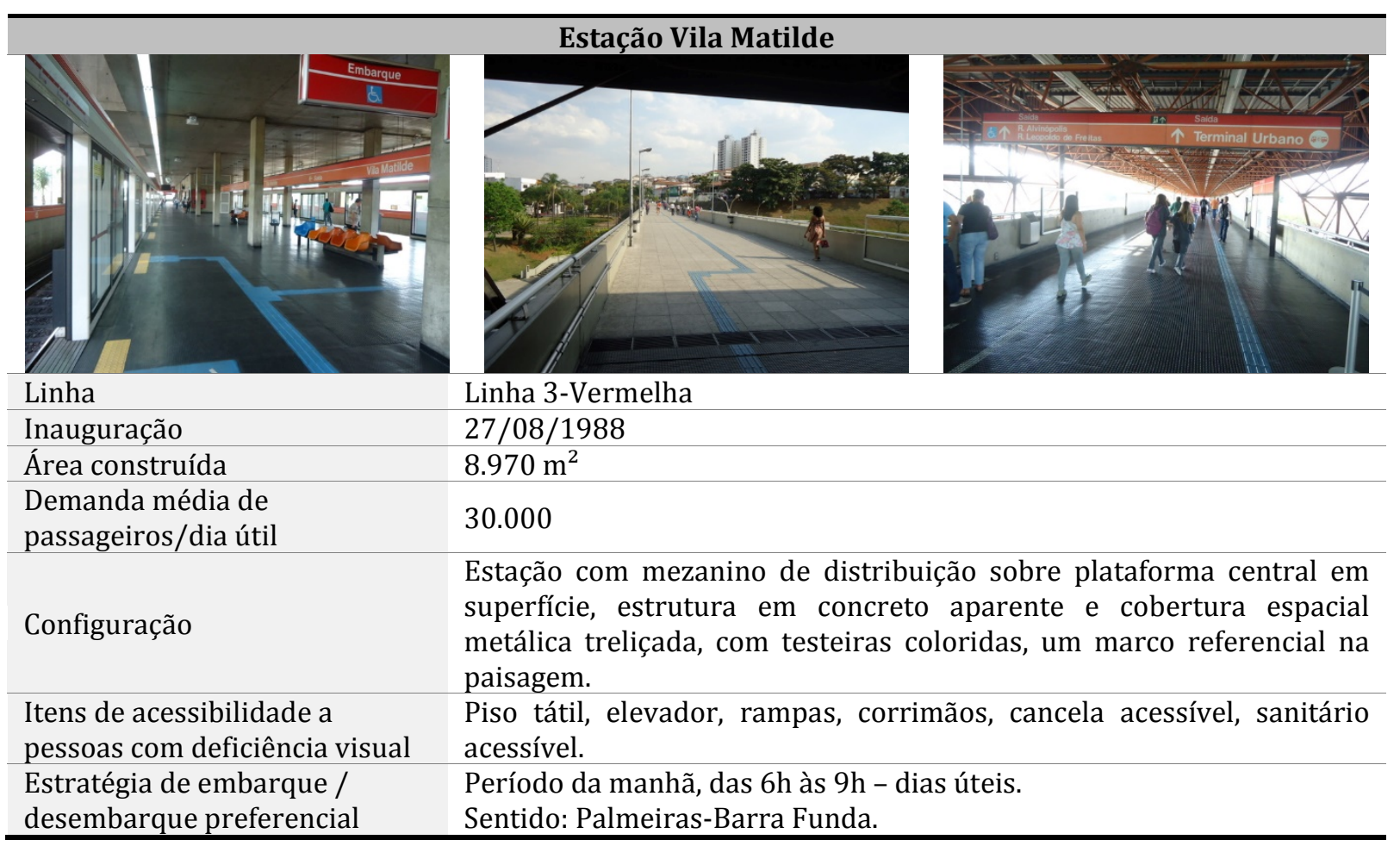

Fonte: Elaborado com base nos dados de CMSP (2015) e CMSP (2015c).

Crédito das imagens: PONTES, F. M., 2013. Acervo CMSP. 


\section{APÊNDICE R}

\section{Características físicas e serviços relevantes nas estações do metrô de São Paulo}

O Quadro R.1 apresenta as características físicas do material rodante (trens) utilizados pelos usuários participantes durante as observações de campo. Apesar das semelhanças entre os modelos, os trens que circulam pela rede do metrô de São Paulo apresentam diferenças de localização e dimensionamento de assentos, barras e apoios de mão horizontais e verticais dificultando sua compreensão pelos usuários com deficiência visual. Devido a necessidades operacionais e de manutenção, diferentes modelos circulam em uma mesma linha, de forma que o usuário não consegue estabelecer um padrão para uso dos trens.

Quadro R.1 - Configuração dos trens utilizados nas observações.

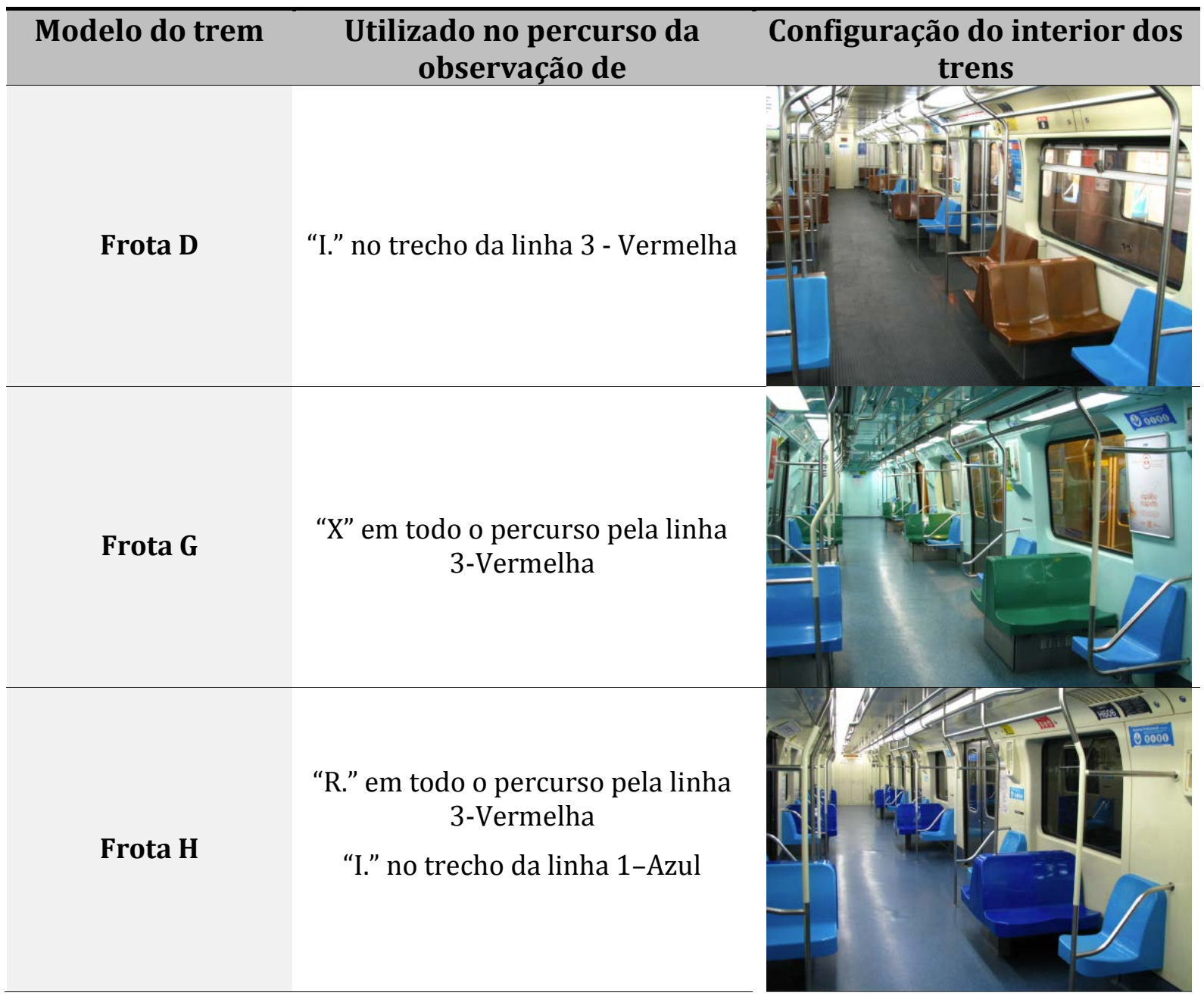

(Continua) 
(Conclusão)

Modelo do trem $\begin{gathered}\text { Utilizado no percurso da } \\ \text { observação de }\end{gathered}$
Frota I
"M." no trecho da linha1-Azul
Frota K
"G." em todo o percurso pela linha
3-Vermelha
"V." no trecho da linha 3-Vermelha
"V." no trecho da linha 4-Amarela do interior dos
"M." no trecho da linha 4-Amarela

Fonte: Elaborado pela autora a partir de dados de CMSP (2015) e ViaQuatro (2015).

Crédito das imagens frotas D, G, H, I e K: ZAITSU, B. T., 2014. Acervo CMSP.

Crédito da imagem frota única da linha 4-Amarela: Autoria desconhecida. Disponível em: <http://ffw.com.br>. Acesso em: 25 out. 2015. 


\section{APÊNDICE $S$}

\section{Síntese das observações de campo - metrô de São Paulo}

A síntese das observações de campo realizadas no metrô de São Paulo constam a seguir:

\section{a) Observação de "R."}

"R." desceu da van e orientou-se pela mureta existente entre a calçada e o jardim, em direção ao acesso da estação Artur Alvim. Não existe piso tátil nesse trajeto, mas "R." foi direto para a rampa de entrada, orientando-se pela parede lateral a esta. "R." esbarrou nas lixeiras ao longo desta parede. Quando questionado "você encontrou a lixeira... você já sabe que tem a lixeira?..." ele disse "[no meu caminhar] ou eu ando tranquilo ou ando contando os passos para saber onde (as lixeiras) estão; eu opto por andar tranquilo".

Depois da rampa existe piso tátil direcional, e "R." demonstrou conhecer a sinalização com pisos táteis, sem problemas para diferenciar o piso tátil direcional do piso tátil de alerta. Comentou que sempre utiliza os pisos táteis no metrô, realizando antes um treinamento que é oferecido pela Companhia do Metrô. Enquanto caminhava, comentou: "Paraíso eu já tentei usar, ele é bem complicado... São Bento eu pensava que era, mas eu fiz treinamento com a C.82, é muito simples... ela é complexa a estação, mas o piso tátil é simples".

Na estação que ele mais utiliza, Artur Alvim, o piso tátil só direcionava para o elevador, e como "R." se orienta principalmente pelo piso tátil, ele diz "se o elevador estiver pifado, eu já me perco, porque tenho que ir para esse outro lado, e aqui tem uns corrimãos atrapalhando", numa referência a organizadores de fluxo ali instalados ${ }^{83}$. Enquanto utilizava o elevador, ele comentou que grande parte das pessoas com deficiência visual não lê Braille, porque a maioria adquiriu a deficiência depois de adulta.

"R." caminhou normalmente pela linha de piso tátil direcional instalada ao longo da plataforma, em direção ao ponto de embarque na outra extremidade; ao ouvir a chegada do trem, ele parou e virou-se de frente para o fluxo de pessoas que saíam apressadas, em direção às escadas. Ele então comentou que parou para aguardar as pessoas passarem, e

\footnotetext{
${ }^{82}$ Citou o nome da funcionária da Companhia do Metropolitano de São Paulo - METRÔ, que oferece o treinamento a pessoas com deficiência, para conhecerem e utilizarem as estações.

${ }^{83}$ Ainda não havia sido instalado piso tátil direcional para as escadas fixas na área interna das estações.
} 
permaneceu parado até que a plataforma esvaziasse, continuando a caminhar logo em seguida. Porém, quando chegou o próximo trem, ele não parou. Perguntado por que ele não havia parado desta vez, ele respondeu que agora ele sabia que estava no contra fluxo, e desta forma seria visível para as pessoas que saíam do trem, e que estas desviariam dele. Ao ser perguntado como ele sabe de que lado estão vindo as pessoas, ele responde que "os primeiros vêm gritando", e assim é possível saber de que lado estão. Quando entrou no trem do metrô, uma senhora que estava saindo faz menção de ajudalo, mas ele não notou; entrou de maneira segura e procurou o assento preferencial, demonstrando conhecimento prévio do leiaute da área interna. Verificou com a bengala se o assento estava vazio e sentou-se. Havia poucos passageiros nesse horário, no sentido Barra Funda. "R." viajou sentado, e atento às informações sonoras com o nome da próxima estação. "R." desceu ao chegar na estação Tatuapé, e se dirigiu à saída para o centro comercial localizado do lado norte da estação, finalizando-se aqui o percurso de observação.

Importante ressaltar que "R." fez todo o percurso até seu destino como normalmente faria sozinho, não havendo nenhuma interferência da pesquisadora, mesmo quando ele esbarrou em objetos ou em pessoas circulando pela estação. Durante o trajeto "R." foi comentando com frequência sobre particularidades da maneira como o piso tátil está instalado.

Analisando-se o discurso de "R.", verifica-se a grande importância que ele dá ao piso tátil, suas queixas a respeito da maneira como está instalado, incluindo-se interferências surgidas durante o uso, e também o grande apelo que faz para que as linhas direcionais dos pisos táteis sejam instaladas na diagonal, no sentido de circulação das demais pessoas. Também se verifica seu desejo de que o piso tátil nas áreas internas das estações seja instalado conduzindo para as escadas, além de conduzir para os elevadores, devido aos problemas causados quando algum elevador está quebrado. A interferência das demais pessoas que esbarram e atrapalham sua caminhada também tem destaque na análise.

Como consideração complementar, após ter sido finalizada a observação programada, "R." ficou conversando com a pesquisadora sobre assuntos diversos, entre eles, sobre sistemas de transporte e ocupação urbana. Lembrando que "R." havia ficado totalmente cego há oito anos, durante a conversa, a pesquisadora percebeu que ele guardou uma 
imagem da cidade como era na época em que perdeu a visão, e fazia considerações como se a paisagem não tivesse sofrido alterações ao longo do tempo, como por exemplo, a retirada de todos os outdoors da cidade de São Paulo, devido à Lei Cidade Limpa ${ }^{84}$, vigente desde cerca de seis anos antes da pesquisa. Numa análise geral, isso pode influenciar nas tomadas de decisão de pessoas que adquiriram a deficiência visual e guardam na memória fatos antigos, por exemplo, ao optar por determinado caminho na rua em função de segurança, movimento etc., e que pode ter sido alterado.

\section{b) Observação de "I."}

O encontro da pesquisadora com "I." se deu em seu local de trabalho, próximo à estação Vergueiro, e foram caminhando até lá. "I." seguia com destino a uma escola de línguas, próximo à estação Marechal Deodoro. Ela informou que prefere ir acompanhando alguém nesse percurso, porém, quando está só, ela segue muretas e paredes dos edifícios, junto à calçada, para chegar à estação, entretanto, quando a parede é interrompida por uma área aberta, ela perde a noção do rumo precisando ser reorientada ao caminho da calçada. "I." explicou que tem noção de onde está a estação pela distância percorrida desde o edifício, e por uma árvore de galhos baixos que esbarra antes de chegar lá. Bem próximo à entrada da estação, ela esbarrou em grandes contêineres de coleta seletiva, mas isso não pareceu incomodá-la, pois constitui outra referência, afirmou.

Ao entrar na estação ela conseguiu chegar às catracas com dificuldade, sem utilizar o piso tátil que poderia orientá-la. Ela disse que sempre pede auxílio a um funcionário do metrô quando chega aí, pois afirmou que "tem medo de cair nos trilhos". "I." utiliza referências de som e sombras e declara ser "desatenta"; tem a necessidade de ser conduzida várias vezes até decorar o caminho.

Ela disse que não consegue utilizar o piso tátil com autonomia porque não consegue diferenciar as "bolinhas" das "barrinhas", que compõem os pisos táteis de alerta e direcional, respectivamente. "Eles [os pisos táteis] são imperceptíveis, têm a mesma textura, o mesmo material." E prossegue: "Se você não estiver muito ligado não dá pra perceber, entendeu? Tá vendo? [tateando o piso com a bengala] Tem de ter alguma forma... não dá pra saber se é pra cá, ou pra cá. Deve ter alguma forma, um mapa, um bip, por

84 Lei № 14.223, de 26 de setembro de 2006. Dispõe sobre a ordenação dos elementos que compõem a paisagem urbana do Município de São Paulo. Ficou conhecida como "Lei Cidade Limpa". 
exemplo, que a pessoa tenha, que avise à direita, tal coisa, bilheteria ou catraca e à esquerda tal coisa, a aí a pessoa escolhe o que ela quer, porque senão não tem muita utilidade. Esse é o motivo pelo qual eu não me dedico tanto a seguir o piso tátil."

Entretanto, durante a conversa ao longo do percurso, ela defendeu a ideia de se buscar melhorar as adaptações existentes: "Eu acredito, se adaptar a estação mais para o deficiente visual, se colocar mais piso tátil e o sistema de áudio, eu acredito que dá para ele ter autonomia sim de forma segura. Não precisa nem de tanto treinamento. Eu acredito que dá.". Quando a pesquisadora pergunta se ela gostaria de experimentar essa autonomia ou se ainda preferiria o auxílio de um funcionário, ela responde: "Eu gostaria. Eu precisaria de um treinamento, duas, três, quatro vezes em cada estação, precisaria me dedicar, mas eu gostaria sim. Precisaria ver este esquema de áudio, tipo um guia eletrônico, tipo um GPS ${ }^{85}$; é um GPS mesmo." A pesquisadora rebate, comentando que o sinal GPS não chega às áreas internas, mas ela prossegue: "É, mas uma coisa que funcionasse interna. Tipo assim, você passa a catraca, linha tal à direita, linha tal à esquerda, escada rolante a tantos metros, sabe assim? Escada rolante descer, sabe? Seria muito interessante."

Como consideração complementar, "II. fez uma crítica aos mapas táteis: “O pessoal faz mapa para a pessoa ler antes, mas isso não resolve porque, primeiro [para] os deficientes visuais ler mapas é muito difícil, e segundo, porque daqui a meia hora você não lembra, não consegue guardar na sua cabeça um mapa e transformar em realidade. Teria que ser vários mapas, né? Mapas sequenciais, trecho a trecho...".

Ao ser indagada por que, então, não utiliza o piso tátil, ela admite que, para isso, necessitaria se dedicar, treinar várias vezes em cada estação. "Se for uma estação que eu vou pegar sempre eu posso pedir para alguém me ensinar umas duas ou três vezes o caminho. Eu digo isso porque eu sou meio desatenta e em uma eu não 'pego'. Me ensina umas duas ou três vezes, pra da próxima eu ir sozinha.".

Ela reconheceu a direção das catracas pelo som e movimento de sombras e, ao passar, um funcionário do metrô ofereceu auxílio. Como estava sendo acompanhada pela pesquisadora, que é funcionária do metrô, sua assistência não se fez necessária.

${ }^{85}$ A sigla GPS foi utilizada por “I." como referência a um dispositivo que utilize o sinal GPS para navegação. 
"I." sabe que deve pegar a "linha vermelha", mas não sabe como se dirigir a ela, sendo sempre guiada por um funcionário ou colega de trabalho. Ela disse que está acostumada a utilizar as escadas rolantes. A sensação de movimento que se pode identificar como subir, descer, parar ou mover lateralmente, como é o caso do trem, também é um sinalizador em seu percurso, fazendo-a perceber a entrada e saída do degrau na escada rolante.

"I." se locomoveu muito bem tanto nas escadas rolantes como nas fixas, mas disse que prefere as rolantes. Ela afirmou que se sente mais segura, pois está parada com os dois pés no degrau, assim como as outras pessoas acima e abaixo dela, e assim é menos provável que seja empurrada do que na escada fixa, pois neste caso, ela e os demais transeuntes estão se movimentando juntos, e não em ritmos diferentes, como na escada fixa.

Na plataforma ela transparece o receio de ser empurrada por pessoas apressadas, por isso sempre pede o auxílio de acompanhante. 0 trem está cheio, a viagem é feita em pé. Ela nem se interessa em procurar o assento preferencial, diz que está acostumada a pegar o trem nesse horário e o percurso é rápido. Ela prefere já ir se posicionando próxima à porta oposta a que entrou, pois sabe que é por ali que vai descer na estação de transferência entre linhas, a estação Sé. Um rapaz quer passar, e dirigiu-se a "I.", que depois comenta com uma das pesquisadoras: “Você viu que pessoa educada?... Não, ele foi muito educado... ele perguntou se eu ia desembarcar e pediu com toda educação pra gente liberar a porta", pois o não empurrar e a solicitação verbal são um fato raro.

A sequência do percurso de desembarque na estação Sé, linha 1-Azul, embarque na linha 3-Vermelha, sentido Barra Funda, e desembarque na estação Marechal Deodoro, ocorreu sem intercorrências. "I.", sempre demonstrando grande familiaridade com escadas. Nas escadas fixas, ela subiu naturalmente, apoiada no acompanhante, mas com a ponta da bengala contornando habilmente degrau por degrau, enquanto subia, dimensionando exatamente cada espaço sendo firmado por seus pés.

O trajeto de observação foi finalizado na saída para a rua Albuquerque Lins; "I." segue tranquila, pois contou que, além de estar habituada a fazer esse percurso todos os dias de aula, também morou por um tempo nessa região, justificando a familiaridade.

Analisando-se o discurso de "I." nota-se que durante a conversa sobre sua maneira de caminhar houve manifestação a respeito do piso tátil - que ela não utiliza, pois não o 
percebe com sua bengala. Para caminhar pela estação ela pede o auxílio de um funcionário que geralmente está junto às catracas da estação e que a leva até dentro do trem. Ela afirma ter muito medo de cair da plataforma, de ser empurrada pelos demais usuários. Com relação às escadas, "I." afirma preferir as escadas rolantes, ficando à direita do degrau e deixando a esquerda livre para passagem das demais pessoas. Ela prefere a escada rolante à escada fixa porque se sente mais segura, "com os dois pés no chão", e por isso sente menor risco de cair.

\section{c) Observação de " $X$ "}

Esta observação, não participante, iniciou-se no acesso sul da estação Marechal Deodoro. O horário escolhido para a observação, 18h, é considerado pelo Metrô como um horário de pico, quando existe um grande número de pessoas circulando. Aguardou-se a chegada de alguém com características de deficiência visual que estivesse desacompanhado, e foi escolhido um rapaz aparentando em torno de 25 anos de idade que se aproximava para entrar na estação, o qual foi denominado "X", realizando-se o acompanhamento totalmente sem nenhuma abordagem.

"X" caminhou de forma independente e rápida desde a rua até chegar próximo às catracas, utilizando bengala longa, mas não utilizando o piso tátil. Caminhou rápido, esbarrando em colunas e pessoas. Parecia conhecer o espaço, a estação, mas aparentemente sua rapidez e a grande quantidade de pessoas formando filas para passar nas catracas o levaram a afastar-se, até que um senhor o segurou pelo braço e conduziu-o a um funcionário do metrô, que o abordou, oferecendo auxílio, o que foi aceito. 0 funcionário o guiou até a plataforma de embarque sentido Corinthians-Itaquera e permaneceu ao seu lado até a chegada do trem, indicando-lhe a porta para entrar.

No trem ele permaneceu desacompanhado, realizando quase todo o percurso em pé, pois estava lotado, e os assentos preferenciais estavam ocupados por outras pessoas que também tinham direito a esses assentos; só se sentou quando o trem chegou à estação Bresser-Mooca, ao vagar o assento mais próximo.

"X" demonstrou estar tranquilo o tempo todo, mesmo com tantas pessoas na estação e no trem lotado. Ao descer na estação Artur Alvim, uma funcionária já o aguardava para auxiliá-lo. No percurso ele continuou tranquilo, conversando com alguém pelo telefone celular. Utilizou o sanitário, e a funcionária o acompanhou até o ponto de ônibus, onde foi finalizada a observação. 


\section{d) Observação de “G."}

A pesquisadora encontrou-se com "G." e seu cão-guia Julia na saída do Expresso Tiradentes, em conexão com a estação Pedro II do metrô. Eles chegam pela rampa de acesso, porém ele informa que "a chegada pode ser rampa ou elevador; eu prefiro elevador por segurança, porque na rampa o pessoal corre muito, mas a Julia gosta do elevador porque ela é preguiçosa; se eu falo 'rampa' ela vai de rampa, se eu não falo nada, ela vai de elevador".

"G." seguia em direção à estação Palmeiras-Barra Funda, onde pega um ônibus para voltar para sua casa. Logo no início avisa: "Se alguma coisa acontecer no meio do caminho, se perder alguma filmagem, nós não podemos voltar, porque a Julia vai entender como um erro dela, e isso a confunde". Optamos por entrar na estação, e ele dá o comando "Vamos lá, Julia", e ela segue direto para uma das catracas de entrada. Depois de passar para o interior da estação, ele segue falando: "Julia, Barra Funda". Todos esses comandos foram dados em tom de voz normal, mesmo para um ambiente com muito ruído, como uma estação de metrô no horário de pico.

"G." relata que "Não necessariamente eu vou pra Barra Funda, posso ir [para o lado oposto] Corinthians-Itaquera. Isso eu mesmo treinei ela. Depois que ela tava treinada comigo, a gente aprende a ensinar certos comandos". Seguimos em direção à escada rolante que dá acesso à plataforma, mas no meio do caminho, "G." para, retira um biscoito canino do bolso e o dá para Julia. Ele explica que aquilo é uma recompensa que ela recebe por cada etapa do percurso que completa. Julia o direciona, então, para a escada rolante. No percurso ele explica: "como ela [Julia] é preguiçosa, se eu quero que ela vá de [escada] fixa, tem que falar pra ela, porque senão ela vai na rolante".

Ao chegar na plataforma, Julia segue até próximo da borda e entra na frente de "G.", impedindo-o de prosseguir, numa indicação de que ele deve parar ali para esperar pelo trem. Ela permanece o tempo todo nessa posição, protegendo-o, até a chegada do trem, quando o ajuda a embarcar. 0 trem não está muito cheio, e ele consegue sentar num dos assentos preferenciais. Julia se acomoda sob o assento. Durante a viagem "G." vai respondendo às perguntas da pesquisadora: "não se pode usar a bengala e o cão-guia ao mesmo tempo; ou você é guiado pela bengala, ou você é guiado por um cão-guia, ou por uma pessoa; você não pode misturar duas coisas, vai dar problema; a única exceção é se a Julia se machucar, aí eu posso pegar a bengala na mochila e ir pra um lugar seguro". 
Ao ser perguntado sobre como ele faz para ir a uma estação que não conhece, ele explica: "teoricamente todo metrô tem uma escada de saída da plataforma [...] pra sair do metrô eu mando a Julia procurar uma escada rolante, elevador ou catraca, depende da situação [...] ela sabe achar esses pontos-chaves". E para ir a lugares que não conhece, que a Julia não conhece, "alguém me descreve onde eu tenho que ir e eu oriento ela do que eu preciso fazer". Ele dá um exemplo: "se eu for na sua casa, você me descreve: 'G.', você desce no ponto [de ônibus] tal, aí você anda dois quarteirões e vira à esquerda. Aí eu vou dar esses comandos pra ela". E quando não tem a descrição para chegar ao lugar, só o endereço, "eu ponho no GPS ${ }^{86}$, aí eu junto a tecnologia com a Julia e pronto.".

Ao chegarmos ao destino estação Palmeiras-Barra Funda, Julia começa a se mexer, se levanta e "G." a segue em direção à saída do trem. Após desembarcar eles seguem muito rápido, mesmo no meio da multidão de pessoas. E assim vão por todo o caminho até o ponto de ônibus no Terminal Urbano, sempre com paradas estratégicas para que Julia receba suas recompensas. Ao final da observação, "G." retira o arreio de Julia para que a saudemos, pois enquanto ela estava com o arreio significava que estava a trabalho, e não poderia ser distraída. 0 arreio é o dispositivo instalado nas costas do cão-guia, usado para comunicação com o animal.

Como sugestão de melhoria para sua mobilidade nas estações do metrô, "G." sugere que seja fornecido um mapa descritivo de cada estação, que poderia ser disponibilizado via internet, por exemplo.

\section{e) Observação de "V."}

"V." chega à estação Fradique Coutinho acompanhada de uma colega de trabalho pois, conforme relata, "daqui [da estação] no meu trabalho são cinco quadras... é na rua dos Pinheiros mesmo [...] daí eu sempre venho com o pessoal do meu trabalho, porque é bem mais rápido, o pessoal coloca um monte de mesas na calçada... aqui tem muitos restaurantes". Entramos na estação utilizando o elevador, o qual ela prefere às escadas. Ao chegarmos nas catracas, a colega segue em outra direção e "V." opta por utilizar a ajuda de um funcionário do metrô. Durante o caminho até a plataforma de embarque, ela relata que, "em abril a gente perdeu um amigo, o "A."87, depois eu fiquei muito mais

\footnotetext{
${ }^{86}$ A sigla GPS foi utilizada como referência a um aparelho que utiliza o sinal GPS para navegação.

${ }^{87}$ Usuário com deficiência visual que caiu entre os carros de um trem na estação Sé em abril de 2015, após ter interpretado o vão como sendo uma porta, e que veio a falecer.
} 
preocupada", por isso faço questão da ajuda dos funcionários, mas, "se não tiver alguém pra ajudar, aí eu me viro, mas tenho medo... depois da morte do "A.", olha, pra eu andar sozinha no metrô, tem que estar muito, muito com pressa, realmente não poder esperar, porque o medo aumentou muito".

Durante o percurso no trem entre a estação Fradique Coutinho e República, ela fala sobre a sua deficiência, contando que começou a perder a visão aos sete anos, gradualmente, até chegar à cegueira com percepção de luz aos 18 anos. Ela afirma ter "uma memória visual [espacial] razoável". Muito atenta às mensagens sonoras que eram dadas dentro do trem, principalmente a respeito de lentidão na circulação dos trens da linha 3-Vermelha, para onde ela se dirigia.

Chegando à estação República, ela desce e já tem um funcionário da linha 4-Amarela esperando-a para conduzi-la até a área da linha 3-Vermelha, onde outro funcionário ${ }^{88}$ a conduz ao local do embarque preferencial sentido Corinthians-Itaquera. Ao chegarmos a esta plataforma é possível se entender um outro motivo pelo qual ela e outras pessoas com deficiência visual preferem o auxílio de um funcionário: a plataforma totalmente lotada dificulta o deslocamento e o embarque de todos os usuários, mas principalmente de uma pessoa com deficiência visual, que acaba por optar pela condução do empregado por um caminho seguro até a área do embarque preferencial.

Ela atribui boa parte de seu medo à grande quantidade de pessoas que utilizam o metrô nos horários de pico, e conta: "eu já andei no metrô de Nova Iorque, lá não tem nem funcionário, só que as pessoas lá andam mais devagar, você não tem essa muvuca nas estações, enfim, eu não andei sozinha lá, mas eu acho que os cegos de lá têm mais cuidados [facilidades] pra andar, porque lá não tem essa muvuca". E compara: "aqui eu sempre tive medo de cair da plataforma; ficava pensando 'e se alguém empurrar, o que é que eu vou fazer, vou levar um choque, aí quando o metrô passar eu já morri... Por isso eu prefiro andar com o funcionário, pra ter essa segurança também".

0 trem chega vazio, devido a estratégia que o Metrô realiza para desafogar as plataformas de algumas estações, e "V." pede à funcionária que a acompanha: "me joga aqui, ó, que eu consigo sentar às vezes", indicando o lado esquerdo, onde ficam os assentos preferenciais (independentemente da frota). Ela relata que no embarque, pela

\footnotetext{
${ }^{88}$ Devido às diferentes operadoras que administram as linhas 3 e 4 (CMSP e ViaQuatro), os funcionários só fazem o percurso até o limite entre as duas áreas.
} 
manhã, "é uma luta de MMA, arranca cabelo, puxa bolsa, tudo pra sentar, uma briga pra sentar (risos). Já vi gente brigar feio, quase rolar no chão, só não rola porque não tem espaço." Mas ela prossegue dizendo que "o que me incomoda são os murmúrios quando eu tô em pé, porque de manhã não dá pra sentar, como eu falei pra você, é muito difícil sentar, aí fica aquele murmúrio assim: 'aí, ninguém dá lugar', 'tem um deficiente aqui e ninguém dá lugar', ai, eu morro de vergonha porque não queria estar passando por aquele constrangimento".

Durante a conversa, "V." precisa fazer uma ligação telefônica, e observa-se que ela utiliza um iPhone 89 , e ela comenta: "eu uso o iPhone porque ele tem o VoiceOver, que é como um sintetizador de voz que já vem de fábrica, aí você só ativa, aí ele lê os aplicativos, você só vai passando o dedo e ele vai lendo". Com relação a outras marcas e modelos anteriores, ela relata: "eu tive antes um Nokia, de botão, e a gente instalou um sintetizador de voz, mas era completamente diferente. Com uma semana que eu estava com o iPhone, eu já nem me lembrava mais como era o Nokia... Não consigo mais viver sem o iPhone".

Com relação a melhorias no sistema, "V." pede: "uma coisa que pro cego é super importante é que sempre avisem as estações; hoje já não falha mais [nos trens novos] mas naquele trem antigo às vezes falha... Com essas vozes aí das meninas [mensagens prégravadas] ficou bem melhor, ainda mais neste trem que o alto falante é super alto". Finalmente chegamos à estação Vila Matilde, onde outro funcionário a espera, conduzindo-a até o ponto de ônibus no Terminal Urbano junto à estação, finalizando a observação.

\section{f) Observação de “M."}

"M." chega sozinho à estação São Bento pelo acesso da rua Boa Vista, onde trabalha, e faz todo o percurso desde a entrada até a plataforma de embarque sem utilização do piso tátil. Ele disse que prefere as escadas rolantes e não precisa do piso tátil nessa estação, porque já está acostumado. Ele relata: "posso usar a escada fixa, mas eu prefiro a rolante; eu sinto no pé que é a rolante, mas eu não sei se está descendo ou subindo; eu sinto no pé

\footnotetext{
${ }^{89}$ Em smartphones com o sistema Android há o TalkBack que verbaliza as informações à medida em que a tela é tocada, e no iOS, do iPhone, há o VoiceOver, software que lê sonoramente as informações exibidas na tela, de modo a tornar os aparelhos acessíveis, assim permitindo uma ampla gama de possibilidade de utilização para pessoas com deficiência visual. No entanto, verificou-se durante as pesquisas uma preferência quase unânime pelo iPhone, possivelmente pelo fato do VoiceOver ter surgido junto ao sistema iOS, enquanto que o TalkBack é uma adaptação no sistema Android.
} 
que ela se dividiu, mas aqui [nesta estação] eu já conheço; se um dia inverter [o sentido], eu erro, porque aqui já tô acostumado que sempre nesse horário ela desce".

Ao chegar à plataforma, "M." espera o trem bem em frente à escada que acabou de descer, mas bem afastado da borda da plataforma, um cuidado de todos que caminham autônomos, sem acompanhamento. Ele relata que "aqui eu guardei a posição da porta, mas às vezes tem aquilo que eles chamam de parada programada, e não para no lugar certo, mas eu tenho um resíduo [visual], dá pra ver [a porta]". Dentro do trem ele afirma: "eu aqui não sento, porque já vou descer na próxima [estação], já procuro ficar aqui perto da porta; eu fico do lado direito, do desembarque".

Ao descer na estação Luz da linha 1-Azul, "M." se dirige à estação Luz da linha 4-Amarela, mas agora ele utiliza o piso tátil: "aqui eu sigo para ir mais rápido... porque aqui estou meio condicionado, a gente pega o piso [tátil] e vai até mais rápido do que quem não está seguindo o piso". Próximo aos bloqueios contadores de transferência: "aqui é meio confuso, aqui eu preciso ir devagarzinho". Mas é praticamente o único trecho de seu percurso que ele diminuiu o passo, porque "M." andou o tempo todo muito rápido, inclusive pelas estações Luz e Pinheiros da linha 4-Amarela, estações bastante profundas, com uma grande quantidade de níveis a serem vencidos, com uma multidão de pessoas circulando ao mesmo tempo.

No último trecho do percurso ele faz um comentário: "aquela luz verde ou vermelha indicando se a escada está vindo pro seu lado ou não, é muito boa, mas nem sempre está bem clara, você viu, a da primeira escada estava escura, a desta escada estava bem mais clara; não sei, acho que foi colocada ali pro pessoal que tem baixa visão, não sei, eu acho". Com relação a telefones celulares, "M." afirma que já usou tecnologia Android, mas a acessibilidade é menor, prefere a do iPhone, que ele utiliza atualmente. Ele relata também que utiliza aplicativos com GPS dentro dos ônibus para saber se está chegando o ponto onde vai descer.

Observa-se a grande frequência com que ele se referiu às condições do piso tátil e do piso em geral, além das explicações que deu sobre os recursos que utiliza para identificar as escadas. Ele também comentou sobre sua paixão pelo tema metrô, que ele procura estudar para conhecer melhor. Uma coisa que chamou a atenção da pesquisadora foi a naturalidade com que ele passou pelos diversos encontrões com 
usuários apressados, que tropeçavam em sua bengala; tanto que não mencionou quase nada sobre os diversos incidentes desse tipo que ocorreram durante o percurso. 


\section{APÊNDICE T}

\section{Síntese das entrevistas - metrô de São Paulo}

A síntese dos depoimentos fornecidos durante as entrevistas com funcionários e pessoas diretamente relacionadas ao atendimento a pessoas com deficiência visual no metrô de São Paulo constam a seguir:

\section{a) Chefe do departamento de segurança pública}

A coleta de dados na entrevista possibilitou a compreensão de aspectos relacionados à segurança dos usuários com deficiência visual que possam impactar no uso de dispositivos eletrônicos nas áreas públicas da rede de metrô. 0 chefe do departamento de segurança pública informou que, apesar da constante vulnerabilidade a furtos e roubos que estão sujeitos esses usuários ao circularem em áreas de grande concentração e movimentação de pessoas, também existe o aspecto de serem indivíduos que chamam a atenção entre o público, e isso afasta o interesse de furtadores, pois estes desejam agir de maneira discreta, para não chamarem a atenção e poderem continuar a repetir esses atos.

Com relação ao uso do metrô por pessoas com diferentes necessidades, em sua opinião deveria ser institucionalizado que as pessoas com deficiência fossem habilitadas a usar o sistema metrô e assinar um contrato com regras bem claras, de forma a ficar mais fácil controlar e contornar os problemas que venham a acontecer com essas pessoas; algo similar ao que existe no transporte por avião, que possui regras rígidas e claras.

Com relação a tecnologias, ele sugere a possibilidade de se gravar todo o percurso realizado nas dependências do metrô, em um aplicativo instalado no próprio telefone celular do usuário (tal como os aplicativos de apoio em corridas ou caminhadas), para que seja possível se resgatar as informações, se necessário.

\section{b) Supervisor (1) de estações}

Responsável por estações por onde circulam em torno de 500.000 pessoas por dia, a entrevista com esse supervisor possibilitou identificar que o perfil do usuário do metrô em geral está mudando, e isso também se aplica ao usuário com deficiência visual, que 
deseja hoje mais autonomia dentro da estação, menos dependência de acompanhamento de empregados, especialmente os usuários mais jovens, e que a maioria ainda solicita auxílio devido à lotação de estações e trens, o que interfere na mobilidade.

Quanto à disponibilidade de funcionários para acompanhamento, o supervisor relata que muitas vezes as pessoas que estão sendo conduzidas pedem auxílio para chegarem até determinado local na rua, fora da área da estação, e isso acaba por tomar tempo, incutindo em demora no atendimento de outros usuários que estão à espera. Mesmo que o procedimento determine o acompanhamento dos usuários com deficiência até os limites das estações, é compreensível que ocorra uma sensibilização dos funcionários diante de pessoas necessitadas, fazendo parte da política de bom atendimento da empresa. 0 problema é que muitas vezes isso gera reclamações por parte dos usuários que ficam à espera de atendimento na estação.

A entrevista também mostrou que, do ponto de vista dos funcionários das estações, ele considera que existe a falta de informação para conhecimento das questões da deficiência, não só das incapacidades, mas principalmente do que são capazes, como é sua rotina, porque estão utilizando o metrô. Seria necessário que todos soubessem que a maioria dos usuários com deficiência visual utiliza o metrô para ir trabalhar e estudar, e que têm horários tão rígidos quanto qualquer outro usuário. As pessoas em geral desconhecem que muito são graduados e pós-graduados, que conseguem utilizar equipamentos eletrônicos, como computador e celular, da mesma maneira que as demais pessoas. Para esse supervisor, seria muito importante que houvesse reciclagem de funcionários para sua conscientização e humanização.

\section{c) Supervisor (2) de estações}

A coleta de dados por meio da entrevista com este supervisor, funcionário que atua na linha de frente da operação do metrô há 24 anos, possibilitou conhecer suas considerações a respeito da circulação das pessoas com deficiência visual pelas estações: os usuários habituais praticamente não precisam de auxílio; a maioria quer ser independente, eles não querem embarcar na segunda porta do primeiro carro, conforme indica a sinalização visual e tátil, para segurança e monitoração destas pessoas; este fato se nota principalmente entre os mais jovens, notando-se que os mais velhos solicitam e aceitam melhor a condução do funcionário. 
Ele observa que os jovens com deficiência visual estão muito voltados às tecnologias eletrôncas, utilizam muito o celular, e não utilizam mais relógios de pulso. Também observa que a maioria utiliza fone em um único ouvido, provavelmente deixando o outro livre para perceber informações do ambiente.

O supervisor considera ainda que os funcionários que fazem a condução dos usuários com deficiência deveriam ser treinados para entender melhor o seu papel na condução, entender melhor a importância de seu trabalho para estas pessoas.

\section{d) Coordenador da equipe de monitoração de manifestações em redes sociais}

A entrevista com o coordenador da equipe de monitoração de manifestações em redes sociais favoreceu identificar aspectos do transporte de pessoas com deficiência visual sob a ótica do usuário. Sua experiência com as reclamações e sugestões registradas nas redes sociais é diária. As manifestações tornam-se constantes pela facilidade que este meio oferece para isso. Ele identifica que "as pessoas com deficiência visual são maltratadas no dia-a-dia porque lhes faltam opções".

O coordenador considera que "o caminho para a independência dessas pessoas não tem volta", principalmente "devido à inserção destas pessoas no mercado de trabalho", o que exige que elas se desloquem utilizando basicamente o transporte público. Ele identifica que as pessoas mais jovens com deficiência visual procuram ferramentas para comunicação rápida: "para o jovem é natural fazer várias coisas ao mesmo tempo". E conclui que o metrô precisa desenvolver recursos para atender à autonomia dessa parcela importante de nossa sociedade.

\section{e) Responsável pela monitoração de manifestações nos canais de comunicação (exceto redes sociais)}

A funcionária entrevistada faz parte da equipe de monitoração de manifestações nos canais de comunicação (exceto de redes sociais). Ela recebe e analisa as reclamações e sugestões dos usuários com deficiência em geral. Atua também com elaboração de procedimentos de atendimento a esses usuários. Ela identifica que a maioria das pessoas com deficiência reconhece o serviço prestado pelo metrô como muito bom, mas que existem alguns problemas para utilizá-lo de maneira autônoma e segura, dentre eles, o receio de cair na via. 
Ela identifica três grandes grupos de usuários com deficiência visual: (a) aqueles que são autônomos, só pedem auxílio em estações grandes, de conexão entre linhas; (b) aqueles que não são autônomos, sempre pedem auxílio; e (c) aqueles que não pedem auxílio porque querem ser autônomos, e este último grupo é o mais problemático, porque a maioria precisa de auxílio, mesmo não o admitindo, e acabam por se arriscar. Aqueles com baixa visão são os que mais se arriscam.

Questões comuns que ela identifica: (a) reclamações por demora no atendimento por funcionários; (b) muitos pensam que estão sendo monitorados pelas câmeras existentes na estação (o que não é verdade, pois as câmeras possuem outras funções); e (c) os mais jovens têm tendência a serem mais autônomos, utilizam telefones celulares (a maioria iPhone) com mais frequência e estão mais presentes no mercado de trabalho do que os mais velhos.

Os que querem autonomia dizem que a acessibilidade e segurança precisariam ser incrementadas, sugerindo: instalar painel de portas de plataforma em todas as estações, disponibilizar mapas táteis das estações, e descrição sonora das estações disponível na página do metrô na internet.

A funcionária entrevistada também sugere que o treinamento dos funcionários que fazem o acompanhamento das pessoas deveria sofrer ajustes, para melhoria constante.

\section{f) Responsável pelo treinamento de funcionários para condução de pessoas com deficiências e treinamento de orientação a usuários com deficiência visual}

Por meio da entrevista com a funcionária responsável pelos treinamentos relacionados a pessoas com deficiência obteve-se informações com base na visão dos funcionários que convivem diariamente com o público em geral, e também na dos usuários.

Essa funcionária relata que, além do treinamento dos empregados, o Metrô desenvolve parcerias com instituições e organizações da sociedade civil para intercâmbio de informações e realização de visitas que proporcionam à pessoa com deficiência visual o reconhecimento do interior dos trens e das estações, com o objetivo de garantir maior desenvoltura e segurança em seu dia a dia. Mas, além disso, o próprio Metrô realiza treinamentos para a autonomia dessas pessoas.

Em seus contatos durante os treinamentos ela percebe algumas particularidades, tais como: (a) as pessoas com deficiência visual não gostam de usar o elevador, queriam que 
o piso tátil direcionasse para as escadas rolantes ${ }^{90}$; (b) utilizam telefone celular e outras tecnologias eletrônicas portáteis, principalmente os jovens; (c) pequena parcela se comporta de maneira independente porque a maioria tem medo de errar o caminho; e (d) também sentem medo de andar sozinhos porque os demais usuários caminham apressados e distraídos, causando encontrões (alguns chegam a perder a bengala, que fica totalmente danificada). A respeito do piso tátil, ela informa que o piso de borracha é o preferido; os usuários alegam que no piso tátil de cerâmica quase não se distingue as diferenças de sinalização.

Quanto ao treinamento que é oferecido às pessoas com deficiência visual pelas instituições, ela considera que deveriam disponibilizar mais tempo para treinamento dentro do metrô, pois o próprio metrô não tem uma estrutura para atender à demanda de usuários com deficiência que necessitam ser treinados (a maioria). Da maneira atual, chega a demorar até um ano para que essas pessoas memorizem todo o percurso necessário, pois os treinos ocorrem apenas uma vez por semana.

Complementando suas observações, ela também compartilha a percepção de que existe falta de informação sobre as necessidades e capacidades das pessoas com deficiência, por parte das pessoas em geral.

\section{g) Responsável pela área de pesquisas}

A entrevista com a responsável pela área de pesquisas favoreceu o conhecimento a respeito de pesquisas e análises realizadas pela empresa. Em sua experiência, ela identifica que é possível maior autonomia de pessoas com deficiência visual em estações menores. Já nas estações com plataformas centrais, mais profundas ou de conexão entre linhas, existe mais medo, devido à sua maior complexidade espacial.

Ela identifica que existe um grupo de usuários autônomos, formado principalmente por pessoas com baixa visão, cujo resíduo visual lhes permite que se desloquem com pouco menos dificuldade. Em sua avaliação, o que é determinante nesse grupo é a capacidade de memorizar os trajetos e o desenvolvimento de outros sentidos para auxiliar em seus deslocamentos. Mesmo assim, identifica que alguns usuários desse grupo deixaram recentemente de circular de forma autônoma, devido ao aumento do receio de se acidentar.

\footnotetext{
90 No metrô de São Paulo, o piso tátil direciona somente para elevadores e escadas fixas.
} 
Essa funcionária relata que, nas pesquisas realizadas, não existe consenso entre os usuários com deficiência visual a respeito da acessibilidade das estações do metrô de São Paulo. A maior parcela considera que os espaços não são totalmente acessíveis, em seguida, vêm aqueles que acham que algumas estações permitem que a pessoa com deficiência visual circule sozinha e outras não. Os mais críticos são os que adquiriram a deficiência depois de adultos e aqueles com baixa visão, possivelmente pela memória espacial ou por conseguirem enxergar um pouco.

Os principais problemas para os que acham que as estações não são adaptadas adequadamente estão relacionados ao fato de o piso tátil não levar para as escadas rolantes e não haver porta de plataforma em todas as estações. Estes usuários relatam que a preferência pelas escadas rolantes decorre do fato de o trajeto ser mais rápido, já que os elevadores nem sempre vão direto do acesso até a plataforma; além disso os elevadores não são exclusivos e têm muita fila, não atendem à demanda.

Nas pesquisas realizadas, também se identifica uma grande quantidade de reclamações sobre o piso tátil, mas, realizando-se uma ampla análise, verifica-se que a maioria das reclamações não pode ser atendida com modificações do piso tátil, pois referem-se ao desejo de embarcar em carro diferente do primeiro $^{91}$, para facilitar o desembarque na estação de destino e a eventuais interferências causadas por barreiras móveis colocadas sobre o piso tátil como estratégia operacional do metrô, em horários de maior fluxo. Ainda com relação ao piso tátil, ela identifica que a grande maioria possui treinamento em Orientação e Mobilidade e sabe usar o piso tátil; o grupo que é menos preparado é o de usuários com baixa visão, possivelmente porque, por enxergarem um pouco, se preocupam menos em buscar treinamento.

Como melhorias, ela percebe que a melhor compreensão do percurso a ser realizado nas estações poderia ser ampliada com o auxílio de mapas táteis e descrições sonoras contendo as principais referências da estação, com a localização das escadas, corredores, bloqueios (catracas), e acessos. Ela também identifica que uma outra alternativa é o desenvolvimento de aplicativo para orientar espacialmente as pessoas com deficiência visual em todas as estações ou, pelo menos, nas que apresentam maior dificuldade de deslocamento. A funcionária conclui que "nem todos os usuários com deficiência visual

91 Conforme explicado no referencial sobre redes de metrô, o Metrô de São Paulo realiza o embarque preferencial no primeiro carro, por questões de conforto e principalmente de segurança, porém nem todos os usuários com deficiência querem embarcar no primeiro carro. 
se sentirão seguros com o uso de um recurso tecnológico, mas com certeza será de grande utilidade e ajudará a reduzir a solicitação de acompanhamento de empregados".

\section{h) Supervisor do Centro de Controle Operacional (CCO)}

A entrevista realizada com um supervisor do Centro de Controle Operacional (CCO) possibilitou o melhor conhecimento sobre a maneira como é realizada a monitoração de pessoas com deficiência visual no metrô. Ele informou que o CCO tem a atribuição de centralizar a informação de origem e destino da pessoa que solicitou auxílio, assim como a identificação do trem que a está transportando. Essa informação é inserida no sistema e, quando faltam três estações para chegar à estação de destino, o sistema emite um alarme ao operador da console de passageiros ${ }^{92}$, que realiza uma ligação telefônica para a estação de destino e informa em qual trem o usuário monitorado irá desembarcar.

Ele informa que, quando essas pessoas não querem ser monitoradas, muitas vezes a informação de sua presença não chega ao CCO, pois fica difícil saber em qual trem e em que porta a pessoa embarcou, assim como é praticamente impossível saber em qual estação vai descer, e isso pode causar problemas de insegurança.

Na opinião do supervisor, o que poderia ser feito para facilitar e tornar mais seguras as viagens para os usuários com deficiência visual, seria a instalação de portas de plataforma em todas as estações; isolar uma área dentro do primeiro carro para transporte somente de pessoas com deficiência; e cada estação ter seu próprio equipamento de rastreamento das pessoas no sistema.

Quando perguntado se ele conhecia algum sistema eletrônico para guiar pessoas com deficiência visual em metrôs, ele afirmou não conhecer nenhum, mas que, se houver algum, o ideal é que os comandos sejam dados de maneira semelhante aos do aplicativo $W a z e^{93}$, do qual ele se diz grande usuário, no sentido de que sejam dados com certa antecedência e repetidos de maneira eficaz, sem confundir ou tornar o seu uso cansativo.

\footnotetext{
92 "O operador de console, usualmente, é aquele que responde pela evolução das situações contingentes, pois, normalmente, é ele que consegue uma visão mais global do sistema. Mantê-lo informado em tempo real sobre as variações do processo é tarefa que depende, fortemente, da integração das equipes e de uma comunicação oportuna, obtida por meio dos sistemas de supervisão e de comunicação (rádio, telefone, intranet e outros)." (RESENDE, 2011).

93 Waze é um aplicativo utilizado em smartphones para a navegação de veículos automotivos pelas ruas e estradas.
} 


\section{i) Responsável pela área de projeto civil e arquitetura}

0 profissional entrevistado trabalha na área de projeto civil e arquitetura das estações do metrô desde 1973, antes de sua inauguração em 1974. Ele relata que a elaboração e execução do projeto da primeira linha do metrô de São Paulo, realizado pelo consórcio HMD, considerou estações com pouco contato exterior e forte padronização, com apenas pequenas alterações arquitetônicas entre as estações.

As linhas concebidas a seguir passaram a ter projeto e execução sob responsabilidade da Companhia do Metropolitano de São Paulo - CMSP, buscando-se aberturas para a superfície, com base na experiência positiva da estação Sé.

O entrevistado relata que, desde o princípio, mesmo sem a existência de legislação específica ou de normas técnicas de acessibilidade, a CMSP buscou um padrão de conforto para seus usuários, com a instalação de escadas rolantes em todas as estações o que não era comum no Brasil. Com o surgimento de leis e normas determinando parâmetros inovadores de acessibilidade, os projetos foram incorporando esta nova perspectiva.

0 projeto de estações de metrô são influenciados por diversos fatores, dentre eles: geologia, topografia, demanda, plano de vias, método construtivo, interferências com serviços públicos e áreas tombadas. Mais recentemente, as questões ambientais e as exigências de segurança do Corpo de Bombeiros também têm afetado de maneira significativa os projetos das estações. A acessibilidade, mais do que obrigatória, é considerada essencial nos projetos, mas é preciso compatibilizar toda essa diversidade, relata o profissional entrevistado.

Como um dos itens de acessibilidade que foram acrescentados nos projetos mais recentes de estações, ele destaca a instalação de um conjunto de dois elevadores ao invés de elevadores isolados, para garantia de atuação no caso de falhas ou excedente de demanda.

\section{j) Responsável pela área de projeto de sistemas}

A entrevista com este profissional possibilitou a identificação dos aspectos relacionados ao projeto, aquisição e manutenção dos sistemas eletrônicos e eletromecânicos que fazem parte das estações do metrô, assim como do material rodante (trens), que 
interferem ou podem interferir diretamente na acessibilidade dos usuários com deficiência visual.

Ele informa que até o surgimento de legislação específica no início dos anos 2000, não existiam parâmetros de acessibilidade para trens de passageiros, sendo utilizados padrões ergonométricos e padrões de conforto para esse tipo de veículo de transporte.

Com o surgimento das definições legais e normativas, muitas melhorias tiveram que ser acrescentadas, tanto nos novos trens, como nos trens antigos que foram passando por um processo de modernização. Dentre as melhorias, ele destaca o aumento na quantidade de assentos preferenciais e a instalação de sinalização tátil com o número do carro, para eventuais relatos de problemas.

O sistema de informação também passou por mudanças favoráveis, tais como a emissão automática de mensagens sonoras pré-gravadas, melhorando a qualidade da informação do nome da próxima estação, além de acrescentar informação com o lado do trem em que deverá ocorrer o desembarque, orientando melhor as pessoas com deficiência visual.

Ele relata que a diferença entre frotas de trens acarreta à falta de padronização da disposição de seus assentos e barras de apoio, principalmente em função da estrutura dos veículos e de seus diferentes mecanismos existentes.

Nas estações, ele destaca que existe uma grande quantidade de sistemas em funcionamento, invisíveis aos olhos dos usuários, e que estes sistemas sofrem frequentes alterações, em função da crescente automação dos componentes e das instalações. Com relação à possibilidade de instalação de um sistema para guiar pessoas com deficiência visual, ele demonstrou ressalvas para que este sistema não interfira nos sistemas existentes, além de alertar para o fato de que os sistemas existentes podem afetar o seu funcionamento.

O entrevistado também informou que, a exemplo das estações da linha 4-Amarela, e das estações Sacomã, Tamanduateí, Vila Prudente, da linha 2-Verde, e Adolfo Pinheiro, da linha 5-Lilás, todas as novas estações devem ser executadas com painéis de portas nas plataformas. Contudo, nas estações existentes, existem dificuldades de ordem técnica e operacional que dificultam a sua instalação, mas que a equipe de técnicos da CMSP realiza constantemente avaliações e pesquisas para novos desenvolvimentos. 


\section{k) Professor (1) de Orientação e Mobilidade}

Na entrevista com este professor de Orientação e Mobilidade, com 37 anos de profissão, ele relata que a maior dificuldade para o uso do metrô pelas pessoas com deficiência visual é, sem dúvida, a enorme quantidade de usuários nos horários de pico. "Para a maioria das pessoas com deficiência visual essa situação é bastante desorganizadora no uso dos sentidos remanescentes e, consequentemente, na relação espaço-temporal com o ambiente". Todavia, ele reconhece ser este um processo mundial, que julga ser "insolúvel".

Uma interessante observação que ele faz, é a respeito da pessoa com baixa visão que utiliza bengala para caminhar pelo metrô, e quando as demais pessoas percebem que aquela pessoa "enxerga", passam a confundi-la com "malandros, espertos, picaretas, que querem se passar por cegos". Estas ocorrências enfatizam a necessidade de melhor divulgação de informações sobre as pessoas com deficiência visual, seus tipos, capacidades e incapacidades, e ele julga que o metrô poderia auxiliar nesta divulgação por meio de campanhas educativas nos diversos meios que o metrô utiliza.

Como sugestões de melhoria ele propõe: (a) revisão de todo o piso tátil, de maneira a se obter maior contraste, tanto visual como tátil, aumentando a largura das faixas direcionais, melhorando a iluminação de áreas escuras, entre outras; (b) a retomada de instalação de intercomunicadores nas plataformas para que os usuários possam falar diretamente com os funcionários da estação, solicitando auxílio; (c) adequação e manutenção do sistema de som nos trens e nas estações; (d) ampliação da comunicação e informação pelos monitores de TV dentro dos trens; e (e) reciclagem constante e aprimoramento na capacitação de funcionários, além de aumento no quadro efetivo.

Também sugere que se execute um projeto piloto no metrô utilizando outros recursos da tecnologia assistiva (recursos eletrônicos) para a devida avaliação feita pelas próprias pessoas com deficiência visual, tais como "sistema de informação sonora por proximidade e sistema de navegação por roteadores locais". ${ }^{94}$ Da mesma forma, os profissionais devidamente qualificados na Orientação e Mobilidade devem ter a oportunidade de fazer ponderações técnicas.

${ }^{94} \mathrm{O}$ professor fez uma referência a sistemas eletrônicos que possam emitir sinais wireless aos usuários. 


\section{1) Professor (2) de Orientação e Mobilidade}

Esta professora que atua na área de Orientação e Mobilidade há 37 anos identifica que a maior dificuldade encontrada pelas pessoas com deficiência visual que querem utilizar o metrô consiste no grande fluxo de pessoas que circulam nos horários de pico, e a pequena quantidade de funcionários para fazer o acompanhamento. Até aqueles que querem seguir o piso tátil não o conseguem, devido à grande quantidade de pessoas nas estações, o que torna a caminhada muitas vezes insegura, surgindo a necessidade de acompanhante por não poderem se locomover utilizando as técnicas para a locomoção independente com a bengala longa.

Mesmo com acompanhamento, nas estações onde o percurso é longo torna-se difícil a orientação e compreensão da estação, principalmente nas estações de conexão entre linhas.

Como melhorias, a professora sugere que haja sinalização sonora nas plataformas e que as informações sonoras dentro do trem com o aviso de próxima estação sejam claras, o que muitas vezes ainda não ocorre. Também sugere que se disponibilizem mapas sonoros dos arredores e plantas sonoras das estações.

Com relação ao uso de tecnologias eletrônicas para auxiliar na locomoção, ela relata que teve experiência com bengala eletrônica, baseada em ultrassom para identificar obstáculos acima do que a bengala comum é capaz de captar, e considera que seu auxílio é restrito, pois em locais onde existem vários obstáculos, a bengala confunde a pessoa com deficiência visual, pois o dispositivo informa os vários obstáculos ao mesmo tempo.

\section{m) Designer de produto de ajudas técnicas}

Este pesquisador atua há oito anos como gestor de sistemas de informação no centro de controle do metrô (CCO), e sua experiência com o monitoramento do auxílio que é oferecido pelos funcionários nas estações (monitoramento que é realizado pelo CCO), o levou a participar de projetos de produtos de ajudas técnicas específicos para pessoas com deficiência visual em redes de metrô. Para o desenvolvimento de tais projetos, este profissional realiza pesquisas relacionando-se essas pessoas a interfaces eletrônicas.

Com relação a sistemas de navegação, ele relata que "o GPS em aparelhos portáteis para consumidores finais existe desde 2003/2004, e até poderia ser lido por software de voz 
digital para cegos, mas mesmo o software de navegação para pedestres não é específico para cegos"; ele explica que navegadores comuns em smartphones não são adequados para pessoas com deficiência visual devido à sua imprecisão, o que pode colocá-las em perigo, além de gerar confusão com relação ao sentido correto a seguir.

Ele também relata que, em redes de metrô, mais especificamente na Europa, existem sistemas que foram criados para guiar pessoas com deficiência visual, como é o caso do Wayfindr, instalado em uma estação do metrô de Londres, mas que ainda estão em teste, e ele nota algumas restrições no seu uso, tanto pela imprecisão desses sistemas para identificar o exato posicionamento dos usuários, como por questões de interferências indesejadas.

Utilizando o metrô de São Paulo como exemplo, ele explica que, em geral, metrôs utilizam uma grande quantidade de ondas de rádio para o seu funcionamento e segurança, e por conta deste fato, instalar sistemas para guiar usuários com deficiência visual que também utilizam ondas de rádio, como sinais Bluetooth, por exemplo, é um risco. Pode haver interferências mútuas, o que demanda estudos detalhados ou, de preferência, que não se utilize sistema com ondas de rádio dentro do metrô.

Ele chama a atenção para o fato de que existe o risco de as pessoas caírem na via, tornando a circulação nas plataformas o local de maior risco, não podendo haver falhas. Este profissional desenvolveu um sistema para guiar pessoas com deficiência visual pensado exclusivamente para metrôs ${ }^{95}$, mas que pode ser adaptado para outros locais públicos, tanto internos como externos.

Para ele, a maior dificuldade na realização de um projeto deste tipo é a novidade, a ausência de referenciais teóricos e práticos. Ele realizou pesquisas práticas em uma instituição voltada às pessoas com deficiência visual (ADEVA) com seu invento, e observou que as pessoas podem expressar determinadas preferências em uma entrevista, mas depois de vivenciarem na prática, muitas vezes mudam de opinião, evidenciando-se a necessidade de se realizar pesquisas que se complementem.

\footnotetext{
${ }^{95} \mathrm{O}$ profissional informa que o projeto é um sistema instalado no ambiente, fornecendo informações de orientação e navegação para o usuário, por meio de voz sintetizada. Em fase de protótipo, recebeu a designação provisória de "GAT", sigla de "Guia Áudio Tátil”.
} 
Como exemplo dessa dualidade, ele cita que os usuários informaram preferir utilizar fones de ouvido em locais públicos, e no momento da realização do teste preferiram ouvir diretamente do aparelho celular, segurando-o com a mão. Se um projetista parte de apenas uma destas pesquisas, poderá incorrer no erro de projetar um sistema ineficaz por desagradar no seu uso, por exemplo. Ele também observa que alguns itens do projeto podem ser executados de maneira que o usuário tenha várias opções de uso, e que isso é desejável, porém pode torna-lo extremamente complexo de se projetar e executar, o que pode ser indesejável.

Ele também faz um alerta para projetistas a respeito do desconhecimento espacial que muitas das pessoas com deficiência visual possuem, especialmente os cegos congênitos. Ele relata que em uma de suas pesquisas com uma professora de Orientação e Mobilidade, ela afirmou que muitas dessas pessoas não recebem estimulação da família para compreender direções básicas, por exemplo, direita-esquerda. Como a criança não enxerga, a família considera que não adianta falar com ela utilizando-se esses referenciais, e simplesmente ela se torna um adulto que se confunde facilmente quando recebe esses comandos para orientação espacial.

No final da entrevista ele comentou que considera que o piso tátil direcional é útil como complementar ao um sistema eletrônico de navegação, como demarcação de uma área por onde circulam pessoas com deficiência visual, chamando a atenção para que se deixe livre esse percurso. 


\section{APÊNDICE U}

\section{Síntese da visita exploratória - metrô do Porto (Portugal)}

Nas visitas exploratórias em busca das affordances dos ambientes, caminhou-se pelas estações Casa da Música (Figura U.1) e Estádio do Dragão (Figura U.2), verificando-se que no metrô do Porto não existem bilheterias, com a figura humana vendendo títulos, somente máquinas automáticas (Figura U.3).

Figura U.1 - Estação Casa da Música.
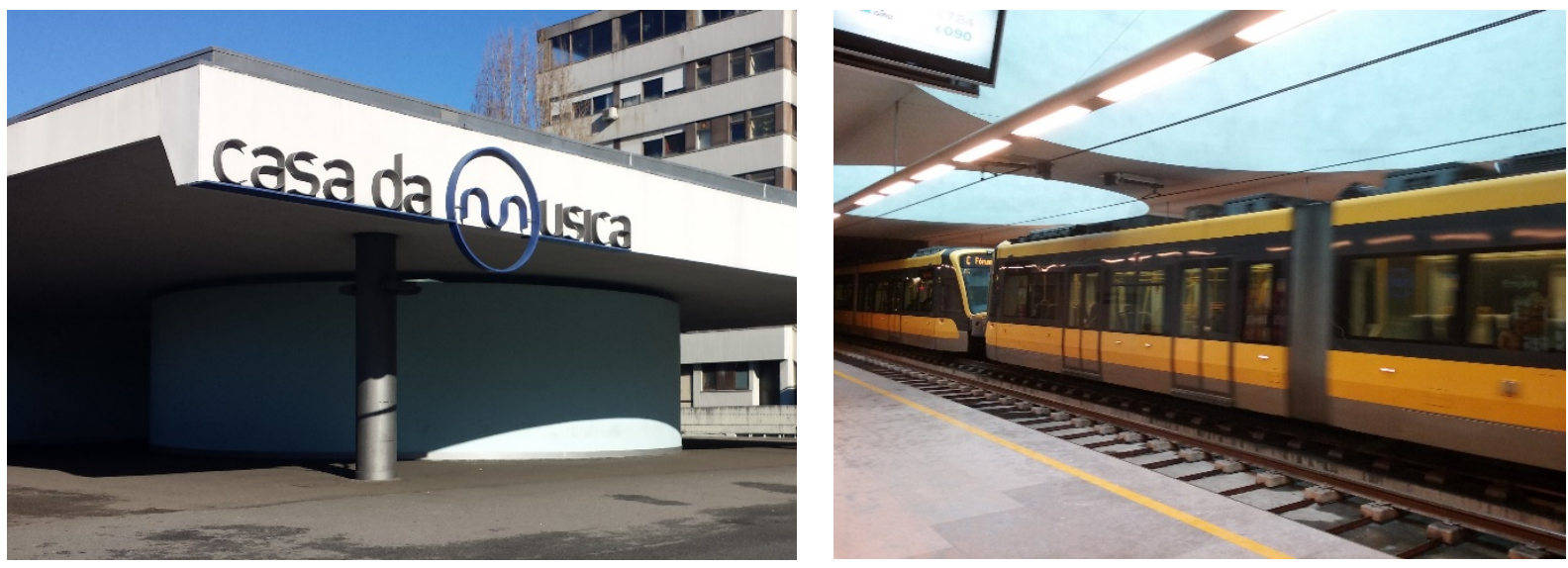

Crédito: MARIANI, E., 2015.

Figura U.2 - Estação Estádio do Dragão.

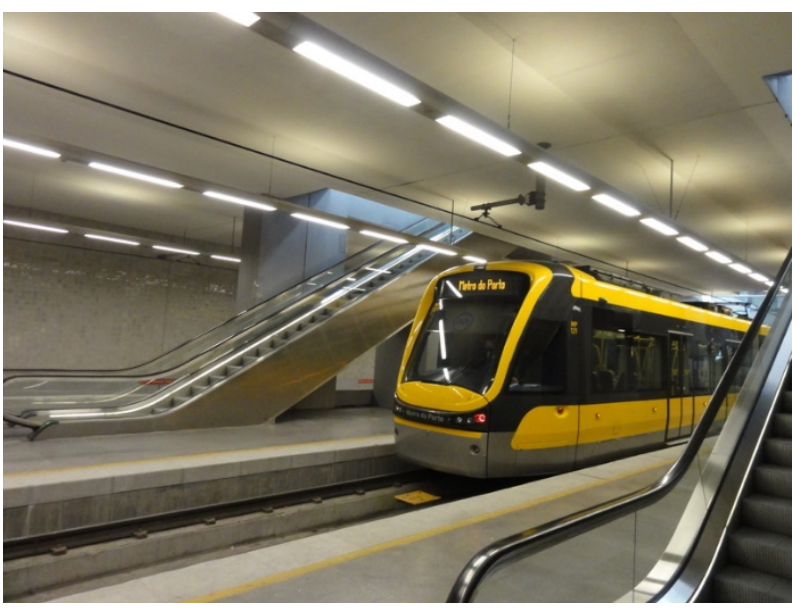

Crédito: FALUBAZ, $2012^{96}$.

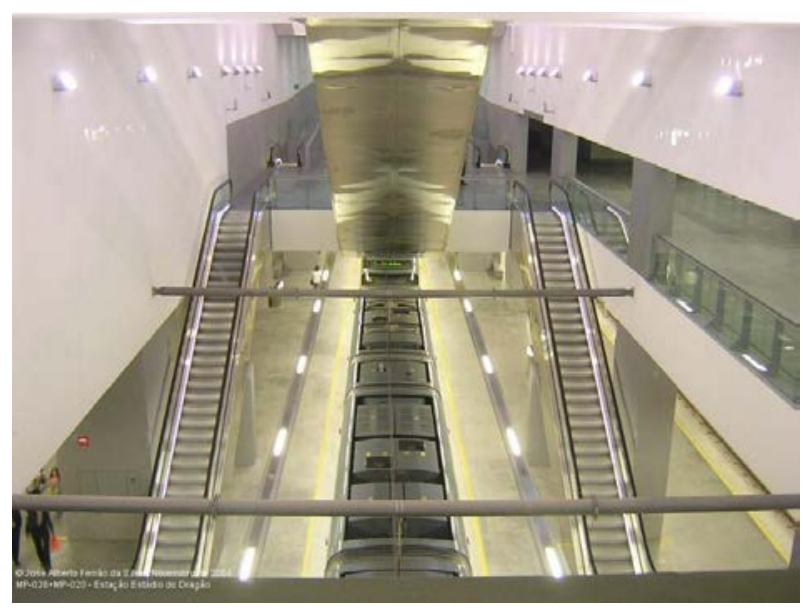

Crédito: SILVA, J. A. F., 2004.

\footnotetext{
${ }^{96}$ Disponível em: <http://www.skyscrapercity.com/showthread.php?p=89132436>. Acesso em: 25 jul. 2015.
} 
Chamou a atenção a ausência de bloqueios, como os existentes na grande maioria das estações de metrô, mas somente uma série de validadores estrategicamente distribuídos, conforme Figura U.4.

Figura U.3 - Máquinas de venda de títulos.

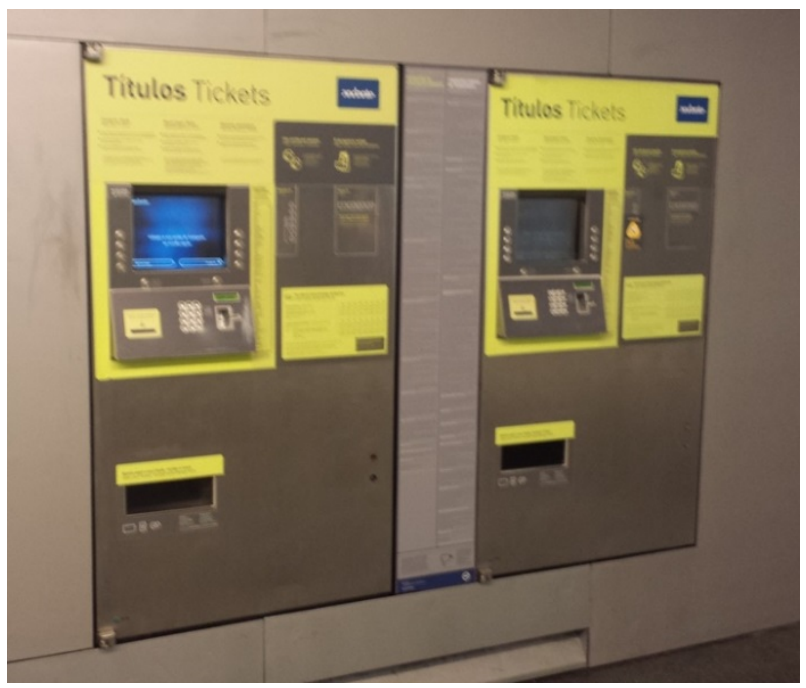

Figura U.4 - Ausência de bloqueios (catracas) em todas as estações.

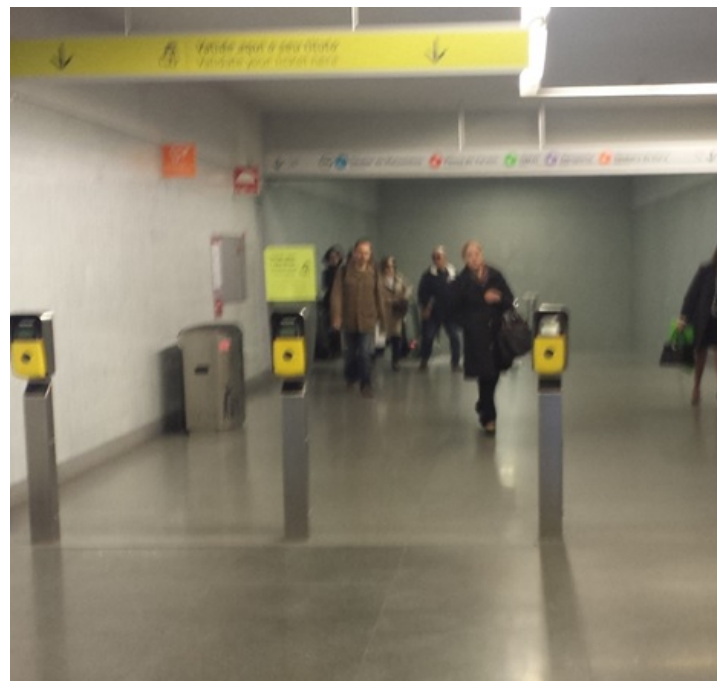

Crédito: MARIANI, E., 2015.

As estações próximas ao centro do Porto são subterrâneas, como Aliados, Salgueiros (Figura U.5) e Trindade (Figura U.6), esta última, onde foi realizada a pesquisa de observação de uso do Navmetro ${ }^{\circledR}$.

Figura U.5 - Estação Salgueiros.

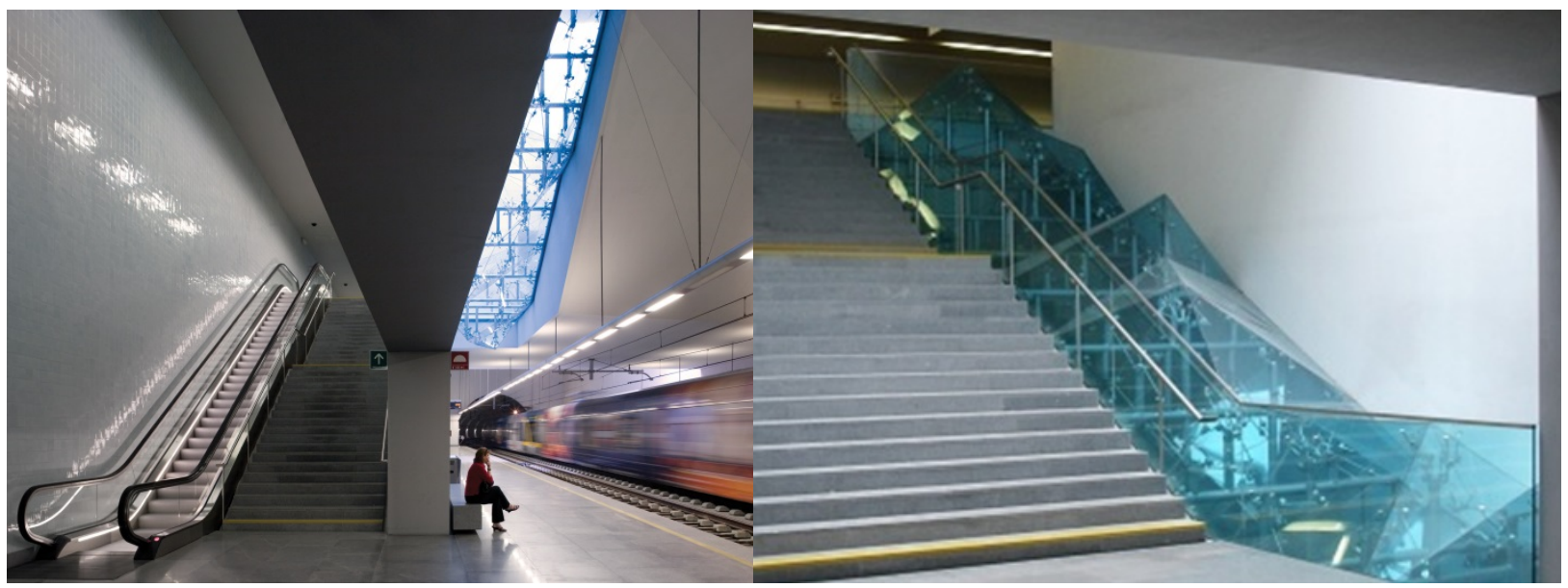

Fonte: Metro do Porto (2015)

Crédito: MARIANI, E., 2015. 
Figura U.6 - Estação Trindade.
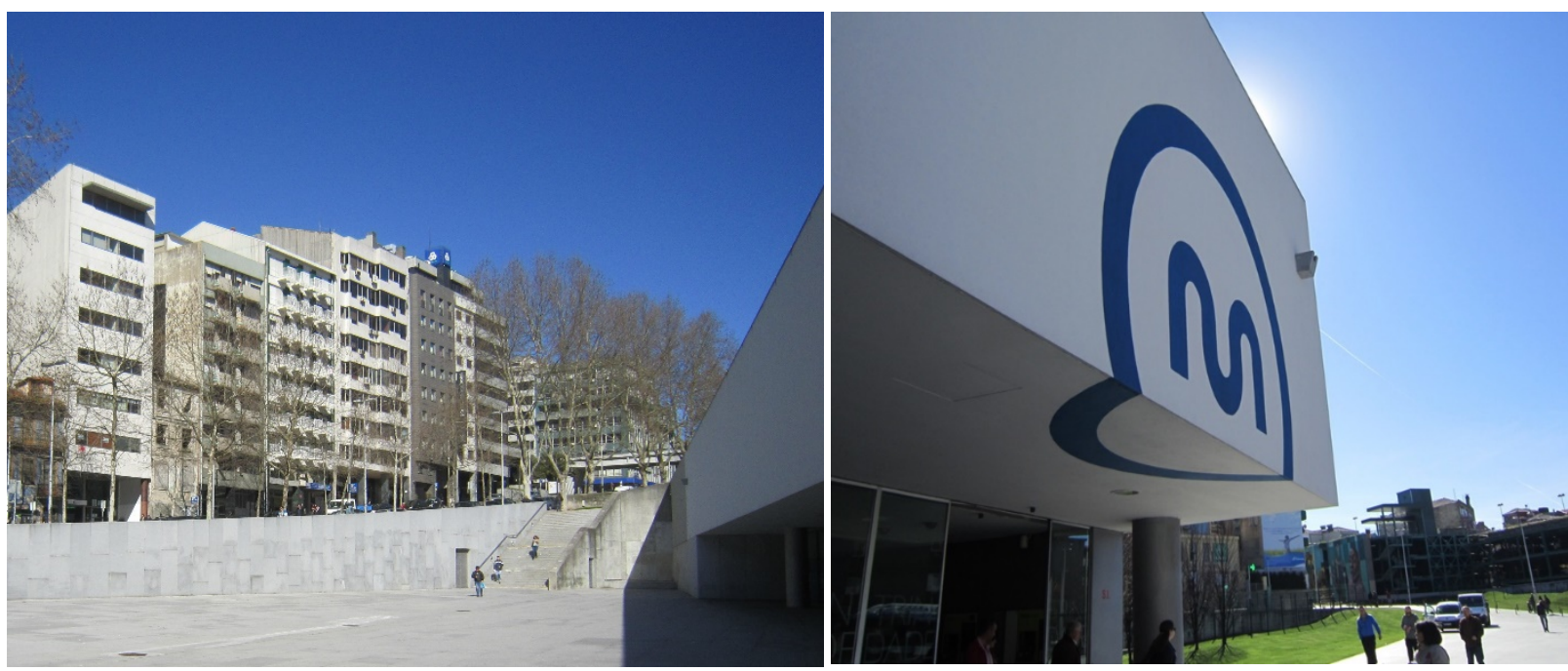

Crédito: MARIANI, E., 2015.

A estação São Bento teve seu projeto elaborado pelo arquiteto português Álvaro Siza, recebendo acabamentos diferentes das demais estações da rede, conforme Figura U.7.

Figura U.7 - Estação São Bento.
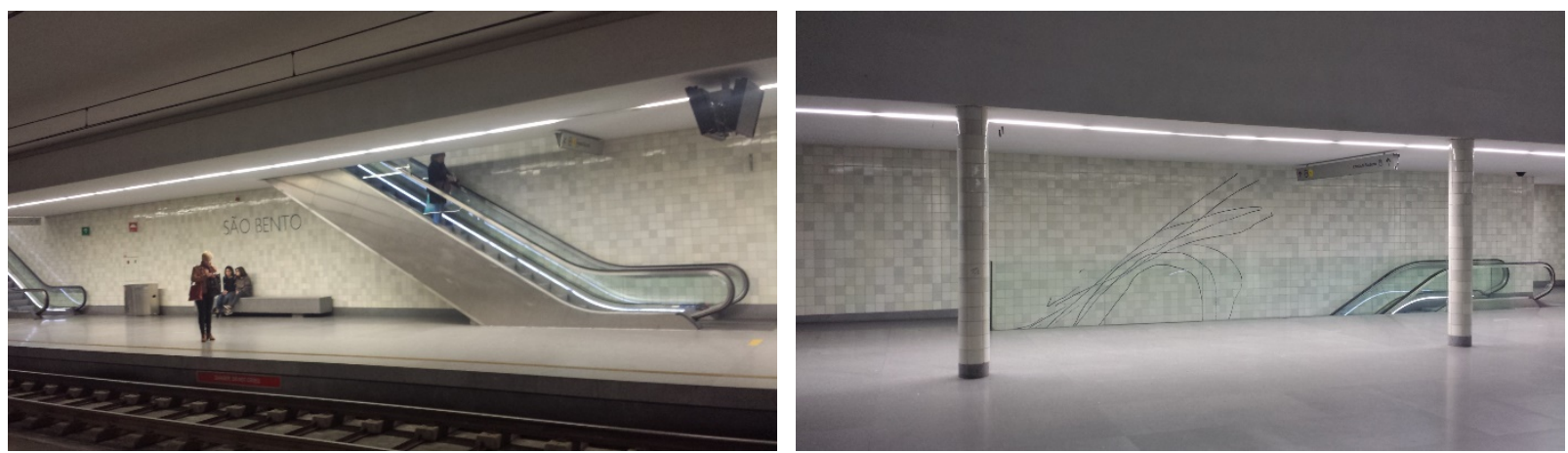

Crédito: MARIANI, E., 2015.

Na visita pelas estações da linha D-Amarela, na região de Vila Nova de Gaia, onde as estações são de superfície (Figuras U.8 e U.9), foram exploradas as estações Jardim do Morro, Câmara Gaia, João de Deus e Santo Ovídio, além de acompanhamento de todo o percurso dos trens circulando no mesmo nível de automóveis e outros modais de transporte, assim como também a circulação de pedestres. 
Figura U.8 - Passagem do metrô pela ponte D. Luís I, entre Porto e Vila Nova de Gaia.

Figura U.9 - Estação João de Deus.

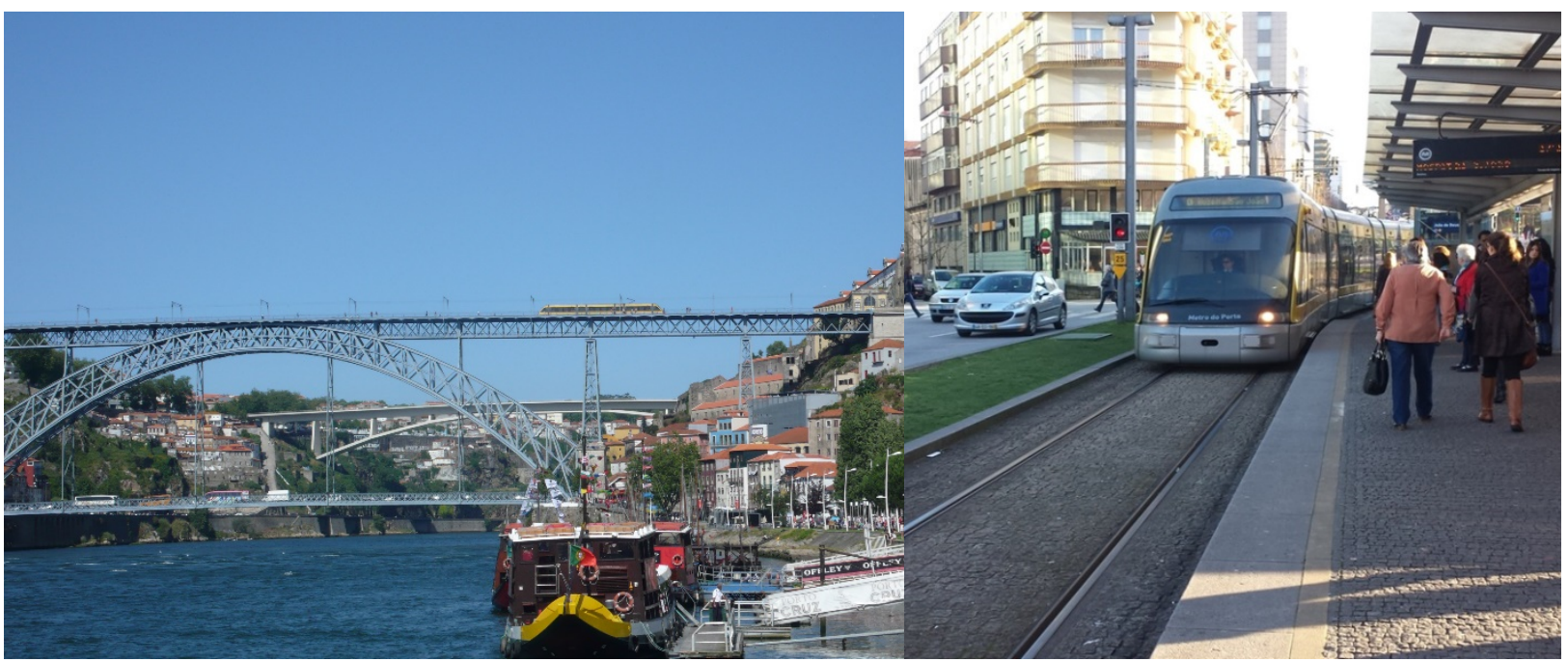

Crédito: GIACAGLIA, M. E., 2013.

Crédito: MARIANI, E., 2015.

Foram visitados também os trechos das linhas ao norte da cidade do Porto, utilizando-se a linha A-Azul até a estação Senhor de Matosinhos, a linha E-Violeta até a estação Aeroporto (Figura U.10) e linha B-Vermelha até Póvoa do Varzim. Nessa ocasião, verificou-se a configuração das estações de superfície, conforme Figura U.11.

Figura U.10 - Estação Aeroporto.

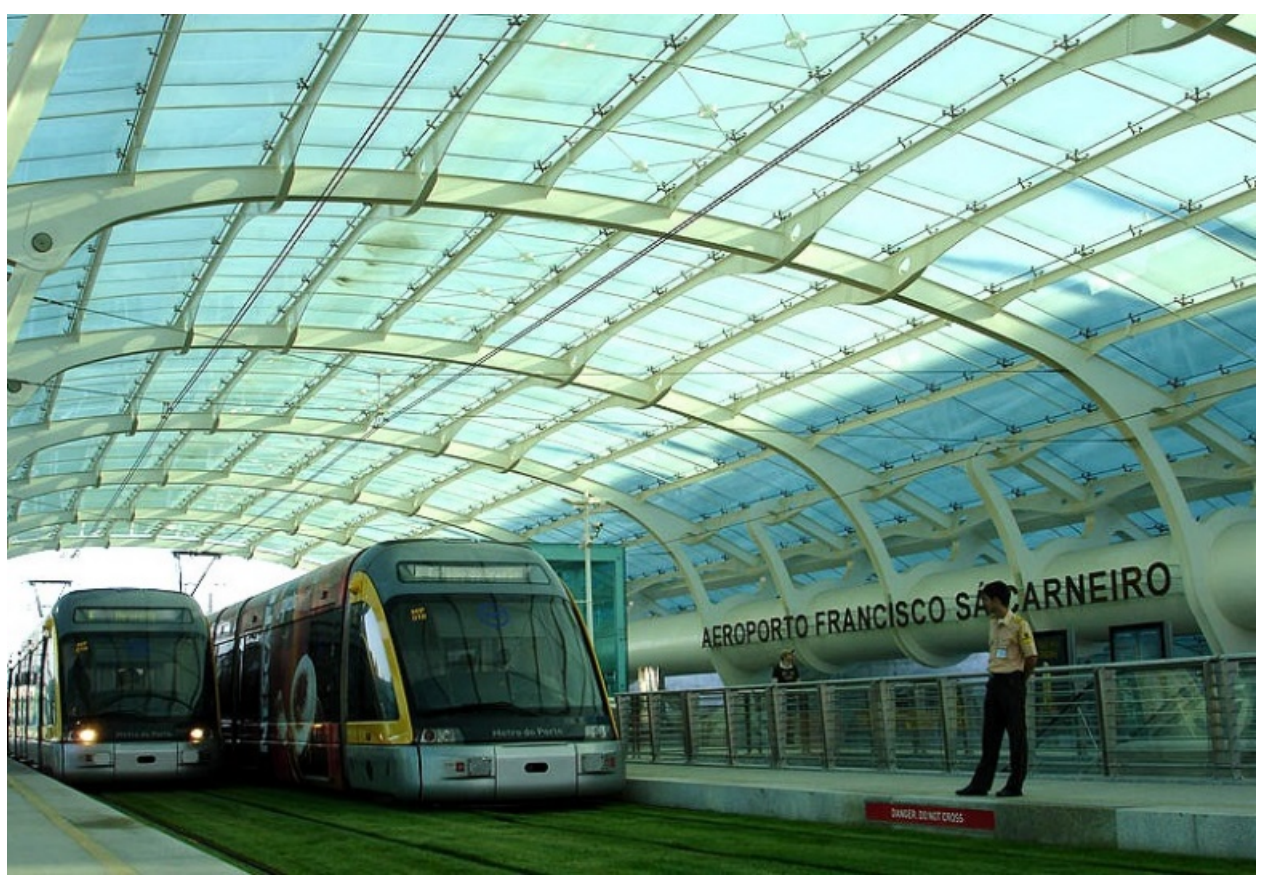

Crédito: PORTUGAL, D. 2007. 97

97 Disponível em: <http://www.skyscrapercity.com/showthread.php?t=559316>. Acesso em: 17 jun. 2015. 
Figura U.11 - Padrão de estações de superfície.
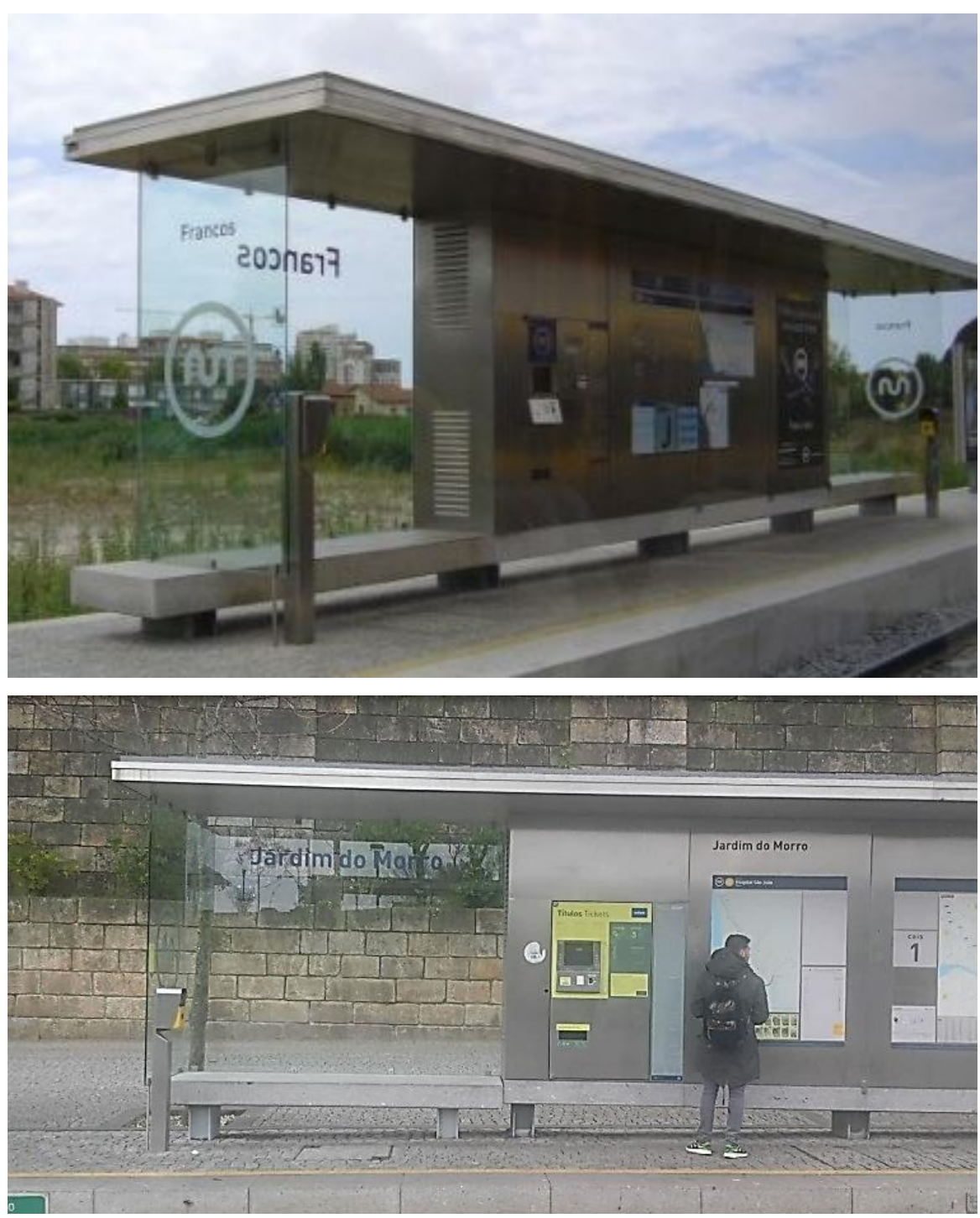

Crédito: MARIANI, E., 2015.

A frota de trens do metrô do Porto é formada por dois tipos de veículos: Eurotram (Figura U.12a) e Flexity Swift (Figura U.12b), em um total de 102 composições, com dois carros por composição. 
Figura U.12 - Frota de trens do metrô do Porto.

(a) - Eurotram

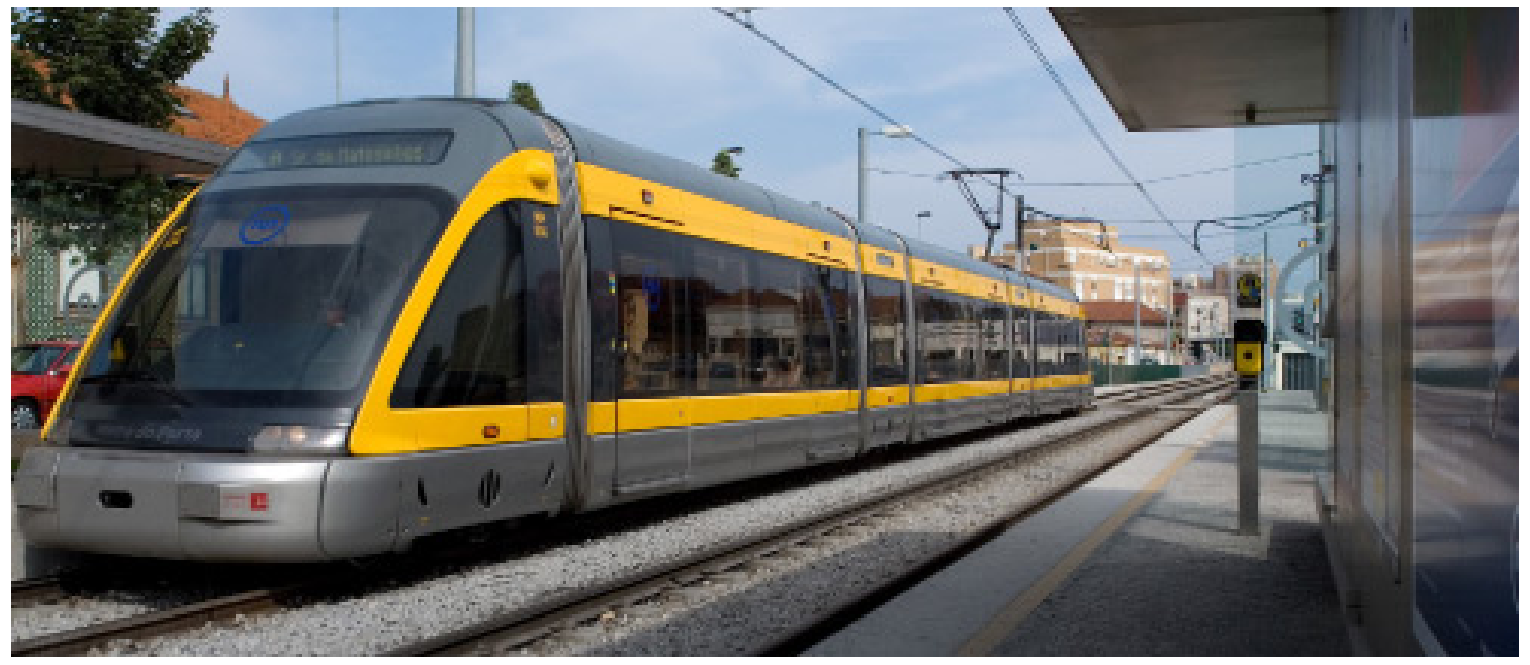

(b) - Flexity Swift

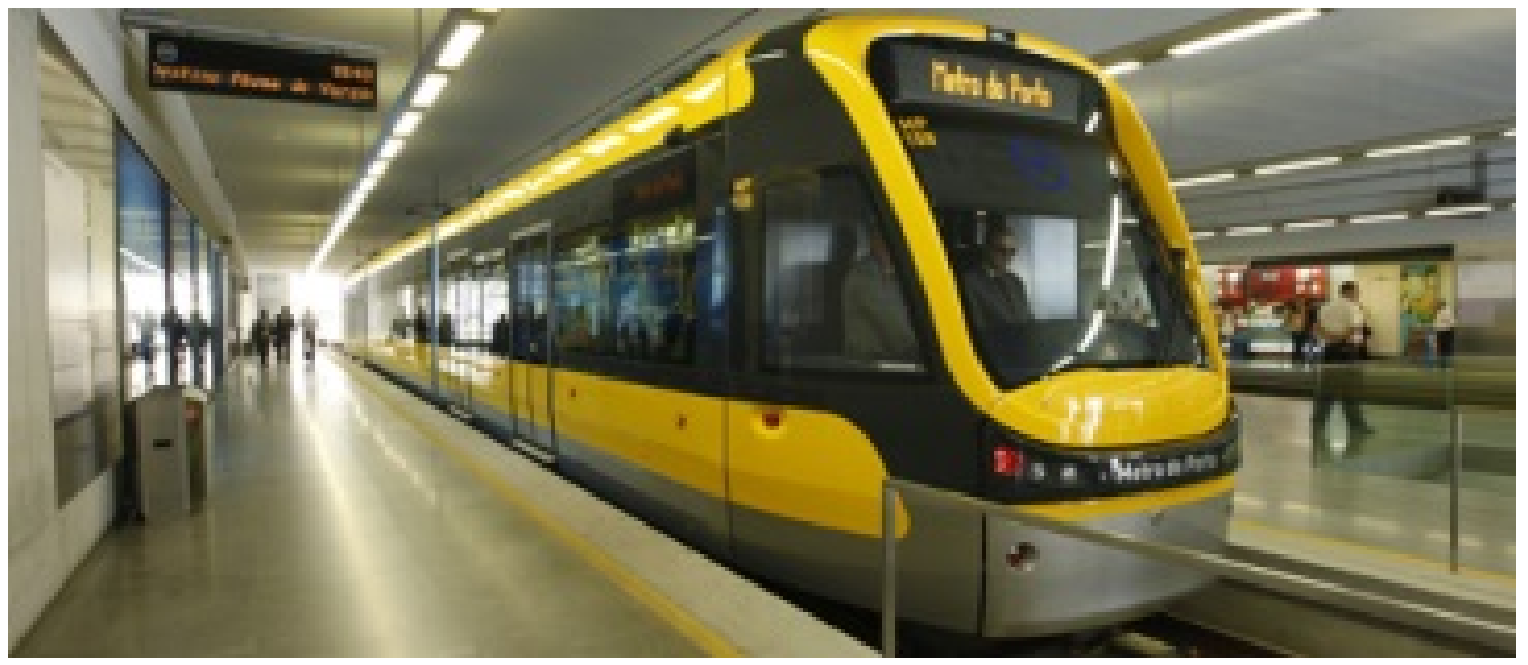

Fonte: Metro do Porto (2015).

Cada carro possui 35 metros de comprimento, largura de 2,65 metros e altura de 3,30 metros, com capacidade para 216 pessoas, 80 das quais sentadas. 0 tempo de parada nas estações de término é de 30 segundos, e nas demais, 20 segundos. (METRO DO PORTO, 2015).

Com relação à acessibilidade nos trens foram considerados itens como: o interior sem degraus; lugares reservados para pessoas com mobilidade reduzida; informação visual automática em painéis de luzes; informação acústica automática; e revestimento com cores sóbrias, onde se destacam os apoios de mão em amarelo (Figura U.13). Para entrar ou sair dos trens é necessário apertar um botão localizado em cada uma das portas (Figura U.14). 
Figura U.13 - Interior dos trens.

Figura U.14 - Botão para abrir a porta do trem.

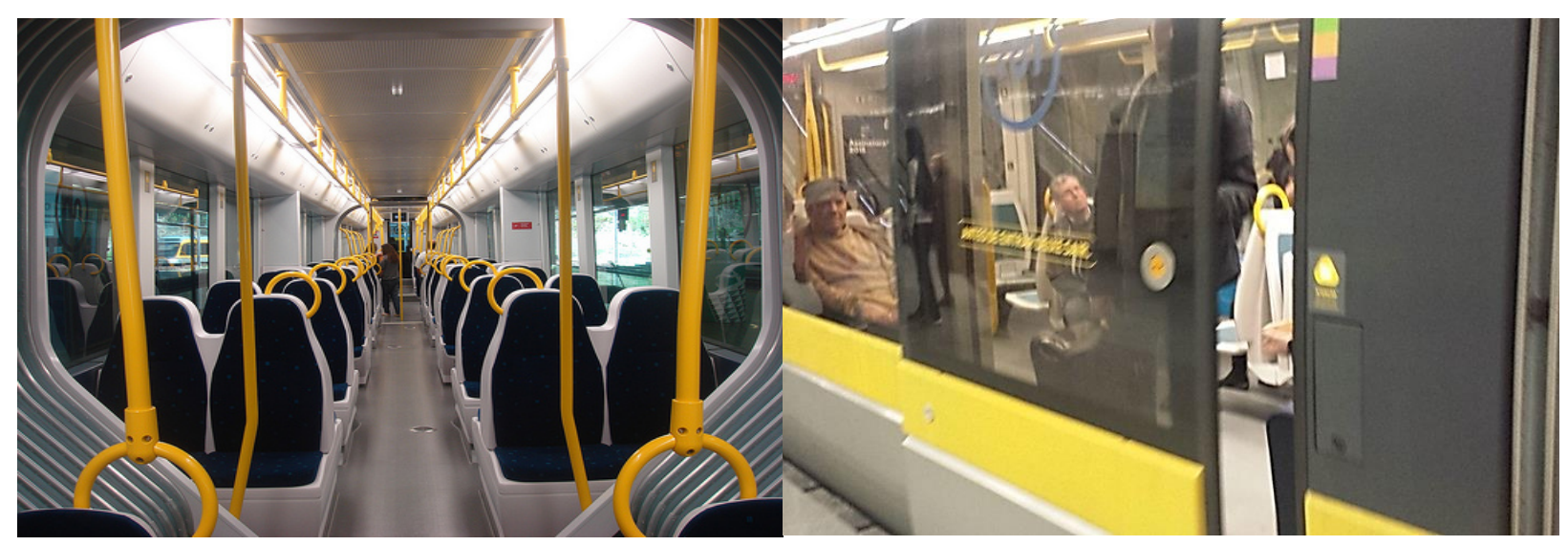

Fonte: Metro do Porto (2015).

Crédito: MARIANI, E., 2015. 


\section{APÊNDICE V}

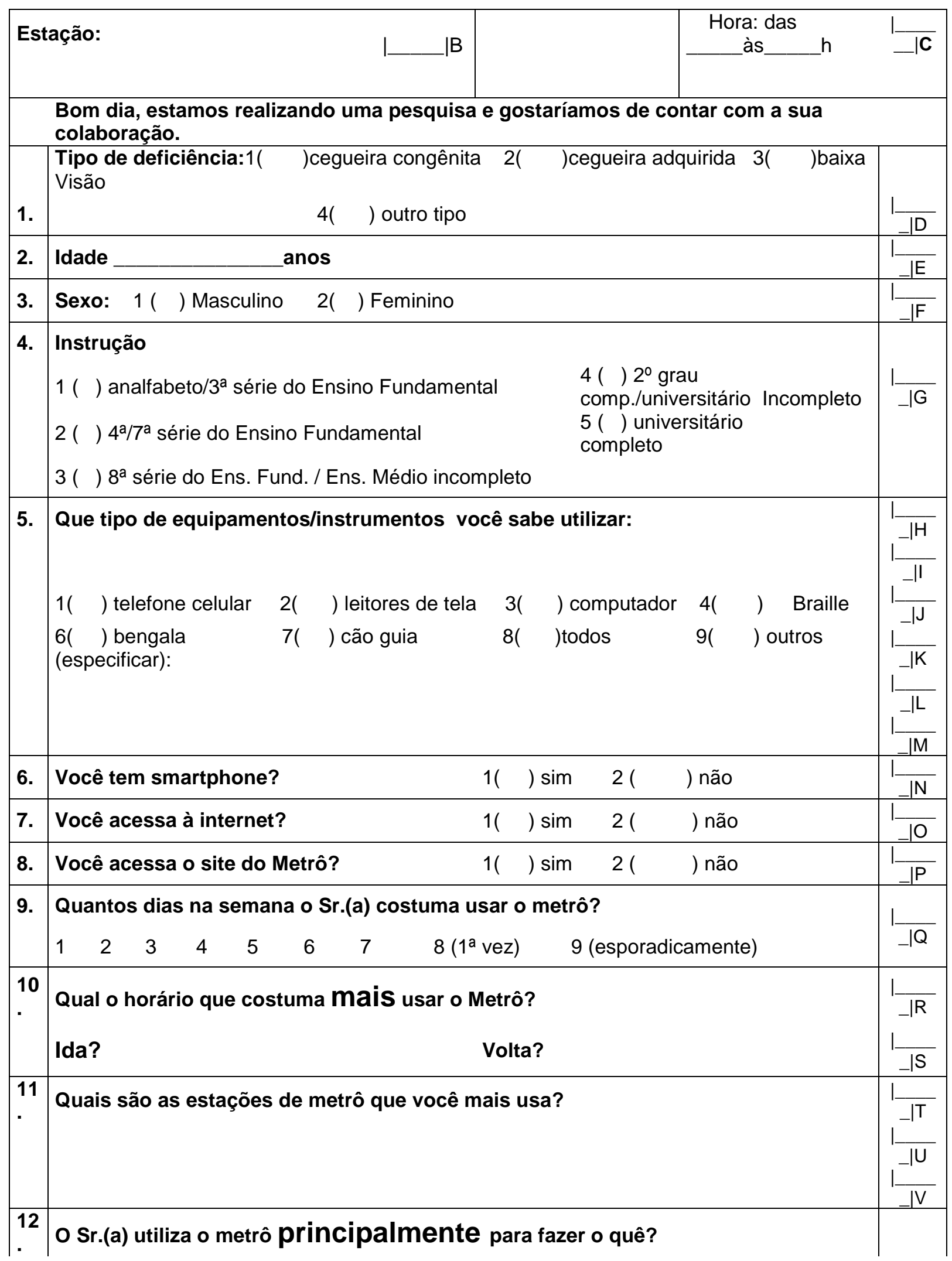




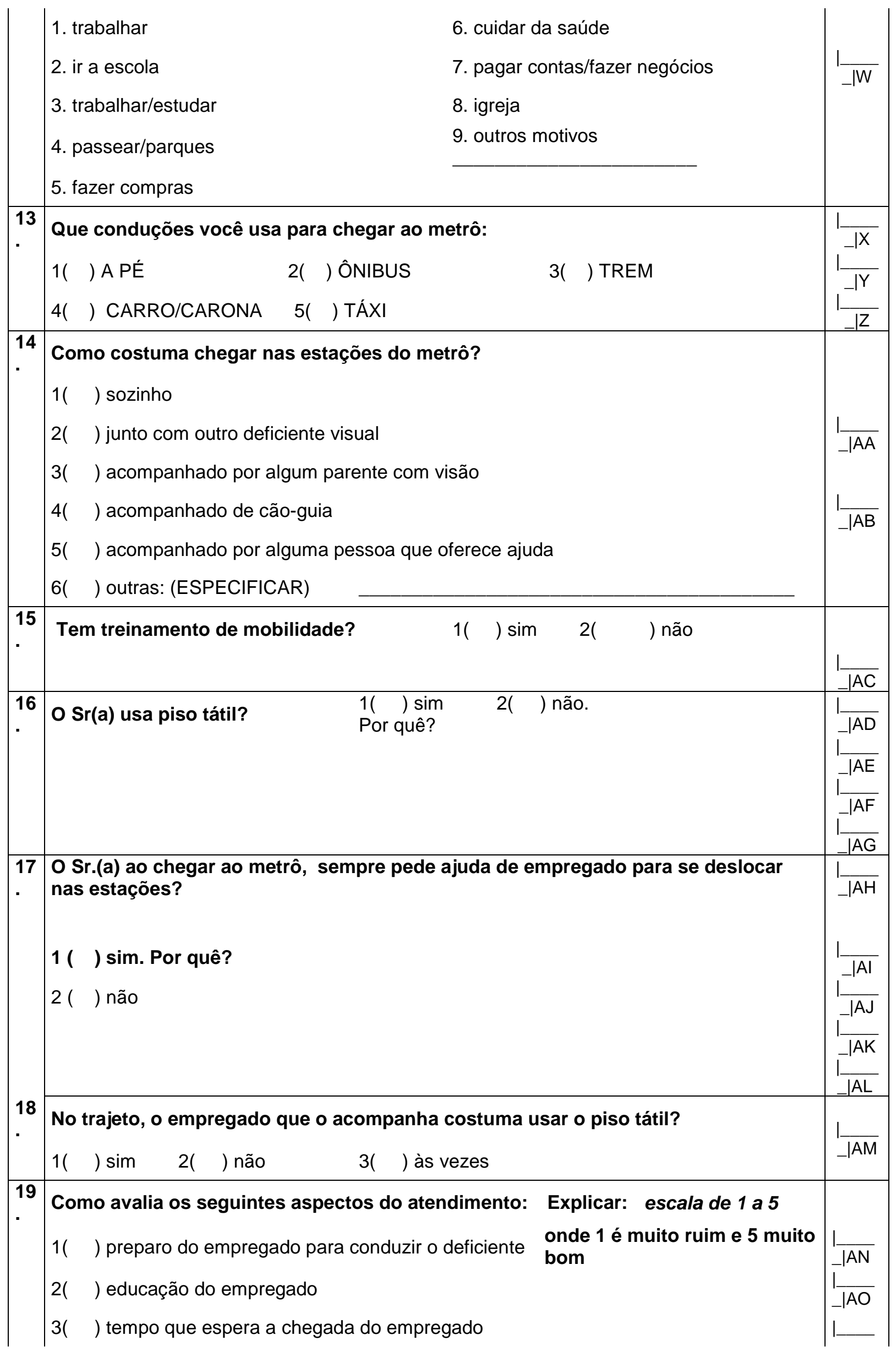


20

.

1( ) gostaria que o empregado descrevesse o caminho para que pudesse me orientar melhor

2( ) gostaria que o empregado conversasse sobre amenidades/assuntos gerais

3( ) outras maneiras (ESPECIFICAR)

21 - em cada etapa?

1) da linha de bloqueio até o trem minutos

2) na transferência entre uma linha e outra, quando for o caso minutos

3) no desembarque na outra estação minutos

22

Considerando que a quantidade de empregados para conduzir pessoas

com deficiência, especialmente nos horários de pico, é limitada, que outra coisa poderia ser feita para agilizar o seu deslocamento?

23

O que o metrô (estações e trens) dispõe hoje, na sua opinião, possibilita ao cego, se deslocar sozinho?

$1(\quad) \operatorname{sim}$

2( ) em alguma estações sim, outras não. (Explicar)

Você gostaria de se deslocar de forma independente, sozinho, no metrô?

$1(\quad) \operatorname{sim}$

2( ) não. Por quê você não se desloca sozinho?

_AP

$\overline{\mid A Q}$

$\overline{I A R}$

IAS

AS

IAT

IAU

IAV

$\overline{\mathrm{IAW}}$

$\frac{}{\text { IAX }}$

$\frac{I}{I A Y}$

IAZ

|BA

3( ) não. O que falta? 


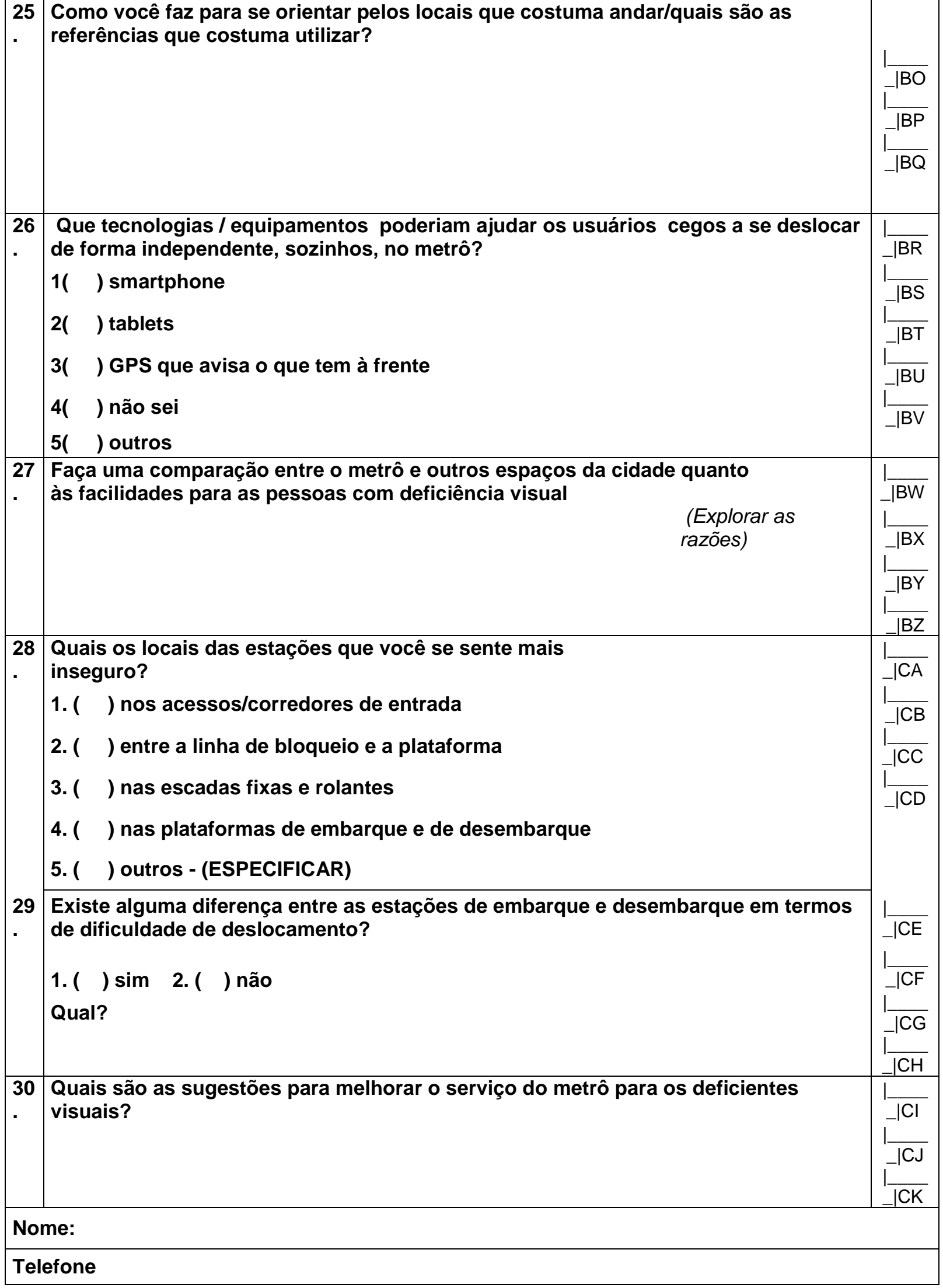

